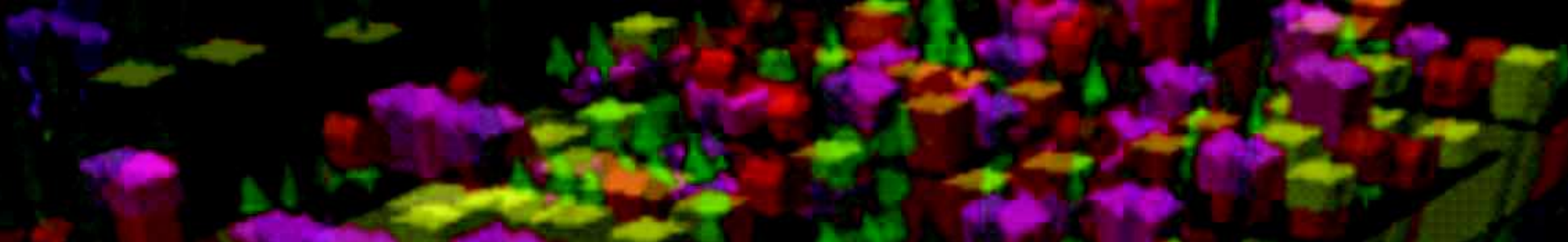


UNIVERSIDADE DE SÃO PAULO

INSTITUTO DE ARQUITETURA E URBANISMO

PROGRAMA DE PÓS-GRADUAÇÃO EM

ARQUITETURA E URBANISMO

\title{
Investigação como prática: MVRDV e as experiências com o habitar
}

\author{
Lívia Paula Zanelli de Morais \\ Orientador: Prof. Dr. David Moreno Sperling
}

Dissertação entregue ao Instituto de Arquitetura e Urbanismo da Universidade de São Paulo, como parte dos requisitos para a obtenção do título de mestre em Arquitetura e Urbanismo. Área de concentração: Teoria e História da Arquitetura e Urbanismo.

São Carlos | 2014 
AUTORIZO A REPRODUÇÃO TOTAL OU PARCIAL DESTE TRABALHO, POR QUALQUER MEIO CONVENCIONAL OU ELETRÔNICO, PARA FINS DE ESTUDO E PESQUISA, DESDE QUE CITADA A FONTE.

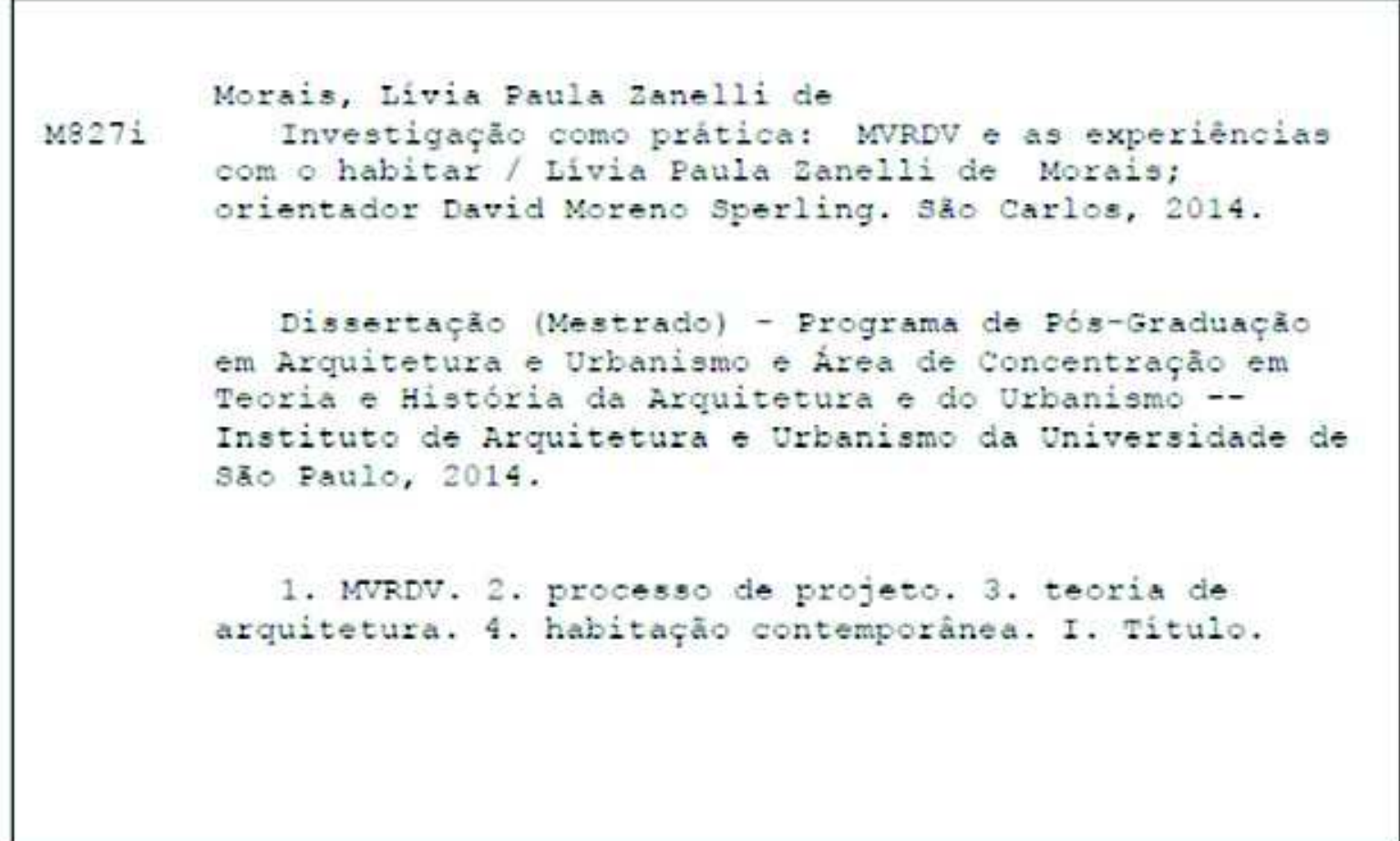




\section{FOLHA DE JULGAMENTO}

Candidata: Arquiteta e Urbanista Lívia Paula Zanelli de Morais

Título da dissertação: "Investigação como prática: MVRDV e as experiências com o habitar".

Data da defesa: 12/02/2015

Comissão Julgadora:

Prof. Dr. David Moreno Sperling (Orientador)

(Instituto de Arquitetura e Urbanismo - USP)

Prof. Dr. Miguel Antonio Buzzar

(Instituto.de Arquitetura e Urbanismo - USP)

Prof. Dr. Leandro Silva Medrano

(Faculdade de Arquitetura e Urbanismo - USP)
Resultado:

CPROVABC

Alrovas

Qprovade.

Coordenador e Presidente da Comissão de Pós-Graduação do Programa de PósGraduação em Arquitetura e Urbanismo: Prof. Dr. Márcio Minto Fabrício 
Para D. Edith 
Agradeço profundamente,

Ao professor David Sperling, pela orientação sempre motivadora | Aos professores Miguel Buzzar e Gabriela Celani, pelas contribuições no exame de qualificação | Aos professores Lúcia Shimbo e Paulo Castral, pela recepção acolhedora no estágio PAE | Aos colegas do NEC, pelas conversas enriquecedoras | Aos meus pais, por acreditarem na educação desde sempre | Ao Mauri, por todas as horas | À CAPES, pelo apoio financeiro para o desenvolvimento da pesquisa. 
MORAIS, L. P. Z. Investigação como prática: MVRDV e as experiências com o habitar. São Carlos: 2014. Dissertação (Mestrado), São Paulo: Programa de PósGraduação em Arquitetura e Urbanismo do Instituto de Arquitetura e Urbanismo da Universidade de São Paulo (IAUUSP), 2014.

\section{Resumo}

Esta pesquisa aborda a produção teórica e prática do escritório de arquitetura holandês MVRDV a partir do seu surgimento nos anos 1990, evidenciando as relações entre investigação projetual, processo de projeto e habitação, e a produção de novas espacialidades resultantes desses diálogos. O MVRDV é conhecido por seu método de trabalho, que desenvolve estudos e projetos experimentais, quantitativos e diagramáticos realizados em software combinados à extensa pesquisa, coleta e interpretação de dados do contexto para desenvolver as soluções projetuais. A proposta desta dissertação é analisar a produção da habitação contemporânea a partir dos modos atuais de fazer arquitetura, baseados em pesquisas, dados e tecnologias digitais e trazer para discussão os aspectos inovadores que o MVRDV traz ao processo de projeto e às espacialidades em habitação. O reconhecimento da pesquisa como prática propicia o desenvolvimento de um cenário que fortalece a teoria de arquitetura e expande o campo de atuação da arquitetura e urbanismo. Enquanto o panorama de trabalho do MVRDV se desenrola é possível visualizar também o contexto das principais questões que emergem na disciplina arquitetônica na atualidade.

PALAVRAS-CHAVE: MVRDV; processo de projeto; teoria de arquitetura; habitação contemporânea. 
MORAIS, L. P. Z. Research as practice: MVRDV and the experiences with dwelling. São Carlos: 2014. Dissertation (Masters), São Paulo: Postgraduate Program in the Architecture and Urbanism Institute of University of São Paulo (IAUUSP), 2014.

\section{Abstract}

This research addresses the theoretical and practical production of Dutch architecture firm MVRDV since its emergence in the 1990s, showing the relationship between research, design process and the production of new spatiality resulting from such dialogues. MVRDV, which is known for its work methodology, conducts studies and experimental, quantitative and diagrammatic projects implemented through software combined with extensive research, collection and the interpretation of data to develop design solutions. The purpose of this dissertation is to analyze the production of contemporary housing from the current ways of doing architecture, based on research, data and digital technologies and bring to discussion the innovations MVRDV introduces to the design process and housing spatiality. The recognition of research as practice enables the development of a scenario that strengthens the theory of architecture and expands the field of architecture and urbanism. While MVRDV's work panorama is developed it is also possible to view the context of the main issues that emerge in the current architectural discipline.

KEYWORDS: MVRDV; design process; theory of architecture; contemporary housing. 


\section{Sumário}

10

19

24

35

36

55

64

70

77

97

99

129

153

156

206

251

290

314

\section{INTRODUÇÃO}

\section{CAPÍTULO 1 | MVRDV: GLOBAL/LOCAL}

1.1 Contexto global: teoria de arquitetura e práticas projetivas

1.2 Contexto local: arquitetura holandesa

1.2.1 MVRDV e o panorama pós 1960

1.2.2 MVRDV: influências no pensamento teórico

1.2.3 MVRDV: influências no pensamento da habitação

CAPÍTULO 2 | MVRDV: TEORIA E PROCESSO DE PROJETO

2.1 Conceitos de projeto

2.2 Processos de projeto

2.2.1 Estudos experimentais / Projetos teóricos

2.2.2 Diagramas e software

CAPÍTULO 3 | MVRDV: PROJETOS DE HABITAÇÃO

3.1 Silodam

3.2 Mirador

3.3 Parkrand

CAPÍTULO 4 | CONSIDERAÇÕES SOBRE A PESQUISA

BIBLIOGRAFIA DE REFERÊNCIA 
INTRODUÇÃO 
Esta pesquisa tem origens no interesse pela produção mais recente da arquitetura contemporânea. Em meio à instantânea divulgação de projetos nos meios digitais que tem ocorrido na atualidade, nosso foco mira especialmente as relações entre teoria de arquitetura, processo de projeto e habitação multifamiliar. Esse interesse nos fez voltar a atenção para a produção dos escritórios mais jovens, mas já consolidados e com um pensamento teórico formado.

Dentro deste tema, o objeto de estudo tratado aqui é a relação entre pesquisa e prática desenvolvidas pelo escritório holandês MVRDV. O escritório foi fundado em 1993 em Rotterdam, na Holanda, pelos arquitetos Winy Maas (1959), Jacob van Rijs (1964) e Nathalie de Vries (1965), todos graduados pela Universidade Técnica de Delft em 1990 e com passagens por escritórios renomados: Maas e van Rijs trabalharam no OMA e de Vries no Mecanoo. Os sócios também têm experiências como professores em escolas de arquitetura como Universidade Técnica de Delft, Universidade Técnica de Berlim, Instituto Berlage, Architectural Association, Yale University e Universidade Técnica de Viena.

O objetivo desta dissertação é analisar os aspectos inovadores que o MVRDV traz ao processo de projeto e às espacialidades em habitação através do seu método de trabalho baseado em pesquisas, dados e tecnologias digitais. A relevância do assunto se justifica pela busca da solução do programa habitacional, que segue como tema base da arquitetura desde suas origens, com a habitação multifamiliar exercendo um importante papel não só na prática de arquitetura, mas também no desenho urbano.

O desafio da arquitetura moderna de suprir a demanda por moradia frente ao aumento populacional das cidades contribuiu para a difusão de certa uniformidade na habitação. No entanto, na década de 1960, alguns agentes começaram a sinalizar mudanças. Para atender as diferentes demandas da sociedade o arquiteto holandês John Habraken desenvolveu a ideia de 'suportes', uma estratégia que favorecia a flexibilidade e a participação do usuário na tomada de decisões em relação à construção do espaço habitacional. A pluralidade no pensamento da arquitetura e urbanismo também aparece no manifesto de Robert Venturi, Complexidade e Contradição (1966) e em Collage City (1970), de Colin Rowe e Fred Koetter, no qual a uniformidade do modernismo era rejeitada e deveria ser revista. Anos mais tarde, Delirious New York (1978), de Rem Koolhaas, também 
contribuiria para o afastamento do pensamento uniforme moderno com seus conceitos de acumulação e justaposição de diferenças na cidade.

Desse modo, a diversidade como conceito orientador para o desenvolvimento da habitação de massa se consolida como um aspecto importante do discurso arquitetônico a partir dos anos 1970, e, em especial na arquitetura holandesa que o faz em conjunto com uma reinterpretação da tradição moderna e de novas experimentações tipológicas. É também na Holanda que dois projetos marcam essa mudança em prol de atender a demanda por diferenciação de estilos de vida e de um novo caráter urbano: o concurso para Kruisplein (Rotterdam, 1980), vencido pelos fundadores do escritório Mecanoo e o projeto para IJplein do OMA (Amsterdã, 1988) que, naquele momento, já incluía estudos sobre densidade. Esses projetos marcam o início de um período produtivo na Holanda e que tem o edifício Silodam do MVRDV (1995-2003) como um dos exemplos mais recentes.

Assim, o início dos anos 1990 marca a diluição de padrões rígidos de projeto controle, estabilidade e repetição - frente à indeterminação e mutabilidade da cidade contemporânea. Com isso, o conceito de projeto como uma composição fechada começa a ceder espaço para sistemas abertos que permitem uma maior variedade de combinações.

Nesse contexto, o tema da habitação surge como possível propositor de elementos reestruturadores da cidade, especialmente frente aos modelos anteriores já esgotados. A partir de então, questionamentos sobre a revisão do projeto habitacional aparecem com mais frequência, não somente em relação ao programa da unidade (para atender aos novos modos de vida que demandam espaços mais heterogêneos), mas também em relação a sua inserção no tecido urbano.

O que se imagina é um potencial aumento da escala de atuação do habitat, que poderia impulsionar a renovação do espaço residencial não só através da área onde está inserido, mas também na configuração, segundo expressão de Manuel Gausa (1998), de 'novas ordens urbanas'. Ordens que não se restringem à edificação, mas que se expandem para redes (de transporte e comunicação, por exemplo) que asseguram seu desenvolvimento.

Faz-se importante também a consideração da diversidade, que coloca a habitação em convivência com outras atividades heterogêneas. As aglomerações urbanas passam a ser marcadas por espaços urbanizados heterogêneos e descontínuos. Para Gausa (1998), a expansão das cidades contemporâneas conduz à formação 
de crescimentos polinucleares, multicêntricos e descontínuos processos de fragmentação, assemelhando-se a uma mancha de tinta com vários pontos.

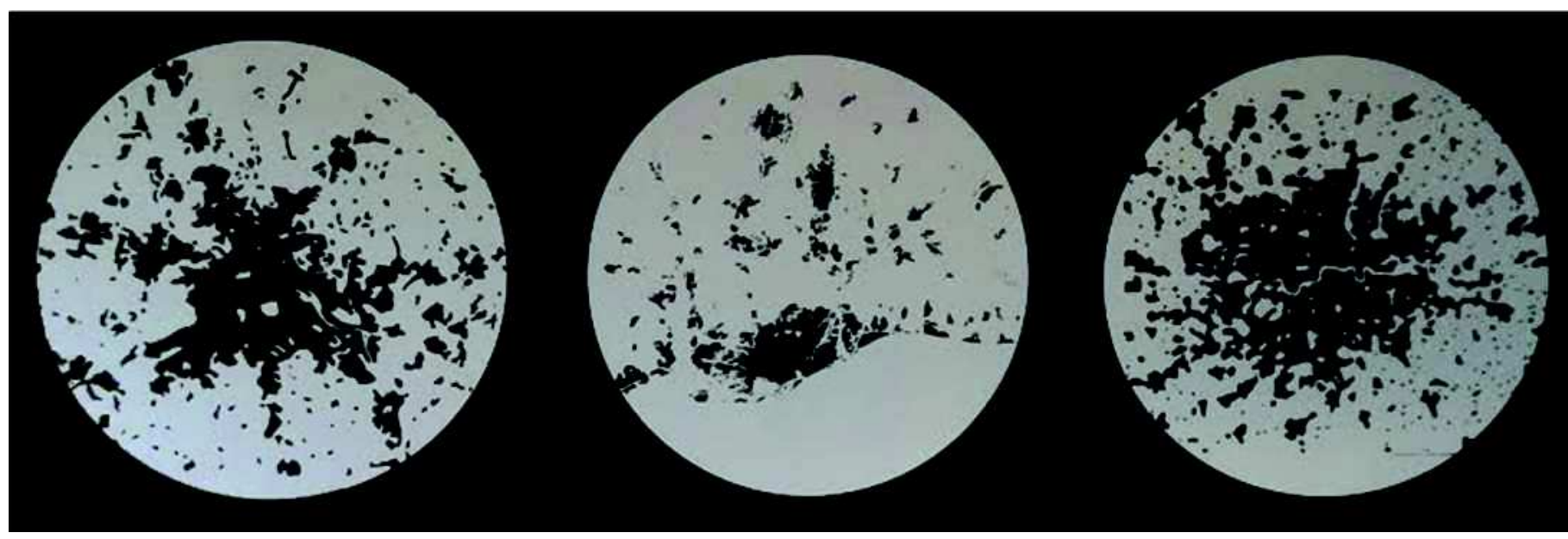

Crescimento em 'mancha de tinta'. As estruturas das conurbações apresentam semelhanças apesar do seu contexto: Berlim, Barcelona e Londres em escala. Fonte: Quaderns 211, 1995.

Feitas essas considerações, vemos a importância do desenvolvimento de projetos com aspectos mais estratégicos do que figurativos, ou seja, que se relacionam com linhas de força, fluxos e aspectos imateriais, nos quais a habitação avança além das questões de desenho ou da tipologia para um papel mais estrutural e relacionado com os sistemas articuladores que organizam o espaço urbano contemporâneo.

Tais sistemas habitacionais surgem como resposta às questões programáticas e espaciais que resultam em um projeto não só de habitação, mas de possíveis estruturas que atendem às dinâmicas locais e globais ao mesmo tempo. Nesse caso, podemos citar como exemplo o projeto Berlin Voids do MVRDV (proposta vencedora do concurso Europan 2, em 1991). O projeto funciona como um conjunto que se esvazia ou cresce conforme as necessidades da cidade; são combinações de habitação e espaços com densidade e soluções variadas.

O interesse pela produção do MVRDV se dá pela relevância do seu método de trabalho, que desenvolve estudos e projetos experimentais, quantitativos e diagramáticos feitos em software combinados à extensa pesquisa, coleta e interpretação de dados do contexto para desenvolver as soluções projetuais. Mais que a retomada da teoria (apesar da existência de um movimento pró-prática reforçado a partir dos anos 1990, justamente quando o escritório se inicia), o 
MVRDV traz para discussão questões de outras disciplinas, ampliando o campo de atuação da arquitetura e urbanismo.

Indo além, essa retomada da pesquisa como prática nos mostra outra questão: permeando as discussões entre diversas áreas do conhecimento, as experiências do MVRDV também abordam uma diferente dimensão do papel do arquiteto, permitindo estender sua função de técnico para de agente coordenador que estuda as relações entre cidade, economia e cultura.

A partir daí, a pesquisa aborda a teoria de arquitetura como uma forma especulativa, questionadora e por vezes utópica que avalia o ambiente e suas relações com a sociedade buscando, frequentemente, estimular mudanças.

De acordo com Michael Speaks (2002), a teoria mudou a prática de arquitetura entre as décadas de 1970 e 1990 e os trabalhos desenvolvidos por Bernard Tschumi, Peter Eisenmann e Rem Koolhaas ilustram bem esse quadro. Embora as consequências para a prática tenham sido reais, como salienta o mesmo autor, a ênfase na teoria começa a perder força no final dos anos 1990, em função do surgimento de um novo ciclo que combinou pragmatismo e aumento da demanda por arquitetura construída.

Além das discussões sobre a teoria, outros temas emergem no campo da arquitetura a partir da década de 1990. Como exemplo, temos os avanços na tecnologia que permitem novas possibilidades para os processos de projeto (utilizando software), fabricação e representação. Entram em pauta também o fenômeno starchitect e as últimas recessões econômicas que contam como fatores para se repensar o campo de atuação da disciplina arquitetônica.

A era digital traz algumas reflexões sobre o papel da arquitetura em relação à globalização (tema bastante abordado pelo MVRDV em seus estudos com temas como migração, aumento populacional, produção de recursos e meio ambiente) e o significado da digitalização para a arquitetura (um meio que oferece possibilidades pouco exploradas, como por exemplo, a facilidade para uma maior participação do usuário). Esses assuntos acompanham a disciplina passando por projetos de diferentes escalas influenciando a configuração dos espaços, desde as habitações individuais até os projetos urbanos.

Nesse ponto, é importante também abordar a configuração dessas novas espacialidades, especialmente pensando a habitação como cidade. As alterações nos espaços habitacionais - e aqui seus espaços coletivos funcionam como 
importantes articuladores da relação habitação-cidade - podem contribuir para a renovação do espaço urbano.

Em tal contexto, a nova realidade urbana é articulada segundo outras escalas, não mais a partir da continuidade da edificação, mas com origem em redes estruturais, como a infraestrutura de comunicação, transporte e movimentação financeira. Como abordaremos nos estudos sobre local/global do MVRDV, a velocidade da comunicação contribui para a dissolução das fronteiras dos territórios.

Diferentes fenômenos (históricos, culturais, políticos e econômicos) condicionam o presente e, consequentemente, afetam a disciplina arquitetônica, que responde conformando o cenário atual da arquitetura contemporânea. Se, segundo Speaks, entre 1970 a 1990 a teoria teve bastante destaque nas discussões sobre a disciplina, seus limites e forma de atuação, e desde então a arquitetura tem mudado, em parte devido às transformações na tecnologia e também às realidades culturais e políticas, é notório que no caso do MVRDV é difícil desvencilhá-la da prática. Um aspecto significativo do trabalho do escritório é a estreita vinculação entre a dimensão teórica e a especulação de cenários hipotéticos, que permite a experimentação projetual para além da realidade do presente.

\section{Abordagem}

Com origens na habitação contemporânea e seu processo de projeto, inicialmente, esta pesquisa atribuía maior ênfase à analise dos projetos habitacionais do MVRDV. No entanto, conforme o trabalho se desenvolvia, a investigação teórica e o processo de projeto do escritório foram ganhando relevância. A obra do MVRDV como um todo se apresentou interligada e abarcou espaço. O maior peso, antes dado para as análises dos projetos habitacionais, foi redistribuído entre os três pilares da pesquisa: teoria e investigação projetual / processo de projeto / espacialidades.

Tal direcionamento aumentou a importância das análises das publicações do MVRDV e seus estudos, de modo que o objeto de pesquisa é também fonte bibliográfica para este trabalho - consideramos os livros e a produção teórica do escritório como fonte primária fundamental para captação das principais questões presentes em seu discurso.

Desse modo, o próprio discurso do MVRDV guiou a definição da metodologia da pesquisa. Durante a leitura da bibliografia nos deparamos com termos utilizados 
pelos arquitetos que se repetiam nos seus textos, em entrevistas e depoimentos. Assim, os principais aspectos da fala do escritório foram definidos como conceitoschave e permeiam toda pesquisa. No capítulo 1, alguns dos conceitos estão dispersos e são reconhecidos em precedências anteriores que influenciam o MVRDV. No capítulo 2, os conceitos aparecem nos estudos e no processo de projeto do escritório e no capítulo 3 eles estruturam a leitura dos projetos. No capítulo 4 os conceitos encerram o trabalho restabelecendo a conexão da prática com a abordagem experimental.

O MVRDV apresenta seus estudos e projetos por meio de imagens, diagramas e montagens, de modo a não depender demasiadamente de textos. Sendo assim, por analisar as experimentações e projetos do escritório, optamos por apresentar um número significativo de figuras para que o leitor possa apreender os principais aspectos da produção do MVRDV. Para a realização dessa etapa coletamos imagens dos estudos, dos diagramas e software, dos projetos (aéreas, do entorno, externas, internas, das unidades, diagramas e plantas) e mapas de localização. Além das fontes usuais, como livros, periódicos e o próprio site do escritório, lançamo-nos em busca de imagens dos projetos em meios pouco convencionais: websites de imobiliárias, Google Street View e páginas de hospedagem de imagens / comunidades online, como o Flickr (www.flickr.com). Ainda, também optamos por nos aproximar do próprio método de trabalho do MVRDV e desenvolvemos peças gráficas para ilustrar as análises realizadas. Dentre elas estão tabelas, gráficos, diagramas, análises gráficas e simulações com cenários hipotéticos dos projetos analisados.

Até o momento, a obra do MVRDV permanece pouco estudada no Brasil, apesar das diversas questões bastante atuais que o tema abrange - ou até mesmo por sua atualidade. Embora críticos ligados às escolas de arquitetura de outros países já tenham discutido importantes pontos do trabalho do escritório, ainda existem poucos estudos que contemplam o conjunto da sua obra, especialmente sobrepondo e confrontando discurso e prática. As principais referências permanecem sendo as próprias publicações do escritório, ainda de difícil acesso em nosso país.

A decisão de abranger igualmente teoria e prática nos parece dar uma maior contribuição para a discussão do trabalho do MVRDV. A intenção não é de um trabalho que englobe todos os aspectos da produção do escritório, mas uma reflexão que mostre as articulações entre teoria e prática. Nesta pesquisa, tal 
reflexão está centrada nas potencialidades e problemas enfrentados no desenvolvimento dos projetos.

\section{Estrutura}

Além desta introdução, a pesquisa foi estruturada em três capítulos principais e um capítulo de encerramento. O primeiro capítulo tem caráter mais introdutório, contextualizando o cenário onde o MVRDV inicia o desenvolvimento do seu trabalho. Apresentamos alguns referenciais teóricos a partir das neovanguardas, especialmente aqueles que discutem teoria como prática. Trazemos também um panorama sobre a arquitetura holandesa e as principais influências para o MVRDV na formação de seu pensamento teórico e da habitação.

Os capítulos dois e três voltam-se para o objeto de estudo. O capítulo dois engloba a produção teórica e os principais aspectos do processo de projeto do MVRDV. Nessa etapa analisamos os conceitos-chave extraídos do discurso dos arquitetos, apresentamos seus estudos e experimentações, discutimos o uso do diagrama e o consequente desenvolvimento de software criados pelo escritório. No terceiro capítulo analisamos três projetos habitacionais - Silodam (Amsterdã, 1995-2003); Mirador (Madrid, 2001-2005); Parkrand (Amsterdã, 1999-2006) - à luz dos conceitos-chave apresentados no capítulo anterior.

As "considerações sobre a pesquisa" constituem o último capítulo do trabalho no qual retomamos brevemente os conceitos-chave em dois momentos: 1- nas possibilidades de atuação desses termos nas cidades na contemporaneidade; 2- na reflexão sobre a aplicação dos conceitos nos projetos analisados. Encerramos tal abordagem com o desenvolvimento de cenários hipotéticos utilizando os três projetos do capítulo 3.

Os estudos e obras analisados aqui apresentam pontos básicos em comum, mas também contam com singularidades e características próprias que acabam por revelar distintos modos de atuação do escritório e os diferentes resultados alcançados por eles.

Com poucos trabalhos acadêmicos ${ }^{1}$ que tratassem da produção do MVRDV, foi necessário um considerável trabalho de coleta e sistematização de informações. A

\footnotetext{
${ }^{1}$ No Brasil, a tese de doutorado de Leandro Medrano (Habitar no limiar crítico do espaço, ideias urbanas e conceitos sobre habitação coletiva, 2000), que teve como um dos estudos de caso o projeto Wozoco (1997), do
} 
totalidade da bibliografia de referência (publicações do escritório, livros, artigos, periódicos e páginas da internet) foi trabalhada em inglês e espanhol, enquanto as plantas e outros desenhos técnicos dos projetos foram editados após a tradução do holandês para português.

MVRDV e a dissertação de mestrado de Letícia Mendes Teixeira (Habitação coletiva contemporânea: inovações metodológicas e tecnologia da informação no processo de projeto. 2010), que analisou o uso de tecnologias de comunicação e inovações metodológicas no processo de projeto do Silodam (1995-2003) também do MVRDV. De outros países, foram encontrados artigos de autores como Bart Lootsma e Hans lbelings que citaremos no capítulo 1 desta dissertação. 


$$
\begin{array}{r}
\text { CAPÍTULO } 1 \\
\text { MVRDV: GLOBAL/LOCAL }
\end{array}
$$


Neste primeiro capítulo abordaremos as origens do pensamento do MVRDV e situaremos o escritório dentro do contexto da teoria e da prática arquitetônica das últimas décadas. Para isso, dividimos a leitura deste capítulo em dois tópicos principais: "Contexto global: teoria crítica e práticas projetuais" e "Contexto local: arquitetura holandesa"

No primeiro tópico, trataremos brevemente das neovanguardas arquitetônicas e voltaremos maior atenção para as discussões sobre teoria crítica da arquitetura e as novas práticas projetuais pós anos 1990 a fim de compreender o cenário mais atual das discussões teoria versus prática e onde o MVRDV se posiciona. Permeando essas questões traremos as principais influências do escritório, especialmente Rem Koolhaas.

No segundo tópico, nos aproximamos mais do MVRDV dentro do contexto holandês. Primeiramente traçamos um panorama geral da arquitetura na Holanda e em seguida trazemos as origens do pensamento teórico e da habitação para o escritório.

A intenção deste capítulo, além da contextualização e da ênfase aos assuntos precedentes ao MVRDV, é identificar alguns pontos centrais debatidos pelo escritório, como: cenários hipotéticos, novas tecnologias no processo de projeto, a forma das cidades, entre outros.

Por tratar de assuntos contemporâneos, optamos por trabalhar majoritariamente com publicações recentes de teóricos e críticos em atuação dos principais periódicos e escolas de arquitetura pelo mundo e que estão discutindo a prática quase ao mesmo tempo em que ela acontece. Entre alguns deles estão K. Michael Hays, Michael Speaks, Reinhold Martin, Sanford Kwinter, Jeffrey Kipnis, Anthony Vidler, Antoine Picon e, com maior ênfase na arquitetura holandesa, Hans Ibelings e Bart Lootsma.

A verticalização da habitação coletiva foi um assunto recorrente no Movimento Moderno. Com o crescimento das cidades, as moradias unifamiliares passaram a ceder lugar à edifícios multifamiliares, gerando um aumento gradual do adensamento urbano. A partir dessas novas demandas, a habitação passou a ser um importante tema para análises e propostas que refletissem as necessidades das cidades. 
A questão do adensamento, tão discutida pelo MVRDV, já aparecia no universo da habitação social em massa no pós-guerra e depois na Contemporary City (1922) e na Unité d'Habitation em Marsellha (1945-1952), de Le Corbusier.

Devido às suas origens diversas, não existiu um ideal moderno único, porém alguns princípios básicos como a renovação da arquitetura, a rejeição das características anteriores ao movimento e a preocupação social e estética de renovação do habitat humano fazem essas diferentes origens do modernismo apresentarem pontos comuns de convergência que resultam em uma aparência final mais homogênea. No entanto, a partir dos anos 1960 começam a surgir outras correntes de pensamento. Aqui ressaltamos aquelas com posições utópicas que pretendiam extrapolar as ideias das vanguardas através da tecnologia, pois esses conceitos vão, de certa forma, influenciar os estudos, também utópicos, do MVRDV. Dentre eles, o Archigram (Inglaterra, 1960) se mostra o mais radical com seus projetos publicados na revista do grupo (Archigram, 1961-1970) e que sugeria a retomada do espírito de vanguarda, principalmente dos futuristas italianos. A confiança nos novos materiais e tecnologias converteria a arquitetura em elemento transportável, concepção a partir da qual o grupo desenvolveu projetos que vão desde pequenas células residenciais até cidades nômades e no espaço, com uma visão da arquitetura como produto da indústria. $O$ trabalho do Archigram teve grande importância para a comunidade internacional e nos anos 1990, voltou a ser foco tal debate sobre o futuro da vida urbana, um dos temas mais explorados pelo MVRDV e sua think thank The Why Factory.

Outro grupo que aparece nesse cenário são os Metabolistas japoneses (1960) com trabalhos de diferentes escalas que pensam do desenho industrial até as cidades, também baseados nos avanços tecnológicos e em uma concepção de cápsula residencial. Eles contestavam a falta de planejamento urbano apresentando novas soluções como urbes oceânicas, cidades aéreas e unidades agrícolas. O plano para a Baía de Tóquio, que tem um eixo cívico suspenso em cima da água e vários núcleos residenciais organizados ao longo dessa linha (e que faz referência ao plano Obus, de Le Corbusier), apresenta uma proposta de habitação e cidade como um organismo único e que considera a renovação da habitação (não mais como célula isolada) e dos sistemas urbanos.

De acordo com Manuel Gausa (1998), essa revisão da vida urbana perpassa por novas realidades que propiciam um novo tipo de aglomeração feita de espaços 
urbanizados, heterogêneos, descontínuos e determinados por informações e por grandes redes de articulação (transportes, comunicação, energia).

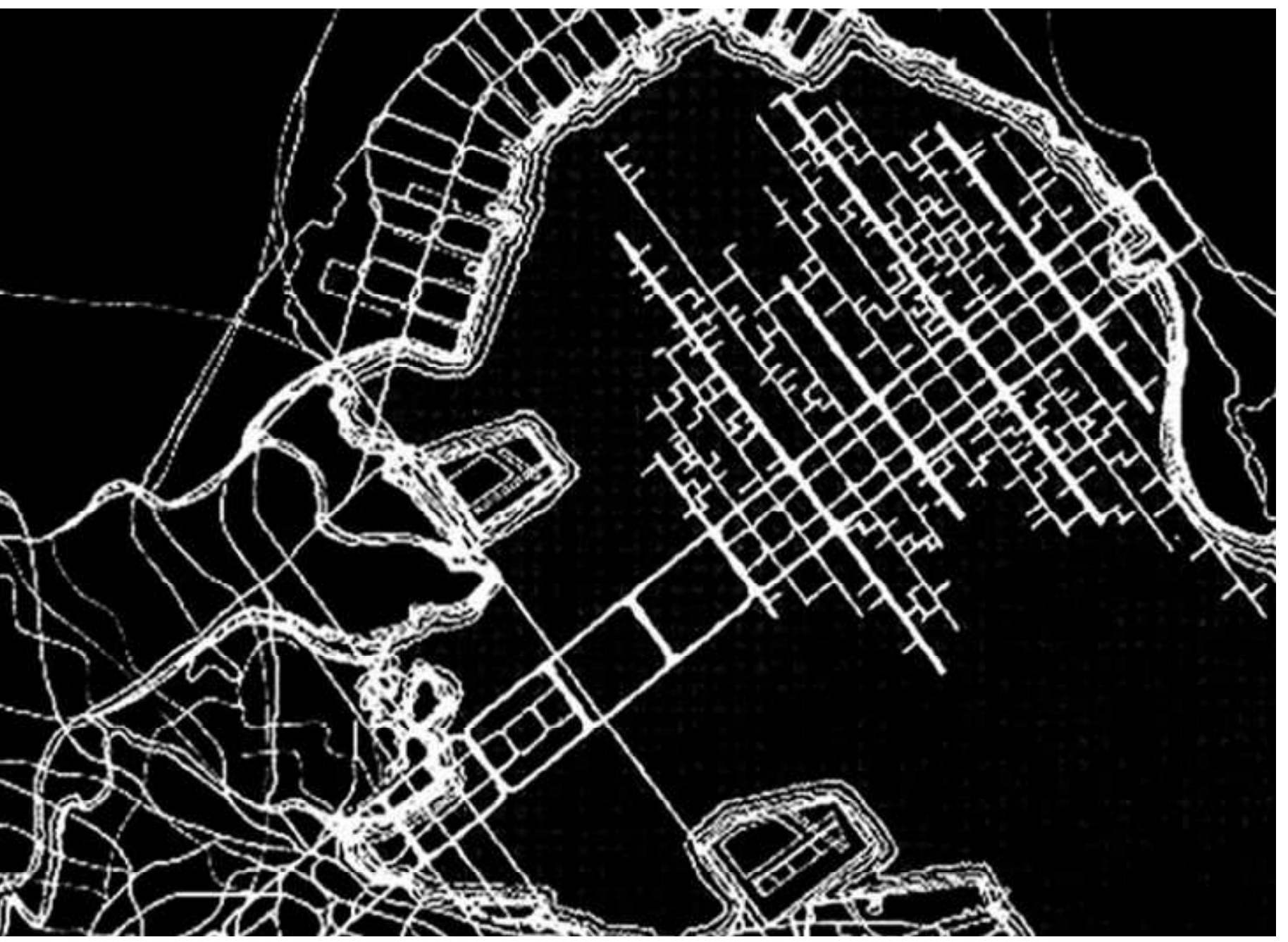

Baía de Tóquio, Kenzo Tange. Fonte: www.itaproject.eu

Também nesse período, o funcionalismo, ainda muito ancorado na arquitetura como uma condição necessária, foi questionado pelos chamados "paper architects", ${ }^{2}$ como o coletivo italiano Superstudio (1966 - 1978).

Em 1978, Bernard Tschumi produziu uma série de cartazes sobre arquitetura. Um deles mostrava a Villa Savoye (1931) de Le Corbusier em mau estado de conservação com a seguinte frase: "A coisa mais arquitetônica sobre este edifício é o estado de decadência em que ele se encontra. Arquitetura apenas sobrevive onde ela nega a forma que a sociedade espera dela. Onde ela se nega pela transgressão dos limites que a história lhe colocou." 3

\footnotetext{
${ }^{2}$ Termo utilizado para definir, especialmente nos anos 1960 e 1970, as produções arquitetônicas utópicas ou projetos experimentais não construídos.

${ }^{3}$ Fonte: An Introduction to Architectural Theory: 1968 to the Present.
} 


\section{The most architectural thing about this building is the state of decay in which it is.}

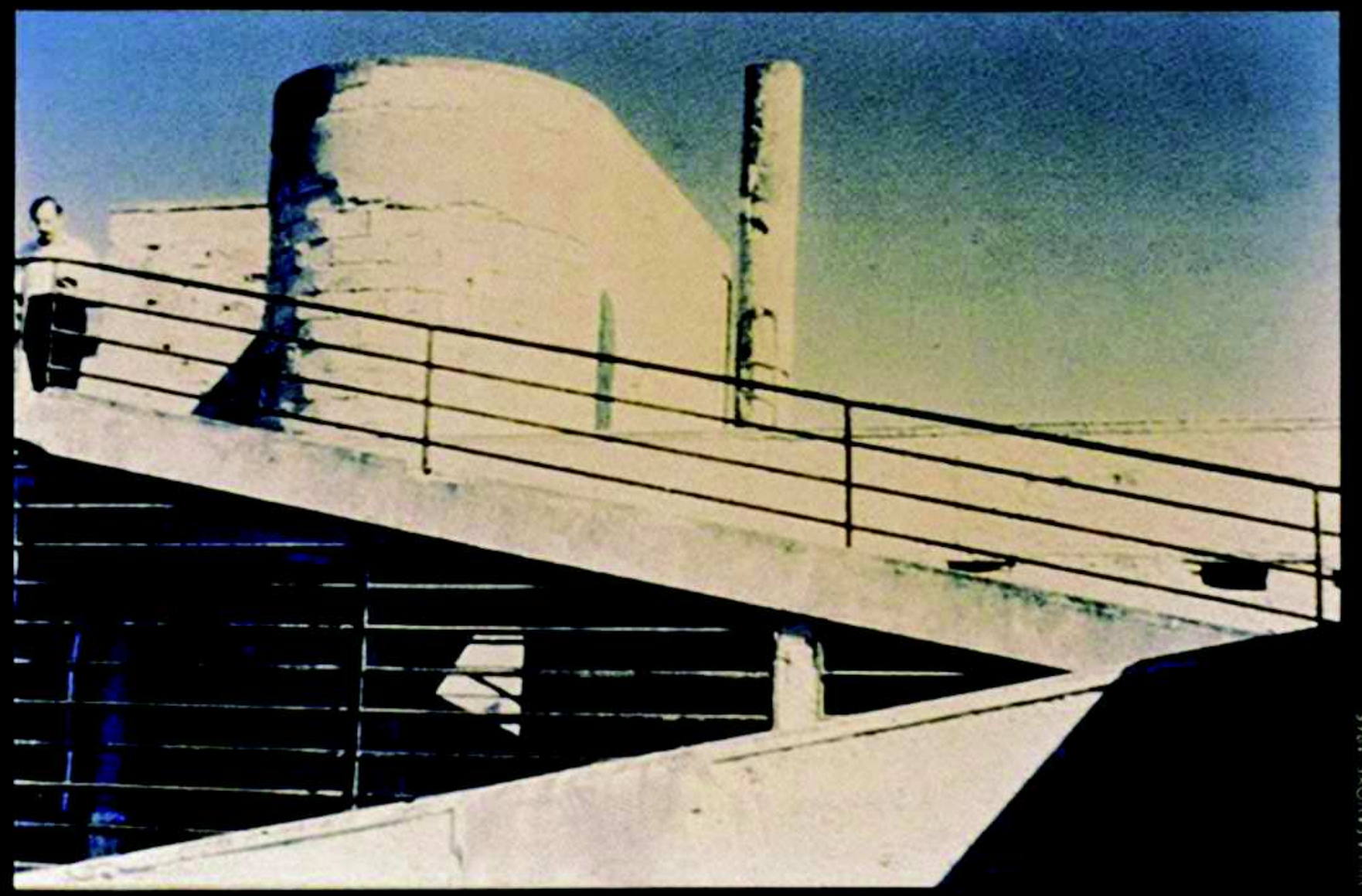

A rchitecture only survives where it negates the form that society expects of it.

Where it negates itself by transgressing the limits that history has set for it. 
A crítica à visão essencialmente modernista era também o que o Superstudio mostrava nas suas "propostas de papel": grandes estruturas que se projetavam sobre cidades e paisagens existentes para serem ocupadas de acordo com as necessidades dos usuários.

Adolfo Natalini afirma no catálogo da exposição de 1978 do Superstudio: "Iniciando a aplicação sistemática da 'demonstração por absurdo', produzimos um modelo arquitetônico para a urbanização total." O MVRDV se aproxima desse método com sua estratégia de 'cenários extremos', prática que chama atenção para as consequências no futuro de problemas da atualidade, como na exposição MetaCity/DataTown (1998).

Superstudio e MVRDV se aproximam com suas "arquiteturas de papel" que não podem ser materializadas e suas abordagens, bastante políticas, refletem a necessidade de mudar a forma de pensar o papel da arquitetura.

Além dessas propostas mais radicais, nos anos seguintes outras produções surgem, como as chamadas neovanguardas arquitetônicas, nomenclatura utilizada por autores como Kenneth Frampton para definir a arquitetura que aparece na segunda metade da década de 1960.

\subsection{Contexto global:}

\section{teoria crítica e práticas projetuais}

Para investigar as origens do MVRDV e posicioná-lo dentro da produção arquitetônica atual, na sequência abordamos, através de dois dos pilares dessa pesquisa (investigação projetual e teoria), o pensamento e a produção arquitetônica das neovanguardas e das pós-vanguardas, este último um termo utilizado por Michael Speaks (2002) para definir a arquitetura do final do século 20 e início do século 21.

Segundo Frampton (1997), é difícil encontrar o caráter fundamental do fenômeno pós-moderno e como ele surgiu na arquitetura. A crítica contemporânea do projeto pode ser vista como reação às alterações econômicas em uma realidade da cultura de massas, do consumo globalizado e do espetáculo da mídia.

Nos primeiros anos da década de 1970 surgem abordagens de projeto como uma prática mais autônoma. Tal pensamento foi reforçado em torno das figuras de 
Robert Venturi, Aldo Rossi e Peter Eisenman e que tiverem suas ideias difundidas em seus livros "Complexidade e contradição em arquitetura" (1966), "Arquitetura da cidade" (1966) e na tese de doutorado de Eisenman "As bases formais da arquitetura moderna" (1963).

A partir desse período a produção arquitetônica surge como contestação dos ideais modernos, reinterpretando seus valores ou propondo alterações radicais dos paradigmas modernistas. O contexto das neovanguardas é o da sociedade pósindustrial, do mundo da imagem e da comunicação.

A crítica à arquitetura moderna teve em seus primeiros projetos o resgate ao referencial histórico. Na década de 1980 tem evidência a desconstrução do espaço moderno, destacando-se os projetos de Rem Koolhaas e Bernard Tschumi para o concurso do Parc de La Villette, em Paris (1983) e a exposição do MOMA (Museum of Modern Art) Deconstructivist Architecture (1988), e na década de 1990 passa a ser associada aos nomes já reconhecidos de Koolhaas, Eisenman e Tschumi. Expressões como conjunção de fragmentos, estética da descontinuidade, recriação de formas autônomas, sugestão de espaços dinâmicos e desconstrução da realidade convencional estão relacionados a esse movimento que busca uma posição inovadora e de experimentação, desconecta-se da história e através dessas expressões se vincula ao seu tempo do caos contemporâneo, da condição efêmera e da desvinculação com o lugar.

As duas últimas décadas do século 20 também foram marcadas pelos desafios tecnológicos (novos software no processo de projeto e novas técnicas na fabricação e construção) e pelas questões (expansão urbana e densidade) referentes à forma das cidades, mas também apareceram temas que discutiam a finalidade da disciplina arquitetônica, seus conceitos próprios e seu grau de autonomia. Esse viés analítico já vinha despontando anteriormente em centros de estudo como a Architectural Association, de Londres, onde passaram Rem Koolhaas, Bernard Tschumi e Zaha Hadid, e o Institute for Architecture and Urban Studies (IAUS) em Nova York, fundado por Peter Eisenman.

O New York Five, liderado por Eisenman, fundamentou seus trabalhos em algumas diretrizes estéticas e ideológicas das vanguardas do século 20 (FRAMPTON, 1997, p. 378) e que repercutiu mais tarde na obra do OMA, de Rem Koolhaas.

Koolhaas utiliza questões atuais e a condição metropolitana como pontos centrais em seu trabalho. Um exemplo é o projeto ZKM, um centro de arte e tecnologia de 
mídias que é definido de acordo com o local, o programa e por suas contradições com o território urbano. Localizado em frente a uma estação de trem que se volta para o centro da cidade, o ZKM se opõe à condição clássica urbana e olha para a periferia.

Em 1989, Koolhaas dá início aos trabalhos de um masterplan para Lille (cidade pertencente ao triângulo Londres, Paris, Bruxelas e que abriga mais de 50 milhões de habitantes ${ }^{4}$ ), um projeto de escala regional que deveria controlar os fatores desencadeadores do caos devido à confluência de múltiplas variáveis neste lugar como centro de um território denso e complexo. O projeto trabalha como elemento ordenador e são os edifícios híbridos e de uso misto que geram certa ordem nessas espacialidades contemporâneas, pois podem adaptar-se às incertezas e mudanças. $\mathrm{Na}$ descrição do próprio $\mathrm{OMA}^{5}$, os programas no fim do século 20 se tornaram abstratos, pois não estão mais ligados a um lugar específico, eles flutuam em busca de um local com o maior número de conexões. Esses elementos formam uma nova condição urbana, que é local e global.

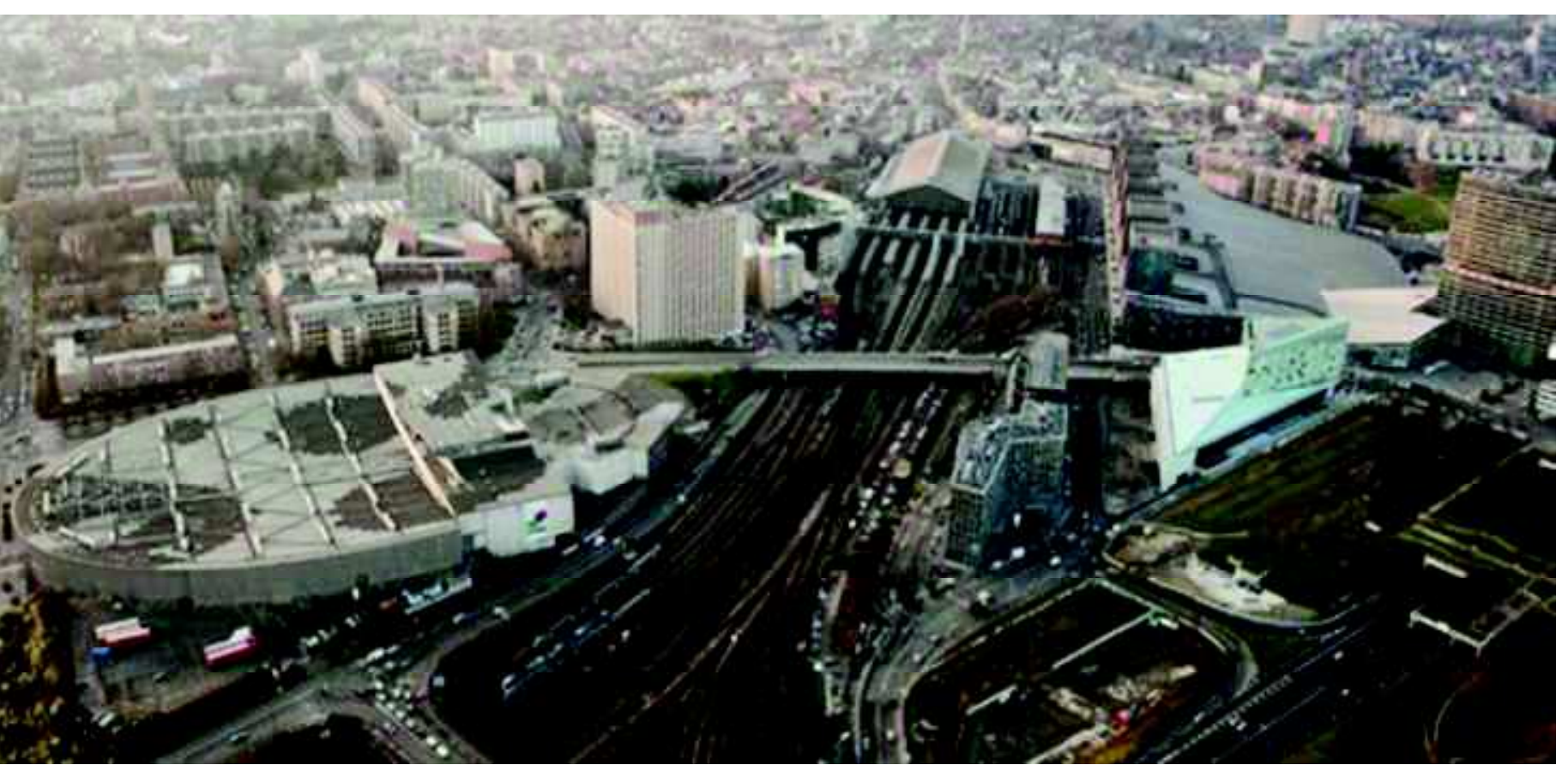

Euralille, 2010. Fonte: www.oma.eu

Enquanto o movimento moderno pode ser visto como conjunto que tem uma ideologia comum, a arquitetura pós-moderna pode ser encarada como soma de

\footnotetext{
${ }^{4}$ Fonte: www.oma.eu

${ }^{5}$ Idem.
} 
diferentes vertentes. Tal condição se intensifica nos anos 1990: apesar do compartilhamento de algumas ideias da disciplina, as buscas são cada vez mais individuais a cada escritório, especialmente ao que se refere às analises do contexto e à relação da arquitetura com os espaços urbanos. Vale ainda ressaltar a alteração do modo de operação do projeto que passou do pensamento crítico das questões sociais e estéticas do movimento moderno à valorização simbólica da arquitetura contemporânea como imagem e consumo visual, bastante divulgada na mídia especializada. Dessa alteração radical do arquiteto protagonista para o profissional despolitizado contemporâneo surge a necessidade de se atualizar a prática do projeto como um processo que contemple os desafios da sociedade atual.

Nesse ponto destacamos algumas reflexões do MVRDV que, dentro de seus estudos, discute conflitos como migração e produção de alimentos frente ao cenário de aumento populacional. Através dessas experimentações o escritório aborda o papel do arquiteto e os limites da disciplina, uma visão experimental e crítica que vem do movimento moderno, porém, enquanto os ideais modernistas focavam a solução de problemas do presente, os estudos do MVRDV projetam possíveis colapsos no futuro para resolver os conflitos atuais.

Retomando as pós-vanguardas arquitetônicas, uma grande crítica que surge a esse movimento (e talvez por isso, espera-se o contrário da produção que a sucede) é a redução da arquitetura à um envelope cenográfico. Segundo Frampton (1997), a arquitetura é reduzida a uma condição em que o construtor/empreendedor determina a carcaça e a substância essencial da obra, enquanto o arquiteto se vê reduzido a dar sua contribuição em forma de uma máscara.

O que muitos críticos vão contestar em relação às práticas pós-modernas é que o discurso que acompanha essas obras é elitista e neutro, tornando esse movimento uma vanguarda sem causa e alienado.

De acordo com Otília Arantes (1998), tanto na teoria como no projeto, houve uma alteração da crítica ao modelo racionalista para as práticas mercadológicas da lógica cultural, da sociedade do consumo individualizado e da proliferação de serviços.

A arquitetura, preocupada com a produção de imagens, e o urbanismo, submetido às pressões do mercado, originaram uma nova ligação entre o projeto, o arquiteto e o mercado especulativo. Com isso, as experimentações teóricas voltaram-se aos critérios estéticos e reduziram a arquitetura ao espaço visual. 
Nossos debates um tanto estéreis acerca da arquitetura ideal para a nossa época tornaram-se insignificantes diante da perspectiva apocalíptica dessa explosão de gigantescas metrópoles. Diante de migrações urbanas de tal magnitude, sem dúvida não existe nada de positivo que possa ser feito pela indústria da construção ou pela arquitetura (FRAMPTON, 1997, p. 416).

Com diversas discussões aparecendo em torno da produção pós-moderna, no final do século 20 duas antologias reuniram uma diversidade de textos sobre teoria de arquitetura e sobre como as 'práticas projetivas' ${ }^{, 6}$ mais recentes trazem novas reflexões. Para K. Michael Hays, editor de "Architectural theory since 1968", o movimento que se inicia nos anos 1960 procurava reconstituir a disciplina arquitetônica com conceitos derivados de outros campos, como filosofia, psicologia e antropologia. Esses temas, algumas vezes divergentes, deram origem à movimentos como o desconstrutivismo.

Kate Nesbitt, com "Uma nova agenda para arquitetura: antologia teórica 1965 1995", destaca a existência de uma multiplicidade de assuntos na teoria da arquitetura nos últimos trinta anos, fato influenciado também pela diversidade característica do período. Para Nesbitt, a teoria crítica aparece como pensamento especulativo e algumas vezes utópico que avalia a sociedade, sua relação com o ambiente construído e pode ter uma expressão política para estimular mudanças.

Essa questão da arquitetura como agente transformador é colocada por A. Krista Sykes, editora de uma terceira antologia, "Constructing a new agenda. Architectural theory, 1993 - 2009”, ao lembrar que arquitetos, historiadores e críticos do período pós-moderno, como Tafuri, reconheciam que a intenção da arquitetura como tarefa abrangente colocava a disciplina em uma posição impossível, provavelmente fadada ao fracasso.

No período entre os anos 1960 e 1990, houve uma preocupação em delimitar a atuação da arquitetura. Para Sykes, a dissolução desse plano nos anos seguintes mostra uma mudança de pensamento em relação à teoria de arquitetura questionando sua falta de correspondência com a prática. Essa ausência aparece nas falas de Michael Speaks e Alejandro Zaero-Polo (favoráveis à tecnologia como meio de produção arquitetônica) e Robert Somol e Sarah Whiting (defensores da

\footnotetext{
${ }^{6}$ Robert Somol e Sarah Whiting, "Notes around the Doppler Effect and Other Moods of Modernisms", Perspecta: The Yale Architectural Journal 33, Mining Autonomy, 2002, 72-77.
} 
autonomia da arquitetura em relação ao social e à cultura). Para Hays (2000) a desconexão com a prática é inerente à teoria já que a prática é limitada pela realidade econômica, social e política. No entanto, o autor enfatiza a importância do pensamento teórico para a evolução da disciplina.

O encerramento das publicações Assemblage e Any e o surgimento de novos periódicos como Praxis: journal of writing + building (1999), Hunch: the Berlage Institute Report (1999), 306090 (2001) e Grey Room (2000) que em contrapartida enfatizam uma maior continuidade entre discurso e projeto, também mostra o processo de reavaliação da teoria.

Nesse cenário, uma diversidade de temas entra em discussão a partir dos anos 1990, especialmente os avanços tecnológicos que permitem novos modos de projeto, representação e construção.

Reinhold Martin (2005) cita dois posicionamentos da história crítica, a primeira focada na crítica política (desenvolvida por historiadores críticos como Tafuri) e a segunda sobre crítica estética (associada a arquitetos como Eisenman). A póscrítica seria um terceiro momento caracterizado pela ausência da crítica. Como exemplo Martin cita a proposta do United Architects (FOA, Greg Lynn Form, Imagery Forces NYC, Kevin Kennon Architect, Reiser + Umemoto e UN Studio) para o World Trade Center em 2002 que, apesar da imagem quase visionária, mantém os padrões políticos e sociais atuais através do projeto. 


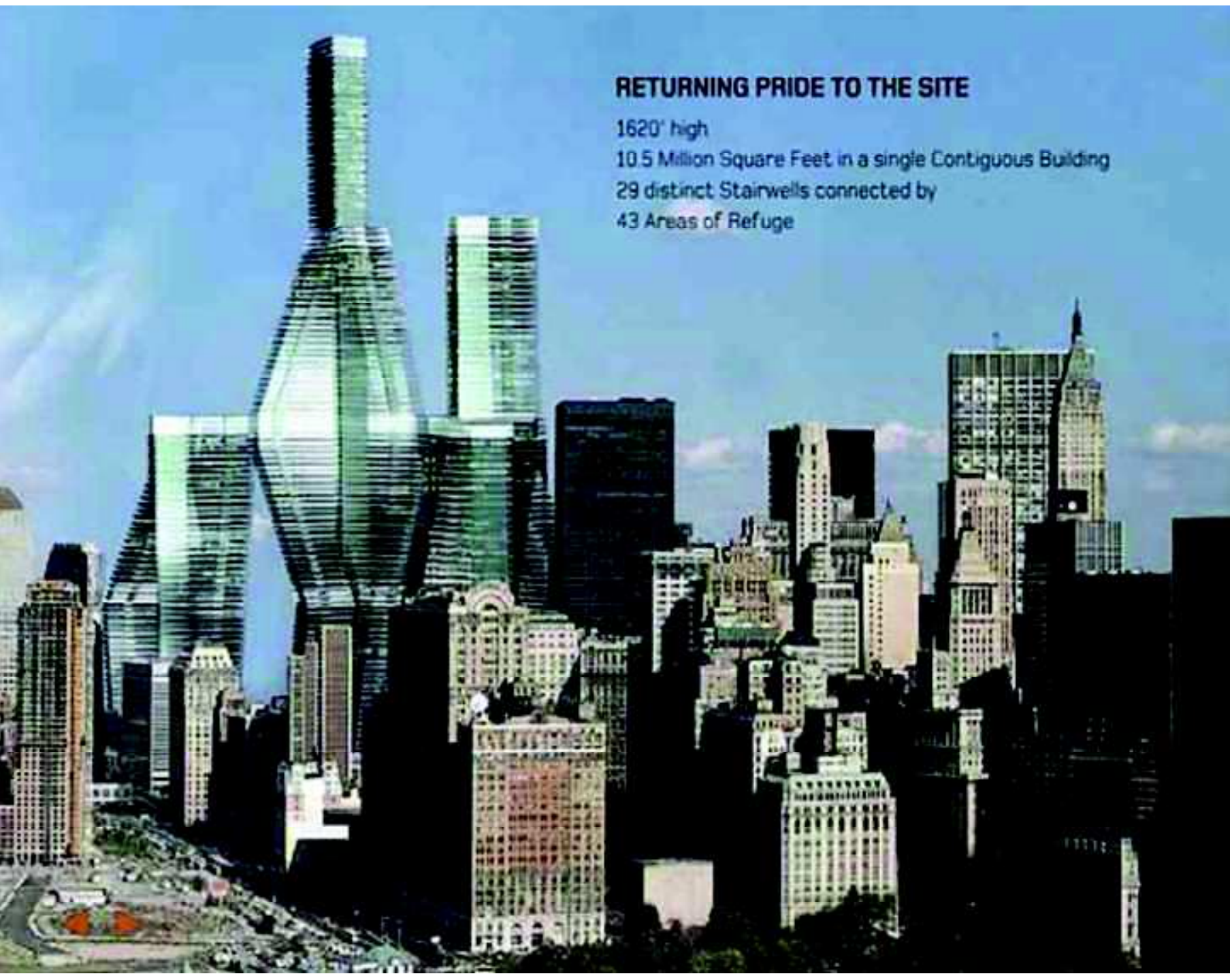

Proposta do United Architects. Fonte: http://renewnyc.com/

Essas práticas pós-críticas, também chamadas de 'práticas projetivas', têm Tafuri e, posteriormente, Hays como principais críticos. Já Eisenman e Michael Speaks se mostram favoráveis à autonomia da estética para que o habitante das cidades também tenha autonomia à parte dos acontecimentos sociais. O que Martin sugere é uma alternativa a essas posições através de uma prática que ele chama de "realismo utópico" e que considera a realidade ao mesmo tempo em que se posiciona frente às questões políticas e sociais, indo além dos limites da disciplina.

Ainda sobre a existência do pensamento crítico, nota-se nos anos 1990 um retorno teórico para a noção de pragmatismo, especialmente por parte de arquitetos holandeses. A fundação do Instituto Berlage, em 1990, potencializa esse debate trazendo novas perspectivas além do pensamento crítico abstrato. Nesse contexto, OMA, MVRDV e UNStudio se apresentam como organizações inovadoras e 
multidisciplinares com grande ênfase em pesquisa em um processo de reconstrução da teoria. Aqui vale definir o que significa 'foco na pesquisa', já que, em geral, todo projeto se inicia com algumas investigações. No caso do MVRDV, as análises abordam também temas que estão além do escopo da arquitetura, mas que interferem, principalmente, na formatação das cidades.

Esse processo de reconstrução é visto por Michael Speaks em seu texto Design Intelligence, de 2002, como uma mudança de modelos, da teoria para o conhecimento baseado em informação. Ele afirma que "se a teoria era o domínio intelectual das vanguardas do final do século 20 , então informação se tornou o domínio intelectual das pós-vanguardas do século $21 . "$

Speaks (2002) acredita que após o declínio das vanguardas não surgiram novas práticas que se adequassem e se desenvolvessem na nova realidade global dinâmica. Observa-se que frente a essas incertezas as práticas pós-vanguardas se mostram mais ativas na busca de inovação que não são encontradas em teorias e conceitos prenunciados.

Essa inovação é buscada na informação, elemento que é constantemente atualizado para poder confrontar as condições do início do século 21 e não se defasar em relação às instabilidades, como o acontecido com as vanguardas modernistas que não se adaptaram às mudanças do seu tempo. Speaks (2002) aponta que as novas práticas têm características individuais, não se enquadrando em classificações ou estilos, porém, notamos algumas similaridades na forma de utilização da informação de alguns arquitetos que somente se distanciam no modo de aplicação nos projetos - falaremos mais sobre essas similaridades ainda neste tópico.

As pós-vanguardas utilizam hipóteses, uma maneira rápida de testar cenários e que ajudam a tomar decisões e direcionam o processo de projeto. Esse método é bastante utilizado pelo MVRDV, como veremos nós próximos capítulos. Tal estratégia do design com informação é combinada com outras disciplinas e favorece a ampliação do campo de atuação de escritórios como OMA/AMO e SHoPArchitects que acabam desenvolvendo desde o projeto do edifício até o marketing do produto.

O OMA pode ser visto como um dos precursores da prática baseada em pesquisa (o masterplan para o IJplein em Amsterdã, 1988, é um exemplo dessa estratégia), mas são os escritórios de arquitetura, também holandeses, UNStudio e Crimson que utilizam a informação de modo mais parecido com o MVRDV. O UNStudio identifica 
as forças e influências do local como "mobile forces", já o Crimson é focado em "orgware", um termo derivado da economia que se refere aos fatores administrativos e relacionados à política que devem anteceder a aplicação de ideias e a implantação física da solução, como exemplo podemos citar a legislação sobre poluição sonora ou as características políticas locais que devem ser levadas em consideração.

Notamos que a conexão entre as práticas pós-vanguardas acontece através dessa abordagem de pesquisa e gerenciamento de informações e não pela identidade estética ou teórica. Em termos formais, alguns escritórios trabalham com caixas, bolhas e até paisagismo, mas para esses arquitetos, é a pesquisa e a multidisciplinaridade o ponto em comum para a busca de soluções projetuais.

Mas para Sanford Kwinter (1999), as novas práticas, especialmente o MVRDV, são versões empobrecidas do OMA de Rem Koolhaas. Para ele, esses escritórios estão "desimpedidos de toda intensidade social ou psicológica - isto é, de qualquer ideal ou valor histórico." No entanto, notamos que sem se fixar completamente em tais aspectos, esses arquitetos podem se concentrar em intervir na contemporaneidade. Retomando o fato de que existem algumas similaridades entre as práticas, observamos que alguns autores já começam a classificá-las em grupos. Jeffrey Kipnis, em Towards a new architecture, 1993, divide as novas estratégias em "InFormação" e "DeFormação". Enquanto a primeira faz uso das tradicionais caixas do modernismo e insere a informação em seu interior buscando uma inovação no programa, a segunda se alinha com as geometrias não cartesianas e topologias dobráveis.

Em InFormação podem ser citados como exemplos os projetos Centro de Arte e Tecnologia de Mídias, em Karlsruhe (1992) de Koolhaas e trabalhos do MVRDV, como o Silodam. Uma diversidade de elementos formais e de programa é inserida em um bloco neutro e as áreas residuais são destacadas como eventos de inovação, algumas vezes definidos como espaços articuladores de circulação. Outro ponto é que a InFormação não busca evidenciar a forma estética tanto quanto a DeFormação. 


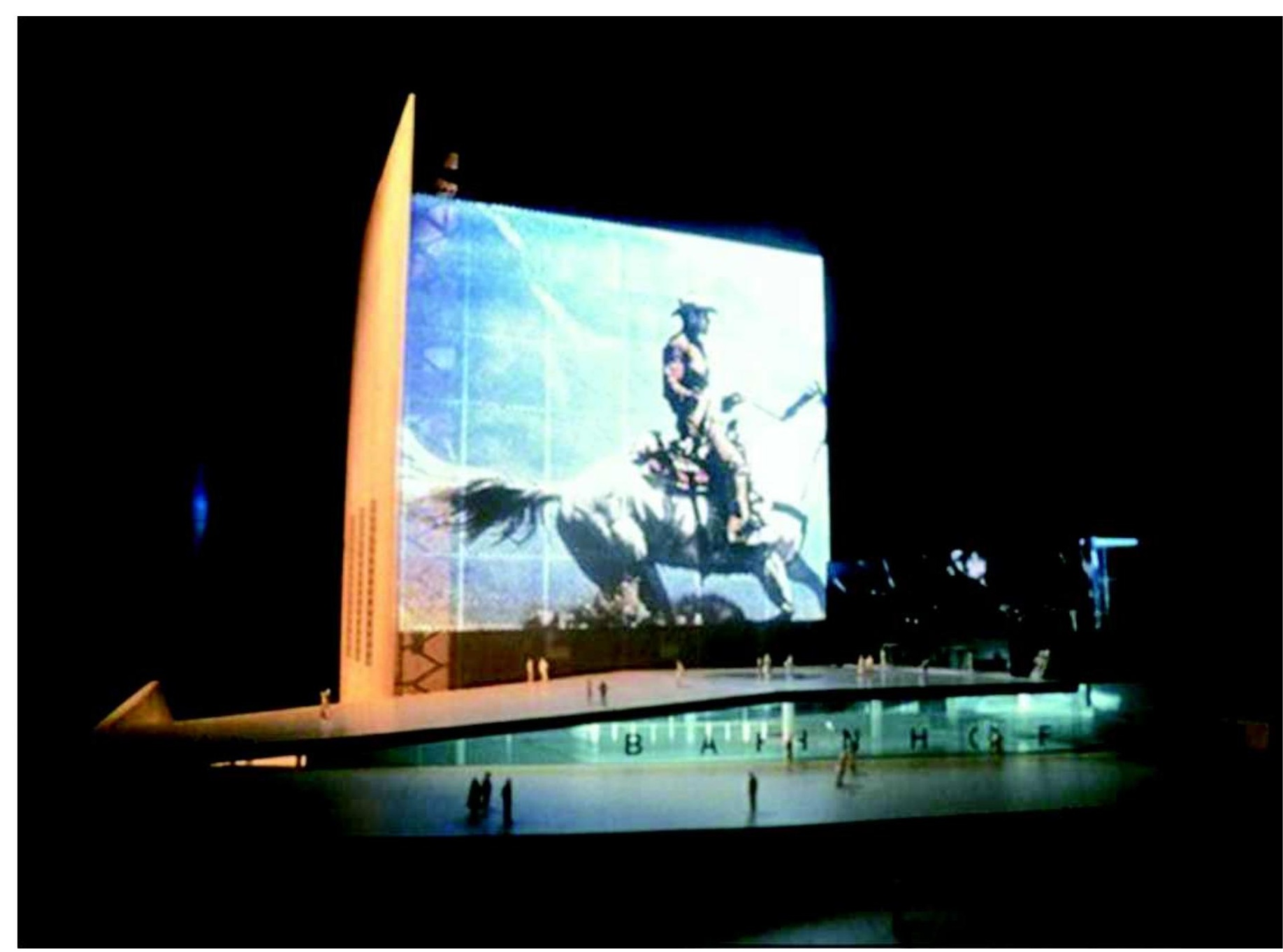

Centro de Arte e Tecnologia de Mídias, em Karlsruhe (1992), OMA. Fonte: www.oma.eu

Kipnis (1993) mostra como cada grupo analisa o outro. Para a DeFormação o uso do monólito modernista é uma forma de referência histórica e as imagens projetadas nesses blocos (como em Karlsruhe) funcionam como ornamentos. Por sua vez, InFormação examina as formas da DeFormação como questão puramente estética e de ornamento.

Anthony Vidler, em Architecture's expanded field ${ }^{7}$ (2008), por sua vez caracteriza o pensamento arquitetônico recente em quatro categorias que ele chama de combinações entre: arquitetura-paisagem (onde se enquadra o MVRDV por desenvolver novas topologias para edifícios e modelos digitais de cidades e regiões com o uso de dados); arquitetura-biologia (analogias biológicas); arquiteturaprograma (novos conceitos de programa) e arquitetura-arquitetura (em relação à recursos formais). Diferente de Speaks (2002), que acredita que a informação é a

${ }^{7}$ A partir de "Sculpture in the Expanded Field" de Rosalind Krauss publicado no periódico October em 1979. 
característica comum dessas práticas, Vidler (2008) aponta que é o uso de diagramas que une essas arquiteturas, mesmo que seus códigos generativos (através de regras e algoritmos) e a aparência se mostrem diferentes. No entanto, mais do que isso, o que o autor enfatiza é a necessidade desses arquitetos trabalharem questões mais amplas que seus antecessores, especialmente aquelas relacionadas ao aumento populacional e ao meio ambiente.

Assim como Vidler, Antoine Picon (2004) também aponta que o maior problema da arquitetura na atualidade é a falta de uma agenda política e social claramente definida. Partindo do princípio de que as tecnologias digitais permitem que os arquitetos se tornem mais envolvidos na criação do ambiente que os cerca (coordenando e negociando soluções), Picon espera que a expansão e a reavaliação da disciplina arquitetônica nos conduza a um aumento do papel social e político da arquitetura.

Nesse sentido, a contribuição das novas tecnologias se dá à medida que a digitalização facilita a manipulação de formas complexas e a visualização multidimensional de cenários que mostram as alterações do projeto e suas consequências para arquitetos e demais envolvidos. A digitalização traz consigo um aumento do interesse por números, padrões e informações, mas todos esses elementos precisam ser alimentados pela investigação teórica.

Para Hays (2005), na virada pós-teórica, arquitetos e estudantes são encorajados a evitar a teoria porque a arquitetura é sujeita às forças dinâmicas que vão além do controle das intenções do design. Somam-se a isso as restrições econômicas e construtivas, as demandas de clientes, o programa e questões políticas. A arquitetura é limitada também por convenções da disciplina, expectativas culturais e a própria movimentação da história. Encontra-se uma variedade de barreiras para a teoria, mas para Hays (2005), a ênfase na prática parece uma recusa em imaginar algo além dos limites do presente ou algum projeto futuro. Ampliamos essa ideia ao considerar também a própria recusa à crítica da prática.

Nesse contexto, o desenvolvimento da teoria vem acontecendo pontualmente de uma associação entre universidades e escritórios de arquitetura. Tal fato se dá, geralmente, porque carecem meios onde as universidades possam aplicar suas pesquisas enquanto, para os escritórios, faltam foco e tempo para experimentações. Como exemplos de arquitetos que têm adotado esse método de trabalho podemos citar Stan Allen e James Corner, que colaboram no pensamento arquitetônico, 
pesquisa e paisagismo e o MVRDV, que realiza pesquisas com dados (os datascapes), planejamento urbano, software para tomadas de decisões (como o Regionmaker) e a publicação dos trabalhos do escritório como pesquisa.

Esses arquitetos acabam se envolvendo muito mais com o ambiente acadêmico do que seus colegas que trabalham exclusivamente com projetos e talvez seja Koolhaas um dos primeiros a trabalhar desse modo, já que sua primeira "prática" mais conhecida foi o livro Delirious New York.

Koolhaas também desenvolveu estudos junto com seus alunos na Harvard School of Design, como o "Project for the city". Na Holanda, o Intituto Berlage associa design com pesquisa e a Universidade de Delft tem, na faculdade de arquitetura, a Delft School of Design mais voltada para pesquisa. Segundo Arie Graafland (2006), esse tipo de associação tem em comum a exploração de campos da arquitetura com pensamento crítico.

No entanto, para Speaks (2003) a teoria crítica é passado. O autor foca nas novas práticas, em especial aquelas que fazem uso da informação de duas possíveis maneiras: 1- como uma forma específica de conhecimento para a profissão, 2- para pensar o futuro conhecendo os efeitos e impactos sociais das suas propostas.

A proposta de pensar o futuro considerando as consequências dos projetos é fundamental, mas ressaltamos a importância da prática associada ao pensamento crítico, principalmente para a educação de arquitetura. Como bem lembrado por Graafland (2006), as universidades precisam do lado pragmático dos escritórios para poder realizar as experimentações da "arquitetura reflexiva".

Curiosamente, esta estética reflexiva acabou fazendo parte da indústria cultural através da produção de livros e revistas especializados, principalmente com tantos tratados de arquitetura que rendem direitos autorais e funcionam como forma de publicidade - voltaremos a abordar este tema no capítulo 2 quando apresentaremos os estudos e publicações do MVRDV.

\subsection{Contexto local: arquitetura holandesa}


Vimos até aqui que o MVRDV surge em um cenário de transformações da disciplina que engloba pragmatismo, o projeto com informação, novas tecnologias digitais, a ênfase na sustentabilidade - mesmo que difusa - e a atuação dos starchitects. Mas antes de abordar a pesquisa e os estudos utópicos do MVRDV no próximo capítulo, é necessário entendermos um pouco mais do contexto dentro da arquitetura holandesa onde o escritório surgiu, suas influências na teoria e na habitação.

$\mathrm{Na}$ década de 1990, a arquitetura holandesa chamava atenção no cenário internacional, principalmente com Rem Koolhaas, com uma busca pela ruptura do conhecimento sobre arquitetura que prevalecia até então, produzindo novos projetos e teorias. A percepção de uma nova produção voltou-se também para outros escritórios holandeses mais jovens como Wiel Arets, Ben van Berkel e, depois, West 8, MVRDV, Neutelings e NOX, sendo que grande parte deles seguiu o exemplo de Koolhaas publicando livros, palestrando, participando de exposições e lecionando em escolas de arquitetura importantes como a Architectural Association em Londres, a Universidade de Columbia em Nova York e a Universidade de Harvard em Boston. Para entender esse cenário produtivo vamos nos voltar brevemente para um período anterior a esse momento.

\subsubsection{MVRDV e o panorama pós anos 1960}

Os anos 1960 foram marcados por insatisfações com a política social na Holanda. Segundo Bart Lootsma (2000), a crise do petróleo, em 1973, aumentou a pressão popular e os questionamentos sobre a falta de planejamento para o crescimento do país. Depois de anos dominados por um desenvolvimento suburbano de grande escala, os bairros dos antigos centros das cidades haviam caído em desuso. Os projetos residenciais eram pensados na escala da pequena casa unifamiliar, mesmo esta fazendo parte de um plano de habitação maior.

Houve uma proliferação de bairros sem planejamento e novas cidades, como Almere. Nessa época, poucos projetos eram pensados como forma de inovação, entre estes, se destacam os trabalhos de Piet Blom para Kasbah em Hengelo, chamados de projetos experimentais por Hans Ibelings (1995), por causa de sua forma e tipologias não convencionais com a ideia de criar espaços públicos como praças ou se abrir ao nível da rua. 


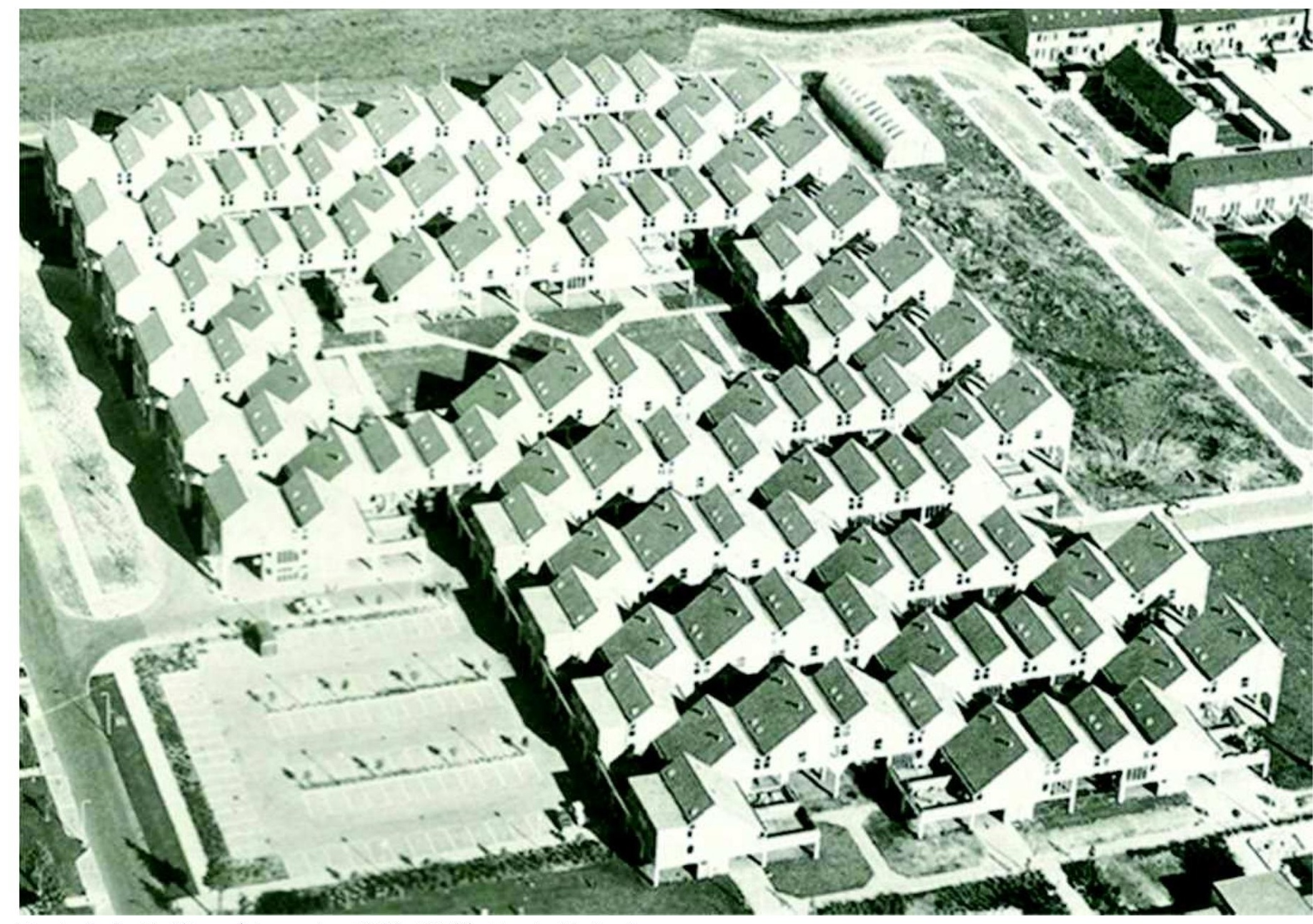

Kasbah de P. Blom (Hengelo, 1969-1973). Fonte H. Ibelings

Se nos anos 1960 existiu um movimento de expansão dos subúrbios com cidades dormitórios, separação de funções e o desaparecimento da dimensão urbana devido à pequena escala das habitações marcadas por casas isoladas, a década de 1970 marcava o início de um período com o surgimento da renovação urbana que buscava uma coerência entre a escala dos projetos e das cidades. Um exemplo é o projeto Arena, de Carel Weeber (Alphen de Rijin, 1974-1978) que rompeu com o paradigma das casas isoladas em favor do retorno do bloco e da escala maior como organizadores principais do planejamento urbano. O radicalismo de Weeber, que rejeitou o que considerava ser uma arquitetura inabitável - produto indesejado da onda de democratização na Holanda - só foi igualado, na visão de lbelings (1995), pela produção de Rem Koolhaas. 


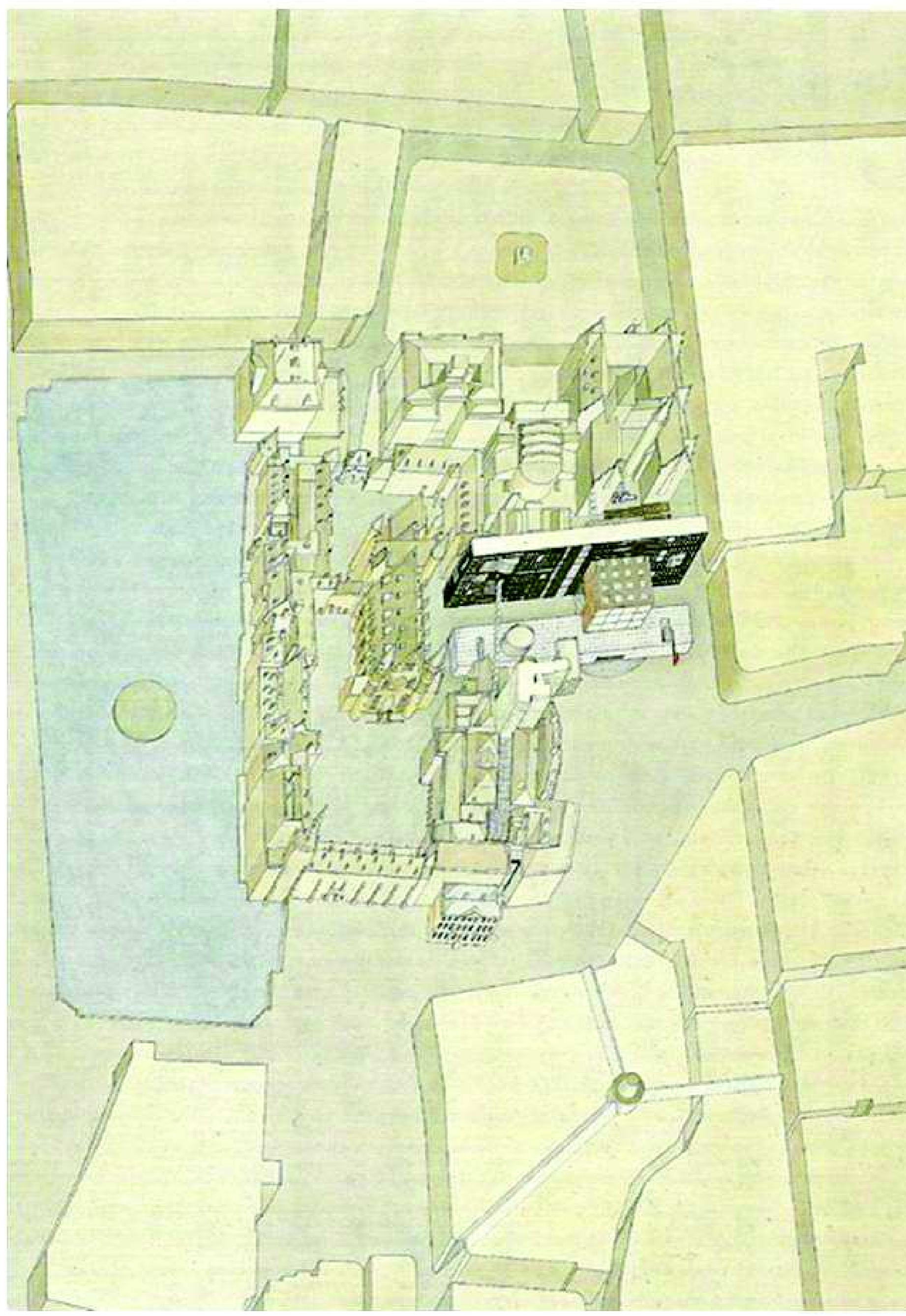

Proposta do OMA para a extensão do Lower Chamber (Haia, 1978). Fonte H. Ibelings 
Para Ibelings (1995), depois dos anos 1970, quando a arquitetura estava mais submetida aos objetivos sociais, houve uma tentativa de recuperar a autonomia da disciplina. São utilizadas definições como Neo-Racionalismo para descrever uma abordagem racional e soluções com formas geométricas mais neutras. Somam-se a isso as ideias de cidade compacta com uso misto, alta densidade e interesses no espaço público urbano de praças e ruas. Neste contexto, Koolhaas aparece mais uma vez como representante de uma concepção de urbanismo com elementos diferentes coexistindo juntos, acentuando os contrastes e contradições da cidade.

Na mesma época, existia outra corrente na Holanda que representava a tradição de cidade onde a reparação do tecido urbano e a recriação da ordem são as principais características. Jo Coenen (1949) pode ser considerado um representante desse movimento que tem as ideias enraizadas na cidade européia, enquanto Koolhaas tem uma abordagem mais ligada à metrópole americana. Para Coenen, influenciado pelo pensamento pós-moderno, o enraizamento de um edifício no contexto sempre desempenha um papel importante, mas os edifícios também devem ser vistos como objetos autônomos. Um exemplo dessa autonomia pode ser notada nos anos 1980 com escritórios como Mecanoo, DKV, Duinker/Van Torre e Van Herk \& De Kleijn. Seus edifícios respeitam a altura e alinhamento dos prédios vizinhos, mas se diferem da vizinhança na aparência. Telhados planos, janelas grandes e varandas, o uso de cores, entradas e tipologias das habitações contrastando com o entorno e a intervenção agindo como transformadora do espaço urbano. O projeto habitacional Tiendplein (1984-1990), do Mecanoo, em Rotterdam pode ser visto como um exemplar dessa corrente (IBELINGS, 1995, p. 144).

No final da década de 1980, vários escritórios na Holanda passaram a contar com o apoio de instituições públicas para o desenvolvimento de pesquisas, o que é o caso do MVRDV a partir da década de 1990. Bart Lootsma (2000) enfatiza que o aumento de interesse pelo público e pelos políticos sobre a arquitetura, que começou nos anos 1980, ganhou força na década de 1990 com os Ministérios da Cultura e Habitação e Planejamento traçando planos para estimular a arquitetura como componente cultural e criando novas instituições como o The Netherlands Architecture Institute (1989) e o Instituto Berlage (1990).

No mesmo período, questões de ordem global passam a influenciar o campo da cultura e, consequentemente, a arquitetura. Para Lootsma (2000), a cultura de qualquer país se abrindo para a internacionalização está sujeita a duas forças 
opostas: uma reavaliação dos valores das tradições nacionais e a vontade de participar dos principais desenvolvimentos internacionais. As duas tendências aparecem na arquitetura holandesa nos anos 1990: encontrar um lugar no discurso arquitetônico internacional sem sacrificar as qualidades locais.

Ibelings (1995) chama atenção para outro evento na década de 1990. Para ele, nessa época, a arquitetura holandesa foi caracterizada pela libertação da herança moderna cada vez mais sentida como opressiva. Os princípios da arquitetura moderna eram usados de forma liberal, principalmente pelas gerações mais novas. Isso resultou em uma arquitetura híbrida, cujo conceito espacial continuou a ser enraizado, e que é realizada em uma variedade de formas, cores, texturas e materiais. Uma abordagem diferente é a consciente pesquisa de novos caminhos, na teoria e na prática. Nesse sentido, destaca-se a posição de Koolhaas como ponto de referência na arquitetura holandesa. Essa mudança de direção foi estimulada pelo congresso organizado por ele em 1990, nomeado 'How modern is dutch architecture?'. Nele, o arquiteto incluiu até seus primeiros trabalhos, como o plano diretor para o norte de Amsterdã (1980-1989) e vários projetos residenciais que foram criados em cima de modelos e exemplos da arquitetura moderna. No entanto, esses projetos foram excluídos, mais tarde, de sua publicação, $S, M, L, X L$. Lootsma e Ibelings vão citar igualmente a postura do crítico Hans van Dijk que argumentava que a arquitetura moderna na Holanda não estava sendo transmitida como uma tradição intelectual, mas sim como uma tradição formal, passada às novas gerações através da educação e inspirada no modernismo pré e pós-guerra. O trabalho do Mecanoo ilustra essa situação: enquanto nos anos 1980 eles se referiam a modelos de modernismo (como o bloco de apartamentos em Bremen, de Alvar Aalto), na primeira metade da década de 1990 essas referências quase desapareceram. "É aí que o Mecanoo pode alegar ser um exemplo da hibridização" (IBELINGS, 1995, p.162). 


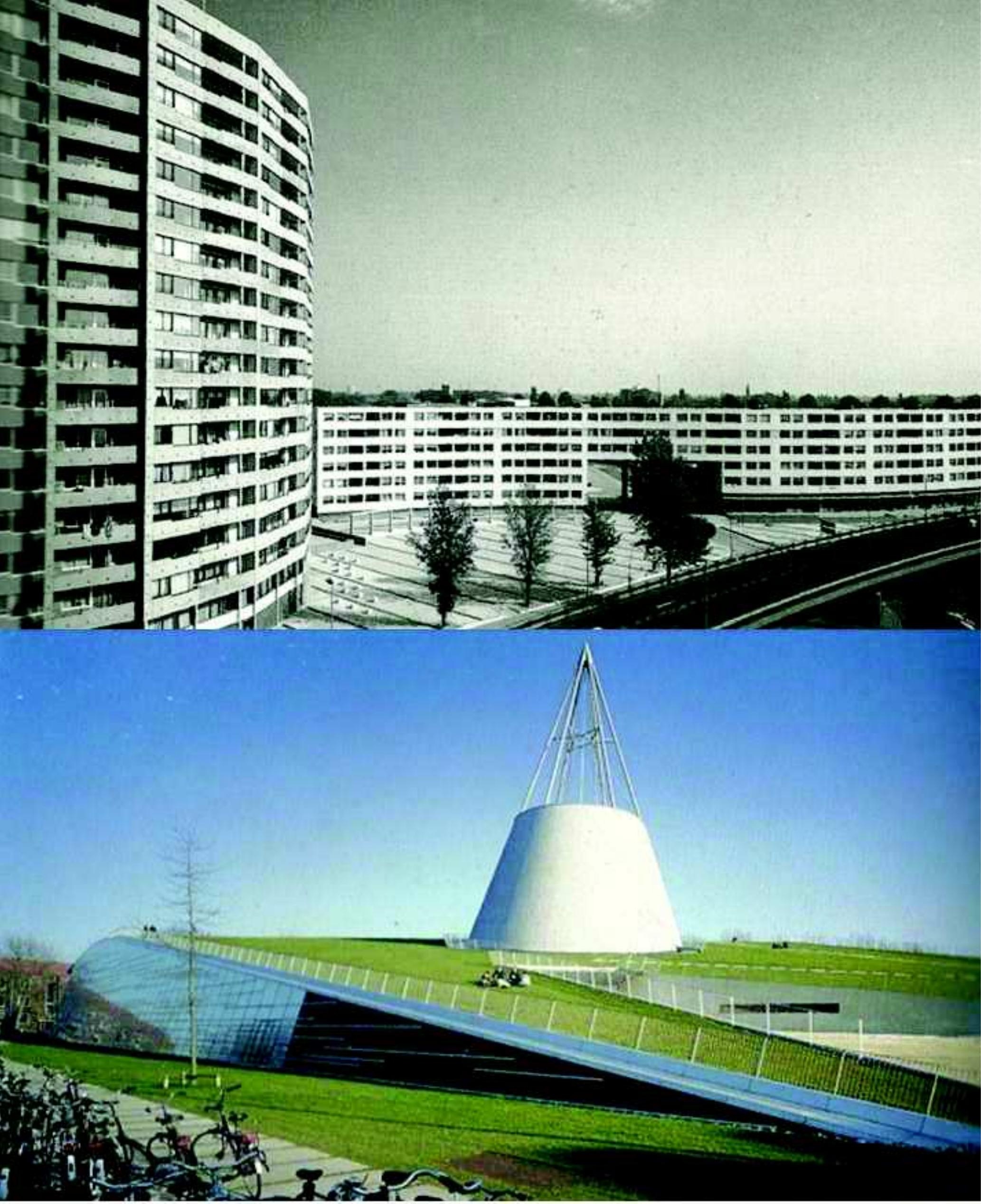

Mecanoo, projeto de habitação Hillekop (Rotterdam, 1986-1989). Fonte: H. Ibelings Mecanoo, biblioteca da Universidade Técnica de Delft (1997). Fonte. B. Lootsma 
Segundo Ibelings (1995), Koolhaas foi o único que levantou questões fundamentais sobre o modernismo e ele é um dos poucos que tentam levar em conta o papel que o arquiteto e urbanista ainda pode ter, em um mundo caracterizado pela desintegração, caos, aumento de escala, novos meios de comunicação e transitoriedade. No início dos anos 1990, vários trabalhos do OMA ficaram prontos, como casas unifamiliares na Holanda e na França, um edifício habitacional em Fukuoka, o complexo em Euralille e o Kunsthal em Rotterdam, reforçando suas ideias sobre a aceitação dos fatos contemporâneos como inevitáveis.

No final de 1970 o trabalho de Koolhaas tinha antecipado as mudanças cruciais que estavam para acontecer por volta de 1990. Seu primeiro livro retratava uma sociedade marcada por um congestionamento radical e um individualismo hedonista em uma metrópole que já era parte de uma rede internacional do capitalismo. Seus estudos sobre o muro de Berlim (1971) e o projeto Exodus de 1972 previram a queda do muro que aconteceu em 1989, inaugurando a ascensão quase global do capitalismo. Em outras palavras, desde o início de sua carreira, ele estava em busca de uma nova marca de modernidade, os primeiros sinais de que estavam apenas se tornando detectáveis (LOOTSMA, 2000, p.19, tradução nossa).

A relação entre tradição e inovação é, para Lootsma (2000), bem ilustrada no trabalho de Koolhaas. Um exemplo é o projeto urbano para IJplein no norte de Amsterdã (1980-1989), no qual o OMA se deparou com a situação de lidar não somente com os clientes e a cidade, mas também com os habitantes dos bairros contíguos e seus futuros moradores. É aí que o escritório de Koolhaas adotou uma nova estratégia; nessa época muitos projetos urbanos não foram concluídos porque os arquitetos apresentavam seus trabalhos, os moradores tendiam a criticá-los e o arquiteto precisava refazê-lo do começo, em um processo sem fim. O que o OMA fez foi apresentar uma série de possibilidades. Se os usuários questionassem algo, eles imediatamente poderiam responder às consequências daquela opção sem ter que preparar um novo estudo. O processo de negociação resultava no projeto final, uma estratégia que também vamos identificar no processo de trabalho do MVRDV. Questionando os edifícios antigos que não atendiam às necessidades de uso misto e adensamento, o OMA desenvolveu novas tipologias para atender as necessidades e os novos modos de vida da sociedade. Destacam-se aí as superfícies contínuas dobradas, uma ideia que apareceu primeiro na proposta para a biblioteca de Jussieu 
em Paris e foi adotada em formas variadas por inúmeros escritórios de arquitetura, incluindo o MVRDV e seu projeto da Villa VPRO.

Segundo Ibelings (1995), o MVRDV foi formado pelas ideias de Koolhaas em três momentos: estudando na Universidade Técnica de Delft, trabalhando no OMA e investigando seu discurso.

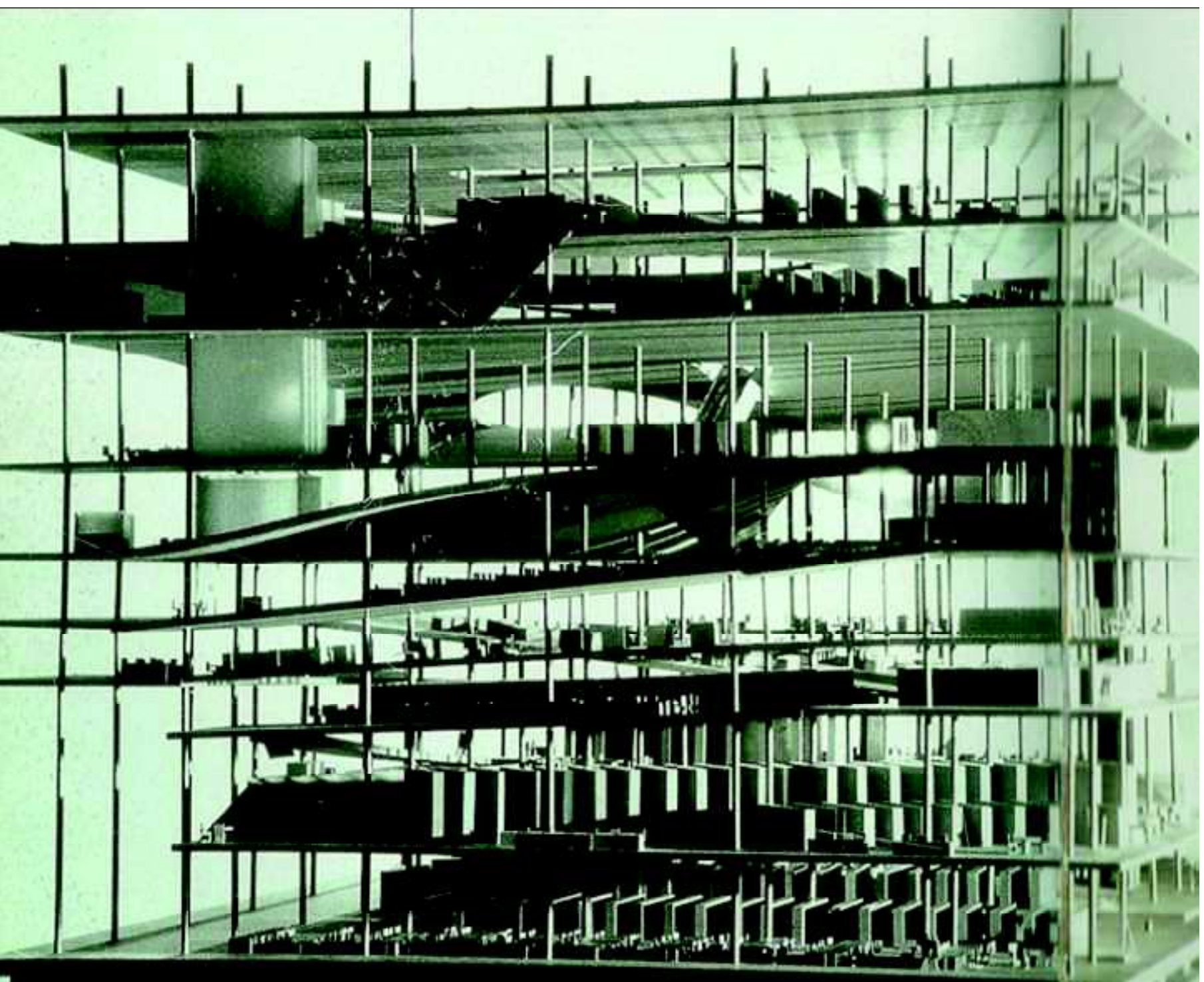

Proposta do OMA para a biblioteca de Jussieu. Fonte: B. Lootsma

$\mathrm{Na}$ mesma época outros trabalhos se desenvolviam, o leste de Amsterdã teve projetos urbanos de Jo Coenen, Sjoerd Soeters e West 8 . Este último elaborou um plano de alta densidade para o bairro de Borneo que foi mais tarde desenvolvido com projetos de vários arquitetos, sendo um deles o MVRDV. Neste plano, a diversidade aparece mais uma vez como forma de hibridização. Para Ibelings (1995), no nível tipológico essa tendência por variedade pode ser observada no projeto habitacional Piraeus de 1994, de Hans Kollhoff, em Amsterdã, onde quase 
todas as habitações são diferentes. Essa estratégia também é vista na proposta vencedora do MVRDV para o concurso do Europan (1991) com o edifício habitacional Berlin Voids.

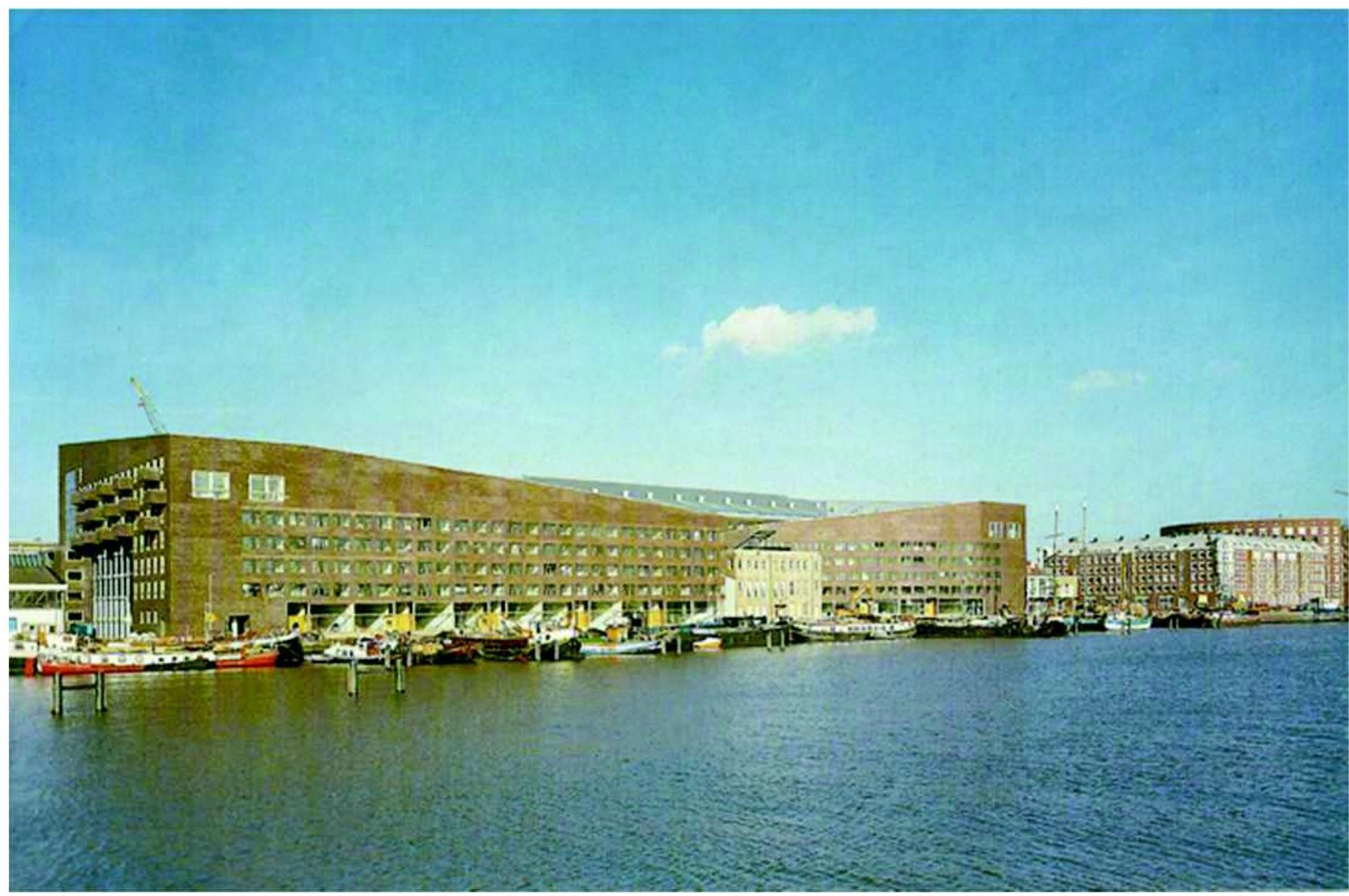

Edifício Piraeus, H. Kollhoff, Amsterdã, 1994. Fonte: H. Ibelings

A questão da diversidade é discutida também nas falas de Adriaan Geuze e West 8 quando estes produziram uma enorme maquete com 800 mil casas que ficou em exposição no Netherlands Architecture Institute (1995). A ideia era ressaltar as consequências do crescimento habitacional através de uma paisagem que parecia um mar sem fim de casas, evocando também os problemas das grandes cidades. Mesmo que os arquitetos fizessem o melhor para dar uma identidade diferente a cada bairro, o resultado mostrava uma grande uniformidade e o quanto era importante coordenar esse desenvolvimento em um nível mais amplo (LOOTSMA, 2000 , p.21). Os resultados desse experimento levaram à criação de um livro escrito pelo West 8 (In Holland staat een huis - em português, Na Holanda existe uma casa). 

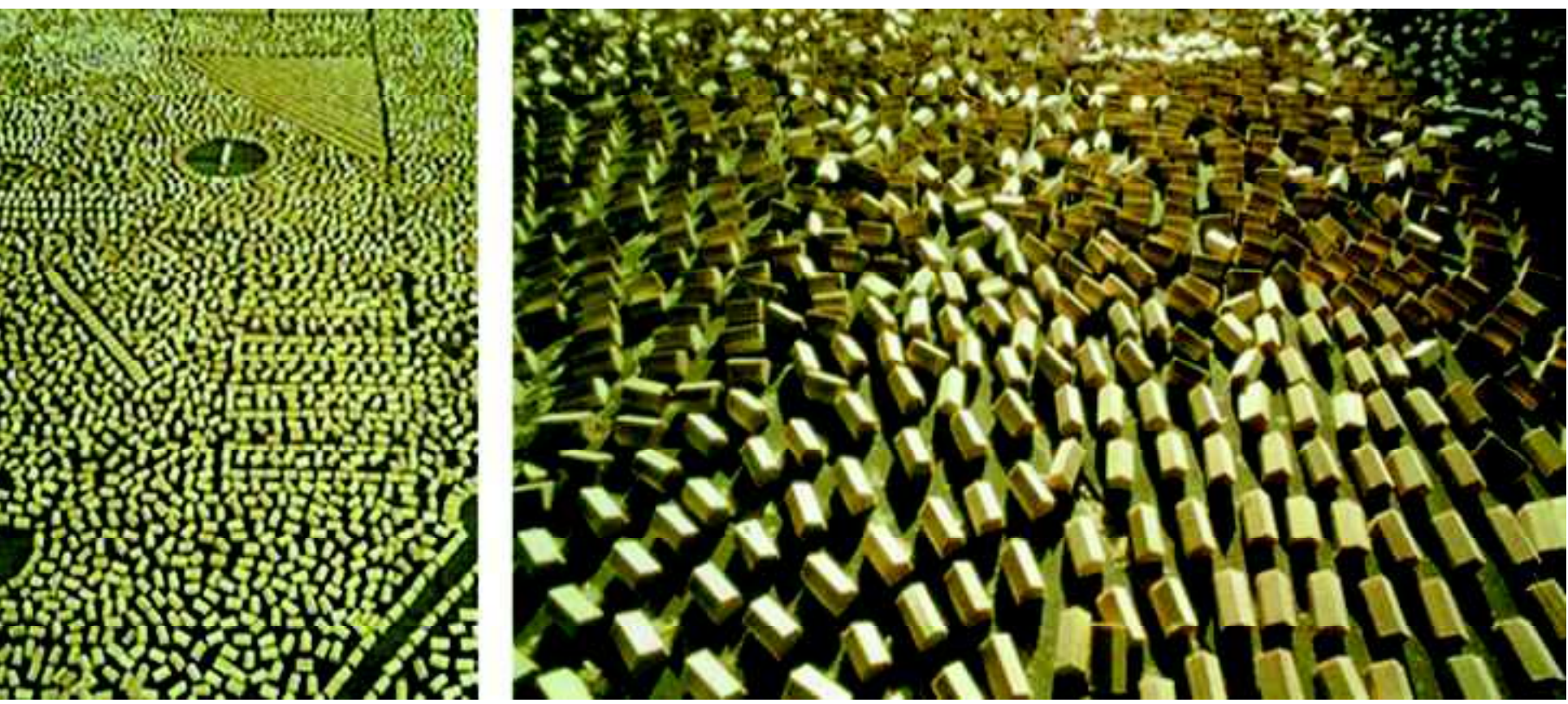

Adriaan Geuse/West 8. Maquete de 800 mil casas (Rotterdam, 1995). Fonte: B. Lootsma

Esses questionamentos levaram os arquitetos a elaborarem planos que deveriam ser justificados. Assim como no caso do projeto de Koolhaas para o IJplein, os escritórios precisavam explicar suas ideias para várias partes diferentes: clientes, profissionais de outras áreas envolvidos, usuários, moradores da vizinhança e a municipalidade.

O fator crucial é a qualidade e a credibilidade dos argumentos empregados e o modo como o arquiteto os integra ao esquema. Escritórios como OMA, West 8, MVRDV, Neutelings Riedijk e UNStudio tentam lidar com essa situação. Eles analisam o contexto de cada projeto, sem considerar suposições prévias, e tentam trazer o potencial inerente à tona (LOOTSMA, 2000, p. 23, tradução nossa).

Lootsma (2000) descreve esse processo como um mapeamento das forças internas e externas que podem influenciar na execução do projeto e no desenvolvimento, mas mesmo com essa metodologia, ainda pode-se identificar uma assinatura comum entre os arquitetos citados. Ben van Berkel e Caroline Bos (UNStudio) com as 'mobile forces' e o MVRDV com o termo 'datascapes'. Sobre essa metodologia de trabalho, Lootsma (2000) situa os dois escritórios como práticas diferentes, mas assume que o modo de trabalho descreve uma situação semelhante. Van Berkel e Bos tentam coletar todas as informações possíveis referentes ao projeto e depois fazem uso do computador para sintetizá-las e criar um diagrama que formará a base do design. Os datascapes do MVRDV são versões elaboradas do que ele chama de 
situações do projeto. Ou seja, são todos os dados quantificáveis do contexto onde o projeto será inserido. Com o uso de computadores mapeiam-se essas informações do entorno sobrepondo-as umas sobre as outras, para revelar as restrições do projeto antes do processo de negociação ser iniciado junto com os demais envolvidos. Assim como Koolhaas, eles assumem as diferentes camadas e fragmentos da cidade dentro do processo deixando-os visíveis. Para o MVRDV (1999) os datascapes podem ser extrapolados para uma escala maior, para exercícios teóricos sobre o crescimento das cidades, onde as consequências desses cenários futuros podem ser visualmente investigadas. ${ }^{8}$

Essas práticas trabalham com a ideia de que o projeto deve ser capaz de funcionar interativamente ao invés de conter preceitos ideológicos na forma construída, conforme acontecia com as neovanguardas. O método e o processo de projeto são o foco do trabalho e a pesquisa da realidade, representada por diagramas e outras análises de dados, torna visíveis as possíveis soluções.

Roemer van Toorn (2004) classifica tais práticas em três tipos: autonomia projetual; cenário projetual e naturalização projetual. O autor identifica os métodos de trabalho nos escritórios de arquitetura holandeses que surgem a partir dos anos 1990:

- Autonomia projetual, com representantes como Claus\&Kaan, Rapp + Rapp, Neutelings Riedijk. Em muitos casos aparece como uma arquitetura simples que mescla elementos funcionais, econômicos e representacionais. Não coloca em pauta questões como movimento, complexidade ou outros processos dinâmicos, mas preocupa-se com a estabilização de valores culturais e econômicos.

- Cenários projetuais, MVRDV e NL Architects. Os arquitetos são coordenadores do projeto que tem a participação do usuário. Os projetos trazem a realidade à tona com a ajuda de cenários baseados nos dados retirados do contexto e da cidade que funcionam como um grande banco de dados. As premissas e as regulamentações holandesas são seguidas rigorosamente, mas existe a preocupação com um programa inventivo e novas soluções como no projeto do NL Architects para um bar em Ultrecht que tem a adição de uma quadra de basquete na cobertura. O MVRDV insere uma diversidade de programas em blocos monolíticos que os próprios arquitetos chamam de "hungry boxes"'. Nessa categoria, os arquitetos buscam

\footnotetext{
${ }^{8} \mathrm{O}$ conceito datascapes será discutido com mais detalhes no capítulo 2.

9 'Hungry Boxes: the endless interiors of MVRDV' foi uma exposição do MVRDV desenvolvida junto com o Netherlands Architecture Institute em 2002 que apresentava os interiores de projetos do escritório através do conceito de "interiores sem fim" no qual programas diversos são compactamente entrelaçados.
} 
revelar informações do dia a dia que ficam escondidas, como acontece no estudo Pig City do MVRDV, que será abordado no capítulo 2.

- Naturalização projetual, com Oosterhius.nl, Maurice Nio, NOX. O que essas práticas têm em comum com a natureza são suas formas com similaridades com as estruturas, processos e formas da biologia. Algumas vezes a fachada não é só uma casca, mas uma membrana que muda de acordo com as atividades, luz e temperatura. Ao contrário dos "cenários projetuais" a "naturalização projetual" não faz simulações relacionadas à sociedade, política, globalização ou usuários, essas práticas exploram a funcionalidade que gira em torno de movimento, autoorganização e interatividade.

Van Toorn pontua como limitações dessas estratégias projetuais o fato delas se deixarem guiar pelo realismo do mercado, ao invés do arquiteto tomar as responsabilidades pelo design e orientar os fluxos sem se recuar aos limites da disciplina. $O$ destaque dado à diversidade e flexibilidade da cultura pode se tornar uma estratégia sem consciência política, histórica ou social. Por essas restrições, van Toorn entende que as três práticas são formalistas e não vêem a utopia como desenvolvedora de possibilidades que vão além do status atual. As práticas projetivas podem se tornar mais completas a partir do entendimento de que a interação entre utopia e realidade pode desenvolver uma nova perspectiva social. Sobre esse aspecto, entre os escritórios holandeses citados por van Toorn, consideramos o MVRDV como um dos poucos que cultiva a utopia como prática em seus experimentos - abordaremos mais essas questões no capítulo 2 .

Diferente de van Toorn, Lootsma (2000) vê a busca por diversidade como resposta aos problemas da sociedade atual, sem se ater aos problemas enfrentados pela disciplina ou as possíveis consequências das novas práticas:

Independentemente do mérito de tais estratégias, desenvolvendo-as o arquiteto consegue preservar certa medida de controle sobre o projeto, e não de uma forma visionária ou autoritária, mas como um coordenador que mantém o processo em curso. A questão mais importante é a diferenciação de tipologias, com o objetivo de responder aos problemas colocados por uma sociedade heterogênea, um tema que tem uma clara importância no planejamento urbano, na construção de habitações, prédios públicos e comerciais. Essa busca é paralela à pesquisa por novas formas de organização, onde transparência e conectividade são prioritárias (LOOTSMA, 2000 , p. 24, tradução nossa). 
Além do reconhecimento da importância do OMA, Lootsma também dá certa evidência ao MVRDV. O autor descreve o escritório como aquele que melhor expressa as mudanças na sociedade holandesa nos anos 1990:

Suas propostas confrontam clientes, usuários e observadores com novos pontos de partida, explorando as tensões entre leis e regulamentações de um lado, e de outro, o aumento da individualização e das forças do mercado. No processo de projeto as diferenças e conflitos entre os datascapes são negociados com cada parte, até um ponto em que o projeto possa ser realizado (LOOTSMA, 2000, p. 123, tradução nossa).

O MVRDV chamou atenção pela primeira vez com o projeto de apartamentos Berlin Voids, vencedor do concurso Europan em 1991. Neste trabalho as unidades habitacionais foram concentradas em um único bloco, de modo que o espaço público fosse criado na forma de um vazio. Dentro desse bloco existiam 34 tipos de habitação, visivelmente diferentes de fora pela fachada em vidro.

A proposta deveria ocupar um terreno localizado em um bairro próximo ao antigo muro de Berlim. O programa previa a construção de 284 habitações e 30 mil metros quadrados de área comercial para desenvolver a região. Para o MVRDV (1998, p.561), a ideia de que a moradia é um lugar temporário é cada vez maior. O número de vezes que uma pessoa muda de casa passou de 2.2 em 1950 para 7.8 para 1994. Os arquitetos utilizam a seguinte afirmação para explicar a diversidade de tipologias:

É como fazer uma carreira, as pessoas devem ter passado por um loft, uma casa no lago, morar sozinho, etc. Existe uma demanda por variedade e não existe mais a casa perfeita, existem centenas delas (MVRDV, 1998, p. 561, tradução nossa).

Além disso, existia a questão sobre o respeito ou a recriação do contexto:

A questão era saber se o entorno do edifício original deveria ser respeitado, empurrando Berlim Oriental ainda mais para um mundo de blocos de apartamentos baixos e desumanos, ou se o novo edifício deveria se assumir maior do que os seus vizinhos, de modo que Berlim pudesse aproveitar a densidade adequada para uma cidade grande. A solução foi combinar os dois tipos, criando um bairro vertical, repleto de tipologias habitacionais e espaços públicos (MVRDV em www.mrvdv.nl, tradução nossa). 
WoZoCo (Amsterdã, 1997) foi o primeiro projeto habitacional do MVRDV construído. Sua solução formal chamou a atenção do mundo todo e o projeto é um dos trabalhos mais publicados do escritório, tendo sido divulgado exaustivamente na mídia especializada. A diversidade das unidades é novamente notada através de sua variedade de janelas, portas, varandas e as unidades em balanço, resultado de uma solução dada às restrições do local quanto à insolação e ocupação do terreno.

Devido à legislação sobre insolação, foi possível alocar 87 unidades na lâmina. As outras 13 unidades não deveriam ser alocadas no solo para não diminuir a área livre. Essas unidades foram penduradas na fachada norte. As unidades internas tiveram uma economia de 7 a $8 \%$ cada, o que financiou as unidades em balanço, uma vez e meia mais caras (MVRDV, 1998, p.322, tradução nossa). 


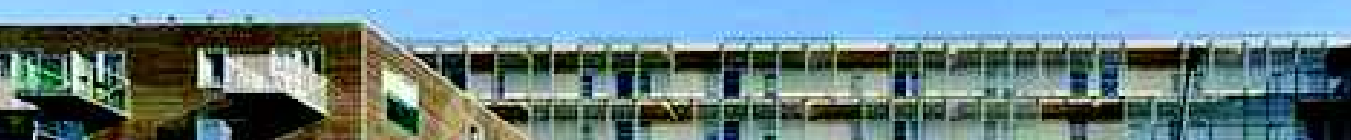
$\frac{\square \quad \square-4}{4}$

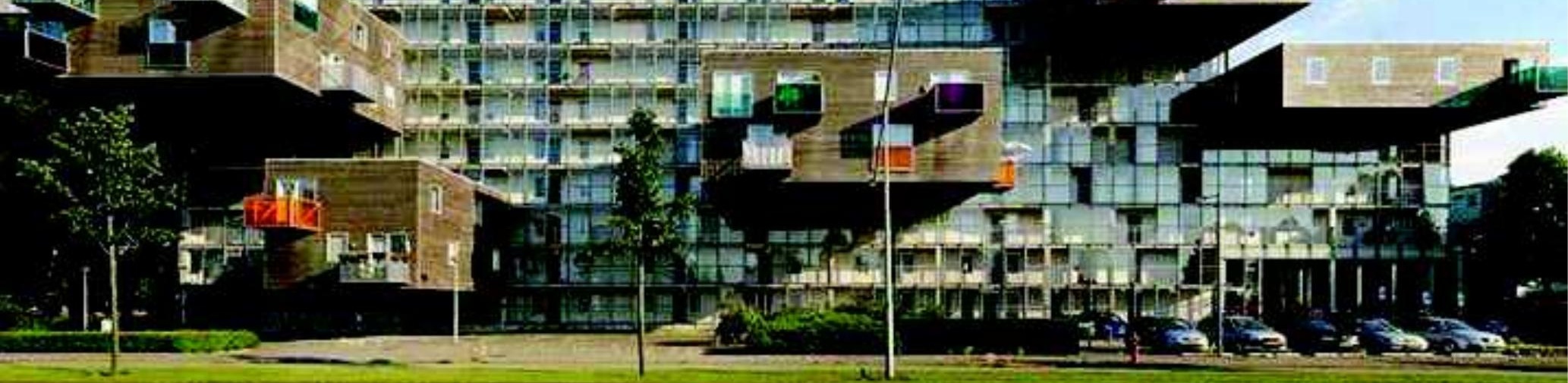

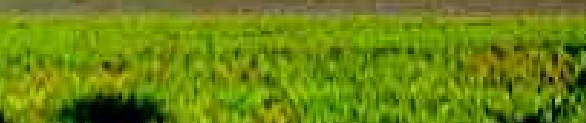

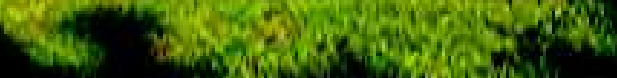

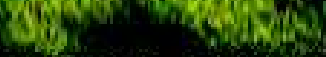

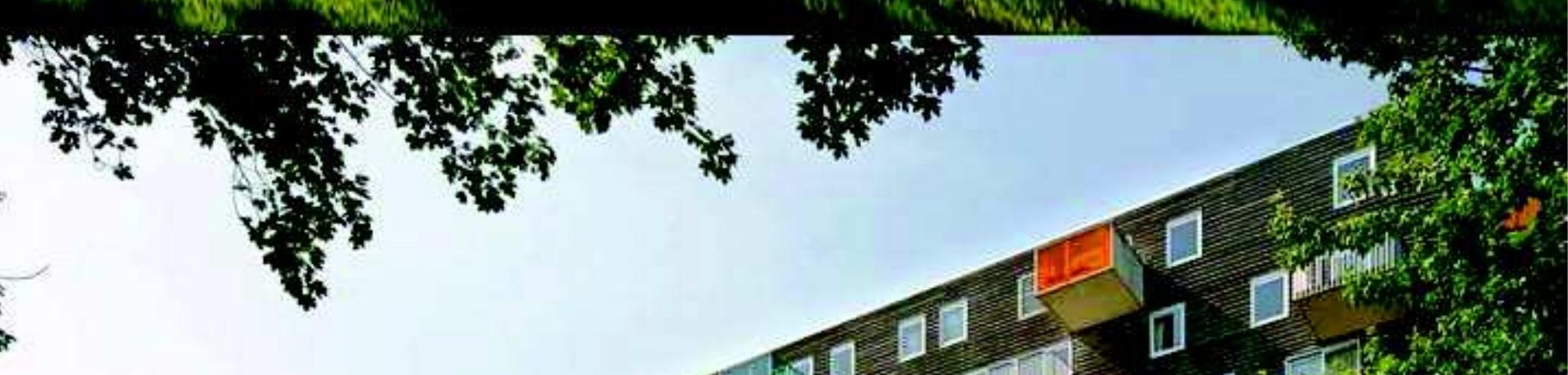

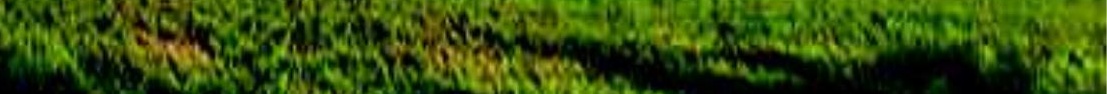

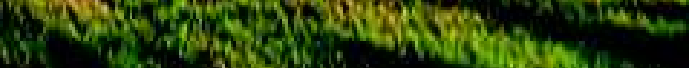

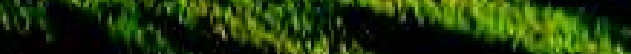

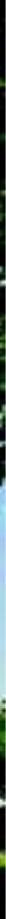


Outro projeto importante do início da carreira dos arquitetos é a sede da empresa holandesa de radiodifusão VPRO (Hilversum, 1994-1997). A VPRO ocupava várias casas espalhadas e decidiu alocar sua equipe em um único prédio em prol da integração e da comunicação. Aqui as características positivas da antiga sede foram extraídas para criar o novo espaço:

Pode esse ar de informalidade (das vilas) caber em um edifício corporativo? A metáfora da vila pode ainda existir? A vila pode ser caracterizada pelo aspecto compacto, sem longos corredores, justapondo diferentes tipos de espaços e por sua relação com a paisagem do entorno (MVRDV, 1998, p. 680 , tradução nossa).

A solução foi dada através de um edifício compacto de cinco pavimentos diferente de um edifício de escritórios padrão: não existem salas divididas, nem corredores de acesso e o prédio se abre como uma continuação da paisagem, onde vários layouts podem ser arranjados. Os pavimentos são conectados por rampas e escadas que podem adquirir outros usos quando necessário. Aqui se percebe a influência das superfícies contínuas dobradas de Koolhaas, que o MVRDV vai redefinir como uma interiorização espacial. Neste projeto, o método de negociação com o usuário final foi fundamental para a geração dos espaços de trabalho não convencionais.

Outra importante influência no trabalho do MVRDV é o arquiteto Herman Hertzberger que adota a preocupação de John Habraken de arquitetura como estrutura a ser habitada e adaptada pelos usuários, aplica esse conceito para todos os tipos de edifícios - escolas, habitações, escritórios - e qualifica suas circulações como áreas articuladoras de encontros sociais, pequenos espaços públicos como forma de inserir a cidade no edifício.

Um dos seus trabalhos mais conhecidos, e que tem uma visível influência no projeto da Villa VPRO, é a sede da companhia de seguros Centraal Beheer (1968-1972). O escritório foi projetado de modo que os colaboradores da empresa ocupassem o espaço de forma livre, de acordo com suas necessidades e com o menor número possível de barreiras físicas entre as diversas áreas. Centraal Beheer e Villa Pro permitem que as empresas vivenciem novos tipos de ambientes de trabalho, tanto no modo de gestão e organização espacial como de apropriação individual do espaço. 


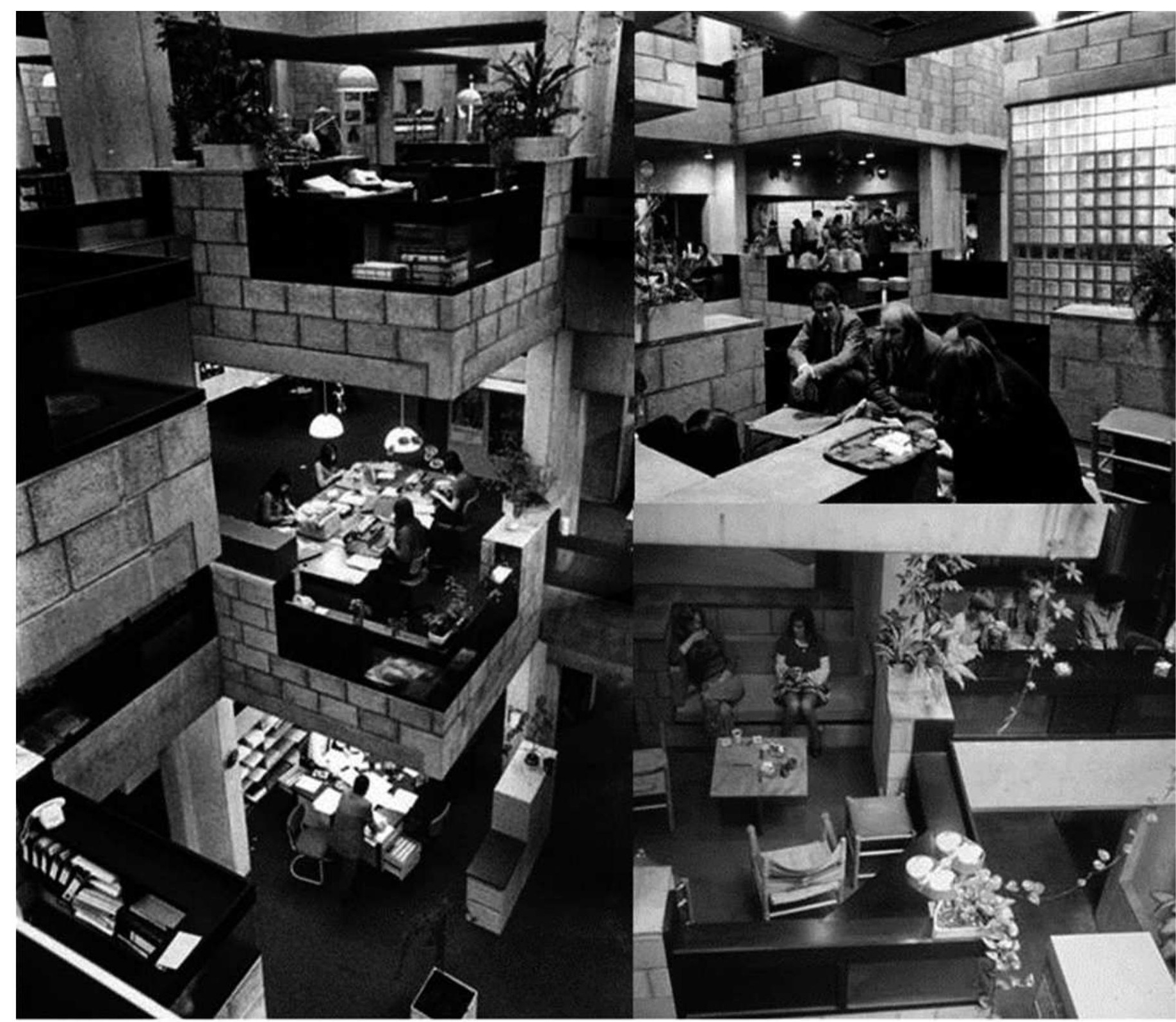

Interior da Centraal Beheer. Fonte: www.nai.nl 


\subsubsection{MVRDV: Origens do pensamento teórico}

É notória a influência de Rem Koolhaas na formação do MVRDV. Recentemente, dois periódicos de arquitetura fizeram publicações sobre Koolhaas e os escritórios originados da "escola OMA".

Em janeiro de 2011 a revista Metropolis publicou o artigo "Baby Rems" com um diagrama com vários escritórios de arquitetura fundados por ex-colaboradores do OMA, ao todo são 46 nomes divididos em duas gerações, entre eles o MVRDV, que mostram o alcance de uma rede global de arquitetos e, consequentemente, de extensão do pensamento arquitetônico, não vista desde Le Corbusier.

O outro periódico, Clog, que começou a ser publicado em 2011 e trabalha com edições monotemáticas relacionadas à arquitetura, teve o seu número de maio de 2014 dedicado à Rem Koolhaas. Nele foram publicadas entrevistas com excolaboradores do OMA, como Erez Ella (de 1999 a 2006), do HQ Architects e Winy Maas e Jacob van Rijs (ambos de 1990 a 1993) do MVRDV, que trabalharam em diferentes épocas no escritório.

Enquanto Erez Ella aprecia o funcionamento do OMA e tenta levar algumas dessas características para o $\mathrm{HQ}$, Winy Maas segue a direção contrária e tenta enfatizar as diferenças entre MVRDV e OMA.

Para Ella, a abordagem de pesquisa do OMA busca questionar assuntos importantes, não apenas para os projetos em andamento, de modo que os estudos funcionem como um trabalho único em contínuo desenvolvimento. Para ele, Koolhaas determina uma infraestrutura que permite acontecer projeto e pesquisa ao mesmo tempo.

Apesar de tentar enfatizar as diferenças com suas origens, as investigações e publicações do MVRDV têm diversas semelhanças, principalmente em seus primeiros anos, com o modelo OMA. Jacob van Rijs fala sobre pesquisa na época em que trabalhou com Koolhaas:

Naquele tempo, qualquer projeto do OMA era sobre pesquisa, você pode encontrar esses projetos e seu repertório publicado em S, M, L, XL. Esse era o charme especial do OMA, você faria a pesquisa que torna o projeto visível (VAN RIJS em entrevista para CLOG, maio/2014, p. 80, tradução nossa). 


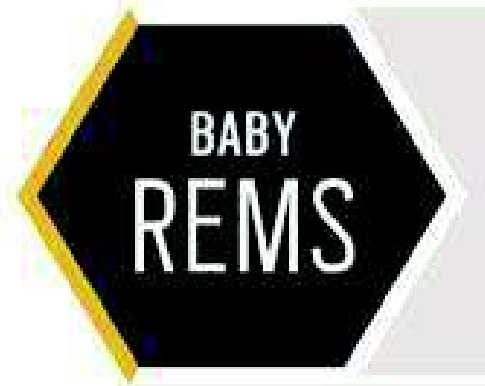

\section{Paul Makovsky}

In 1975 Rem Koolhaas, together with Elia and Zoe Zenghelis and Madelon Vriesendorp, founded the Office for Metropolitan Architecture. Today OMA is one of the most influential arehitectural practices in the world. Not only has the firm designed some of our era's most important buildings-Maison ì Bordeaux, the Seattle Public Library, and the CCTV headquarters, to name just a few-but its famous hothouse atmosphere has cultivated the talents of hundreds of gifted architects. Look at the chart on these pages: it is a distinguished architectural fraternity. These OMA grads have now created an influence all their own, and they are the ones to watch in 2011. [I

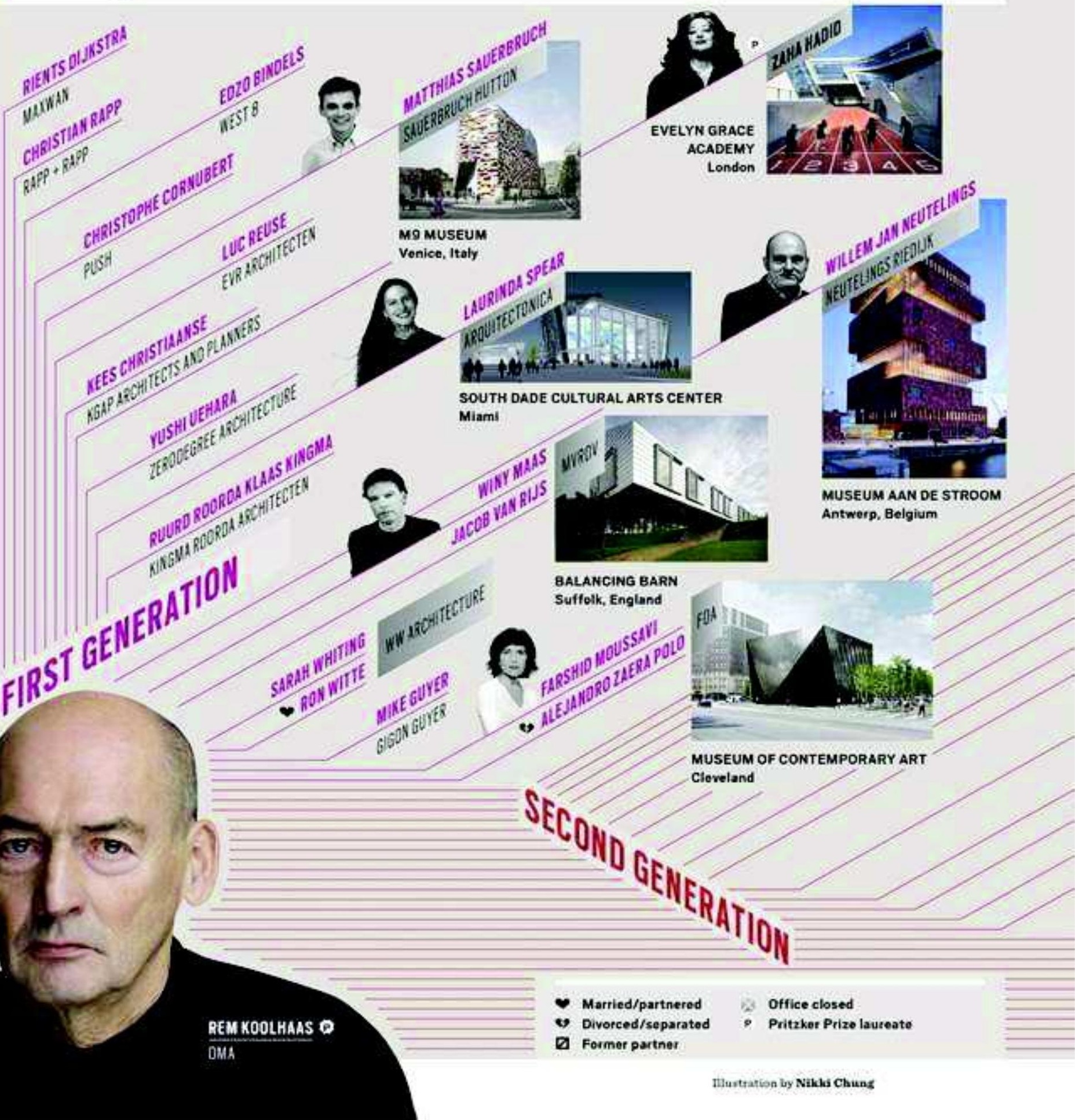




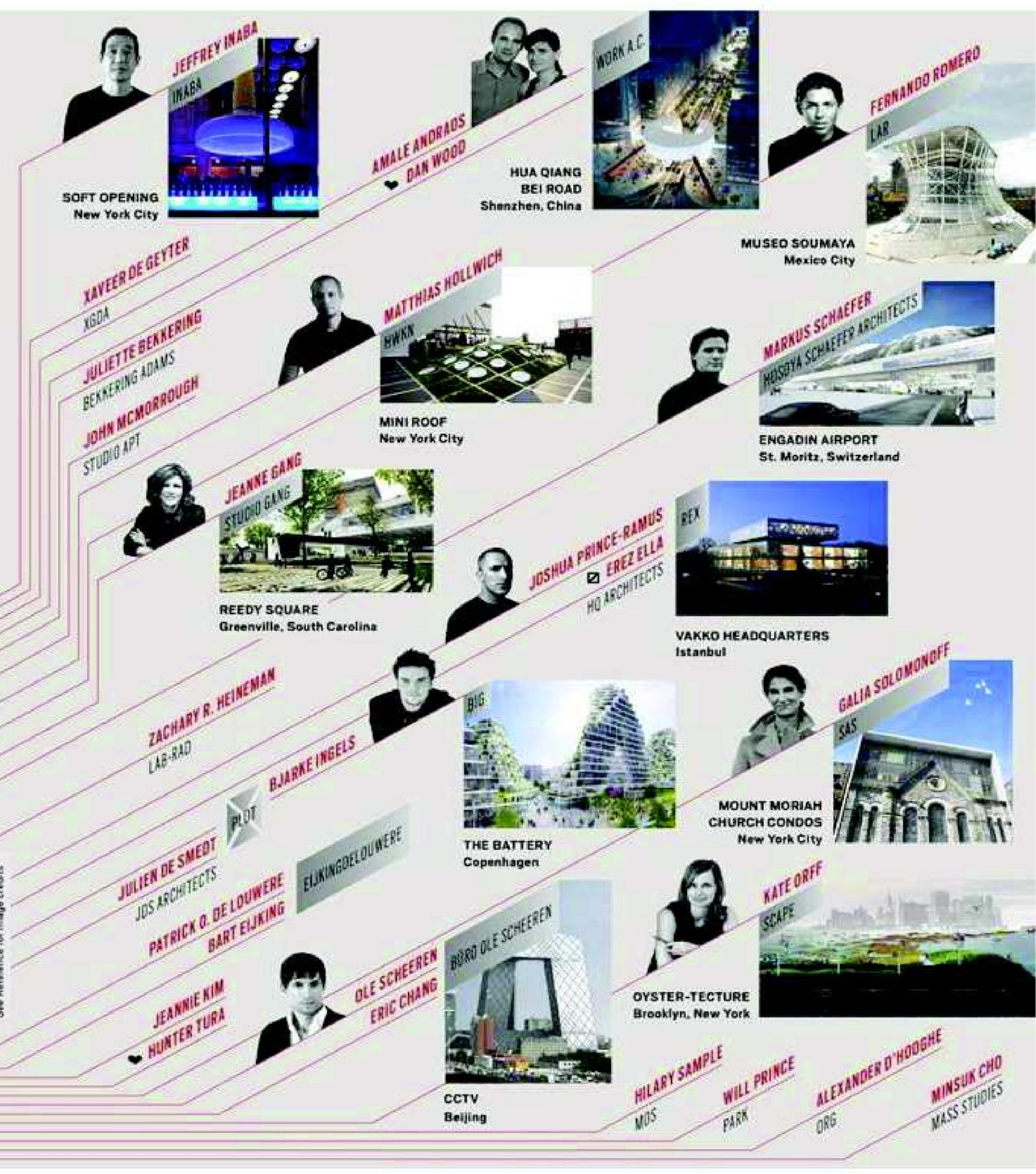


Para Maas, AMO e The Why Factory são parecidas por serem think tanks dirigidas por escritórios de arquitetura, mas em organização e programa são bem diferentes. A TWF é uma organização educacional (atua como parte da Universidade Técnica de Delft), enquanto a AMO é uma empresa comercial. Em termos de conteúdo, AMO trabalha com diferentes assuntos e a TWF se concentra na Cidade do Futuro como um assunto científico.

Encontramos elementos no OMA que nós fomos além, quase em termos evolucionários. Um tipo de jogo de ping-pong. O livro Content (publicação do OMA de 2004) nós respondemos com KM3 (publicação do MVRDV de 2005). Outro motivo é... como nós traduzimos pesquisa, ou como a parametrização leva à maximização (como nos datascapes), para otimizações (como no Functionmixer) em direção às performances evolutivas de dados (em SpaceFighter). Então, não só através dos edifícios é que nós somos diferentes. O diálogo intensifica nossa agenda, então eu penso que o aspecto evolutivo é fantástico. É bom ter um escritório como OMA nas proximidades porque eles elevaram o padrão para todos nós (MAAS em entrevista para CLOG, maio/2014, p. 81, tradução nossa).

Enquanto o MVRDV discute a Cidade do Futuro, Koolhaas pensa a cidade genérica que representa infinitas possibilidades de escolha. A cidade contemporânea tem o senso de hierarquia diminuído, ignora contradições e justapõe situações opostas na paisagem urbana. Enquanto Koolhaas trabalha com uma conceituação crítica das instabilidades da metrópole (e daí surge uma remodelação do programa do edifício, expressado no Downtown Athletic Club, de Delirious New York), MVRDV apresenta a realidade de forma mais pragmática. Eles adotam o uso misto sempre que possível e seus projetos para habitação multifamiliar buscam a diversidade através da acumulação de tipologias distintas, mistura de grupos sociais e modos de vida.

Nesse sentido, outra diferença entre os dois escritórios é que MVRDV associa densidade e diversidade através de projetos que empilham fragmentos diversos (edifícios verticais com plantas diferentes, como o Pavilhão da Holanda na Expo 2000) indo além da ideia de Koolhaas de edifício-massa (como exemplo, o De Rotterdam, 2013, com repetição de plantas em altura mesmo com a sobreposição de blocos com programas distintos).

Quanto às semelhanças, notamos que o MVRDV traz do OMA uma série de aspectos referentes ao processo de trabalho, desde o funcionamento das equipes de projeto, passando pelo uso constante de modelos físicos até a ênfase na 
pesquisa $^{10}$. A questão formal, que no início do MVRDV trazia fortes similaridades com o OMA, acabou se diluindo com o passar dos anos. Nos dois escritórios a pesquisa permeia o projeto, mas também acontece em paralelo, por exemplo: um estudo que hoje foi desenvolvido desvinculado da prática pode ser utilizado amanhã para outro projeto, ou ainda, uma pesquisa criada para determinado programa pode embasar outros trabalhos no futuro.

Além dos estudos, o envolvimento dos arquitetos com o meio acadêmico ${ }^{11}$ é outro ponto de convergência e mais ainda, a publicação de livros com forte apelo visual: cores, fontes, gráficos e imagens reunidos em, algumas vezes, mais de mil páginas. Se a pesquisa em escritórios de arquitetura tem chamado a atenção, o modo Koolhaas de fazer pesquisa é o mais chamativo de todos. Nesse ponto, a inspiração do MVRDV em Koolhaas é a mais visível possível.
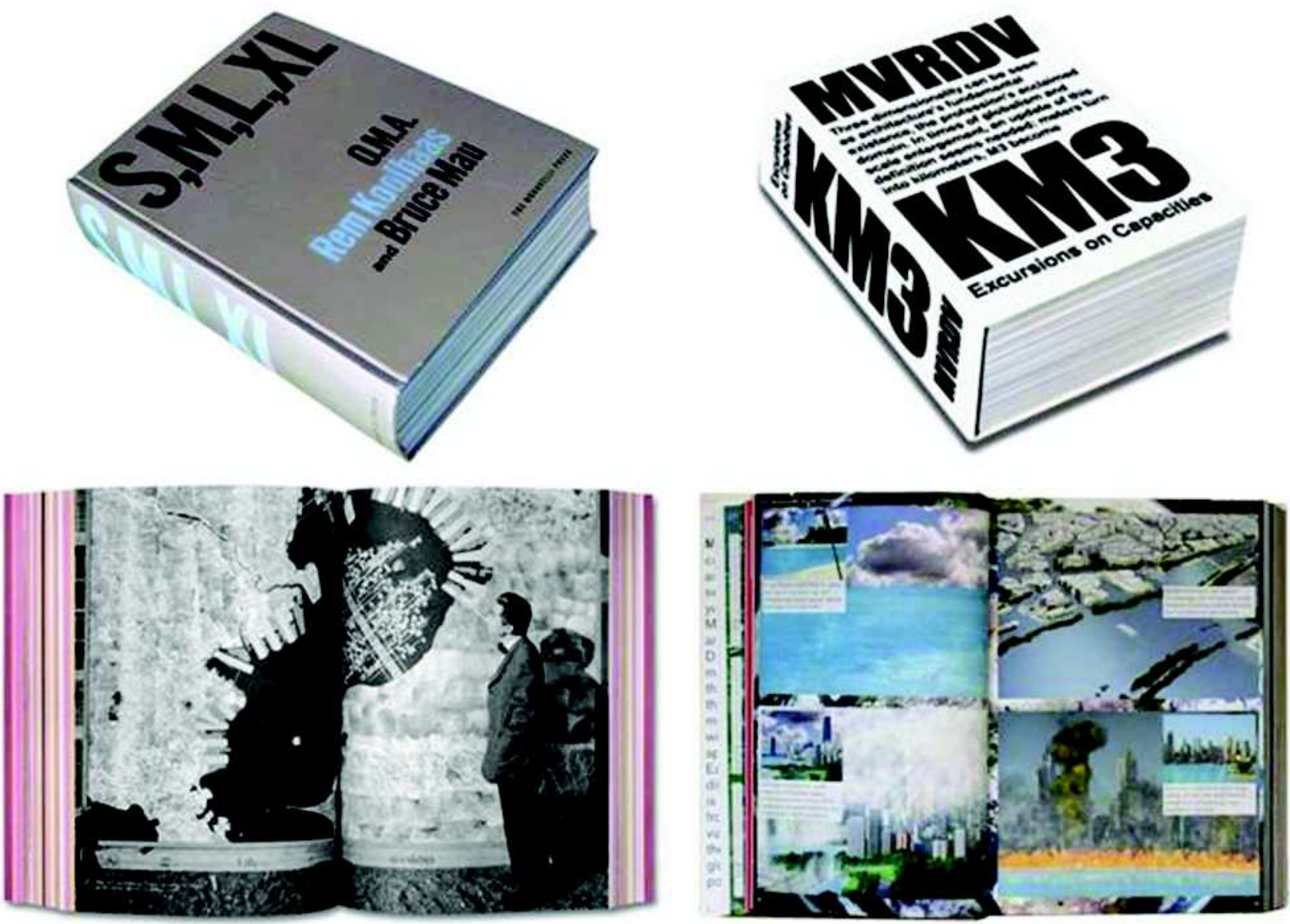

S, M, L, XL de Koolhaas (1995) e KM3 (2005) do MVRDV. Fonte: autora.

\footnotetext{
${ }^{10}$ Informação extraída de entrevistas com ex-colaboradores do OMA (inclusive Winy Maas e Jacob Van Rijs) publicadas no periódico CLOG, maio/2014.

${ }^{11}$ Os sócios do MVRDV já lecionaram em escolas de arquitetura como Universidade Técnica de Delft, Universidade Técnica de Berlim, Instituto Berlage, Architectural Association, Yale University e Universidade Técnica de Viena.
} 
Entre muitos artigos e livros, a proliferação das pesquisas de Koolhaas o posiciona como uma importante figura no mundo do pensamento arquitetônico e gera uma quantidade substancial de trabalhos realizados e não realizados.

Os trabalhos não realizados têm um aproveitamento extra nas publicações do próprio OMA. No entanto, é sabido que o uso de manifestos como portfólios é uma estratégia recorrente vista ao longo de todo século $20 \mathrm{com}$ arquitetos publicando livros que promoviam seus trabalhos. Entre algumas das publicações de Koolhaas, podemos citar o manifesto retroativo à Manhattan, Delirious New York; o guia produzido em conjunto com alunos de Harvard, Project on the City 2, sobre os shoppings e os espaços, técnicas e ideologias gerados por essa explosão de junkspaces e até um documentário sobre os mercados emergentes na África e as dinâmicas urbanas de Laos, na Nigéria. Essa estratégia de contínua publicação será replicada pelo MVRDV como veremos no capítulo 2.

Para Van Rijs (Clog, 2014), o que difere o trabalho deles do OMA é que o MVRDV tem "em geral, um forte caráter social e humano que se traduz para uma arquitetura amigável ao usuário", se referindo às influências de Herman Hertzberger em sua formação na Universidade de Delft. Se no discurso do MVRDV existe essa retomada da postura modernista mais voltada ao social, Koolhaas sinaliza o oposto em entrevista para a revista Wired (julho, 1996). Uma manifestação da desistência da arquitetura como solucionadora dos problemas sociais urbanos:

As pessoas conseguem habitar qualquer coisa. E podem ser miseráveis em qualquer lugar e alegres em qualquer lugar. Cada vez mais penso que a arquitetura não tem nada a ver com isso. Claro, isso é simultaneamente libertador e alarmante. Mas a Cidade Genérica, a condição urbana geral, está a acontecer por todo o lado, e o simples fato de ocorrer em tão grandes quantidades tem que significar que é habitável. A arquitetura não pode fazer nada que a cultura não faça. Nós todos reclamamos que somos confrontados por ambientes urbanos que são completamente parecidos. Dizemos que queremos criar beleza, identidade, qualidade, singularidade. E ainda, talvez em verdade, estas cidades que temos são desejadas. Talvez sua própria falta de caráter proveja o melhor contexto para se viver (KOOLHAAS, em entrevista para Wired, julho/1996, tradução nossa).

Para Koolhaas, a visão modernista de arquitetura como solução dos problemas da cidade é falha e pode produzir paisagens urbanas homogêneas. Ele tomou tal falha como elemento libertador em seu trabalho, pois sem a necessidade de atender um programa maior, existe a liberdade de pensar o projeto com menos restrições. 
Com isso, na manipulação de formas Koolhaas busca a diferenciação através de uma lógica mais recente, distinta da que já foi utilizada em outro projeto e, algumas vezes, reutilizada por outros escritórios. A proposta para o Hyperbuilding (1996) é um exemplo. Devido a sua altura (mais de mil metros) e seu altíssimo custo, o projeto não foi executado, mas sua tipologia reaparece em trabalhos de outros arquitetos (inclusive alguns que passaram pelo OMA) que adotaram semelhante estratégia formal com sobreposições de estruturas verticais e horizontais: o Museu Plaza do REX Architects ${ }^{12}$ (Louisville, 2005), Peruri 88 do MVRDV (Jakarta, 2012), Cross Towers do BIG (Seoul, 2012) e a sede da empresa Tencent do NBBJ (Shenzen, 2012).

Ressaltamos, no entanto, que essa busca pela diferenciação do OMA algumas vezes também se vale da reciclagem de suas próprias propostas, como no projeto De Rotterdam em 1997, ano seguinte da proposta do Hyperbuilding.

Curiosamente, esse diálogo sobre estratégias projetuais nos leva de volta ao MVRDV com seu Berlin Voids (1991), o concurso do Europan vencido por Winy Maas, Jacob van Rijs e Nathalie de Vries quando os dois primeiros ainda trabalhavam no OMA.

12 O REX se originou do OMA Nova York. O titular do escritório, Joshua Prince Ramus, coordenava a filial de Koolhaas nos Estados Unidos, que depois foi reposicionada em 2006 como REX e herdou os contratos em andamento do OMA Nova York. 


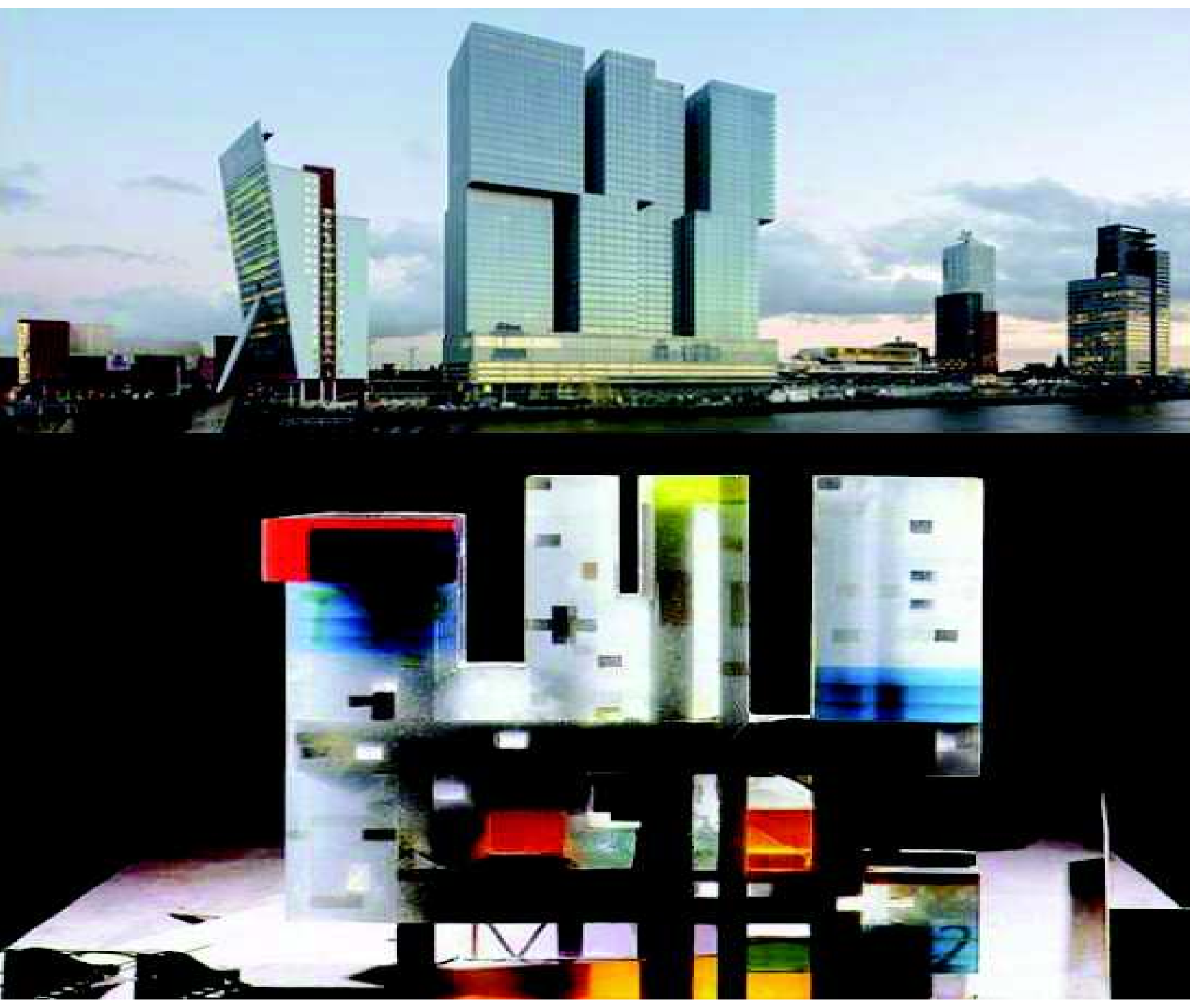

De Rotterdam, 1997, OMA. Fonte: www.theguardian.com; Berlin Voids, 1991, MVRDV. Fonte: www.mvrdv.nl 


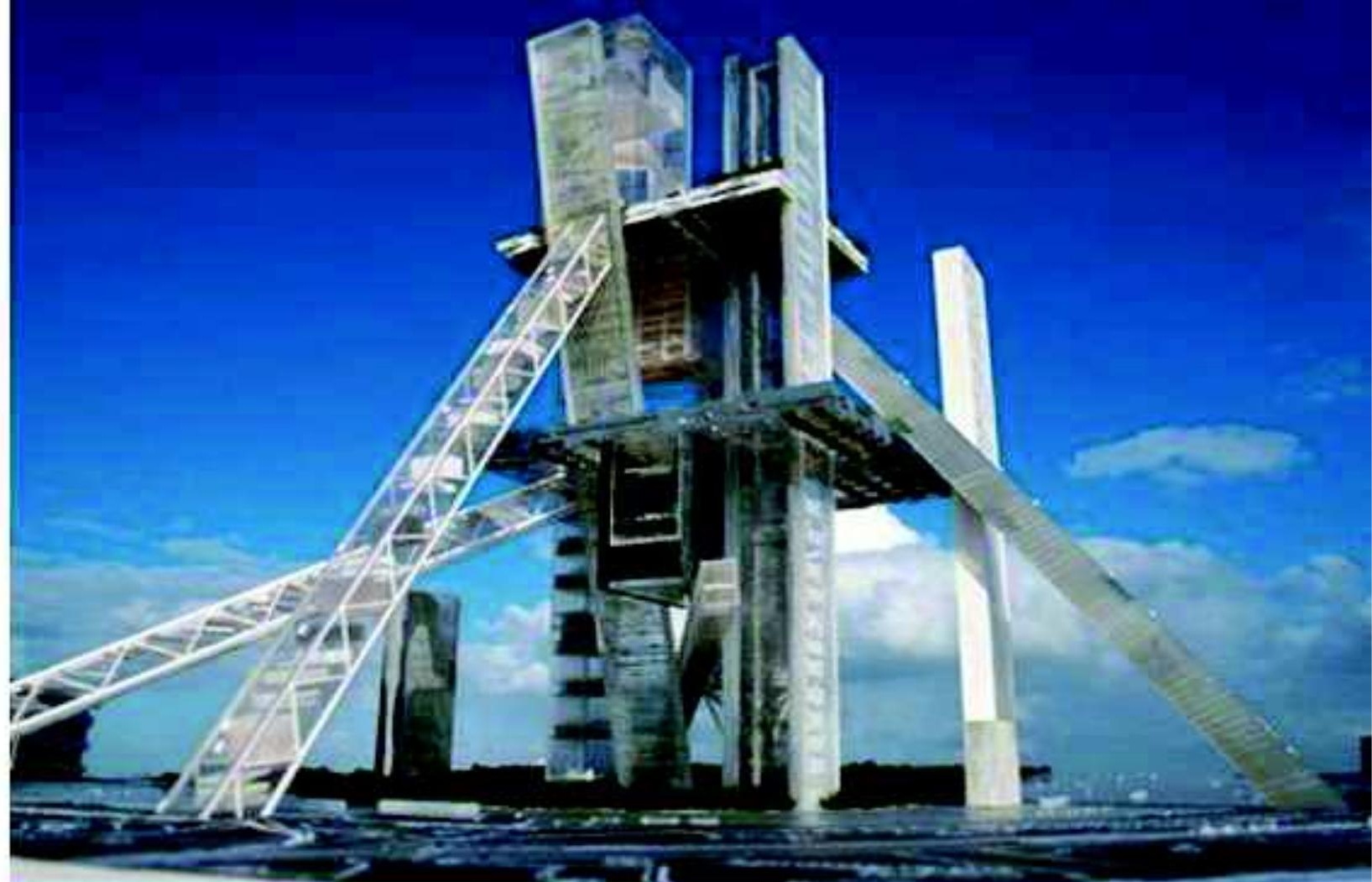

As propostas dos escritórios OMA, REX, MVRDV, BIG e NBBJ.

Fontes: www.oma.eu, www.rex-ny.com, www.mvrdv.nl, www.big.dk www.nbbj.com
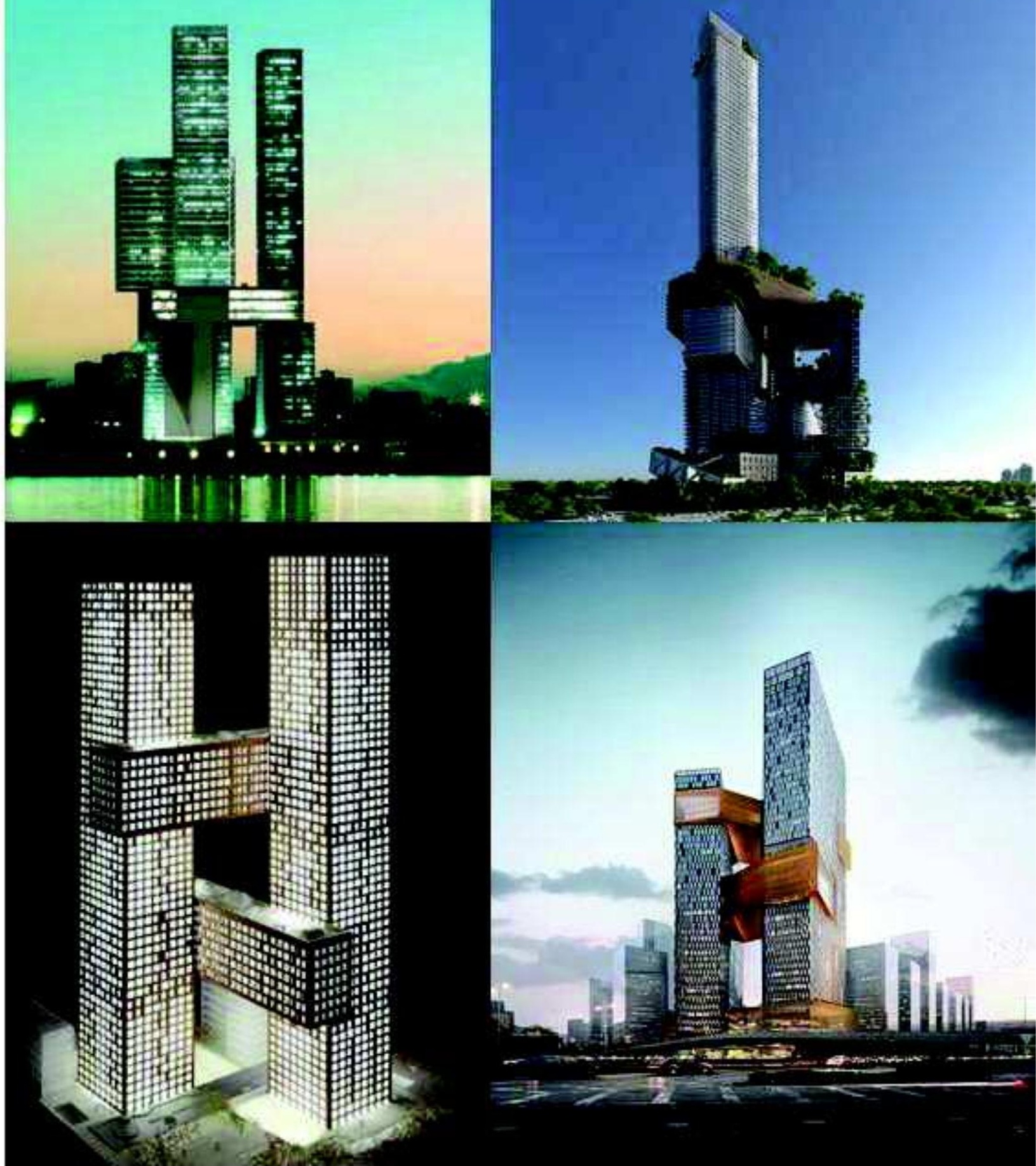
O MVRDV faz parte de uma geração que trabalhou com os arquitetos participantes das discussões teóricas dos anos 1980 e 1990, no entanto, essa nova geração busca outras maneiras de se engajar em uma tentativa crítica. A abordagem de pesquisa e investigação que o MVRDV traz tem também influências da orientação científica das vanguardas do início do século 20. Hoje, tenta-se transformar questões de toda ordem em dados para que essas informações se convertam em espacialidades, na definição de Aaron Betsky (2003), a informação é forma.

Nesse sentido o MVRDV utiliza a informação para mostrar dois lados de uma hipótese, por exemplo: a preservação da natureza e o aumento das reservas ecológicas começa com um aumento considerável da densidade. Uma hiperdensidade em um modo quase Metabolista. Eles mostram a solução, mas também as suas perspectivas reversas e, para isso, recusam a ideia de arquitetura como uma única especialização através da prática de um pensamento multidisciplinar.

\subsubsection{MVRDV: influências no pensamento da habitação}

Durante os anos 1960, John Habraken já discutia a revisão do papel da casa, com os habitantes participando mais efetivamente no processo de desenvolvimento da habitação. A crítica do Team $X$ ao planejamento moderno influenciou o pensamento de Habraken. Seu livro Supports (1962) é uma crítica à habitação coletiva dada como solução ao problema habitacional no pós-guerra, já que tal modelo eliminava o usuário do processo de desenvolvimento da moradia.

Suas ideias de participação do usuário no planejamento poderiam parecer ousadas para a época, mas continuam atuais e aparecem em alguns trabalhos do MVRDV. Habraken formulou a ideia de suporte como um conceito básico na habitação pensando o sistema como uma construção que permite o fornecimento de moradias que podem ser construídas, alteradas e desmontadas, independentemente das outras unidades do edifício. Ele vai além da planta livre e pensa no edifício livre (abertura do edifício não só em planta, mas também em fachada), partindo do princípio de separação da estrutura (suporte) e do conteúdo como um meio de dar aos usuários um papel participativo no processo de projeto, já que são os futuros habitantes que deverão preencher os espaços internos conforme suas necessidades. 

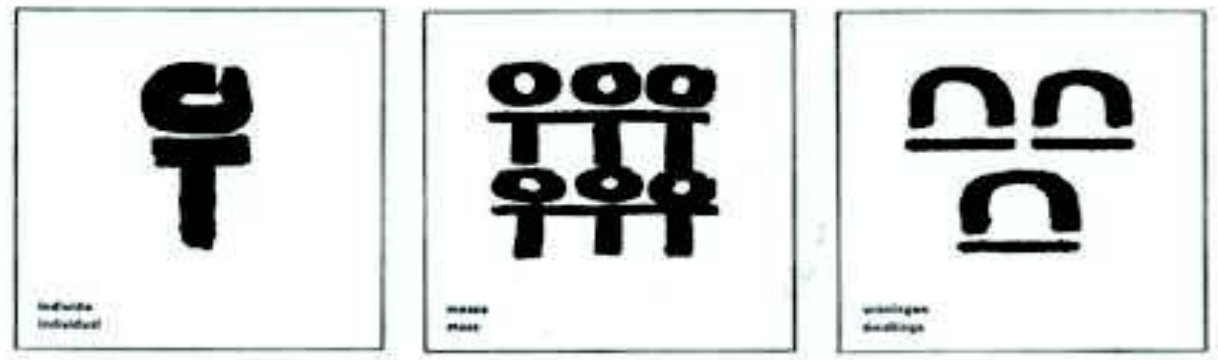

Símbolos utilizados por Habraken para explicar a organização dos suportes em 1966: individual, massa, habitações, comunidade, crafts, habitação coletiva, habitação, arquiteto e do it yourself.
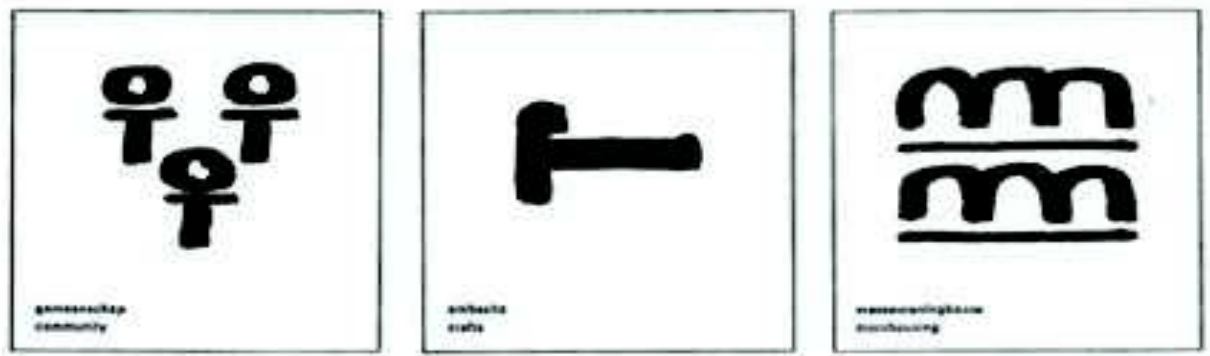

\section{Representação}

esquemática dos suportes (1963).

Habitações inseridas como trailers nos suportes (1963). Fonte: Dash, n. 4, 2011.

O conceito de suportes é utilizado pelo MVRDV em sua proposta para o concurso Sluishuis (Amsterdã, 2002) em que fachadas e interiores seriam formulados pelos futuros moradores em uma solução para atender a demanda por diversidade. As ideias de Habraken evocam as imagens da Plug-in City de Peter Cook e a New Babylon de Constant Nieuwenhuys, mas seu foco não era a crítica à sociedade, mas ao processo habitacional estático. Ele enfatizava o lado social da construção de habitações destacando que os processos construtivos ditavam um produto pronto para o usuário ao invés de ser primeiro um processo social e depois uma questão técnica e organizacional.

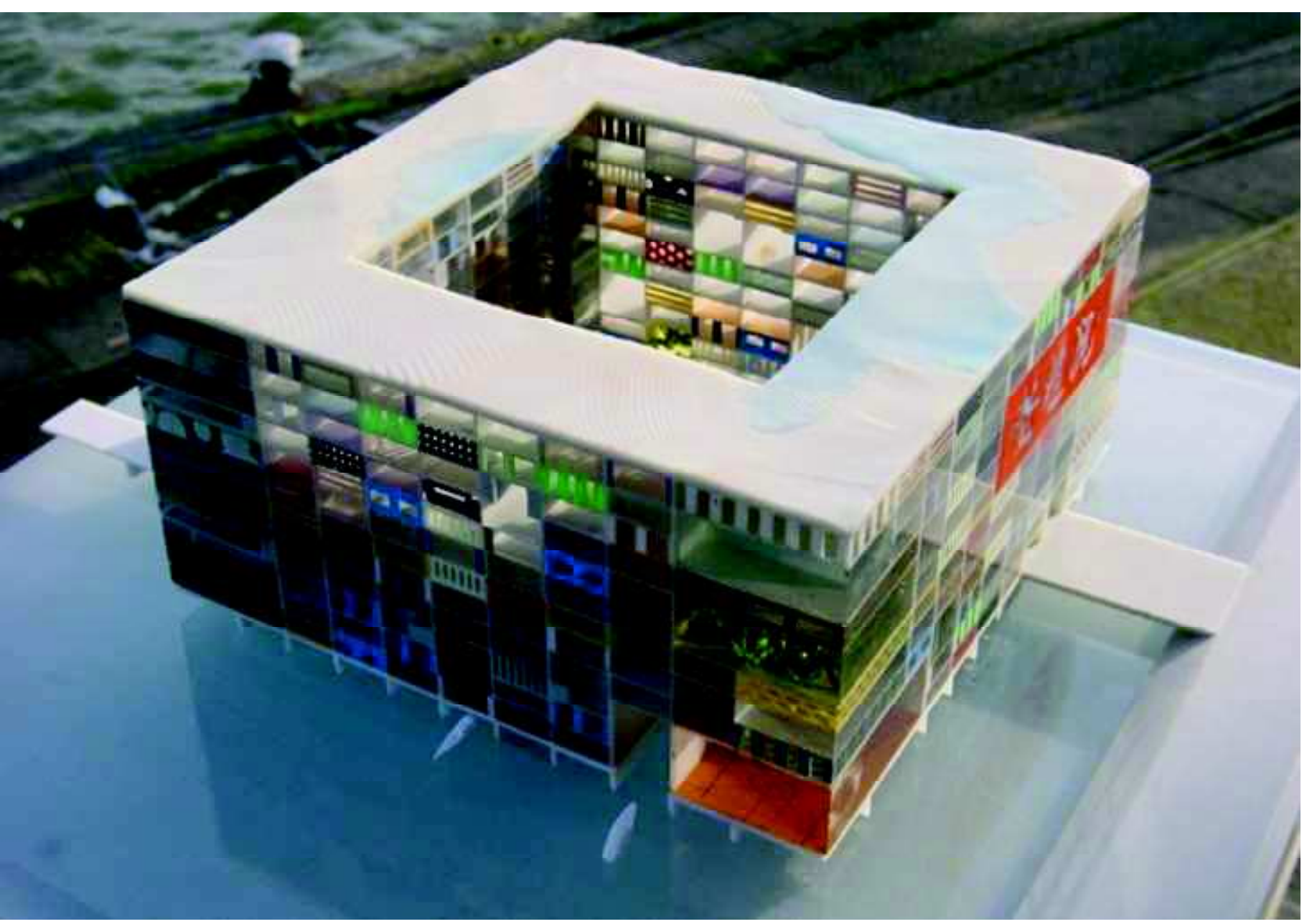

Maquete do projeto Sluishuis, MVRDV. Fonte: http://www.vincentderijk.nl/2001-10-Sluishuis

Outro trabalho do MVRDV que incorpora as ideias de Habraken, mas desta vez em maior escala, é o estudo Freeland (apresentado na Bienal de Veneza de 2012) que propõe um urbanismo desenvolvido por seus usuários, em um modo em que todos os novos habitantes da cidade possam desenhar suas casas, as ruas e o contexto. O conceito surgiu para a cidade de Shenzhen, na China, mas não foi aceito por ser 
considerado radical. A ideia foi reaplicada para um estudo em Almere, na Holanda, que tem uma maior tradição na participação social e um ambiente político e cultural mais favorável para o desenvolvimento desse tipo de proposta.

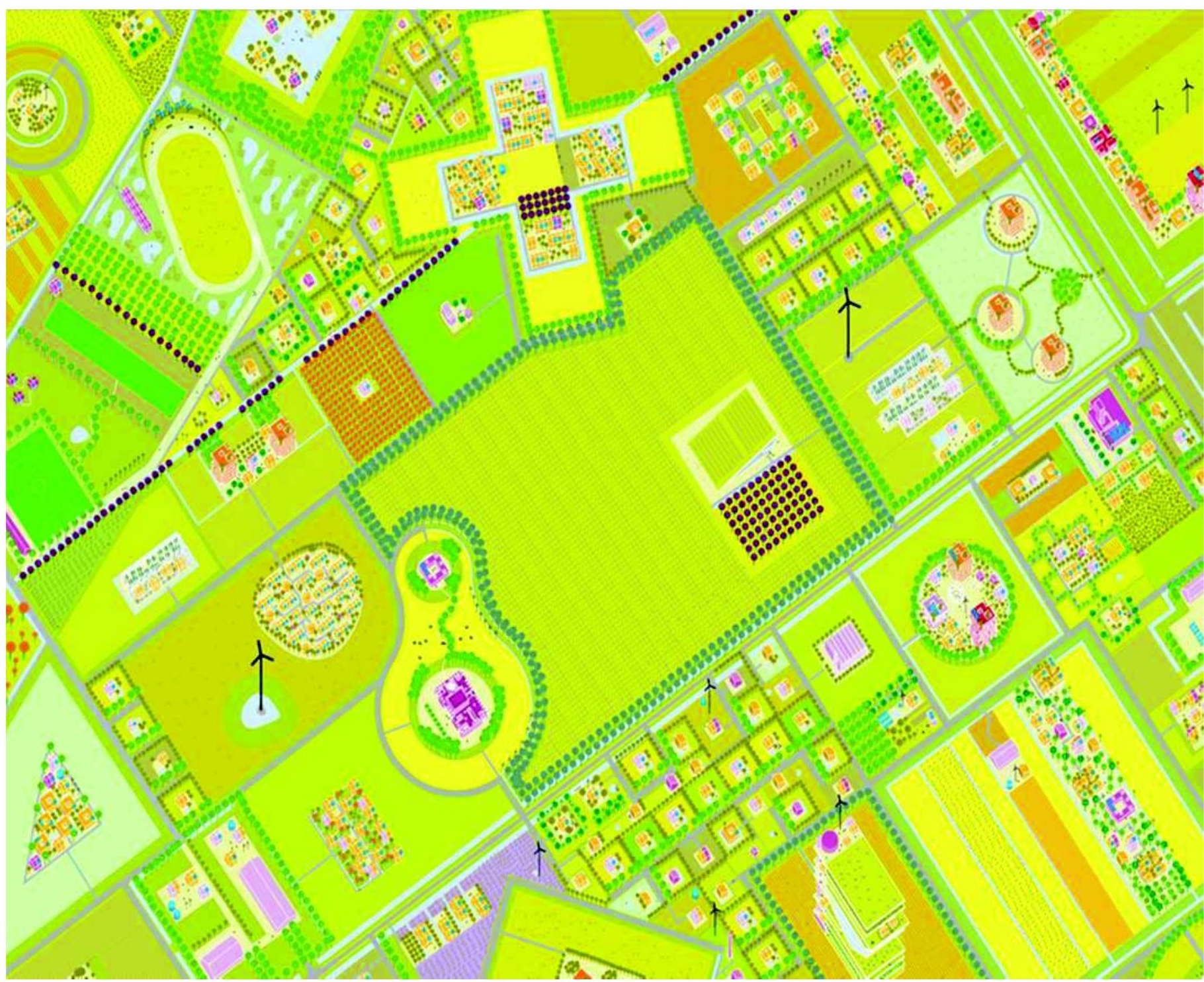

Simulação de diversidade de escolhas feitas pelo usuário em Freeland. Fonte: www.mvrdv.nl 

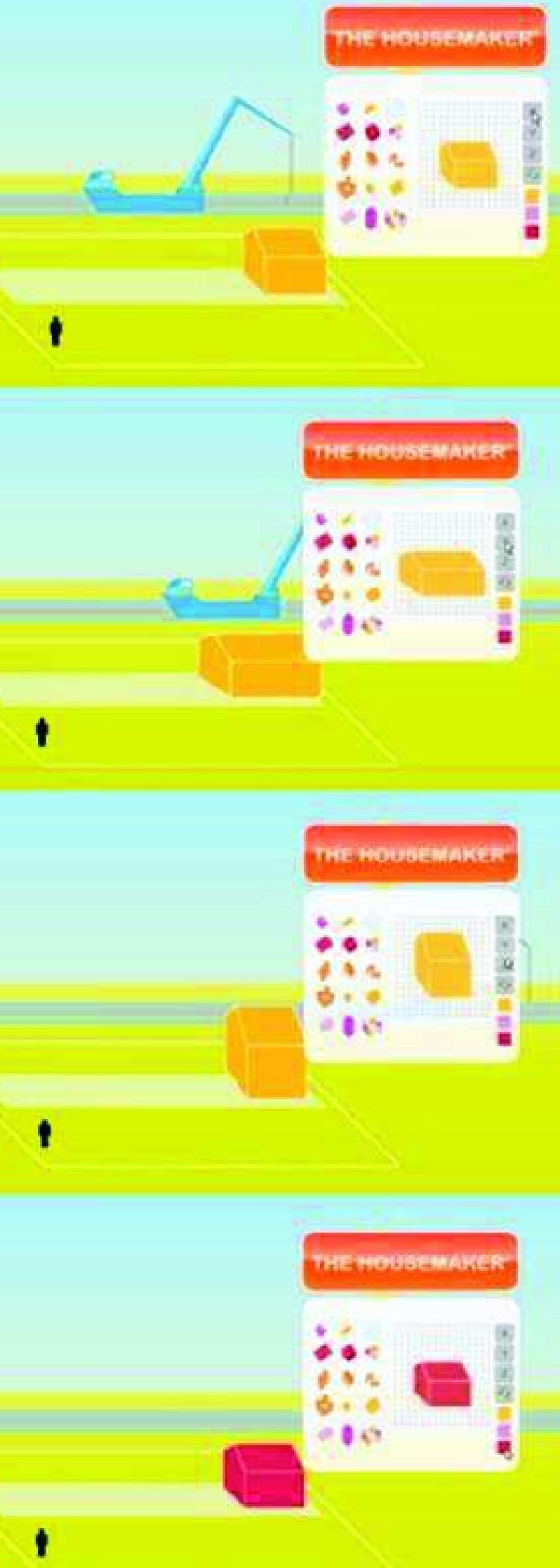

Freeland prevê a participação do usuário em diferentes escalas.

Fonte: www.mvrdv.nl 
Observamos nas imagens de Sluishuis e Freeland que o resultado final simula as diversas formas de ocupação do espaço resultantes das escolhas dos usuários. Diante da necessidade de atender diferentes grupos familiares, a questão da diversidade nas habitações começou a aparecer como fator importante no fim do século 20 .

Podemos apontar a variedade como ponto de atenção na habitação multifamiliar em dois projetos holandeses pós anos 70: o Kruisplein em Rotterdam (1980), do Mecanoo (proposta para um concurso de tema habitação flexível e variada para atender diferentes moradores e estruturas familiares) e os projetos do OMA para IJplein em Amsterdã (1988). Essas ideias acabaram por influenciar outros trabalhos holandeses na década de 90, como o Silodam. Além disso, a proposta do OMA marca o início da divulgação do uso de informações do local na formatação de diferentes propostas para melhor compreensão dos envolvidos no projeto. Como veremos adiante, esse tipo de exercício também acontecerá nos estudos e projetos do MVRDV. 
CAPÍTULO 2

MVRDV: TEORIA E

PROCESSO DE PROJETO 
As transformações na arquitetura nas últimas duas décadas, que incluem o impacto das tecnologias digitais nos processos de projeto e de representação da informação, a ênfase na sustentabilidade e as implicações da globalização e da informação fazem parte do contexto no qual o MVRDV vem desenvolvendo suas atividades. Este capítulo busca analisar o método de trabalho adotado pelo escritório frente à esse cenário, que é composto por uma marcante investigação teórica e que estabelece interlocuções com a cidade, e as escalas local, regional e global. Para isso, organizamos o conteúdo em dois tópicos principais: 1- conceitos de projeto, no qual identificamos temas recorrentes no discurso do MVRDV, como uso misto/espaços múltiplos; naturezas artificiais; interiorização espacial; subúrbio urbano; densidade; diversidade/identidade; global/local e datascapes. ; 2- processo de projeto, que mostra a pesquisa como método através de projetos experimentais, diagramas e software desenvolvidos pelo escritório.

A fim de avaliar o peso e a influência das pesquisas na prática do MVRDV julgamos necessário mapear os estudos e projetos realizados pelo escritório desde seu início $^{13}$. Para tanto relacionamos as investigações presentes nas publicações Farmax (1998), MetaCity/DataTown (1999), Costa Ibérica (2000), The Regionmaker RheinRuhrCity (2002), Five minutes city (2003), KM3 (2005), Spacefighter (2007), Skycar City (2007), NL28 The Olympic Fire (2008), MVRDV Agendas on Urbanism (2012), além de outros divulgados na página da internet do escritório e os trabalhos desenvolvidos pela The Why Factory. Método semelhante foi utilizado para os projetos, que foram extraídos do site do MVRDV e confrontados com suas publicações e periódicos a fim de certificar que toda produção do escritório fosse contemplada.

Os números encontrados são uma confirmação da existência do lado investigativo do MVRDV. Já a análise dos períodos com maior produção teórica nos permite avaliar o possível rebatimento das pesquisas nos projetos.

No total foram catalogados 167 estudos e 178 projetos que listamos na sequência. Com isso, observamos que na primeira década a produção de pesquisas é muito maior do que o número de projetos, fato que se inverte na segunda década de vida do MVRDV. Nesse ponto, ressaltamos que dois fatores podem explicar esse tipo de desenvolvimento: 1- a menor demanda de projetos na primeira década permitiu

\footnotetext{
${ }^{13}$ Consideramos os projetos e estudos realizados desde 1991 (data do concurso Europan 2, quando foi desenvolvido o projeto Berlin Voids) até setembro de 2014.
} 
maior dedicação do escritório à investigação teórica, que por sua vez também foi útil para divulgar o trabalho do MVRDV e ajudou a angariar projetos para a segunda década; 2- a grande produção de pesquisa na primeira década formatou um banco de dados suficiente para embasar parte da prática da segunda década e apesar de estar associado à universidades, é um momento em que os arquitetos dedicam maior parte de seu tempo às encomendas de projetos.

PROJETOS

ESTUDOS

MVRDV: estudos X projetos. Fonte: autora.

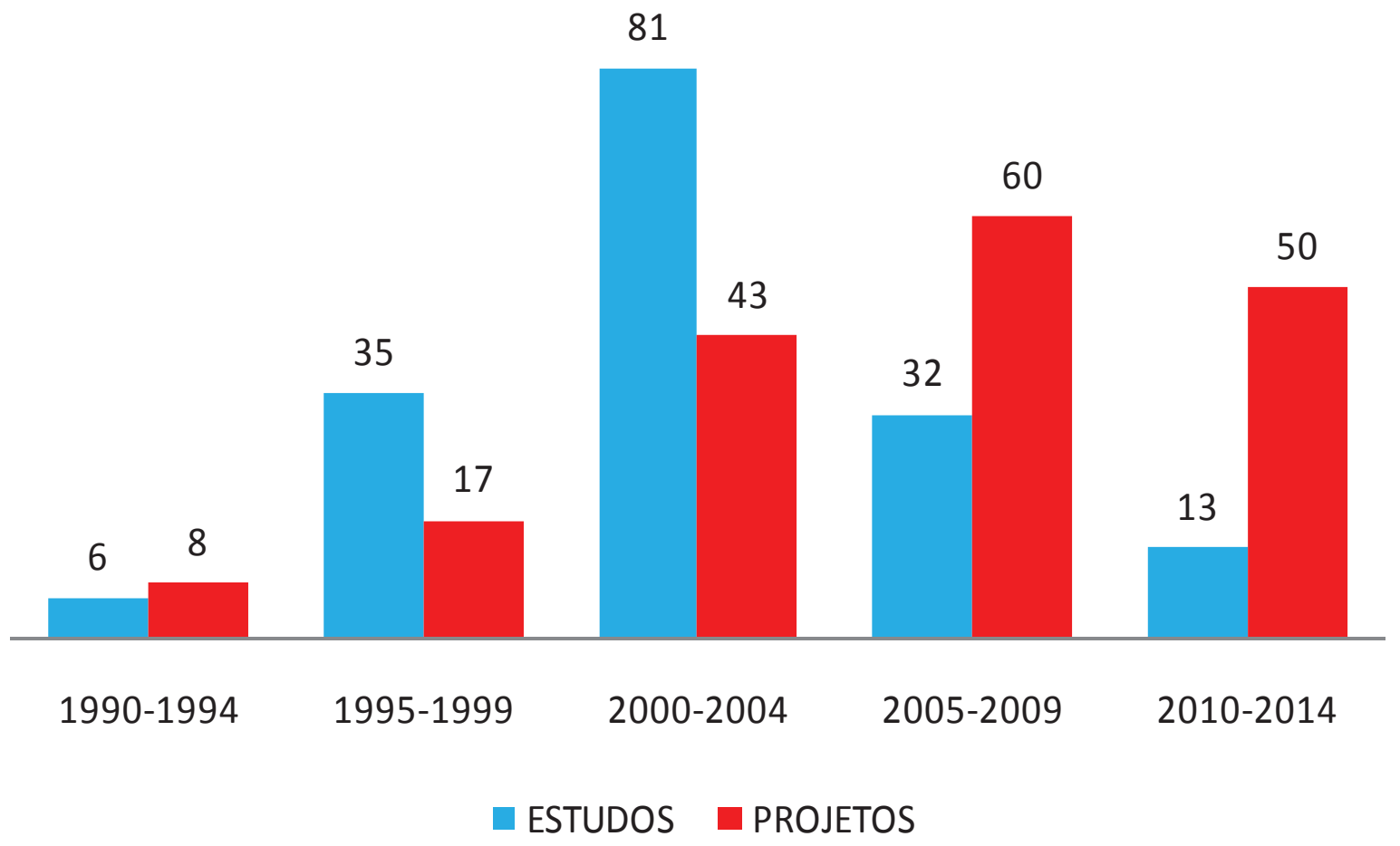

MVRDV: estudos e projetos realizados a cada cinco anos. Fonte: autora. 
ESTUDOS, TEXTOS E FILMES

\begin{tabular}{|c|c|}
\hline 1992 & Emptyscape \\
\hline 1992 & Statistic suspense \\
\hline 1994 & Greyness on the dutch mesa \\
\hline 1994 & Lelyland \\
\hline 1994 & Pompeiian carpet \\
\hline 1994 & Stourhead revisited \\
\hline 1995 & Permanence \\
\hline 1995 & Landscape \\
\hline 1995 & Icebergs \\
\hline 1995 & Doubledecker \\
\hline 1996 & Dutch tendencies \\
\hline 1996 & Datascape \\
\hline 1996 & Who is afraid of massiveness? \\
\hline 1996 & Climate \\
\hline 1996 & And Holland? \\
\hline 1996 & Gothics \\
\hline 1996 & Mainstreet \\
\hline 1996 & Massive pluralism \\
\hline 1996 & The continuous interior \\
\hline 1997 & Windscape \\
\hline 1997 & Rat tests \\
\hline 1997 & Aztects! \\
\hline 1997 & Holland city \\
\hline 1997 & Meteorite city \\
\hline 1997 & Castle maker \\
\hline 1997 & Trojan extrusion \\
\hline 1997 & New! New Babylon \\
\hline 1997 & Z-Mall \\
\hline 1997 & Stack Attack \\
\hline 1997 & Lace \\
\hline 1997 & Noise scape \\
\hline 1998 & Far East \\
\hline 1998 & Downtown Brabant \\
\hline 1998 & Life and death \\
\hline 1999 & MetaCity/Datatown \\
\hline 1999 & Noord-Brabant \\
\hline 1999 & Dutch cases \\
\hline 1999 & Tarra City \\
\hline 1999 & Yplein 2.0 \\
\hline 1999 & Jac P. Thijsselaan \\
\hline 1999 & Zaandam Tower \\
\hline 2000 & Costa Ibérica \\
\hline 2000 & Global machinery \\
\hline 2000 & Port City \\
\hline
\end{tabular}

\section{PROJETOS}

1991 Berlin Voids Europan 2

1993 Shadowtown

1994 NTR Headquarters

1994 Otterlo Lodge

1994 Hoenderloo Lodge

1994 Arnhem Lodge

1994 Sloterpark Pool

1994 Villa VPRO

1995 Silodam

1996 Calveen

1997 Plant City

1997 Flight Forum

1997 EXPO 2000

1997 WOZOCO

1998 Studio Tonik

1998 Ypenburg

1998 Internal Heaven

1999 Brabantstad

1999 UPV Munich

1999 Parkrand

1999 Lloyd Hotel

1999 Tarra Tower

1999 Watervillas

1999 Borneo 12

1999 Borneo 8

2000 Brabant Library

2000 Matsudai Center

2000 Oslo Opera

2000 Hagen Island

2000 Silicon Hill

2000 Musée Universel

2000 Mobiloskop

2001 Expo City Toolenburg

2001 Madrid Urban Games

2001 MIRADOR PALMERAL

2001 Celosia

2001 Musée Pinault

2001 Eyebeam Institute

2001 Retterdam Airport

2001 FRØSILO

2001 Pyjama Garden

2001 Patio Island

2001 Danish Minimalism

2001 Sky Attic 
2000 KM3

2000 Cube

2000 Reality check

2000 3D Gardens

2000 Superloop

2000 Pig City

2001 Free migration world

2001 Cerdà Plus

2001 Expo City

2001 Urban Eden

2001 Container City

2001 Starfish

2001 Vertical IKEAs

2001 SportCity

2001 Urban games

2001 The functionmixer

2002 The Regionmaker

2002 Climate world

2002 New regionalism

2002 Advertisements

2002 HyperCatalunya

2002 Verlende Veilingweg

2002 One Room House

2002 Theatre Pit

2002 Schlachthalle

2002 Endless Interior

2002 Skyhouse

2002 Kissing Towers

2002 The evolutionary city

2002 Cad history

2002 The regionmaker

2003 Ciudad valle Central

2003 Stadtland Schweiz

2003 Parkforum

2003 3DG

2003 Pino

2003 Skygardens

2003 3D Huerta

2003 Olympic Bridge

2003 Alpine road

2003 Knowledge valley

2003 The berlagemixer

2003 The masterprogrammer

2003 The inframaker

2003 The access optimixer

2003 The climatizer
2001 3D Forest

2002 Boz sur Mer

2002 New manor

2002 Haus am Hang

2002 Barcode House

2002 Didden Village

2002 Westerdok

2002 De Effenaar

2003 NYC 2012 Olympics

2003 Leiria Bridges

2003 BJøRVIKA Barcode

2003 Book Mountain

2003 Stadt Land Schweiz

2004 Montceau-les-Mines

2004 Infra Jungle

2004 Le Monolithe

2004 Teda Urban Fabric

2004 Long Tan Park

2004 Epo Offices

2004 Rotterdam Floriade 2012

2004 Market Hall

2004 Serpentine Pavilion

2004 Fiera di Milano

2004 The Rose Window

2005 Toptani Shopping

2005 Busan City Sofa

2005 Anyang Peak

2005 Gyre

2005 Torre huerta Sociopolis

2005 Kampen Foodplains

2005 Cancer Centre

2005 Nanjing Ats Zone

2005 New Leyden

2006 Plant City Jinhua

2006 Europoort Rotterdam

2006 Almere Hout

2006 Pampus Harbour

2006 Parco Monteluce

2006 Donau City Lab

2006 Wembley Casino Hotel

2006 Floating Tower

2006 Music Quarter

2006 Lagoon City

2007 Super Window

2007 Power Centre

2007 Next Gene 
2003 Five Minutes Citu

2004 Trends

2004 Architecture is a device

2004 Hyperoptimized world

2004 Forêt MLM

2004 NL Stad

2004 Riverzone

2004 Coastalzone

2004 Energyzone

2004 Forestzone

2004 Glasstone

2004 Distributionzone

2004 Airportzone

2004 Portzone

2004 Restzone

2004 Chronology

2004 Mt. Rioja

2004 Galicia!

2004 Flipped Neighbourhood

2004 Ghost Farm

2004 Moving Collection

2004 Ballroom

2004 Solo Towers

2004 Soho City

2004 Infrajungle

2004 Noah's arc

2004 CDB Corwn

2004 Vertical Floriade

2004 The Optimixer

2004 The volumemaker

2004 Space?

2004 DE Nieuwe Kuip

2005 Space gap

2005 Zuidplaspolder

2005 68-...

2005 Piece by piece

2005 Via Romanina

2005 Parc/Crap

$2005 \mathrm{HVH}$

2005 Screwdriver

2005 Bigger

2005 Geresi House

2005 Hotel Constantinopoli

2005 The Ruler

2005 Anar-City

2005 Dutch Nostalgia
2007 Apraksin Dvor

2007 Chengdu Theater

2007 Dongli Pool

2007 New Orleans Lower 9TH

2007 Boijmans Art Depot

2007 Balancing barn

2007 Tokyo Fashion HQ

2007 Xinjin Water City

2007 Homerus Quarter

2007 Cleveland Art Institute

2007 Philharmonie de Paris

2007 Motorcity Alcañiz

2007 DNB House

2007 Schweizer Fernsehen

2008 Almere 2030

2008 T?F Tribune

2008 Olympia Quarter

2008 Groot Bentveld Eva

2008 Grand Paris

2008 Hangzhou East Station

2008 RØDOVRE Skyvillage

2008 Scanderberg Square

2008 Singapore Westwood

2008 Eco-City Montecorvo

2008 Citta Sospesa

2008 Tirana Rocks

2008 Glass Farm

2009 Swisslicon Valley

2009 Kube House of Movement

2009 Basel Rheincity

2009 Hong Kong Campus

2009 Galije Resort

2009 Tegel Fields

2009 Museum Berger

2009 Shenzhen 3D Street

2009 Mirador Palmeral

2009 Taipei Pop Music Center

2009 Rotterdam Mountain

2010 Shangai Bund

2010 Songdo Landmark City

2010 Cite descartes

2010 Parc Universitaire Montpellier

2010 New holland Island

2010 Lille Lycée Hôtelier

2010 Teletech Campus

2010 Guosen Tower 


\begin{tabular}{ll}
2005 & Art Village \\
2005 & Carved out tower \\
2005 & Grill \\
2005 & Urban chair \\
2005 & Swirl \\
2005 & Superstairs \\
2005 & Thinslab \\
2005 & Spacefighter \\
2006 & North Sea Wind Park \\
2007 & SkyCarCity \\
2008 & NL Olympic Fire \\
2008 & Green City Calculator \\
2008 & Green Dream \\
2008 & World Wonders \\
2008 & Schielands-Huis \\
2009 & Hong Kong Fantasies \\
2009 & Leisure City \\
2009 & Robotic City \\
2010 & China Hills \\
2010 & Austeria \\
2010 & Vertical Village \\
2011 & Food City \\
2011 & Superkampung \\
2011 & Oslo Le Grand \\
2012 & 4 min City \\
2012 & AnarCity \\
2012 & Biodiversity \\
2012 & Copy Paste \\
2012 & Transformer \\
2013 & Porous City \\
2013 & Resilience \\
\hline &
\end{tabular}

2010 A101 Urban Block

2010 Syke Synergy

2010 Bastide-Neil

2010 Gangnam Hills

2010 Natural Neighborhood

2010 Future Towers

2010 Pushed Slab

2011 Transitlager Reloaded

2011 Almere Oosterwold

2011 Rockmagneten

2011 A Corunã Station

2011 Paris Tribune

2011 Netherlands Supreme Court

2011 Comic Museum

2011 Flowerbed Hotel

2011 Blatyk

2011 Alphabet Building

2012 Peruri 88

2012 Chaise urbaine

2012 Almere Floriade 2022

2012 Yenikapi Archaeo-Park

2012 Dierenpark Theatre

2012 Maquinnext

2012 Glass Museum

2012 Shangai Post-Expo

2013 SR Bank Stavanger

2013 Manhattan Sky Vault

2013 Museum Schiedam

2013 Public Art Depot MBVB

2013 The Gardens of Zaryadye

2013 Mattilennie-Mi Campus

2013 Urban Hybrid

2013 Madla-Revheim

2013 Hongqiao CBD

2013 The Beam

2013 Chungha Building

2013 The Couch

2013 Caen Presqu'ile

2013 Library Quarter

2014 Folie Richter Montpellier

2014 Cheung Fai Building

2014 Serp \& Molot Factory 


\title{
2.1 Conceitos de projeto
}

Desde a sua formação, o MVRDV é conhecido por um método de trabalho que envolve extensa pesquisa, coleta e interpretação de dados do contexto para desenvolver as soluções de projeto. Para Montaner:

\begin{abstract}
A soma e a sobreposição de fragmentos no espaço é um dos processoschave que propõe em seus experimentos, junto com a inscrição de programas complexos em iconologias simples: dispor volumes prismáticos sobre a malha do terreno, elevar formas no ar, desarticular planos horizontais e inclinados, e semi-enterrar edifícios em topografias artificiais. Tudo isso em diversas combinações verticais, em plataformas, torres, megaestruturas ou volumes delimitados, dentro dos quais se situa uma multidão de corpos diversos, livres ou encapsulados, cheios ou vazios (MONTANER, 2008, p.164).
\end{abstract}

Humbertus Adam (2002) aponta a ideia de adensamento e verticalização como o eixo principal do pensamento do MVRDV. Segundo Adam, estudos como Pig City e Costa Ibérica não têm como interesse as alternativas para os hábitos de consumo e produção, mas sim as possibilidades de otimização ${ }^{14}$.

As experimentações e estudos desenvolvidos pelo escritório chamam atenção para os conceitos intrínsecos em seu trabalho. Nesse ponto observamos ser necessário desdobrar esses termos que aparecerão mais vezes ao longo da pesquisa, são eles: datascapes (criado pelos arquitetos); uso misto/espaços múltiplos; naturezas artificiais; interiorização espacial; subúrbio urbano; densidade; diversidade/identidade; global/local. Essas ideias se mesclam dentro dos projetos e na teoria, a ponto da definição de um conceito se desdobrar em outro. E é isso o que diferencia o uso desses termos, que não são inéditos, no trabalho do MVRDV de outros momentos da história da arquitetura. Quando aplicados em conjunto eles acabam se redefinindo. Por exemplo: densidade + interiorização espacial $=$ densidade porosa.

A especificidade do escritório na reinvenção desses conceitos possibilita a criação de hipótese de cidades e construções mais eficientes, centradas na otimização em tempos de incertezas sobre a oferta de recursos.

\footnotetext{
${ }^{14}$ Trazemos o termo otimizar do livro KM3 (2005) do MVRDV. Os arquitetos trabalham a expressão como uma pós-maximização, substituindo maximização por otimização.
} 
Aqui duas publicações do escritório foram de grande utilidade para ilustrar os conceitos chave na fala dos arquitetos: FARMAX - Excursions on Density (1998) e KM3 - Excursions on Capacities (2005).

\section{DATASCAPES}

O termo criado pelo MVRDV significa uma forma de análise estatística pelo qual dados do contexto de todo tipo, passíveis de serem quantificados, são coletados, analisados e representados visualmente. Estes dados utilizados no processo de projeto vão influenciar ou mesmo definir o trabalho. As variáveis englobam leis e regulamentações, premissas dos investidores, restrições técnicas, condições climáticas e instâncias políticas; e as informações delas resultantes somam questões mais complexas às características físicas da área de intervenção.

Para o MVRDV, algumas situações podem ser vistas como "fugas" por trás dos dados: a diferença nos impostos entre Bélgica e Holanda gerou uma cidade linear ao longo da fronteira entre os dois países; as necessidades do mercado resultaram em casas com jardins pequenos na Holanda; as regulamentações em Amsterdã limitaram a implantação de edifícios com programas modernos gerando uma grande quantidade de atividades invisíveis atrás das fachadas medievais.

Diante de acontecimentos deste tipo, para o MVRDV, inicialmente, é possível descrever e explorar o contexto de um projeto apenas com números e informações (MVRDV, 1999). Sua rede de possibilidades - econômica e espacial - parece tão complexa que somente técnicas estatísticas podem auxiliar no entendimento desse sistema. É a conversão do processo de projeto em "espacialização da informação". (SPERLING, 2012).

Em entrevista para o periódico El Croquis (n.86, p.14), os arquitetos afirmam que um modo de compreender o mundo dos números é através de cenários extremos como técnica de pesquisa em arquitetura. Os trabalhos com datascapes tentam decifrar as limitações encontradas em um dado contexto. Eles mostram as limitações, normalmente difíceis de serem visualizadas e que são escondidas por outros parâmetros. Mas trabalhando com a radicalidade, essas limitações aparecem para a atenção pública, o que torna possível a discussão e a criação de um raciocínio em torno delas. Selecionando ou conectando dados de acordo com essas hipóteses, os números do contexto são transformados em diagramas, 
representações visuais das restrições que se tornam visíveis e compreensíveis para todos os envolvidos no projeto.

Além disso, a forma passa a ser o resultado de uma extrapolação de datascapes de demandas e hipóteses que observam, extrapolam, analisam e criticam nosso comportamento.

Através dessas definições, os datascapes podem ser vistos sob duas perspectivas: como meios de análise que prezam pela multidisciplinaridade, abrindo discussão para outras áreas, e como meios de interpretação da realidade que contribuem para os arquitetos compreenderem as complexidades e possibilidades espaciais, particularmente em situações com alta densidade, nas quais as informações de maior impacto podem interferir umas nas outras. O que deve ser observado com cautela é a necessidade cada vez maior de dados, o que pode fazer com que o método datascapes se arraste em uma crescente demanda por busca de informações (MORAIS; SPERLING, 2013).

\section{USO-MISTO / ESPAÇOS MÚLTIPLOS}

O edifício habitacional se conecta à cidade através da inserção de espaços de trabalho, comércio e áreas coletivas. Esses espaços variados atendem à diversidade de habitantes e modos de vida e refletem a heterogeneidade da cidade.

Existe potencial para um futuro desenvolvimento sustentável se considerarmos as aglomerações urbanas como conjuntos integrados e interdependentes. Trabalhamos com a ideia de mesclar funções, integrar diferenças e desenhar objetos que sejam capazes de modificar suas qualidades e características no futuro. Preocupam-nos os aspectos sociais e como trabalhar a mescla de funções fazendo disso algo interessante em circunstâncias de densidade e compactação espacial (MVRDV em entrevista para El Croquis 111, p. 14, tradução nossa).

Por muito tempo a mescla de funções foi proibida na Holanda por motivos de higiene e segurança, mas com o passar do tempo os locais de trabalho foram ocupando os espaços da indústria pesada e novas oportunidades começaram a surgir para os complexos de usos mistos.

O MVRDV encara a mescla de funções como uma forma de gerar sinergia e diversidade em uma área menor, gerando economia. Outra vantagem é a liberação de espaço que pode ser direcionado para lazer ou natureza. Além disso, a 
necessidade de estacionamento é reduzida juntamente com a monocultura característica dos bairros suburbanos.

Segundo os arquitetos do escritório (2005), o uso misto e o uso de espaços múltiplos requerem uma mudança de padrões para resolver a escassez de espaço e a excessiva uniformidade na Holanda. As soluções urbanísticas monofuncionais não atendem a instabilidade da sociedade atual.

Que modelos servirão para criar ambientes vívidos em que várias funções e densidades possam coexistir e sejam conectadas e adaptáveis às mudanças do tempo? Que modelos seriam necessários para produzir soluções adequadas para as demandas complexas do uso misto? Demandas que requerem um aumento de densidade, intensidade e diversidade em relação às políticas ambientais, econômicas e sociais (MVRDV, 2005, p. 1262, tradução nossa).

Nesse contexto, os arquitetos decidiram que um modelo para a mescla de funções deveria consistir de um indicador de mudanças de parâmetros espaciais quantitativos (densidade e diversidade funcional) em relação aos parâmetros qualitativos (sustentabilidade ambiental, econômica e social). Para controlar a interdependência desses parâmetros, o MVRDV desenvolveu junto com a empresa CThrough o software chamado Functionmixer (2001) que ilustra e explica as relações e resultados que são possíveis dentro de um cenário concreto de uso misto. Trataremos desse e de outros software com mais profundidade no tópico 2.2 Diagramas e software dentro do tema Processo de projeto.

\section{NATUREZAS ARTIFICIAIS}

A Holanda reconstrói suas paisagens através de obras para apropriação de áreas do mar e do manejo de suas áreas verdes, criando naturezas que são, de certa forma, inventadas. Esse histórico é levado para a arquitetura e para as cidades pela conexão do exterior com o interior, por meio da inserção de espaços vazios no construído e o próprio entendimento da construção como parte da paisagem. $\mathrm{O}$ pavilhão da Holanda para a Expo 2000 é exemplo de um aglomerado literal de paisagens que, ao invés de estarem umas aos lados das outras, estão empilhadas em cinco pavimentos, alternando a noção humana de paisagem e tentando comprimir o espaço devido à falta do mesmo. 
Segundo os arquitetos há certa artificialidade nas paisagens que caracterizam os países desenvolvidos:

A imagem que temos da natureza raramente corresponde à realidade. Há muito tempo a natureza tem sido operativizada e instrumentalizada, cultivada e adaptada às necessidades humanas. Nas reservas naturais e nas áreas de conservação, todas as atuações são intervenções humanas para proteger a natureza de outras intervenções humanas (MVRDV em entrevista para El Croquis 111, p. 32, tradução nossa).

A manipulação de elementos naturais e a referência ao natural aparecem no trabalho do MVRDV assim como as questões sobre densidade e uso misto, no entanto, os arquitetos afirmam que a natureza é apenas uma atividade urbana necessária para sobreviver. Essa necessidade reforçada no projeto do pavilhão da Expo 2000 surge também na proposta 3D Garden (Hengelo, 2001), na qual a questão era criar equivalências urbanas entre as casas de subúrbio com jardim e os apartamentos com grandes varandas, uma espécie de jardim privado. Ainda, no concurso para Silicone Hill (Estocolmo, 2001), a proposta era uma reconstrução da natureza aumentando a colina onde o projeto foi implantado. Através dessas experimentações, o MVRDV sinaliza uma série de questões sobre o tema, como: a produção de oxigênio nessas condições, plantar e manter um bosque em um andar alto de um edifício e as necessidades de luz, ventilação e legislação de segurança contra incêndio em uma 'natureza construída'.

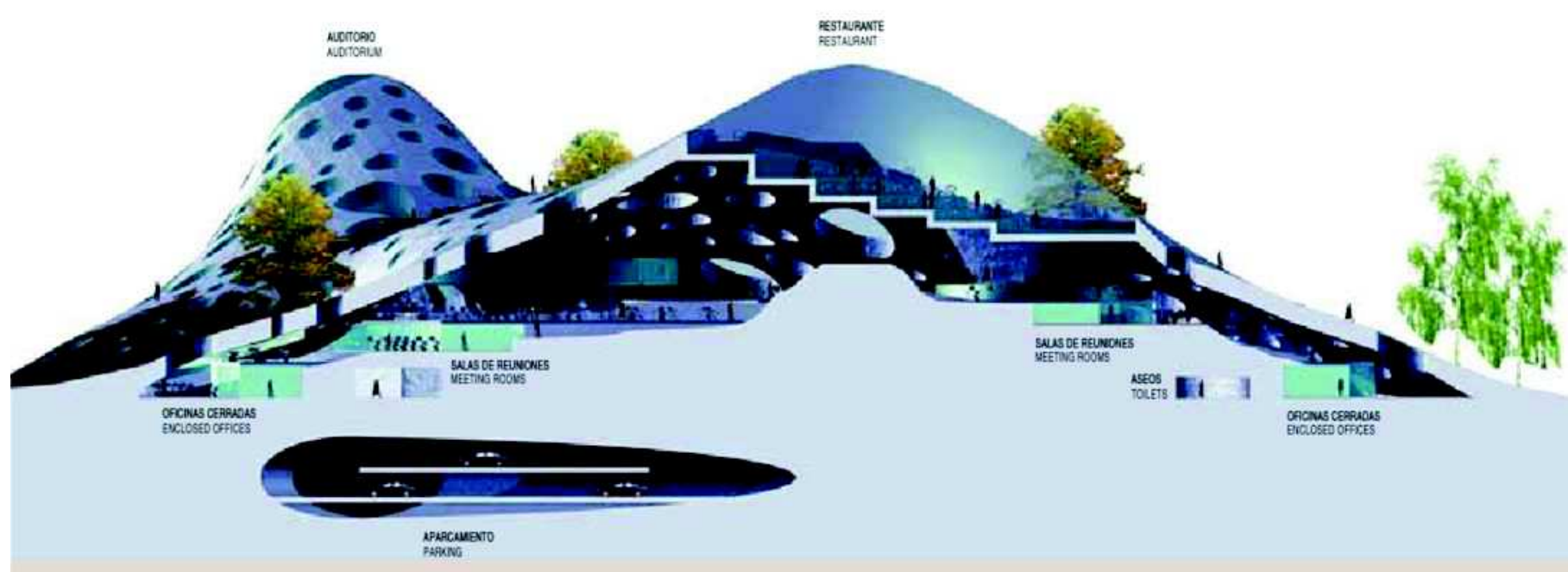

Silicone Hill: corte. Fonte: El Croquis 111. 
O MVRDV se interessa pela interiorização espacial para gerar uma gradação e interdependência entre interior e exterior, de modo que as diferenças entre esses espaços se diluam. É um instrumento adequado para a ideia de compactação, de como gerar espaços em que a tridimensionalidade é potencializada (MORENO; GRINDA, 2002, p. 15).

Nunca descrevemos esses espaços como átrios, no sentido clássico. Nos edifícios com átrio, esses espaços intermediários e climatizados são muitas vezes espaços representativos. Falamos de outro tipo de interiorização, geramos um espaço intermediário que termina por estar definido por suas qualidades climáticas. Tratam-se de áreas que podem ser criadas mediante uma manipulação inteligente do programa, sem adicionar área extra e com estados intermediários de climatização, evitando dessa maneira custos adicionais (MVRDV em entrevista para El Croquis 111, p. 15, tradução nossa).

De outro modo, quando há adensamento e os edifícios se aglomeram, a cidade começa a se interiorizar. Para Winy Maas (1998, p. 652), nessas circunstâncias o espaço público é diminuído e tem cada vez mais "design", parece que esse espaço perdeu sua liberdade, foi colonizado como parte de um ambiente construído, tornando-se um tipo de interior. Essa discussão que Maas levanta pode ser vista em ruas equipadas com uma diversidade de mobiliário urbano como fontes, bancos, vasos, lixeiras, mas também aparece, paradoxalmente, na "interiorização espacial" de seus projetos. Um exemplo é a praça elevada no edifício Mirador, com seus revestimentos coloridos e bancos enterrados.

No projeto da Villa VPRO o interior é construído como se fosse um espaço exterior e no edifício Wozoco o vazio entre as caixas em balanço não deixa de ser considerado por eles um interior público.

A interiorização das superfícies contínuas dobradas, presentes especialmente no projeto da Villa VPRO, é associada, pelo MVRDV, com a questão da materialização de espaço, da inserção da paisagem dentro da arquitetura e da continuidade exterior/interior:

A questão de se construir ou não construir é especificamente importante na Holanda. Em muitos casos, nossos projetos têm que ser construídos em locais que já estão ocupados pela natureza ou em espaços públicos. Isso significa que há sempre uma relação dúbia entre o que você tem que 
construir e o local onde se vai construir (...). Tentar estender espaço devido à falta dele. Este prolongamento da área urbana ou piso térreo é muito popular no momento (...). Não podemos tentar dar razão à manipulação das superfícies para que possamos transformá-la em uma escada quando a escada é necessária, transformá-la em uma rampa quando a rampa é necessária, uma colina quando uma colina é necessária, para construir uma cenografia não-linear que possa ser discutida? (MVRDV em entrevista para

El Croquis 86, p. 27, tradução nossa).

\section{SUBÚRBIO URBANO}

O projeto 3D Garden (Hengelo, 2001) traz essa questão ao tentar juntar o aproveitamento da infraestrutura urbana com as qualidades espaciais e a natureza do subúrbio.

Para o MVRDV, 3D Garden funciona como um protótipo para construir habitações com uma ampla variedade tridimensional:

Calculamos o custo levando em consideração quanto despenderia a construção das varandas em balanço. A surpresa foi que, com o mesmo tamanho de uma casa com uma boa área de terreno, esse tipo de apartamento não teria um custo muito elevado (MVRDV em entrevista para El Croquis 111, p. 19, tradução nossa).

Trata-se de um desenvolvimento urbano híbrido que combina as características de uma habitação na cidade (com as conveniências da localização central, privacidade, estacionamento subterrâneo) com as características de uma casa de subúrbio (jardins, grande oferta de espaço e uma vida em comunidade de bairro). Os arquitetos ressaltam que nesse conceito o preço do terreno pode modificar o tamanho dos jardins em balanço, desse modo, um mesmo protótipo se reformula de modos distintos, segundo os dados de cada localização, neste caso, o valor do terreno.

Segundo Maas e van Rijs (1998, p.14), a Holanda é um país adensado de maneira geral, mas não excessivamente. Com isso, vastas áreas são ocupadas com um modelo suburbano de construções de baixo custo como casas com jardins, escritórios, fazendas e fábricas, além de outros elementos de baixa densidade, resultados da falta de planejamento e de uma preocupação ainda voltada mais à quantidade do que a qualidade. Aceitando isso como um problema não urgente, a tendência é que a ocupação das áreas livres continue de forma desgovernada. 


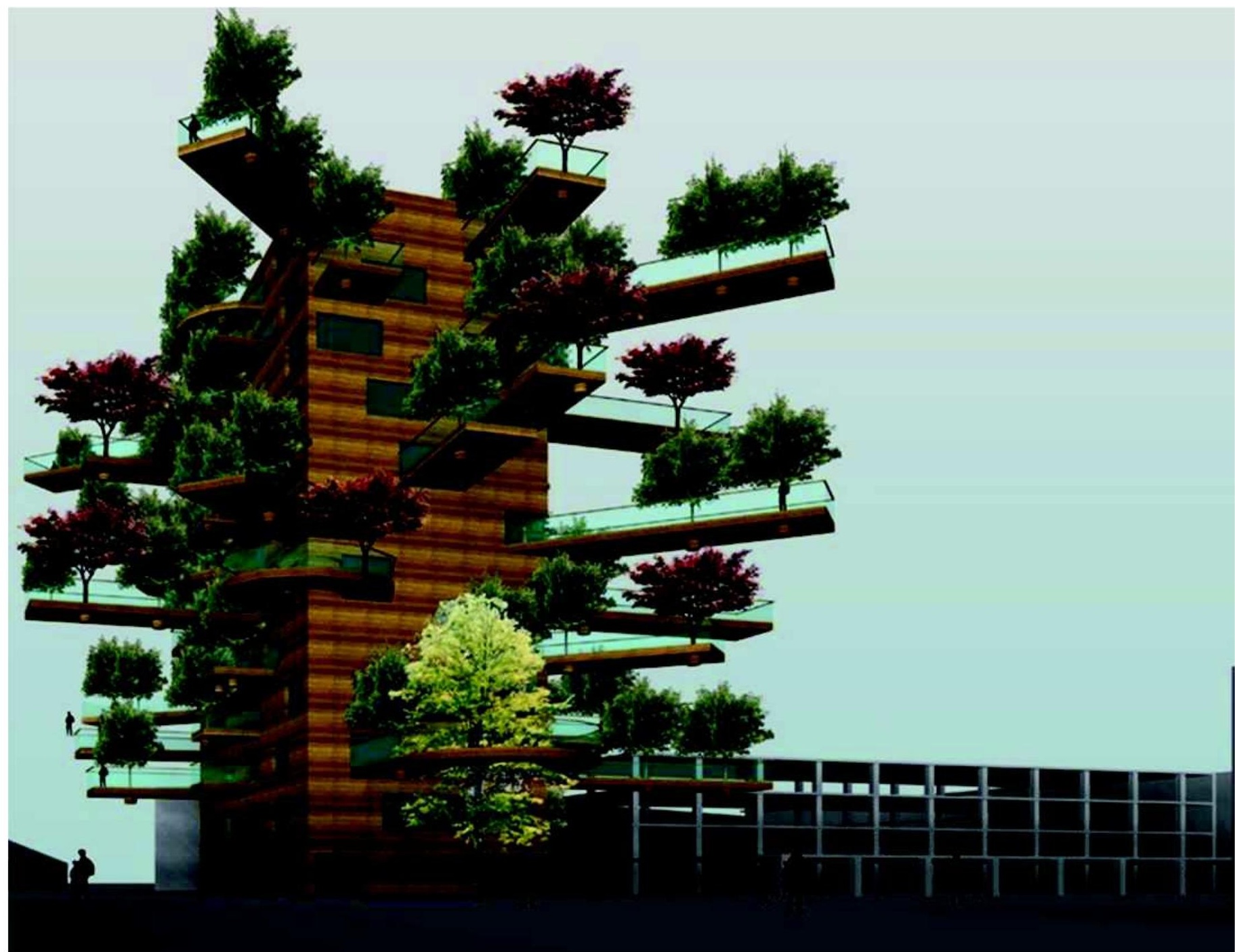

3D Garden, edifício de apartamentos e escritórios, 2001. Fonte: El Croquis

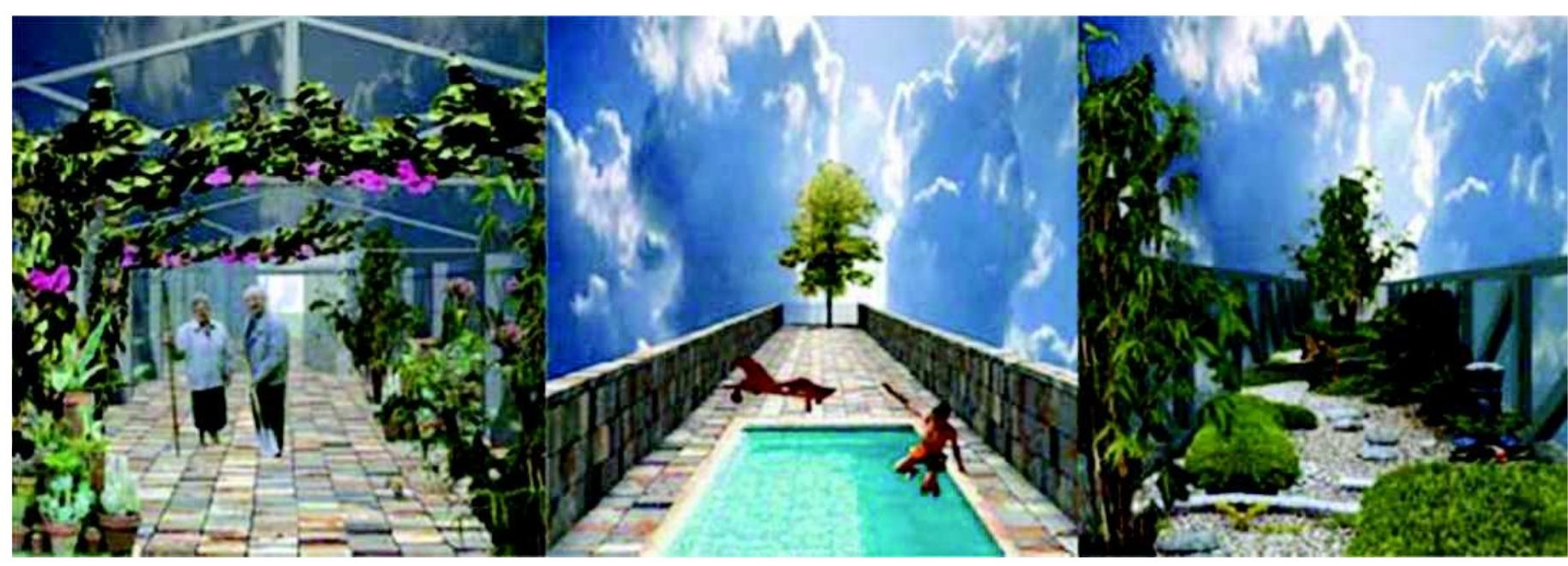

3D Garden, varandas em balanço, 2001. Fonte: El Croquis

É possível reconsiderar essa situação levando a densidade ao extremo? É possível ultra adensar algumas áreas para salvar as paisagens pastorais de 
serem suburbanizadas? Devemos considerar uma área densa mais permanente e outras em um "modo de urbanismo mais leve" descobrindo as vantagens e limitações desse sistema? (MVRDV, 1998, p. 24).

\section{DENSIDADE}

A eficiência se dá através da otimização do uso do solo, liberando áreas livres para outros usos. Também o espalhamento urbano é evitado e a infraestrutura urbana é potencializada.

Para Adam (2002, p.30) a ideia de adensamento e mescla das funções é o fio condutor da obra do MVRDV, a começar pelo Berlin Voids (1991), onde os espaços vazios e os coletivos se intercalam com apartamentos de diversos tipos. A casa tradicional de bairro, agrupada em torno de um pátio, foi decomposta e colocada na vertical.

Um dos estudos mais polêmicos do MVRDV sobre o tema foi Pig City (2000). A Holanda é o país da Europa que mais consome e exporta carne suína, para tanto o MVRDV simulou cenários de ocupação do solo necessários para o cultivo de porcos e propôs a junção dos elementos naturais da produção com a industrialização. Dessa forma, os arquitetos idealizaram 77 torres de 620 metros de altura, chamadas de fazendas verticais, suficientes para acomodar toda a produção de carne suína do país. Mas o que chama a atenção no trabalho foi que a solução não sugeriu nenhuma alteração nos hábitos dos consumidores, mas sim na otimização da produção (Adam, 2002, p. 32). O mesmo aconteceu no estudo Costa Ibérica (2001). Os arquitetos não sugeriram que a cidade de Benidorm, na Espanha, fosse reformulada para se tornar um lugar mais agradável, mas sim um lugar que tivesse seu potencial multiplicado com a inserção de mega estruturas que liberassem mais área livre no litoral. Condição semelhante pode ser relembrada nas conferências de Le Corbusier nas quais propunha construções altas, aumento de densidade e de superfície livre.

Os questionamentos do MVRDV passam também pelo funcionamento do urbanismo, que trabalhava até então em duas dimensões, para ser pensado em três dimensões, e altamente adensado. Dessa discussão surge a exposição KM3 (2001) sobre como as construções existentes poderiam se tornar mais eficazes.

No texto When dense, when lite? (1998), Harm Tilman destaca: 
Os centros urbanos continuarão a crescer, de acordo com o The Economist, isso se deve ao fato que as cidades estão sempre se reinventando. Esse crescimento está espalhando as cidades para fora, criando novos centros urbanos. Isso significa que regiões polinucleares emergem. Nos próximos anos as políticas urbanas precisarão incentivar o crescimento nas áreas centrais existentes. Isso significa que as cidades deverão ser modernizadas, organizadas, transformadas. O centro deve ser operado muito mais ativamente do que é e aí surge a densidade urbana (TILMAN, 1998, p. 122, tradução nossa).

Tilman (1998) cita o filósofo Massimo Cacciari para explicar as relações da cidade:

Sociologia, filosofia e urbanismo nos treinaram para ver a metrópole como um sistema funcional de relações e ligações. As ciências urbanas derivam espacialmente definindo a metrópole como um todo das partes, como uma relação das relações. A espacialização da dinâmica urbana é o resultado desse movimento (CACCIARI, 1986 apud TILMAN, 1998, p. 123, tradução nossa).

Alguns fenômenos mostram as consequências da especialização funcional e a dissolução do espaço público. Tilman (1998) cita exemplos como a distinção entre espaço coletivo e habitação, novos bairros comerciais e shoppings na periferia, os subúrbios só alcançados de carro, a distribuição de cidades especializadas (parques temáticos, campus) e o aumento da segregação social e tipológica nas áreas residenciais.

Nesse sentido, o autor faz uma comparação entre Atlanta e Portland: Atlanta é a cidade paradigmática americana, seus subúrbios explodiram, o centro da cidade abriga apenas $10 \%$ dos trabalhadores. Portland é o oposto, uma região metropolitana compacta, a área de desenvolvimento é limitada; a ideia não é limitar o crescimento urbano, mas sim acomodá-lo ligando-o à rede de transporte público.

Tilman (1998) aponta que considerações funcionais e econômicas avaliavam que a alta densidade nos centros urbanos deveria ser evitada. Similarmente, a alta densidade é justificada pelo alto valor dessas áreas urbanas. A densidade é variada porque, em princípio, a área construída está relacionada à área do terreno. No planejamento de uma cidade, um aproveitamento de 1,5 a 1,8 era considerado ótimo. Essa linha de raciocínio leva a certa homogeneização tomando a cidade compacta como ideal. 
A densidade é, segundo o autor, a terceira dimensão das cidades e um veículo para afirmações provocativas. Outros meios, além da habitação, são necessários para produzir uma cidade compacta comparável à Nova York ou Hong Kong. Então a mistura de usos é essencial para fazer uma cidade compacta atrativa. Densidade urbana também engloba o adensamento funcional, social e econômico nas cidades. Densidade é uma ferramenta crítica ligada às dimensões urbanas como os fluxos entre as partes da cidade. Existe uma nova realidade demográfica e econômica nas cidades.

O MVRDV realizou vários estudos sobre as cidades mais adensadas do mundo em prol da identificação de algumas possíveis resultantes desse processo, como a falta de insolação ou a sensação de claustrofobia.

Em 1995 Winy Maas and Jacob van Rijs publicaram o texto Icebergs, mostrando que dentro das condições de adensamento, cada vez mais programas estão sendo alocados no subsolo. Reservatórios de água, eletricidade, estacionamento, armazenamento, arquivos, lazer, fábricas, escritórios e até mesmo habitação. Por trás desse processo estão razões como regulamentações, questões ambientais e segurança. Eles ressaltam que o existente é colocado no subsolo e as partes mais aceitáveis da sociedade moderna são colocadas no topo, como icebergs. Como em muitos dos seus estudos, eles não fornecem uma resposta, mas instigam novos questionamentos:

Devemos aceitar esse método e explorar esse reservatório potencial? Que tipo de comportamento e orientação pode ser imaginado nesses lugares sem contexto e sem referências? (MAAS; VAN RIJS, 1998, p. 349, tradução nossa).

Em 1996, Winy Maas entrevistou o psicoterapeuta Jac Hoevenaars. O texto publicado em FARMAX permanece em uma posição quase neutra sobre a relação entre densidade e claustrofobia. Segundo Hoevenaars, a claustrofobia é um tipo específico de fobia que acontece em todas as culturas em grau similar. $20 \%$ do mundo reconhecem tendências de claustrofobia, mas apenas $1 \%$ realmente a tem. $\mathrm{Na}$ Alemanha, uma pesquisa estudou a relação entre o tamanho das cidades e essas fobias e o resultado mostrou que não há relação entre o medo e o tamanho do lugar de residência, embora exista a impressão de que o adensamento possa parecer agravar o quadro. Hoevenaars destaca que, apesar dessa sensação, a 
proximidade com vizinhos ou terceiros faz as pessoas ficarem mais tranquilas, sabendo que podem ter alguém com quem contar nas proximidades.

Ainda pesquisando possíveis pontos negativos resultantes do adensamento, em 1997, o MVRDV realizou o estudo Aztecs! sobre as regulamentações da iluminação na Holanda. Quando o movimento moderno surgiu foram introduzidos códigos para alcançar maior higiene nas habitações. Para prover iluminação suficiente, as leis holandesas passaram a regulamentar que cada ambiente de uma habitação deveria receber um mínimo de três horas de sol direta por dia. Essas leis terminaram por influenciar o potencial de adensamento e, para alcançar densidades mais competitivas e manter a legislação, era necessária a mescla de habitação com outros programas. Para trabalhar com a rígida legislação holandesa, o MVRDV reeditou em 1997 o software Castle Maker (criado em 1995 por Ronald Wall e Rafael Seidle). Seu princípio é fornecer um método para gerar edifícios otimizados de acordo com as restrições de iluminação e programa. A localização determina a forma, e os parâmetros variáveis podem ser o terreno, o coeficiente de aproveitamento, altura, largura e comprimento, ângulos dos raios solares, profundidade dos apartamentos ou escritórios e a possibilidade de vazios. Os resultados gerados podem ser infinitos e fornecem a porcentagem de habitação, escritórios e áreas comerciais.

Outra preocupação sobre o adensamento das cidades é o possível aumento da violência. Um estudo da Universidade Oxford (MVRDV, 2005) afirma que é prematuro concluir que a superpopulação contribua para um aumento da agressividade, Hong Kong, uma das cidades mais adensadas do mundo, tem um dos índices de violência mais baixos (MVRDV, 1998, p. 134). O adensamento das cidades asiáticas chama a atenção do MVRDV e em 1998, Jacob van Rijs fez uma análise sobre a tipologia das torres residenciais de Hong Kong. Ele mostra que esses edifícios refletem bem a legislação local: o andar tipo tem forma de cruz para otimizar a circulação e as plantas das unidades, bastante recortadas, não tem exigência de área mínima. O coeficiente de aproveitamento em Hong Kong é 10, adicionado à taxa máxima de ocupação de 40\% e uma altura mínima de 61 metros, o que faz as torres serem praticamente inevitáveis (VAN RIJS, 1998, p. 177). Para além das questões da densidade, podemos discutir através desse estudo a aceitação ou não da realidade nas investigações do MVRDV. Retomando outras pesquisas do escritório, como Pig City e Costa Ibérica, percebemos que a as torres 
não são simplesmente aceitas, mas reinventadas criticamente, sendo que a partir delas são geradas outras análises e cenários.

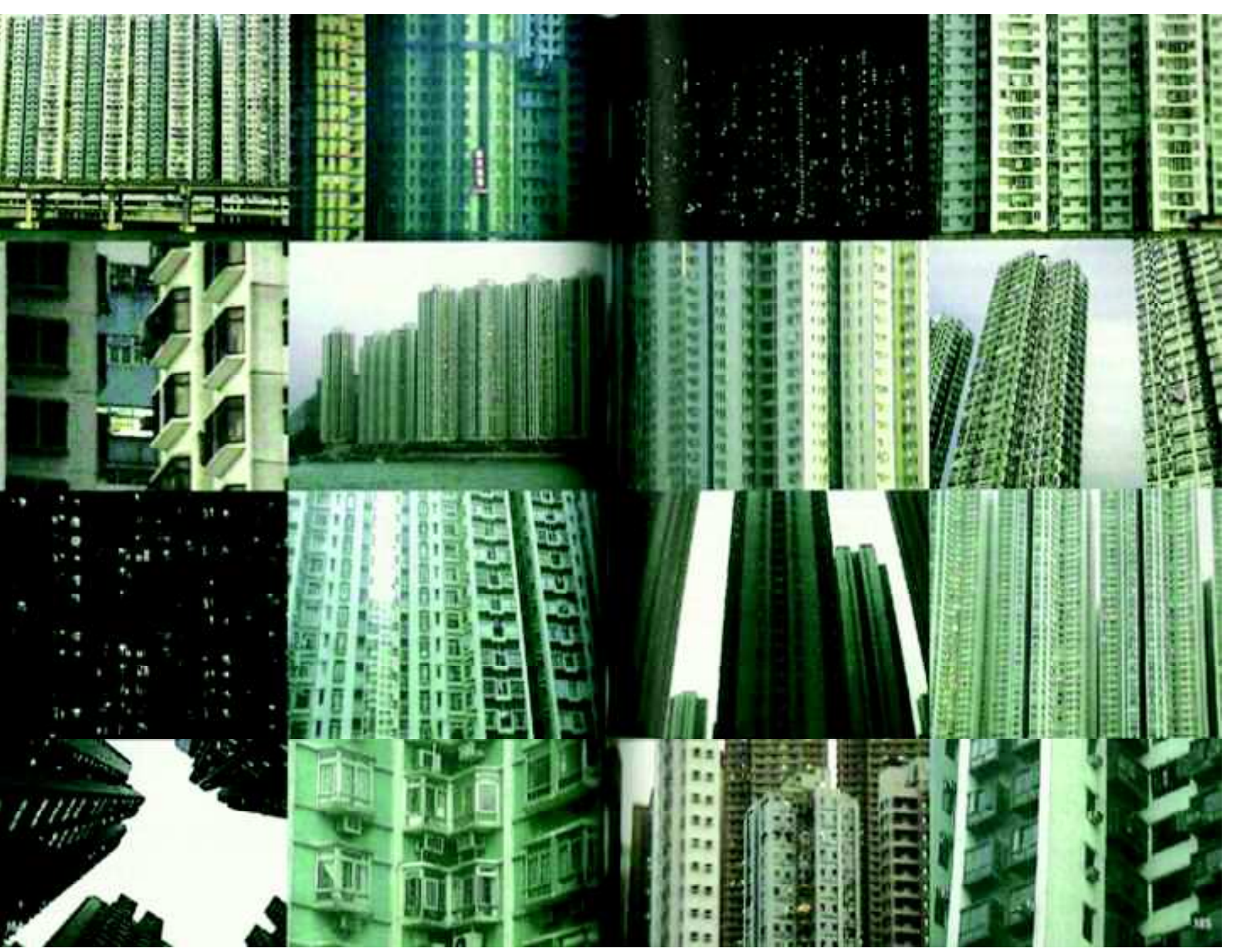

Torres de apartamentos em Hong Kong. Fonte: FARMAX.

Ainda nas cidades asiáticas, o levantamento fotográfico de Bart Lootsma realizado em 1998 na cidade de Guagzhou, China, e publicado em FARMAX, chama a atenção para o rápido aumento da densidade populacional nas cidades chinesas.

Lootsma cita Anthony Giddens ${ }^{15}$ que descreve o aumento dos sistemas abstratos, redes institucionais de especialistas que baseiam suas decisões em fatos e métodos científicos. Esses sistemas abstratos permeiam a sociedade, em nível global e diário. Segundo Lootsma, isso pode ser visto na Ásia de maneira mais extrema que no ocidente. Guangzhou ainda tem ruas estreitas de pedestres e um centro colonial

\footnotetext{
${ }^{15}$ Anthony Giddens, "Living in a Post-Traditional Society" in Ulrich Beck, Anthony Giddens e Scott Lash (eds), Reflexive Modernization. Cambridge: Polity, 1994, p.75-84.
} 
altamente adensado, mas a cidade cresce rapidamente. De 1982 a 1993 a densidade populacional dobrou de 478 para 839, mas a velocidade do transporte público caiu de $17 \mathrm{~km} / \mathrm{h}$ para menos de $10 \mathrm{~km} / \mathrm{h}$ desde os anos 60 (LOOTSMA, 1998, p. 474).

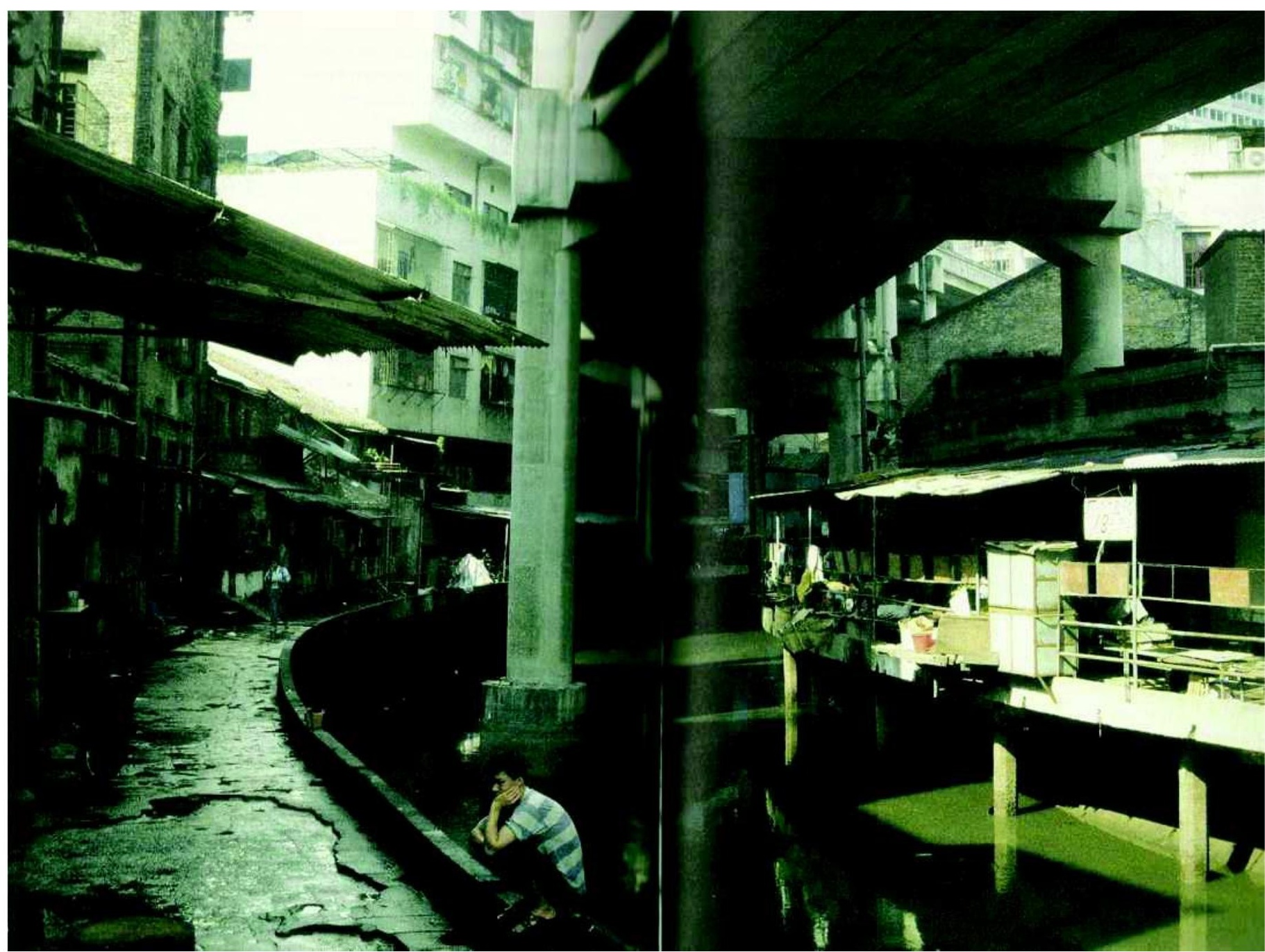

Viaduto com dois níveis de pistas e a cidade precária embaixo, em Guangzhou. Fonte: FARMAX.

Lootsma associa o sistema abstrato do trânsito de Guangzhou com os datascapes do MVRDV. Os números tomam uma forma material e dão origem a uma paisagem nova e artificial em cima da cidade existente que tenta conectar uma grande escala regional e supra-regional. É como se a avaliação de dados incompletos recortasse apenas uma camada da cidade, não examinando suas conexões e consequências. Tais informações revelam a necessidade de infraestrutura para mobilidade na área escolhida, mas ignoram seus efeitos em outras partes do território urbano. 
A criação dos sistemas abstratos desincorporam os meios tradicionais de vida e esses passam a fazer parte de um submundo, o que pode ser visto na realidade da população que mora nos leitos dos rios, que ainda levam uma vida tradicional, muito diferente do ambiente nas autoestradas elevadas (LOOTSMA, 1998, p.475, tradução nossa).

\section{DIVERSIDADE E IDENTIDADE}

A variedade de tipologias em um projeto responde às necessidades de uma sociedade diversa que não se adapta mais a um único programa. Segundo Maas:

A contínua mudança de posições coloca nossa sociedade em uma condição de relatividade. 'Como fazer?' se tornou 'Onde fazer?' ou 'Por quanto tempo temos que fazer?'. Para entender tais possibilidades, podemos explorar e desdobrar esse campo. O máximo de diferenças torna a cidade uma composição de programas que obtém sua coerência pela diversidade (MAAS, 1998, p. 614, tradução nossa).

Desde Berlin Voids, o MVRDV discute a habitação contemporânea levando em consideração as questões da individualidade e da coletividade. Os projetos para Ypenburg (1998-2005), um conjunto residencial implantado ao sul da cidade de Haia, é outro exemplo da recorrência desse tema. Desde 1990 existe uma diretriz na Holanda, o programa VINEX, que determina o desenvolvimento residencial holandês e orienta que os conjuntos habitacionais tenham identidades diferentes a fim de evitar uma disseminação urbana homogênea. De acordo com os arquitetos (em El Croquis 111, p.22), o conceito abstrato de habitação ideal do modernismo é substituído por uma ampla gama de várias habitações ideais.

Segundo Adam (2002, p.36), nas casas pátio de Ypenburg os arquitetos buscam um novo caminho entre os pólos opostos da diferenciação e da homogeneização, a individualidade e a coletividade. Rompendo com a ideia convencional de casa, eles dispensam jardins tradicionais e poupam os interiores visíveis evitando que a diferenciação se dê através de algum tipo de exposição. 



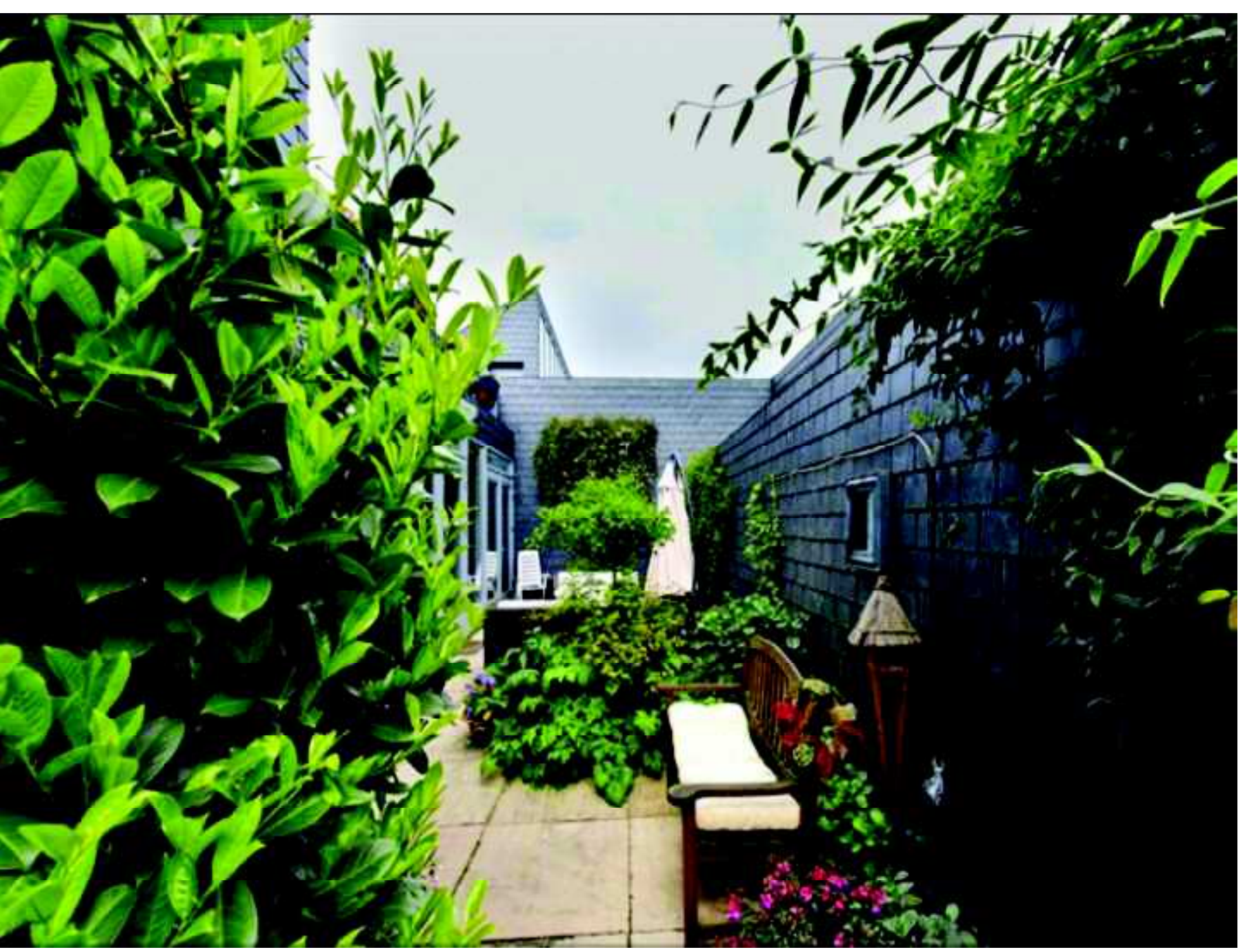

Interior das casas pátio, Ypenburg. Fonte: www.mvrdv.nl

Para Moreno e Grinda (2002, p.13) nos projetos do MVRDV há uma preocupação em gerar uma identidade própria do edifício, de modo que ele mostre claramente o que é e como foi desenvolvido (através de leis, restrições, etc). Mas os arquitetos argumentam que um edifício complexo não representa necessariamente uma sociedade complexa:

Nós escolhemos muitas vezes o oposto: expor unicamente o mais importante, eliminar o ruído no resultado final, mas isto não tem nada a ver com mostrar a identidade. Uma cor ou uma seleção de um edifício não constituem sozinhas a sua identidade, o que tratamos de mostrar é bem mais o modo como os edifícios se comportam no limite entre interior e exterior ou entre público e privado (MVRDV em El Croquis 111, p. 13, tradução nossa).

A organização dos espaços que otimiza a relação entre os diferentes programas e a sincronização das atividades entre as pessoas é dificultada pelo crescimento da 
individualização. No texto Campingland (1997), publicado em FARMAX, Arnold Reijndorp e Vincent Kompier falam sobre o estilo de vida focado na imagem apresentada ao mundo, especialmente pela mídia como responsável por definir como a casa deve ser. Nesse contexto, novos meios de diferenciação são necessários e a organização coletiva de tempo dá lugar a uma organização individual de acordo com as necessidades de cada um.

\section{GLOBAL/LOCAL}

Na introdução do livro The Regionmaker, RheinRuhrCity, Winy Maas aponta que os projetos em grande escala voltaram a fazer parte do domínio arquitetônico, fato comprovado no MVRDV pelo aumento do número de projetos encomendados por governos para a realização de estudos, junto com economistas e geógrafos, sobre identidade e o futuro das regiões.

Segundo Bert van de Knaap (2002, p. 67) uma região é fácil de ser definida quando é vista a partir de seu núcleo, mas o problema surge quando a atenção se volta para as bordas. Uma região é uma estrutura espacial fluida no sentido em que suas atividades não são fixas e seu tamanho flutua todo tempo.

Saskia Sassen (2002, p.79) também questiona os limites de uma região e critica aqueles que argumentam que a globalização é uma forma de padronização. Ela afirma que padrões e dinâmicas de homogeneização do mundo interagem com as especificidades da região ou de uma cidade. O resultado disso é um mescla de ambientes padrões onde ainda permanecem as características da região.

O MVRDV também aponta que, apesar da globalização, o mundo não está se tornando um todo homogêneo. Por mais que exista uma dissolução das fronteiras entre nações, a ideia de novo regionalismo é ligada à globalização e não pode ser lida apenas do ponto de vista de uma região isolada já que qualquer processo de regionalização tem efeitos em outras áreas do mundo. Regiões de diferentes tipos irão definir uma nova estrutura global (WALL, 2002, p. 29). É aí que o MVRDV foca seu trabalho em regiões:

As especificidades de determinado local devem ser mantidas ou essas singularidades desaparecerão no futuro? Esse é um importante tema a se discutir sobre identidade. Uma postura muito aceita para seguir essas singularidades é a alta especialização. Por um lado a especialização impulsiona o progresso, por outro poderia estimular a mútua 
interdependência entre as regiões e depois conduziria a uma estabilização da maior parte das áreas do globo. Mas muita gente acha que as singularidades não deveriam ser acentuadas para tender a ser mais global, pelos desafios do mundo virtual (MVRDV em El Croquis 111, p.13).

Para os arquitetos as regiões funcionam como áreas de influência sobrepostas e conectadas e vão além dos limites e fronteiras de cidades ou países. A influência de cada região no sistema global pode ser alterada por qualquer mudança em sua constituição. Para entender essas alterações e otimizar o entendimento das informações em escala regional foi criado o Regionmaker (software desenvolvido pelo escritório em conjunto com a cThrough, 2002). A partir da análise de vantagens comparativas das mudanças, o programa passa a sugerir direções de desenvolvimento para dada região baseado nas hipóteses selecionadas pelo usuário (MVRDV, 2005). ${ }^{16}$

Os conceitos chave citados acima aparecerão no processo de projeto do MVRDV, tanto nos estudos e experimentações, como nos software e diagramas e, consequentemente, chegarão aos projetos. No entanto, um mesmo conceito pode aparecer de maneira distinta em vários trabalhos. Como exemplo, podemos considerar a densidade do Mirador diferente da densidade do Masterplan em Ypenburg. A utilização desses conceitos será desdobrada nos próximos capítulos.

\footnotetext{
${ }^{16}$ De certa forma, o planejamento em escala regional já havia sido proposto por Le Corbusier com os viadutoscidade em Argel e no Rio de Janeiro. Tais propostas aparecem como projetos exploratórios e conceituais, mas que guardam um caráter utópico assim como os estudos mais ambiciosos do MVRDV que simulam o planejamento em escala global.
} 


\subsection{Processo de projeto}

Para Montaner (2008), o MVRDV conseguiu fundir dois métodos que caminhavam por vias diferentes: o primeiro se refere aos estudos sistemáticos, quantitativos e diagramáticos feitos em programas de computador e o segundo trata da importância do projeto, através das experimentações.

A sentença 'a informação é a forma' resumiria esse método, que traduz a informação e as estatísticas em diagramas, e esses, por sua vez, em arquitetura. No MVRDV dá-se uma sábia síntese dos dois procedimentos, o que, em algumas ocasiões, gera o que já são obras-primas contemporâneas, como o Silodam, mas em outras produz experimentos delirantes à espera de alguma oportunidade mais adequada; de qualquer modo, trata-se sempre de provocações inquietantes (MONTANER, 2008, p. 167).

Embora Lootsma (2003) afirme que o aspecto estético é, geralmente, a parte mais negligenciada do trabalho do MVRDV, fica claro que a forma não é exclusivamente resultado da informação e da solução do programa. Existe uma preocupação com o aspecto estético manifestada, por exemplo, na aplicação de materiais para diferenciar as tipologias habitacionais no Silodam e, nas casas em Hagen Island (dentro do Ypenburg Masterplan), na lapidação da forma final gerada pelo processamento dos dados, assim como no detalhamento dos espaços coletivos no Mirador e no Parkrand.

Além disso, o MVRDV utiliza estratégias de decomposição para manipular as formas do vocabulário arquitetônico, como: informar, dobrar, climatizar, conectar, cobrir, escavar, extrudar, levantar, aterrar, suspender, interiorizar, pousar, elevar, mesclar horizontalmente, mesclar verticalmente, abrir, expandir, espiralar, dividir, comprimir, empilhar, inclinar. Tais estratégias são utilizadas para classificar os projetos apresentados no livro KM3 (2005). 
A maioria das críticas ao trabalho do MVRDV questiona sua semelhança às ideias modernistas de produzir edifícios que revelassem na forma informações científicas, econômicas e sociais. No entanto, no caso do MVRDV, essa abordagem tem um caráter mais de pesquisa do que de linguagem arquitetônica. Vale ressaltar ainda que naquele período a área de investigação podia ser mais facilmente definida e enquadrada dentro de uma cidade, estado ou país já que os territórios eram mais fechados e com menos influências uns nos outros do que no mundo globalizado de hoje. De acordo com Lootsma (2008), o MVRDV retorna à tradição de Le Corbusier e sua cidade para três milhões de habitantes, que, também diante dos problemas do crescimento demográfico, tentava reorganizar a cidade para lidar com as consequências do aumento populacional. O autor aponta outras semelhanças com os trabalhos do modernismo: o MVRDV pensa o mundo como Van Lohuizen concebeu o Randstad na Holanda (conurbação entre Amsterdã, Haia, Utrecht e Rotterdam), um anel de cidades autônomas que não se relacionariam. Ou seja, seus experimentos são realizados considerando uma forma política e ideológica favorável para a geração de processos de espacialização (ambientes-cenários hipotéticos e autônomos) e quando trata-se de projetos reais eles se posicionam a favor do processo de negociação porque tem o propício contexto da Holanda a seu favor.

\subsubsection{Estudos experimentais / projetos teóricos}

A utilização da pesquisa como método de trabalho é baseada em hipóteses e especulações, de modo que esses estudos gerem novas informações sobre o tema e os cenários que envolvem o projeto.

Em qualquer projeto ou concurso é imprescindível realizar um trabalho de busca que nos permita explorar as possibilidades de um tema específico. Alguns desses exercícios passam a fazer parte de um banco de dados mais amplo de temas e interesses, do domínio de uma investigação de maior alcance. $\mathrm{O}$ que começa sendo específico se torna relevante para propósitos mais genéricos (MVRDV em El Croquis 111, p. 10, tradução nossa).

O MVRDV adota um método inquisitivo em seu trabalho. As pesquisas, em grande parte, têm certo aspecto pedagógico por se iniciarem com questionamentos "E se?" e "Como?" fazendo com que o leitor reflita sobre determinado assunto enquanto 
desenvolve a leitura dos estudos do escritório. Essa capacidade de gerar a reflexão do público sobre questões diversas é um importante ponto das pesquisas do MVRDV, além disso, vários temas tratados por eles são demandas que, hoje, estão fora do domínio da arquitetura. Isso traz a participação de especialistas de outras disciplinas e também discute os limites do campo da arquitetura.

A acumulação de estudos e pesquisas sobre temas específicos levou os arquitetos para outra área de trabalho, o do arquiteto escritor ou editor de livros. A publicação de livros por arquitetos não é novidade e é válida para a organização do conhecimento produzido e, principalmente, como meio de comunicação ao divulgar as ideias do escritório, além de suas realizações concretas, e transmitir convicções em textos e imagens. O que chama atenção nas publicações após $S, M, L, X L$ de Rem Koolhaas são os projetos gráficos quase tão em destaque quanto o conteúdo, diagramados com muitas imagens, gráficos e fotografias. Distribuídos em volumes robustos, alguns livros chegam a ter mais de mil páginas, uma maneira eficaz de publicizar os escritórios. 


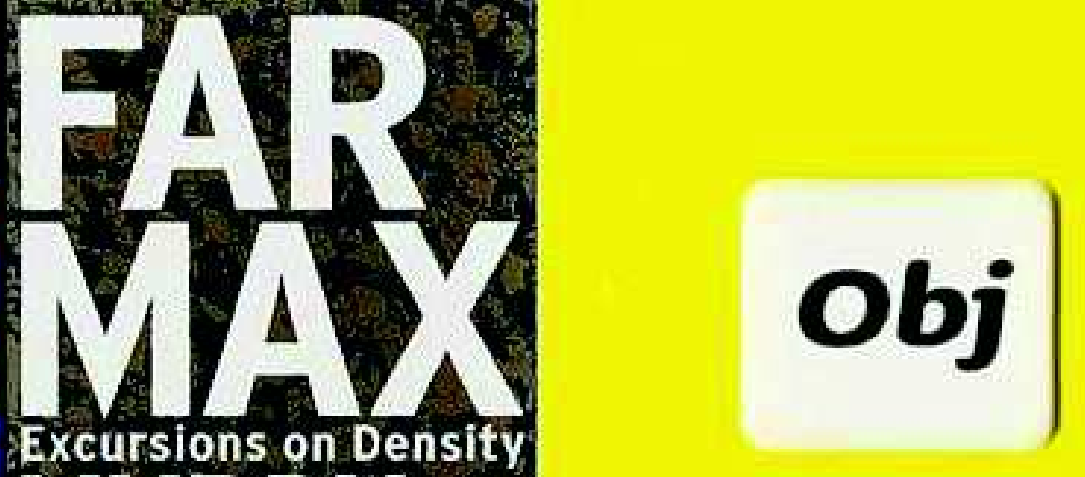

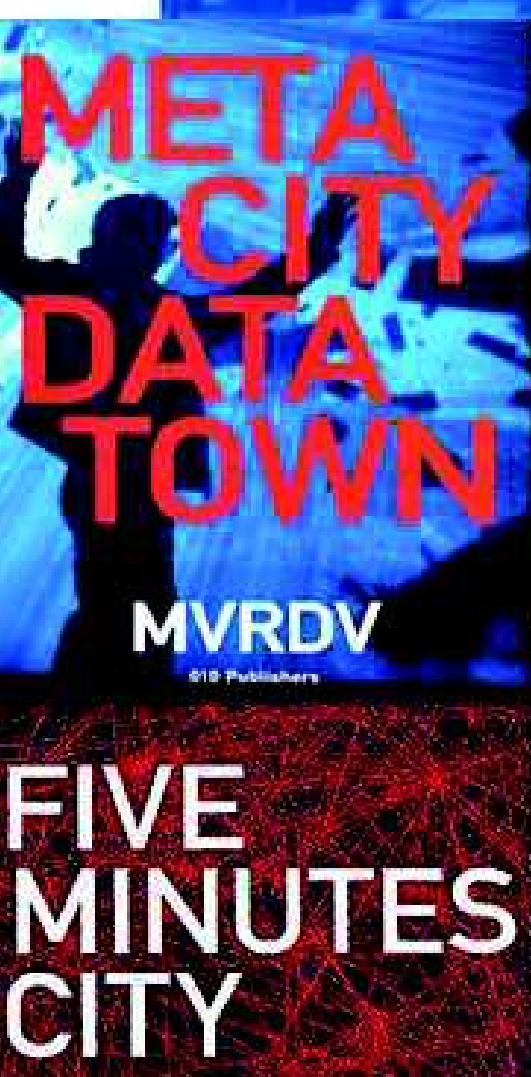

ARCHITECTURE AND IIMIMOBILITY

WINY MAAS

noges:

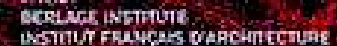

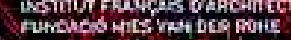

Tife

Dhámbinks IIIvillutiliv

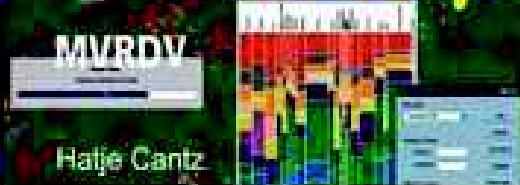

SPAGE

FIAHTR

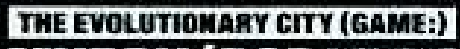
MURDV/DSD:

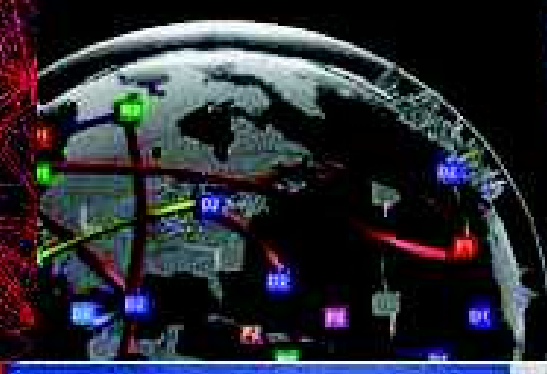

Hatow

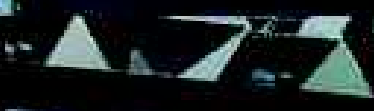

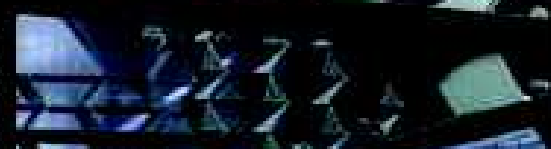

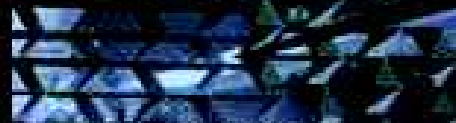
WVROV I Uwh A Pre-emptize filtory ary

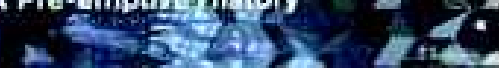

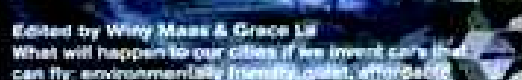

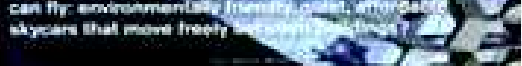

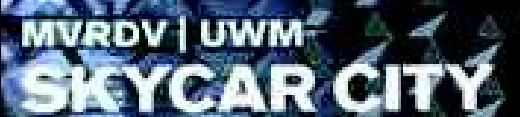

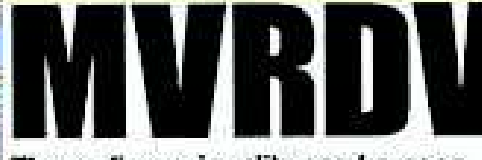

Three-dimensionality can be seen as architecture's fundamental

existence, the profession's acclaime domain. In times of globalization an scale enlargement, an update of thi: definition seems needed: meters tu into kilometers, M3 becomes

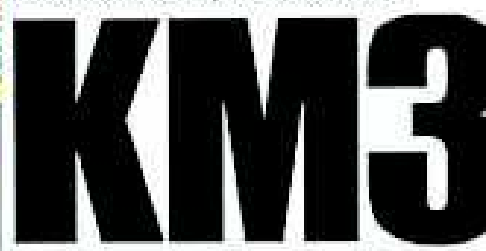

Excursions on Capacities

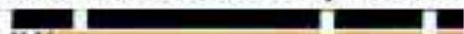
NAI Dat Berloge Instituto AVBR I

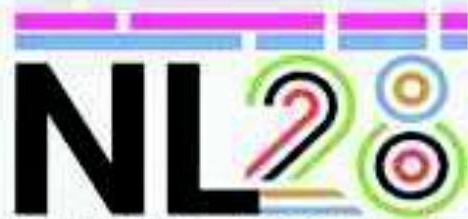
OLYMPIC FIRE Fufare Games = maipubihnoer

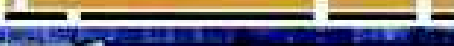
Agendas on Urbanism

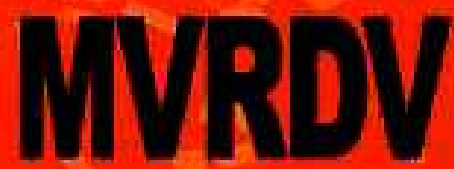

whos aution?

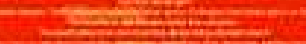

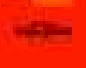

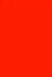

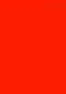

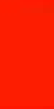
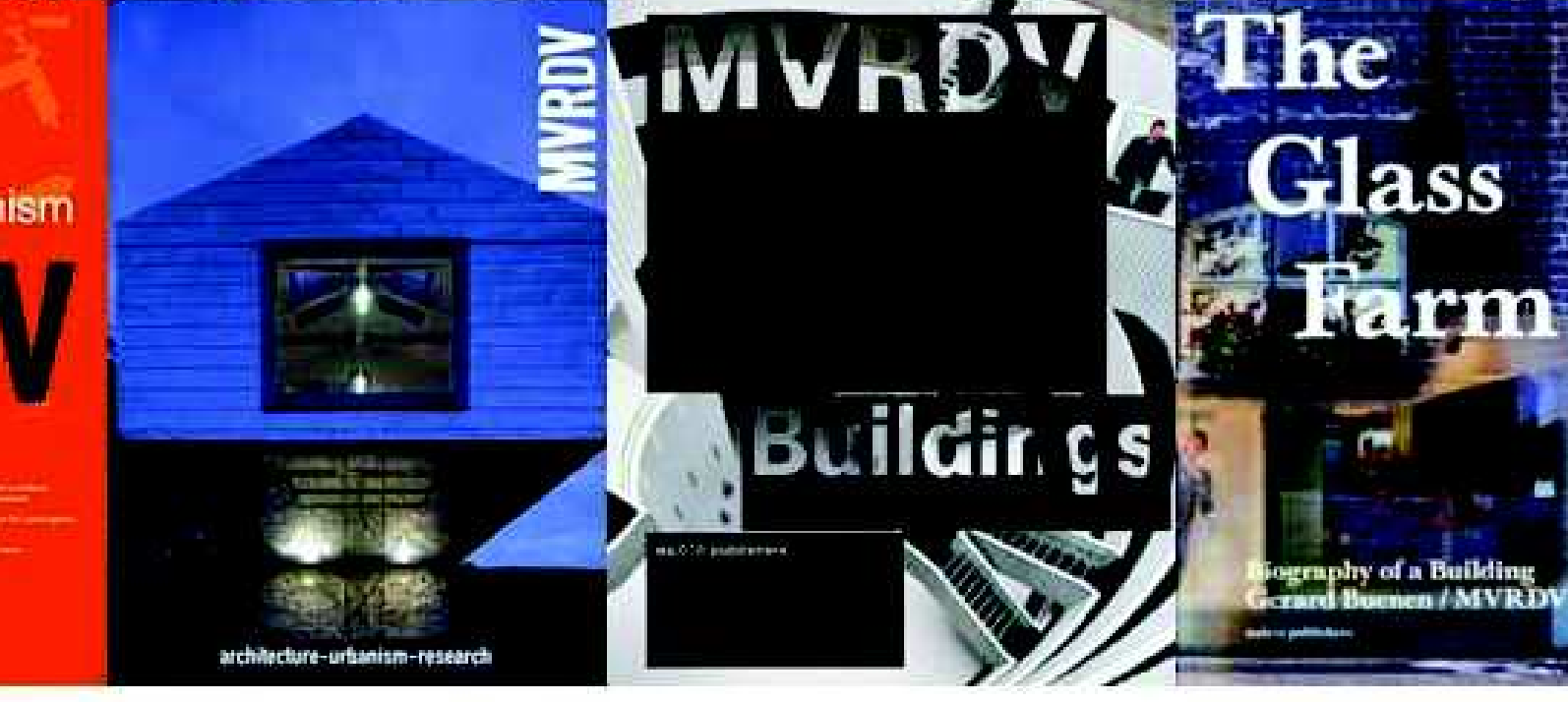

$\frac{1}{2}=$

풀

논?

구료

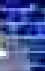

Buiflatir gs

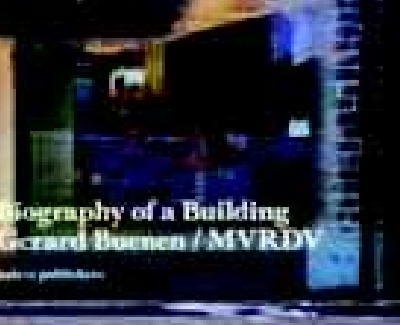

Publicações do MVRDV. Fonte: www.mvrdv.nl 
No texto introdutório do periódico El Croquis, número 111, de 2002, Cristina Diaz Moreno e Éfren Garcia Grinda chamam atenção para a abertura dos escritórios de arquitetura em mostrar seu processo de projeto para o público. Apesar de sabermos que esse processo não é completamente revelado, existe uma grande exposição de peças gráficas na mídia - hoje, muito atualizadas pela rapidez da internet - que permitem que os projetos sejam discutidos no mundo todo.

O que antes se restringia ao escritório agora parece ter se tornado domínio público, é exposto, apresentado e objeto de textos e discussões públicas. Se antes se mantinha reservado para garantir a continuidade da prática, agora se exibe e sua crítica e renovação é o que permite traçar o difícil panorama das práticas culturais contemporâneas. Nem as obras em si mesmas nem a argumentação que as geram parecem despertar o interesse de décadas passadas. Somente as ferramentas e os protocolos de trabalho levantam no âmbito público suficiente massa crítica de discussão. Talvez por isso, para os arquitetos não haja nada mais mórbido que as fotografias do interior dos escritórios mostrando uma jornada habitual de trabalho; e os críticos se converteram em pesquisadores e guias de passeio imaginários por esses espaços que antes eram impossíveis de se visitar (MORENO; GRINDA em El Croquis 111, p. 6, tradução nossa).

Para Lars Muller (2009), editor e professor de Harvard, desde Vitruvius os arquitetos tem conhecimento da importância em transmitir a estrutura teórica das suas atividades artísticas em meio independente e, como editores de revistas ou autores de livros, eles contribuem substancialmente para debates sobre a cultura arquitetônica. Nas palavras de Peter Eisenman, um dos arquitetos que abriu o contexto atual da publicação autoral acerca de processos e teorias projetuais, o livro sobrevive ao edifício:

Livros duram mais que prédios. Se não fossem os Quatros Livros de Palladio, nós nunca teríamos conhecido suas obras. O fato de, no final de sua vida, ele ter redesenhado todos os seus projetos, como ele os tinha concebido, e não como foram construídos, confirma sua fala inicial. De maneiras diferentes, o mesmo poderia ter sido dito de Le Corbusier, Venturi e Koolhaas. ${ }^{17}$

Porém, em muitos casos, a principal crítica à teoria é a sua falta de correspondência com a prática. Para Michael Hays e Alicia Kennedy (2000) esse desencontro tem

\footnotetext{
${ }^{17}$ Em Lars Müller. Book Builder at Harvard GSD. Disponivel em: http://www.artelibro.it/en/2009/06/lars-muller$\%$ E2\%80\%93-book-builder-at-harvard-gsd/
} 
sua utilidade: a teoria revela aspectos da prática arquitetônica que, enquanto não úteis ou corretas para a construção de agora, podem se tornar um recurso para futuras arquiteturas. O texto teórico expõe as lacunas da disciplina que deixam de ver além do presente.

Para o MVRDV uma postura mais ativa da arquitetura como disciplina demanda uma maior aproximação da prática com a pesquisa. Porém, como a pesquisa em arquitetura não é economicamente reconhecida como em outras áreas, ela só pode sobreviver em um escritório com flexibilidade e colaboração de instituições educacionais, subsídios, concursos, e financiamentos de empresas (MAAS, 2005, p.42).

O primeiro livro do MVRDV foi FARMAX (1998), seguido por MetaCity/Datatown (1999), Costa Ibérica (2000), Regionmaker (2002), Five Minutes City (2003), KM3 (2005), Spacefighter (2007), Skycar City (2007), Agendas on Urbanism (2012), MVRDV Buildings (2013), além de uma coleção de pesquisas publicadas junto com a The Why Factory. Os livros organizam diversos estudos e projetos que levantam questões sobre: o escopo da arquitetura; o papel do arquiteto; a contribuição da arquitetura além do seu domínio com outros assuntos como globalização, migração, desigualdade social e inovações econômicas. Diante desse aglomerado de demandas podemos ver as publicações como alternativas para discutir uma agenda mais ampla para arquitetura.

Além de suas próprias pesquisas e publicações, o MVRDV aumentou seu escopo de trabalho (assim como outros escritórios de arquitetura: Frank Gehry com a Gehry Technologies e o OMA de Koolhaas com a sua consultoria AMO) e se associou à Universidade Técnica de Delft para formar a think tank de nome The Why Factory (T?F). Organizada como uma fundação, seu objetivo é fornecer argumentos para o mundo da arquitetura e urbanismo e suas pesquisas especulam principalmente sobre o futuro das cidades. Os estudos são baseados em três campos: modelos teóricos, novas propostas para as cidades existentes e a utilização de bancos de dados em software. Seus estudos são divulgados em livros, filmes e exposições. ${ }^{18}$

${ }^{18}$ www.thewhyfactory.com 


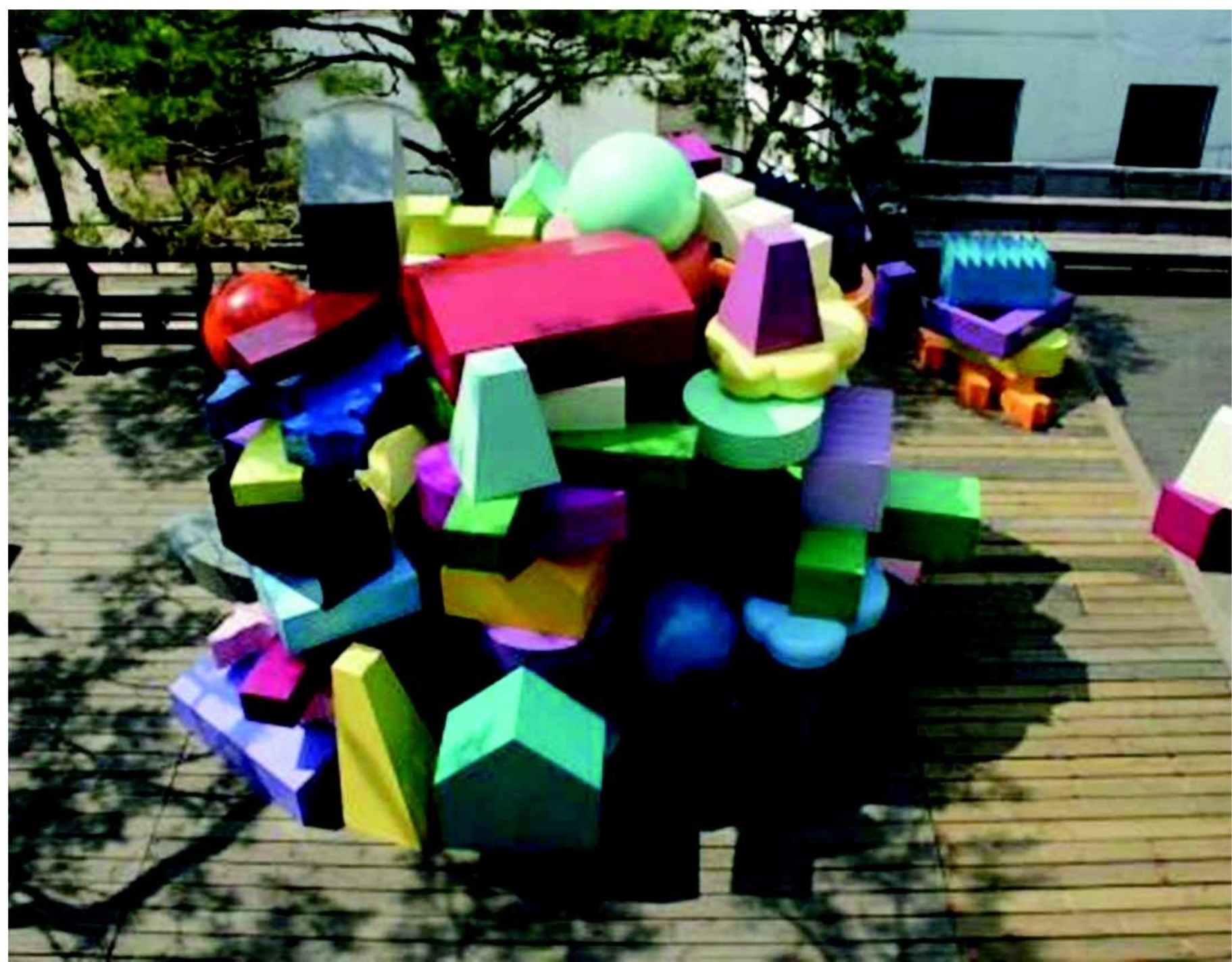

Exposição Vertical Village, Seul, 2012. Fonte: www.thewhyfactory.com

Um dos exercícios teóricos mais divulgados do MVRDV foi a exposição MetaCity/Datatown, depois transformada em livro. Nesse estudo, os arquitetos consideraram que a globalização e o aumento populacional poderiam transformar algumas regiões do planeta em grandes campos urbanos. Dessa forma, eles idealizaram uma cidade hipotética chamada Datatown utilizando estatísticas holandesas que já eram disponíveis.

Datatown é baseada apenas em dados. É uma cidade que quer ser escrita somente pela informação, uma cidade que não conhece topografia ou não tem ideologia determinada, nenhuma representação, nem contexto. Somente uma gigante e pura quantidade de dados (MVRDV, 1999, p. 58, tradução nossa). 
A cidade é auto-suficiente e tem uma população de 250 milhões de pessoas vivendo em uma área de 400 x 400 quilômetros. Uma cidade quatro vezes mais densa que a Holanda, um dos países mais adensados do mundo. Com a cidade imaginária pronta, os arquitetos simularam 21 cenários diferentes para testar seus efeitos no meio ambiente.

E se todos os habitantes de Datatown quisessem morar em casas isoladas? E se todos preferissem blocos de apartamentos? O que seria feito com o lixo? Que tipo de parque a cidade precisaria? (MVRDV, 1999, p. 71, tradução nossa).

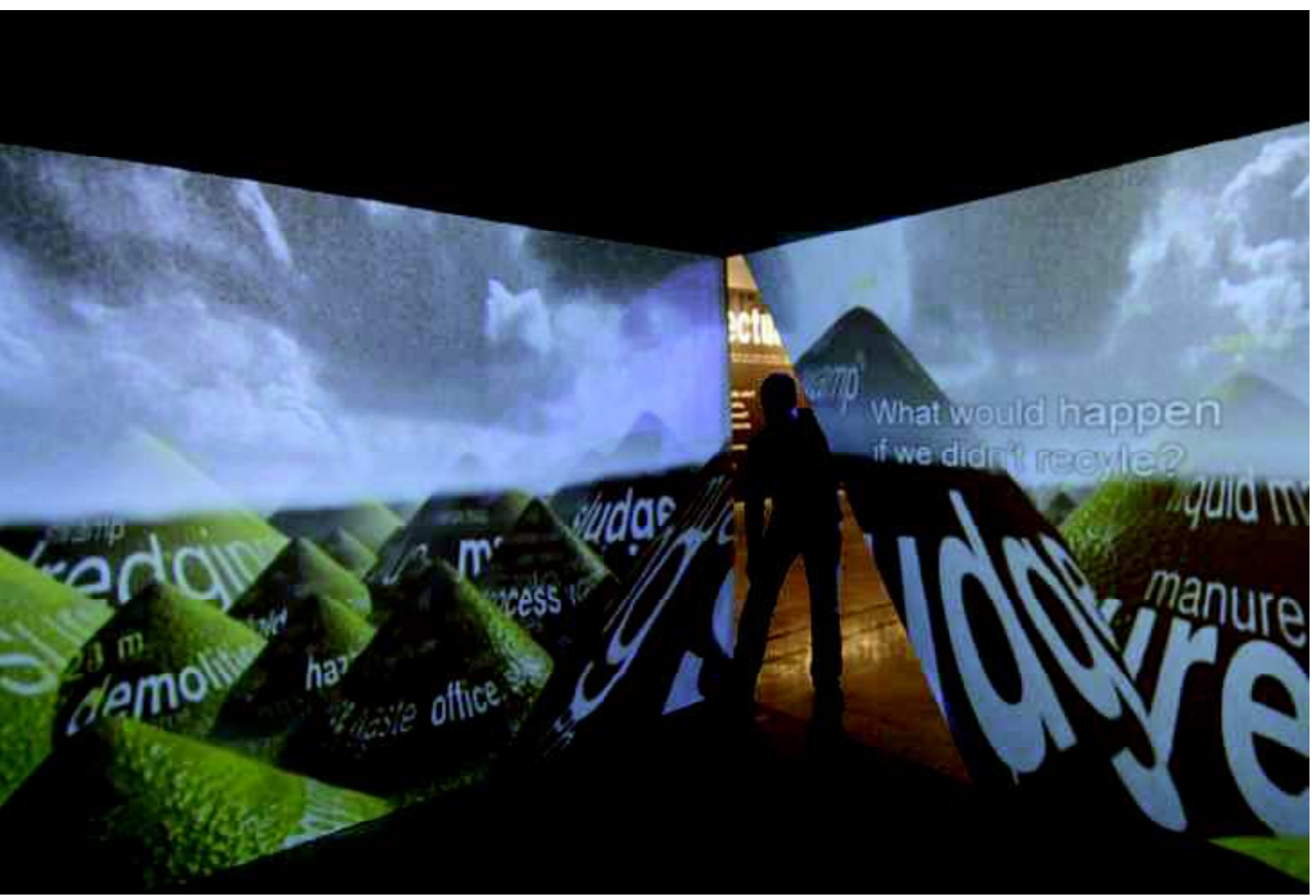

Exposição MetaCity/Datatown: projeções sobre o manejo de lixo. Fonte: www.mvrdv.com.br

A utilização de simulações e cenários extremos é uma das principais ferramentas de trabalho do MVRDV:

A visualização de ideias e problemas de um modo específico nos questiona em que direção queremos nosso meio ambiente. A visão das montanhas de lixo em Metacity/Datatown é horrível e bonita ao mesmo tempo. A utilização 
do extremo pode ser útil para gerar clareza, nos mostra onde se encontra o limite (MVRDV em El Croquis 111, p. 32, tradução nossa).

Metacity/Datatown pode ser visto como um experimento mirabolante, mas também aponta outras duas possibilidades: primeiro, nos faz questionar se a paisagem urbana pode ser reduzida a números; segundo, como forma de pesquisa, mostra alertas sobre o futuro. Convertendo dados da cidade em informação e depois apresentando as consequências espaciais dos datascapes através de hipóteses geradas por computador, o MVRDV demonstra como as escolhas coletivas e comportamentos podem moldar o ambiente.

As hipóteses radicais de MetaCity/Datatown causam reações de curiosidade e espanto e podem, portanto, funcionar como uma ferramenta didática com a qual os usuários tomam decisões a partir do entendimento das consequências dos seus hábitos. Por exemplo, se cada pessoa tivesse seu lixo quantificado e convertido no volume de uma montanha conhecida, talvez fosse possível despertar mudanças de comportamento em relação à produção de resíduos.

Para Betsky (2003), o que diferencia o trabalho do MVRDV de outros escritórios é que a manipulação de dados permite aos arquitetos tratarem a arquitetura como uma forma de pesquisa específica. Para o escritório, fatos e números se convertem em argumentos, sendo que a ideia de concepção artística da arquitetura é substituída pela pesquisa através do desenvolvimento de estudos e projetos hipotéticos utilizados para observar, analisar e criticar nosso comportamento.

Lootsma (2003) afirma que muitos arquitetos e críticos vêem os datascapes como mini-teorias que os arquitetos utilizam para justificar seu trabalho. Para o MVRDV, as análises estatísticas como processo de projeto podem ser vistas também como uma investigação sobre o futuro das cidades, pesquisas que podem induzir a uma autocrítica da arquitetura e urbanismo e mesmo uma redefinição da prática (MAAS, 1999, p. 19).

Porém, deve-se considerar que o uso dos datascapes corre o risco de se perder em uma crescente demanda de informações e se esses dados não forem completos, em termos de planejamento, efeitos colaterais indesejados podem ser relegados, na prática, para as proximidades da área estudada (MORAIS; SPERLING, 2013) Segundo Adam (2002, p. 32) a postura do MVRDV aceita as condições de partida e apresenta soluções como o resultado inevitável de análises estatísticas que 
conferem a arquitetura uma aparente objetividade. Eles utilizam métodos analíticos convencionais e desenvolvem a proposta como se a solução fosse uma equação matemática. Segundo o autor esse posicionamento não resulta novas visões, mas novas configurações das condições existentes. "Eles distorcem o real até este se tornar irreconhecível, a afirmação se transforma em subversão." (ADAM, 2002, p. 32).

Como em outros momentos da história (como as vanguardas modernistas ou os movimentos arquitetônicos formados nos anos 1960), o MVRDV faz estudos para o desenvolvimento das cidades, sendo, na maioria dos casos, projetos não realizáveis, mas que chamam atenção para determinados assuntos por considerar soluções extremas. Em oposição aos datascapes, que aceitam a condição urbana e absorvem suas informações, o estudo manifesto para o planejamento de 'Rotterdam 2045' (1995) questiona a permanência e o valor da cidade de maneira radical. Os arquitetos consideram um modo de urbanismo leve ${ }^{19}$ que possa ser mais conectado à natureza do que ao urbano e questionam a conservação dos edifícios como se fossem monumentos, de modo que as cidades existentes teriam a chance de se dissolver em meio à paisagem.

Na chamada LiteCity surgem combinações extremas de programas, de habitação à fazenda, e propostas de redução de custos de produção dos elementos urbanos que, em alguns pontos, parecem oferecer alternativas às tecnologias em uso: estradas gramadas ao invés de asfalto, fossas ecológicas ao invés de tubulação de esgoto, eletricidade para aquecimento no lugar de gás, celulares ao invés de linhas de telefonia, estruturas de madeira ao invés de fundações, mini ônibus ao invés de linhas de metrô, de maneira que se possa liberar o solo para grandes áreas verdes.

\footnotetext{
${ }^{19}$ Segundo os arquitetos, um urbanismo sem desenho e designações, com menos regulamentações e mais liberdade. Um urbanismo que se manifesta mais com comportamentos temporários do que com uma condição determinada (MVRDV, 1998, p.36).
} 


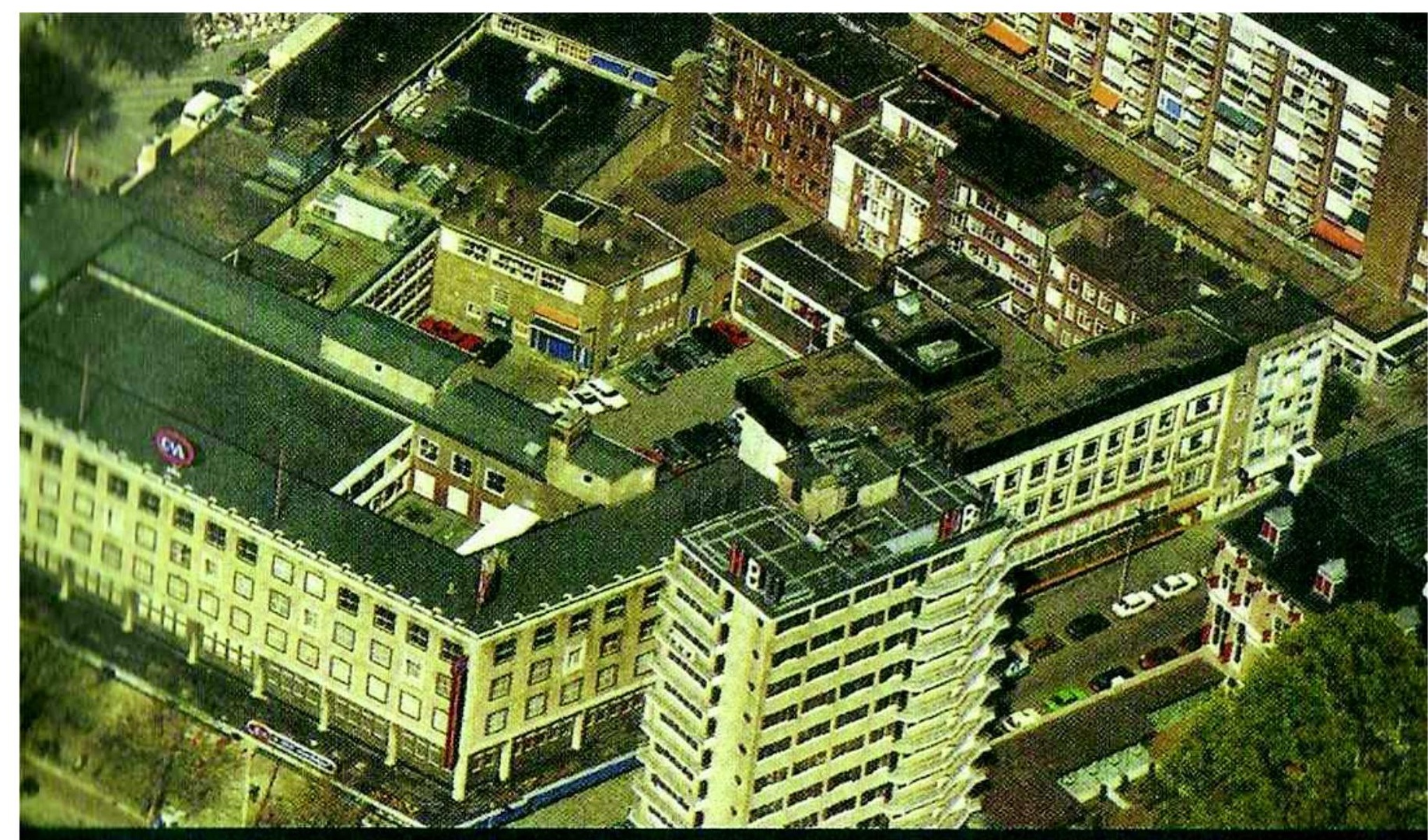

Is this all valuable

Rotterdam 2045. Fonte: FARMAX.

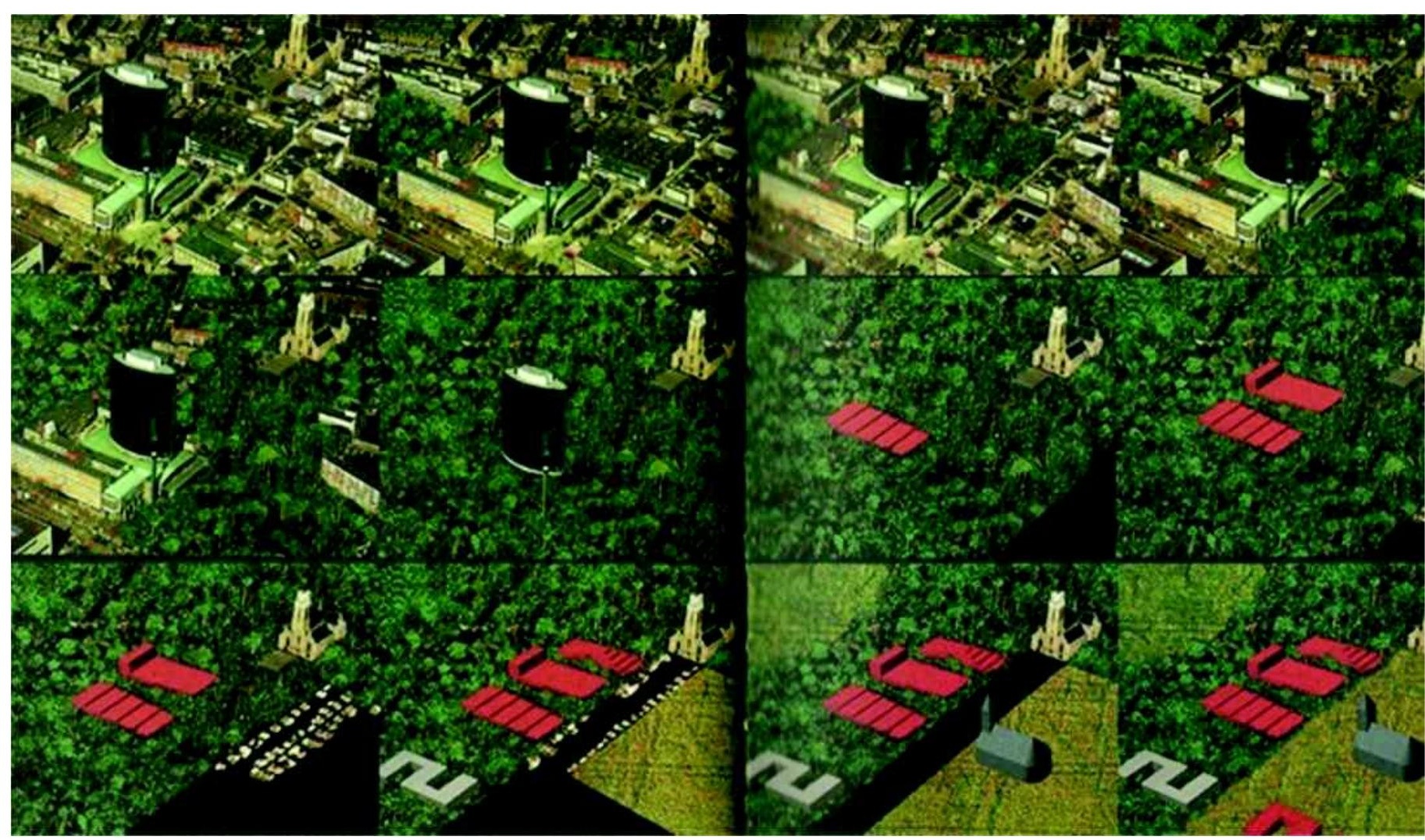

Rotterdam 2045: cenários. Fonte: FARMAX. 
Diferente do uso misto máximo de LiteCity, Lelyland, um estudo para o desenvolvimento de Lelystad (1996) tem funções mais especializadas. A cidade, que foi planejada na década de 1950 para atrair pessoas das áreas mais adensadas como Amsterdã e Utrecht, sofreu um esvaziamento por conta do aumento no preço dos aluguéis. O planejamento previa que a cidade teria 100 mil habitantes até 2000 , mas isso não aconteceu e Almere, cidade vizinha também planejada, obteve mais sucesso em seu desenvolvimento. As consequências para Lelystad foram o não crescimento e o esvaziamento de propriedades, sendo esta a cidade da Holanda com densidade mais baixa. Para o MVRDV, redistribuindo a terra e as áreas construídas seria possível acomodar as pessoas que gostariam de sair das áreas adensadas de Almere e Amsterdã com a oportunidade de ter casas e jardins maiores, mais natureza e agricultura. Mediante essas características, visualizamos nessa proposta aspectos de uma cidade dormitório, lembrando que, tanto Lelyland como LiteCity são estudos apresentados no livro FARMAX que tem a densidade como seu principal tema. Os arquitetos consideram também como opções para Lelystad: 1- cidade para os idosos (ideia que estratifica cidades por faixa etária e nega a diversidade de modos de vida); 2- cidade para segundas moradias (que possivelmente precisaria de algum apelo turístico e enfrentaria problemas relativos à sazonalidade); 3- retiro para a urbanidade com condições ideais para as pessoas trabalharem em casa ou uma comunidade com eco-fazendas. A especificação dessas hipóteses transparece a ideia de que a população de Lelystad viveria em isolamento e sem a diversidade social das cidades vizinhas.

Já nas pesquisas sobre densidade podemos comparar três estudos diferentes para o adensamento do centro de cidades holandesas: Trojan Extrusion (Rotterdam, 1995), Gothics (Amsterdã, 1996) e New! New Babylon (Rotterdam, 1997). Todos propõem aumentar o potencial construtivo das áreas centrais em níveis diferentes de radicalidade. Vale ressaltar que a maioria dos estudos reunidos nos livros do MVRDV tem mais imagens do que textos, sendo apresentados como propostas conceituais ainda no plano das ideias.

Em Amsterdã, o que gera a investigação são os pátios internos das típicas quadras européias, sempre isentas de grandes programas. Gradativamente essas áreas foram sendo ocupadas por shoppings, estacionamentos e lojas de departamentos, mas conservando sua fachada antiga. A questão destacada pelo MVRDV é o adensamento dessas áreas sem destruir a ilusão de preservação do patrimônio 
antigo. Os arquitetos sugerem extrudar o centro da quadra e o moldam a partir da projeção de todas as possíveis vistas das ruas medievais para esse bloco central, de modo que o novo volume não seja visível pelas pessoas que circulam pelas áreas antigas preservadas. A densidade é multiplicada com a criação de montanhas invisíveis no meio das quadras. Notamos que existe o aumento da ocupação do solo, mas a verticalização é determinada pela vista da rua. Existe a preservação real dos prédios antigos - e não só seu envelope - mas ainda a ideia de ilusão permanece, já que a proposta não assume completamente a nova configuração.

Nos dois estudos para Rotterdam, os arquitetos também têm como ponto de partida as restrições de adensamento causadas pelos edifícios existentes, vistos como sagrados ou até mesmo com status de monumento. As restrições quanto ao adensamento são aceitas, mas contestadas com uma proposta radical.

No estudo de 1995, um novo gabarito é adotado e os prédios existentes são envolvidos pelas construções que completam o espaço entre eles e a nova altura. A partir daí, o nível do solo é repensado e reaparece nas coberturas. O estudo de 1997 é mais radical na criação de um plano acima dos prédios existentes, sugerindo uma grande estrutura com áreas vazadas para possibilitar o desenvolvimento da cidade.

Além da New Babylon de Constant Nieuwenhuys, nos últimos três estudos, duas ideias são reconhecidas. Primeiro, a separação de circulações na cidade que ocorre nos dois estudos, vista na Ville Radieuse de Le Corbusier e criticada por Jane $\mathrm{Jacobs}^{20}$, e que pode diminuir a força da relação pedestre-rua onde acontece a diversidade e intensidade de usos pregada pelo MVRDV. ${ }^{21}$ Segundo, a grande estrutura sobre a cidade existente é uma ideia também encontrada nas propostas dos Metabolistas.

\footnotetext{
${ }^{20}$ JACOBS, J. The death and life of the great american cities. Nova York: Vintage, 1992.

${ }^{21}$ Aqui não podemos quantificar quão afetada seria essa relação, pois o estudo não fornece maiores detalhes sobre a comunicação entre o nível do solo existente e o novo nível criado.
} 

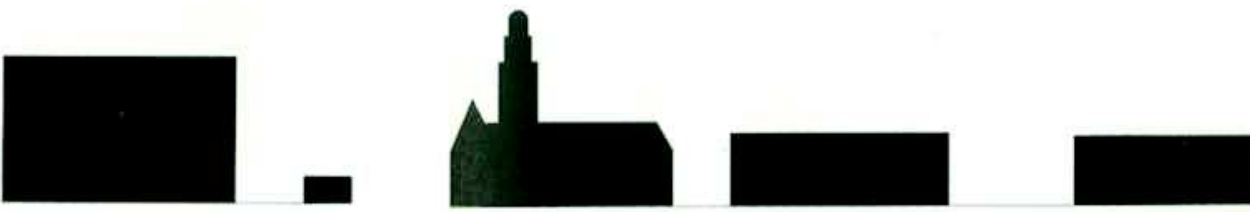

Section through existing situation
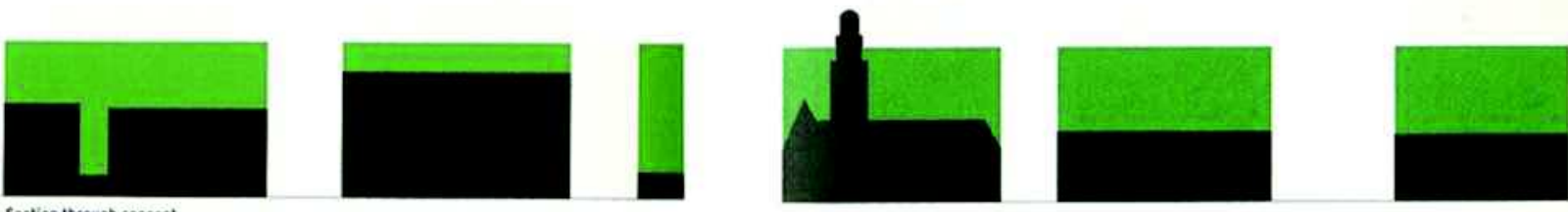

Section through concept
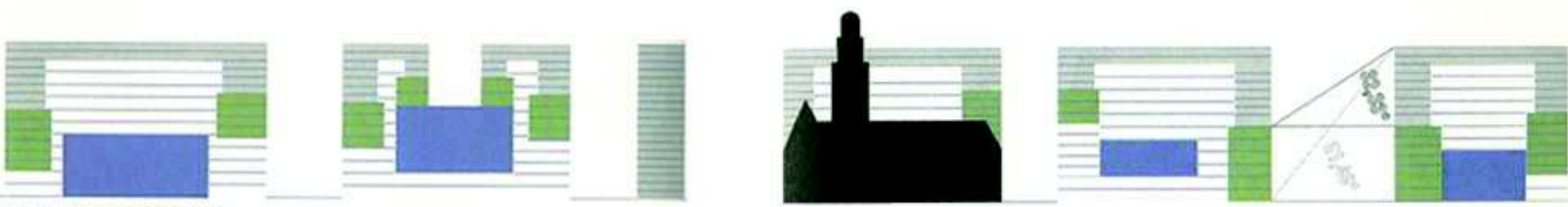

Section through new programme

Diagramas Trojan Extrusions. Fonte: FARMAX.

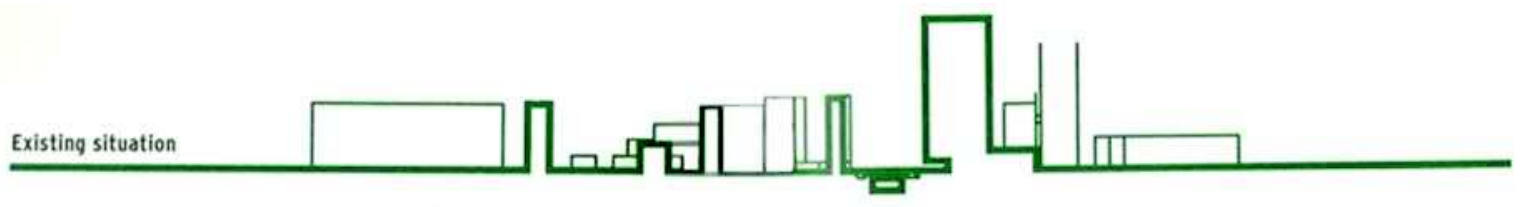

If the existing public space including trees were to be declared a protected ared, building development could then only begin some twenty-five metres up.

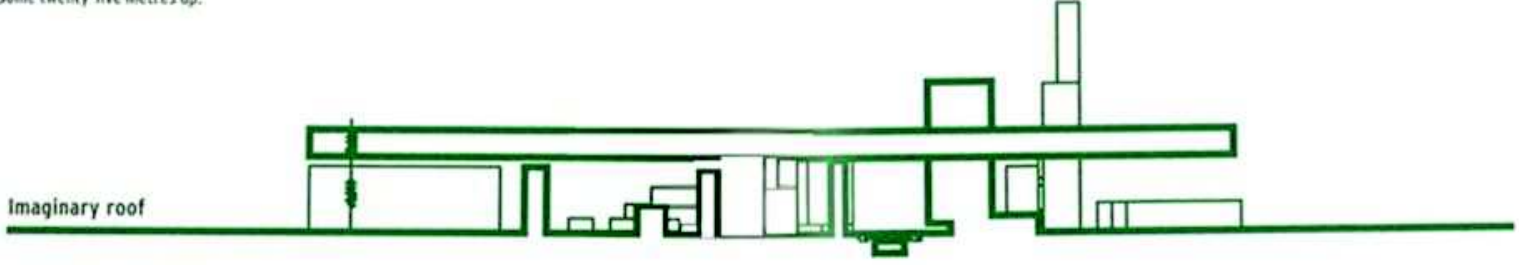

This would create an urban 'attic-lever', a Nen Babylox a network above the existing city with its own laws and logic. one free of the burden and impracticalities of the existing ground level.

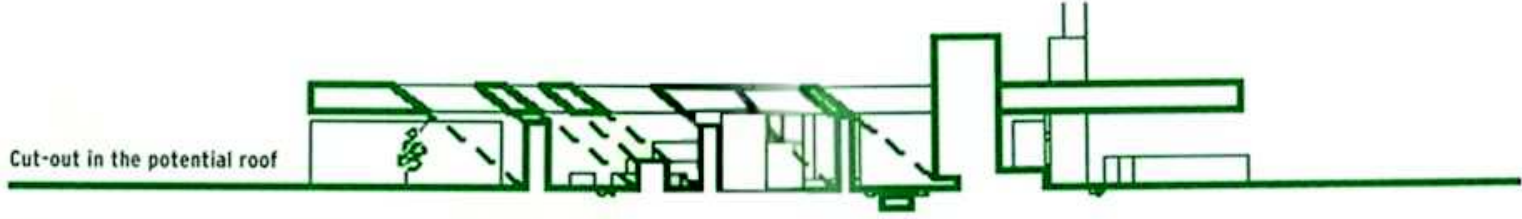

By punching holes in this 'attic-lever', the existing develogment nould be provided with light and dwelling would not be relegated to the roofscape of the city.
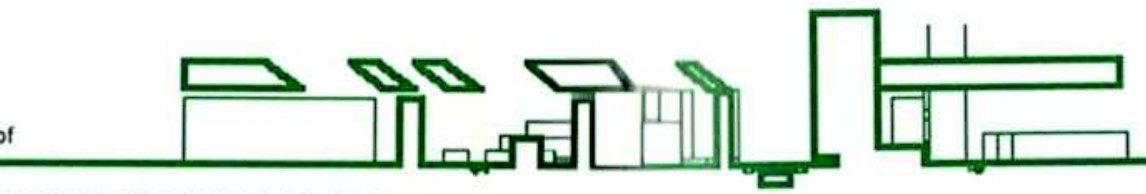

The existing city would then be Blessed wi th a pernanent Paylus Potter': a iandscope of sunbeums.

Diagramas New! New Babylon. Fonte: FARMAX 


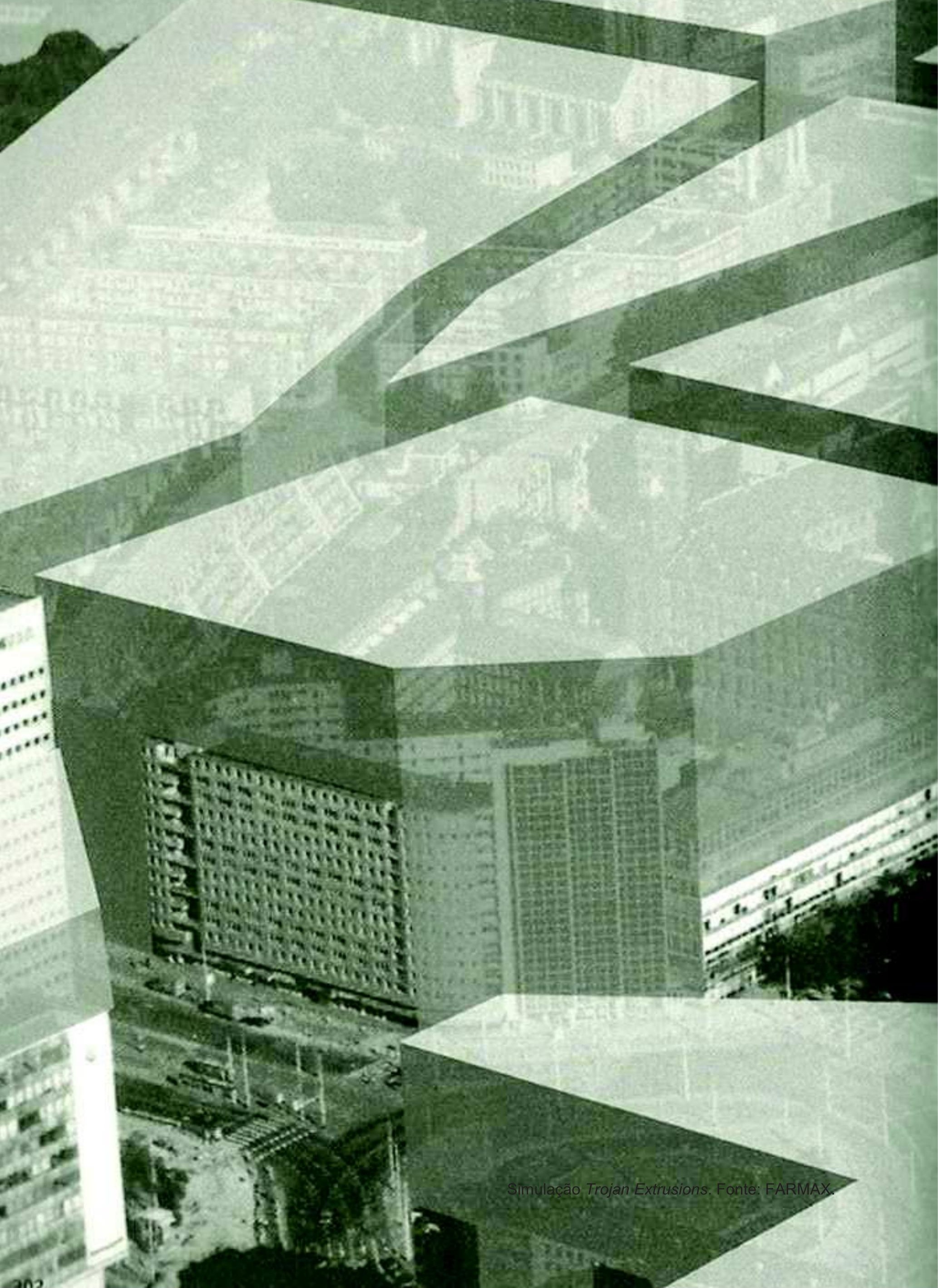




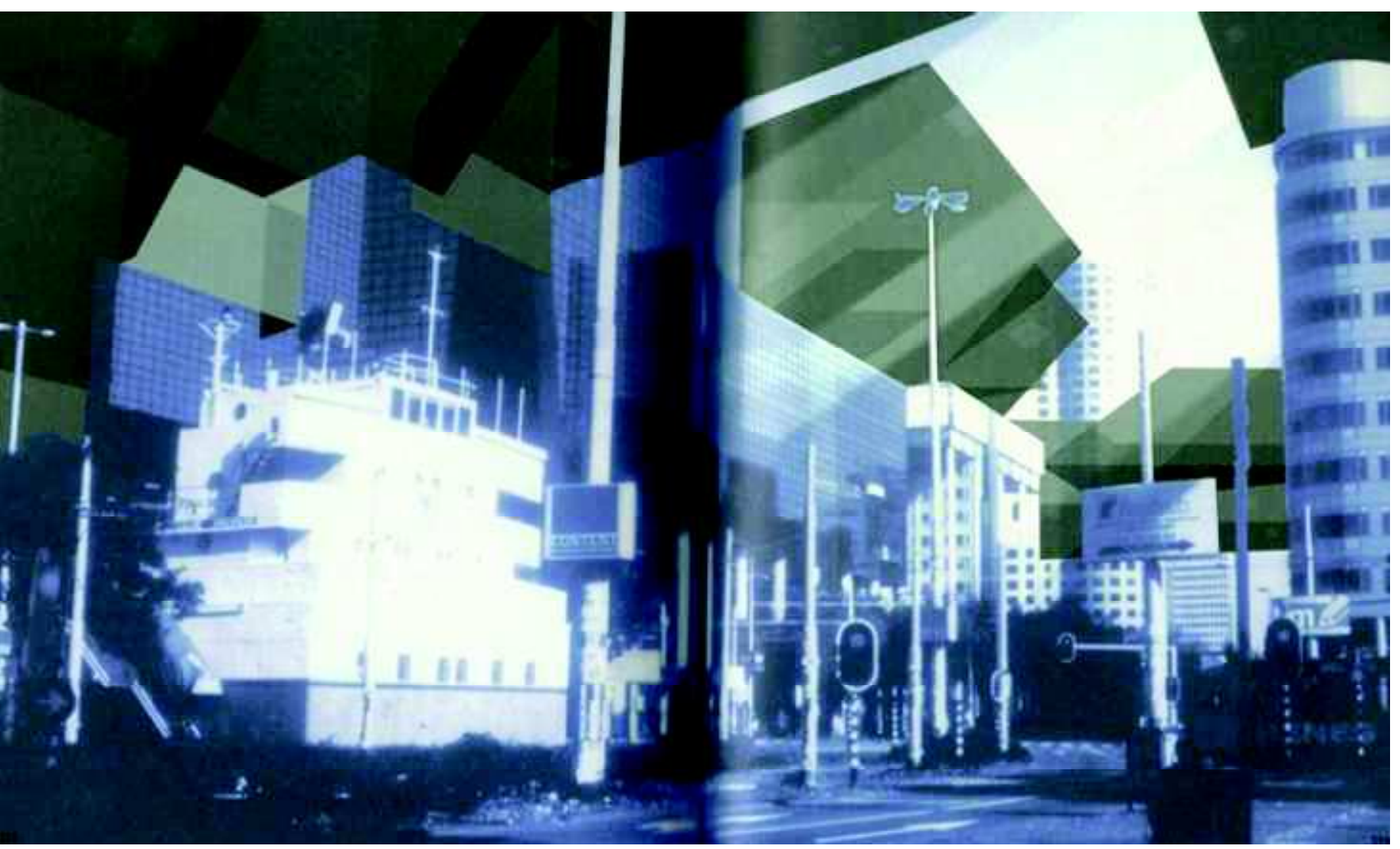

New! New Babylon. Fonte: FARMAX

Em se tratando da inserção de grandes estruturas no contexto urbano, os estudos e projetos experimentais do MVRDV indicam que os arquitetos acreditam excessivamente no desenvolvimento das tecnologias. Em Stack Attack, proposta para um parque na nova cidade de Leidschenrijn (1997), o escritório questiona qual o papel da natureza no cenário de adensamento e se ela deve existir em novas configurações para aumentar a qualidade de vida. Com essas questões em mente, os arquitetos definem o programa e propõem prédios-parques com campos de futebol, pistas de esqui e vista para o entorno. Nesses novos edifícios é possível praticar esportes e encontrar todos os tipos de espécies vegetais do mundo, pois qualquer condição climática pode ser reproduzida artificialmente.

Observamos semelhanças entre esse estudo e o projeto do próprio MVRDV para a Expo 2000. O pavilhão de cinco pavimentos pode ser considerado uma pequena amostra de Stack Attack, mas ao contrário de sua versão maior; seu programa muito mais simples e sua condição de estrutura temporária não demandaram nenhuma tecnologia específica e tornaram a execução do prédio viável. 


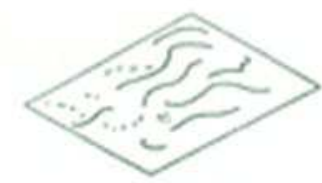

Sahara
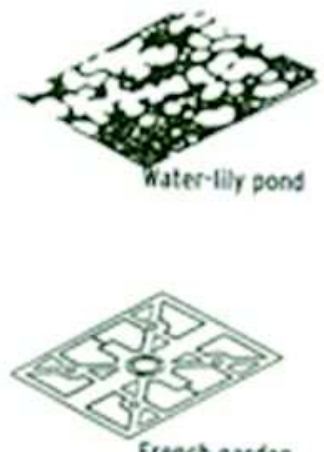

frence garcen
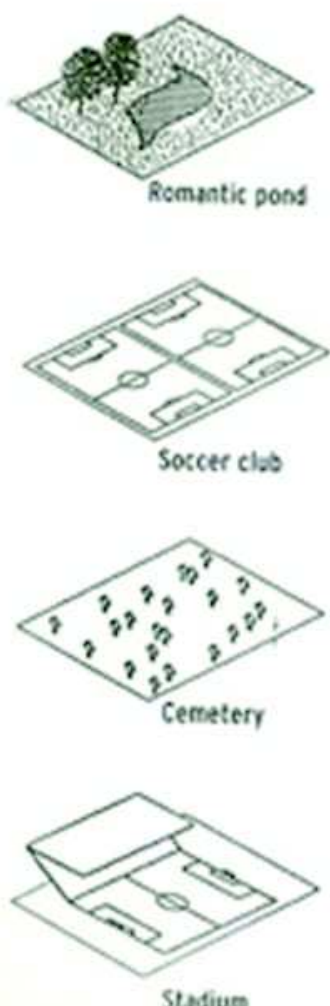

Stadium

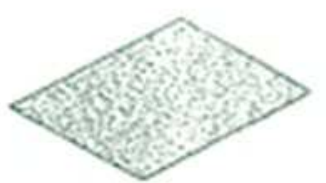

Neadew

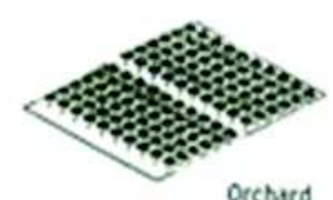

Orchard

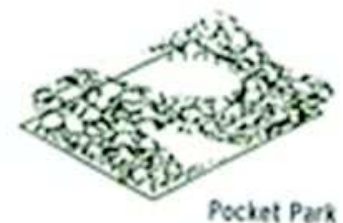

Pocket Park
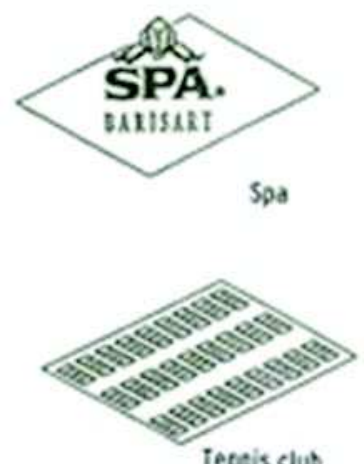

Tentis slut
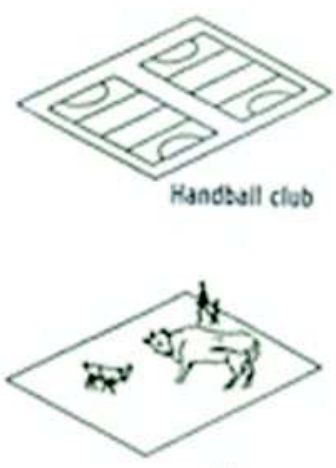

200
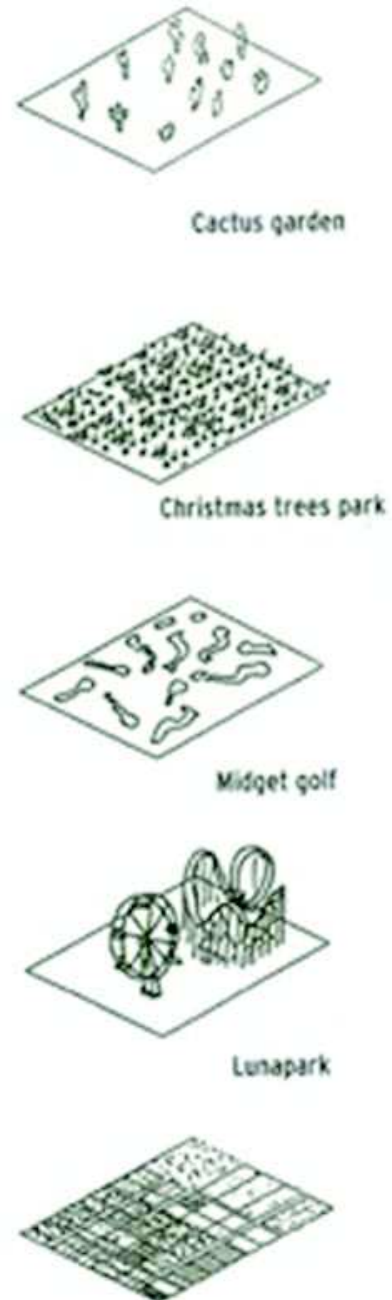

Allotment garcens
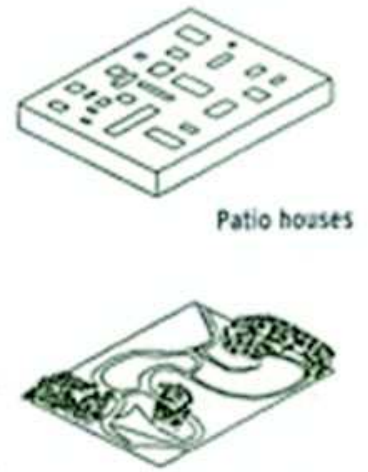

Enclish garten
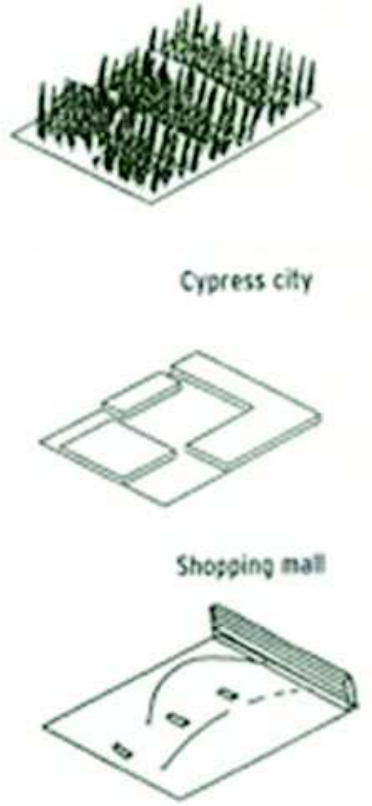

Sports club

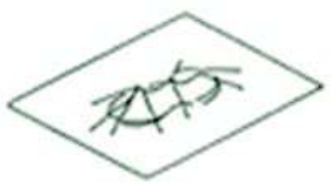

Vunifestations
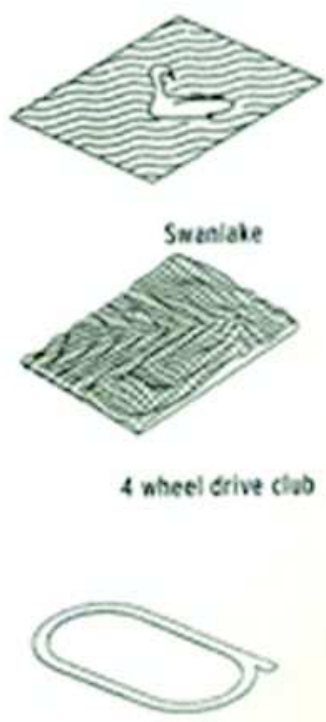

At lietics club

Stack Attack: diagrama com programa do parque. Fonte: FARMAX. 
Elevation
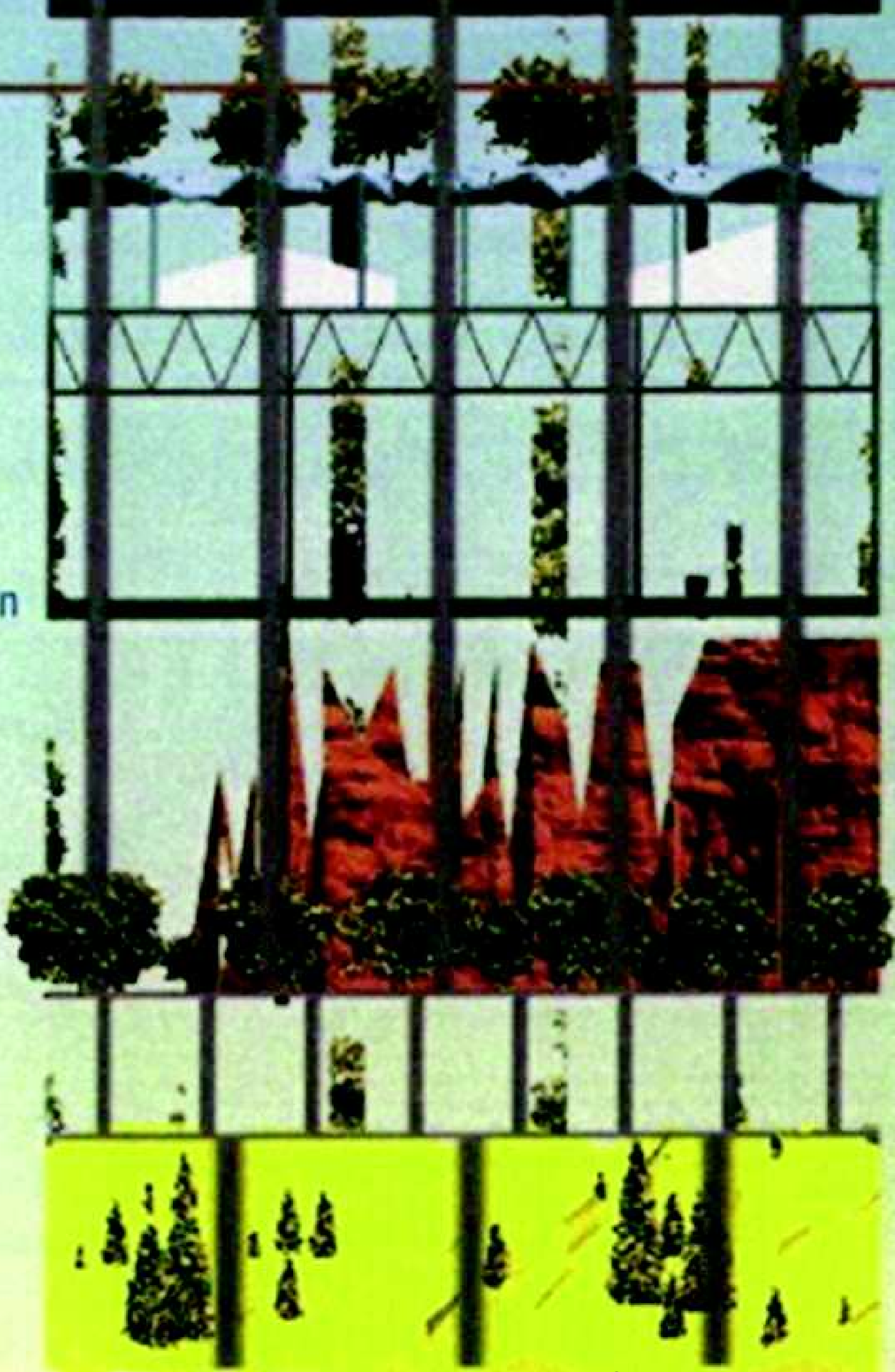

Stack Attack. Fonte: FARMAX.

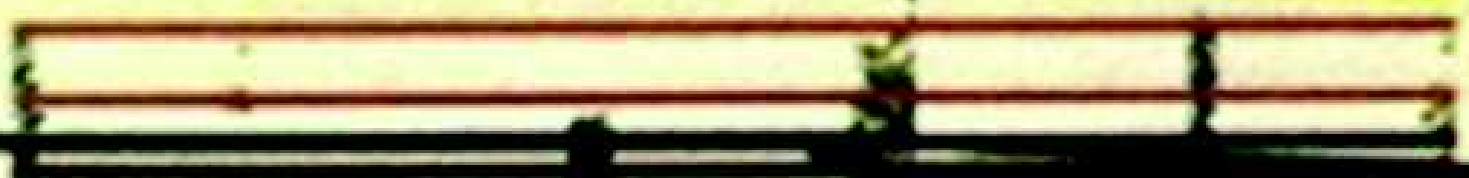


Nas pesquisas sobre infraestrutura urbana, o MVRDV direciona seus estudos para o tema mobilidade levando em considerando a intensificação e adensamento das autopistas, ao invés da construção de novas estruturas. As áreas em torno dessas rodovias seriam destinadas a um desenvolvimento intenso por causa da sua proximidade às estradas. Imagina-se que a reflexão que deve ser feita é se essas zonas se tornariam realmente acessíveis ou se as pistas de alta velocidade conformariam barreiras físicas dentro das cidades. E como citado anteriormente nos estudos para o desenvolvimento do centro de Rotterdam, tais estruturas poderiam criar um distanciamento entre pedestre e rua.

Mainstreet (1996) foi uma pesquisa sobre o desenvolvimento de Almere. A proposta buscava fortalecer radicalmente a imagem de cidade verde concentrando o crescimento na área urbana existente e tomando a rodovia A6 - que atravessa o centro da cidade - como eixo organizador. O escritório propõe a expansão do uso da A6 com pistas locais e uma coordenação de programas para transformar a via em alameda. A alta velocidade da estrada é mantida e observamos que o espaço urbano é regulado pelos ritmos da circulação.

Para o MVRDV, o meio de transporte individual parece continuar dominando a sociedade, mesmo com estímulos ao transporte público e tarifas extras no transporte individual.

Não podemos forçar as coisas para irem a tal direção, estimulando o automóvel ao invés de domesticá-lo? Não poderíamos apontar para uma abordagem mais apocalíptica, que inicialmente faria o congestionamento aumentar resultando em pedidos de soluções? (MVRDV, 1998, p. 454). 


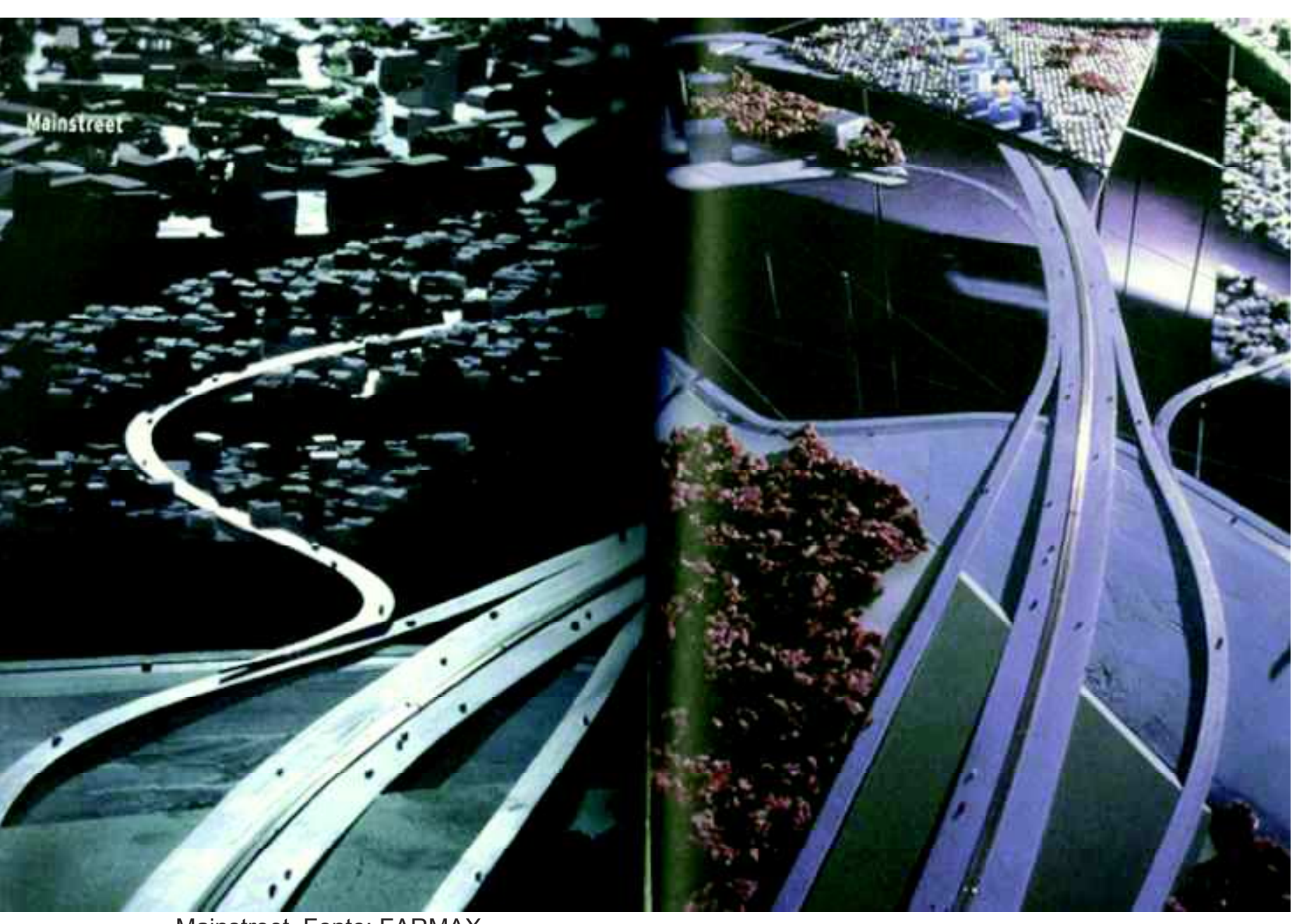

Mainstreet. Fonte: FARMAX.

Aceitando esse fato, o estudo Lace (1997) investigou cenários de mobilidade sugerindo que seria melhor aceitar o carro e desenvolvê-lo em prol de soluções para os aspectos de consumos de energia, poluição e barulho. Os arquitetos trabalham também a ideia de adensamento das rodovias, com um empilhamento de pistas, ao invés da construção de novas estradas. A crença no desenvolvimento da tecnologia deve ser citada novamente, pois observa-se que os arquitetos acreditam na evolução do automóvel e das tecnologias construtivas como solução para as implicações dessa proposta.

No livro KM3 os estudos são ainda mais radicais. Como descrito pelo MVRDV, eles maximizam a otimização proposta em FARMAX. As pesquisas são mais globais, saem do território holandês e alcançam outras regiões do globo, mas são bastante conceituais e ainda permanecem no campo das ideias.

Entre os estudos estão especulações sobre mudanças climáticas e outros processos espaciais globais, como a migração livre e recursos naturais do planeta. 
Os arquitetos mantêm o método de iniciar a apresentação dos estudos com vários questionamentos e depois tentam respondê-los com a utilização de diferentes cenários.

Em Climate World (MVRDV, Wieland\&Gouwens, cThrough, 2002-2003) as questões que levam ao desenvolvimento da pesquisa são: como lidar com as alterações climáticas? O que podemos aprender com efeitos como El Niño? Eles alteram as cidades e o ambiente? Como reagir a esses efeitos? Devemos mudar nosso comportamento? Devemos desenvolver tecnologias para sobreviver a eles? Devemos migrar para lugares melhores? Podemos comparar essas alternativas para poder negociar, convencer ou escolher? Os pesquisadores partem para simulações com cenários catastróficos em vários lugares conhecidos do globo e depois mostram propostas já conhecidas (redução da emissão de CO2, pintar as construções com cores claras, encorajar o uso do transporte público, adensamento das cidades em prol de encurtar as distâncias, fontes alternativas de energia) e algumas mais radicais (desvio de rios para evitar enchentes, rios artificiais para áreas de seca, recriação de ilhas desaparecidas no oceano pacífico e métodos artificiais para influenciar o clima). Nesses estudos, o MVRDV amplia o campo de atuação dos arquitetos e mostra o seu ponto de vista sobre a necessidade e o potencial do pensamento visionário na arquitetura e urbanismo.

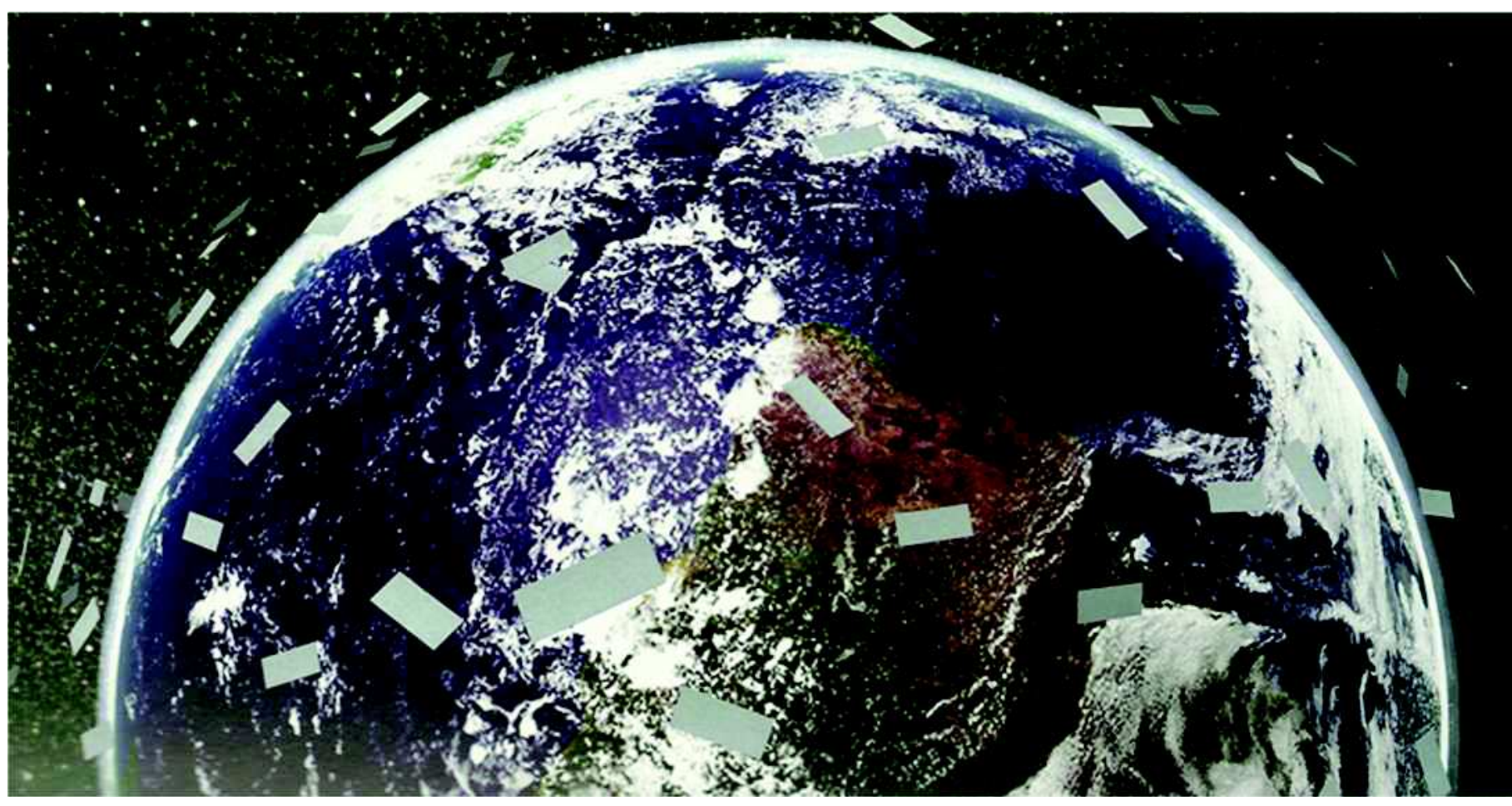

Estruturas gigantes projetariam sombra em determinados locais do globo, diminuindo a temperatura dessas regiões. Fonte: KM3. 
Outro estudo que amplia o campo de atuação dos arquitetos é Free migration world (Instituto Berlage, MVRDV, 2001) que questiona o bloqueio do potencial de crescimento do mundo globalizado pela existência de fronteiras que são formadas por questões políticas, econômicas, religiosas, etc. "Mas o que existiria sem fronteiras e se a migração fosse livre?" (MVRDV, 2005, p. 70). Há mais de 150 milhões de imigrantes no mundo. Segundo seu estudo, a migração livre sugere que todos teriam a mesma chance de melhorar de vida, mas esse processo conduziria a uma completa alteração na população mundial. As sociedades mais ricas absorveriam pessoas e os países mais pobres ficariam esvaziados. Através de uma simulação utilizando dados do PIB, os pesquisadores mostram que teríamos uma super adensada Europa e uma vazia África, que poderia se tornar a reserva ambiental do mundo. Segundo o estudo, a Europa deve se preparar para receber milhões de imigrantes nos próximos 50 anos a fim de compensar o declínio populacional e combater os problemas previdenciários originados pelo envelhecimento da população.

Dentro desse questionamento de fronteiras, o estudo Hyperoptimized World (Instituto Berlage/MVRDV, 2004) aborda o risco de esgotamento dos recursos e a otimização de sua produção em um mundo sem fronteiras onde tudo pode ser produzido na melhor localização. A capacidade do planeta poderia aumentar alocando seus recursos onde eles são mais eficientes. Seriam identificados os melhores lugares para coletar energia, produzir alimentos e florestas. Depois, a localização de indústrias, infraestrutura e aglomerações urbanas, sugerindo um novo mapa de densidade. Por exemplo, se as primeiras regiões com melhor potencial para geração de energia renovável fossem utilizadas, a produção dessas áreas serviria uma população de 16 bilhões de pessoas, número estimado de habitantes para 2098. Assim inicia-se um ciclo de otimização, maximização e pós maximização. O MVRDV desenvolve estudos sobre a questão local/global, considerando um mundo formado por regiões.

Novamente enfatizando cenários, Hyper Catalunya (MVRDV, 2002) mostra as consequências das mudanças demográficas na Catalunha com 72 possibilidades conectando o fluxo de população com as configurações territoriais que vão desde uma mega cidade global até uma muralha catalã nacionalista. Através de uma análise de dados populacionais os pesquisadores mostram que o baixo crescimento 
é sustentado pela imigração e a previsão é que em 2050 a Espanha tenha a maior porcentagem de população idosa do mundo. Diante desses números, o MVRDV propõe como alternativa o aumento da imigração para manter a população economicamente ativa de trabalhadores. A Catalunha poderia se transformar em uma cidade global multicultural de 16 milhões de habitantes. Nessa pesquisa 0 MVRDV olha para o processo pós-solução e faz algumas reflexões considerando a permanência e a integração dessa população:

Que tipo de organização espacial deve ser considerado para abrigar essa nova população? Abrigá-la em clusters formados por cidades médias? Uma região poli nuclear com centros especializados? Espalhar a população ao longo do território transformando a região em um grande subúrbio com casas isoladas para uma sociedade individualista? Ou combinar diferentes modalidades formando uma alternativa espacial mais rica? (MVRDV, 2005, p. 118, tradução nossa).

Ampliando a área de atuação para outras regiões do globo, o MVRDV faz uma pesquisa sobre os potenciais agrícolas do vale central do Chile (Universidad de Talca/MVRDV, 2003) refletindo sobre o aumento de potencial da região na sua produção especializada de frutas e vinhos e também como importante peça global capaz de descentralizar as cidades sul-americanas super povoadas, mas sem perder suas qualidades agrícolas. No entanto, observamos que ao defender a especialização de regiões o MVRDV entra em uma grande polêmica. Segundo os arquitetos, os locais com melhor clima, melhor solo e mais abundância de água estão no hemisfério sul, que poderia ser o grande fornecedor de insumos do planeta devido à extrema urbanização do norte. Tal dicotomia, consumo no norte e produção no sul, relembraria a cultura colonial, com o sul exportador de matériaprima e consumidor de produtos industrializados, de modo que a especialização de regiões poderia entrar em conflito com a diversidade da sociedade contemporânea, além de um aumento de custos gerado com logística e aumento de desperdício de alimentos (a utilização do método oposto, com fontes de produção de alimentos espalhadas no mundo e localizadas o mais próximo possível dos consumidores traria economia.

A região do Reno-Ruhr é outro foco de investigação do MVRDV (2001-2002) que investiga a especialização de regiões. A área, com histórico fortemente industrial, entrou em decadência com o espalhamento das indústrias pelo mundo. Apesar da 
instalação de universidades nos anos 1970, dos investimentos em infraestrutura nos anos 1980 e 1990 e das tentativas de atrair indústrias de mídia e computadores o desenvolvimento se manteve negativo. A taxa de desemprego não diminuiu, o número de habitantes não voltou a crescer e, com isso, o custo de manutenção de toda infraestrutura sobrecarregou a região. "A região seria a Detroit da Europa, uma paisagem abandonada?" (MVRDV, 2005, 134).

A criação da zona do Euro ajudou a consolidar o conceito de região em substituição à ideia de nação. Reno e Ruhr são duas áreas muito próximas que poderiam trabalhar em cooperação ao invés de competirem entre si. Uma combinação das especializações traz muito mais competitividade global à região. É o que Saskia Sassen $^{22}$ vai chamar de cultivo do regionalismo.

De acordo com Butzin, professor da University of Bochum, ${ }^{23}$ nós ainda não entendemos a nova condição global, cada cidade ainda pensa que deve ter um papel importante sozinha. É neste contexto que o MVRDV vai propor a RhineRuhrCity, a região vista como uma única cidade. A partir daí os arquitetos vão mais uma vez simular cenários, como:

1- Divisão de poderes: Uma cidade fornece o que outra não tem e cada uma desenvolve seu ponto forte.

2- Campus: O sucesso da região ficaria por conta do desenvolvimento da mídia em televisão, telecomunicações e software de engenharia industrial.

3- Parque: A diminuição de postos de trabalho, habitantes e valor do mercado imobiliário poderia trazer vantagens. Ao invés de investir massivamente em infraestrutura, essas áreas têm a oportunidade de serem transformadas em parques, florestas e reservas de água, abandonando certas áreas.

4- Centro da Europa: Cogita a possibilidade da RRC se tornar um grande sucesso, uma cidade global com forte crescimento populacional. Talvez a combinação de fácil acesso, natureza abundante e redução das restrições econômicas e impostos possa impulsionar o desenvolvimento dessa cidade aberta.

Novamente ressaltamos que algumas das hipóteses do MVRDV podem esbarrar na seguinte dificuldade: as cidades especializadas podem ser uma contradição à diversidade, um dos conceitos mais trabalhados pelo escritório. Podemos tomar como exemplo o declínio da própria região do Reno-Ruhr ou mesmo Detroit. As

\footnotetext{
${ }^{22}$ Em entrevista publicada no livro Regionmaker/The RheinRuhrCity, 2002, p. 89.

${ }^{23}$ Em KM3, 2005, p. 138.
} 
cidades assumem riscos ao optar por priorizar o desenvolvimento de uma única atividade, por exemplo, a região passaria mais uma vez por dificuldades se na nova proposta as empresas de mídia e telecomunicações mudassem para outra região.

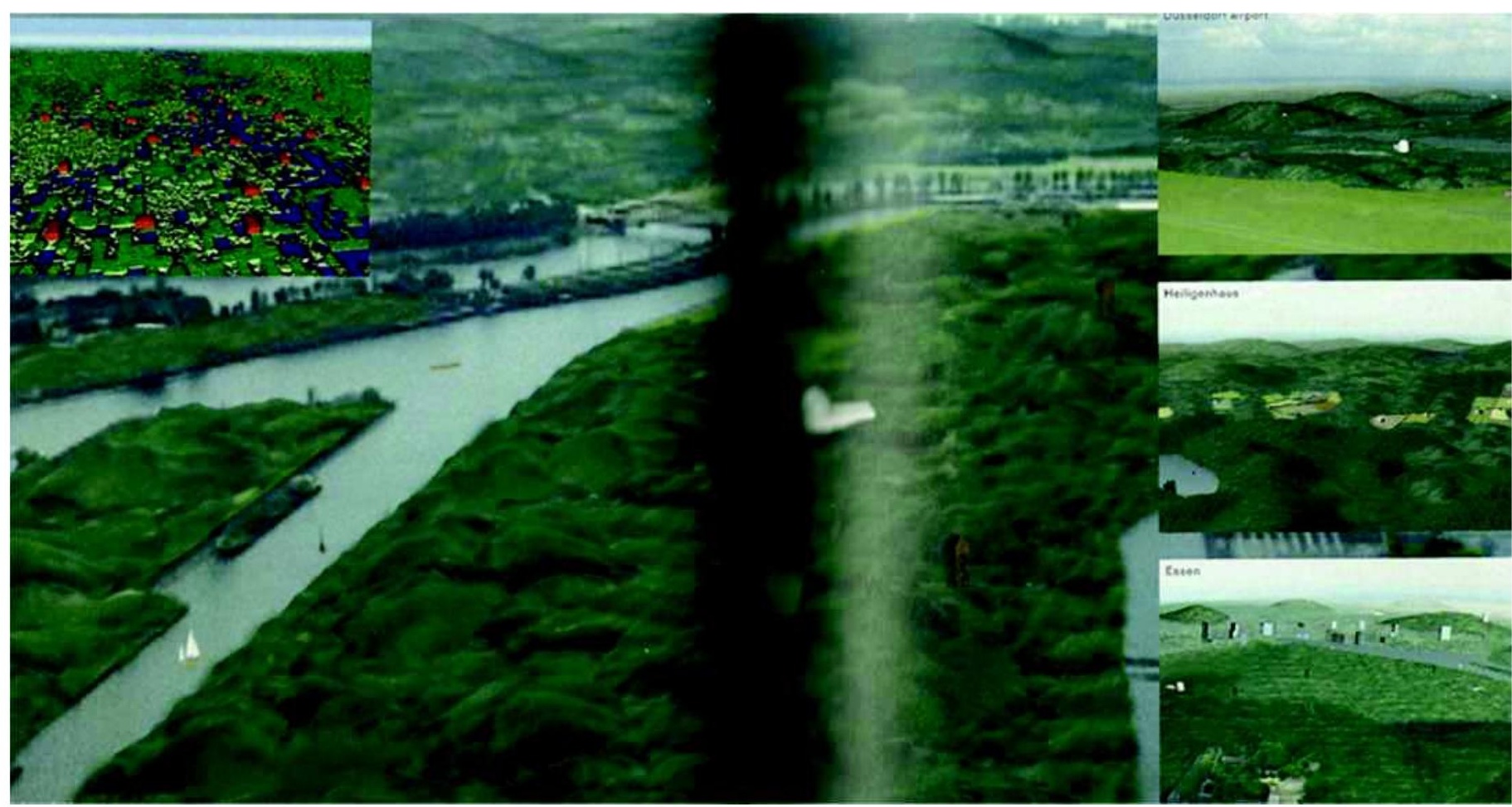

Simulação da RRC como parque. Fonte: KM3.

Para além dessas questões contemporâneas mais urgentes, o MVRDV vai investigar também a otimização em condições que, por enquanto, beiram a ficção científica. Em SkyCarCity (2005) os arquitetos analisam as possibilidades do uso de carros voadores e que se movem livremente entre os prédios, levantando a ideia de uma completa revisão do território urbano, com uma cidade com "ruas" em todos os níveis ou completamente sem ruas. Essa revolução passa por alterações desde o sistema de endereços até as relações do habitante com a cidade (MVRDV, 2005, p. 472). 


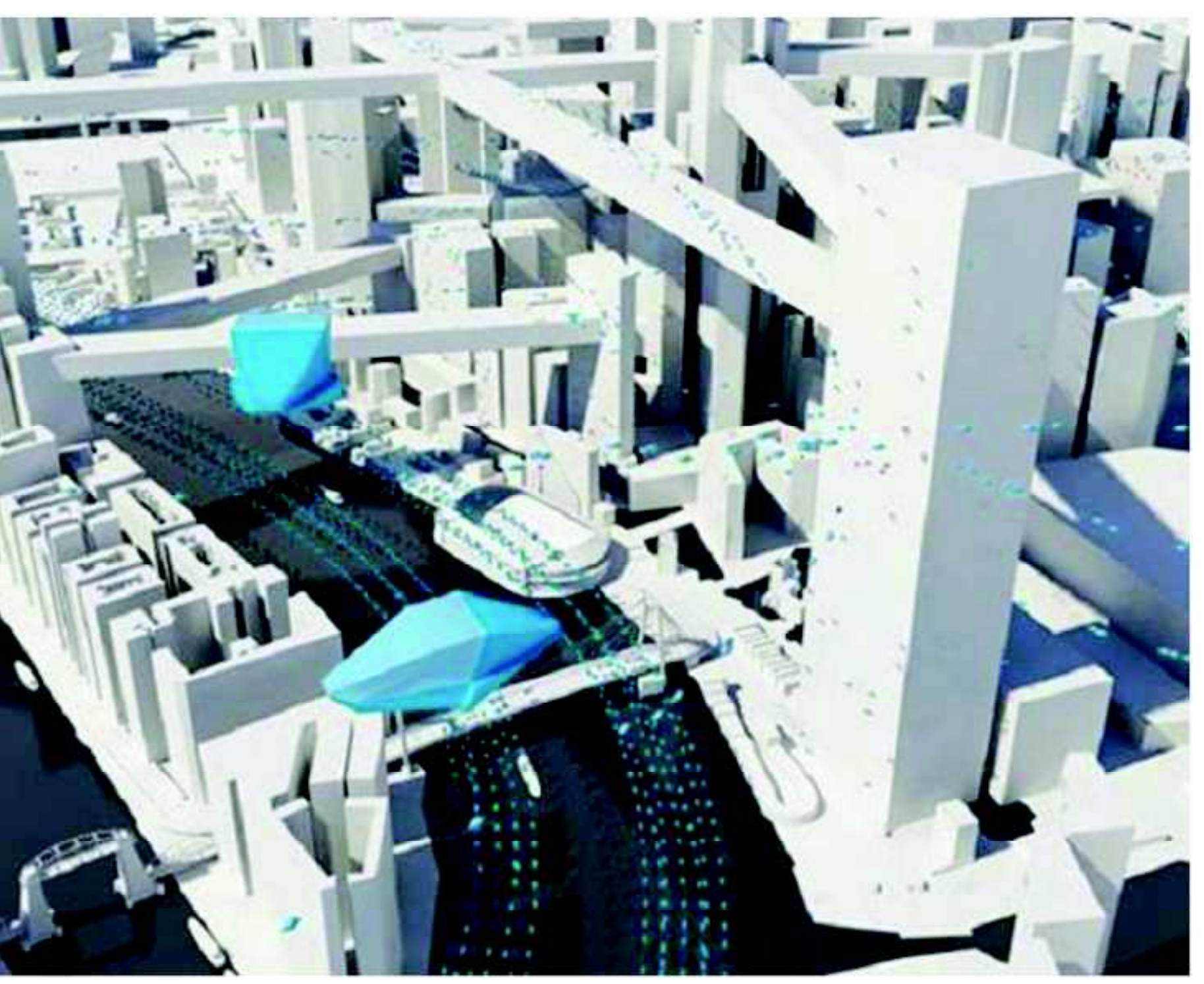

SkyCarCity. Fonte: http://rolfvanderleeuw.webs.com/6traffic.htm

Outro estudo, Space (2004), vai ainda mais longe. Os arquitetos promovem investigações sobre uma possível ocupação do espaço, investigando as consequências na terra e no corpo humano, as regiões estáveis do espaço que poderiam ser exploradas, as formas da estrutura do habitat nessas condições, elevadores espaciais conectados ao planeta e as estruturas extraterrestres, rede de transporte na órbita da Terra entre as estações espaciais, produção artificial de gravidades, entre outros. Para eles, a tecnologia aparece como salvadora da humanidade, a última visão modernista concluída. 


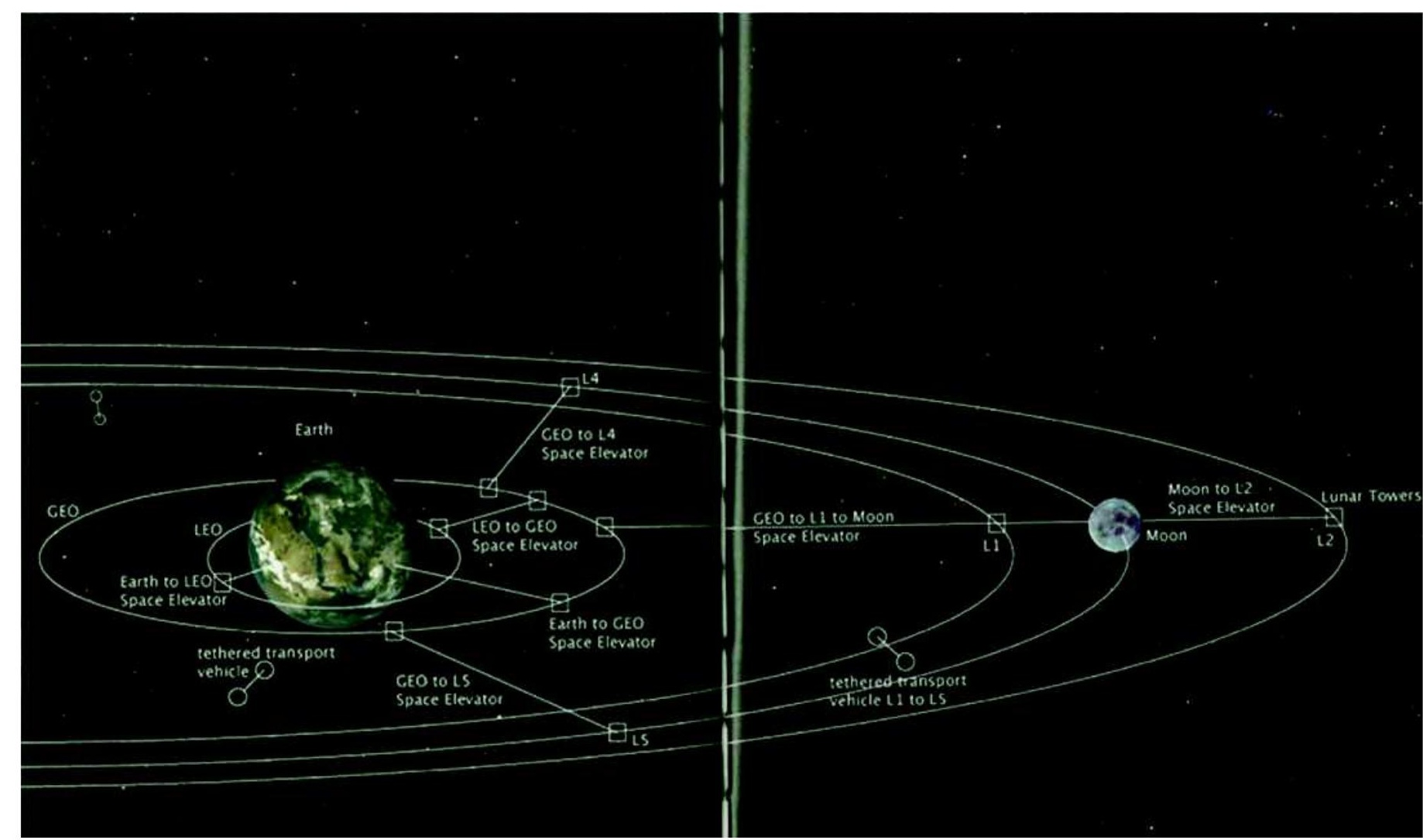

Space. Fonte: KM3.

As pesquisas da think tank The Why Factory são mais focadas nas cidades, especialmente na crise urbana, revelando certa tensão entre a disciplina da arquitetura e urbanismo e a dinâmica da própria cidade. Maas (2009) ressalta que é necessária uma dimensão visionária da arquitetura discutindo uma agenda comum em maior escala e especulando sobre os novos valores da cidade. The Why Factory defende, portanto, a necessidade de pesquisar, teorizar e politizar o futuro urbano como área de atuação da arquitetura.

Entre seus estudos estão as investigações que olham para o rápido crescimento das cidades asiáticas como The Vertical Village (2012) e Hong Kong Fantasies (2012). O primeiro deles se baseou no desenvolvimento de um novo modelo para as cidades asiáticas caracterizado por autonomia, diversidade, flexibilidade e a vida em comunidade dos bairros tradicionais que foi substituída por torres de apartamentos. O estudo contou com a criação de dois software The VillageMaker@ e The HouseMaker(c), que geram habitações e encontram a melhor localização para elas. Hong Kong é vista como uma cidade de destaque no cenário mundial, principalmente por suas altas taxas de adensamento, ainda com algumas qualidades, e por sua posição como centro financeiro na economia global. A 
segunda pesquisa toma a cidade como estudo de caso e propõe analisar padrões nas cidades grandes que criam valores cívicos. Essa análise revela não só as deficiências de Hong Kong, mas também as falhas nas ferramentas com as quais as cidades são avaliadas.

Já Green Dream (2010) e Foodprint Manhattan (2012) discutem possibilidades e tendências, como as cidades "verdes" e as fazendas urbanas. Para os pesquisadores $^{24}$, o termo "verde" ainda gera dúvidas e as pessoas não sabem exatamente o que sustentabilidade significa, sendo que as potencialidades desse termo permanecem pouco exploradas. Eles enfatizam que edifícios verdes não fazem uma cidade verde sozinha, portanto considerar o território urbano como espaço coletivo é fundamental. A partir daí, as propostas passam por Jardins Suspensos em Barcelona (que mostram a escala de intervenção necessária para atingir uma porcentagem de auto-suficiência na produção de alimentos dentro das fronteiras da cidade de Barcelona), City Wind (que sugere uma alternativa às redes de energia distribuídas de modo ineficiente, incorporando turbinas de vento nas cidades) e aplicações da biotecnologia nas áreas urbanas, com a proposta Fluocity (que utiliza bactérias para emissão de luz fluorescente). Também sobre produção de alimentos, Foodprint Manhattan simula como os moradores de Manhattan poderiam ter seus alimentos cultivados na própria ilha já que, por questões de logística, economia e qualidade, o consumidor deve estar o mais próximo possível das fontes de produção de alimentos. $O$ estudo analisa os padrões de consumo e a capacidade de produção, visualizando quanto é consumido e quais são as consequências espaciais dessa produção.

\footnotetext{
${ }^{24}$ Em thewhyfactory.com
} 


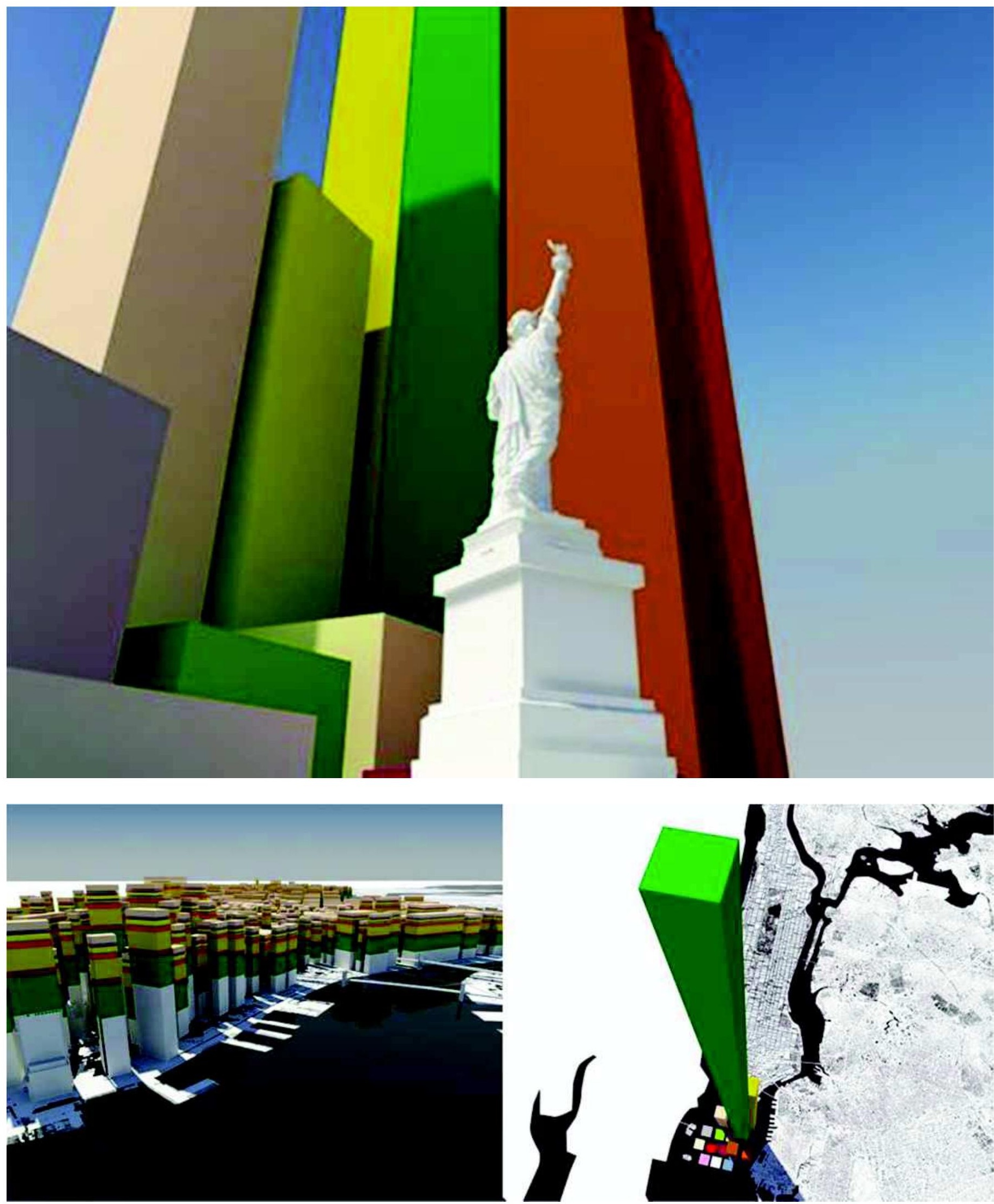

Simulações. A produção de alimentos colocada em cima dos prédios existentes adicionaria uma camada de 200 metros de altura em cada edifício. Uma torre única para cada alimento resultaria em uma mega estrutura de $23 \mathrm{~km}$ de altura para a torre de produção de carne. Fonte: thewhyfactory.com 
Os estudos do MVRDV e da The Why Factory, muitas vezes manifestos ou provocações, utilizam os cenários extremos para enfatizar questões urgentes das cidades e de seu futuro. Em certas ocasiões, os arquitetos parecem acreditar demasiadamente no desenvolvimento da tecnologia, mas seus questionamentos não deixam de ser investigações importantes que podem se desdobrar em outras pesquisas ou mesmo repensar o papel da arquitetura enquanto disciplina, caracterizando a pesquisa também como prática.

É hora de começar a pensar sobre as nossas cidades em uma forma completamente nova. O ambiente urbano é fundamentalmente diferente do que jamais foi antes, mas ainda estamos tentando defini-lo fisicamente da mesma maneira. Nós não sabemos como seguir em frente, porque estamos presos em uma realidade fragmentada (MAAS, 2009, p.215, tradução nossa). 


\subsubsection{Diagramas e software}

Se a utilização do diagrama na arquitetura como forma de representação possui precedentes históricos na antiguidade clássica e na arquitetura moderna, o interesse pelo método pode ser reportado ao surgimento e desenvolvimento de computadores e processadores de dados. É neste mesmo período em que são percebidos deslocamentos significativos da representação arquitetural, dos objetos e das formas para os processos de geração dos objetos, das formas e dos espaços. Os diagramas arquiteturais de análise e proposição, antes reservados ao trabalho dos escritórios, passam a ser conceituados e publicizados, concorrendo com as representações codificadas de arquitetura e as imagens ou simulações das obras edificadas (MORAIS, SPERLING, 2012).

Para definir diagrama, Lootsma (2003) busca Bijlsma, Deen e Garritzman ${ }^{25}$ que propuseram:

O diagrama é uma representação gráfica da evolução de um fenômeno. Existem linhas, a estrutura e a forma; ele trabalha por redução, abstração e representação. Como meio, o diagrama tem duas funções: é uma forma de notação, analítica e reflexiva, que sintetiza, mas é também um modelo para pensar, processar e produzir (BIJLSMA; DEEN; GARRITZMAN, 1998 apud LOOTSMA, 2003, p. 1, tradução nossa).

O diagrama constitui, para Lootsma (2003), uma solução prática que expressa a complexidade da sociedade contemporânea, facilitando a comunicação dos arquitetos com outros profissionais, clientes ou o público em geral. É uma ferramenta conceitual que mostra a evolução das ideias.

Anthony Vidler (2006) aponta que o diagrama é tanto constitutivo e projetivo, é performático ao invés de representação. Para o autor, o diagrama ilustra uma definição, ajuda na prova de uma proposição, representa o curso ou o resultado de qualquer ação ou processo. Ele cita a importância do diagrama para Deleuze ${ }^{26}$ :

(...) nunca funciona para representar um mundo preexistente, ele produz um novo tipo de realidade, um novo modelo de verdade. Ele não está sujeito à história, nem pairam sobre a história. Ele cria história por desfazer realidades

\footnotetext{
${ }^{25}$ OASE: Diagrams (Rotterdam), n.48, 1998.

${ }^{26}$ Em G. Deleuze, Foucault, Editions Minuit, Paris, 1985, p. 42.
} 
anteriores e significações, a criação de tantos pontos de emergência ou de criatividade, de conjunturas inesperadas, de contínuos improváveis (DELEUZE, 1995, apud VIDLER, 2006, p. 4).

A repetição do uso do diagrama na atualidade vem da necessidade de um meio de representação que mostre com facilidade as múltiplas possibilidades do projeto. A partir daí surgem as principais mudanças em seu uso através das técnicas digitais de representação. O diagrama se transforma em uma forma de desenho dinâmico que compreende não só os elementos físicos, mas também as forças e fluxos do contexto. De acordo com Braham (2000), o diagrama tenta se ajustar às constantes mudanças da cidade contemporânea.

Stan Allen (1998), desdobrando como Vidler o que propõe Deleuze, afirma que os diagramas na arquitetura funcionam igualmente como "máquinas abstratas", não mapeiam ou representam objetos ou sistemas já existentes, mas antecipam novas organizações e especificam ainda as relações a serem realizadas. O diagrama não é simplesmente uma redução de uma ordem existente.

Para Lootsma (2003), se os datascapes do MVRDV fossem classificados segundo as categorias propostas por Bijlsma, Deen e Garritzman citadas anteriormente, eles tenderiam mais a análises e representações. São visualizações de leis, regras, normas e probabilidades estatísticas, e mostram que o espaço que nos rodeia é permeado pelas atividades da sociedade. Em um único projeto, existem vários sistemas abstratos de trabalho. Esses sistemas nunca indicam um limite máximo dentro dos quais o arquiteto pode produzir seu projeto. De acordo com Lootsma (2003), uma vez que os diferentes datascapes foram demonstrados, o projeto se torna objeto de uma negociação em que o arquiteto desempenha o papel de coordenador. Ainda, segundo o autor, o MVRDV conserva um diagrama secreto em algum lugar que realmente gera os projetos.

Vidler (2000) traz ainda para a discussão sobre o MVRDV a noção de "arquitetura diagrama", termo que Toyo Ito definiu para nomear a arquitetura de Kazuyo Sejima. Retomando Allen:

(...) não é necessariamente uma arquitetura produzida por meio de diagramas, mas que se comporta como tal, com efeitos máximos performativos e com meios arquitetônicos mínimos, caracterizados às vezes por certa indiferença, como no caso do MVRDV, mas sempre com atenção à força do diagrama (ALLEN, 1998, p. 18). 
Segundo Vidler (2000), o grande perigo desse método de trabalho é a forma arquitetônica tornar-se a imagem construída do diagrama, resultando em um problema que é a facilidade de gerar e representar formas. E é por causa dessa espontaneidade de geração da forma que alguns autores demonstram preocupações com as necessidades humanas que não podem ser otimizadas nesse processo. Para Braham (2000), o método diagramático não pode ignorar o sujeito e para Montaner (2010), tal estratégia só pode evoluir se considerar a vitalidade da experiência das atividades humanas com a diversidade de informações contemporâneas.

Percebemos que, apesar de parecer lógico, o método do MVRDV ainda necessita de decisões por parte do projetista. Esse processo se inicia com a seleção de alguns parâmetros (qualitativos e quantitativos) e a interpretação das informações do local. Notamos então que existe uma seleção na coleta de dados, já que é impossível averiguar todas os elementos do contexto. A partir daí os dados são organizados em diagramas que indicarão as consequências espaciais, as limitações e as possibilidades. Isso mostra que, embora o processo de negociação seja baseado em informações objetivas, ele ainda só pode ser concluído com a participação do projetista na tomada de decisão, que parte de sua intuição. Essas decisões intuitivas também são utilizadas para refinar a forma final dos projetos que não são exclusivamente o resultado de um processo lógico onde estão somadas as necessidades técnicas e operacionais.

Observamos ainda que a utilização de diagramas na produção arquitetônica do MVRDV segue dois aspectos distintos: narrativas e negociações. Como narrativa o diagrama funciona como um resumo da história do desenvolvimento do projeto, mas simplifica o processo e omite etapas. Como processo generativo, os diagramas narram a evolução de uma ideia do ponto de vista formal, incorporando e respondendo a fluxos e fenômenos do entorno (visuais, insolação e ventilação) e explicitam como estes componentes, a distribuição do programa, a criação dos acessos e vistas resultaram na forma final. É um meio de representação pós-projeto que sintetiza a evolução de uma ideia sem refletir acerca de outras demandas relacionadas à sociedade. Desse modo seria, segundo a definição de Stan Allen (1998), um esquema e não um diagrama. 

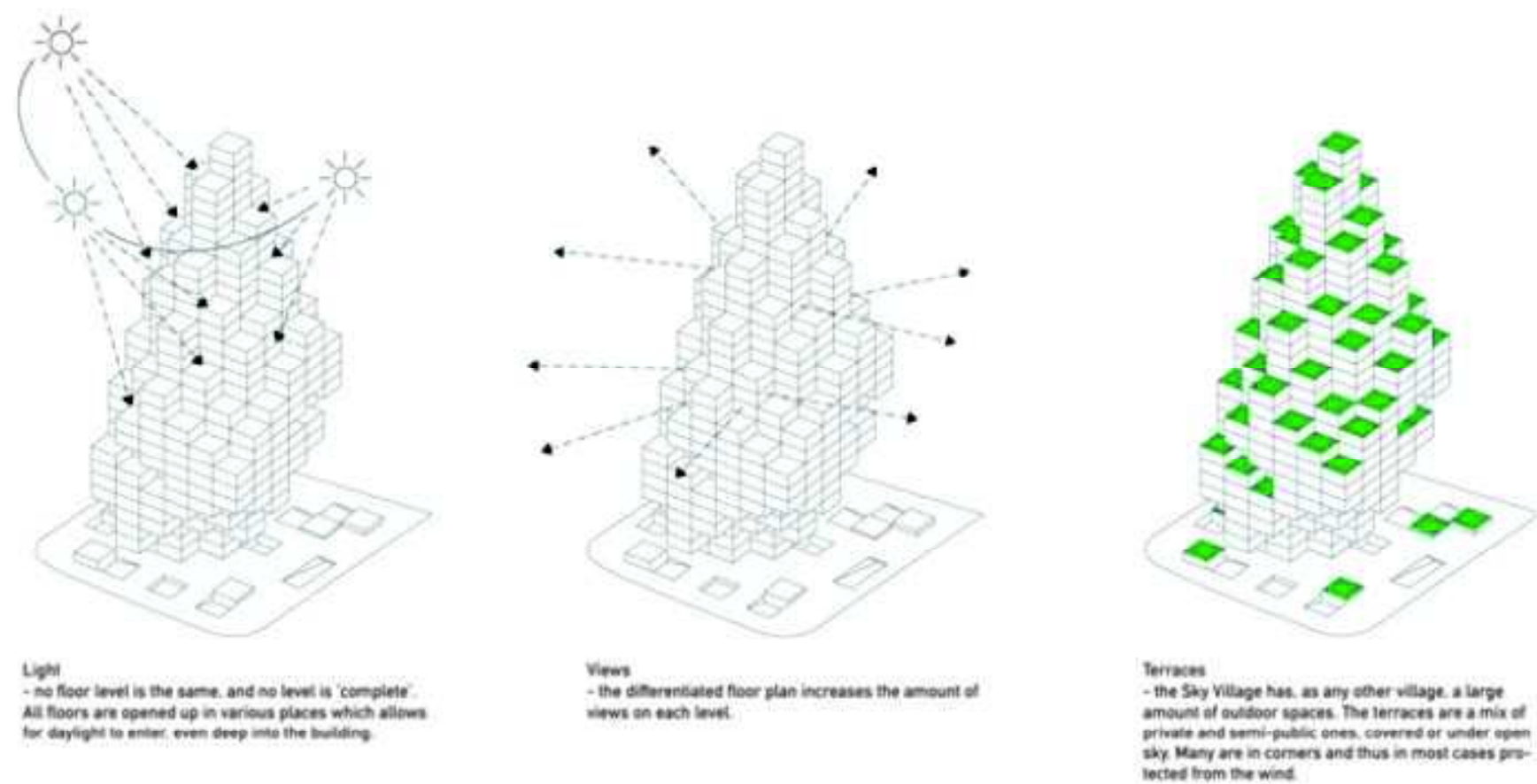

Sky Village (Copenhague, 2008). Diagramas mostrando definições por iluminação, vistas e terraços. Fonte: www.archdaily.com

Como processo analítico, seus diagramas buscam promover a compreensão dos aspectos sociais, econômicos e políticos estabelecendo estratégias mais participativas que se alteram conforme as negociações e decisões tomadas em relação ao projeto. 


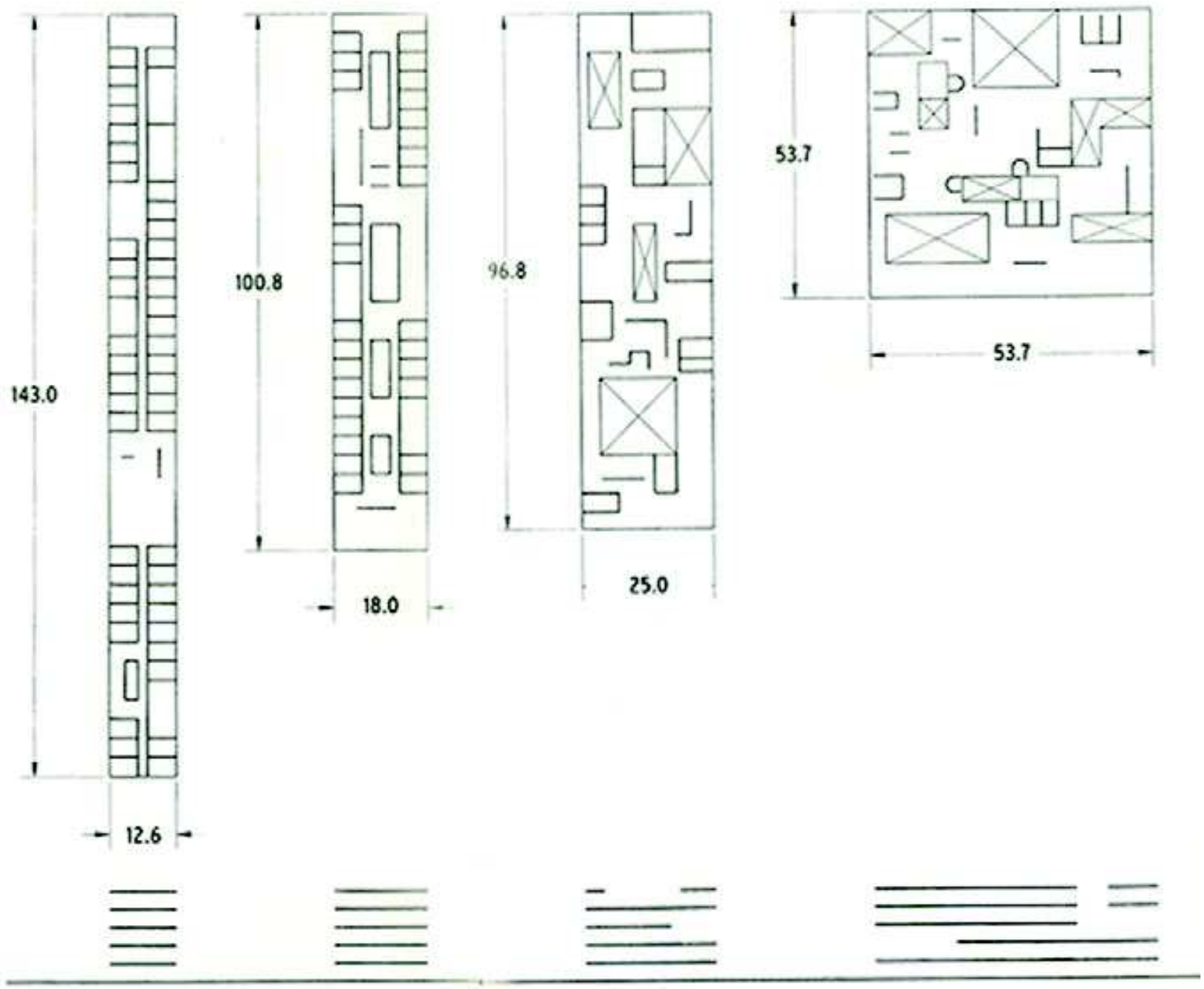

Diagrama da Villa VPRO: compactação. Fonte: FARMAX.

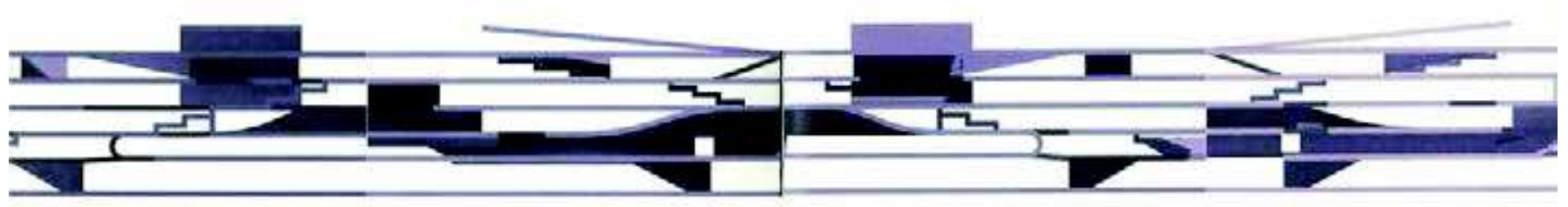

Diagrama da Villa VPRO: conexões entre os pavimentos. Fonte: FARMAX.

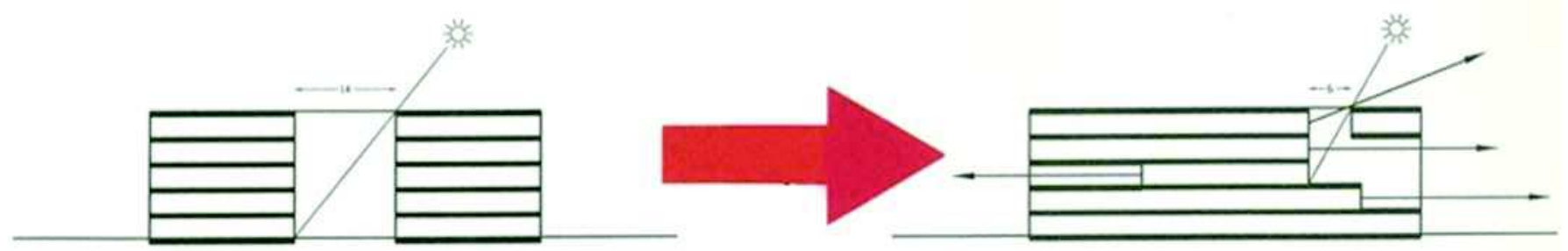

Diagrama da Villa VPRO: vistas e iluminação. Fonte: FARMAX. 


\section{Discussions}

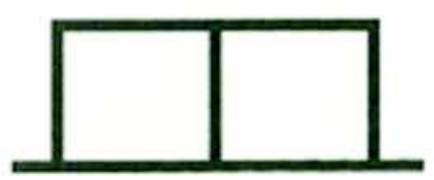

161094

2 Storeys 14 deep

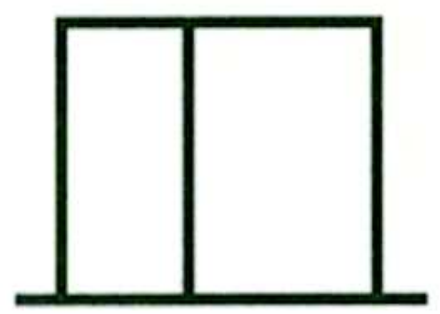

231194

4 Storeys 7 metres deep No wide views to park

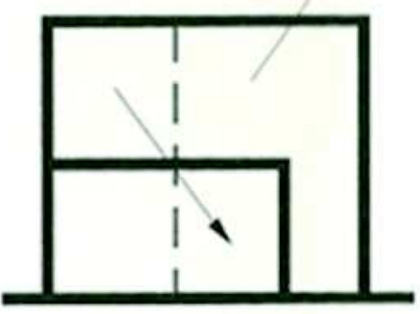

141294

House in a house

No roof access house :

Small gardes access boose 2

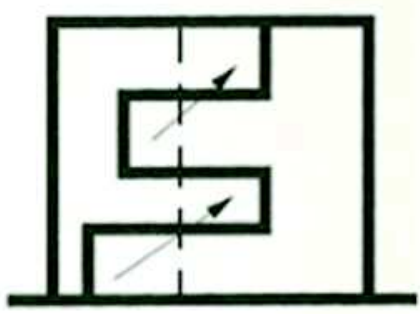

120195

Alternating floors 3

Ico little gardes access for bsuse 1

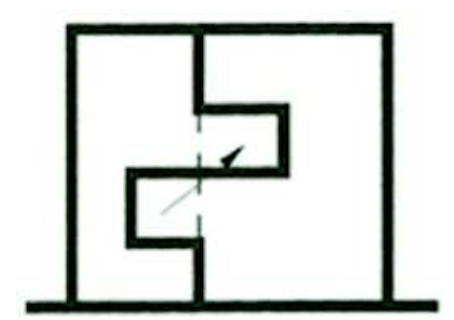

200295

Alternating floors 4

Includes garden access - roof access

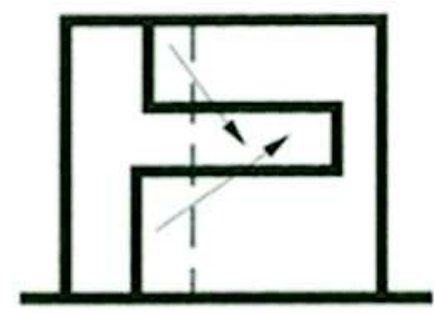

040194

Alternating floors 2

Too little garden access fer house 1

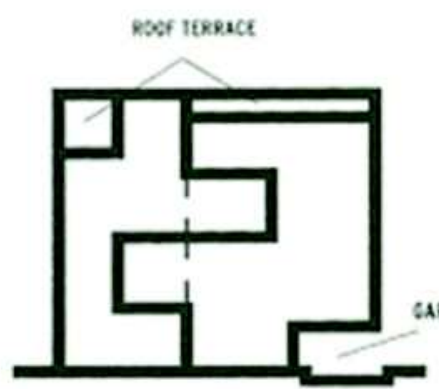

090395

Outdoor space

Rool terrice house 1

Garaçe + toot terrace acust 2

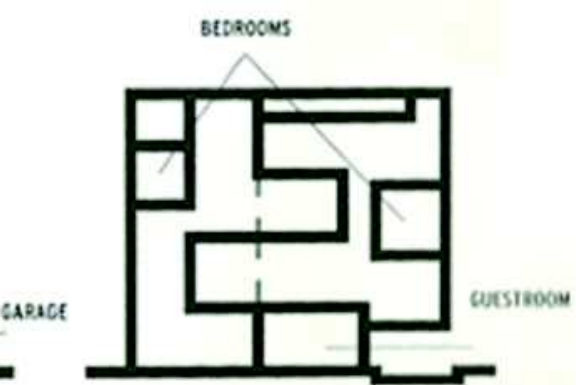

130495

Final result

Bedrooms is $1+2$

Panoble house 2

Iacl. fire regulatisas

Diagramas do projeto Double House por data (Utrecht, 1997). Fonte: FARMAX. 


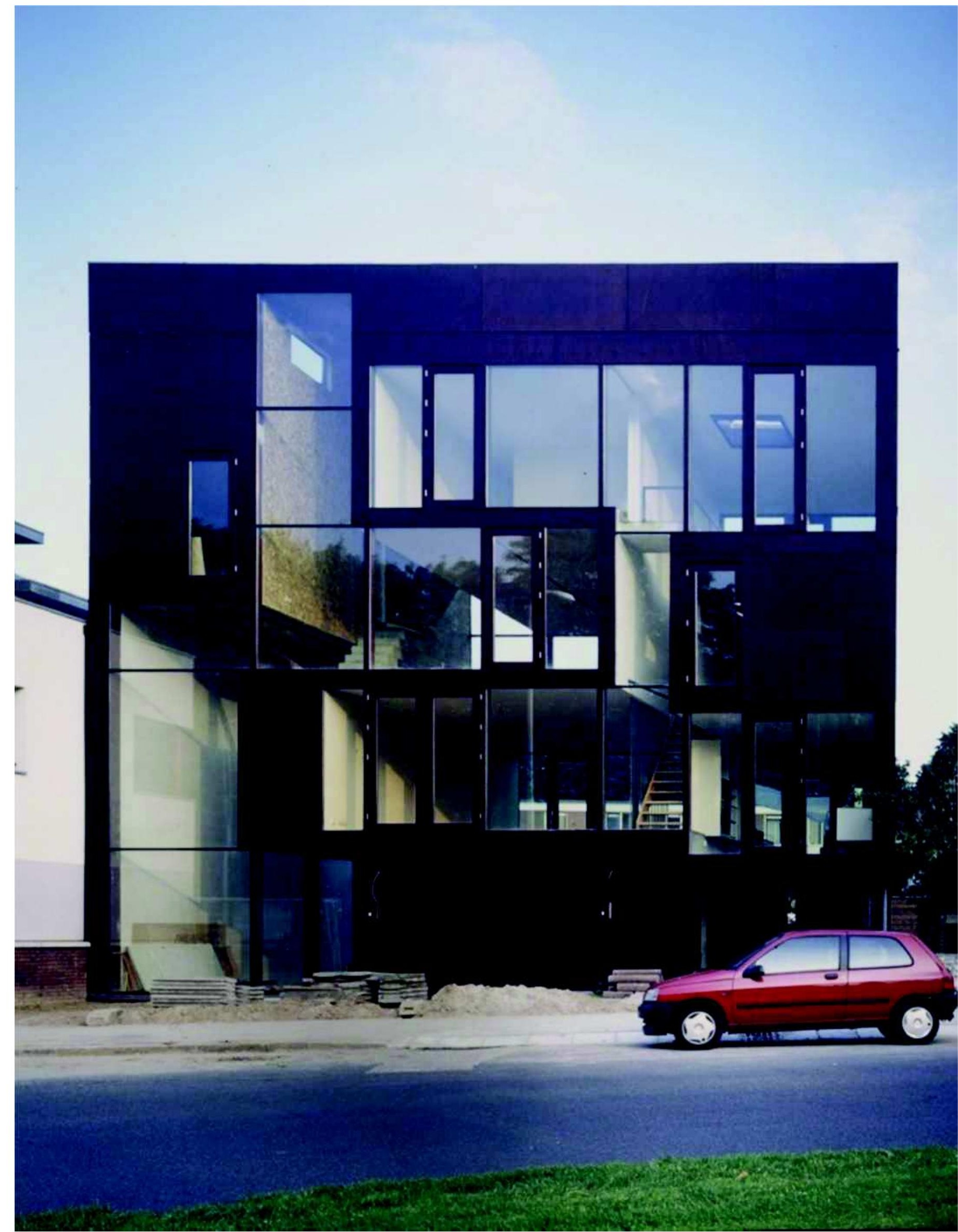

Fachada do projeto Double House (Utrecht, 1997). Fonte: www.search.nl 
A necessidade do MVRDV de trabalhar com um grande número de informações, desenvolver hipóteses e visualizá-las no projeto Silodam resultou na criação do software Functionmixer. Posteriormente foram criados outros programas, como o Climatizer, Volumemaker, Optimixer e o Regionmaker - este último baseado no Functiomixer, alterando-se, porém a escala a ser trabalhada, de "local" para "regional", no sentido de controlar os processos urbanos e regionais. Os software foram desenvolvidos em caráter experimental junto com instituições de pesquisa e empresas de tecnologia.

O domínio virtual pode ser usado como ferramenta. Sua tecnologia pode manipular grandes quantidades de dados e sistematicamente revelar complexidades: pode arquivar e atualizar conhecimento, armazenar informações, conectar bancos de dados, fazer comparações, visualizar opções, prever desenvolvimentos e especular em novas direções. O virtual cria um novo coletivo, uma nova esfera pública - para acompanhá-lo (MAAS, 2005, p. 1250, tradução nossa).

Para Maas (2005), a ideia de desenvolver software para planejamento que tenham a interatividade do usuário torna-se mais necessária. Dados estatísticos e territoriais estão disponíveis na web. Sistemas de análise e monitoramento estão progredindo, e o nível de detalhe foi ampliado através de sistemas de satélite que permitem o acesso ao conhecimento e análises comparativas.

Tais implementações auxiliam o desenvolvimento de projetos em bases e processos digitais. De acordo com Maas (2005), torna-se possível criar pacotes de software, facilitar o acesso aos dados geográficos e sociais, ligando-os com diferentes bancos de dados globais. Os software incorporariam todo tipo de usuário: planejadores, agências de desenvolvimento, centros comunitários e políticos e permitiriam que eles tivessem acesso aos dados e também pudessem comunicar, controlar, discutir, debater, avaliar e protestar.

$\mathrm{Na}$ concepção de Maas (2005), os dados e software podem ser integrados a um sistema de planejamento e um grande programa pode coordenar sistemas especializados e inter-relacionados, por exemplo: Inframaker seria um software capaz de absorver conhecimento e movimento propondo soluções de tráfico otimizadas. Housing Generator poderia desenvolver casas e bairros otimizados. Light Calculator otimizaria e controlaria as necessidades de luz natural. $O$ 
Functionmixer poderia propor a melhor mescla de funções. O Evaluator avaliaria e criticaria as possibilidades baseado em parâmetros de inovação. Esses programas podem ser ajustados pelos usuários e a seleção de parâmetros indica os efeitos das escolhas em diferentes culturas e ideologias políticas e econômicas. O que o MVRDV destaca é que, em um mundo permeado por conexões e com a utilização dos software para projeto, o planejamento não é feito somente pelos arquitetos, mas também por profissionais de outras áreas. Soma-se ainda a participação do usuário e "todo mundo torna-se um fabricante de cidades" (MVRDV, 2005, p. 1248).

O que é interessante notar é que 30 anos antes, como o próprio MVRDV faz questão de lembrar no livro KM3, esses programas, de alguma maneira, já tinha sido imaginados.

No início dos anos 60, Buckminster Fuller e John McHale compilaram estatísticas, mapas e diagramas para formatar um inventário dos recursos do planeta. Fuller já mencionava a possibilidade de uma ferramenta que fosse acessível a todos, e direcionasse os processos políticos a resolverem os problemas com mais facilidade. O texto de Christopher Alexander e Serge Chermanyeff "Community and Privacy: Towards a New Architecture of Humanism", de 1963, criticava o papel da arquitetura por se basear em verdades preconcebidas e intuições. Segundo o MVRDV, ao invés disso eles defendiam uma abordagem analítica e sistemática para o planejamento. Já pensando na manipulação de todas as possíveis combinações eles introduziram processos, que ainda não criavam, mas poderiam identificar padrões. Mais tarde, Christopher Alexander e Marvin Manheim desenvolveram um programa de computador, em 1962, chamado HIDECS no qual essas ideias começaram a ser implementadas.

O MVRDV relembra também os estudos de Yona Friedman, Charles Jencks e Nicholas Negroponte. Friedman, assim como os arquitetos do MVRDV fazem hoje, também defendia a pesquisa e em 1963 desenvolveu o Urban Mechanisms para monitorar eventos urbanos e mapas revelando o impacto de determinadas escolhas. Em 1967, ele propôs, através do Flatwriter, que o usuário desenhasse sua própria casa através de um repertório sistematizado. Ele afirmava que na prática do design coletivo, o projetista deveria preparar um repertório que mostrasse todas as alternativas ao usuário, revelando também as consequências de cada escolha, benefícios e custos. 
Charles Jencks, em 1969, propôs outro sistema que teria todas as informações relevantes fornecidas por uma instituição central e que permitiria a utilização pelos usuários para tomadas de decisões. Segundo o MVRDV (2005), Nicholas Negroponte é quem, talvez, tenha se aprofundado mais nessas pesquisas, associando a tecnologia dos computadores com o planejamento através da manipulação do ambiente por computadores programados manualmente.

Sintonizados com estas iniciativas precedentes, em 2001, o MVRDV em colaboração com outras instituições desenvolveu o Functionmixer, primeiro software criado pelo escritório, que tem o objetivo de otimizar tomadas de decisão por municipalidades, planejadores e grupos de habitantes no desenvolvimento de bairros de uso misto e projetos multifuncionais. O programa é baseado na decomposição do ambiente em unidades funcionais que são combinadas em infinitas possibilidades conforme as escolhas dos parâmetros pelo usuário. 0 programa gera as possibilidades e fornece as melhores opções, sendo possível comparar soluções e analisar limitações. O Functionmixer trabalha com parâmetros espaciais quantitativos (densidade e diversidade) e qualitativos (sustentabilidade econômica, ambiental e social) que foram escolhidos por especialistas de diversas áreas. O MVRDV desenvolveu seu próprio modelo e algoritmos. Para a criação de uma versão demonstrativa foram eleitos poucos parâmetros, sendo eles: habitação, trabalho, indústria, florestas e agricultura (quantitativos); poluição, proximidade com o mar, localização das indústrias, concentração da agricultura, relação habitação/trabalho (qualitativos). O pixel foi escolhido como unidade mínima, pela facilidade de ter funções atribuídas, e ser colocado em conjunto e desagregado. $O$ resultado não é um desenho definido, mas um esquema abstrato para o desenvolvimento de um projeto.

Em seguida, uma plataforma especial, o Optimizer (2004, cThrough), foi criada para desenvolver novas funções no Functionmixer e também no Regionmaker. O Optimizer é uma ferramenta de projeto que consiste em um processo que avalia e otimiza configurações espaciais. As especificidades dessas configurações são controladas pelo projetista como usuário do software. Esse controle é feito através da calibragem dos parâmetros, ou seja, o usuário pode determinar o número de parâmetros escolhidos e o grau de influência de cada um. Em 2005, uma versão mais apurada do Functionmixer previa custos de construção e parâmetros 
relacionados ao controle da iluminação natural e barulho, prevenção de crimes e acessibilidade. 


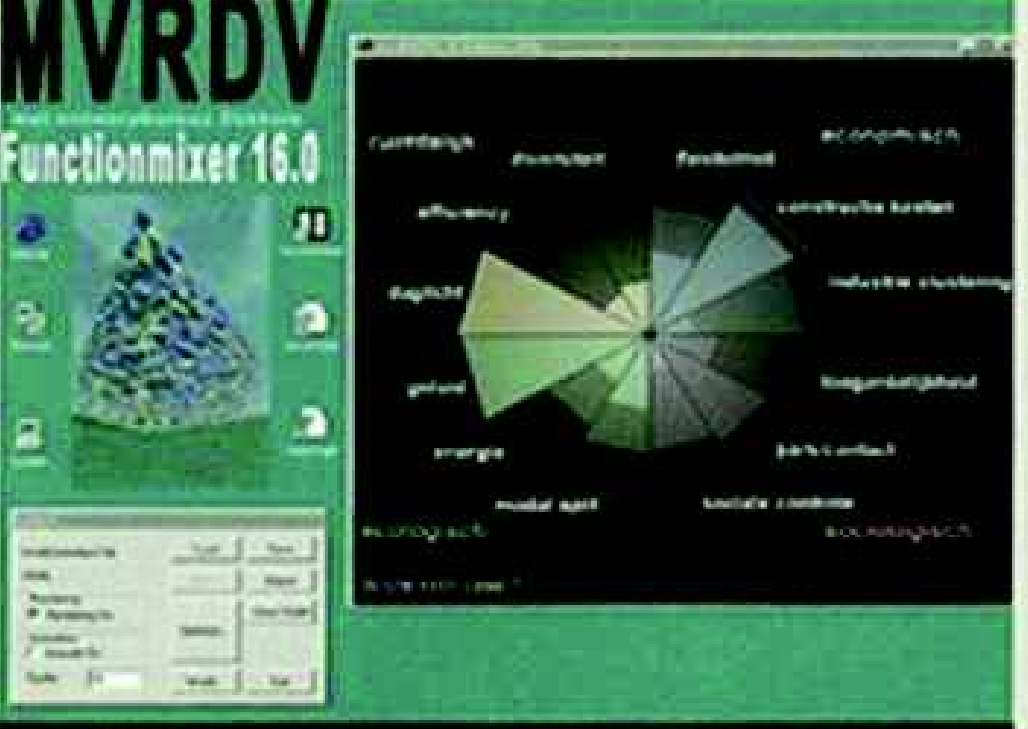

The Score diagram show s changes in Dayliaht, Nolse and Construction costs.
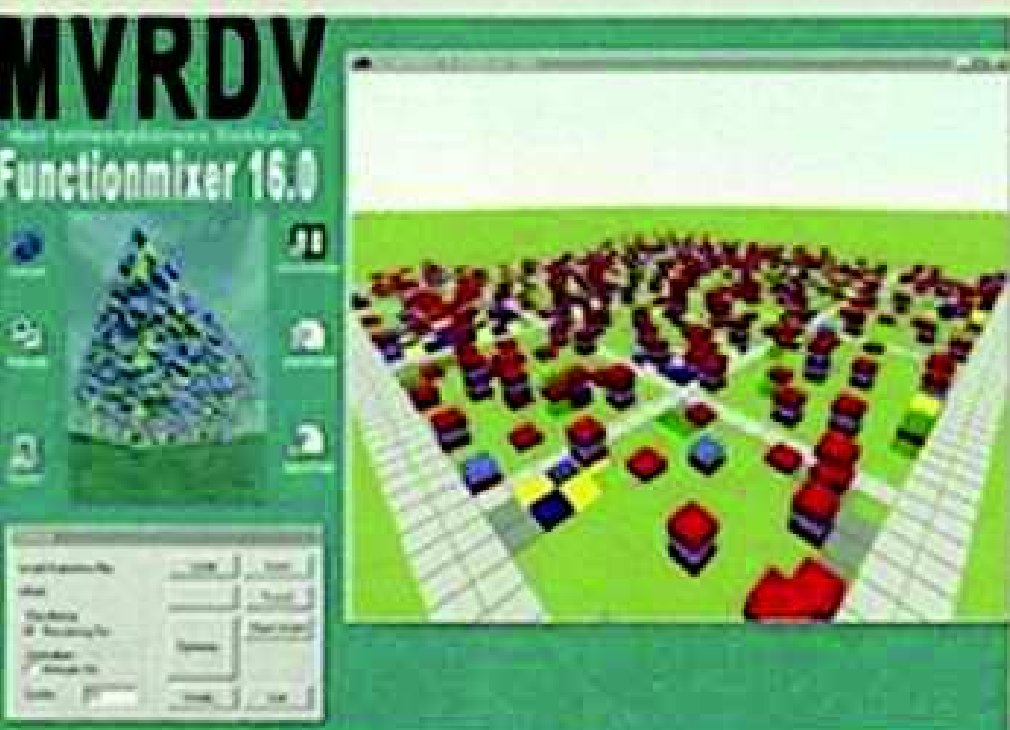

This creates a Multimi. Cify with a fSI of 1 ...

T1

VRDV Enctionnixer 180 $\frac{\partial}{2}$

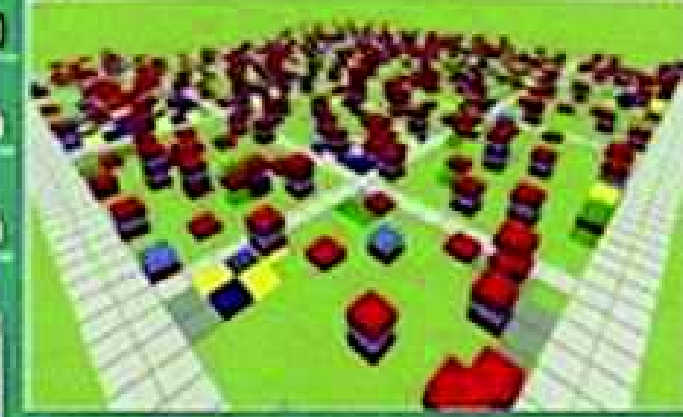

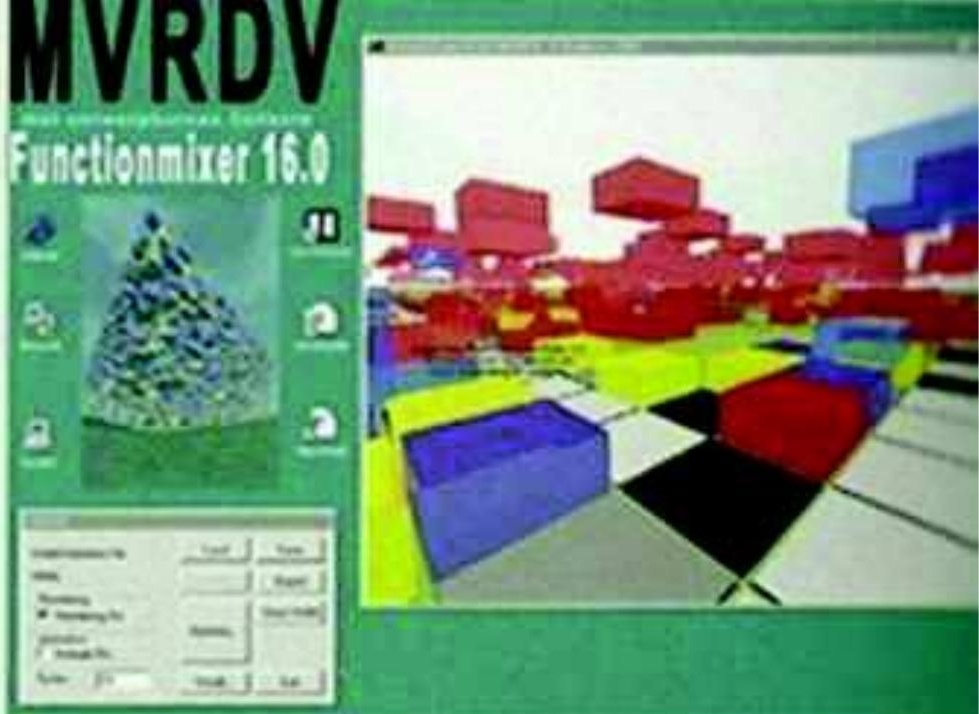

Program shifts verticasty. Housing moves to lighter areas. top of other program.

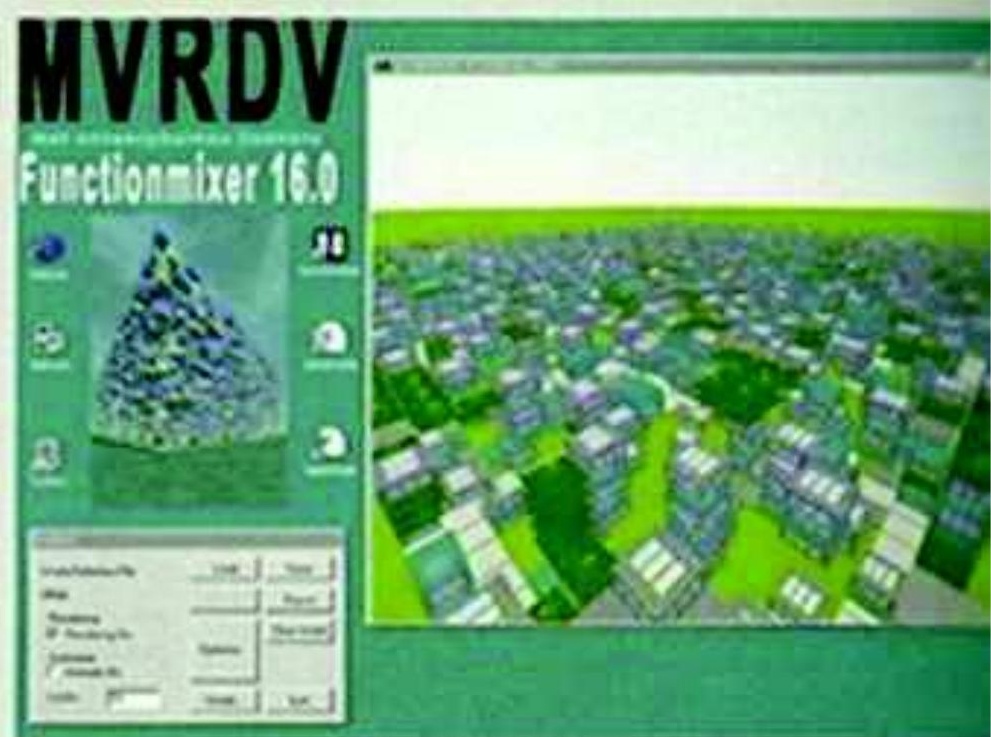

that can be materialized with tacades.

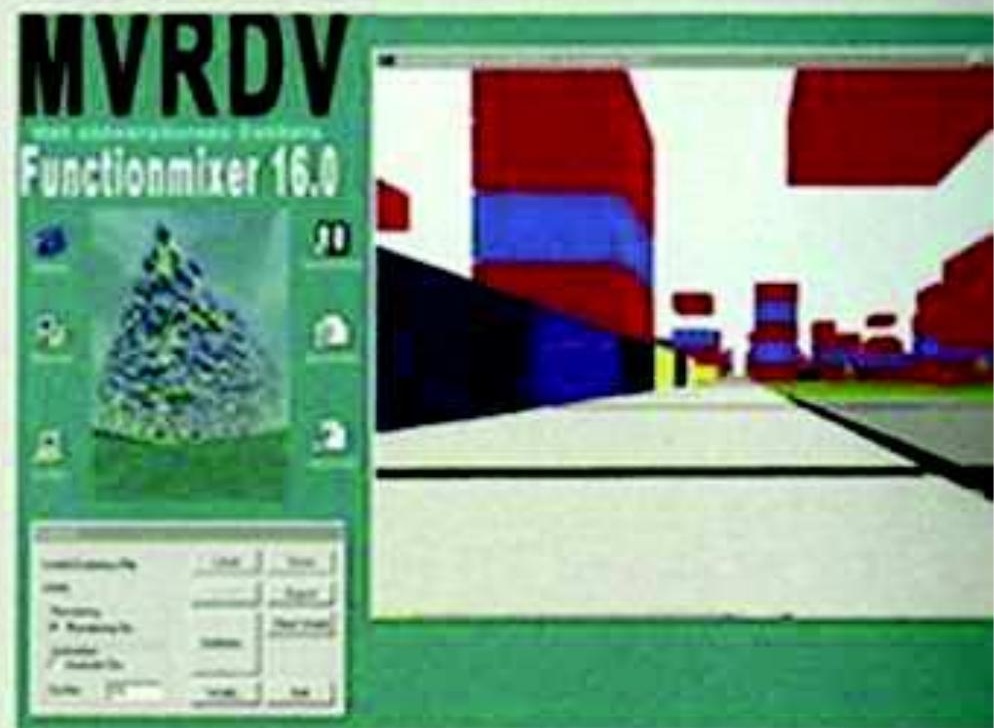

and seen from inside the neighborhood. 
Em 2004, o Functionmixer serviu de base para o desenvolvimento de outro programa, o Volumemaker. Esse software foi criado especificamente para otimizar volumes em um planejamento de longo prazo para a revitalização do bairro de Bjorvika, em Oslo, e é baseado na legislação local. Desenvolvido com o conceito de uma biblioteca de possíveis volumetrias e parâmetros, o programa também realiza a apresentação de diferentes configurações para serem avaliadas.

Aumentando o limite de atuação, o Climatizer (MVRDV e cThrough, 2003) foi um software criado para a realização de estudos sobre as mudanças climáticas, permitindo a visualização dos efeitos do comportamento humano nas alterações de clima. O programa cria, define, simula, compara e sugere climas. Pela primeira vez nessa série de software o planeta inteiro foi trabalhado e uma ferramenta de zoom precisou ser criada para visualizar pequenas e grandes escalas. Os pixels foram substituídos por triângulos para seguirem $\mathrm{o}$ formato do globo e novas representações gráficas em barras foram criadas para otimizar o tempo de cálculo. O objetivo é obter informações sobre emissões de $\mathrm{CO} 2$, medir a influência do aumento de temperatura em determinada região, escolher variações nos parâmetros de habitação, transporte, energia, agricultura, indústria e floresta e também optar pelo nível de intensidade do comportamento humano e o período de tempo em que esses fatores selecionados vão atuar. Os impactos podem mostrar, por exemplo, alagamentos na costa leste dos Estados Unidos e a construção de diques como forma de adaptação. 
Ainda em 2003, o MVRDV e o Instituto Berlage fizeram quatro estudos de software: - Masterprogrammer, baseado no Functionmixer, mas totalmente voltado para ser aplicado em Rotterdam; o Inframaker, para analisar as questões de infraestrutura e mobilidade, já apontando uma parcela do Regionmaker, o Access Optimizer, que tinha como proposta otimizar a relação entre a estrutura física da cidade e sua infraestrutura e o Berlagemixer, um software que operasse em maior escala, prenunciando o Regionmaker.

A necessidade de uma nova ferramenta surgiu em um momento em que grandes projetos em escalas regionais passam a ser solicitados ao escritório em toda Europa (MAAS, 2002). Para o MVRDV (2002), apesar da globalização, o mundo não está se tornando um todo homogêneo. Por mais que exista uma dissolução das fronteiras entre nações, o novo regionalismo é ligado à globalização e não pode ser lido apenas do ponto de vista de uma região isolada já que qualquer processo de regionalização tem efeitos em outras áreas do mundo. Regiões de diferentes tipos irão definir uma nova estrutura global (WALL, 2002).

No Regionmaker, as regiões são como áreas de influência sobrepostas e conectadas e vão além dos limites e fronteiras de cidades ou países. A influência de cada região no sistema global pode ser alterada por qualquer mudança em sua constituição. A partir da análise de vantagens comparativas dessa mudança, o software passa a sugerir direções de desenvolvimento para a dada região baseado nas hipóteses selecionadas pelo usuário (MVRDV, 2005). O programa é baseado na decomposição do ambiente em unidades funcionais que se combinam de maneira ótima e formam soluções otimizadas. O programa gera inúmeras possibilidades de combinações e sugere a melhor solução baseado nos parâmetros escolhidos pelo usuário. Como nos outros software, uma das suas funcionalidades é poder comparar soluções, mostrando suas vantagens e desvantagens e facilitando tomadas de decisão.

Quando o Regionmaker é iniciado, o usuário escolhe a região a ser trabalhada, seguido do download de mapas, dados e informações de censos da área escolhida. A estrutura do software se assemelha ao Functionmixer e é constituída por alguns componentes básicos: envelopes, unidades, parâmetros, interface de ajustes, critérios de avaliação, cenários, visualização, pontuação e um banco de dados de regiões. O "envelope" contém a região como uma área em terceira dimensão com escalas, tamanhos e limites e também informações físicas e geográficas. 

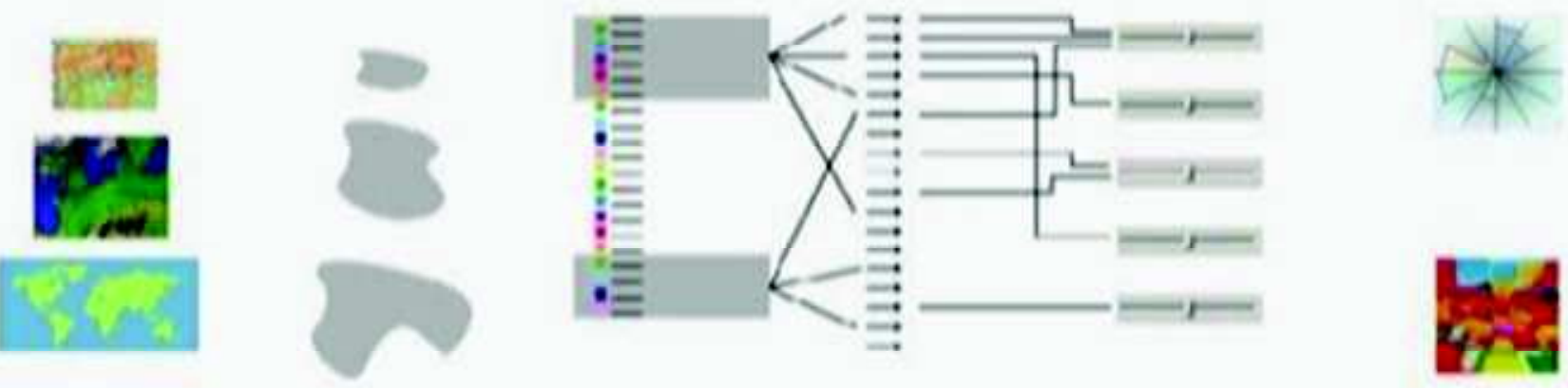

Relações podem ser estabelecidas em diversas escalas. Fonte: filme The Regionmaker, Demo NLZH, MVRDV/Wieland \& Gouwens.

A "unidade" é a menor entidade presente no envelope, e é caracterizada como um bloco de $5 \times 5 \times 3$ metros que pode se juntar a outras unidades criando "casas" ou "bairros". Os parâmetros funcionam como regras locais que controlam o comportamento das unidades. Essas últimas possuem seus próprios parâmetros que se relacionam com outras unidades, que ditam como as combinações podem ser feitas. As qualidades dessas combinações serão contabilizadas pelos "critérios de avaliação" e os resultados podem ser comparados e classificados em um ranking gerado pela soma da pontuação das avaliações individuais das unidades. 


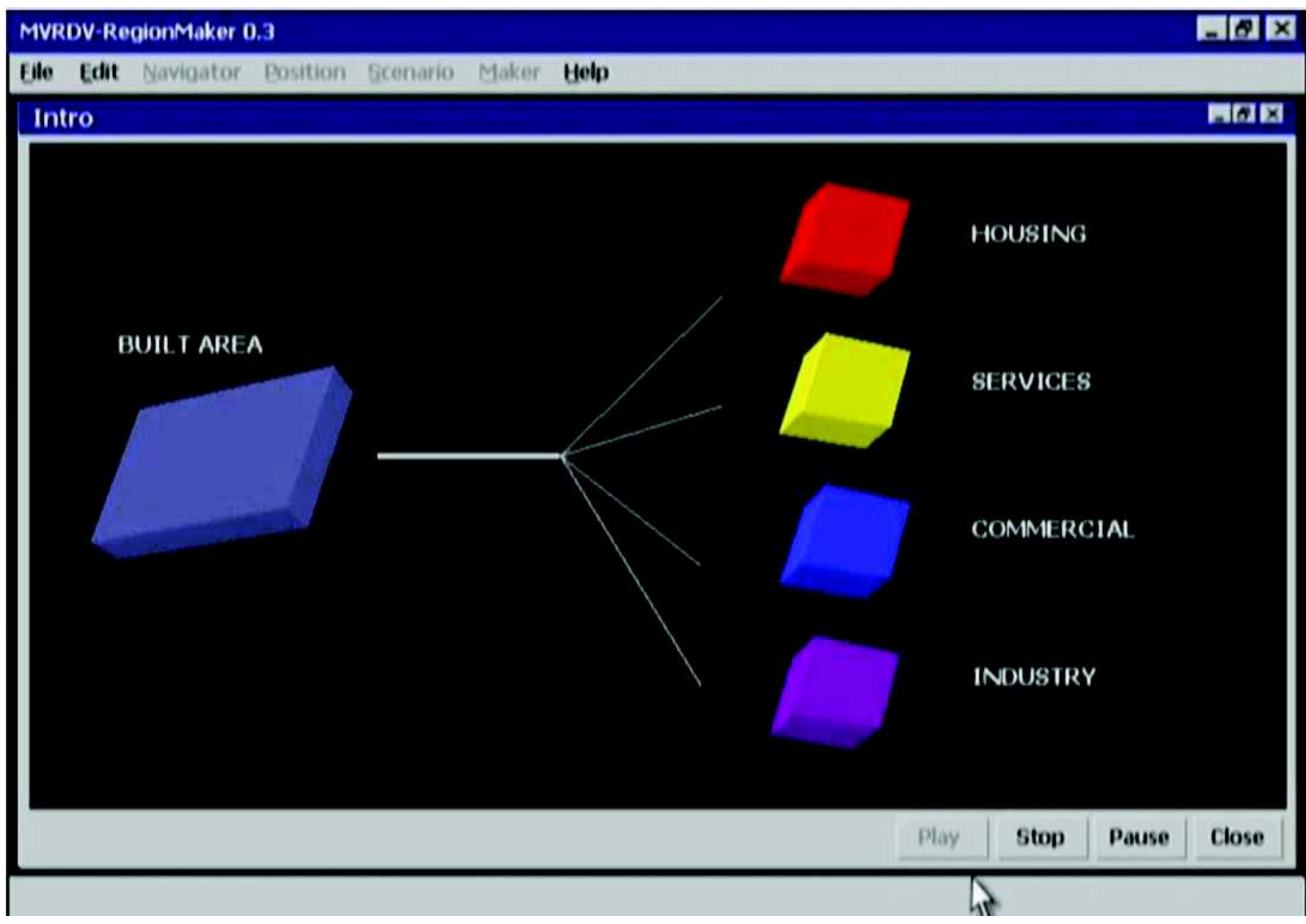

As unidades. Fonte: filme The Regionmaker, Demo NL-ZH, MVRDV/Wieland \& Gouwens.

Os critérios de avaliação ainda podem ser ajustados e elaborados pelo usuário que define qualidades e relevâncias, como por exemplo, uma hierarquia composta de conceitos de sustentabilidade, inovação e fatores econômicos. O resultado do processamento de todos esses dados pode ser visualizado em uma simulação tridimensional ou em diagramas. Os cenários gerados são salvos e comparados, assim como podem ser escolhidos níveis de zoom para o desenvolvimento de certos detalhes, seleção de perspectivas, adição de cores, fachadas e pessoas. 
Position

focio fconomic Indicators

$+1$

0

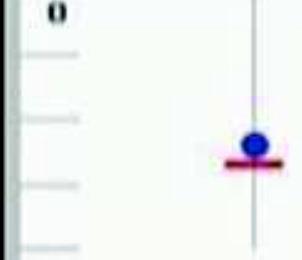

$-1$

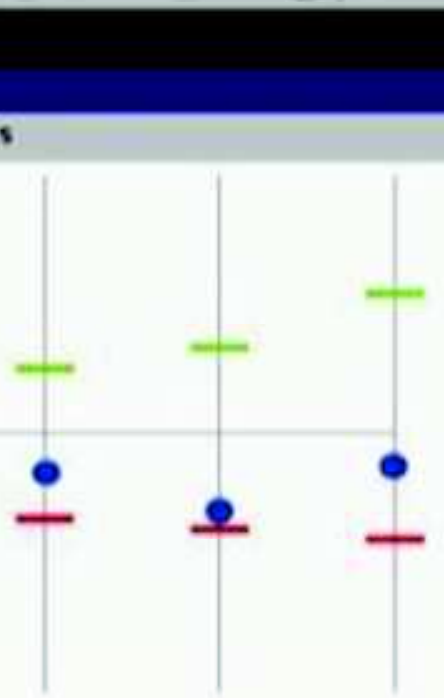

Navigator

जबत्व

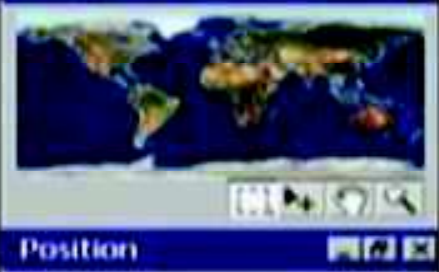

anta

Main Reoion

Eocio-Eceyomic Indicators Reculation.

Lanchuse

Population Economy Human Cap Culture

Close

Region: Zuid tblland Compare-Reoion:Lorsion/Paris / Puhroebiet

Indicadores sócio-econômicos. Fonte: filme The Regionmaker, Demo NL-ZH, MVRDV/Wieland \& Gouwens.

\section{MVROV-ReoionMaker 0.3}

\section{Elo Echt Navioator Bosition Licniario Maker Helo}

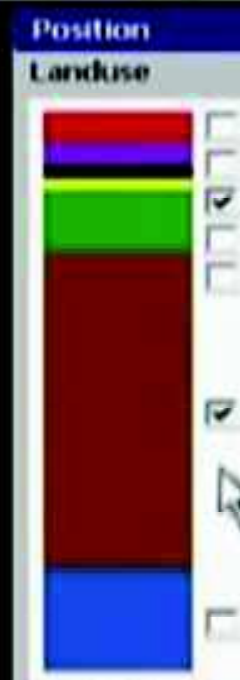

Zued Holliand

Detals
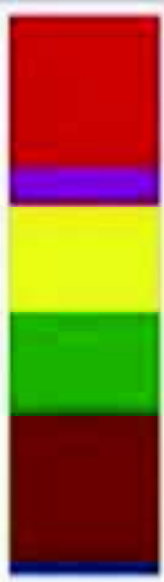

Lorwkn

Detals
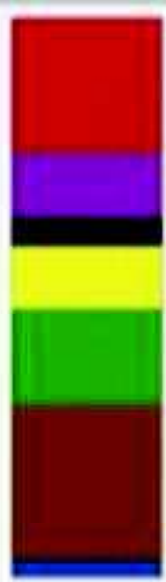

Pais

Details are
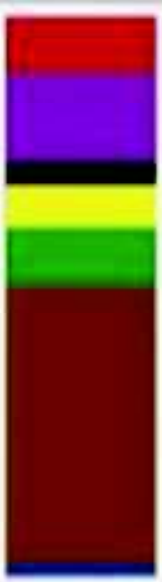

Infrastructure

Recreation
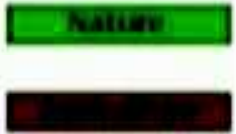

Ruhrovbiet

Detals

\section{Navioatior}

जलिख

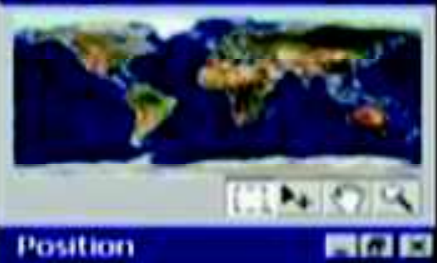

focto fronomic Indicators

Reculation I rovirorument

Lanchuse

Det ant Erara

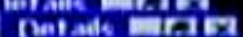

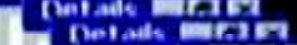

Detals mâx

Ruhroebiet

Now

Cocktan'

Pepulatien!

s. Boser Ink.

Dentity

I.

\section{Region: Zuid tbolland Compare-Region: Lonkon / Paris / Ruhroebiet}

Uso do solo. Fonte: filme The Regionmaker, Demo NL-ZH, MVRDV/Wieland \& Gouwens. 

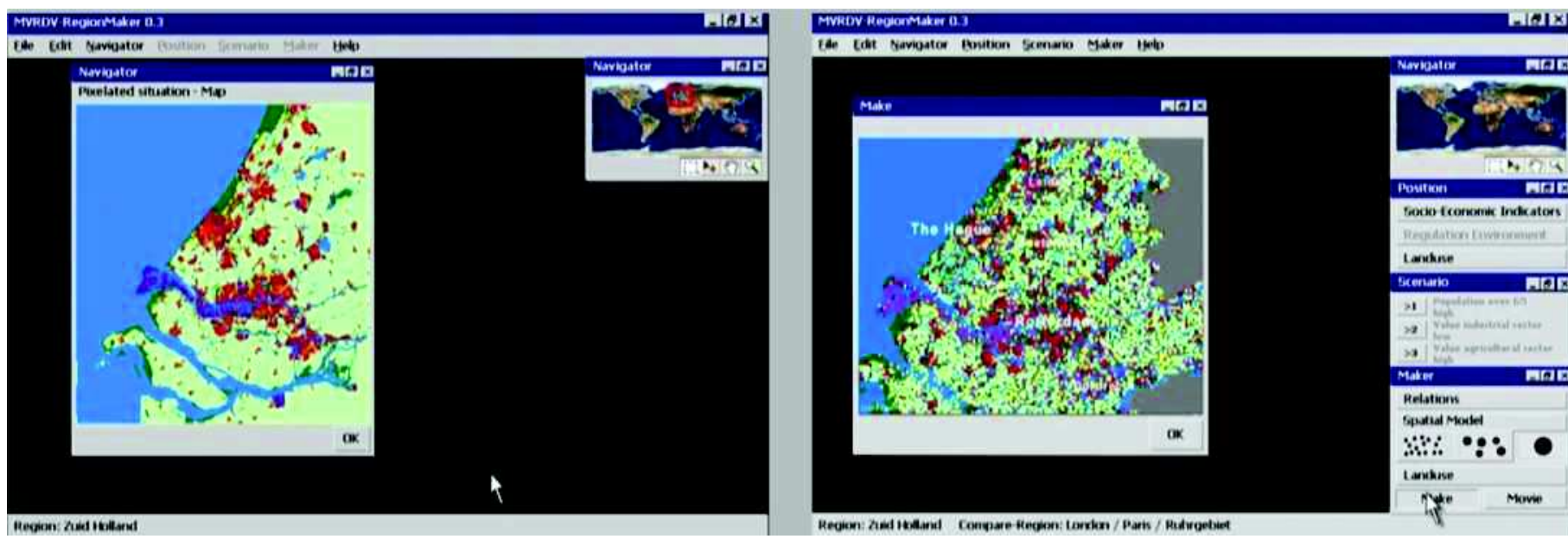

Antes e depois do processo. Fonte: filme The Regionmaker, Demo NL-ZH, MVRDV/Wieland \& Gouwens.

Observamos que os software do MVRDV se diferem das plataformas pesquisadas nos anos 60 pelo desenvolvimento das tecnologias ao longo das décadas que os separam. Na atualidade a internet funciona como uma importante ferramenta de comunicação, armazenando dados e difundindo esse conhecimento. O MVRDV buscou desenvolver plataformas complementares para solucionar os entraves dos software, mas a limitação encontrada nos dias de hoje diz respeito à dinâmica da sociedade contemporânea com uma constante produção de informação. Os programas dedicados à ambientes restritos, como o Masterprogrammer, com um banco de dados disponível e controlado, funcionam, mas a falta de domínio das informações instáveis e incertas do restante do mundo ainda é um obstáculo.

Os software podem oferecer múltiplas possibilidades de soluções, mas fica a cargo do arquiteto escolher em que momento o processo precisa ser congelado. Essa ideia se fortalece através da nossa experiência ao utilizar o Optimixer. ${ }^{27}$ Mesmo tratando-se de uma versão simplificada e com quantidade menor de parâmetros para serem ajustados, a produção de soluções mostrou-se infinita e coube a nós decidir quando parar o processo. Durante esta atividade, foram produzidos três cenários distintos (conforme figuras abaixo), que sobrepostos geraram a imagem de capa desta dissertação.

${ }^{27}$ O livro KM3 inclui DVD com uma versão demonstrativa do software Optimixer. 
Outro ponto relevante sobre os software do MVRDV é que para se pesquisar mais sobre determinado assunto, outros parâmetros devem ser adicionados e, então, novas possibilidades surgirão, num ciclo sem fim de respostas que o projetista necessita escolher. Observamos que, por enquanto, tornar os software mais completos, é uma tarefa complexa, pois exige o domínio de um banco de dados global, incompleto e instável. Ainda, o programa elege as melhores hipóteses pela suas pontuações, mas é o projetista que coordena essa pontuação através dos ajustes dos parâmetros que ele decide se são bons ou não.

O avanço que podemos observar é que, sendo impossível simular o mundo, os software podem testar as ações e comportamentos e ao colocá-los num contexto é possível ver os efeitos desses eventos. Ainda não se obtém o resultado final, mas os programas economizam tempo e permitem um maior aprofundamento na pesquisa, o que pode ser um possível avanço para a introdução da ciência na arquitetura.

Nesse contexto destacamos três questões: 1- a ideia do MVRDV "everyone is a city maker", marcada pela interação do usuário no desenvolvimento de projeto, com o arquiteto assumindo o papel de coordenador nesse processo; 2- um escritório de arquitetura é o responsável por capitanear o desenvolvimento de um meio que supere as limitações até então encontradas de projeto; e, 3- este meio está diretamente vinculado à proposição da arquitetura em tempos de globalização, favorecendo a compreensão e atuação em escalas urbanas maiores e o processamento de grande quantidade de informações, rápidas análises e respostas para soluções hipotéticas.

Assim, notamos que o desenvolvimento de software é uma das formas que o MVRDV encontrou para recuperar a autonomia da disciplina, o papel de protagonista da arquitetura e coordenador do processo na interação com outras disciplinas.

Tanto com os diagramas e mais ainda com os software, a impressão que temos é que o MVRDV não revela seu processo de trabalho integralmente. Nas matérias e artigos sobre projetos a partir do ano 2000, os software não são divulgados como método; na maioria das vezes, apenas diagramas-narrativas aparecem como processo de projeto. Com poucas exceções, diagramas de negociação e programas de computador aparecem um pouco à parte dos projetos reais, permanecendo ainda mais restritos ao campo das pesquisas. A interação entre investigação e prática 
será investigada no capítulo seguinte, onde serão analisados alguns dos projetos habitacionais do MVRDV. 


\section{CAPÍTULO 3 \\ MVRDV: PROJETOS DE \\ HABITAÇÃO}


Apesar de serem três trabalhos distintos, podemos apontar uma mesma identidade nessas obras (ao contrário da ausência de uma marca que o MVRDV afirma na citação acima) que são definidas pela variedade de unidades habitacionais (na maioria diferenciadas por cores e materiais) e a presença de vazios coletivos.

A partir da identificação desses primeiros pontos, os projetos serão analisados conforme as seguintes etapas:

1. Análise de imagens, peças gráficas e textos extraídos de fontes secundárias (periódicos, livros, teses, artigos e páginas da internet). A partir daí a leitura passa a ser feita pelas partes do projeto, em um processo que leva à compreensão do todo: diagramas da fase de concepção, inserção no contexto urbano, pavimentos (visando as diferentes circulações e áreas coletivas), agrupamento das tipologias e as unidades habitacionais.

2. Análise crítica através dos conceitos chave do MVRDV: datascapes; uso misto/espaços múltiplos; naturezas artificiais; interiorização espacial; subúrbio urbano; densidade; diversidade/identidade; global/local. Por tratar-se de um trabalho teórico de arquitetura que investiga a habitação contemporânea, as análises focarão mais a produção de espacialidades do que os processos de projeto.

3. Produção de peças gráficas analíticas para enfatizar pontos importantes dos projetos.

É importante ressaltar que a ênfase dada pelos arquitetos ao processo de projeto aparece em graus diferentes no Silodam, Mirador e Parkrand. A relação entre pesquisa e projeto se reflete nas informações e nos materiais divulgados de cada obra e a exploração projetual alcança níveis distintos em cada uma deles. 


\subsection{Silodam}

"O Silodam foi nossa chance de fazer um projeto com uma nova tipologia... de desafiar o que era considerado típico, econômico, racional e normal na Holanda." (MVRDV em MVRDV Buildings, p.68, tradução nossa).

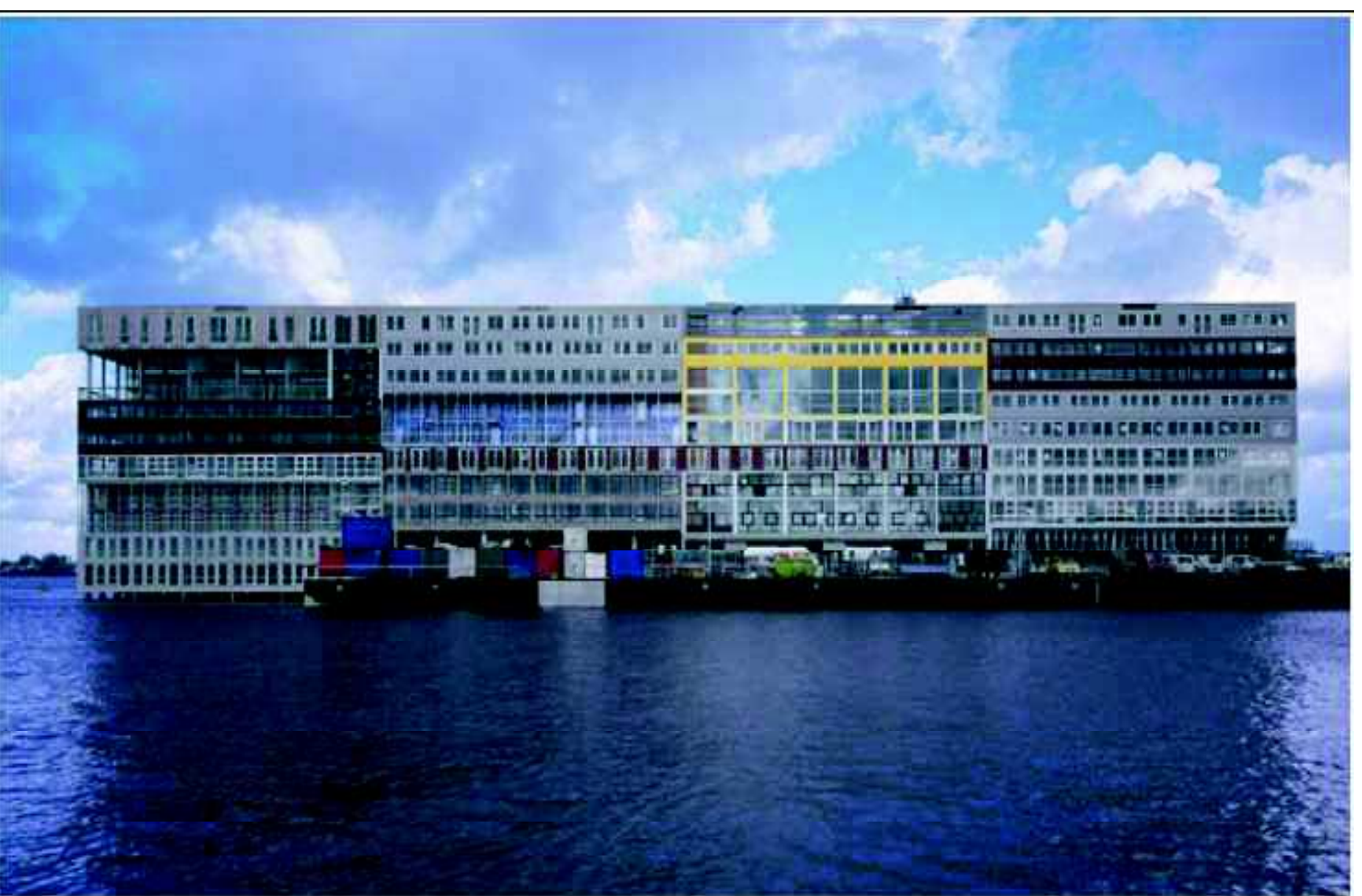

Silodam. Fonte: El Croquis.

Localização: Amsterdã

Data: 1995-2003

Cliente: Rabo Vastgoed, Utrecht NL e De PrincipaalB.V

Programa: $19.500 \mathrm{~m}^{2}, 142$ apartamentos para venda + 15 apartamentos para locação (22 tipologias) + $600 \mathrm{~m}^{2}$ de área comercial, marina para pequenos barcos e dois estacionamentos automáticos com 109 vagas

Orçamento: EUR 16.8 milhões (EUR 861/m²)

Uma operação urbana foi iniciada na zona oeste de Amsterdã para adensar a cidade e atender as demandas por habitação. Por ser uma área vulnerável, essa 
ação teve altos custos com diques, fundações e retrofitings. Assim, para financiar tal operação, foi construído o Silodam com 142 apartamentos para venda e 15 para locação.

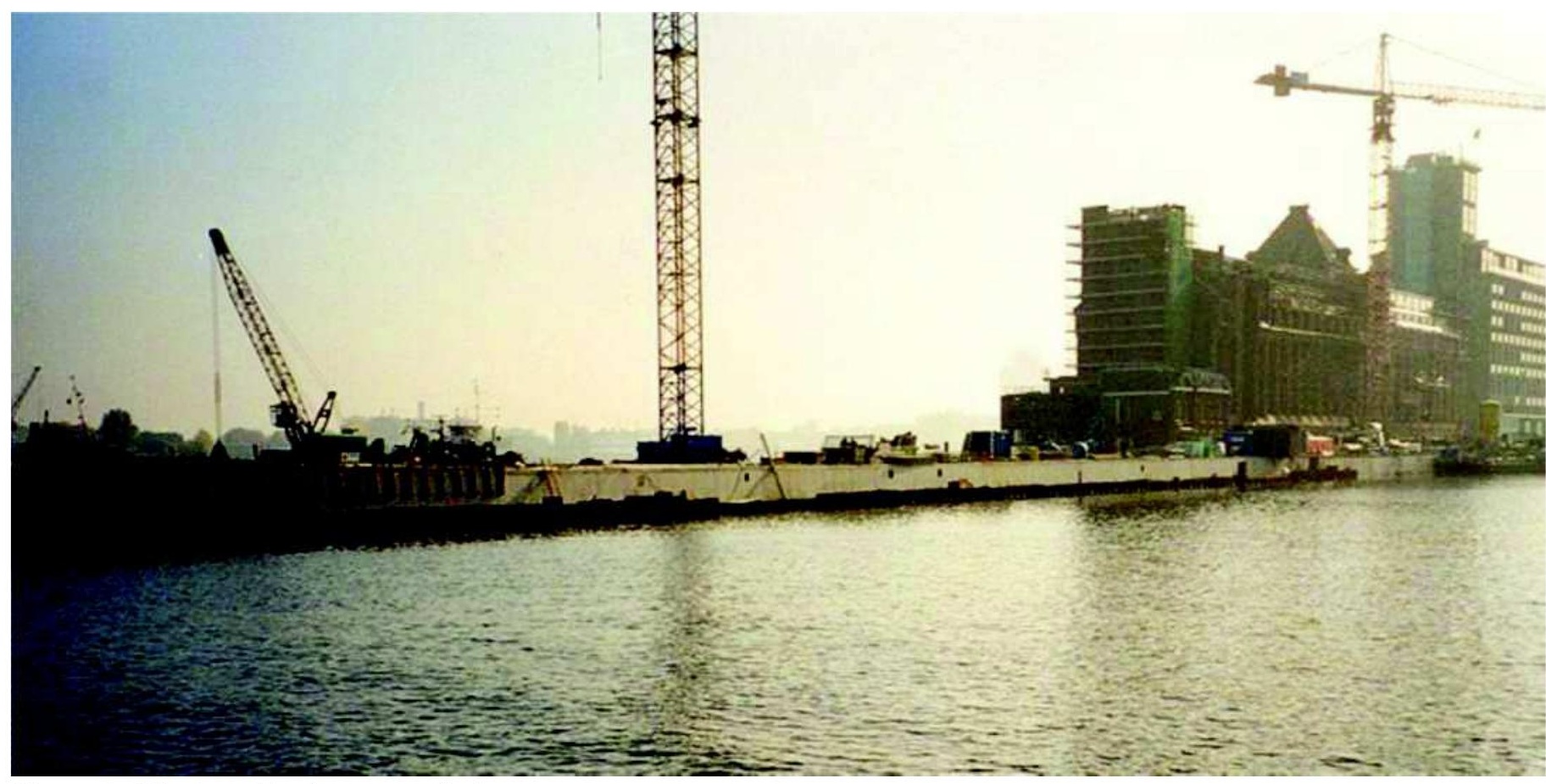

Obras do Silodam. Fonte: www.silodam.org

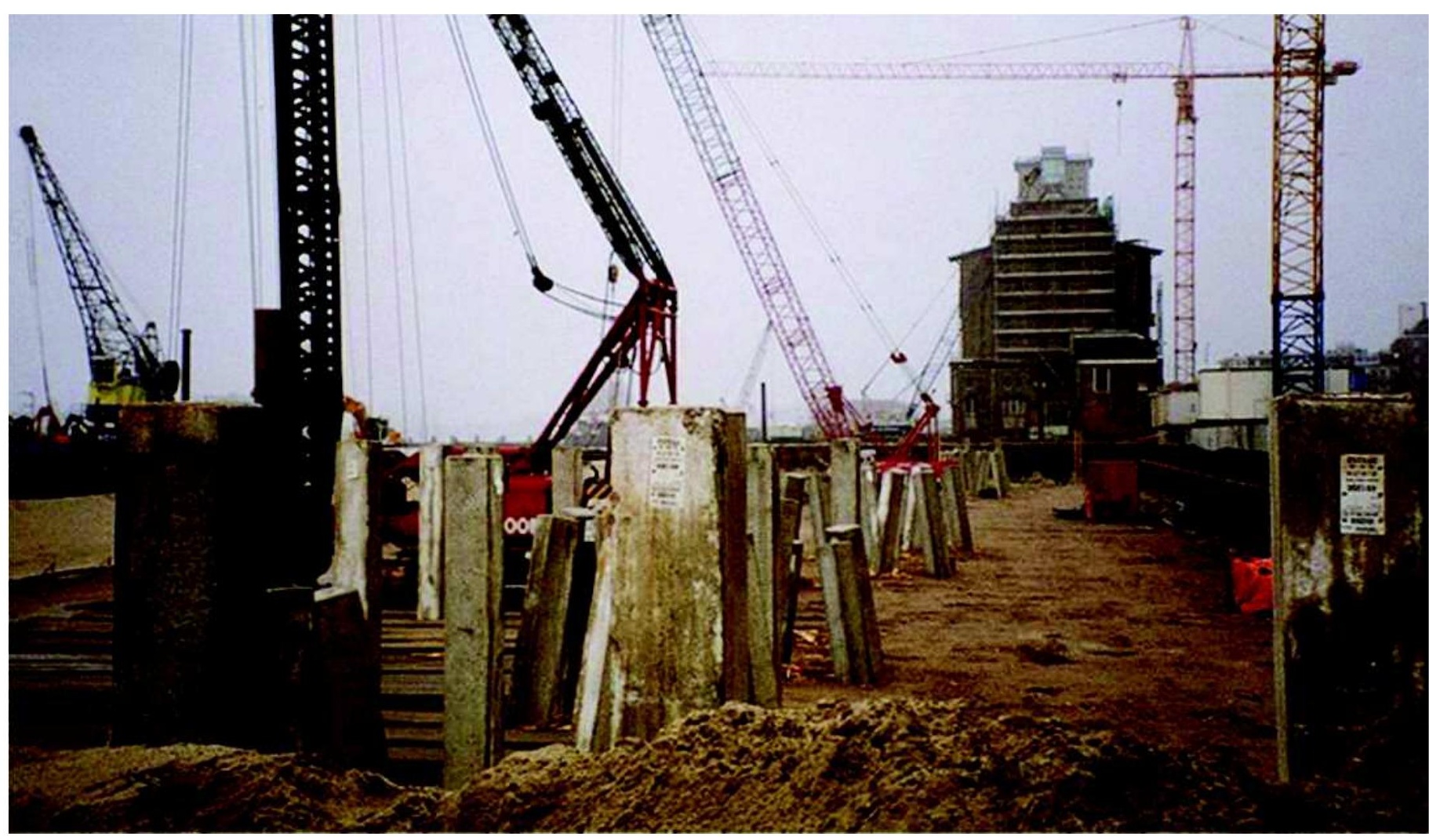

Obras do Silodam. Fonte: www.silodam.org 
O Silodam é um edifício de uso misto, constituído por apartamentos, escritórios, área comercial e espaços coletivos. O edifício é dividido em quatro torres conectadas com diferentes plantas e um módulo de 5,4 metros mostra uma repetição organizada das unidades. Três núcleos de escada e elevadores servem as quatro torres e essa circulação vertical se conecta a uma rede de circulação horizontal que muda em cada pavimento (corredores internos, corredores na fachada, galerias, corredores com pé direito duplo, etc), o que gera um tipo específico de estrutura de habitação e fachada.

O edifício tem diferentes tipologias que variam de tamanho na profundidade, nos módulos e no pé direito. Essa diversidade de apartamentos é organizada em "mini bairros" de quatro até oito unidades, dispostas na horizontal ou vertical. As habitações contam com área externa, podendo ser varandas, terraços, galerias ou pátios e a maioria com vista panorâmica do rio IJ.

Os percursos coletivos do edifício incluem uma grande escada aberta que tem acesso da rua, a marina, o deck, as galerias envidraçadas dos andares mais altos e os corredores coloridos de cada mini bairro, no entanto, muitos dos espaços públicos originais do projeto foram deixados de lado por questões de viabilidade financeira.

\begin{tabular}{|c|c|c|c|}
\hline LOFTS & HUTS & PATIO & \multirow{2}{*}{ MAISONETTE } \\
\hline \multirow{2}{*}{ GYMNASIUM } & HOBBY & \multirow{2}{*}{ X-HOUSE } & \\
\hline & \multirow{3}{*}{ UNITE } & & OFF BEAT 3 ROOM \\
\hline PANORAMA & & \multirow{2}{*}{ BALCONY } & PANORAMA \\
\hline PANORAMA & & & GARDEN HOUSE \\
\hline HOBBY & SENIOR & SENIOR & \\
\hline VALERIUS HOUSE & $\frac{\text { STUDIOS }}{\text { STUDIOS }}$ & LIVE \& WORK & $\frac{\text { DOORZON }}{3 \text { BEDROOM FLAT }}$ \\
\hline \multirow[b]{2}{*}{ VENETIAN WINDOW } & HALL \& TRAY & \multirow[b]{2}{*}{ MARINA } & FAMILY HOUSE \\
\hline & STORAGE & & LIVE \& WORK LOFT \\
\hline
\end{tabular}

Diagrama das primeiras ideias com espaços coletivos como o ginásio. Fonte: www.mvrdv.nl

\section{Datascapes na prática projetual}

A necessidade de trabalhar com um grande número de informações levou o MVRDV a utilizar gráficos e diagramas para visualização e apresentação desse material. Os arquitetos utilizaram dois tipos de diagramas para testar diferentes simulações e 
ajustá-las conforme necessário. Um deles é um corte esquemático do edifício que, organizado em datas, registra a evolução das negociações, mostra a localização, qualidades e quantidades das tipologias. A apresentação desse material nas reuniões facilitou as tomadas de decisões junto aos clientes e a comunidade. Outro diagrama, um complemento do primeiro, surgiu como medida de controle econômico para que os interesses financeiros não comprometessem as escolhas feitas a partir do primeiro diagrama. Através de uma curva de Gauss foi estabelecida a combinação ótima do tamanho das tipologias.

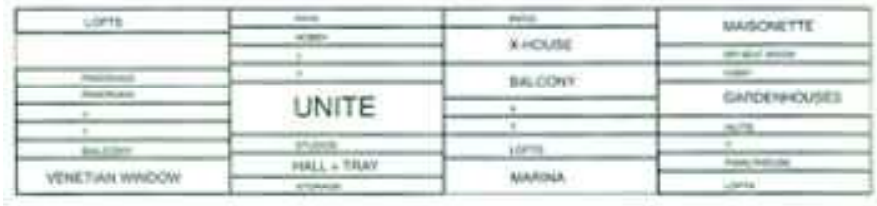

mons

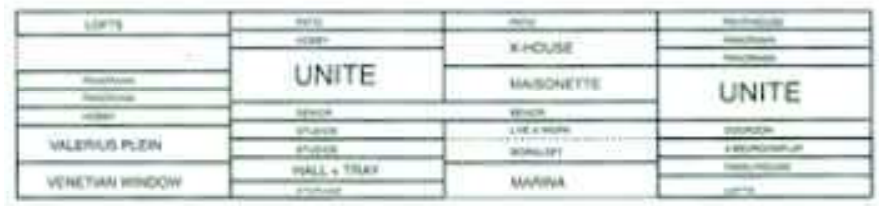

man

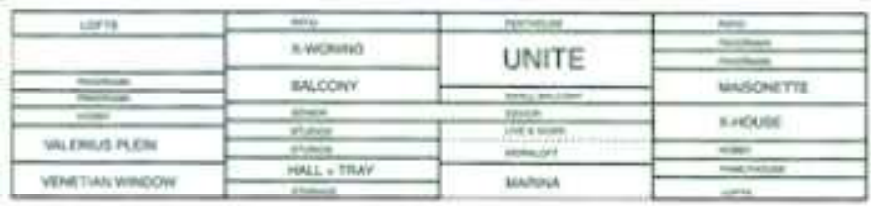

aosest

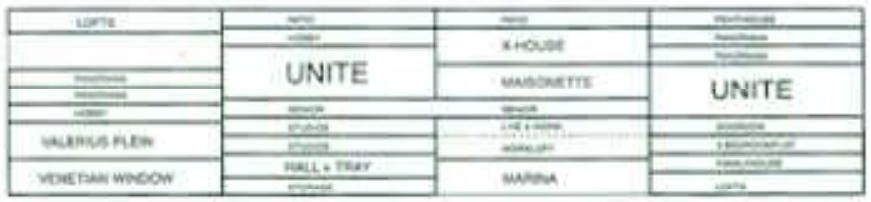

moss

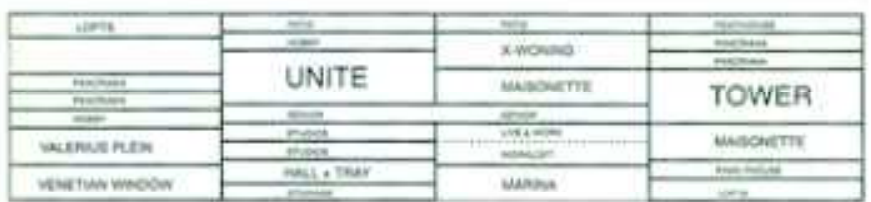

How

\begin{tabular}{|c|c|c|c|}
\hline $\operatorname{ton}$ & $=$ & 7 & $=$ \\
\hline Arnons & sucuet & \multirow{2}{*}{ UNITE } & $=$ \\
\hline 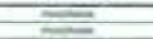 & swiconr & & Xebune \\
\hline$=$ & 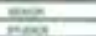 & $\operatorname{sen}$ & tenotertm \\
\hline wethusmis & $\pi$ & Din & $\approx$ \\
\hline vaervas wacow & helictiner & menes & 5 \\
\hline
\end{tabular}

zover

Corte esquemático em datas diferentes mostrando a evolução dos ajustes econômicos através das combinações e localização de tipologias. Fonte: FARMAX.
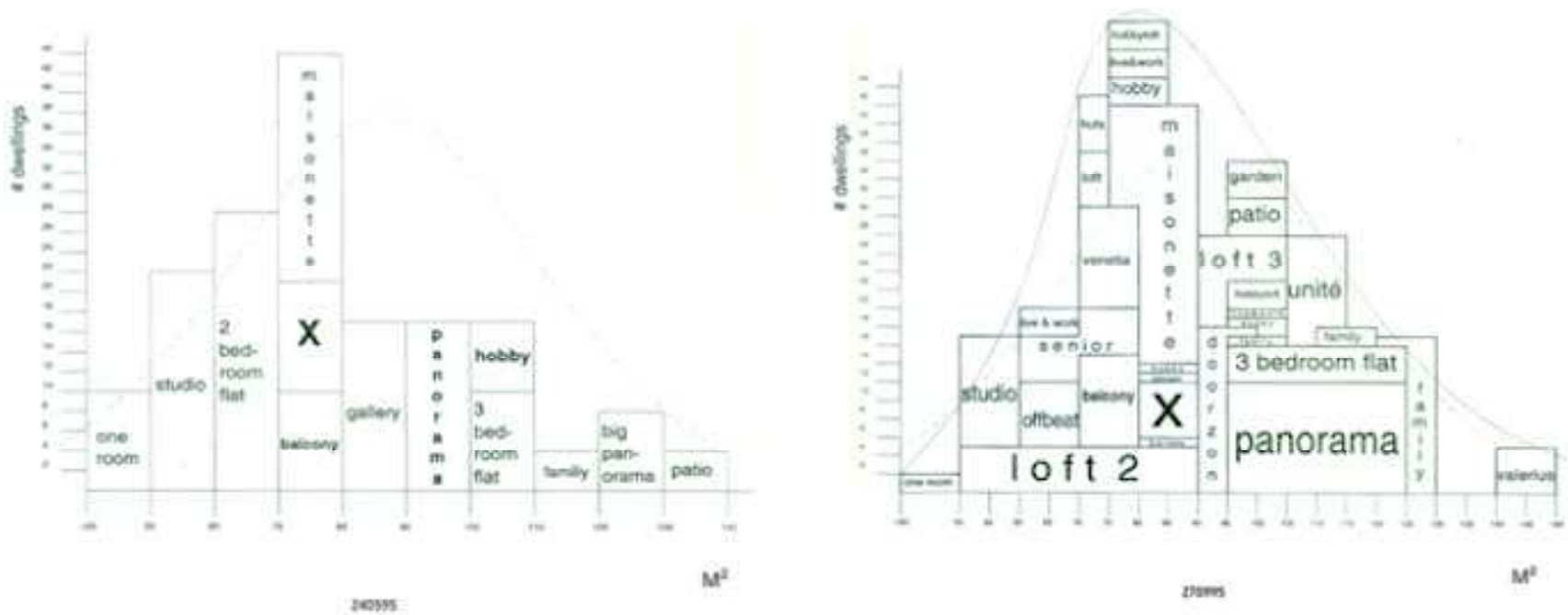

Negociações econômicas. Combinação ótima dos tamanhos das tipologias. Fonte: FARMAX. 


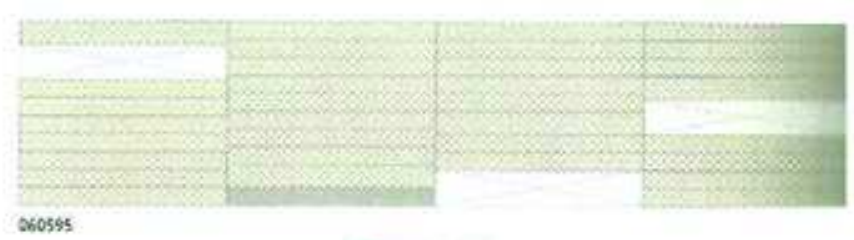

Monoculture?

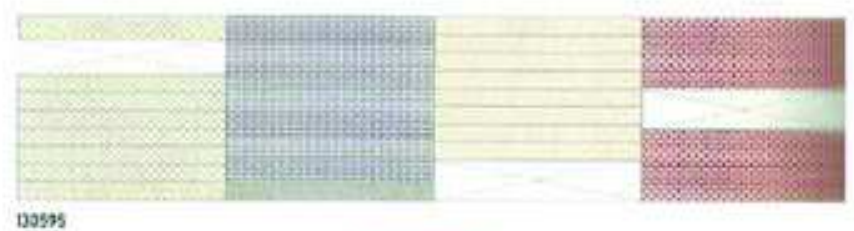

Apartheid?

Negociações políticas. Fonte: FARMAX.

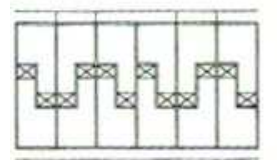

Habitaçāo

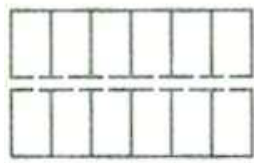

Habitaçäo

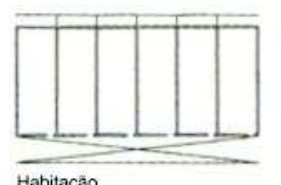

Habitaçăo

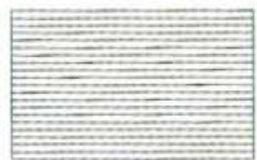

Terraço

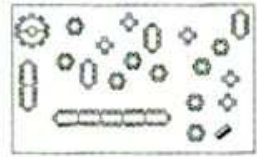

Restaurante

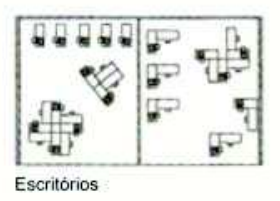

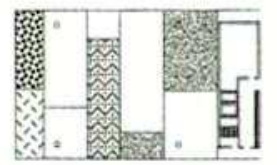

Lotes

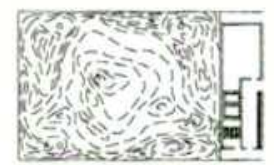

Caixa de areia

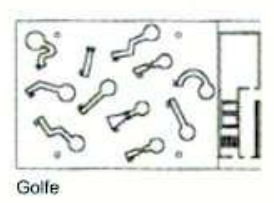

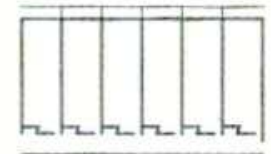

Habitaçăo
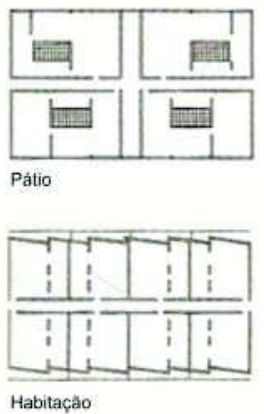

Social stratification?

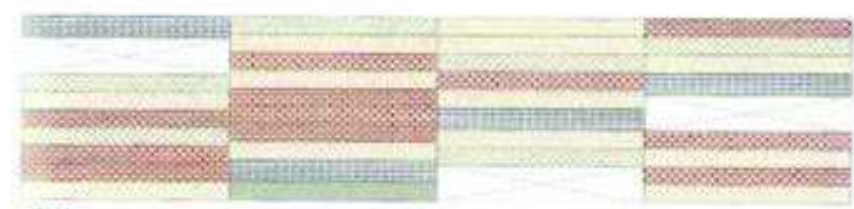

Mix ?

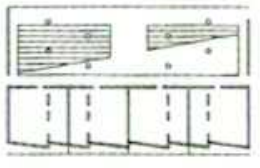

Pequenos estúdios
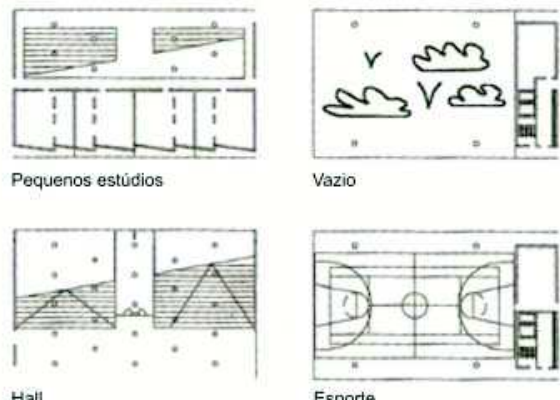

Hall

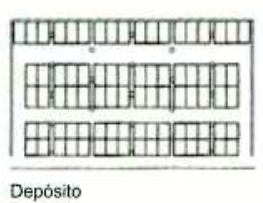

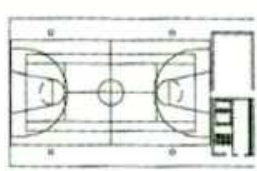

Esporte

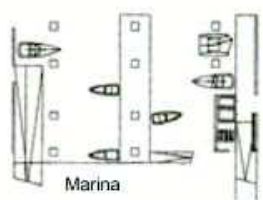

Diagramas iniciais com espaços públicos. Fonte: FARMAX.

Os "diagramas-negociações" são utilizados como ferramenta de posicionamento e avaliação das informações de todo contexto. Agem como um instrumento facilitador durante o processo de projeto, pois sintetizam uma realidade complexa, possibilitando que os arquitetos participem integralmente das negociações sobre o programa. Mediando e paralisando o processo de geração de propostas quando necessário, o arquiteto deixa de atuar apenas como projetista de edifícios e passa a operar também como político ativo nas tomadas de decisões relativas ao espaço e ao desenvolvimento urbano. É como se o edifício finalizado incorporasse os dados 
da realidade e refletisse seu contexto naquele momento (MORAIS; SPERLING, 2013).

Observamos neste projeto que os diagramas funcionam como representação gráfica da lógica geradora do Silodam comparável ao script de um algoritmo. Eles são uma espécie de comunicação espacial e visual constituída pelo programa do projeto dividido em diferentes escalas e subdivisões: torres, mini-bairros, tipologias e subdivisões internas das unidades habitacionais. O embasamento em algoritmos não aponta para seu uso a partir de programas de computador, mas a partir de procedimentos analógicos assentados em uma lógica informacional vinculada à cultura digital (MORAIS; SPERLING, 2013).

Segundo o MVRDV as reuniões com clientes e possíveis usuários permitiram o confronto de ideias entre os participantes. Enquanto um sugeria um edifício monocultural, outro rebatia essa possibilidade e quando um terceiro indicava a separação das tipologias, outros modelos eram apresentados para confrontar a proposta (MVRDV, p.535, 1998). Esses debates ficaram registrados na evolução dos diagramas e se refletem na solução final do edifício. Porém, observamos que esse movimento participativo para na porta das tipologias. Não há evidências da participação dos usuários no desenho das unidades habitacionais (que têm programas bem tradicionais, conforme verificaremos nos próximos tópicos), o que nos faz pensar em duas possibilidades: 1- o MVRDV, retomando a ideia de suportes de Habraken, toma o conteúdo como um elemento independente da estrutura, desenvolvidos em momentos distintos, 2- diferente dos espaços coletivos, as tipologias não tem grandes inovações, talvez por esbarrarem em questões políticas ou culturais.

\section{Inserções de uso misto/espaços múltiplos}

Desde o início, o principal conceito do Silodam era combinar escritórios, áreas comerciais e espaços públicos em convivência com as habitações, um programa que deveria ser inserido dentro do bloco de 20 metros de profundidade com dez andares de altura gerando economia e liberando espaço para outras funções. Os primeiros diagramas mostravam várias atividades para uso público, como quadra de esportes, golfe, restaurante e até uma caixa de areia que não foram levados adiante. Ainda assim, com os espaços coletivos remanescentes (marina, deck e galeria para uso dos moradores; escadarias, hall e área comercial com acesso 
público) continuam existindo soluções arquitetônicas que buscam relacionar a habitação ao espaço público. Até mesmo as áreas externas dos apartamentos (varandas) têm, em sua maioria, configurações que as aproximam da rua sem demais barreiras (por exemplo, as varandas das unidades de locação, com acesso direto da rua). As áreas de circulação também assumem um papel de espaço de convivência por suas diversas características e localização dando continuidade à ideia de rua que permeia o edifício. Os espaços de uso exclusivo dos moradores podem ser acessados pelo público mediante visita agendada na página da internet www.silodam.org, um registro online que mostra a gestão organizada desse ambiente.

Notamos que o processo de projeto e o resultado final dos espaços coletivos no Silodam posicionam a arquitetura como ferramenta de desenho e gestão da cidade, elevando o papel da habitação de célula unifuncional para um possível articulador do complexo urbano.

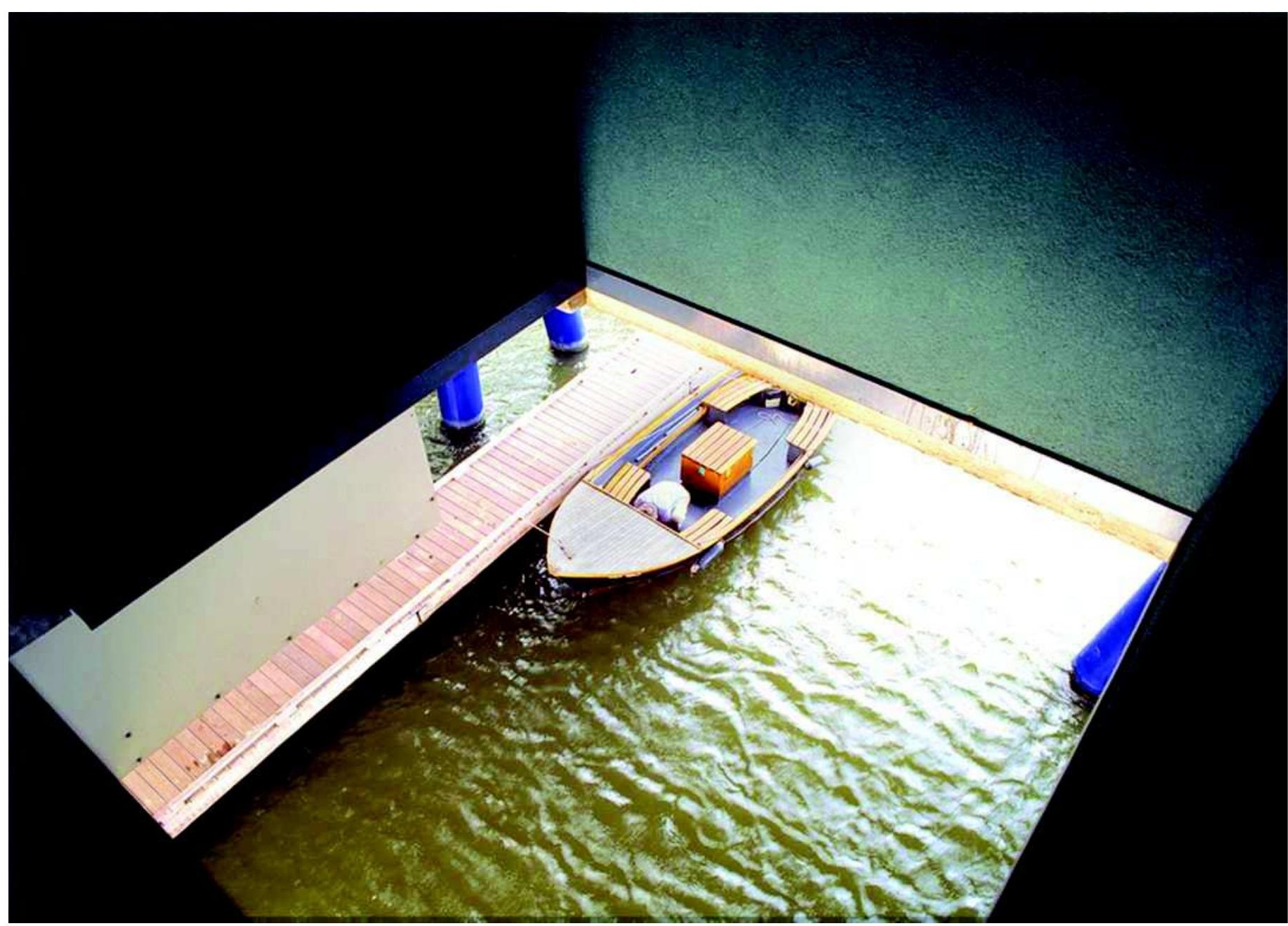

Vista da marina. Fonte: www.mvrdv.nl 


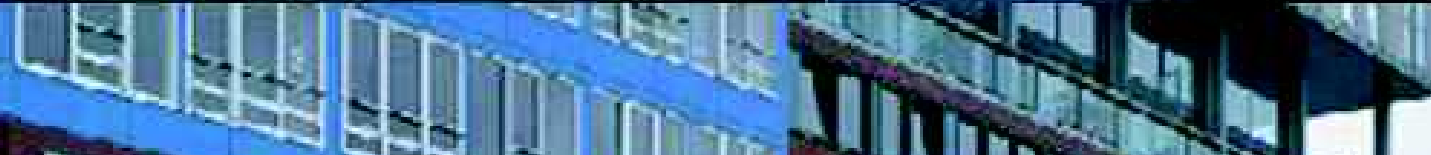

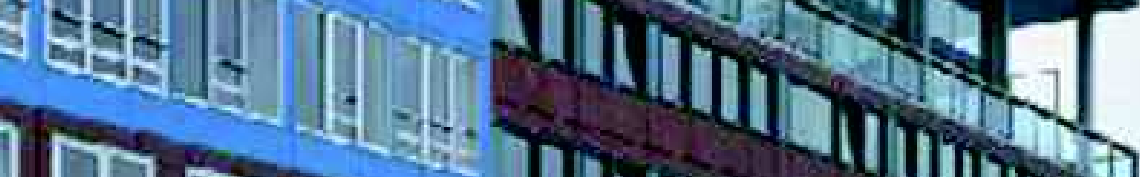

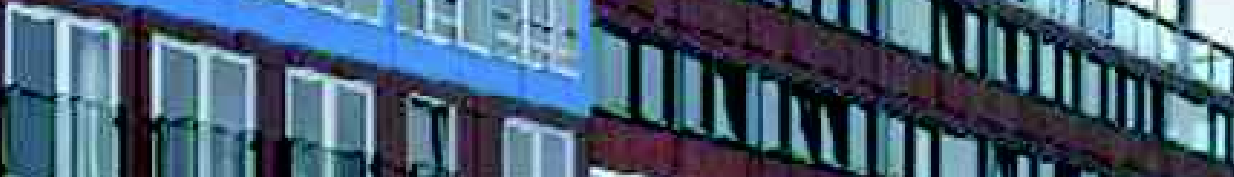

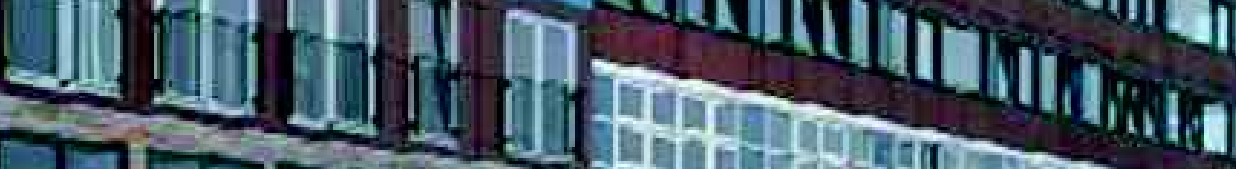

J月明旺

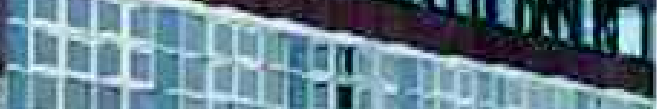

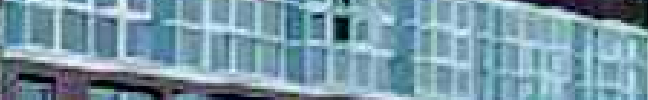
7170070
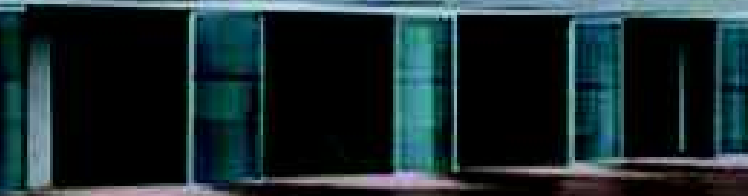

1.1. 


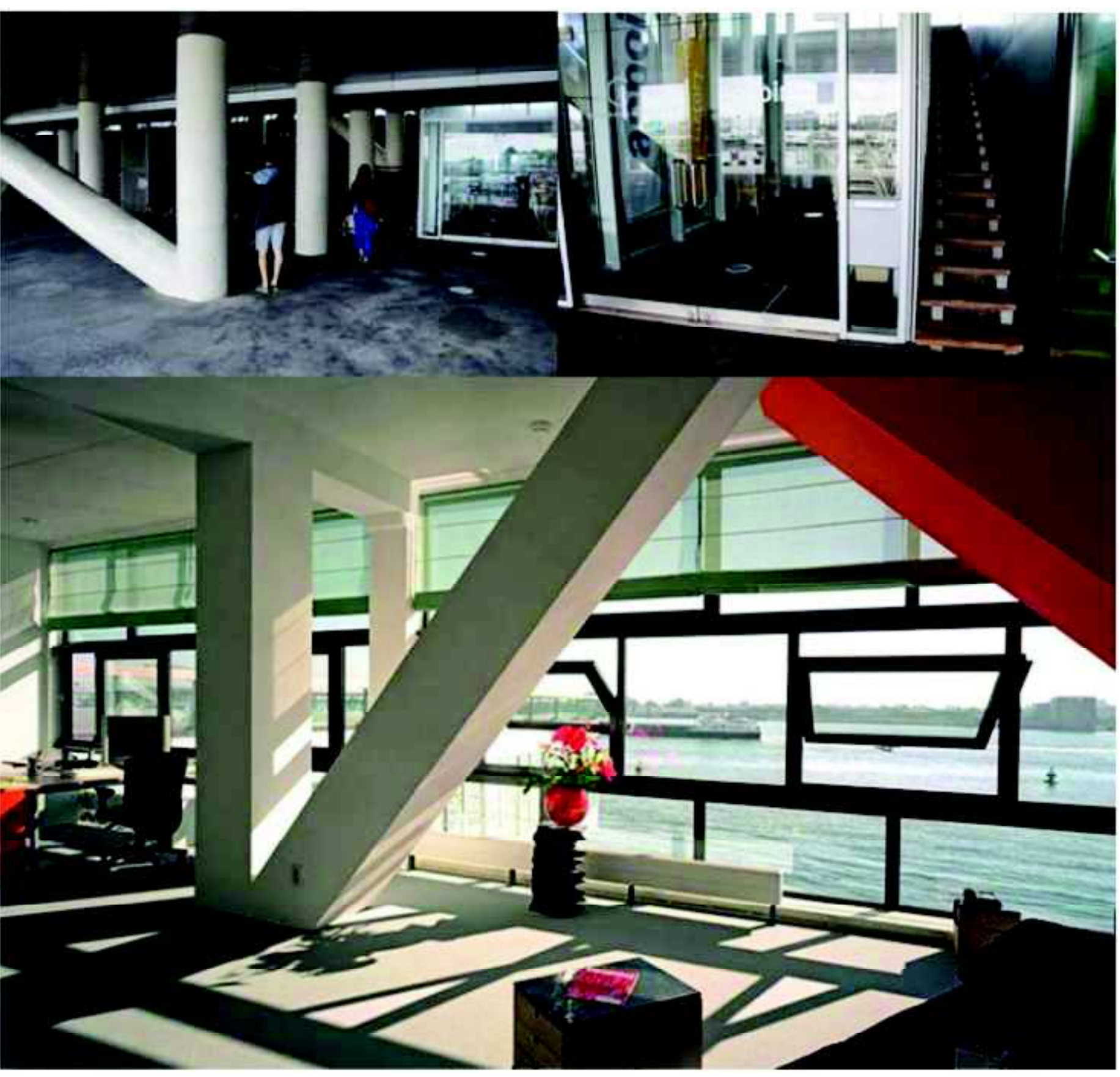

Área comercial e espaço coletivo. Fonte: www.flickr.com, usuário Philip Szymanski. Unidade com espaço de trabalho. Fonte: www.mvrdv.nl 


\section{Naturezas artificiais: criando espaço}

Diferente dos jardins da Vila VPRO que criam uma ligação interior-exterior, no Silodam a vegetação não aparece como elemento integrado ao projeto. Aqui, a natureza artificial é uma atividade urbana necessária para gerar espaço.

Como na tradição holandesa de ocupar o mar, alavancada pelo desenvolvimento de tecnologias para instalação de diques, o Silodam é implantado em um solo artificial criado para ele. Visto de longe, o edifício passa a ideia de reversibilidade, parece estar atracado ao píer como uma estrutura temporária de contêineres, mas, de perto, fica evidente que a construção do edifício se mescla às obras de infraestutura que fabricam um terreno artificial dentro do rio IJ para recebê-lo.

Notamos a ocupação de uma área "não urbanizável", uma inserção estratégica na paisagem diferente da vocação portuária do local graças à sua boa localização, ideal para atender as demandas por habitação da cidade e qualificar a área do porto.

Ao mesmo tempo em que esse manejo da natureza requer obras pesadas, observamos o quanto ela poupou a necessidade de mais espaço. Considerando que o Silodam é a decomposição de uma fatia da paisagem urbana, que ao invés de ter suas casas umas ao lado das outras, empilha as unidades em um único volume, o projeto cria espaços na verticalidade e libera o Rio IJ de maiores intervenções.

\section{Interiorização espacial: a cidade no edifício}

A circulação na Unitè d'Habitation, com a ideia de rua interna que se repete nos pavimentos, é revista no Silodam através de caminhos internos diferente em cada andar. $\mathrm{O}$ conceito inicial que tratava esses percursos como uma continuação da rua com acesso irrestrito não funcionou completamente na prática da pós-ocupação por questões políticas, mas alguns dos seus espaços coletivos ainda podem ser acessados livremente, como as escadarias, o hall e a marina, sendo que esta última também assume papel de acesso/entrada ao edifício.

A presença de espaços intermediários abertos no projeto potencializa a relação habitação/cidade e os tornam espaços de socialização, além disso, existem áreas dentro das unidades que se relacionam com o exterior, como varandas e terraços, de modo que se estabeleçam relações visuais entre a rua e a habitação.

O Silodam apresenta, portanto, três tipos de espaços: espaços de domínio público, espaços de domínio privado e espaços intermediários que dissolvem os limites entre cidade e a habitação.

Aqui, a interiorização espacial ainda tem a função de articular e comunicar as quatro torres que formam seu volume único através dos percursos internos e demais espaços cobertos com diferentes alturas e níveis de fechamento onde essas "ruas" se desdobram. 


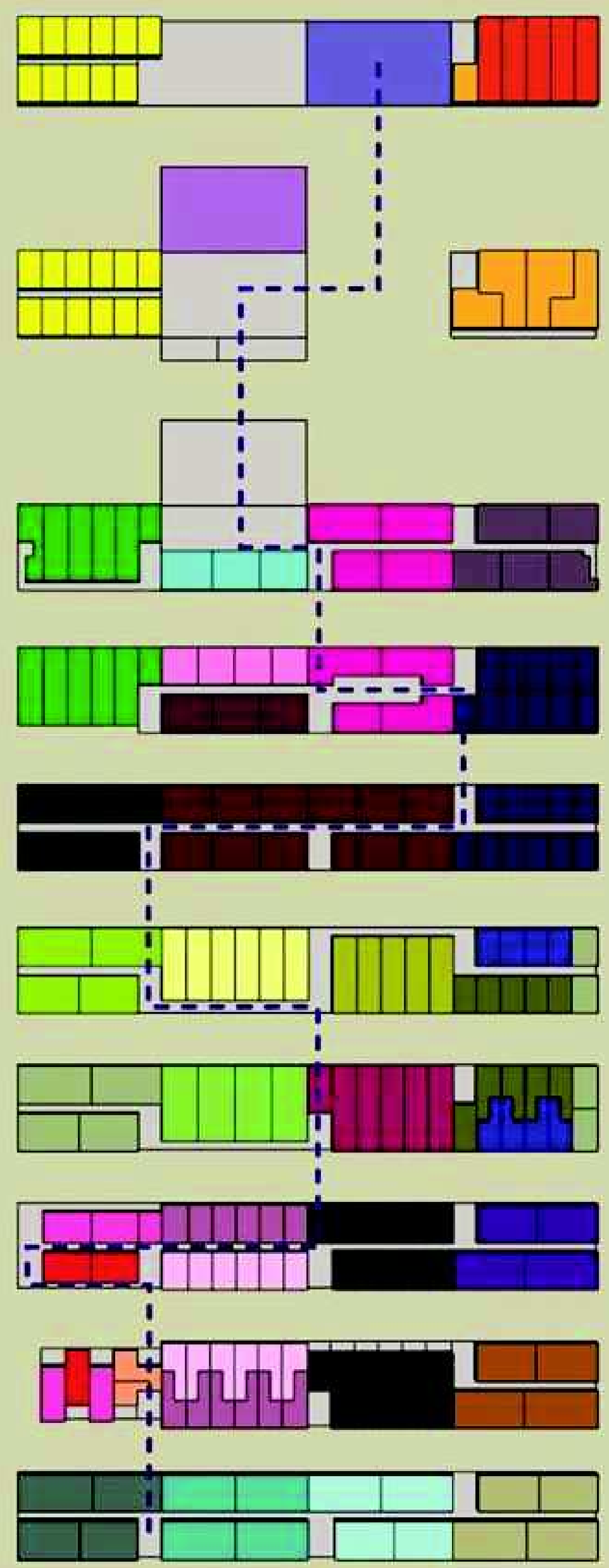

Possível rota pública a partir da marina: um dos conceitos iniciais era o acesso irrestrito aos espaços coletivos, incluindo todos os pavimentos não-tipo. Fonte: autora. 

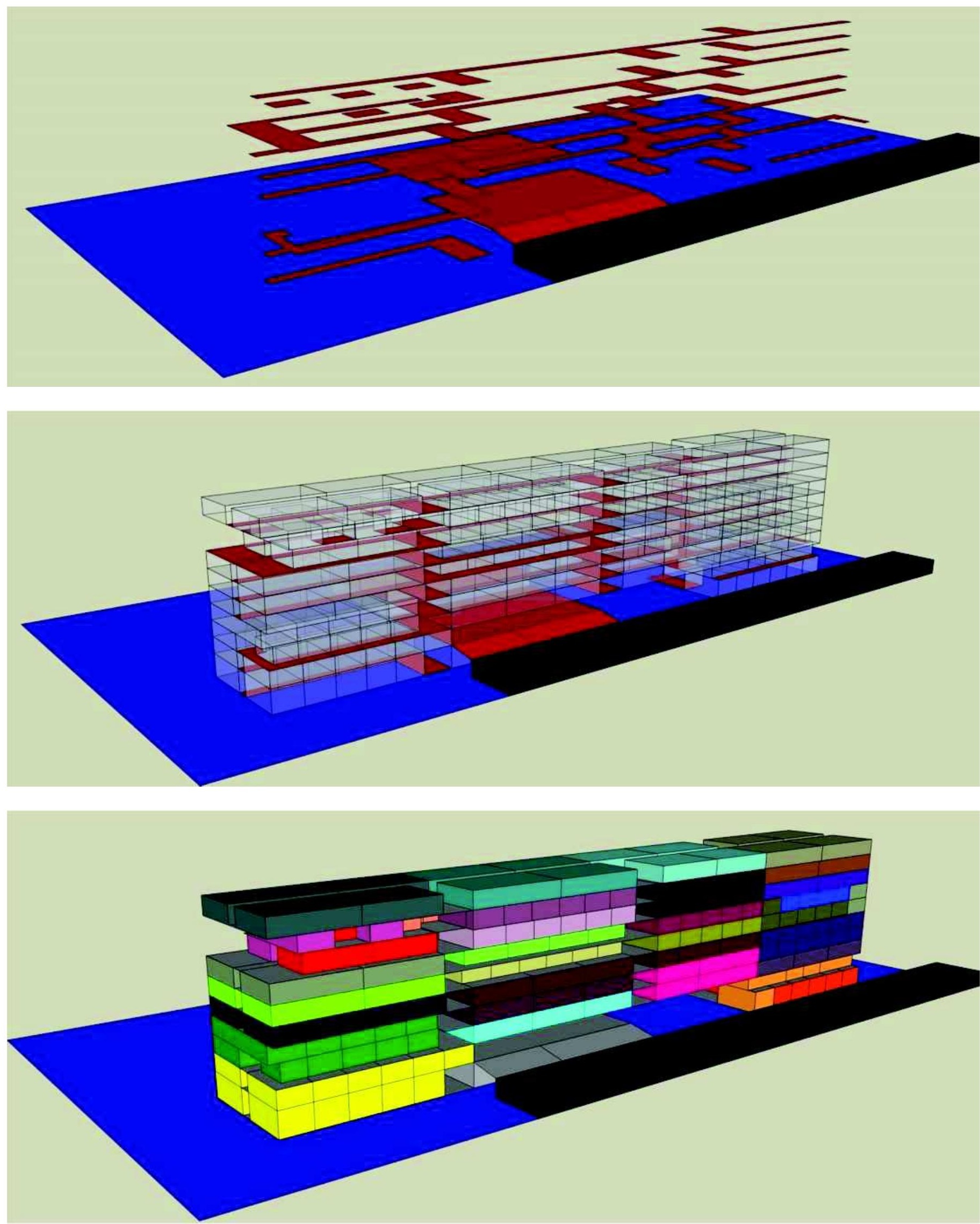

Modelo 3D: os diferentes percursos que formam áreas coletivas, as circulações entre as tipologias e a variedade de mini-bairros. Fonte: autora. 



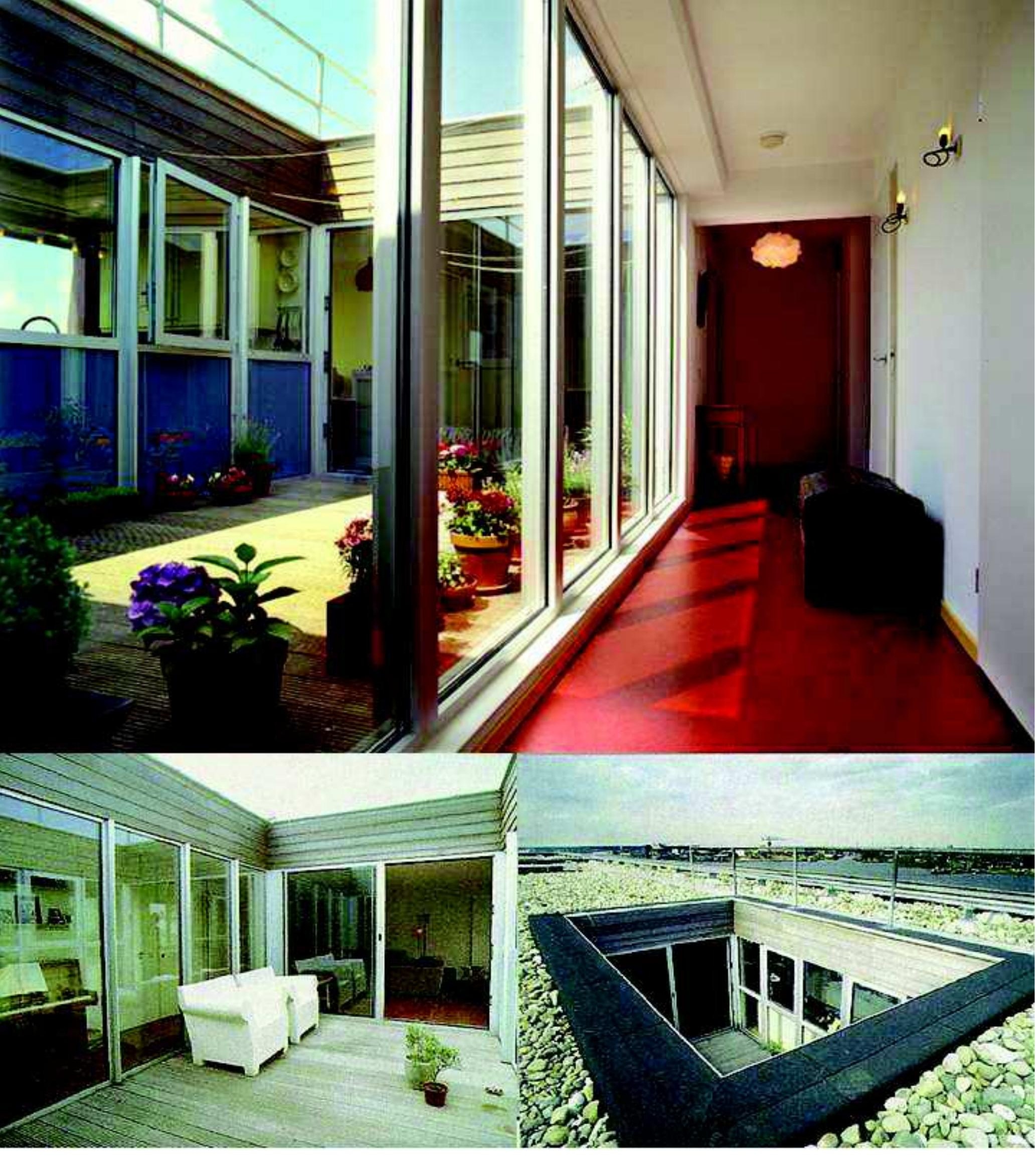

Pátio dentro de uma unidade. Fontes: www.mvrdv.nl e Farmax 


\section{Subúrbio urbano e comunidade}

Diferente do projeto 3D Garden (citado no capítulo 2), o Silodam não insere grandes jardins para tentar trazer as características espaciais e a natureza dos subúrbios. Ainda assim podemos identificar certo desenvolvimento urbano híbrido através da combinação das conveniências da localização central, a privacidade das unidades e as facilidades do estacionamento subterrâneo com a proximidade do rio IJ, a oferta de áreas externas dentro das unidades e espaços coletivos espalhados pelo edifício que incentivam a convivência entre os moradores e promovem uma sensação de comunidade.

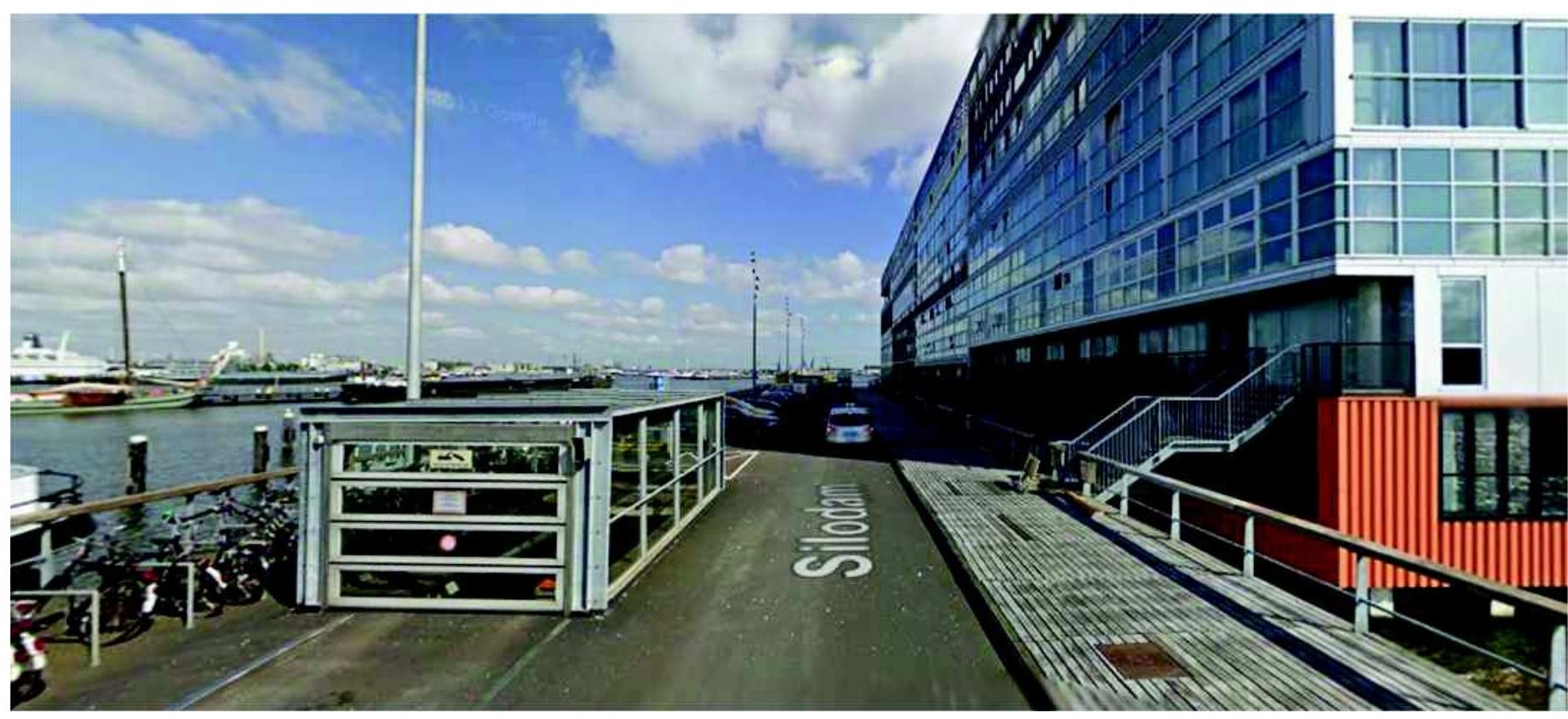

Caixa de acesso ao estacionamento automático subterrâneo. Fonte: Google Maps. 


\section{Densidade como quebra-cabeça tridimensional}

A densidade é definida pelo número de habitantes em determinada área e pode ser medida pela relação entre o número de habitações ou de pessoas por quilômetro quadrado ou hectare. Nesta pesquisa vamos utilizar as duas definições (habitações e habitantes) com o intuito de comparar a densidade dos projetos com a densidade das cidades onde estão inseridos e também investigar qual o nível de adensamento que as obras analisadas alcançam. A densidade dos projetos é calculada pela relação entre o número de habitantes do edifício e a área do terreno onde foi implantado.

Observamos nos últimos anos, e em várias regiões do mundo, políticas urbanas que incentivam a retomada de desenvolvimento nas áreas centrais das cidades e o aumento das atividades nesses espaços o que, consequentemente, leva ao aumento da densidade. Rotterdam, por exemplo, lançou em 2007 o programa 'Rotterdam Climate Initiative' a fim de conter a expansão territorial e atrair novos moradores para a área central da cidade. Já em Amsterdã - como tem acontecido também com outras cidades litorâneas da Europa, vide o projeto Frøsilos (Copenhagen, 2001-2005) do próprio MVRDV - a área portuária passou por um processo de reconversão (graças à sua proximidade ao centro, à oferta de infraestrutura, à oferta de transporte por barco, bicicleta, carro ou trem e às interessantes visuais da cidade e do rio $\mathrm{IJ}$ ) transformando-se em bairro residencial que, devido ao aumento dos preços, acabou atraindo majoritariamente uma população com poder aquisitivo mais elevado.

Com o Silodam, o MVRDV vai pensar o adensamento desse novo bairro através da verticalidade, mas sem se referenciar ao arranha-céu e sim trazendo uma escala ligada às questões da cidade tridimensional (que os arquitetos abordam no livro KM3), inserindo no gabarito homogêneo (que caracteriza o centro histórico de Amsterdã) um novo tipo de densidade.

Se densidade e uso misto são os conceitos chave do MVRDV mais mencionados em seus trabalhos, no Silodam essa lógica aparece mais uma vez com a casa tradicional ao redor de pátios agrupada e colocada na vertical em prol da liberação do solo. O edifício se assemelha, em termos de escala, aos prédios vizinhos do entorno, o que o diferencia é sua densidade elevada e ao mesmo tempo porosa: o projeto une ideias aparentemente contraditórias (compactação + inserção de vazios + variedade) graças à inserção reinterpretada de elementos tipológicos, como pátios, galerias e passarelas, diferentes em cada pavimento.

Não é a intenção deste trabalho definir índices de densidade ideais para os projetos, entretanto, é necessária a utilização de alguns números para ilustrar essas análises. 
Para isso, como primeiro método, calculamos a densidade do Silodam multiplicando o número de unidades habitacionais do projeto pelo número de pessoas que podem morar nelas $^{28}$ e obtivemos os seguintes valores:

a- Número de moradores possíveis no Silodam: 397 habitantes

b- Densidade Amsterdã (2013) 3.200 habitantes $/ \mathrm{km}^{2}$

c- Densidade Silodam: 132.000 habitantes $/ \mathrm{km}^{2}$

Por estar implantado dentro do rio IJ, não existe a delimitação de um terreno como nos projetos Mirador e Parkrand, portanto consideramos sua projeção horizontal (o espaço que ele ocupa de $3.000 \mathrm{~m}^{2}$ ) como área do lote.

Como segundo método, utilizamos a classificação de níveis de adensamento abaixo de Aurora Fernández $\mathrm{Per}^{30}$ (habitações $/ \mathrm{km}^{2}$ ) para situar o projeto entre os possíveis modos de densidade. O Silodam se encaixa na primeira categoria: elevada densidade (52.000 habitações $\left./ \mathrm{km}^{2}\right)$.

\begin{tabular}{l|l}
\hline Mais que 30.000 habitações $/ \mathrm{km}^{2}$ & $\begin{array}{l}\text { Elevada densidade. Habitação aparece associada à verticalidade como as torres nas grandes } \\
\text { metrópoles asiáticas e americanas. }\end{array}$ \\
\hline 20.000 a 30.000 habitações $/ \mathrm{km}^{2}$ & Alta densidade. Centros urbanos consolidados. \\
\hline 10.000 a 20.000 habitações $/ \mathrm{km}^{2}$ & Média densidade. Centros urbanos com blocos independentes e ampla área livre disponivel. \\
\hline 5.000 a 10.000 habitações $/ \mathrm{km}^{2}$ & Baixa densidade. O conceito de uso misto surge nas a tividades urba nas. \\
\hline Menos de 5.000 habitações $/ \mathrm{km}^{2}$ & $\begin{array}{l}\text { Baixa densidade associada as formas de ocupação de subúrbios. Os projetos originados do plano } \\
\text { Vinex tem tais caracteristicas esão, aproximadamente, } 95 \% \text { voltado para o uso residencial. }\end{array}$
\end{tabular}

A densidade alta otimiza a ocupação do solo, diminui os deslocamentos, gera economias com infraestrutura e ativa zonas de atividades urbanas que favorecem a economia e cultura. No Silodam, o MVRDV mostra a viabilidade da associação de baixa ocupação com alta densidade, diferente das visões radicais de seus estudos visionários, mas que se inicia neles.

\footnotetext{
${ }^{28}$ Para calcular o número de habitantes utilizamos o seguinte fator de conversão:

- Estúdios (apartamentos com um único espaço): 1,25 habitante/unidade

- Apartamento de um dormitório: 1,25 habitante/unidade

- Apartamento de dois dormitórios: 2,50 habitantes/unidade

- Apartamento de três dormitórios: 3,75 habitantes/unidade

- Apartamento de quatro ou mais dormitórios: 5 habitantes/unidade

PER, A. F, MOZAS, J., ARPA, J. Dbookdensity, data, diagrams, dwellings: análisis visual de 64 proyectos de viviendacolectiva. Barcelona: Actar, 2009, p.19.

${ }^{29}$ Fonte: Demographia World UrbanAreas, $10^{\mathrm{a}}$ edição anual, maio/2014.

${ }^{30}$ PER, A. F. Densidad nueva vivienda colectiva. Vitoria: A+T, 2006.
} 
Vista a partir das embarcações. Fonte: www.flickr.com, usuário Bem Thé Man

Vista a partir do rio IJ. Fonte: www.flickr.com, usuário mdiepraam

Vista a partir do rio IJ. Fonte: www.silodam.org

Vista a partir do rio IJ. Fonte: www.flickr.com, usuário Hans Jan Durr

Vista a partir do rio IJ. Fonte: www.flickr.com, usuário albert bakker
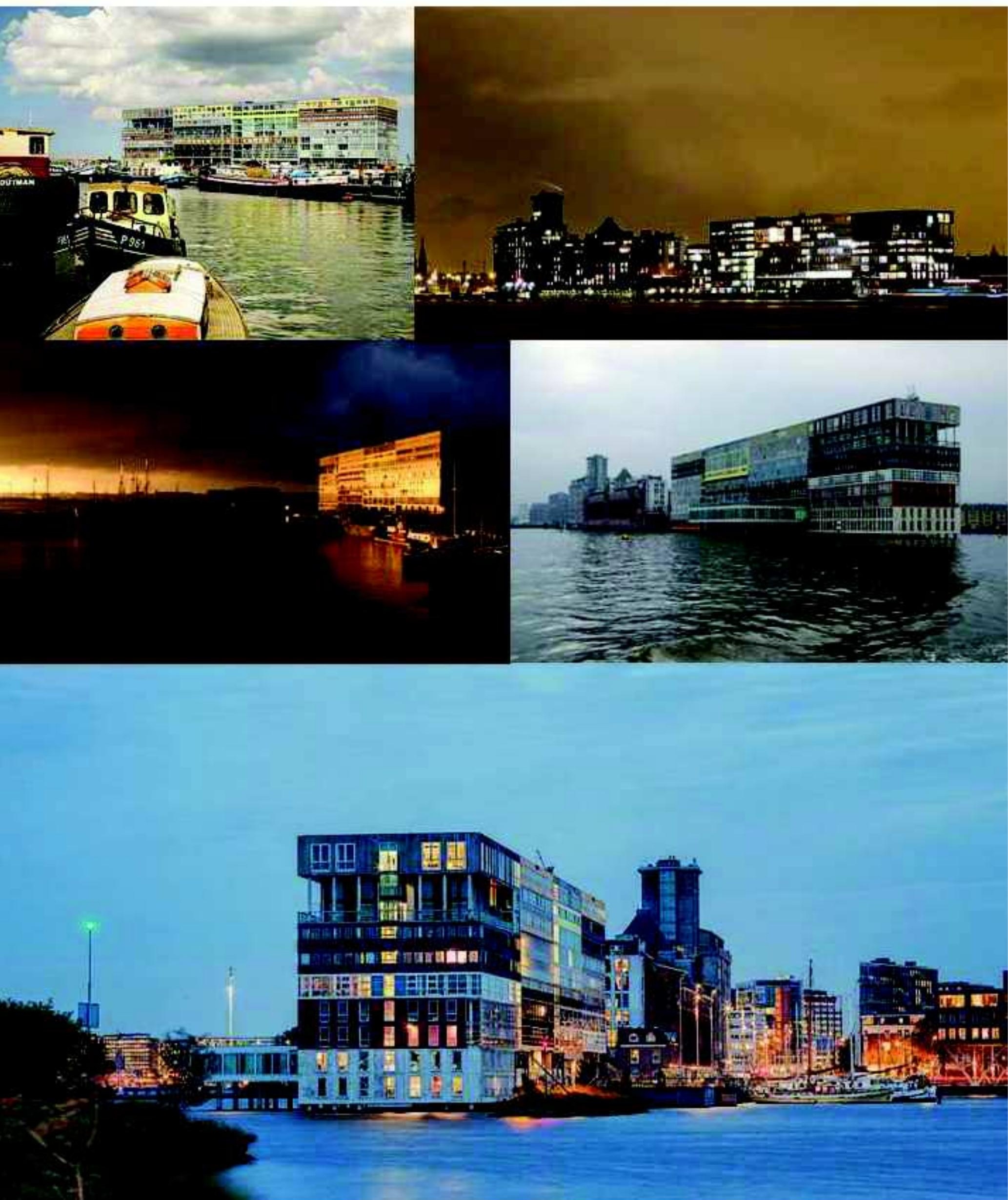


\section{Diversidade/ldentidade como cenário}

A busca por diversidade permeia os espaços do Silodam. Das circulações até as tipologias existe a clara tentativa de uma combinação das necessidades dos diferentes usuários que se reflete principalmente nas fachadas com suas cores e materiais diferentes. É um cenário de diversidade que extrapola as premissas do plano Vinex de evitar uma disseminação urbana homogênea e garantir identidades distintas aos conjuntos habitacionais.

Vale ressaltar a importância de se pensar a diversidade em conjunto com outro conceito chave do MVRDV, o uso misto, de modo que o primeiro favoreça a combinação de espaços múltiplos. Para promover essa associação, gráficos, diagramas e cortes entram como ferramenta de processo de projeto no Silodam para pensar a diversidade e a mescla de funções em altura.

O projeto apresenta 22 tipologias diferentes, alguns tipos contam com área de trabalho e todas unidades têm espaço exterior próprio, seja na forma de varandas, terraços ou pátios. As unidades se diferenciam em tamanho (70 a $\left.245 \mathrm{~m}^{2}\right)$, localização, divisão dos espaços internos, número de dormitórios (1 a 4), pé direito (2,7 a 3,6 metros), número de pavimentos, materiais construtivos (as fachadas empregam alumínio, painéis de aço, painéis de laminado resistente a água, madeira, tijolo aparente, concreto, chapas onduladas, vidro e as esquadrias são de madeira ou alumínio) e preços, tipos de janelas, áreas externas e acessos (corredor, galerias, passarelas, escadas). Os espaços domésticos são livres de hierarquias, não existem suítes nem outros espaços exclusivos, os banheiros são distribuídos em áreas comuns acessíveis a todos os moradores e apenas uma das 22 tipologias não tem cozinha integrada ao estar ou outros espaços de convivência.

No entanto, notamos que o conceito de identidade não avança para o interior dos apartamentos: por exemplo, um morador pode escolher a tipologia $x$-houses por entender que esse modelo atende às suas necessidades básicas, porém a maioria das unidades não são flexíveis o suficente para sofrer adaptações ou grandes alterações. Com exceção das tipologias mais abertas M4 (habitação com espaço de trabalho), G1 e G3 (studios) e F3 (lofts), os apartamentos têm plantas tradicionais, segmentadas em dormitórios, salas, banheiros, depósitos, etc.

$\mathrm{Na}$ maioria dos casos, a diferença entre as plantas das unidades fica restrita ao tamanho dos apartamentos e ao número de dormitórios. Nos demais aspectos identificamos uma lógica comum de distribuição dos ambientes que consiste em banheiros e depósitos na parede onde está a entrada do apartamento, com circulação de acesso aos dormitórios paralela à esse núcleo. Separadas do bloco íntimo (tanto nas unidades de um ou dois pavimentos) estão os únicos ambientes integrados que são: cozinha e sala com acesso para a varanda. 


\title{
VARANDA
}

\author{
ESTAR
}

COZINHA

\section{CIRCULAÇÃO}

\section{DEPÓSITO E BANHO}

Fluxograma: lógica tradicional de configuração das unidades. A linha vermelha representa a divisão entre área social e íntima e as linhas em azul mostram as divisões na área íntima. Fonte: autora.

Talvez a explicação para a falta de evolução nas tipologias esteja nas origens do projeto. 0 Silodam foi construído para que o lucro da venda dos apartamentos financiasse uma operação urbana em Amsterdã. Houve inclusive um tempo de espera entre projeto e início das obras para que uma maior valorização dos imóveis fosse obtida. As unidades precisariam dar lucro e, para tanto, as tipologias deveriam ser bem aceitas no mercado, assim, as plantas mais tradicionais ofereciam menor risco. Contraditoriamente, essa tradição foi inserida dentro de um modelo que enfatiza espaços coletivos inovadores.

À associação apartamentos conservadores e inovação das áreas comuns foram adicionados os fatores "design assinado" e marketing. Tal combinação se sobrepôs à 
invenção tipológica e acabou atraindo um público alvo diferente daquele considerado nas discussões iniciais do projeto. O Silodam parte de um estudo sobre preferências e necessidades de diversos usuários, tentando atender as demandas da sociedade atual desenvolve 22 tipologias diferentes, mas no fim o edifício é majoritariamente habitado por um só tipo de morador: profissionais urbanos bem sucedidos financeiramente propensos a seguir tendências de design e tecnologia, uma espécie de novo yuppie. ${ }^{31}$

Uma pesquisa que realizamos em páginas da internet de imobiliárias locais nos ajudou a embasar essa ideia não só pelos valores praticados ${ }^{32}$ para venda e locação, mas também pelas fotos dos apartamentos depois de ocupados, bem equipados e mobiliados. Uma unidade de três dormitórios é locada por 2.500 euros e pode ser comprado a partir de 340 mil euros.

Uma análise mais detalhada das unidades habitacionais é feita a seguir. Na sequência, são analisadas as plantas de cada pavimento do Silodam. Foram destacadas as áreas coletivas, os apartamentos e as áreas comerciais representadas pelas cores vermelho, azul e amarelo, respectivamente. Essa atividade foi importante para a leitura da etapa que relatamos na sequência: os mini-bairros e o agrupamento das tipologias.

Esses mini-bairros são conectados pela circulação. As diferentes tipologias e a inserção de um programa misto, além da própria forma, o uso de cores nos permitem associar o Silodam à Unité d'Habitation, no entanto, diferente dos corredores internos repetidos do projeto de Le Corbusier, na obra do MVRDV notamos uma revisão da verticalização: as circulações não seguem um padrão e não há pavimento-tipo. Os percursos horizontais e verticais funcionam como ruas que interligam apartamentos e áreas comerciais que não estão somente espalhados pela cidade, mas também compactados nesse único volume. Ainda, nota-se um senso de coletividade na utilização conjunta das caixas de escada e elevadores, sem privilégios ou espaços exclusivos para os apartamentos maiores.

${ }^{31}$ Expressão dos anos 1980 e 1990 que denomina jovens profissionais urbanos, geralmente de classe média alta ou alta.

${ }^{32}$ Valores de junho/2014 encontrados em http://www.funda.nl 

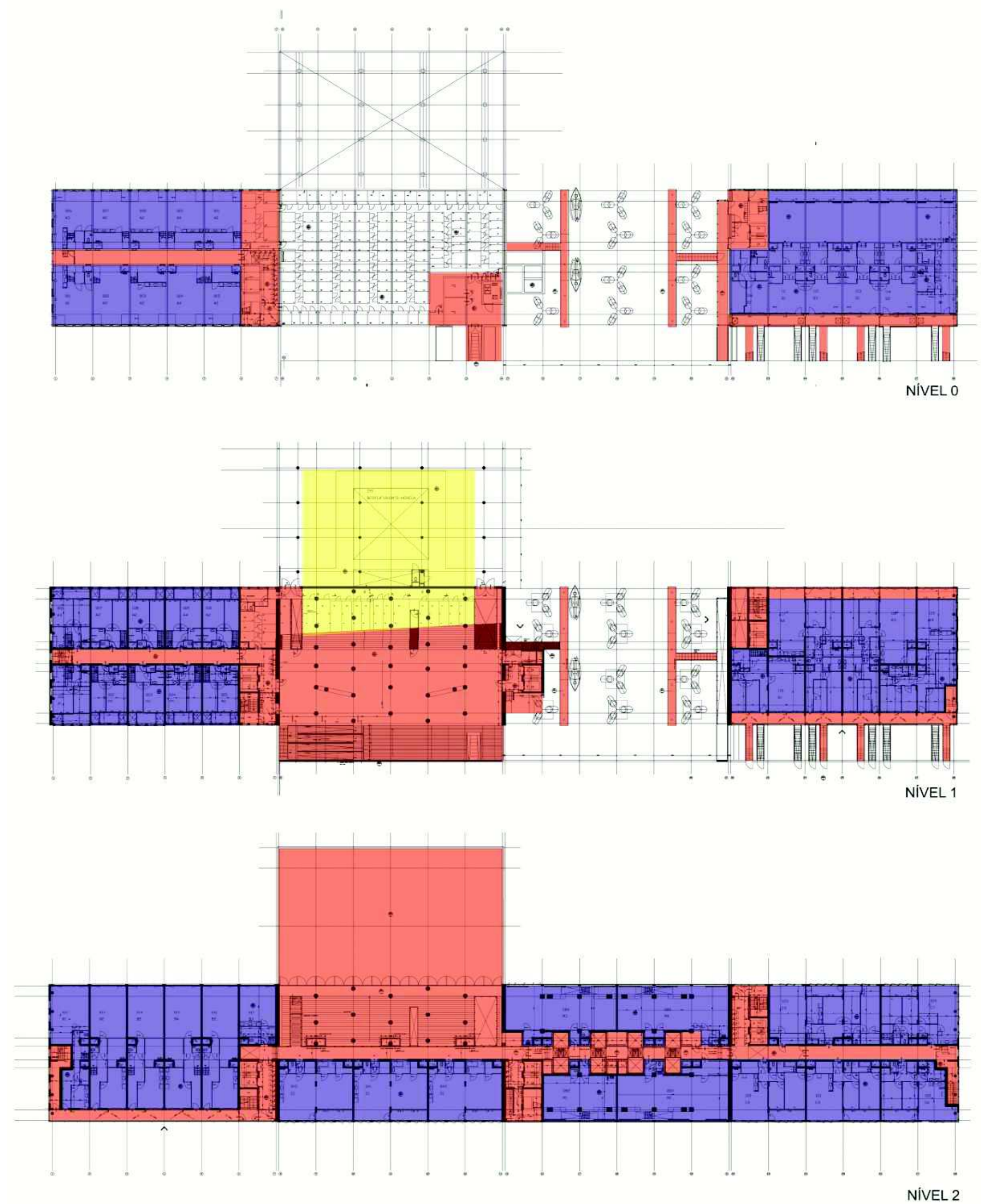


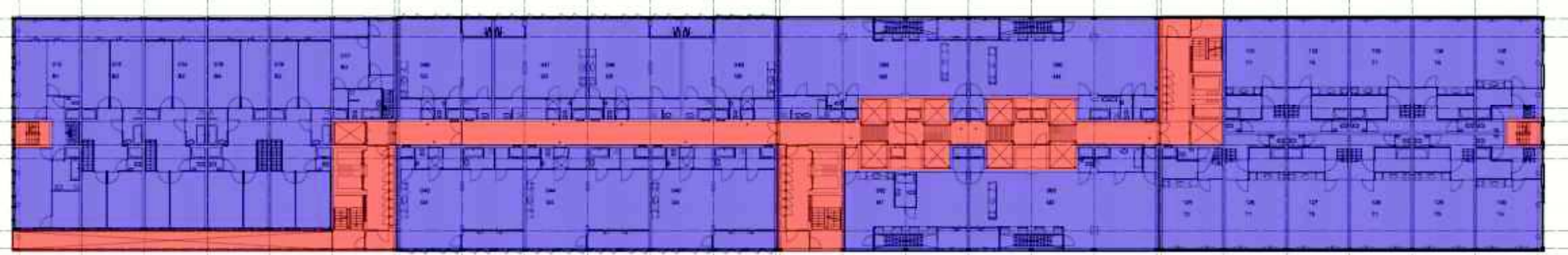

NIVEL 3

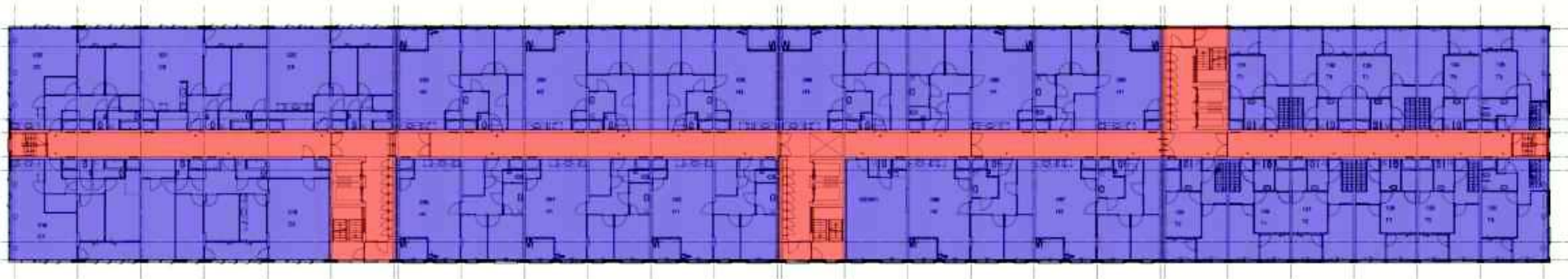

NIVEL 4

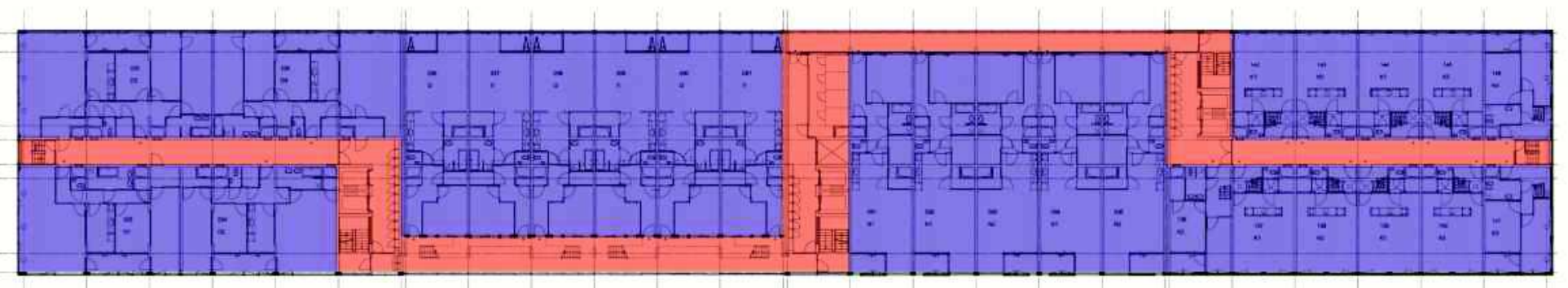

NIVEL 5

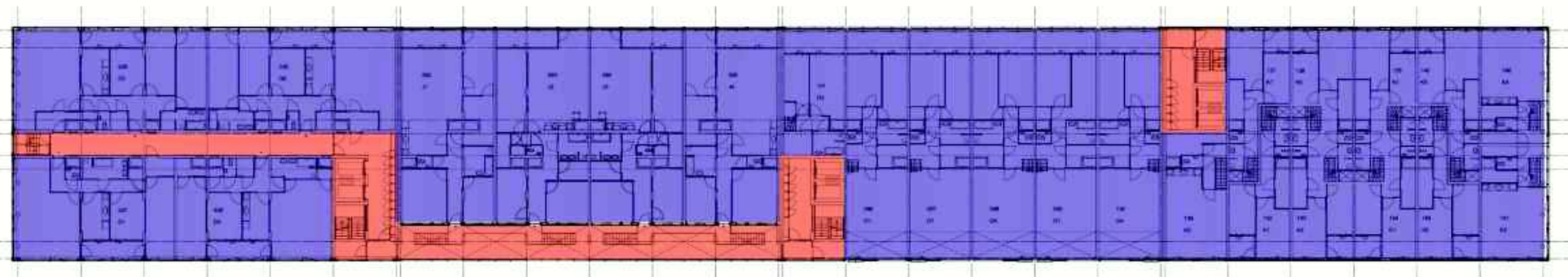

NIVEL 6

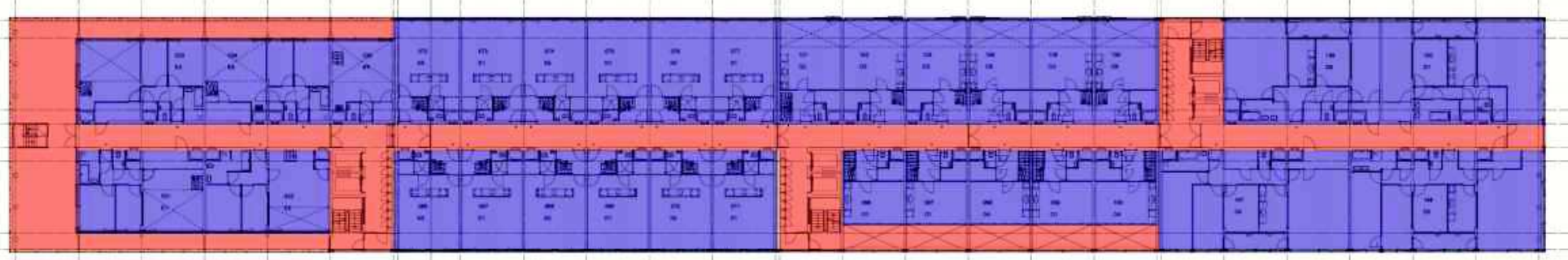

NIVEL 7 

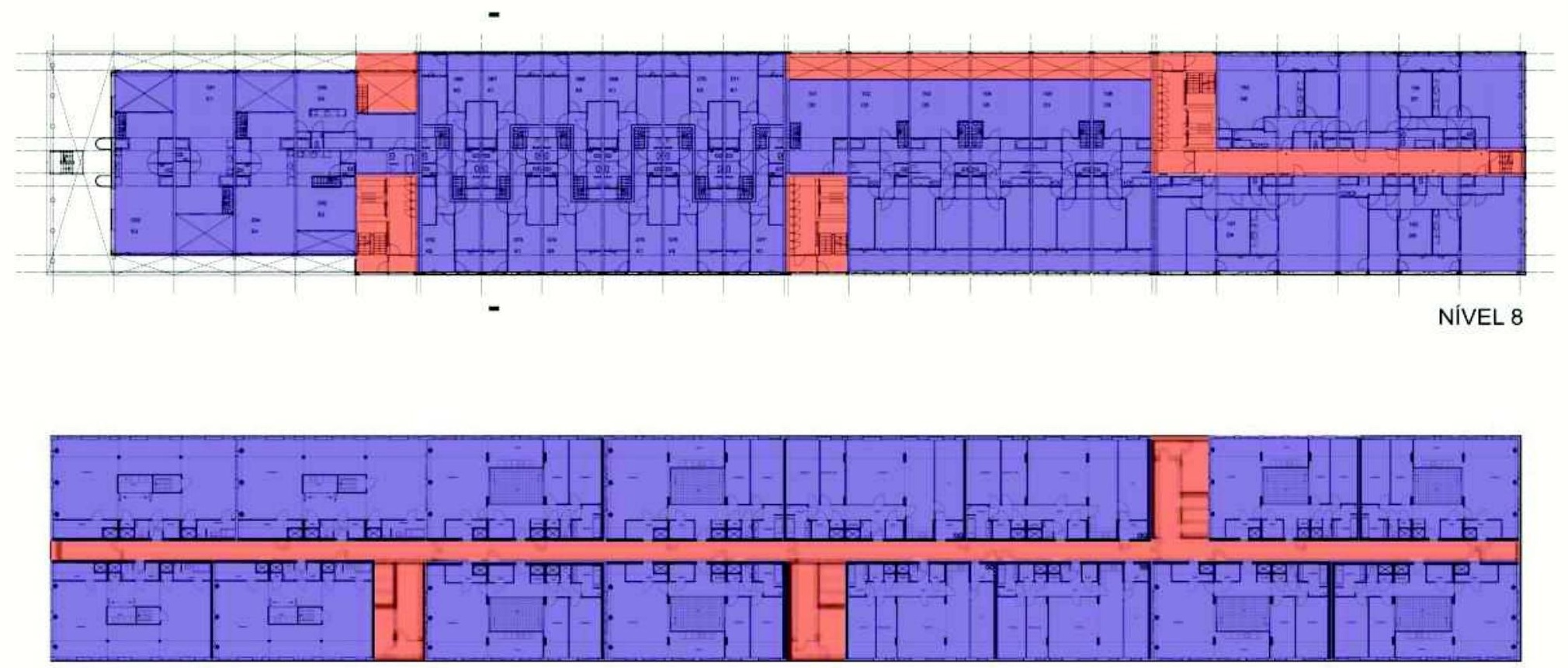

NIVEL 9 
Nas imagens a seguir, cores diversas foram utilizadas para destacar os mini-bairros totalizando 17 grupos diferentes.

Os tipos de apartamentos incluem: lofts, ateliês, duplex, apartamentos com pátios, apartamentos com área de trabalho, habitação de baixo custo, apartamentos para terceira idade, etc.

A marina no nível zero e a praça da entrada no nível um são os elementos do projeto mais permeáveis e que possibilitam uma comunicação com a cidade a partir da ausência de barreiras entre rua e edifício. Esses espaços propõem continuidade, gerando uma gradação entre espaço externo e interno, formando uma extensão intermediária.

No nível quatro observamos a ocupação das "torres" dois e três pelos apartamentos para terceira idade, que poderíamos chamar de localização privilegiada bem no meio do Silodam, facilitando a utilização de todos os percursos por meio dessa população. No nível sete e oito nota-se a presença de uma "praça elevada" utilizada como mirante e funcionando como uma circulação que se abre também para servir como área comum, é um dos resquícios dos vários espaços coletivos imaginados pelos arquitetos no início do processo de projeto. Ainda assim, é uma área nobre da edificação que deixou de ser comercializada para ser destinada ao uso coletivo. Observa-se também a situação das tipologias panorâmicas desde o nível cinco até o nível oito, ocupando as pontas do edifício com ampla vista para o rio IJ. Por fim, a cobertura (nível dez) é utilizada pelos pátios de alguns apartamentos do nível nove e para iluminação zenital dos corredores desse último pavimento. 

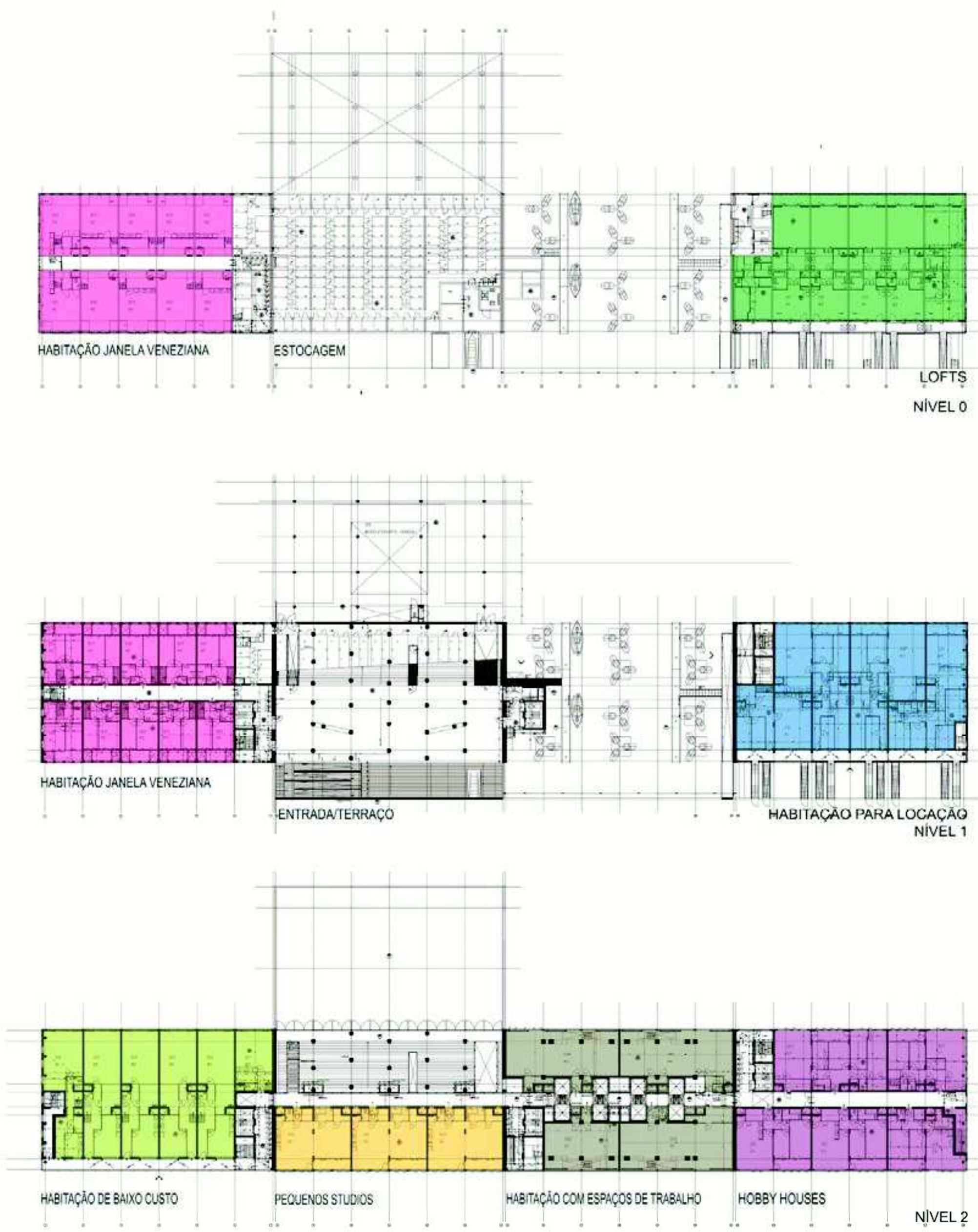


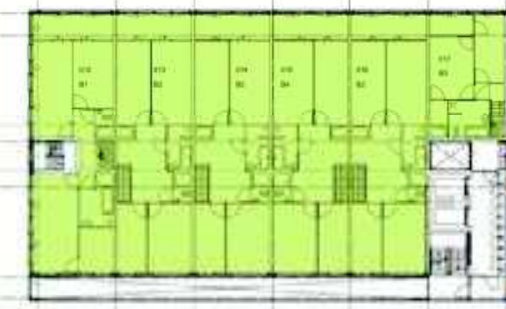

HaBITACAOA DE GAIXO CUSTO

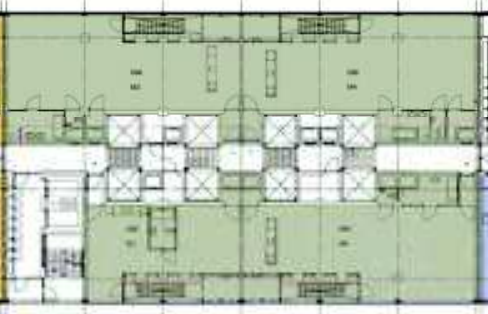

HABITACÁO COM ESPACOS DE TRABALHO

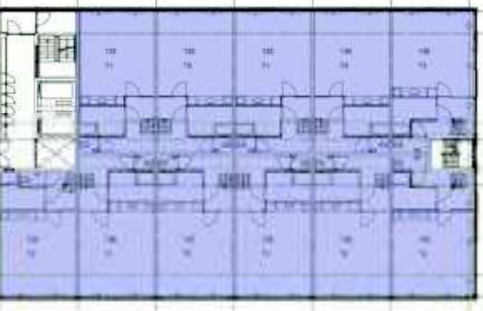

DUPLEX

NIVEL 3

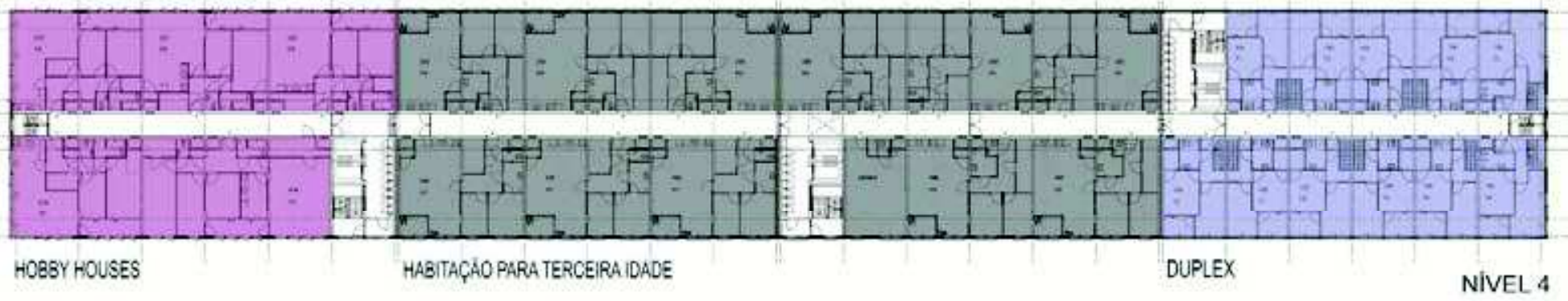

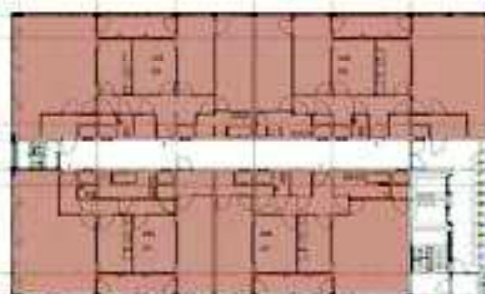

PANORAMICA

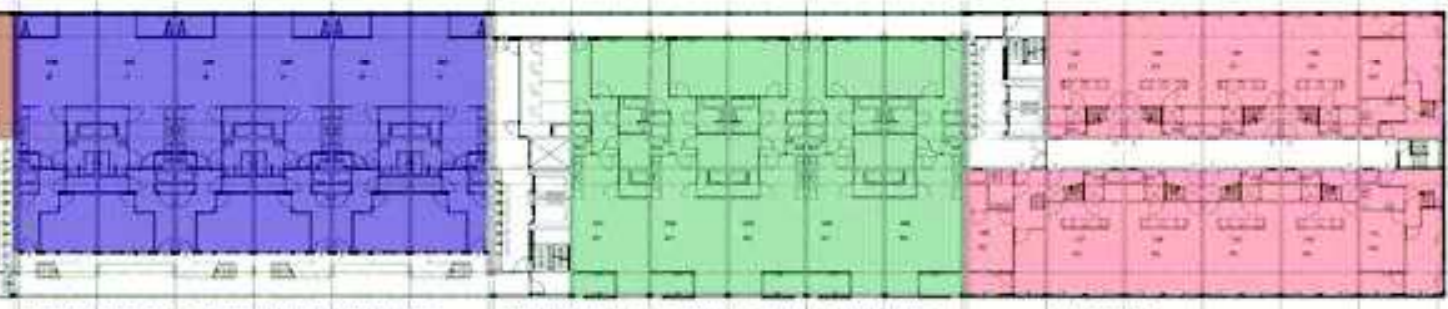

APARTAMENTOS COM GRANDES VARANDAS APARTAMENTOS COM PEQUENAS VARANDAS
X HOUSES

NIVEL 5

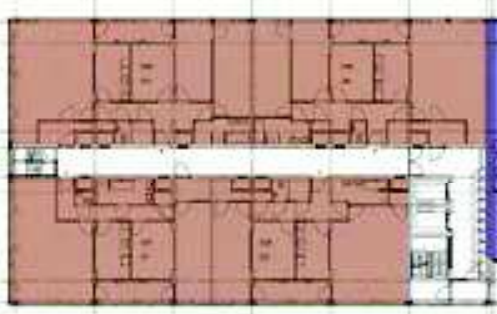

PANORAMICA

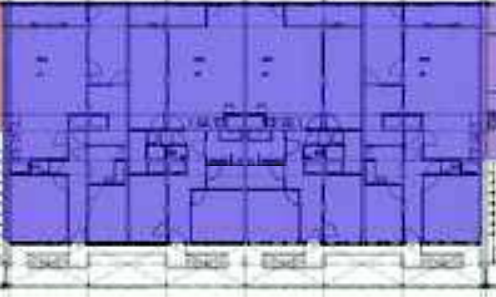

APARTAMENTOS COM GRANDES VARANDAS

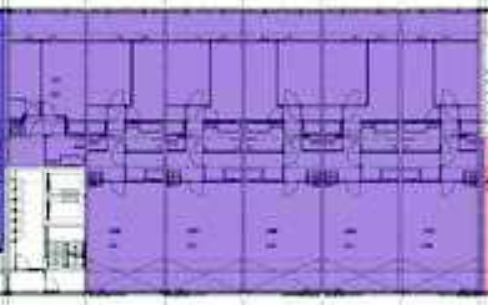

UNITE

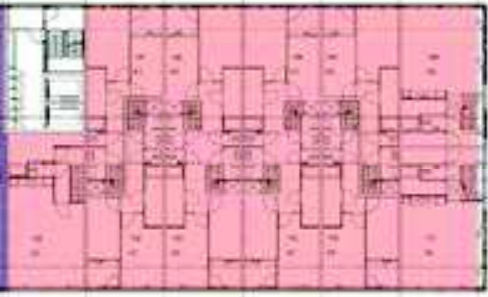

XHOUSES

NIVEL 6

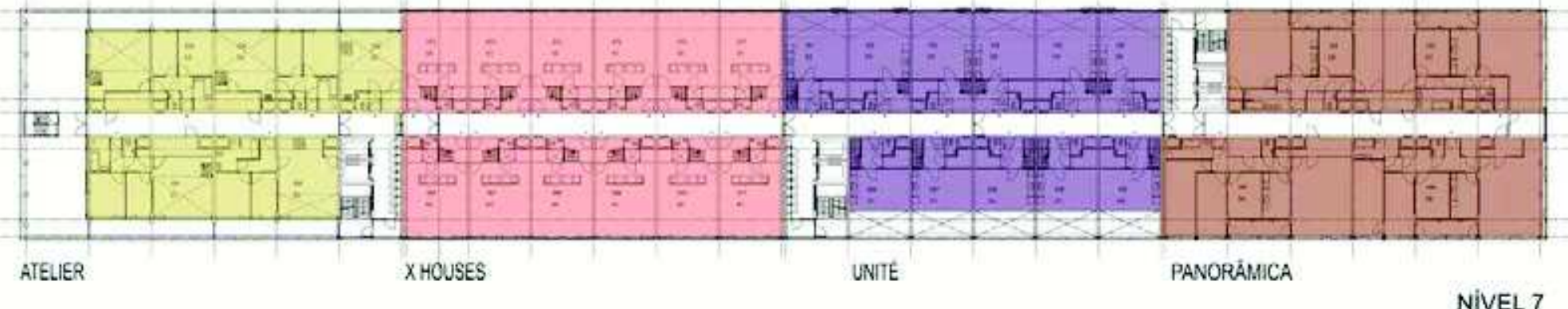



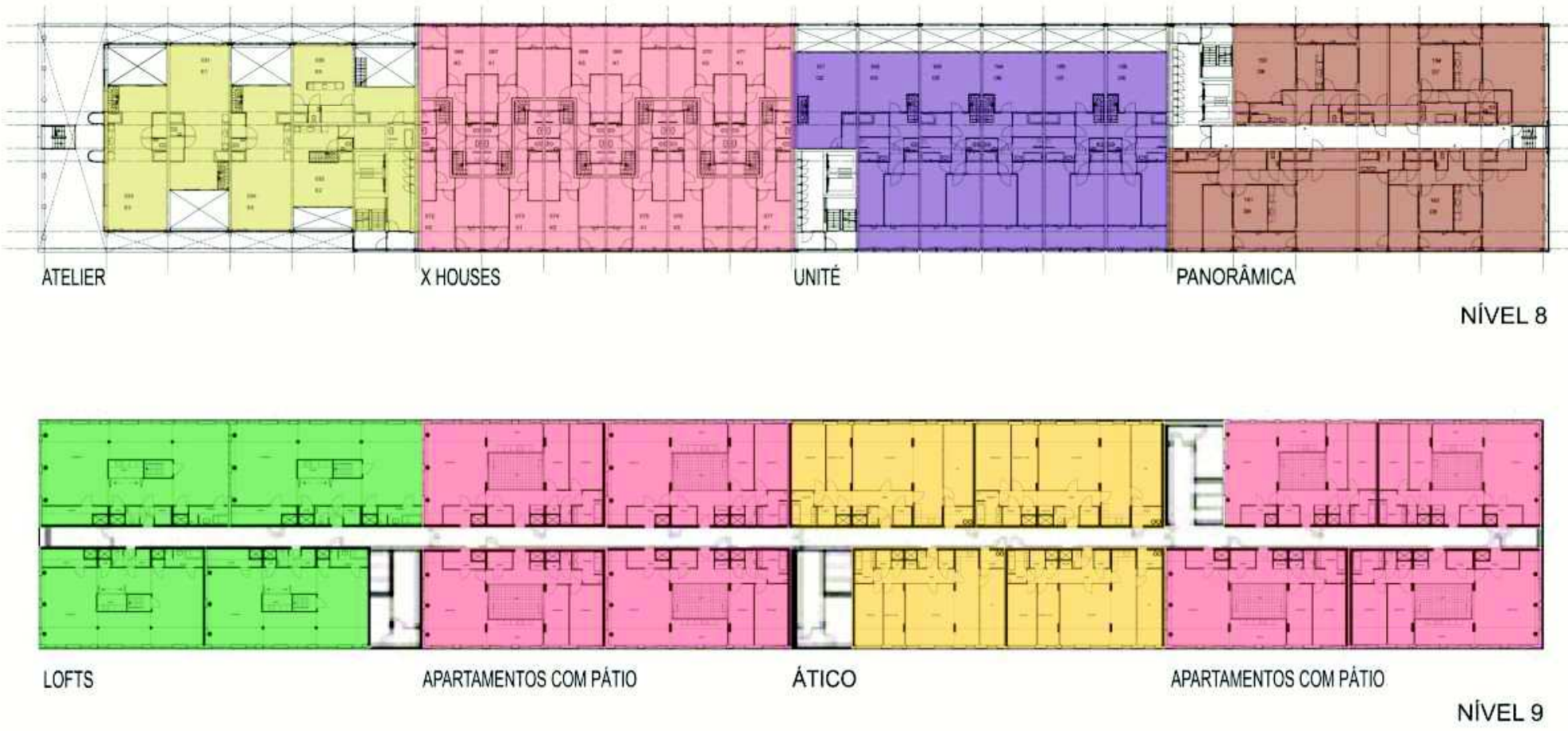


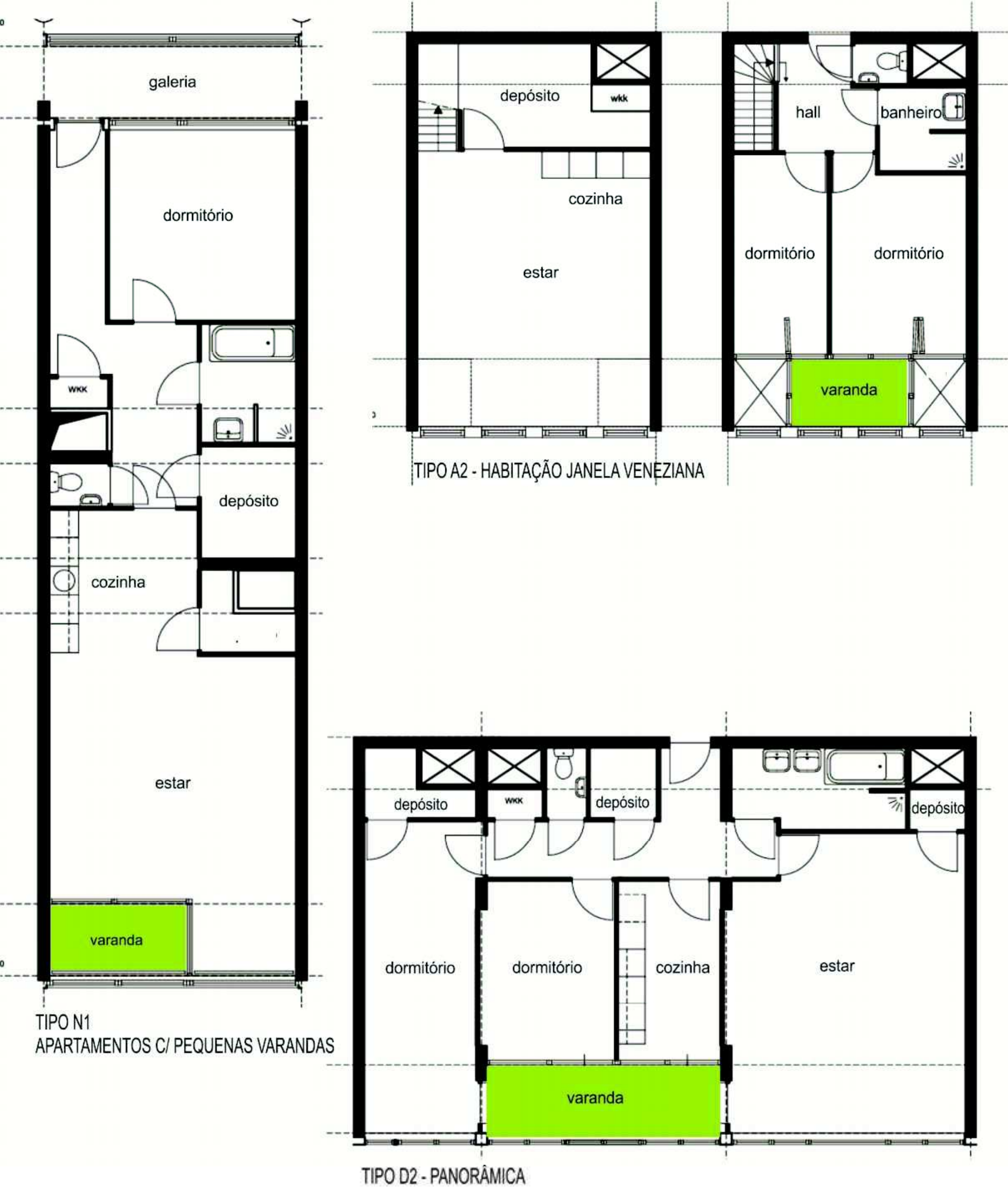



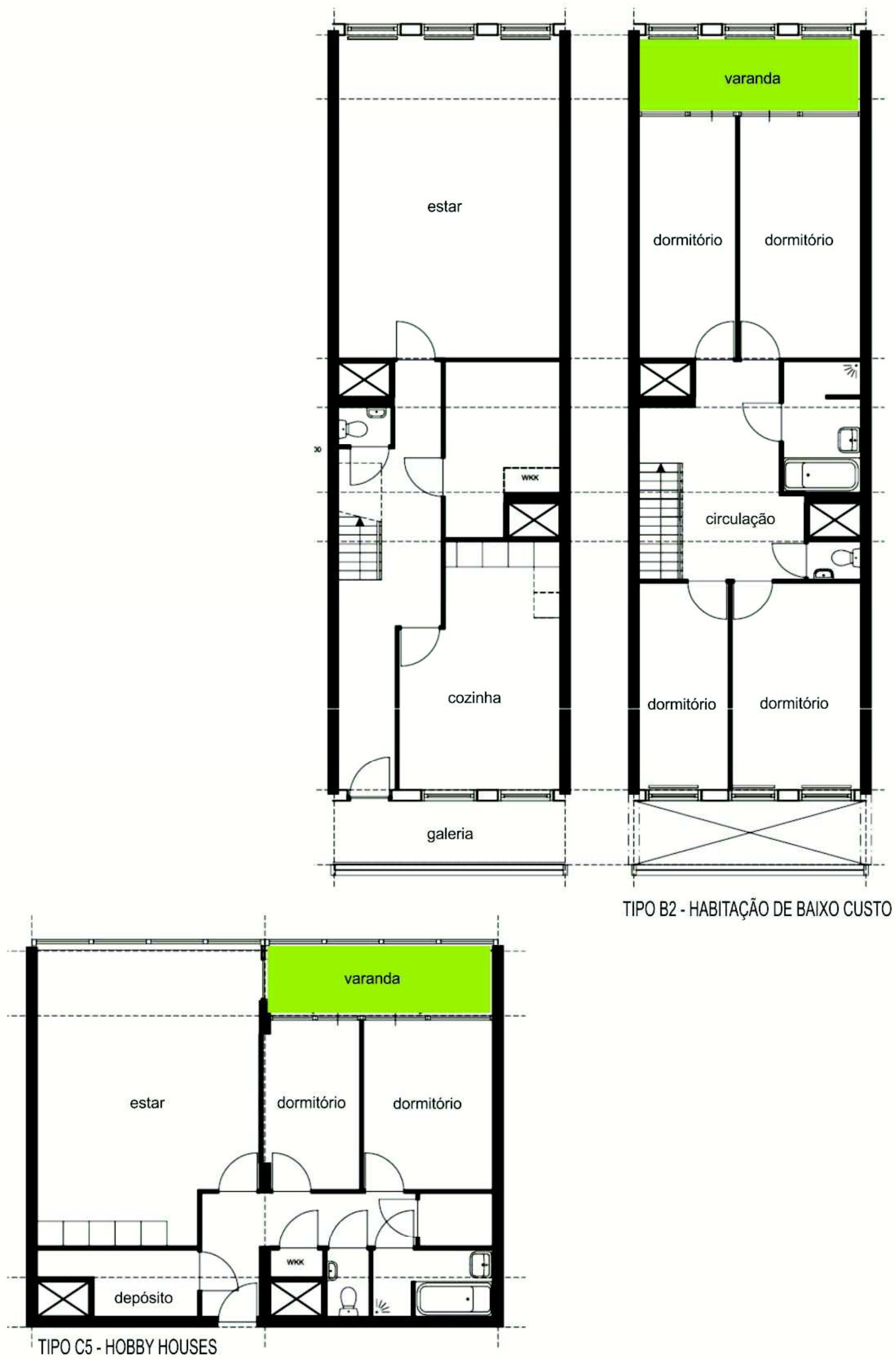

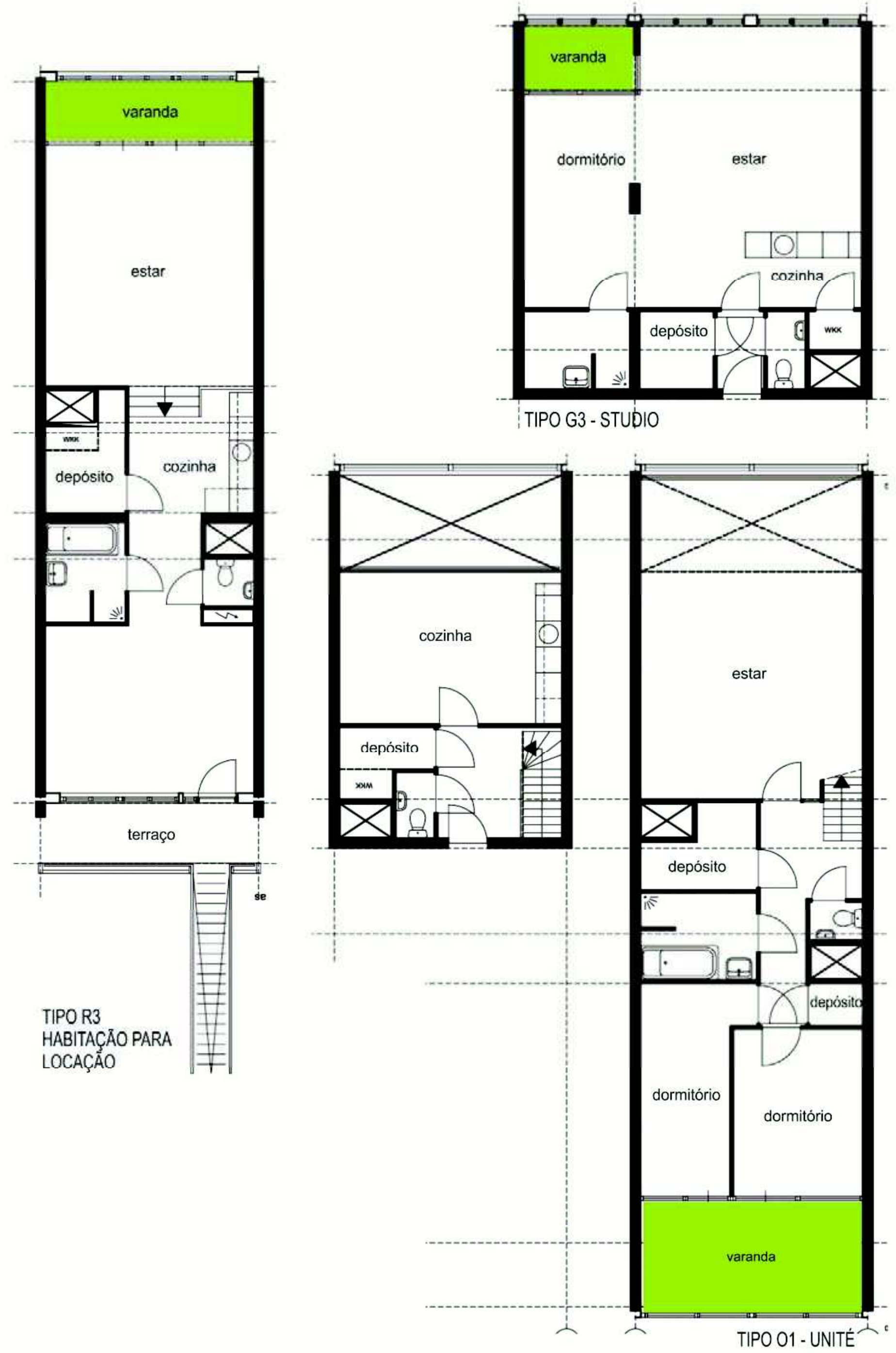

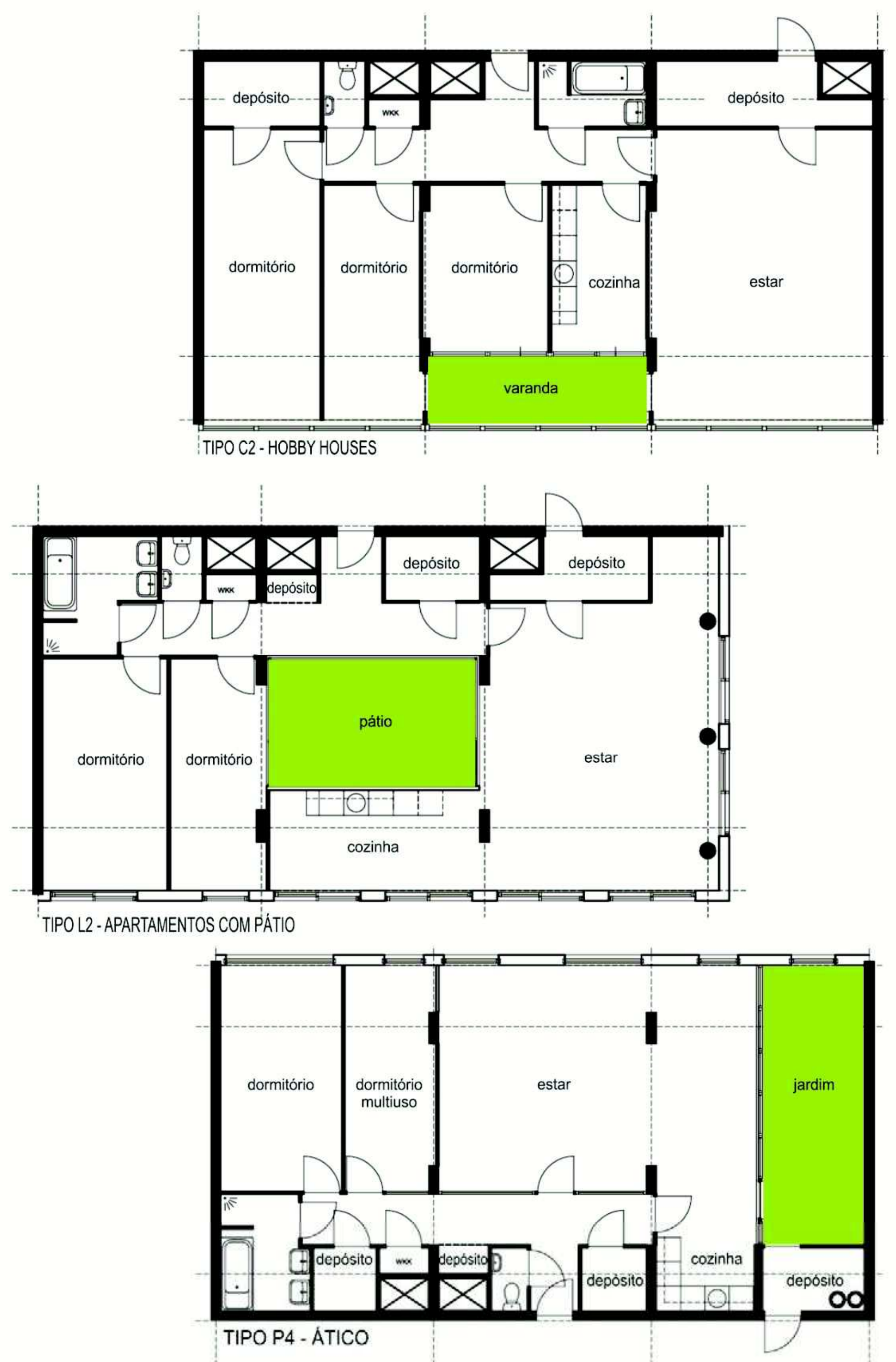

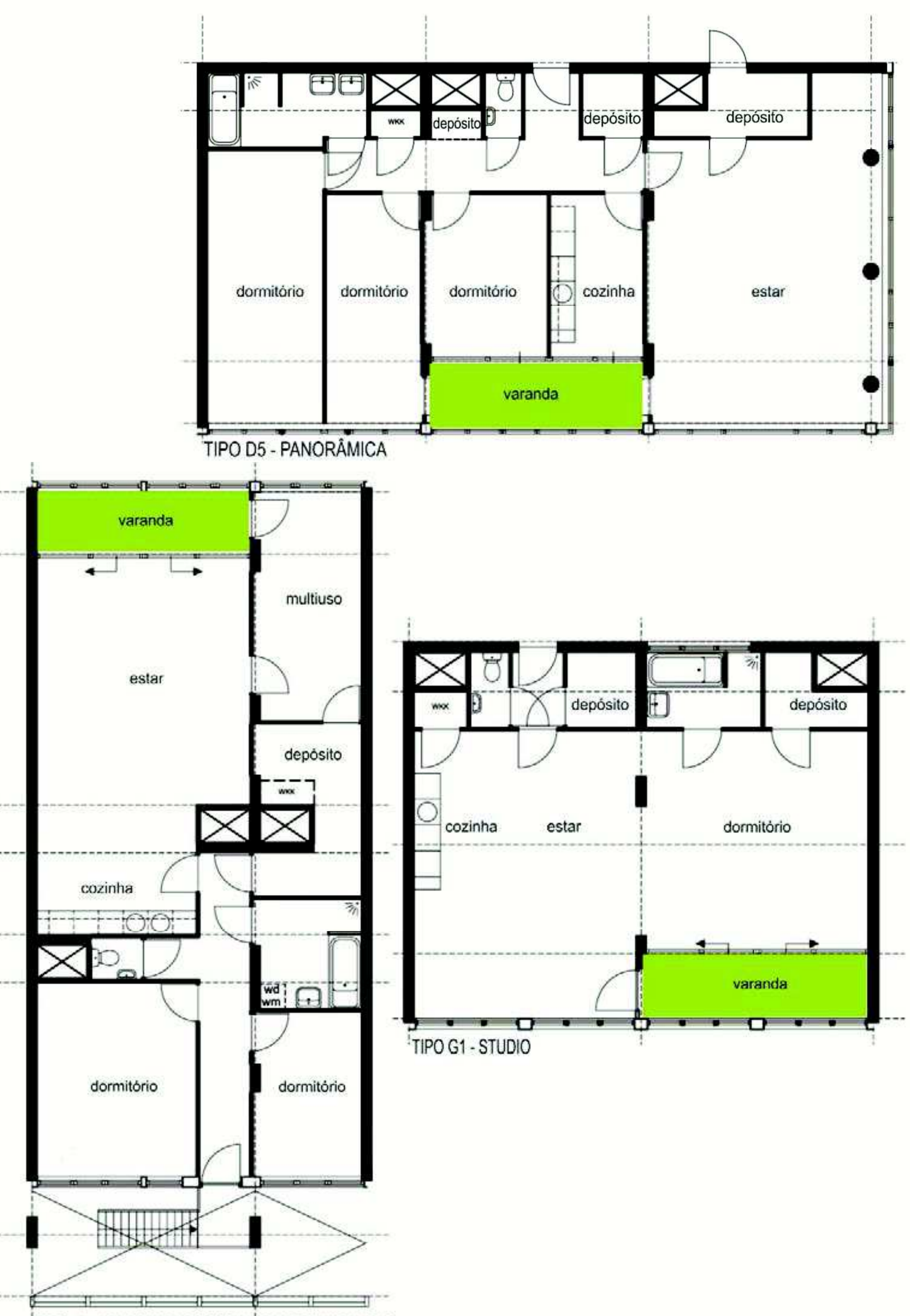

TIPO JI-APARTAMENTOS COM GRANDES VARANDAS 

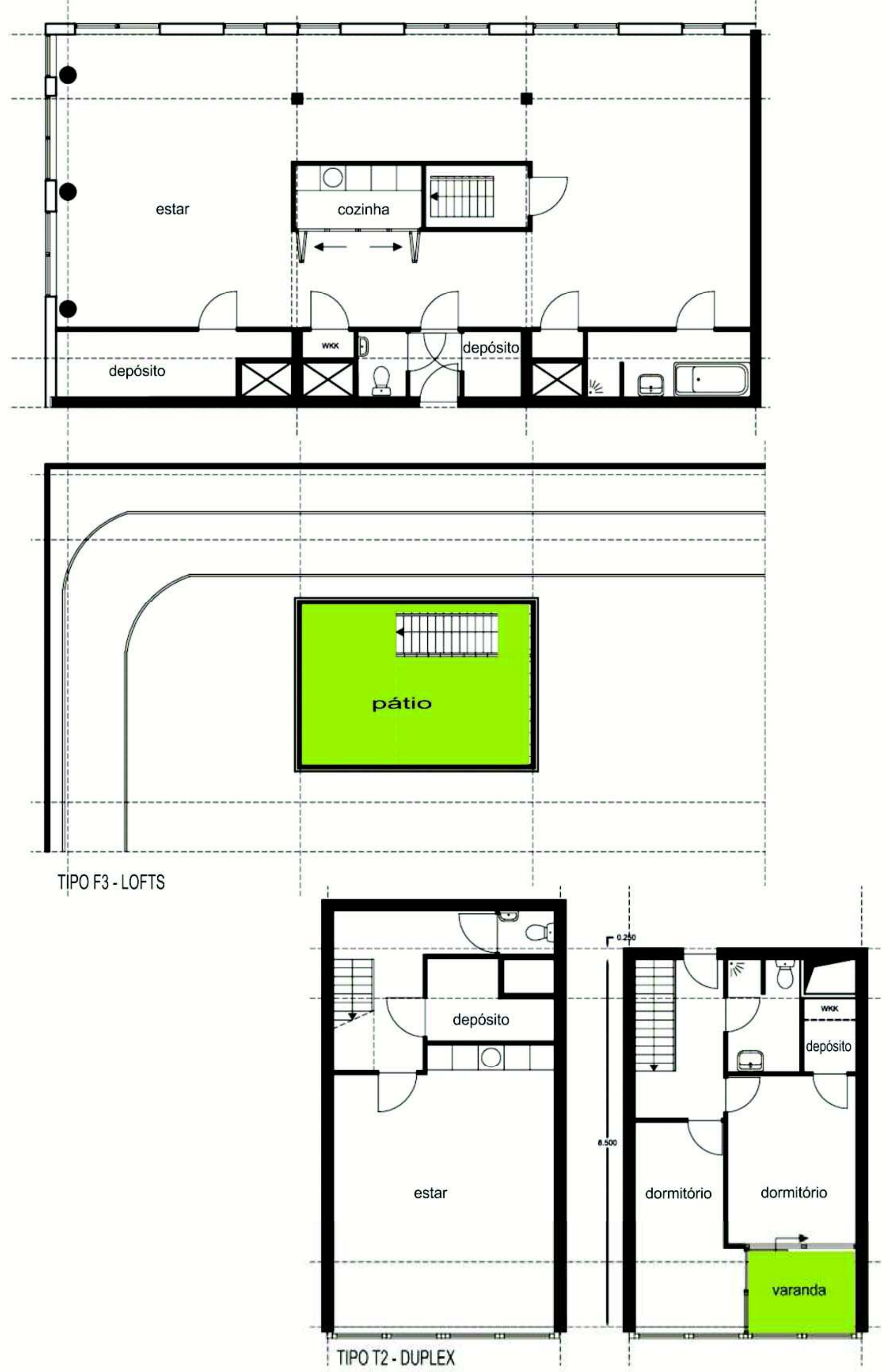

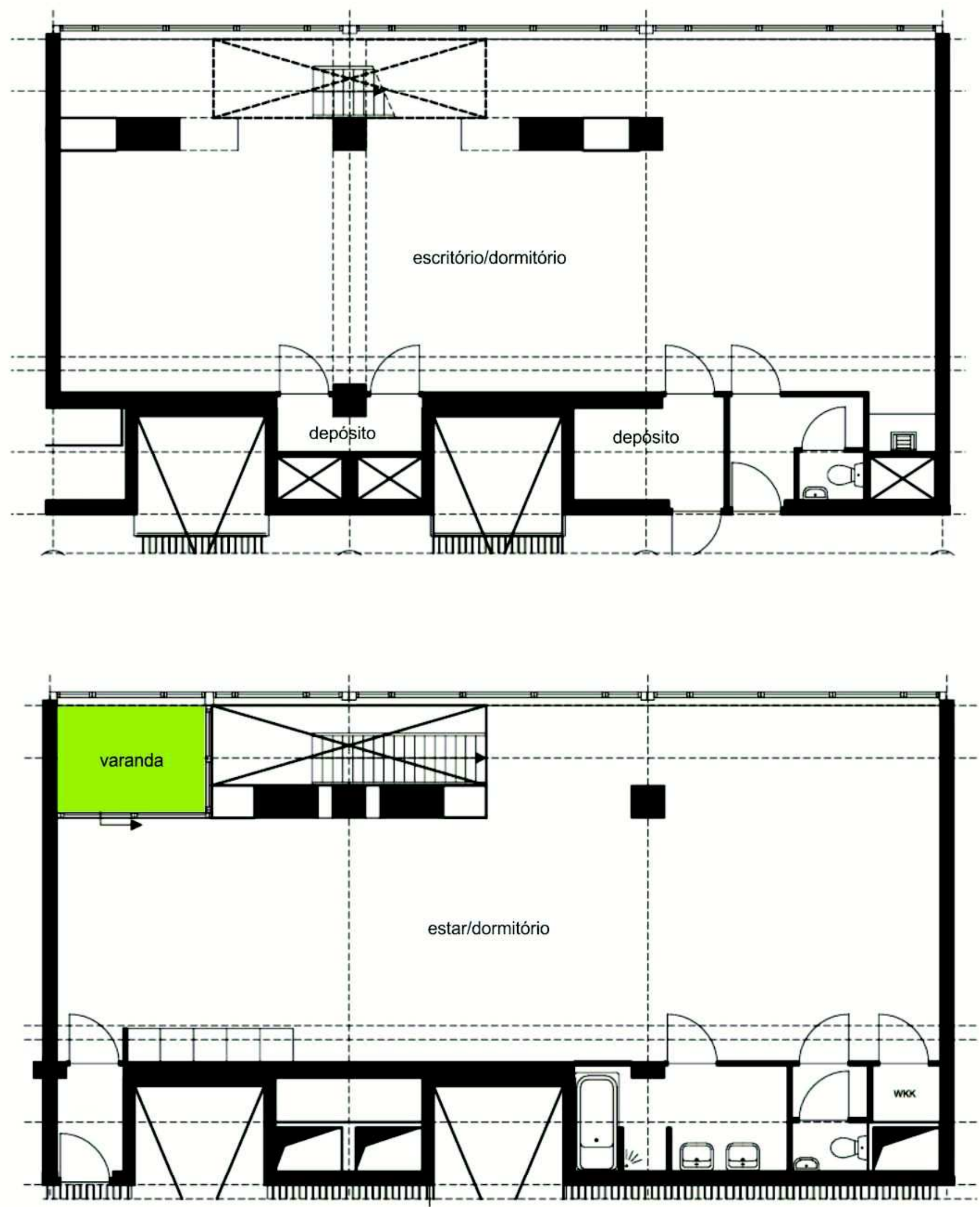

TIPO M4 - HABITAÇÃO COM ESPAÇOS DE TRABALHO 


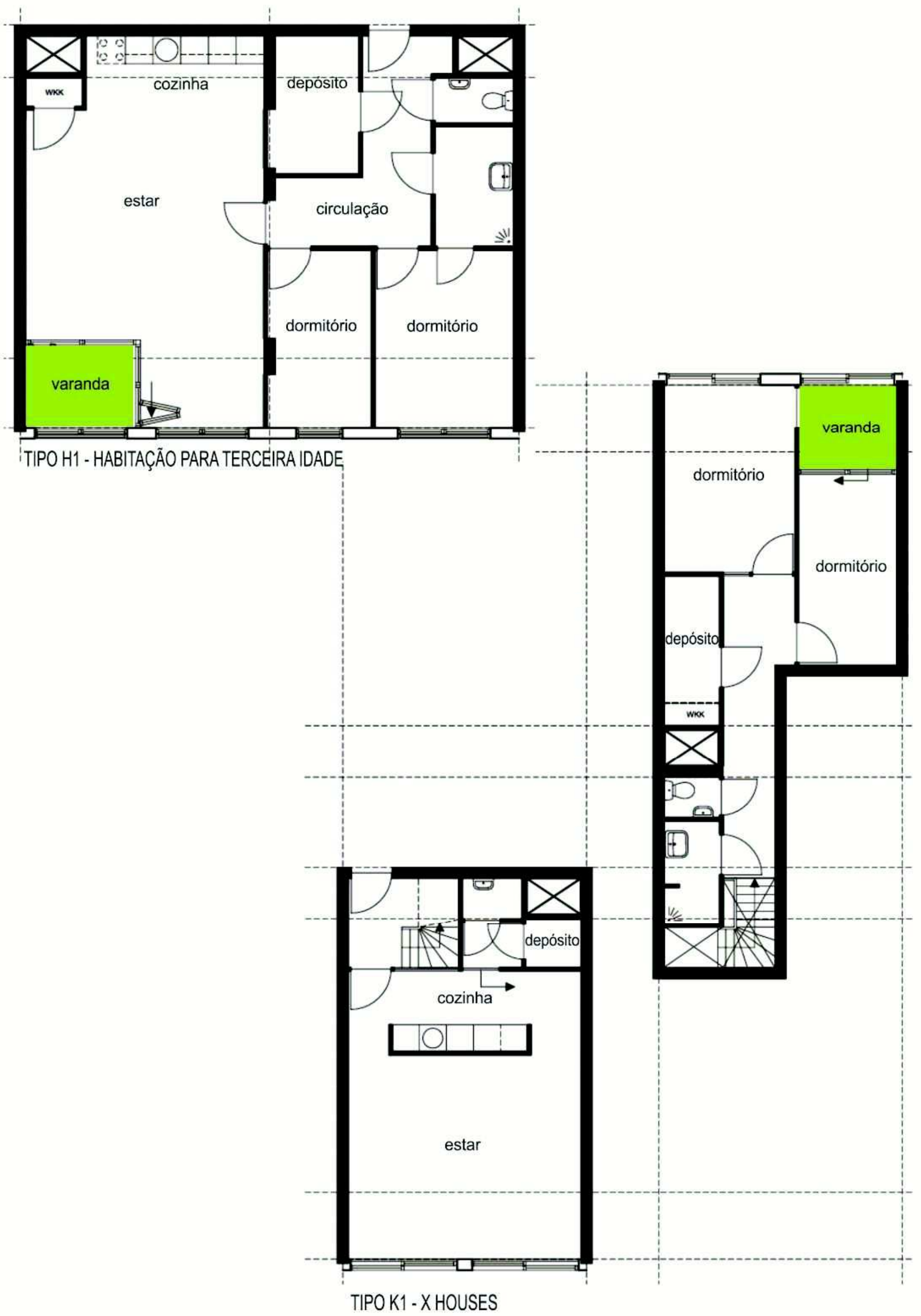




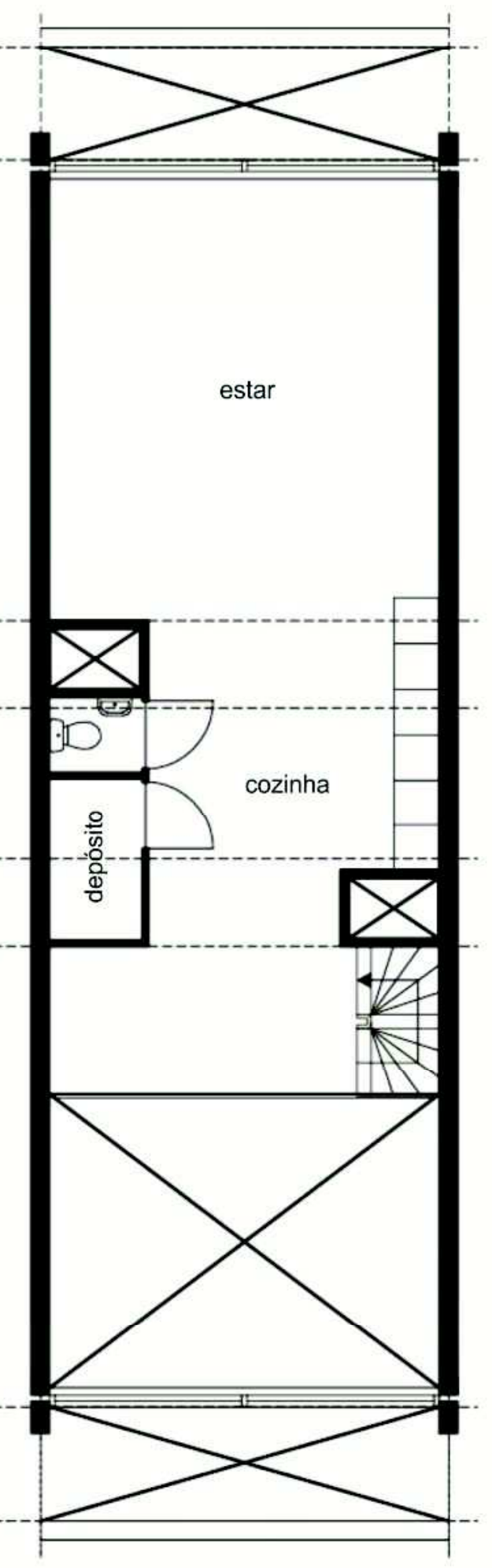




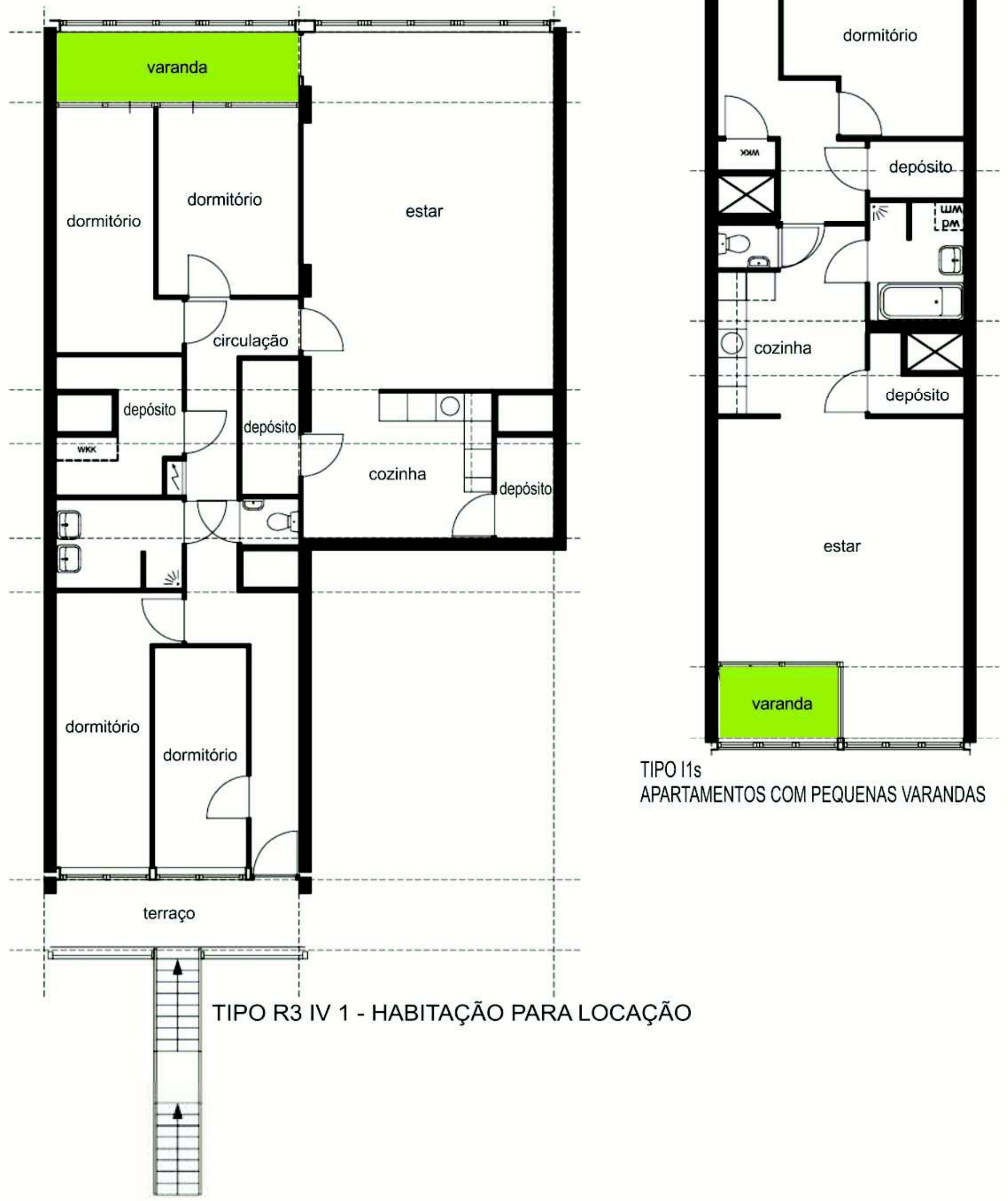



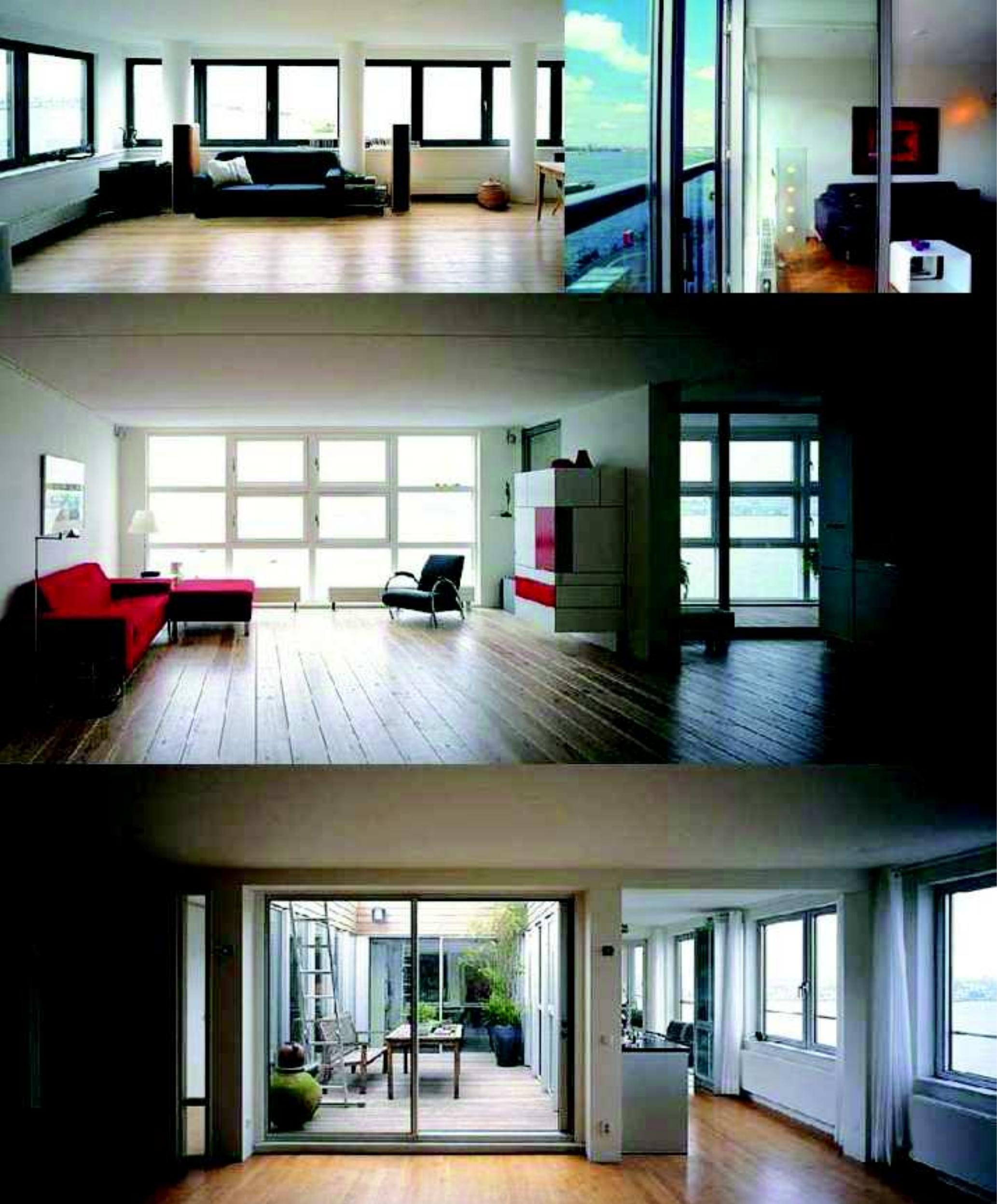


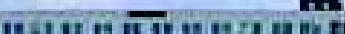

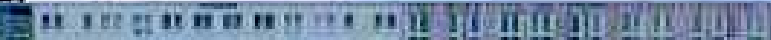

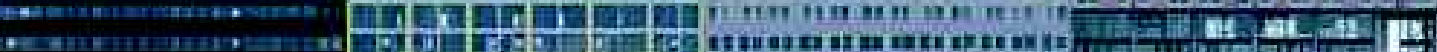

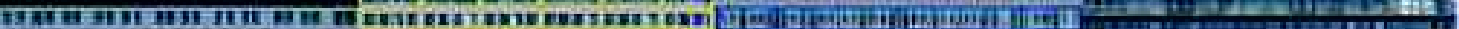

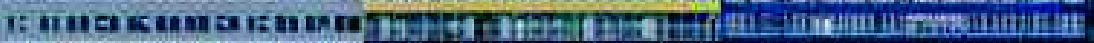

1H

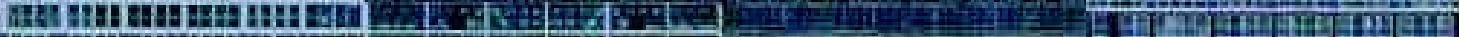

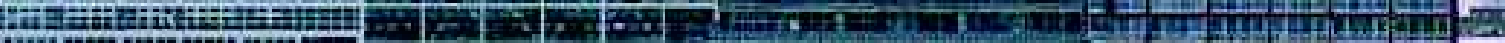

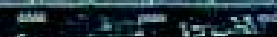

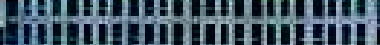

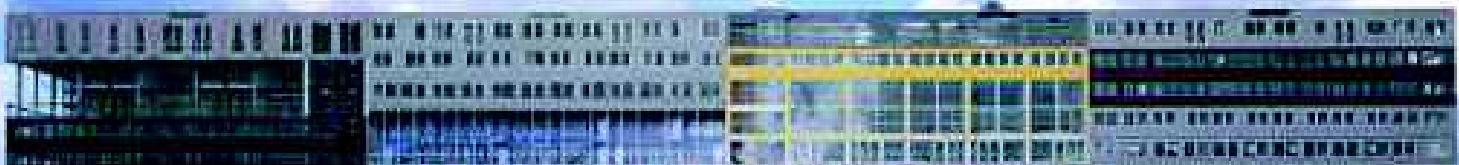

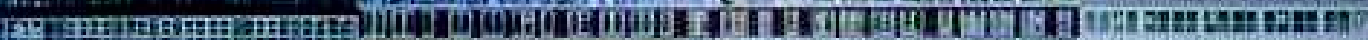

2.

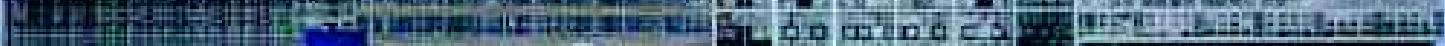
rinintistaino

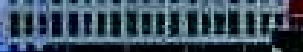
hos

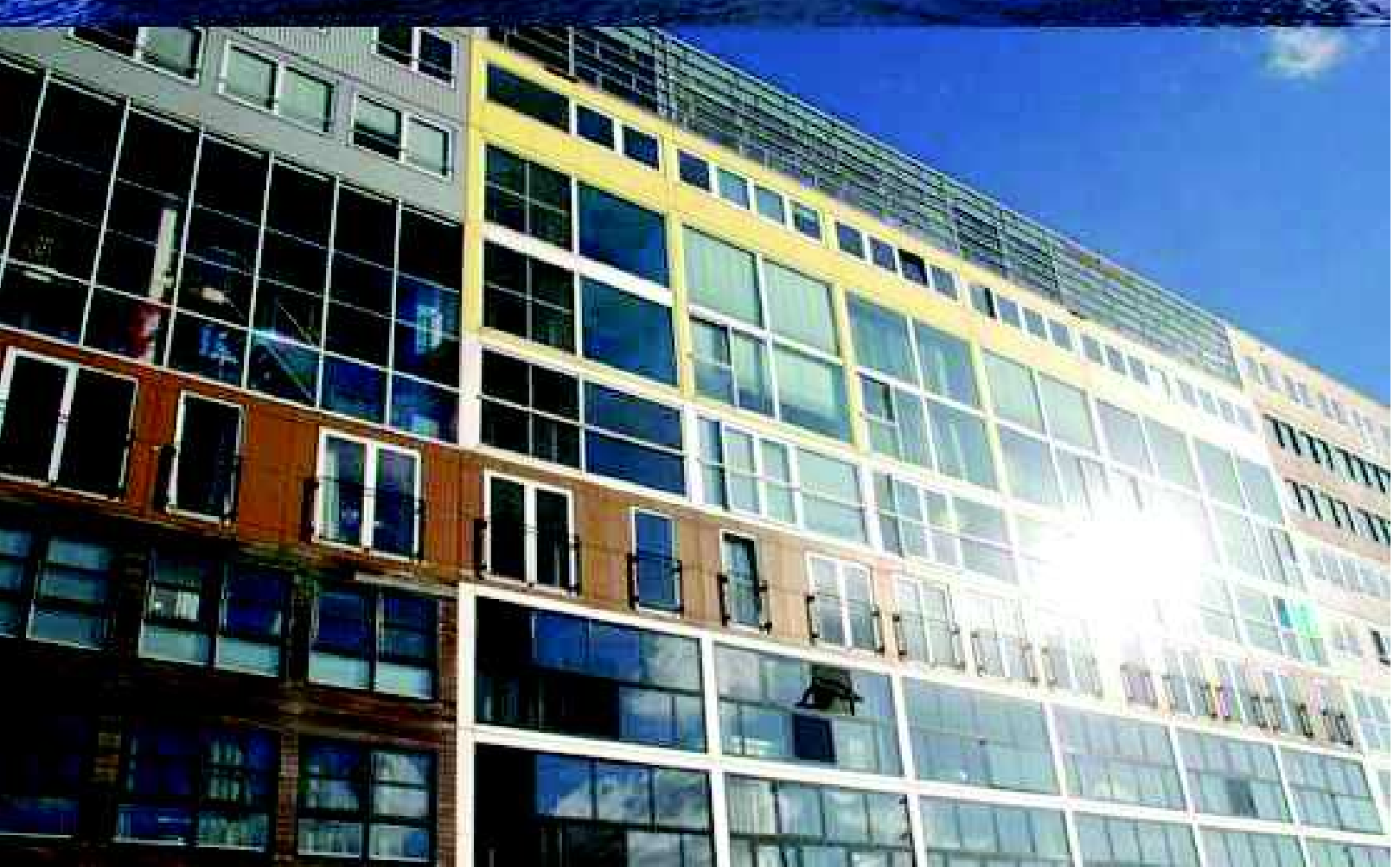




\section{Global através do Local}

O projeto está inserido em uma zona portuária próxima do centro histórico com fácil acesso aos meios de transporte e aos centros comerciais permitindo que os moradores não se sintam isolados dos acontecimentos da cidade.

O Silodam, além de atender a demanda por habitação, faz parte de um projeto de escala maior em conjunto com outras operações, que é a renovação da área portuária, estimulando o pensamento da moradia não só como ferramenta de reformulação do espaço habitacional (a célula), mas também como instrumento para formatação de novas ordens urbanas nas quais, não apenas a tipologia residencial determina a morfologia da cidade, mas sistemas de comunicação e transporte atuam como referência para a organização do solo e suporte de atividades.

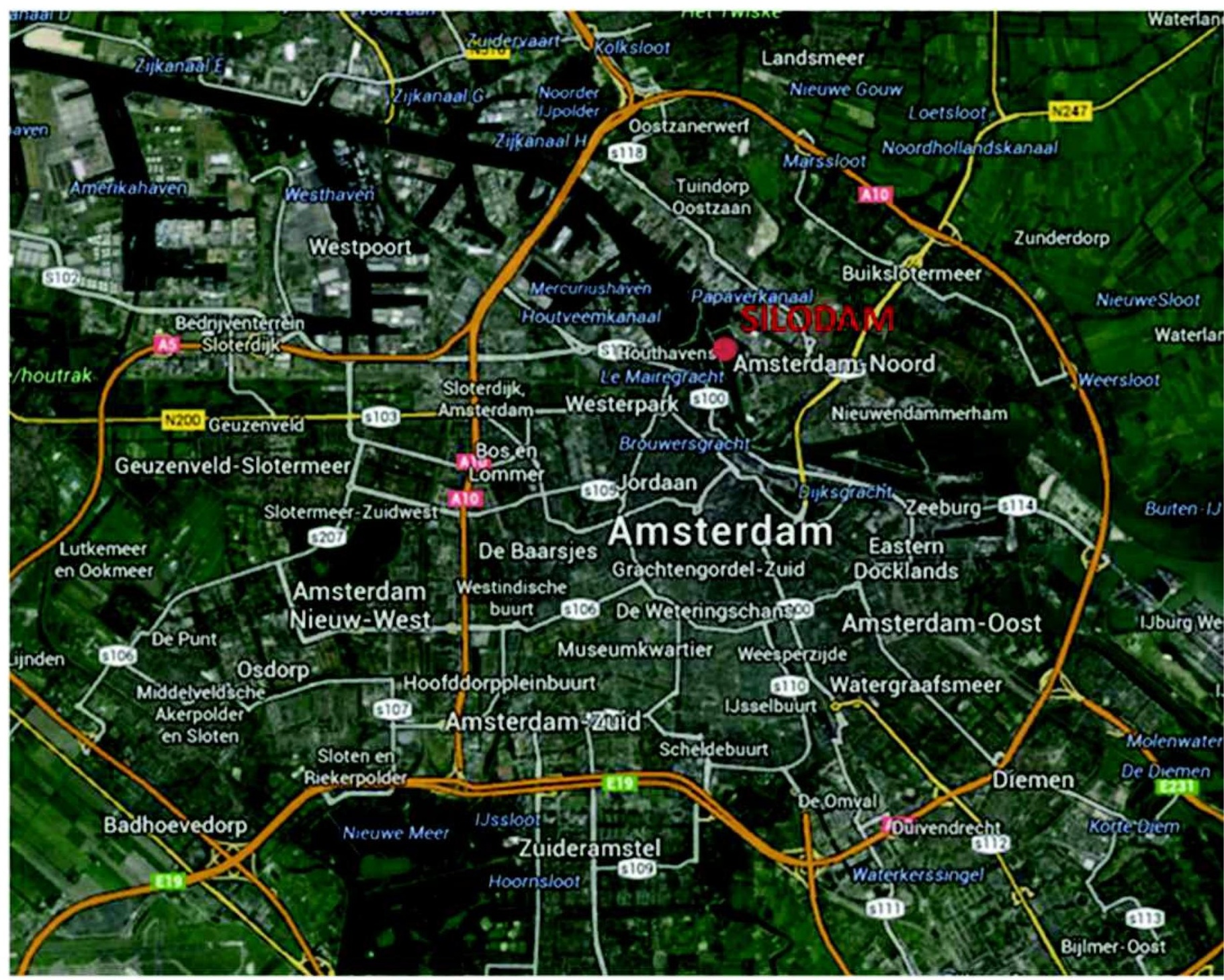

Localização do Silodam em Amsterdã. Fonte: Google Maps. 


\section{Considerações sobre o projeto}

O Silodam marca uma transição na habitação holandesa coletiva no que tange a uma maior liberdade para o usuário com sua variedade social e arquitetônica. Por questões financeiras, mas também por certo conservadorismo em relação ao impacto dos espaços coletivos à individualidade atual da sociedade, as áreas comunitárias foram reduzidas radicalmente. Ainda assim, o grande diferencial do Silodam é a articulação do seu sistema de acesso, sendo às vezes definido como um caminho ramificado, corredor, ponte ou passagem e que se desdobra em espaços coletivos. A diferenciação dessa circulação é feita também através do uso de cores que identificam cada setor conformado por certo tipo de habitação, uma estrutura que também se torna evidente na fachada.

O edifício integra ainda em sua estrutura parte da complexidade funcional da cidade, pois abriga não só habitações, mas também equipamentos de uso coletivo e áreas comerciais que são capazes de diluir os limites entre os espaços públicos e privados.

Quanto ao processo de projeto, notamos um afastamento da investigação teórica durante o desenvolvimento das unidades habitacionais, fato que demonstra a existência de possíveis barreiras culturais, técnicas, políticas ou econômicas que impediram a total aplicação da pesquisa na prática. A ausência de pesquisas nesse ponto do projeto também leva a falta de discussões com os envolvidos no trabalho. A distribuição do programa e a formatação dos espaços coletivos foram bastante debatidas e divulgadas enquanto o desenvolvimento interno das unidades habitacionais não foi abordado. Para ilustrar tal fato, podemos mencionar o uso parcial das ideias de John Habraken, citado no capítulo 1. O conceito de suporte/enchimento de Habraken foi concebido como uma rede tridimensional de ruas, passagens e pontes, inspirado no uso do espaço público em tecidos urbanos históricos. Essa ideia é observada na circulação do Silodam, mas a participação do usuário na definição do "enchimento" vai até a distribuição dos mini-bairros. Tal lacuna talvez seja o motivo da maior contradição do projeto: seu exterior passa a impressão de uma rica variedade para diferentes usuários, fazendo o observador imaginar que tamanha variedade se reflita nas unidades habitacionais, porém, mesmo com 22 tipologias distintas, percebemos que as unidades variam em tamanho e materialidade, mas nem tanto em programa e distribuição espacial. As nomenclaturas dadas aos diferentes mini-bairros e suas respectivas unidades parecem funcionar mais como marketing do que realmente como oferta de espaços diversos.

O projeto tenta acomodar as diferenças através da oferta de várias tipologias, inclusive com referências a exemplos históricos (vide modelo Unitè), mas sem grandes alterações entre os programas das unidades a oferta de 22 tipos pode ser entendida como uma cenografia superficial das diferenças, em vez de um alojamento real destes. Desse modo, o projeto nos faz pensar sobre a eficiência do Silodam na acomodação de diversidade e retoma o projeto 
para o concurso do Sluishuis (do próprio MVRDV e citado no capítulo 1) que coloca plataformas abertas com espaços e fachadas a serem definidos pelo usuário, bem ao modo de Habraken. É a radicalidade do Sluishuis que o torna referência na discussão da diversidade na habitação, atendendo de forma mais ativa os diferentes usuários. De qualquer maneira, sendo específica como o Silodam ou genérica como Sluishuis, o reconhecimento da importância da diversidade é um fator positivo nos projetos do MVRDV. 


\subsection{Mirador}

"Nós não só queríamos fazer um edifício que emoldurasse as montanhas Guaderrama, mas que também tivesse espaço público e desse uma identidade a todo o bairro." (MVRDV em MVRDV Buildings, p.224, tradução nossa).

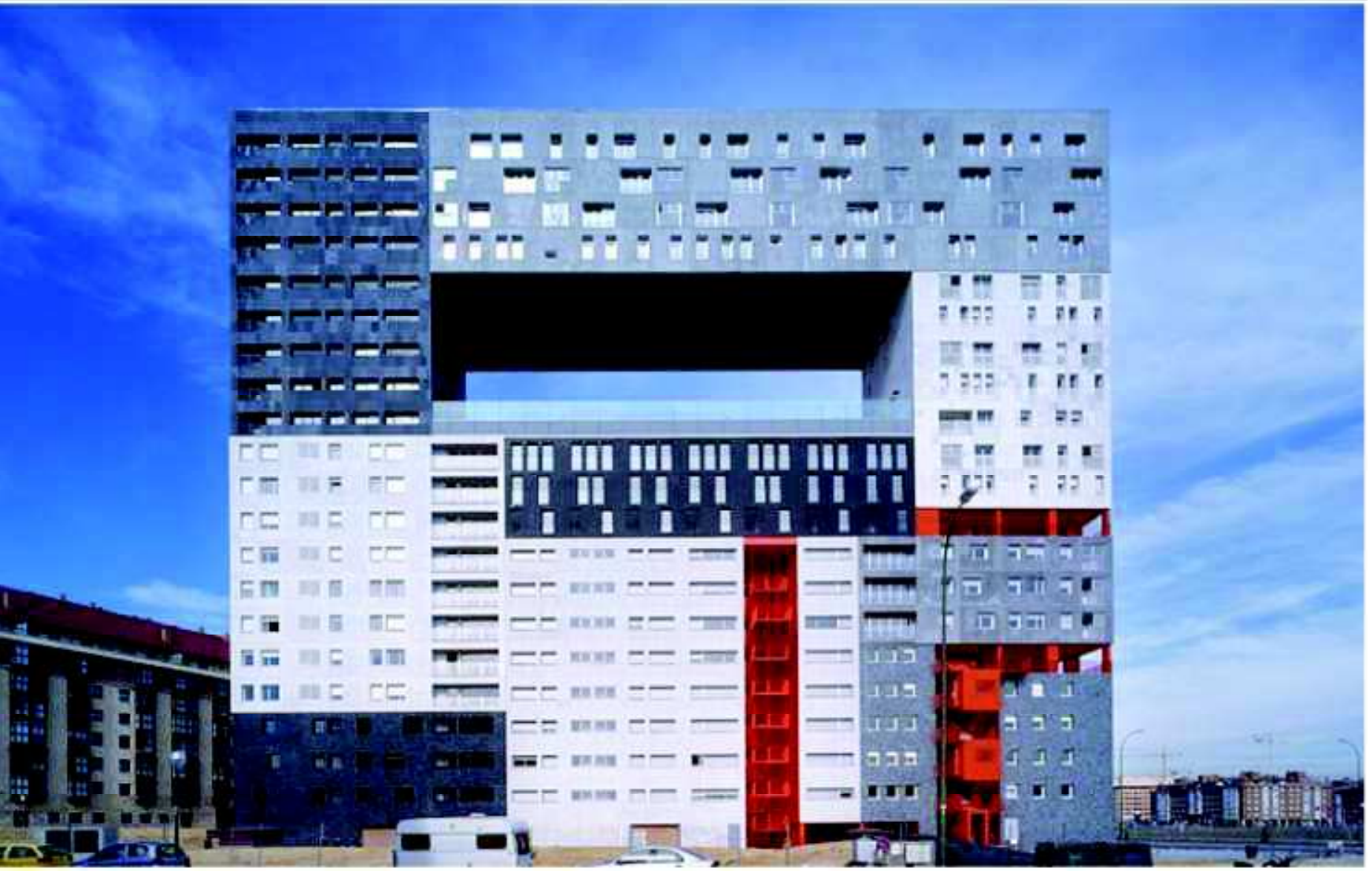

Mirador. Fonte: www.mvrdv.nl

Localização: Madrid

Data: 2001-2005

Cliente: EMV del Ayuntamiento de Madrid (Empresa Municipal de la Vivienda y Suelo de Madrid)

Programa: $18.300 \mathrm{~m}^{2}, 156$ apartamentos, serviços, praça elevada e estacionamento subterrâneo.

Orçamento: EUR 10 milhões

O Mirador está localizado em Sanchinarro, bairro periférico no norte da cidade de Madrid, uma região caracterizada pela uniformidade de edifícios residenciais com 
quatro a cinco pavimentos, e vias de tráfego rápido, mas também várias áreas ainda sem ocupação e vistas interessantes para as montanhas de Guaderrama.

O projeto surge nesse contexto como alternativa ao bloco de apartamentos com pátio interno dentro de um programa municipal de habitação social. O projeto com 20 andares, desenvolvido pelo MVRDV em conjunto com a arquiteta local Blanca Lleó, reconfigura o bloco padrão com o intuito de liberar terreno: é como se o edifício fosse levantado e seu pátio interno, antes no térreo, alocado nos andares mais altos.

O Mirador resgata vários aspectos do Silodam como a circulação diferenciada e os mini-bairros, aqui chamados de sub-blocos. Nove sub-blocos com cinco a oito apartamentos são combinados em torno do espaço vazio comum de $580 \mathrm{~m}^{2}$. Os apartamentos em cada sub-bloco variam com tipologias de um pavimento, duplex e triplex o que quebra a lógica serial da habitação social e insere uma complexidade incomum a esse tipo de moradia.

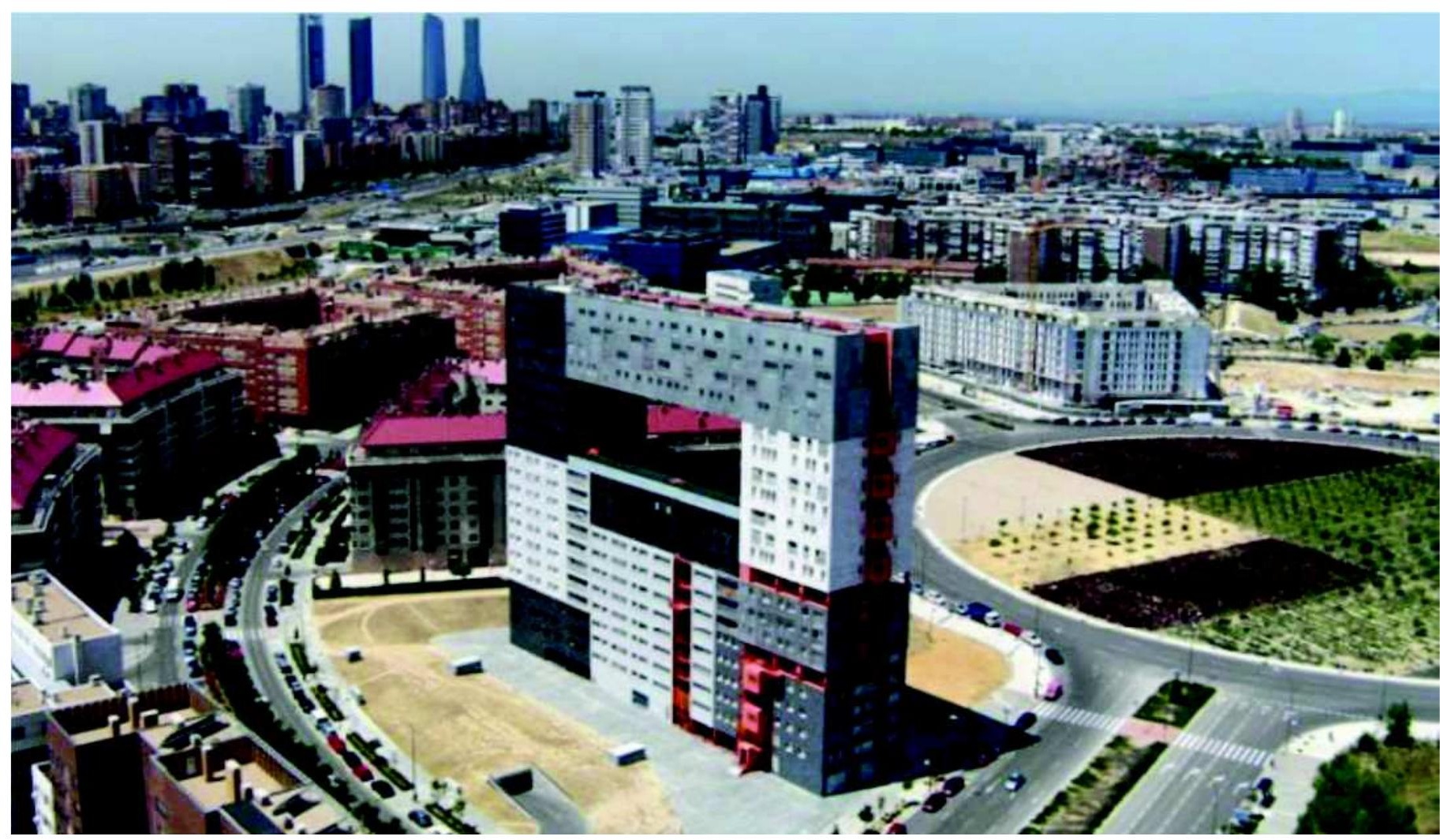

Mirador. Fonte: www.encasa.globaliza.com 


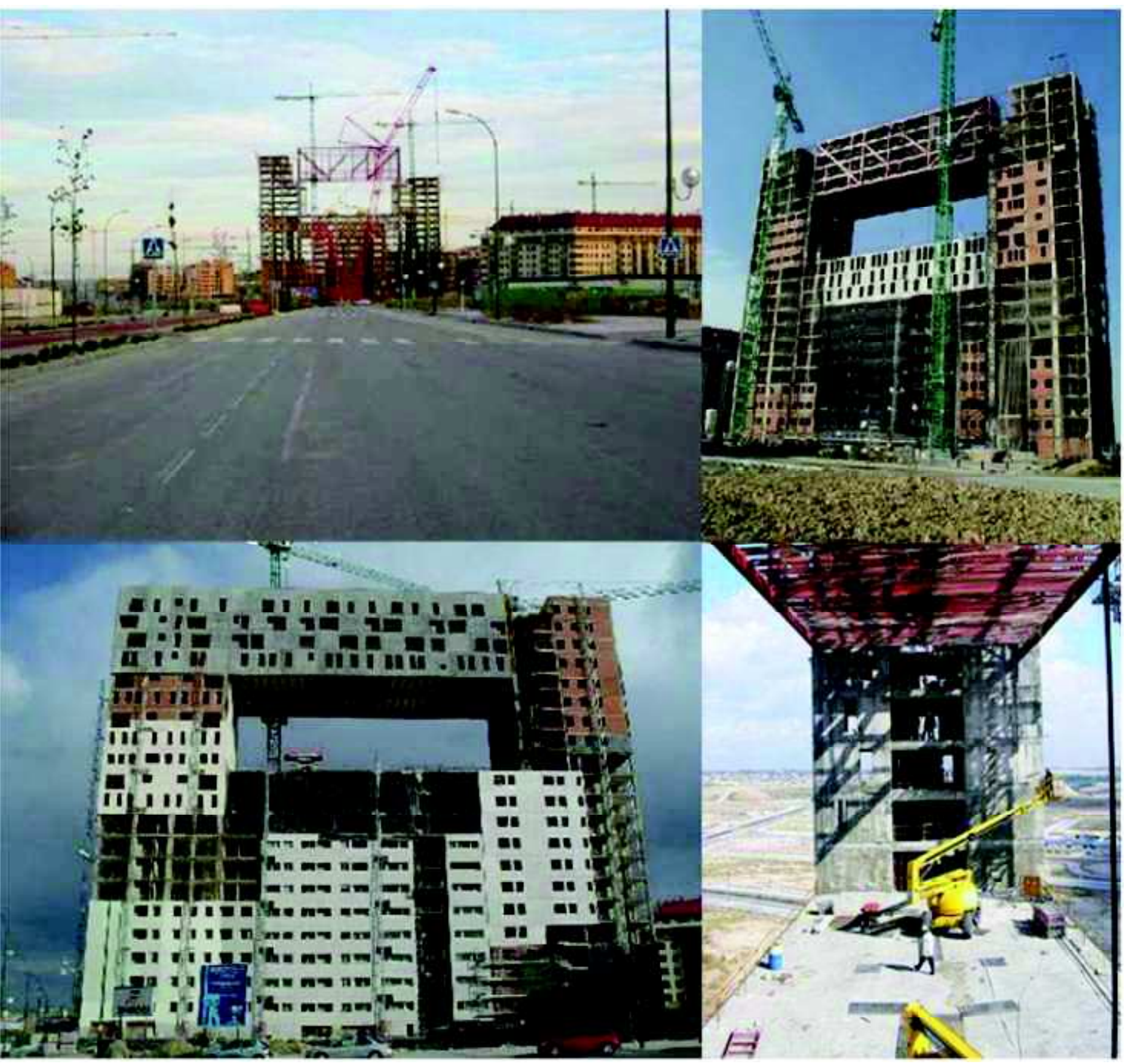

Mirador em construção. Fonte: www.skyscrapercity.com

\section{Datascapes em outra cultura}

O hábito de iniciar o projeto baseado em uma investigação das influências sociais e econômicas esbarrou em dificuldades locais. Diferente do Silodam, o Mirador não teve uma interação entre os arquitetos, clientes e usuários. Os moradores desse edifício não escolheram morar nele, mas foram alocados conforme uma ordem de inscrição no programa municipal de habitação. As informações sobre processo de projeto divulgadas pelo MVRDV são poucas e tratam-se apenas de alguns diagramas sobre forma, circulação e a combinação de sub-blocos. 
Notamos que neste projeto o MVRDV se deparou com uma série de dificuldades de uma cultura diferente da holandesa e a quantidade de dados trabalhados é infinitamente menor que a do Silodam, o que se deve também ao bairro em desenvolvimento que oferecia menos variáveis. Nesse cenário, os arquitetos utilizaram como dados quatro pontos principais: as visuais, a homogeneidade do bairro, a liberação de área livre e a necessidade de tipologias diversas.

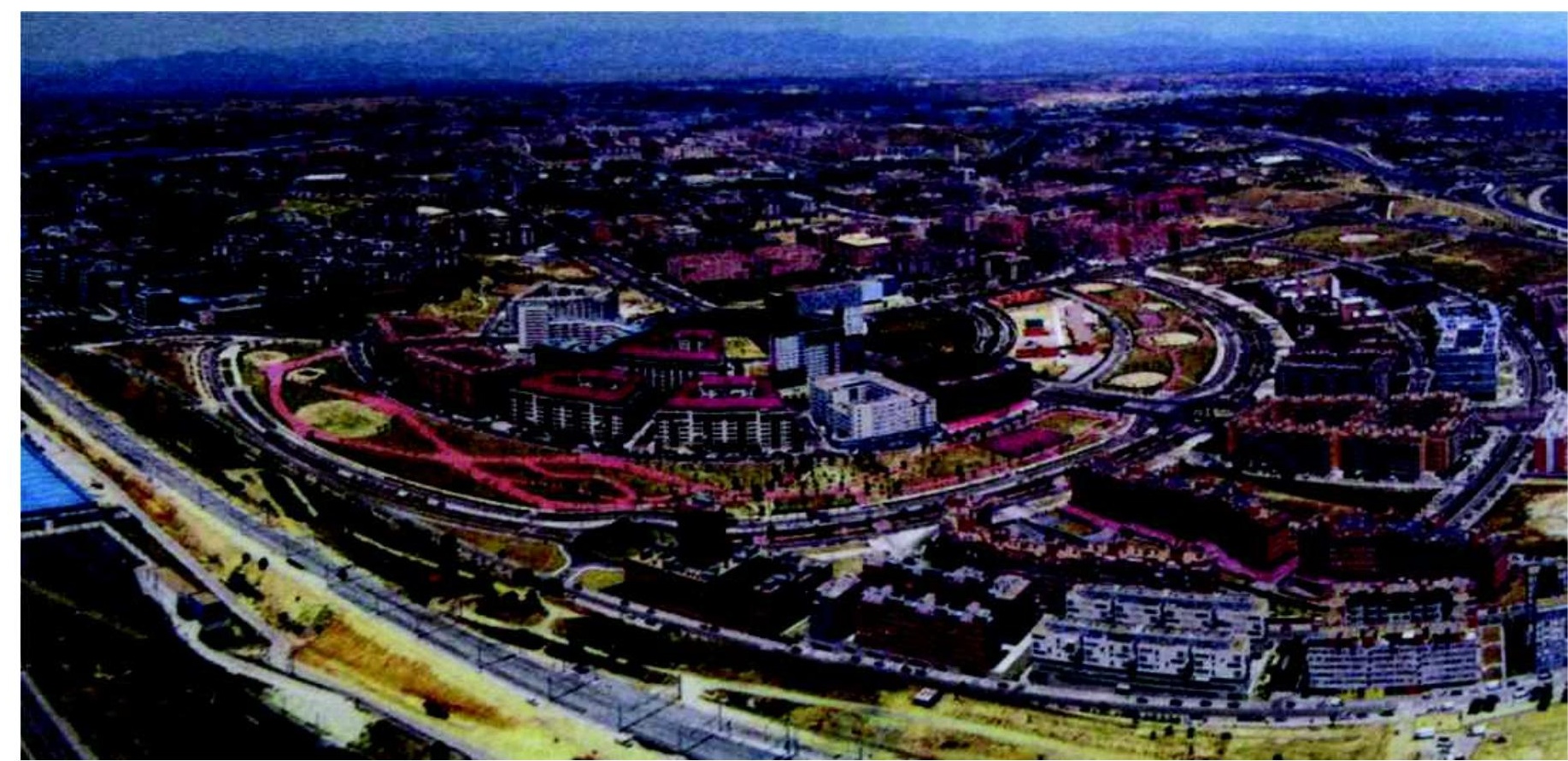

Entorno do Mirador com os blocos residenciais com pátios. Fonte: MVRDV Buildings.
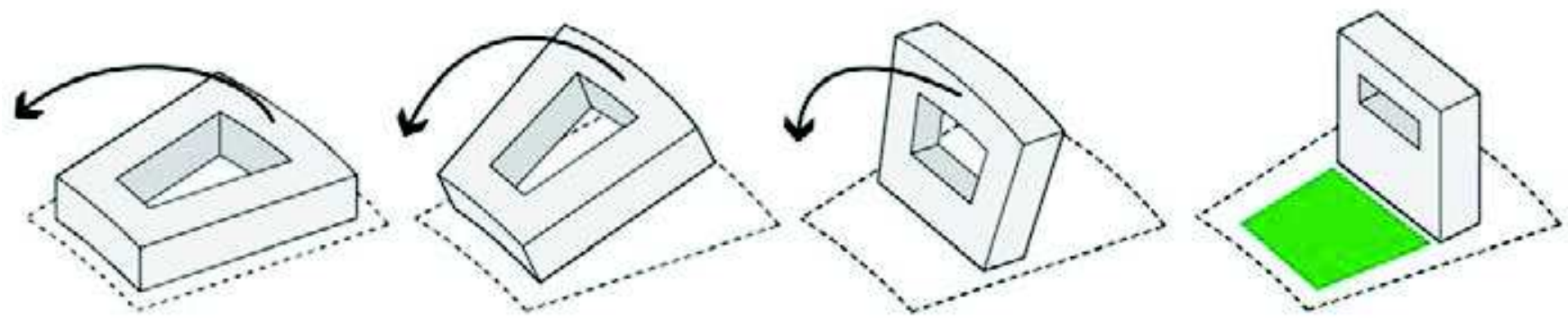

O bloco tradicional levantado libera área e gera um mirante como espaço comum. Fonte: www.mvrdv.nl 

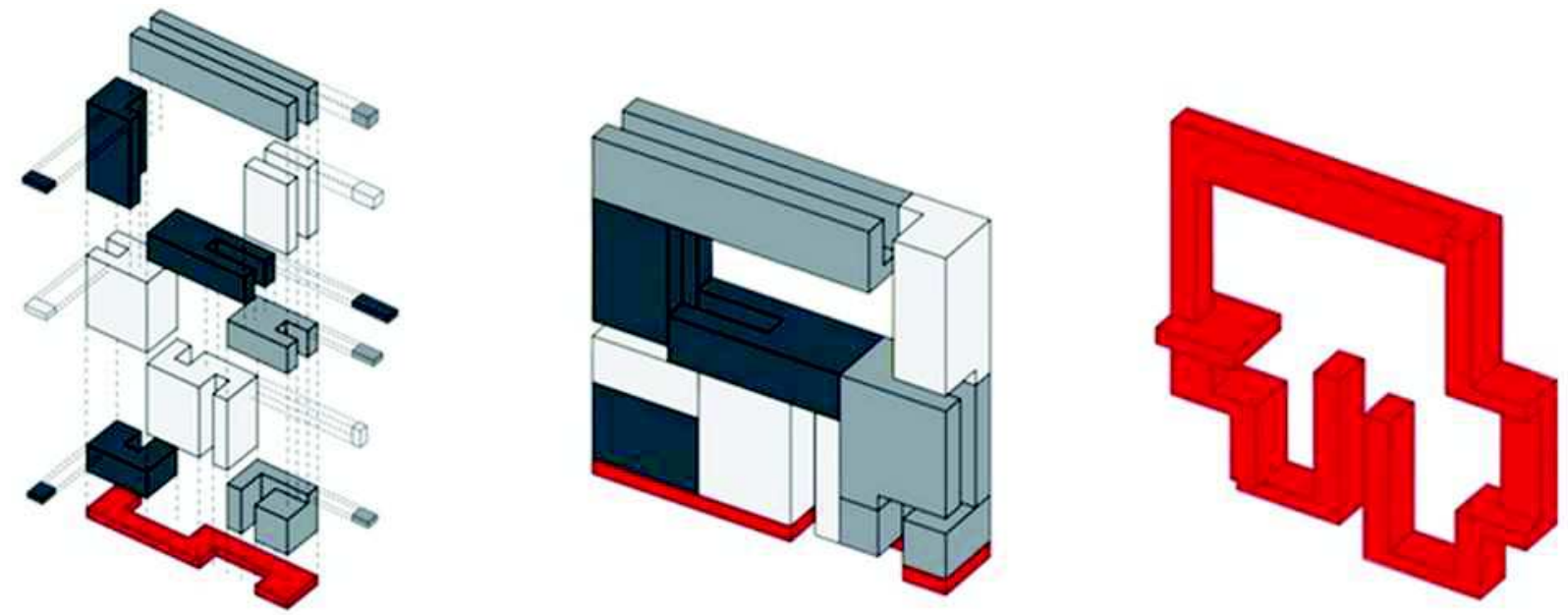

1- relação parte/todo. 2- aberturas e porosidade. 3- acesso e circulação. Fonte: www.mvrdv.nl

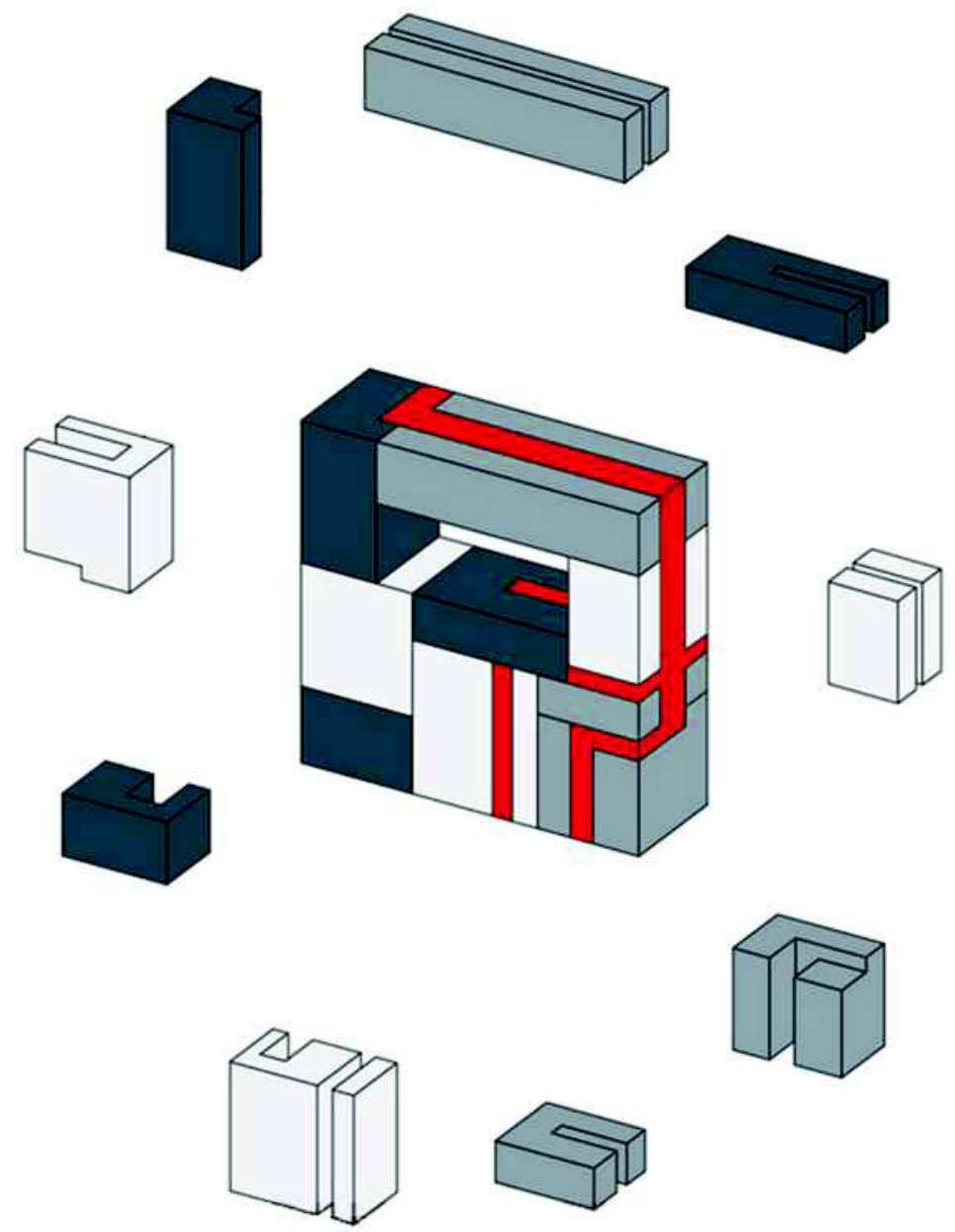

Diversidade de tipologias através da combinação de sub-blocos diferentes. Fonte: www.mvrdv.nl

\section{Vestígios do uso misto/espaços múltiplos}

O projeto inicial previa um edifício com habitação, serviços no térreo (cogitava-se um ponto de venda de uma grande rede de lojas de departamento da Espanha) e a 
praça pública elevada. Porém, durante a construção os arquitetos precisaram transformar os espaços comerciais em apartamentos térreos devido às intervenções políticas que não permitiam comércios de pequena escala em Sanchinarro (somente grandes centros comerciais).

A obra concluída manteve a diversidade de unidades habitacionais (15 tipologias agrupadas nos sub-blocos com o intuito de integrar grupos sociais e modos de vida distintos), a circulação variada que se abre em pequenos espaços coletivos e a praça elevada, sendo que todos são espaços de uso exclusivo dos moradores.

O trabalho com a circulação, como instrumento articulador dos espaços, muitas vezes presente na arquitetura holandesa, especialmente nos projetos de Koolhaas como Kunsthal (1992), biblioteca de Jussieu (1992), Euralille (1994), Grand Palais (1994) e biblioteca de Seattle (1999), mas também na Villa VPRO e Silodam do MVRDV, mais uma vez aparece como elemento estruturador do projeto. As circulações são como pequenas ruas verticais que conectam os nove sub-blocos. As escadas de emergência se destacam como aberturas entre os blocos e formam pequenas praças ao ar livre, espaços de reunião interligados por uma vibrante cor vermelha que conduzem os usuários até o vazio central.

O restante do terreno, que deveria se integrar a praça em frente ao edifício foi cercado por grades pelos moradores que também contrataram porteiros e seguranças, como nos prédios vizinhos.

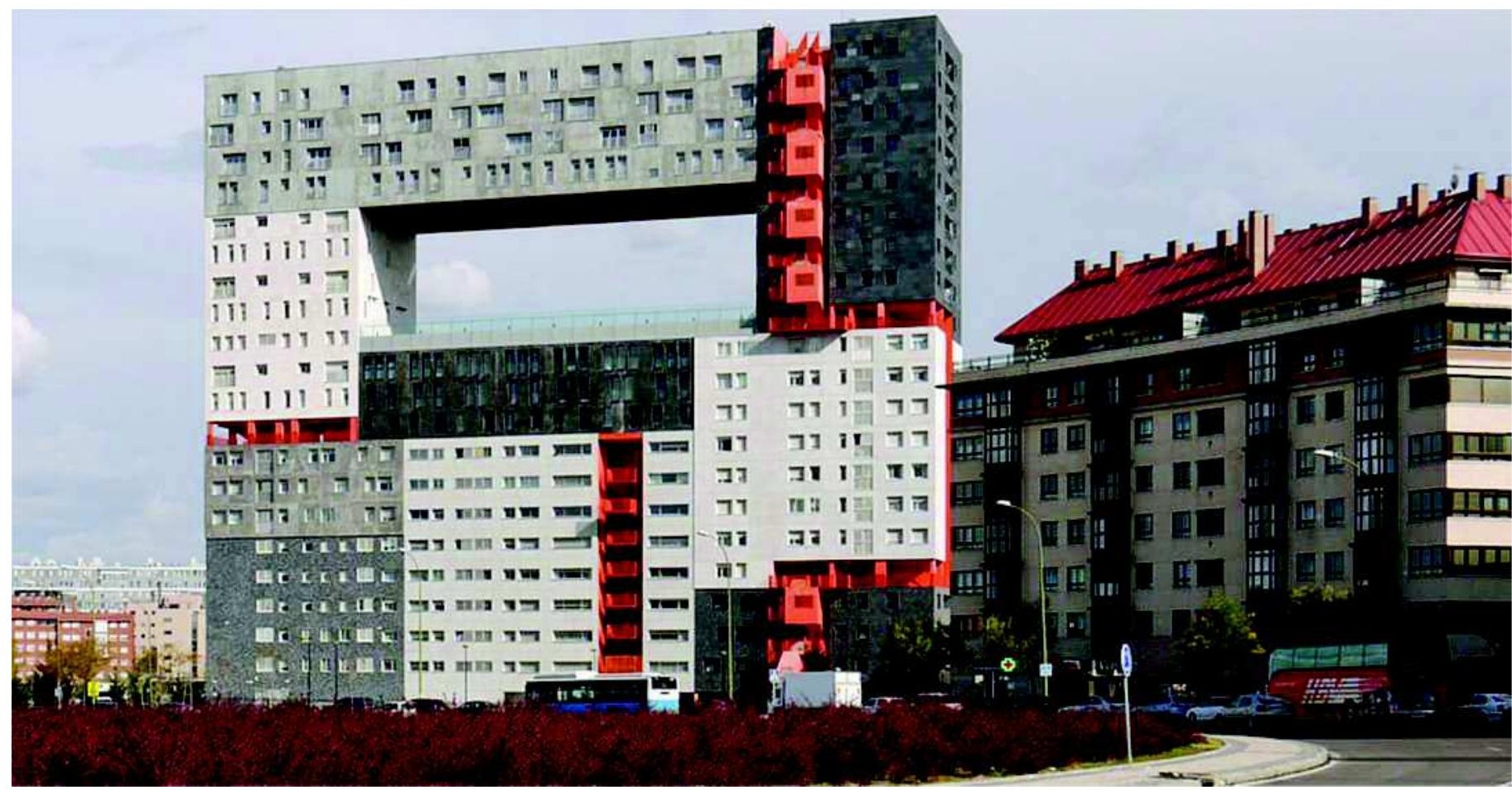

A circulação destacada dos sub-blocos. Fonte: www.wikimedia.com 


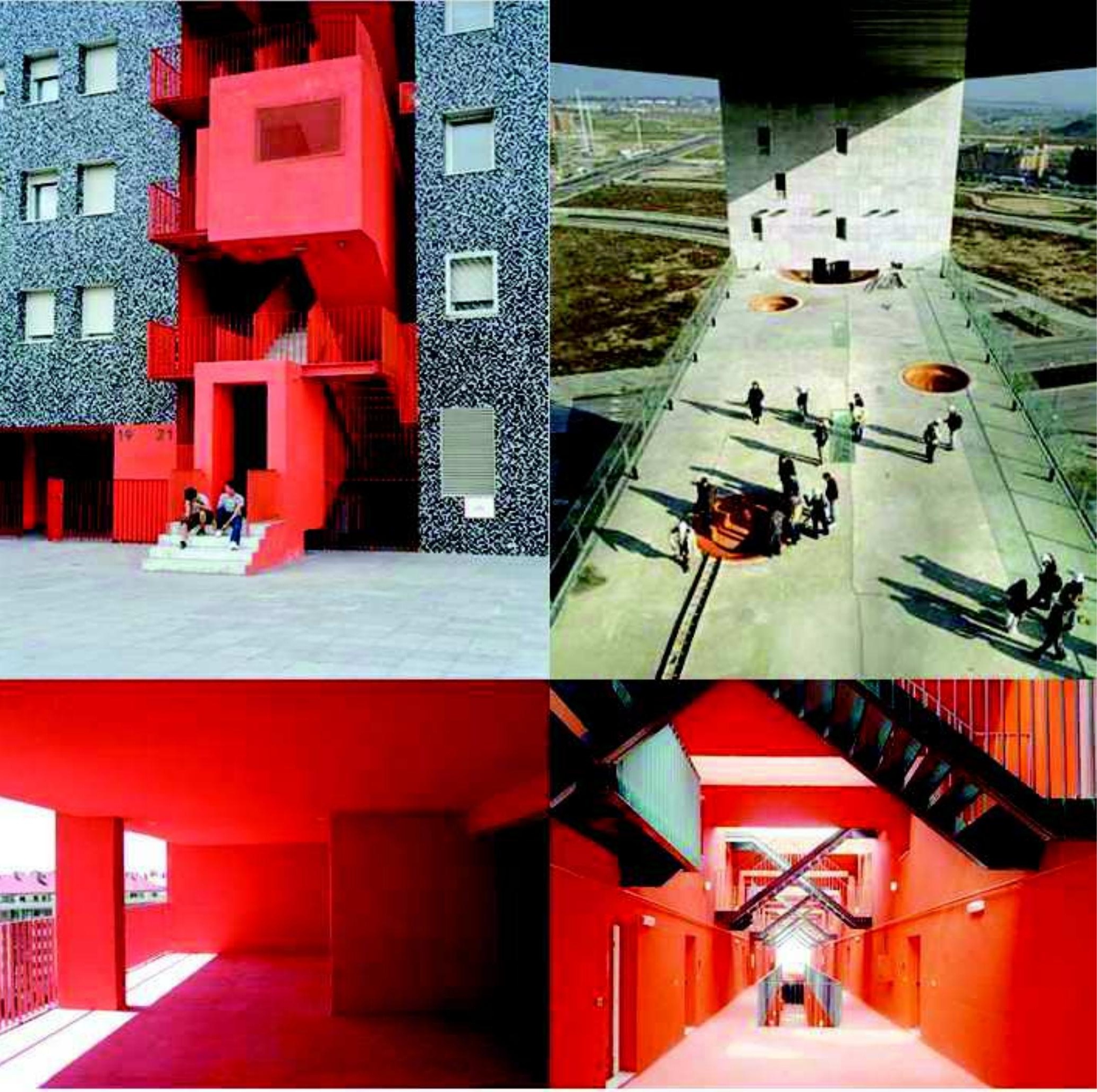

Início da circulação. Fonte: www.nytimes.com

O espaço vazio coletivo. Fonte: www.en.wikiarquitectura.com

Espaço coletivo na circulação. Fonte: www.mimoa.eu

Corredores, passarelas e escadas: Fonte: www.mvrdv.nl 


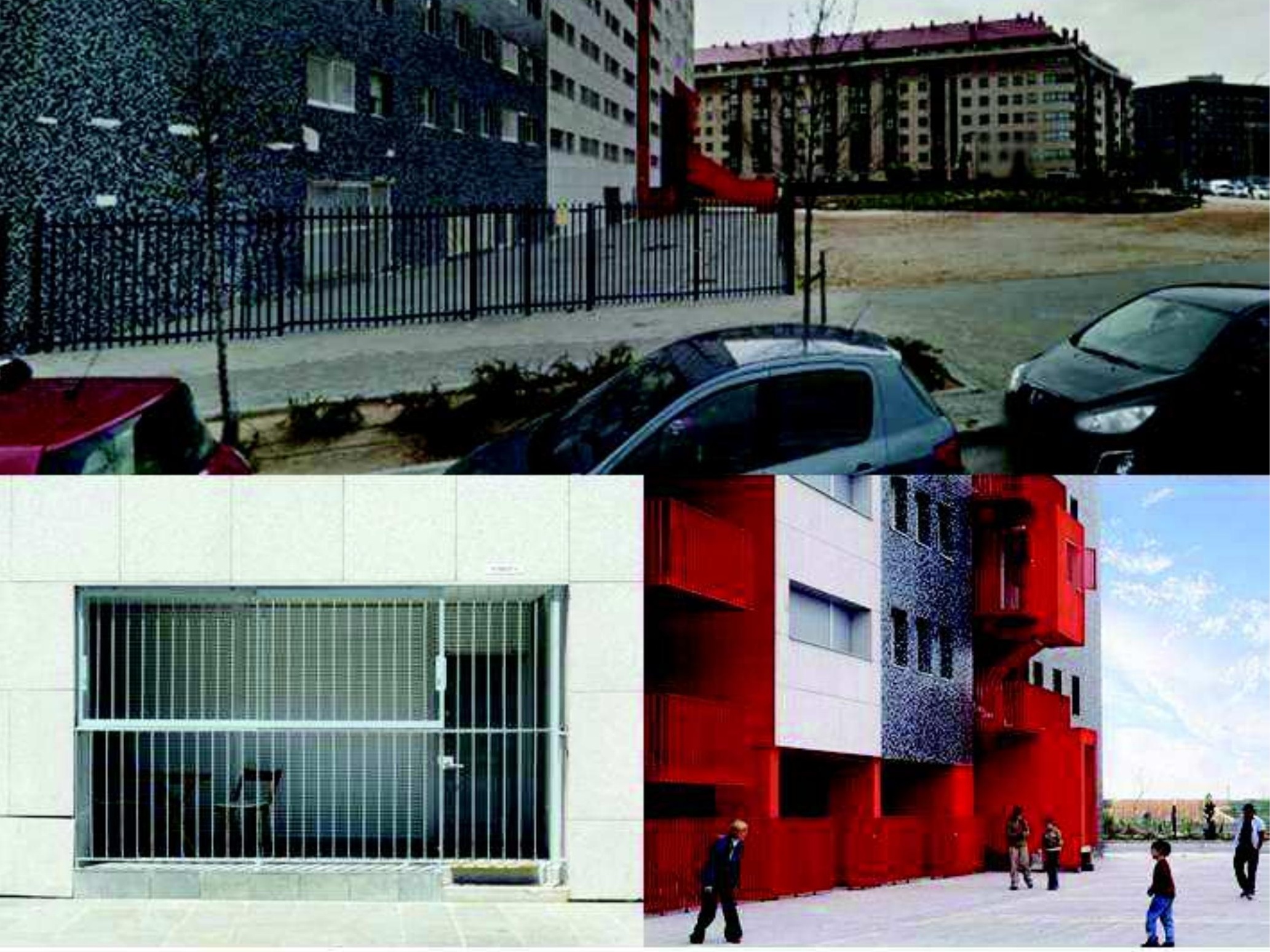

Grades no térreo. Fonte: www.nuevasarquitecturas.com

Grades cercando o terreno. Fonte: www.wikimedia.com

Grades separando Mirador e praça em fevereiro de 2014. Fonte: www.google.com/maps

Grades em apartamento térreo. Fonte: www.nuevasarquitecturas.com

Grades no térreo. Fonte: www.panoramio.com 


\section{Naturezas artificiais: liberando terreno}

Esse conceito no Mirador está diretamente relacionado à densidade. Sanchinarro surgiu através do PAU (Planos de Atuação Urbanística) e sua formação foi bastante influenciada por interesses financeiros, o que resultou em um bairro com poucos equipamentos, comércio e vida urbana. Mesmo na periferia, é uma área já adensada formada por habitações homogêneas e fechadas sem áreas livres qualificadas que instiguem a convivência dos moradores e a ocupação de espaços públicos.

Frente a esse cenário, o MVRDV opta por verticalizar o projeto, liberar terreno e conectar o exterior e o interior por meio do vazio no $12^{\circ}$ andar, colocando mais uma vez a construção como parte da paisagem. Contudo, o terreno liberado não foi alvo de projeto e, portanto, não há uma conexão entre essa natureza artificial da área livre com o projeto que, ao final, parece pousado no lote.

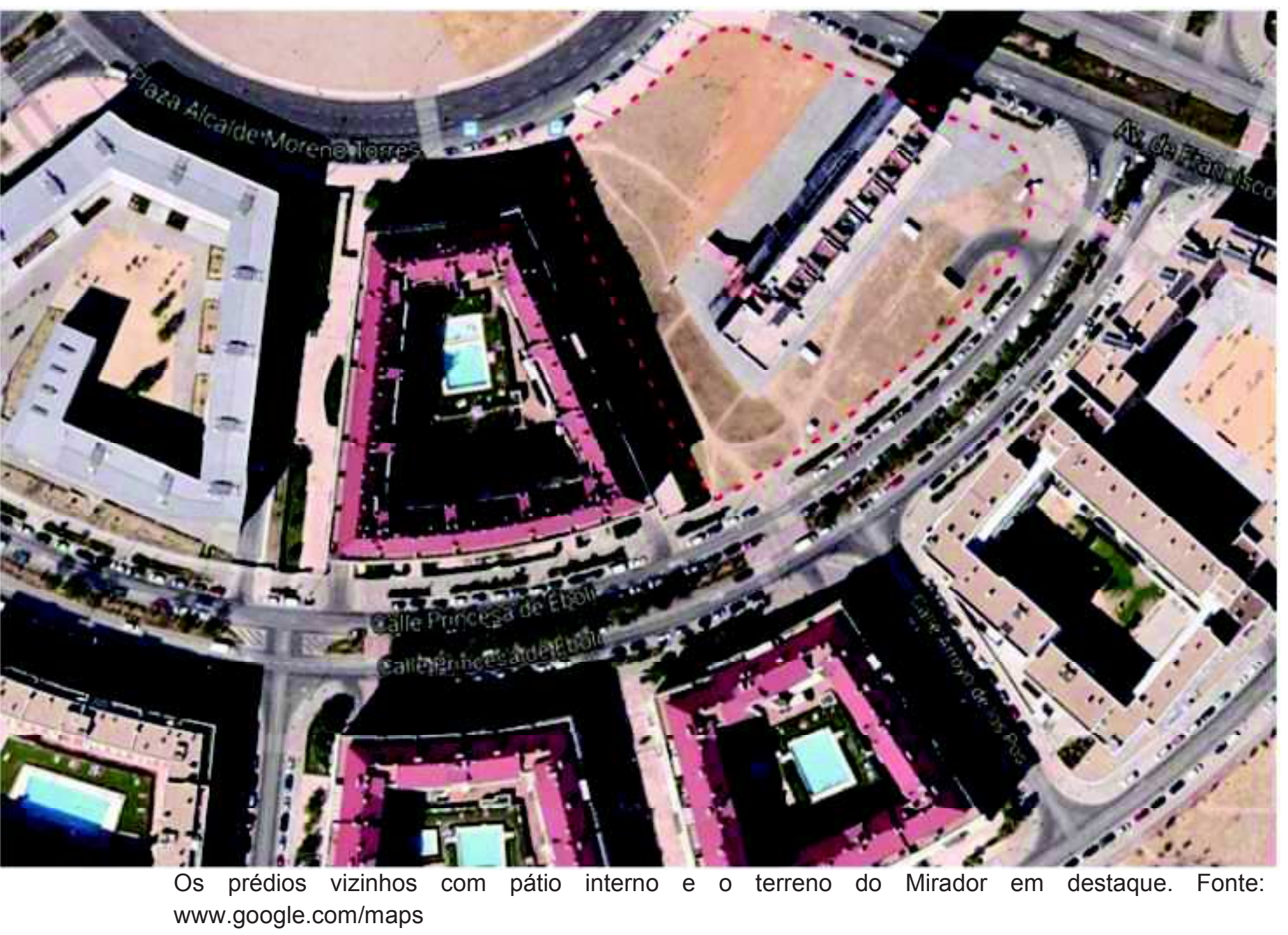




\section{O vazio como interiorização espacial}

A ideia de rua interna do Silodam se repete no Mirador. Aqui a circulação também se alterna nos diferentes pavimentos e trabalha como elemento de ligação entre os mini-bairros/sub-blocos com a diferença que agora ela aparece com muito mais ênfase na fachada. Novamente a circulação se abre, em certos momentos, formando espaços intermediários de convívio para os moradores. Além disso, algumas tipologias contam com varandas fortalecendo a relação das unidades com o exterior.

No entanto, o componente que mais enfatiza o conceito de interiorização espacial é o grande vazio no $12^{\mathrm{a}}$ andar do edifício. Inicialmente, esse elemento foi pensado como um espaço público com acesso diretamente da rua e até mesmo considerava uma escada rolante que o conectava diretamente ao térreo, mas que foi cancelada por razões financeiras, servindo, porém, como instrumento de negociação. Segundo o sócio do MVRDV Jacob van Rijs, eles incluíram a escada rolante no projeto sabendo que era um excesso, mas depois a cancelaram para poder manter o mirante (MVRDV Buildings, p. 227).

O espaço, que inicialmente foi utilizado por toda população do bairro, se tornou área de uso exclusivo dos moradores depois de vários pedidos à Empresa Municipal de Vivienda y Suelo (EMVS) por razões como: reclamações de barulho pelos moradores das unidades vizinhas ao mirante; problemas de segurança com garrafas arremessadas do vazio e os altos custos com iluminação e com os elevadores que ligam o térreo ao espaço comum, pagos pelos moradores que, no primeiro ano de ocupação, contrataram guardas para controlar o grande número de pessoas que procuravam o espaço. Assim, o grande destaque do projeto transformou-se em um de seus maiores problemas. Segundo um dos seguranças do edifício, o terraço se tornou objeto de discussão porque os bombeiros afirmavam que os ventos eram fortes e os pais não permitiam que crianças brincassem ali, preferindo que elas utilizassem o terreno vazio no térreo (MVRDV Buildings, p. 228). Outro espaço alvo de críticas por parte dos moradores são as caixas de escadas, abertas em alguns trechos e sujeitas às intempéries.

Na pós-ocupação, o MVRDV analisa esses espaços comuns como investimentos para o futuro e acreditam que os usuários precisarão de tempo para se acostumar a eles. Ainda, os arquitetos esperam que as próximas gerações passem a estimar o 
mirante e, à medida que as unidades forem vendidas para o mercado, os novos moradores valorizarão essas áreas porque escolherão morar ali (MVRDV Buildings, p. 232). É evidente que o uso de dados e a investigação projetual não garantem a ausência de erros nas escolhas de projeto, mas notamos que a crença no tempo como solucionador desses problemas é crítica à medida que dissipa a urgência que existe por espaços habitacionais em uma cidade que cresce rapidamente, assunto tratado pelo próprio MVRDV em seus estudos.

Contudo, apesar dos problemas do vazio, é relevante reconhecer seus aspectos positivos. O espaço público do Mirador congrega uma variedade de sub-blocos com diferentes moradias, em contraste com a produção em massa de habitações que se repetem em Sanchinarro. Ainda, a consideração do vazio como material arquitetônico (com suas qualidades espaciais através de linhas de fuga, aberturas visuais e sua dimensão horizontal) se revela um instrumento valioso graças ao seu espaço negativo que quebra a homogênea densidade dos cheios do entorno.

O MVRDV eleva as áreas comuns da cidade, frequentemente localizadas no térreo para o meio do edifício revistando o gesto de Le Corbusier que insere os espaços coletivos na cobertura da Unité d'Habitation.

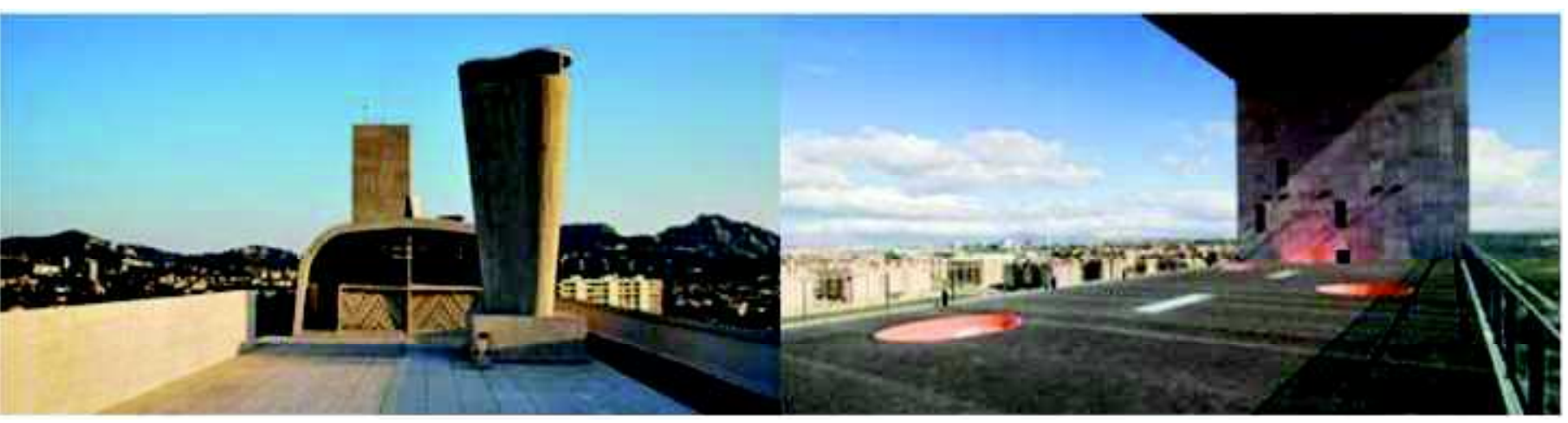

Terraços da Unité d'Habitation e do Mirador. Fonte: www.flickr.com, usuários neil mp e jarq. 


\section{Inversão do subúrbio urbano}

A estratégia de empilhar as casas típicas do subúrbio mescladas com espaços comuns e evitar a ocupação das áreas livres com construções de baixa densidade aparece também no Mirador. Apesar de o projeto estar localizado no subúrbio de Madrid, a intenção do MVRDV é evitar a repetição de um modelo consolidado no bairro que ocupa todo lote e volta as habitações para um pátio central sem relações com a rua e a cidade.

A proposta dos arquitetos é retomar a ideia de comunidade somando-se a isso algumas facilidades como comércio e serviços (que na prática não se realizou conforme relatamos no tópico Vestígios do uso misto/espaços múltiplos), estacionamentos subterrâneos e os espaços coletivos dentro do edifício. Aqui, ao invés de levar características dos subúrbios para áreas centrais, os arquitetos invertem a ideia e trazem aspectos das áreas centrais para o subúrbio com a intenção de preservar os terrenos desses bairros afastados. 


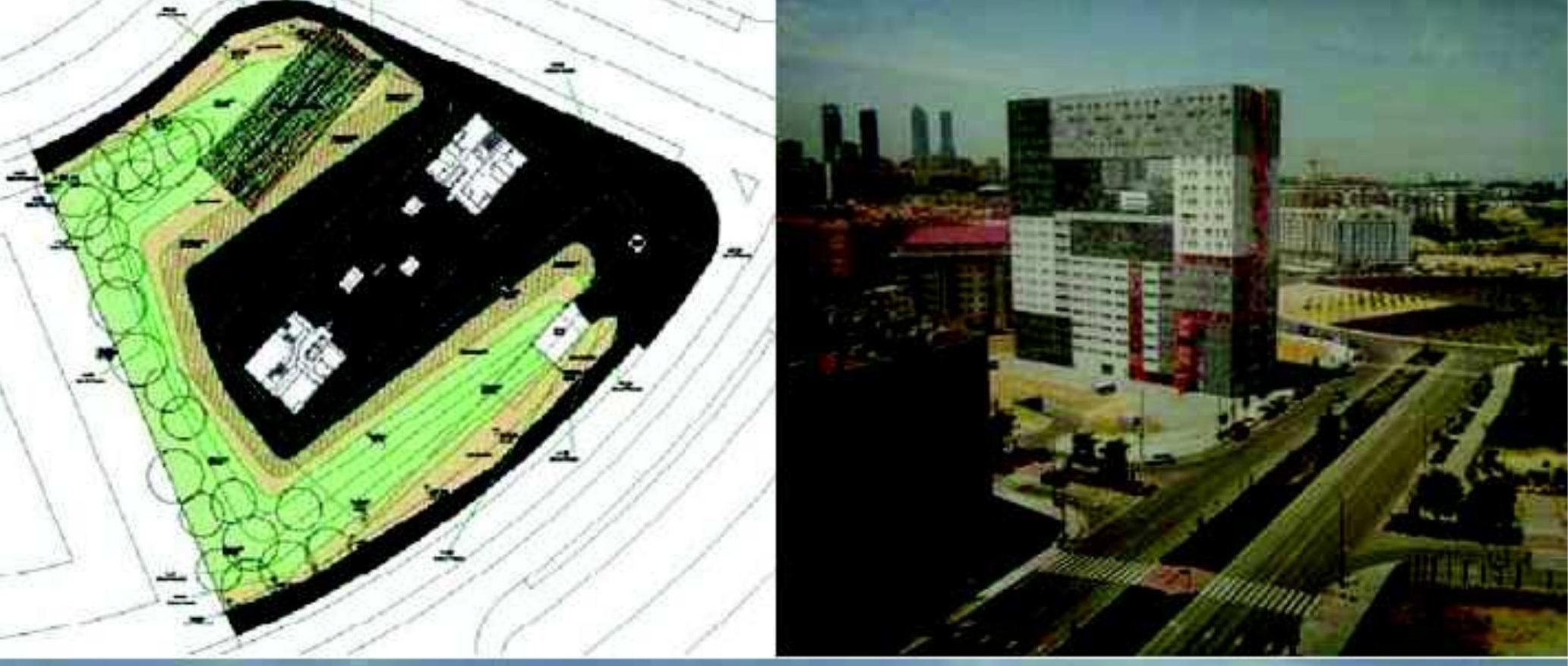




\section{Densidade porosa}

A inserção de um projeto que trata de densidade na periferia pode soar como contradição, mas o MVRDV aceita o fato de Sanchinarro já ser um bairro adensado e que dispõe do mínimo de infraestrutura pronta e busca, como no Silodam, o adensamento com baixa ocupação. Ao invés de expandir horizontalmente e consumir mais área verde do bairro, os arquitetos resgatam seus estudos sobre subúrbio urbano, solução que já havia aparecido no projeto Wozoco.

$\mathrm{O}$ conceito de resguardar a paisagem liberando solo e preservando suas qualidades (grandes superfícies, os horizontes para a serra e vegetação) faz com que a escala do Mirador seja completamente diferente dos seus vizinhos, quase como um elemento pousado que parece querer colonizar o local. Esse aspecto é potencializado pela sua falta de conexão com o próprio terreno que ele libera somada à separação com grades feita pelos moradores na pós-ocupação. $O$ único elemento que parece conectá-lo ao local é o mirante voltado para as montanhas de Guadamarra.

Apesar de sua escala desproporcional ao entorno, o Mirador tem média densidade, conforme mostramos a seguir. Como primeiro método, calculamos a densidade do edifício multiplicando-se o número de unidades habitacionais do projeto pelo número de pessoas que podem morar nelas (mesmo método do Silodam) e obtivemos os seguintes valores:

a- Número de moradores possíveis no Mirador: 502 habitantes

b- Densidade Madrid (2014) ${ }^{33}: 4.700$ habitantes $/ \mathrm{km}^{2}$

c- Densidade Mirador: 50.200 habitantes $/ \mathrm{km}^{2}$

A área do terreno é de $10.000 \mathrm{~m}^{2}$. A população de Madrid é 3.300 .000 habitantes $^{34}$ (excluindo a região metropolitana). Assim, novamente utilizamos a classificação de níveis de adensamento de Aurora Fernández $\mathrm{Per}^{35}$ (habitações $/ \mathrm{km}^{2}$ ) para situar o projeto entre os possíveis modos de densidade. O Mirador se encaixa na terceira categoria: média densidade (15.600 habitações $/ \mathrm{km}^{2}$ ).

\footnotetext{
${ }^{33}$ Fonte: Demographia World Urban Areas, 10a edição anual, maio/2014.

${ }^{34}$ Instituto Nacional de Estadística, janeiro/2012. www.ine.es

${ }^{35}$ PER, A. F. Densidad nueva vivienda colectiva. Vitoria: A+T, 2006.
} 


\begin{tabular}{l|l}
\hline Mais que 30.000 habitações $/ \mathrm{km}^{2}$ & $\begin{array}{l}\text { Elevada densidade. Habitação apa rece associada à verticalidade como as torres nas grandes } \\
\text { metrópoles asiáticas e americanas. }\end{array}$ \\
\hline 20.000 a 30.000 habitações $/ \mathrm{km}^{2}$ & Alta densidade. Centros urbanos consolidados. \\
\hline 10.000 a 20.000 habitações $/ \mathrm{km}^{2}$ & Média densidade. Centros urbanos com blocos independentes e ampla área livre disponivel. \\
\hline 5.000 a 10.000 habitações $/ \mathrm{km}^{2}$ & Baixa densidade. O conceito de uso misto surge nas atividades urba nas. \\
\hline Menos de 5.000 habitações $/ \mathrm{km}^{2}$ & $\begin{array}{l}\text { Baixa densidade associada as formas de ocupação de subúrbios. Os projetos originados do plano } \\
\text { Vinex tem tais caracteristicas esão, a proximadamente, } 95 \% \text { voltado para o uso residencial. }\end{array}$ \\
\hline
\end{tabular}

A densidade média do Mirador vai ao encontro da demanda por habitação associada à sua localização que ainda gera muitos deslocamentos da população até a área central da cidade, se a densidade fosse maior o número de deslocamentos aumentaria consideravelmente, mas nesse caso, as decisões sobre a quantidade de habitações partiram das regras locais e não dos arquitetos. Aqui o MVRDV definiu que a média densidade seria combinada com baixa ocupação, buscando trazer, dentro de todas as limitações, sua bagagem de pesquisas e estudos para uma realidade diferente da holandesa.

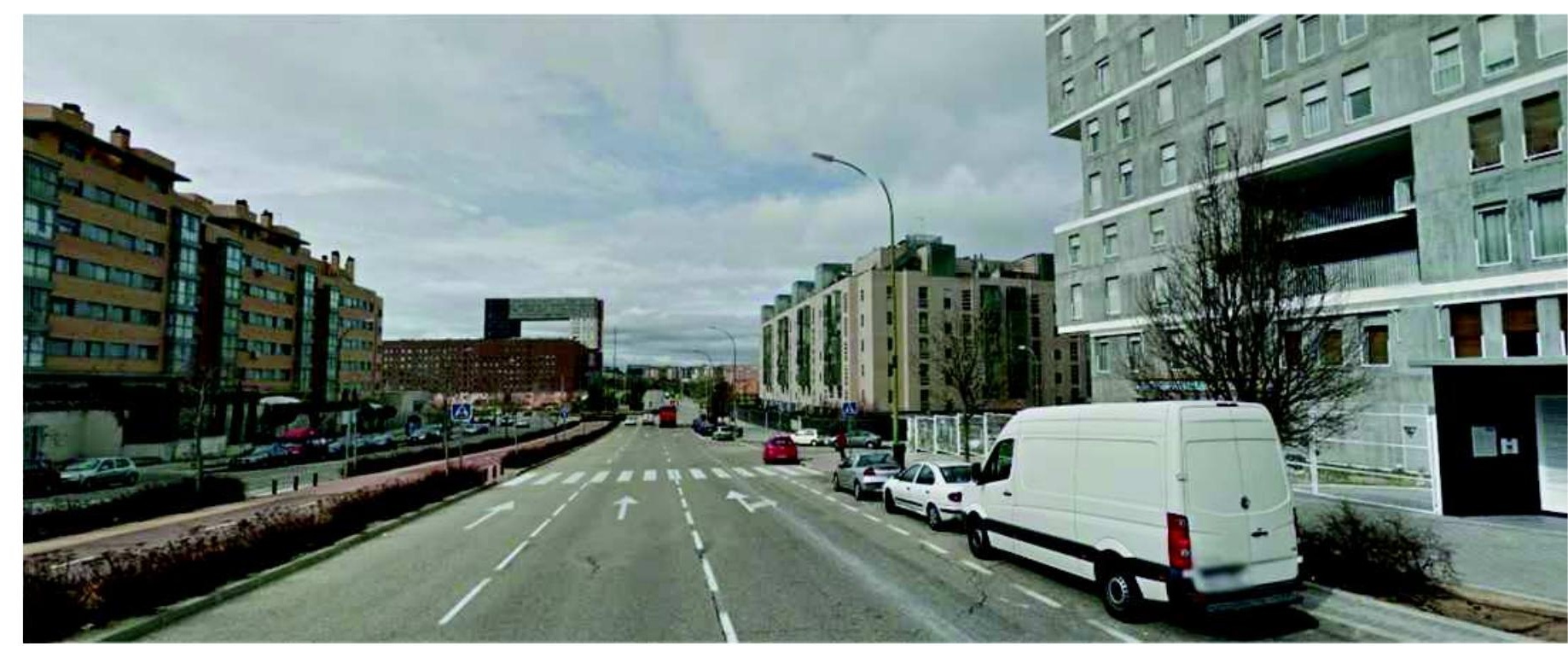

Mirador ao fundo e Celosia, outro projeto do MVRDV em Sanchinarro, em primeiro plano à direita. Fonte: www.google.com/maps. 


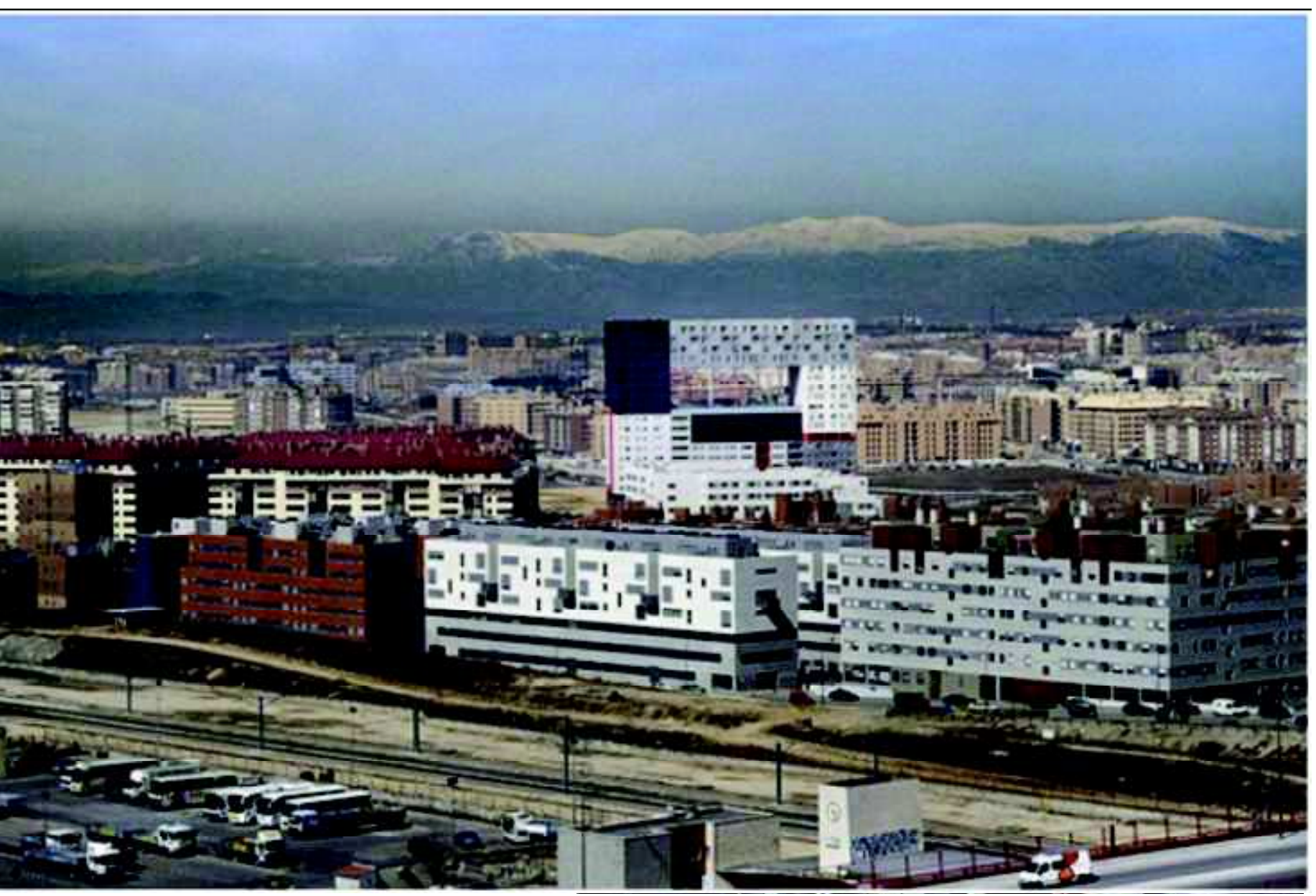

Vista aérea de Sanchinarro. Fonte: MVRDV Buildings 
Vista da Avenida de Francisco Pi y Margall. Fonte:

www.wikimedia.com

Mirador. Fonte: www.nytimes.com



s. 


\section{Diversidade/ldentidade como marco}

A aplicação da diversidade no Mirador é mais um conceito que aparece de modo semelhante ao Silodam. Pavimentos, circulações e tipologias distintas são agrupados em um único bloco que também revela seu conteúdo diverso no exterior. Pedra, concreto, cerâmica e placas metálicas marcam as fachadas dos sub-blocos conectados pela circulação de cor vermelha e que se desdobra em uma sequência de escadas, halls, plataformas, ruas interiores e até becos transformados em aberturas expostas nas fachadas.

Se a diversidade de espaços comuns está espalhada nos sub-blocos que compõem o Mirador, a identidade aparece através do bloco total como um marco no bairro de Sanchinarro, principalmente pela escala e pelo vazio como grande ponto de atenção. O edifício pode ser visto desde a rodovia A1 (Madrid - Burgos).

O MVRDV coloca uma escala monumental no Mirador e gera uma identidade diferente que chama atenção para a questão da homogeneidade de Sanchinarro e também busca redefinir a paisagem da região. Utilizando a definição de Koolhaas, "bigness é um território teórico deste fim de século: em uma paisagem de desordem, dissociação, desmembramento e rejeição, a atratividade da grande dimensão está na sua possibilidade de reconstruir a unidade, de ressuscitar o real, reinventar 0 coletivo." ${ }^{36}$

No entanto, o aumento da escala associado ao vazio faz com que a atenção se volte mais ao efeito que ele produz do que para a estrutura em si, prova disso é que o edifício ficou conhecido popularmente como 'Bin Laden', pois, para os moradores da região, um avião poderia atravessá-lo. Neste ponto vale resgatar um dos primeiros projetos do MVRDV, Berlin Voids, que também discutia a questão da identidade no seu entorno homogêneo da Berlim Ocidental, mas optou por respeitar a escala do contexto.

$\mathrm{Na}$ sequência, apresentamos as plantas de cada pavimento do Mirador. Novamente foram destacadas as áreas coletivas, os apartamentos e as áreas comerciais (adotamos as plantas do projeto inicial que previa comércio) representadas pelas cores vermelho, azul e amarelo, respectivamente.

\footnotetext{
36 "Bigness ovvero il problema della grande dimensione", Domus, n. 764, Ottobre 1994, pp. 87-90
} 

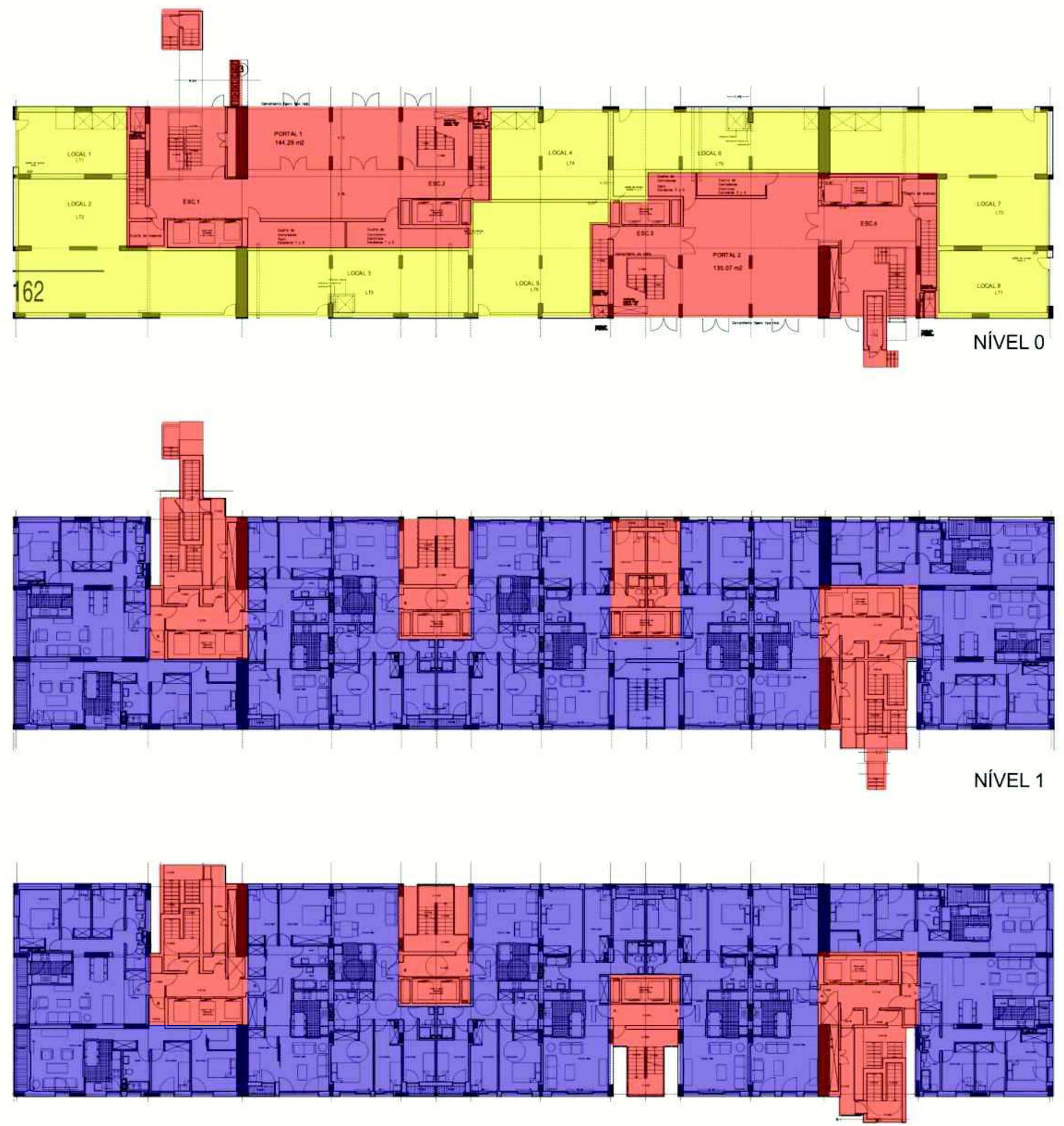

NIVEL 2

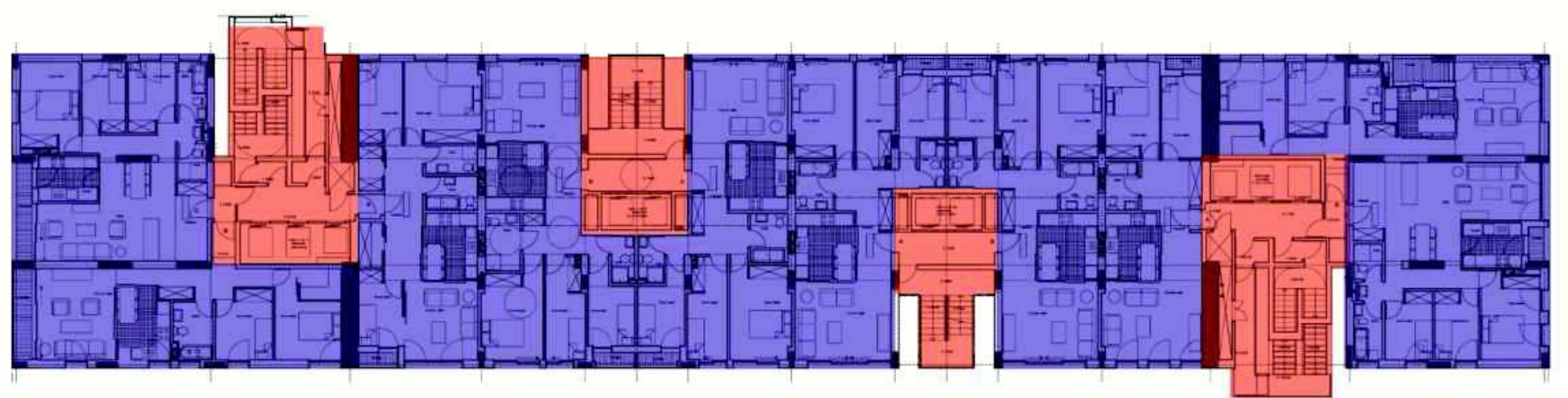

NIVEL 3 

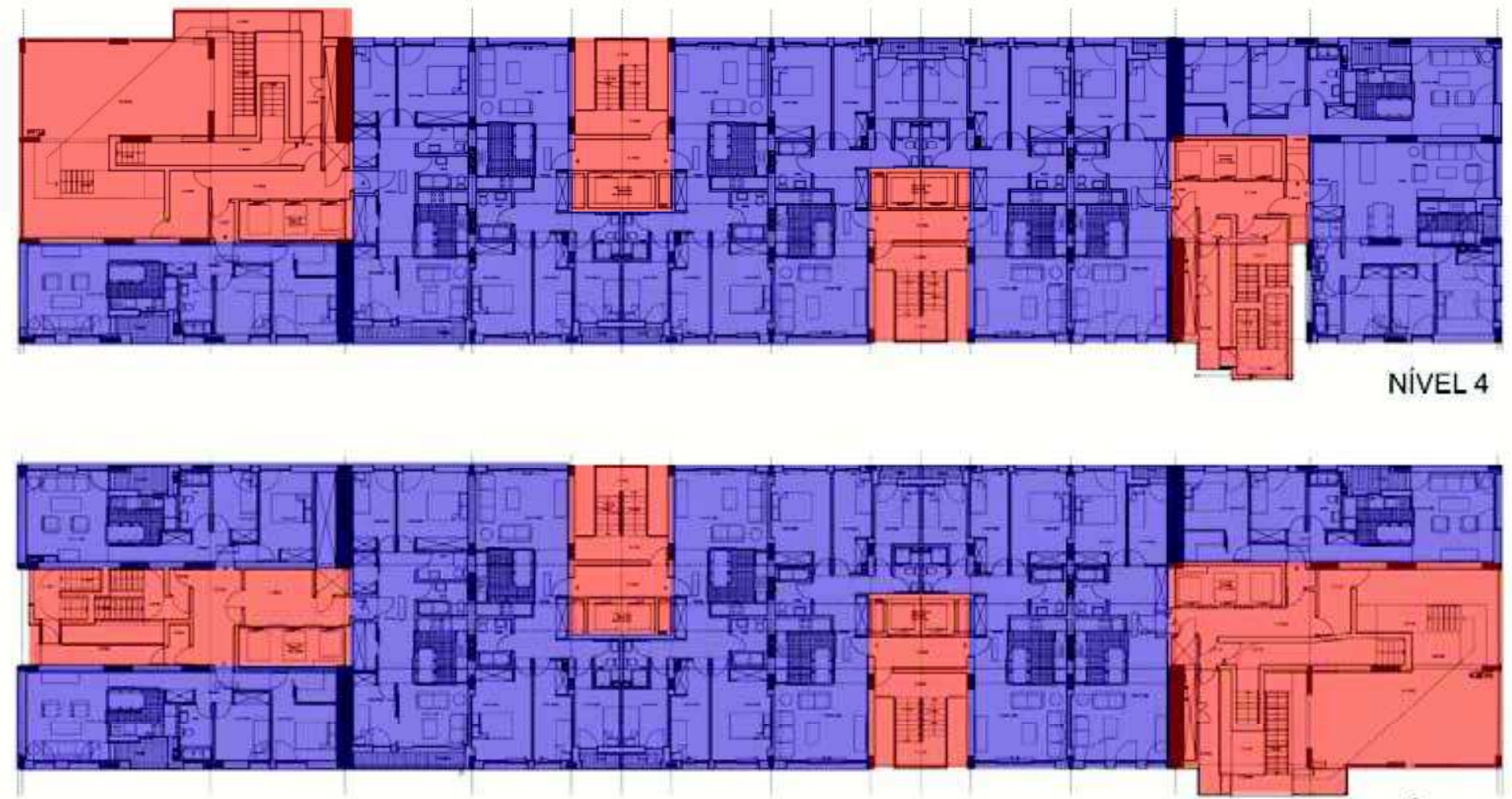

NIVEL 5
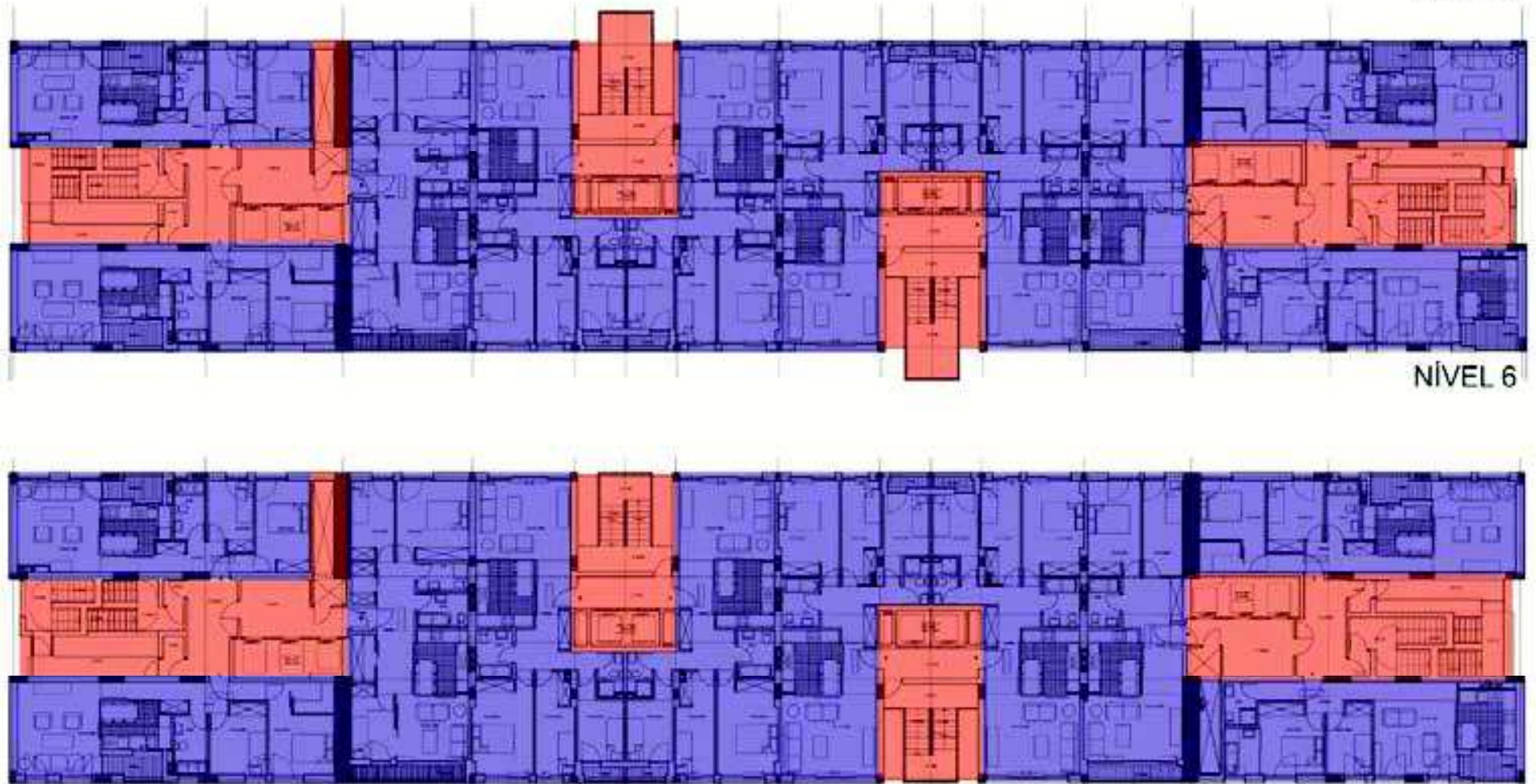

NIVEL 7

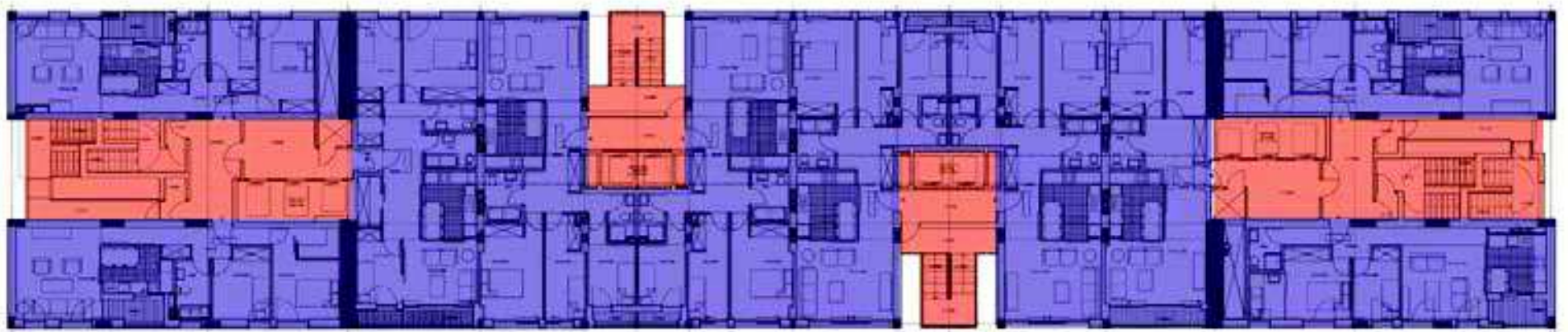

NIVEL 8 

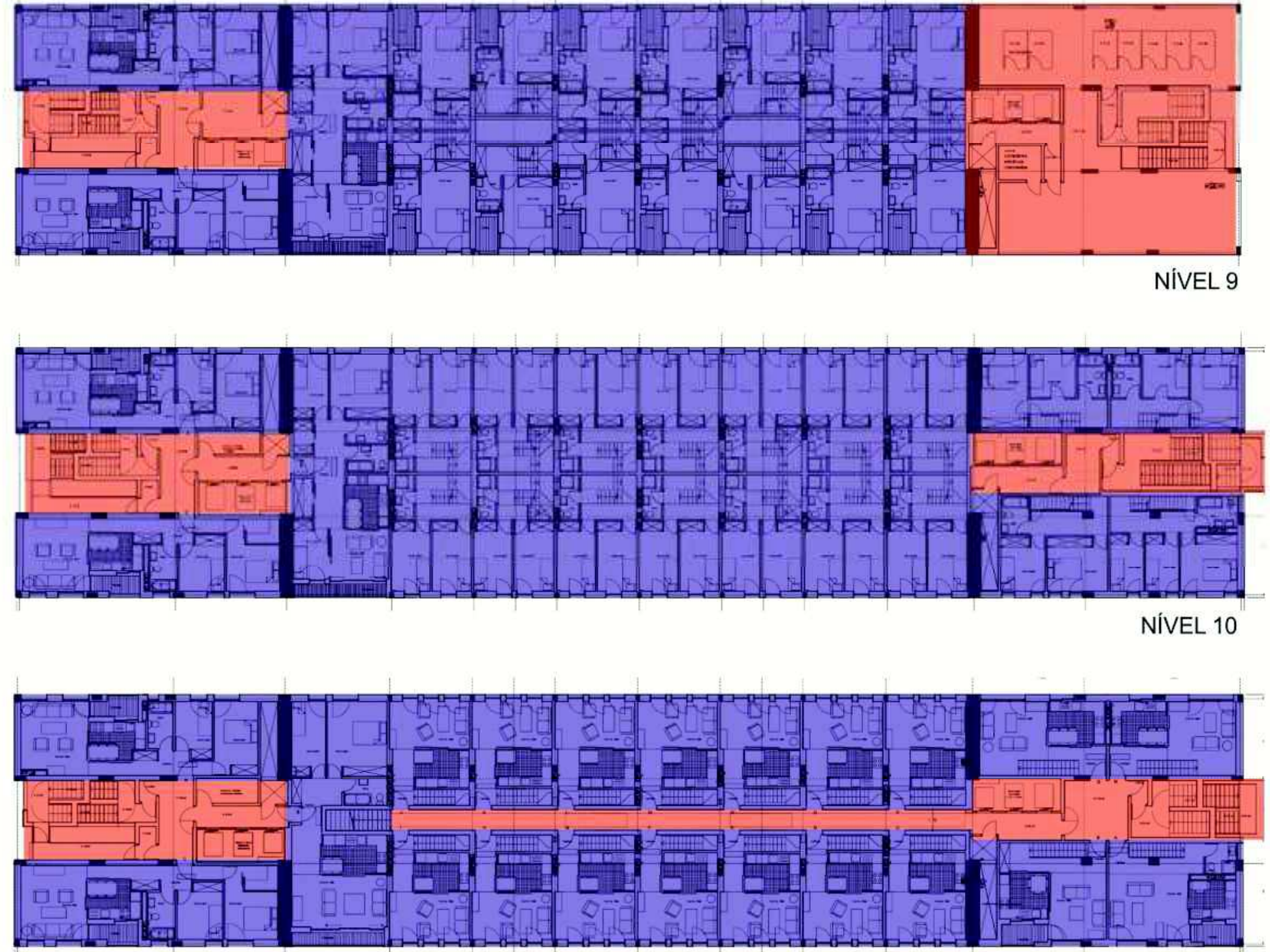

NIVEL 11
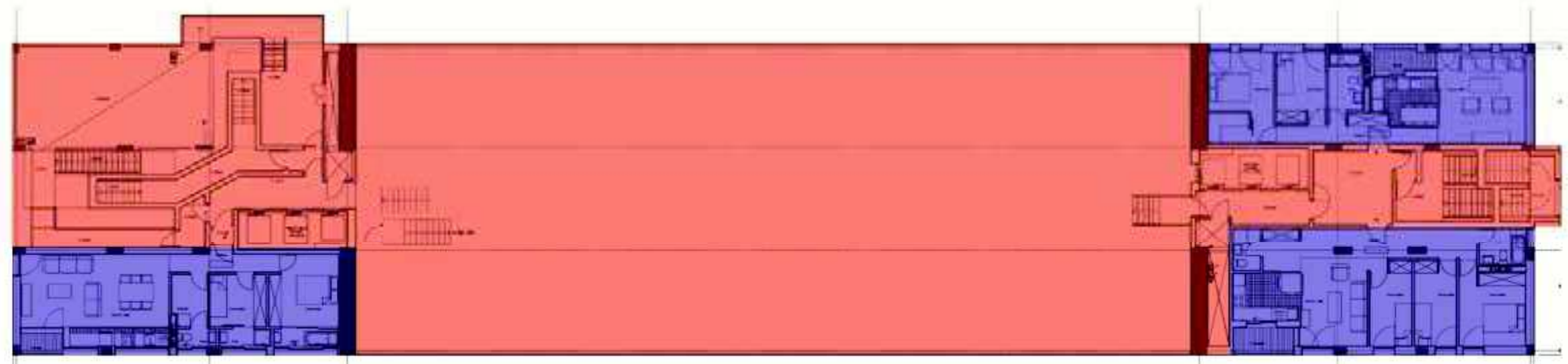

NIVEL 12
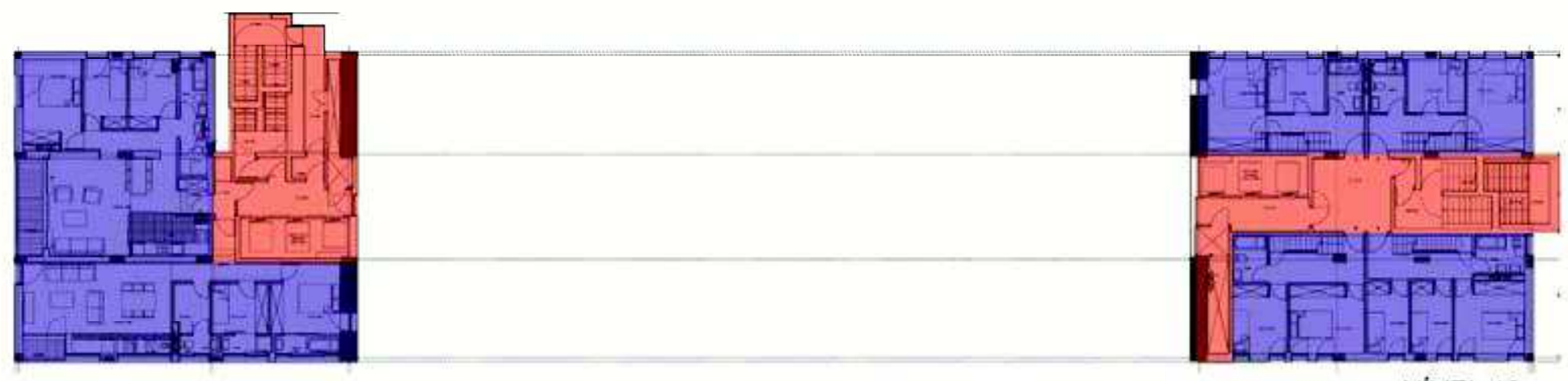

NIVEL 13 

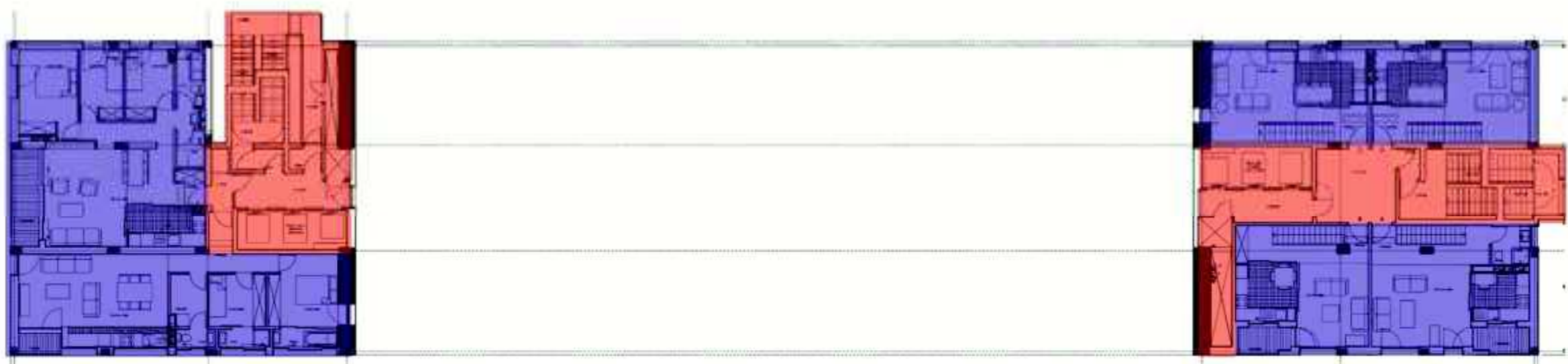

NÍVEL 14
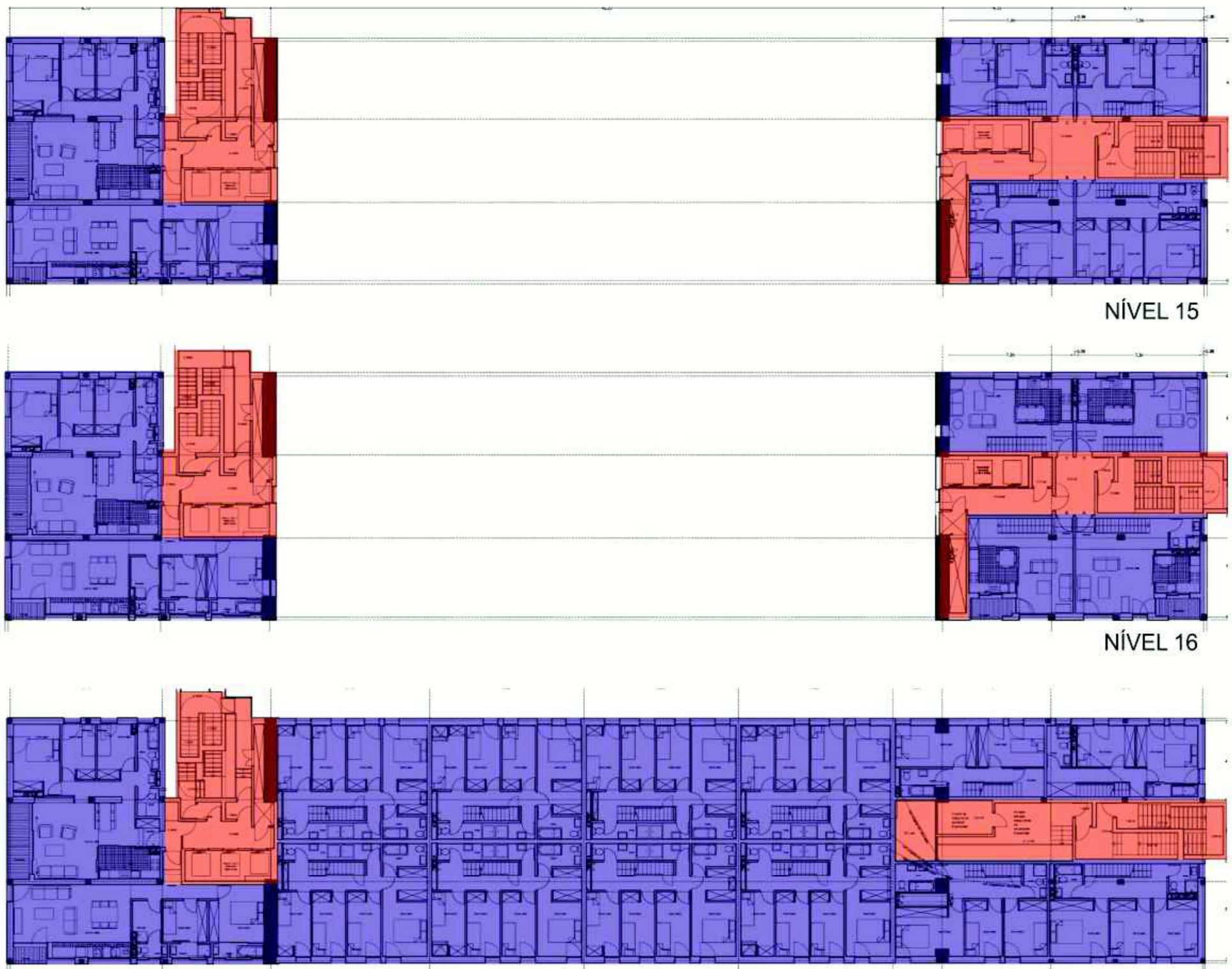

NÍVEL 17

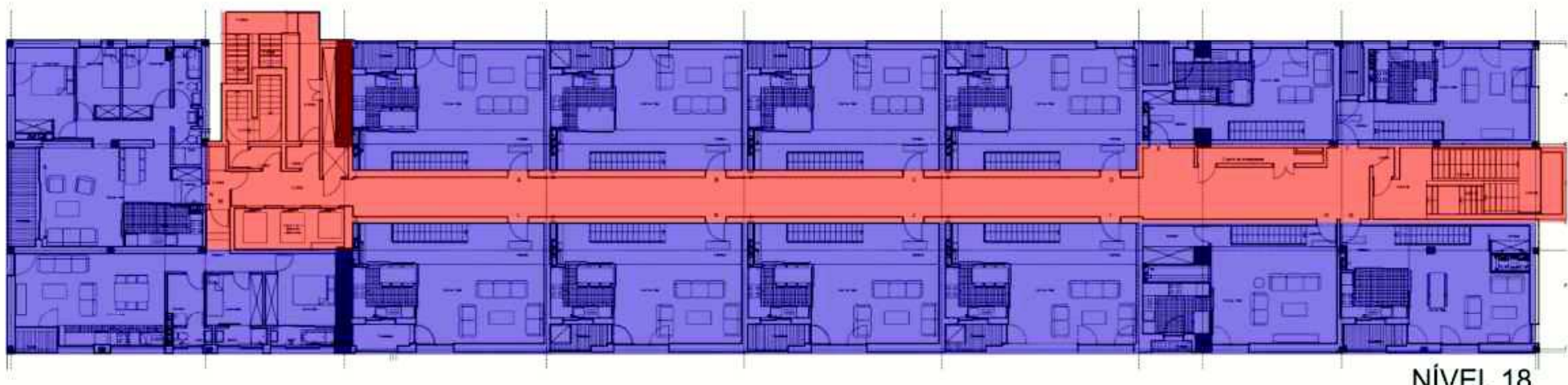



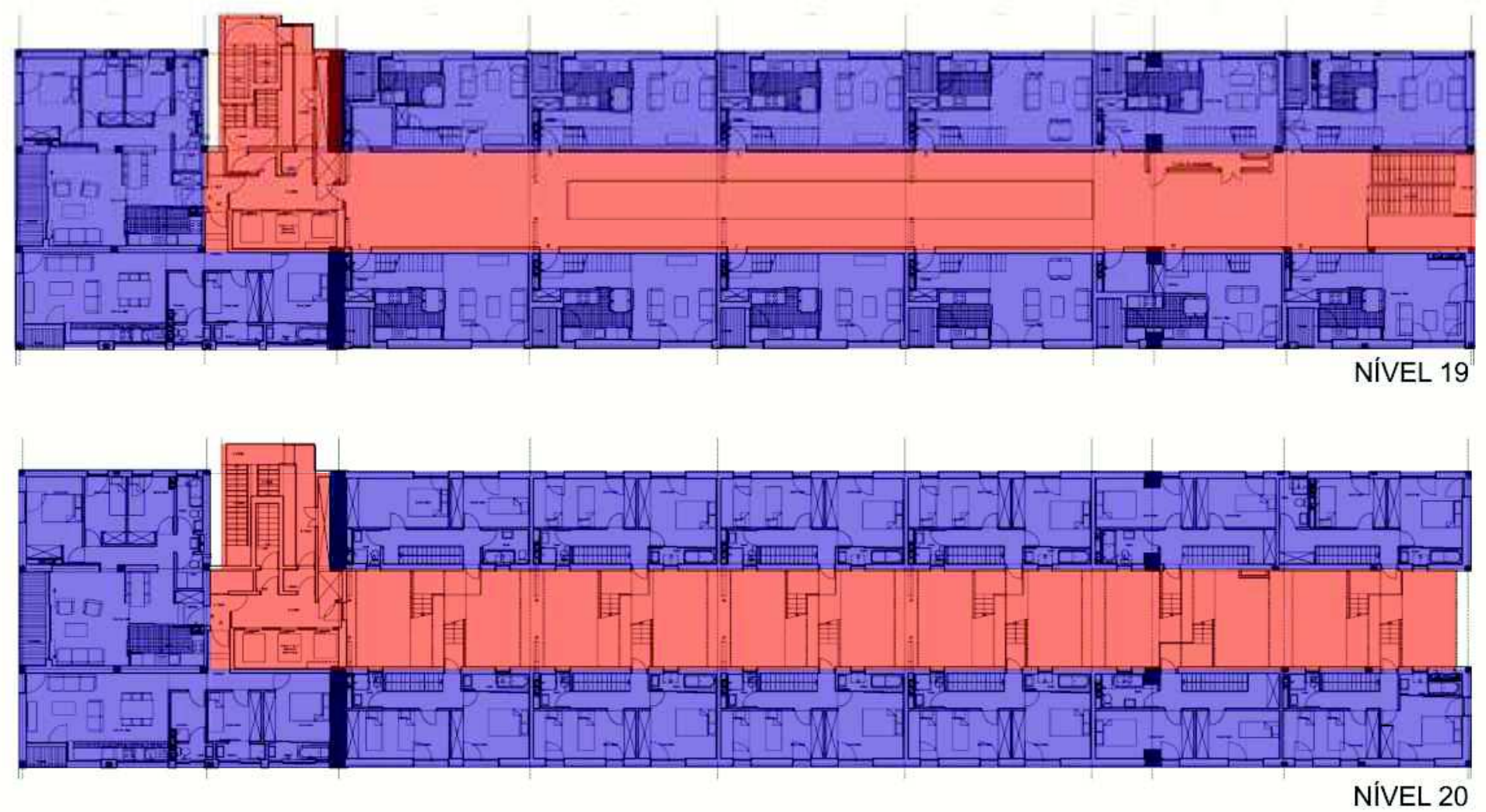
O Mirador conta com 15 tipos de apartamentos, sendo que algumas dessas unidades ainda apresentam variações, somando um total de 36 tipologias. As habitações se diferenciam em tamanho (de 65 a $107 \mathrm{~m}^{2}$ ), número de dormitórios (dois a quatro), número de pavimentos (único, duplex, triplex) e acessos. Em 2005, ano em que foi concluído, os apartamentos custavam entre 101.400 e 148.600 euros $^{37}$. As plantas são bem tradicionais e compartimentadas: das 36 variações, 12 possuem espaços exclusivos como suítes ou varandas, no entanto a grande maioria das unidades tem a cozinha integrada ao estar colocando esse ambiente como espaço de convivência em uma planta segmentada.

Mesmo variando em tamanho, as unidades têm programas muito parecidos e por serem plantas bastante divididas não são flexíveis e nem permitem adaptações. Como no Silodam, a diversidade de modos de vida, na prática, precisa se adaptar à uma gama restrita de opções de apartamentos que são, além disso, sorteados para os inscritos no programa municipal de habitação e não escolhidos pelos moradores. A seguir apresentamos em um fluxograma a lógica de configuração das unidades em dois modos: o primeiro com um núcleo hidráulico e o segundo com o núcleo desfeito pela inserção de mais um banheiro. Nos dois casos a rígida divisão entre área íntima e social permanece e também se valida para os apartamentos com mais de um pavimento.

\footnotetext{
${ }^{37}$ Fonte: http://www.elmundo.es/elmundo/2007/09/26/madrid/1190799765.html
} 


\section{BANHOS}

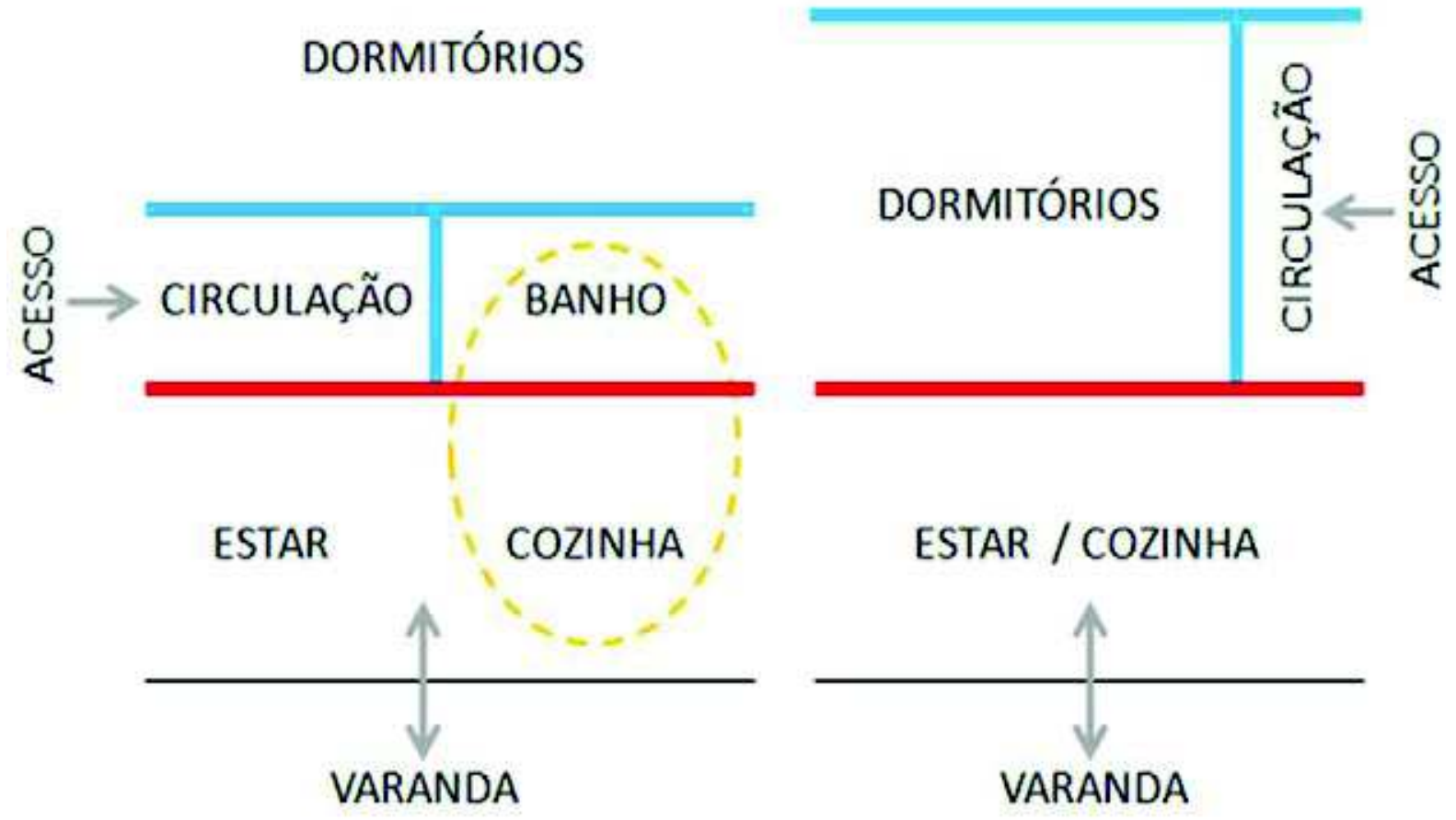

Fluxograma: lógica tradicional de configuração das unidades. As linhas vermelhas representam as divisões entre área social e íntima e as linhas em azul mostram as divisões nas áreas íntimas. Fonte: autora.

A seguir identificamos os nove sub-blocos com a localização das tipologias e na sequência as plantas das unidades habitacionais.

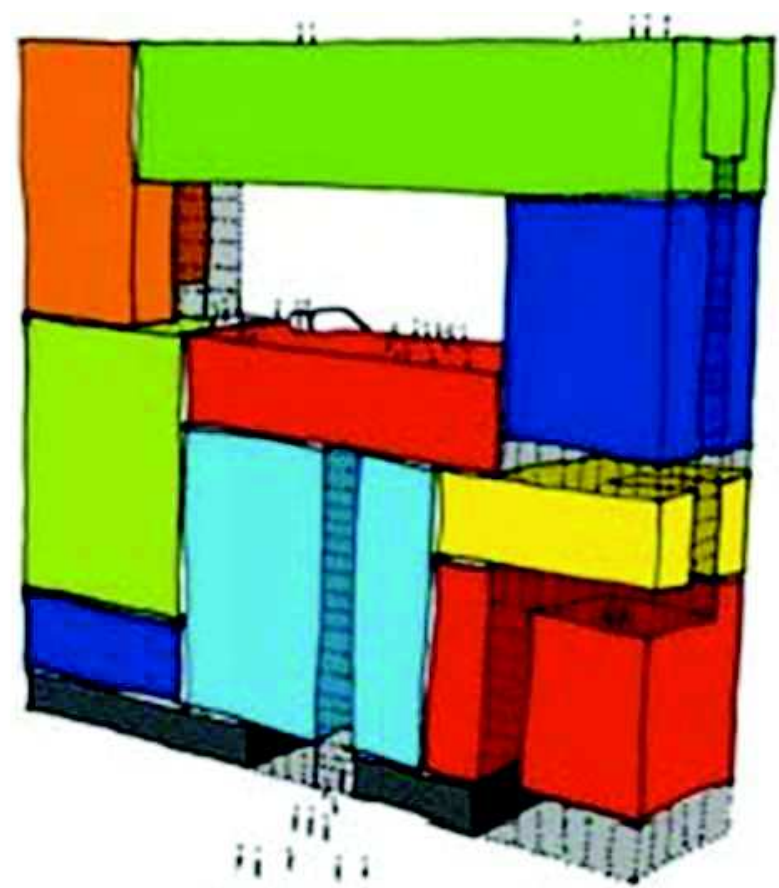

Identificação dos sub-blocos. Fonte: El Croquis. 


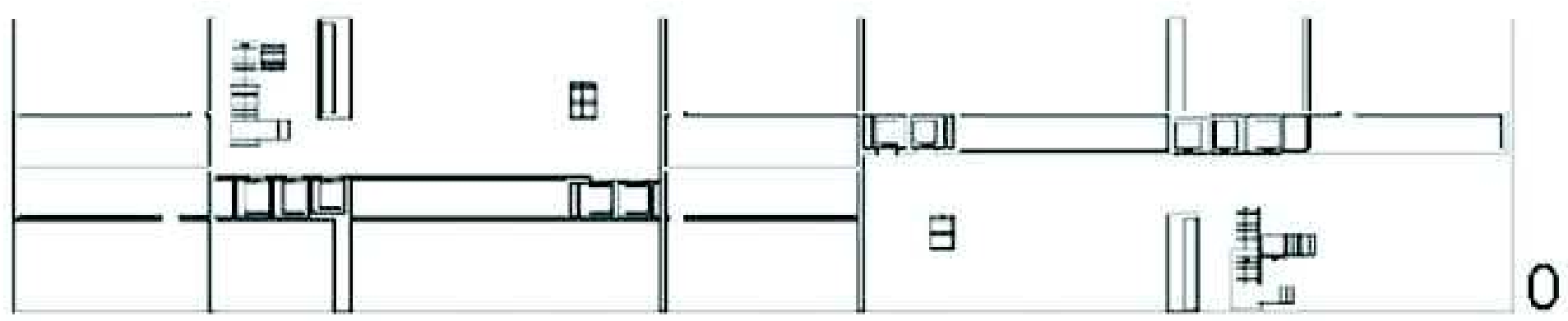

2 QUADRADAS

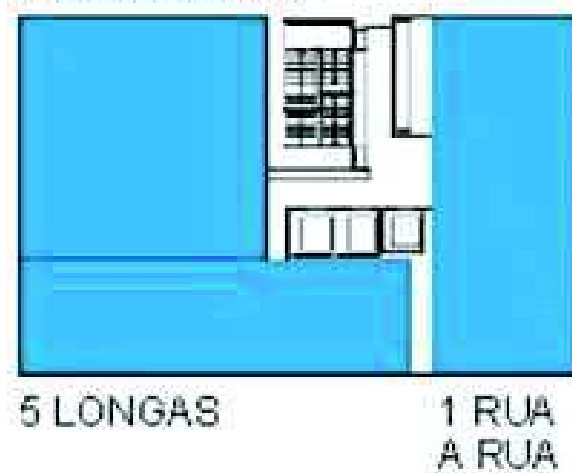

2 QUADRADAS

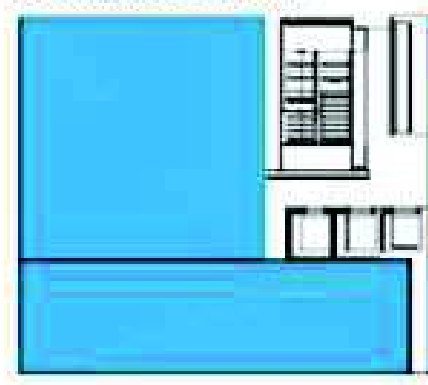

5 LONGAS
1 RUA

A. RUA

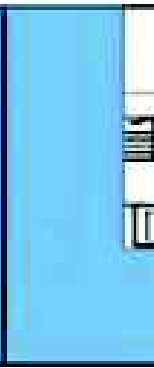

3 RUAA RUA EM L.

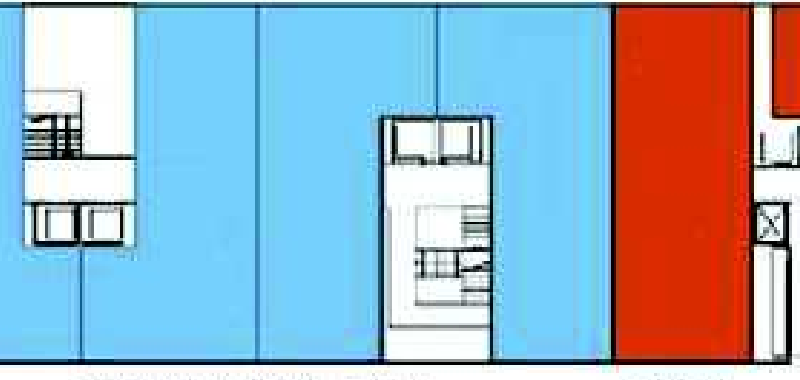

4 RUA

A RUA

PEQUENA

5 LONGAS

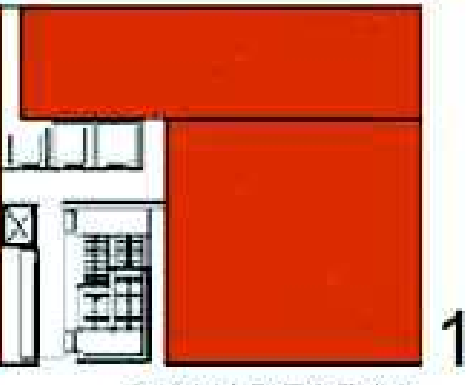

2 QUADRADAS

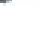


5.2 LONGAS B

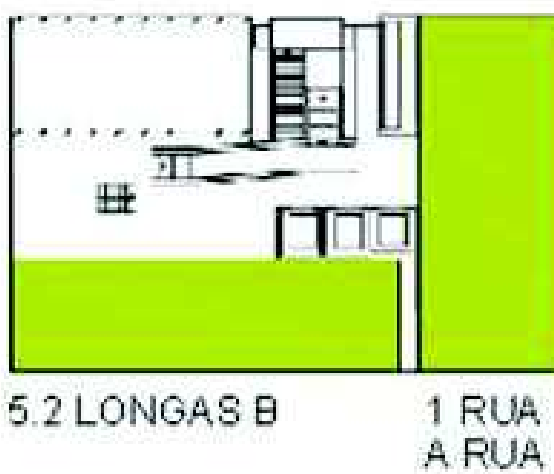

5.2 LONGAS B

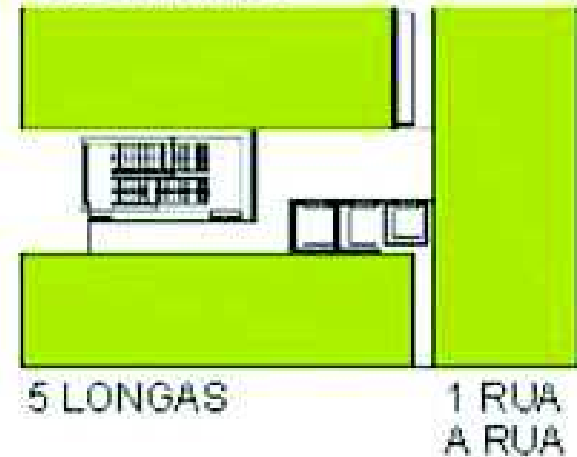

5.2 LONGASB

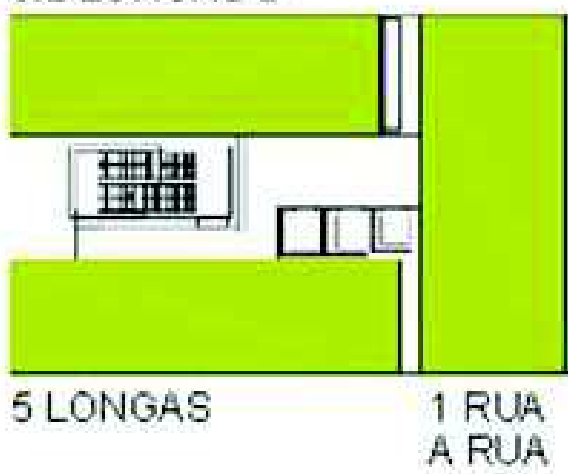

5.2 LONGAS $\mathrm{E}$

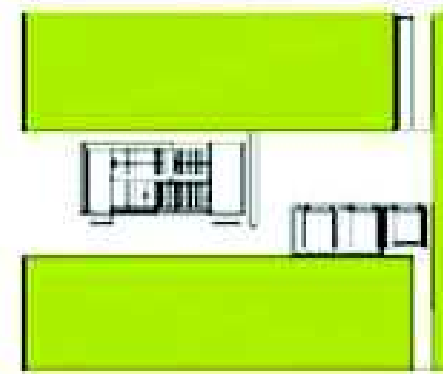

5 LONGAS

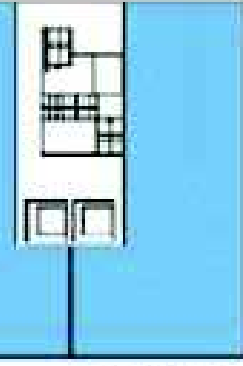

3 RUAA RUA EM L

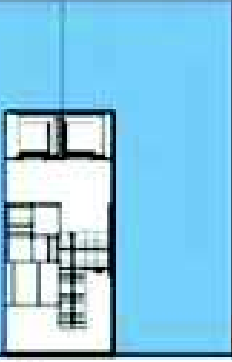

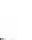

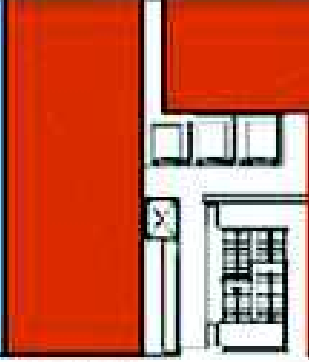

4 RUA

A RUA

PEQUENA
2 QUADRADAS
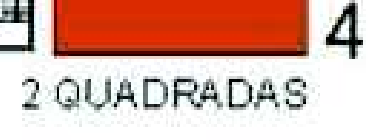
5.2 LONGAS B
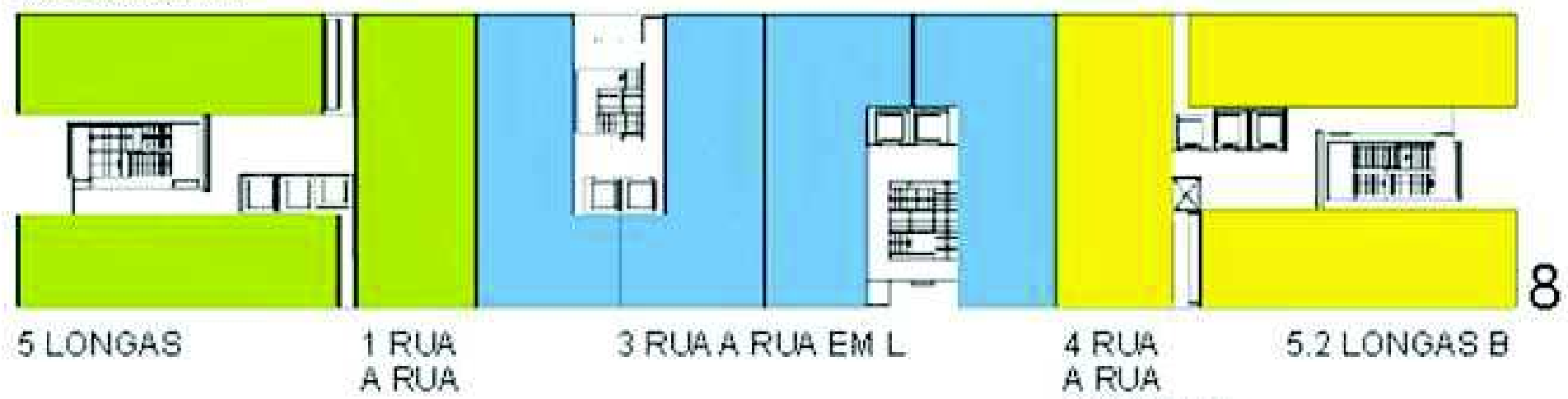

3 RUA A RUA EM L

4 RUA

A RUA

5.2 LONGASB PEQUENA

\subsection{LONGAS B}
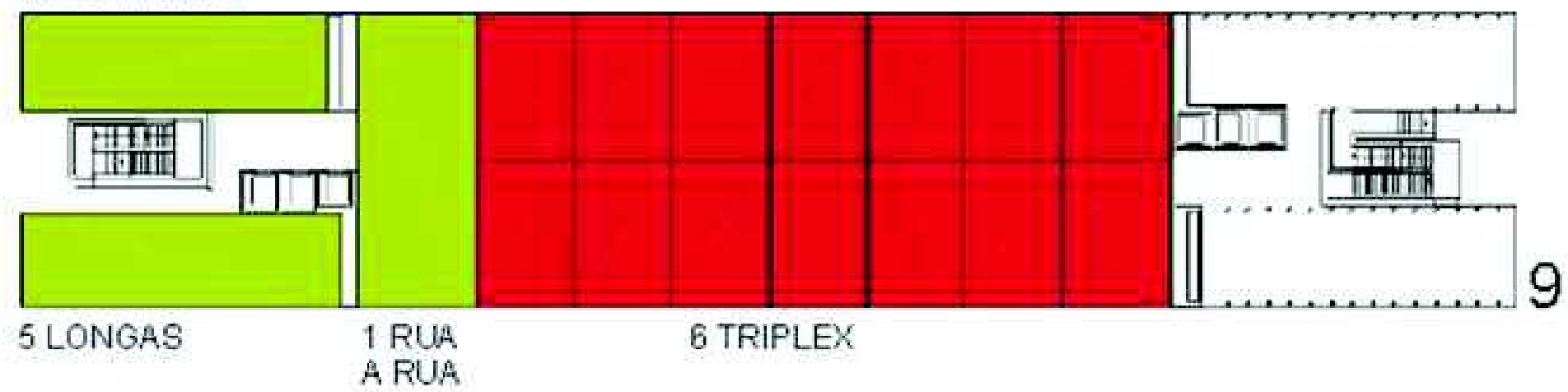

A RUA

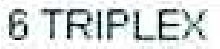

5.2 LONGASB

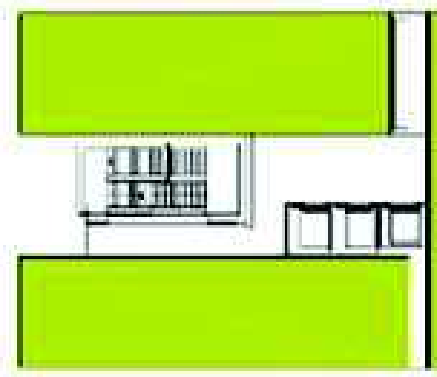

5 LONGAS
8_9_12 DUPLEX

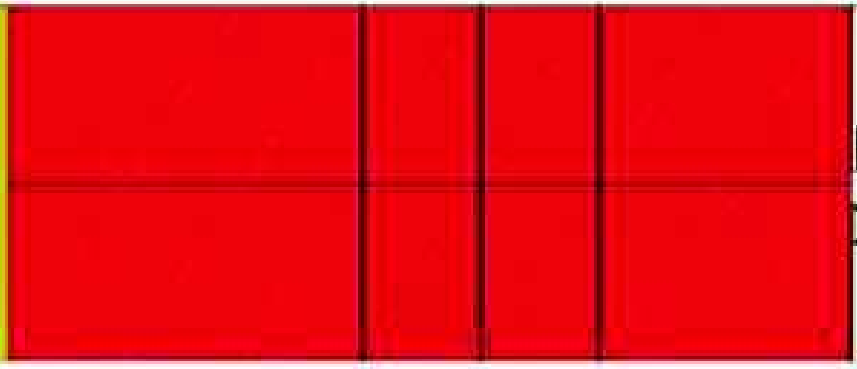

6 TRIPLEX

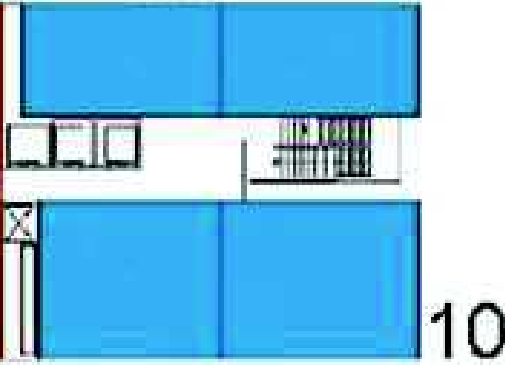

8_9_12 DUPLEX
5.2 LONGAS B

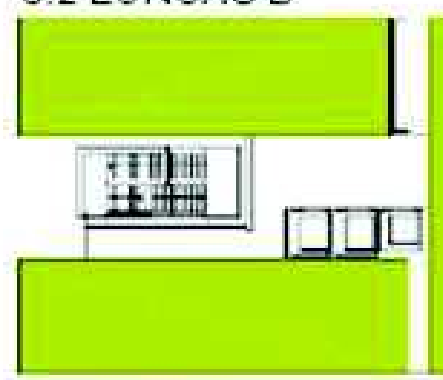

5 LONGAS
4 RUA

A RUA

PEQUENA
8_9_12 DUPLEX

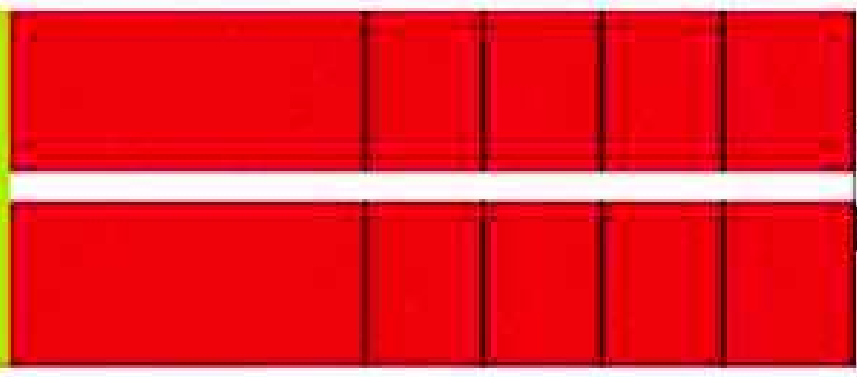

6 TRIPLEX

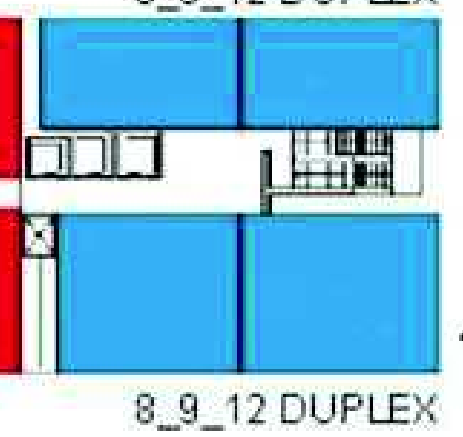




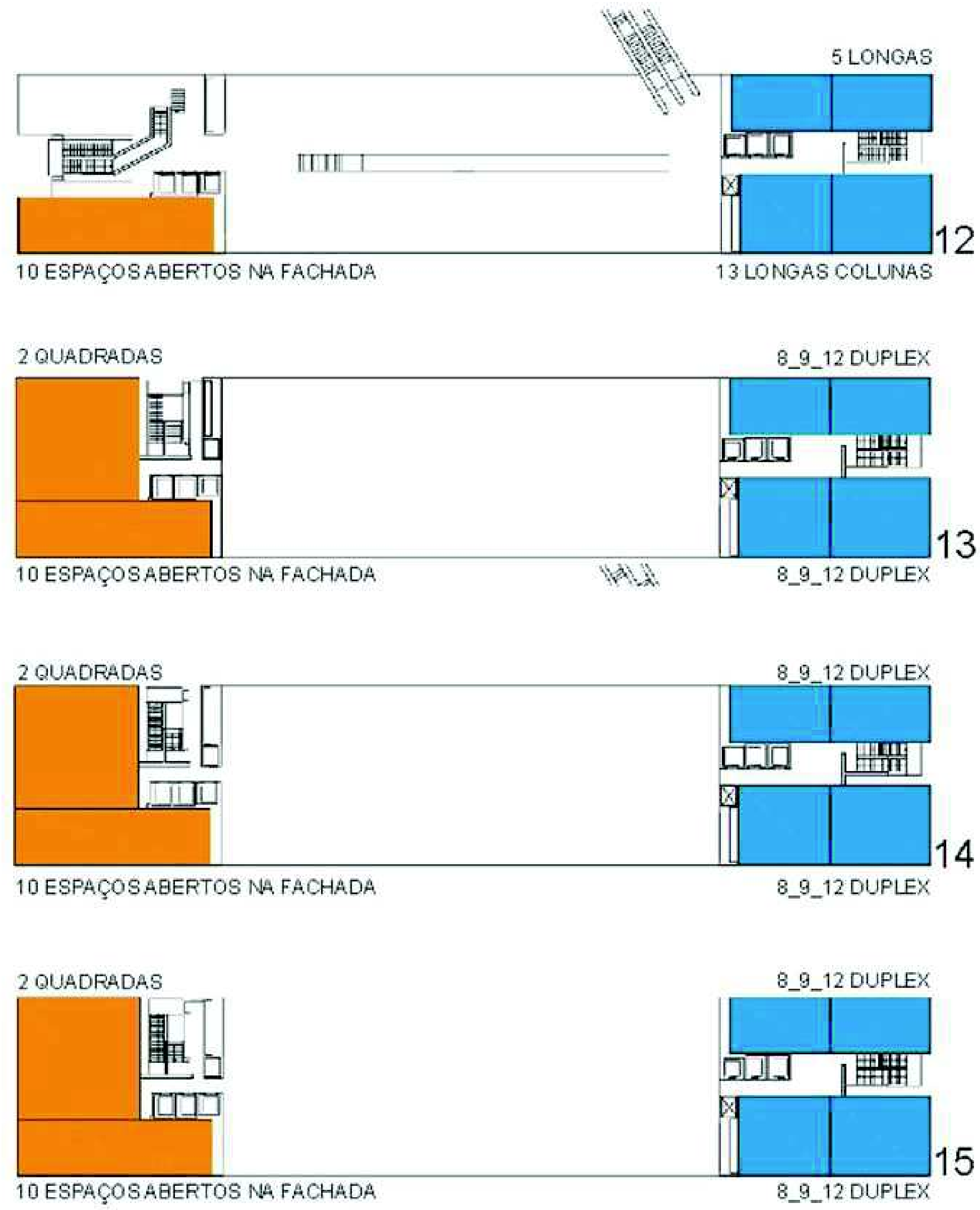




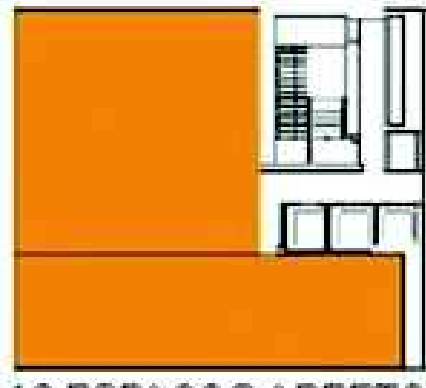

10 ESPAÇOS ABERTOS NA FACHADA

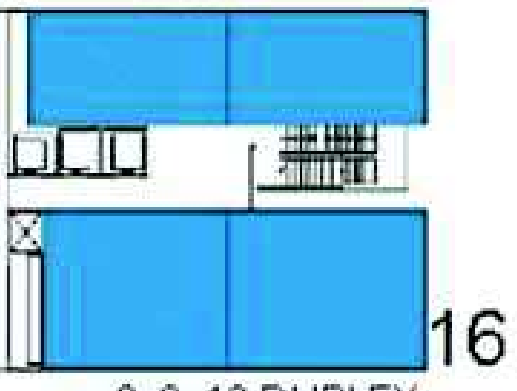

8_9_12 DUPLEX

\section{QUADRADAS}

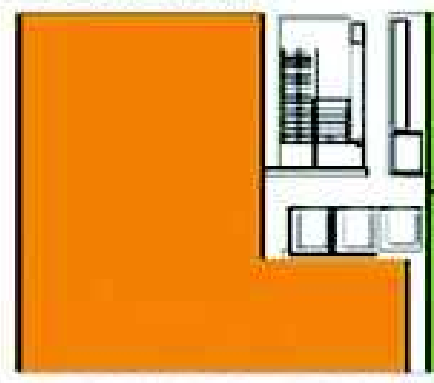

10 ESPACOS ABERTOS NAFACHADA

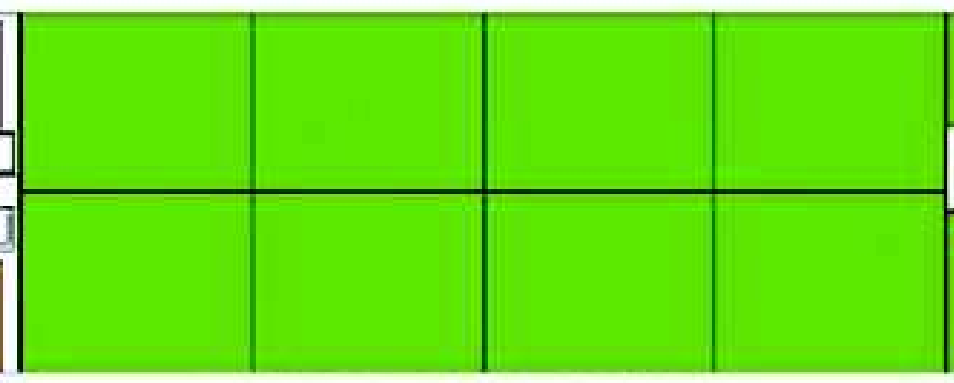

14 DUPLEX GRANDE PONTA

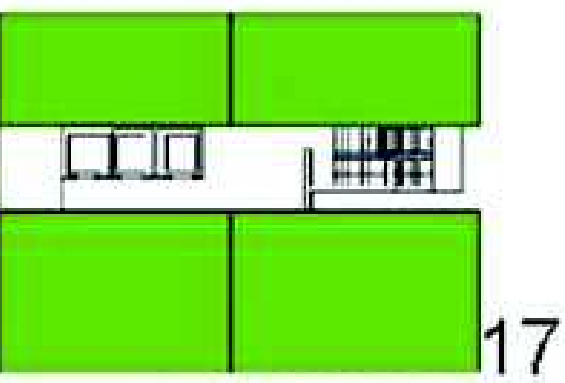

8_9_12 DUPLEX

2 QUADRADAS

15 DUPLEX PONTE

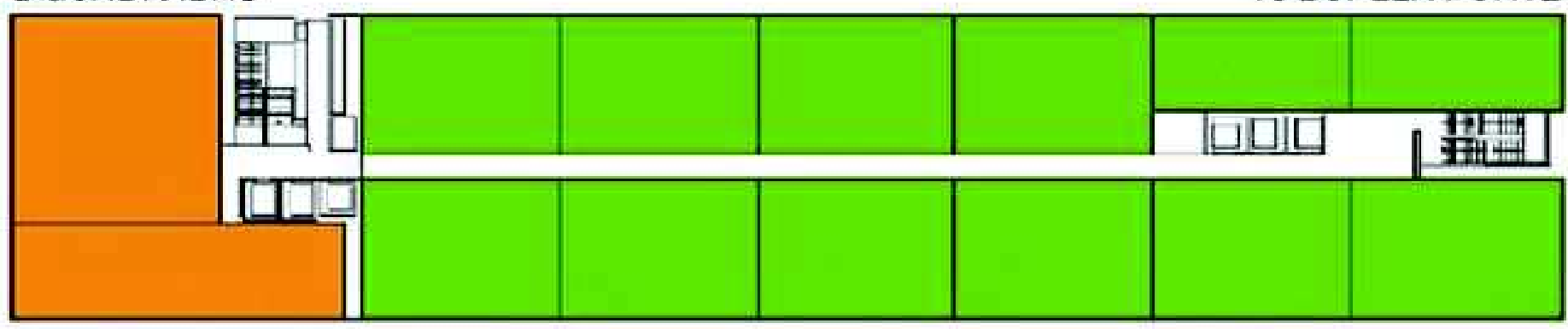

2 QUADRADAS

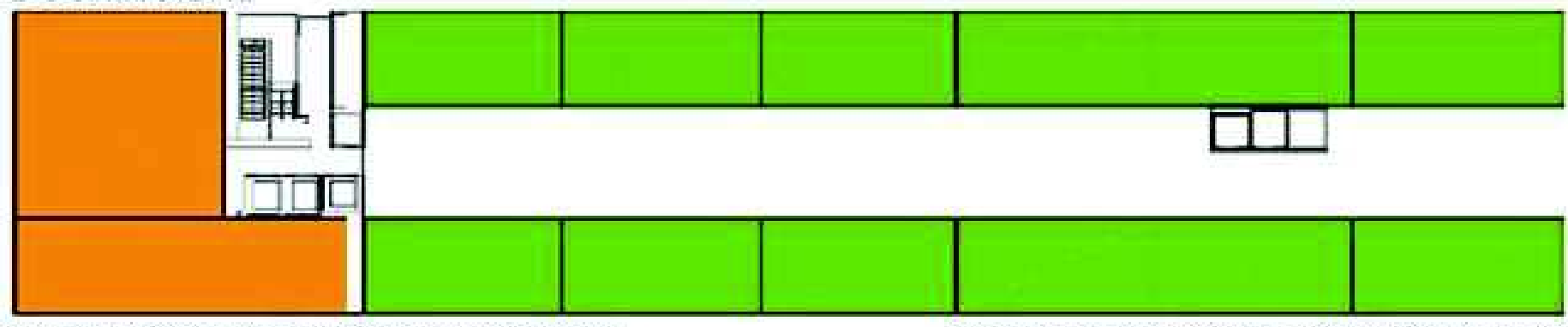


2 QUADRADAS

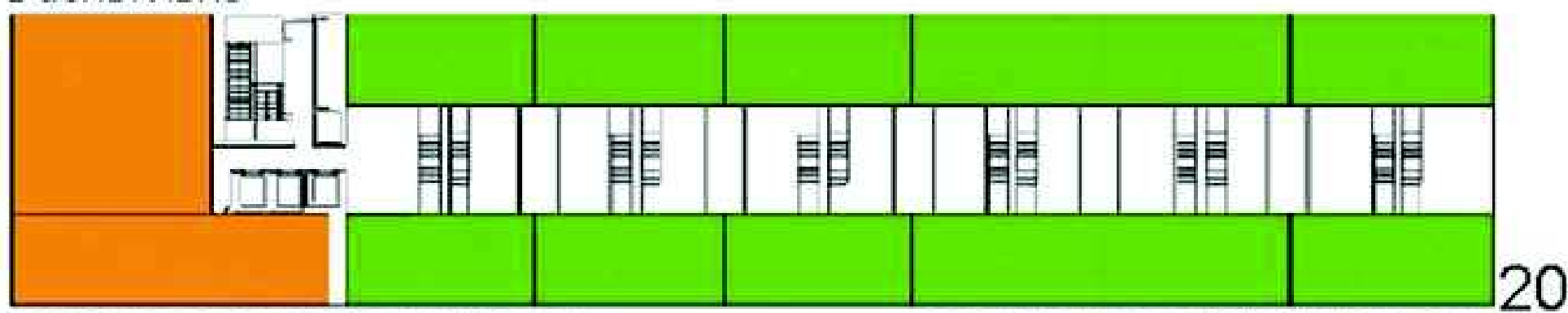

10 ESPAÇOS ABERTOS NA. FACHADA

15.2 DUPLEX PONTE COM SOLARIUM 

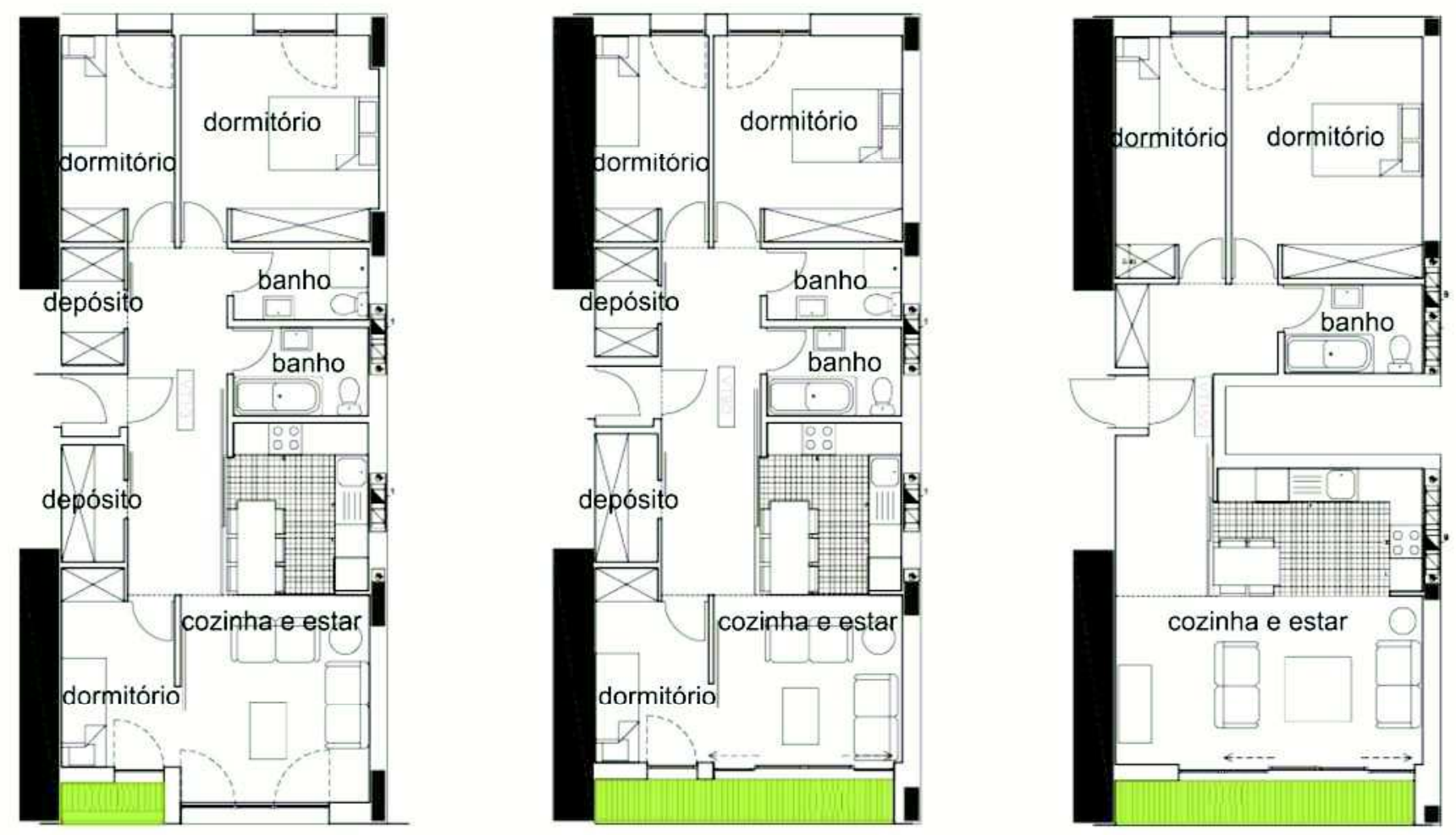

1_RUAA RUA 82 m² $^{2}$
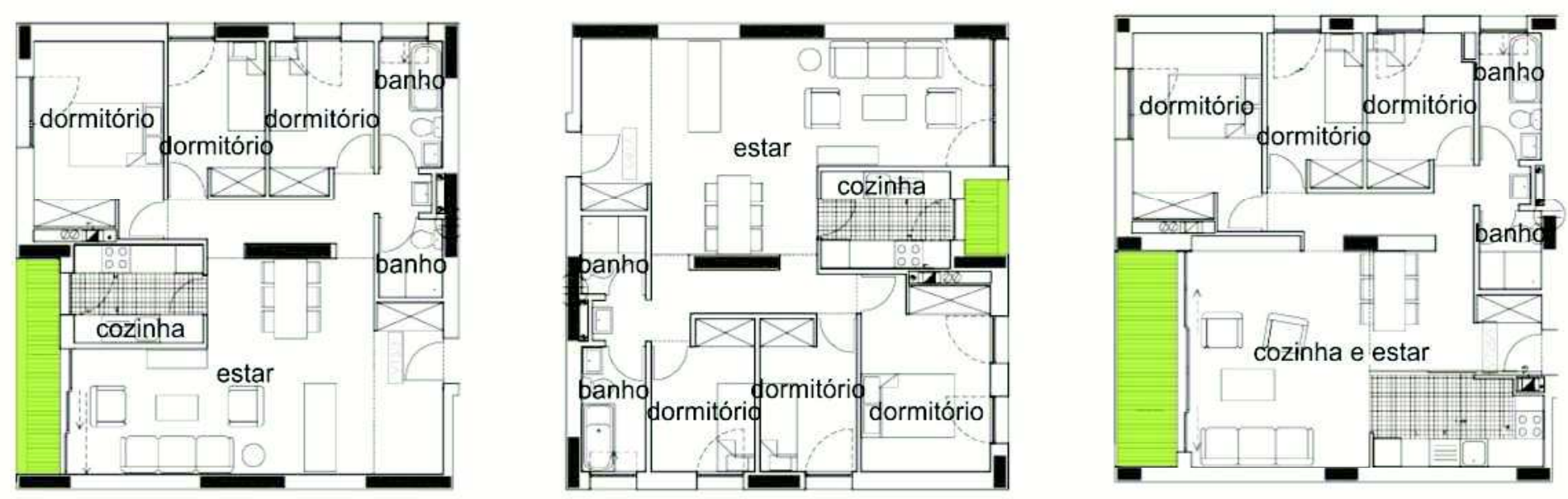

2_QUADRADAS $94 \mathrm{~m}^{2}$

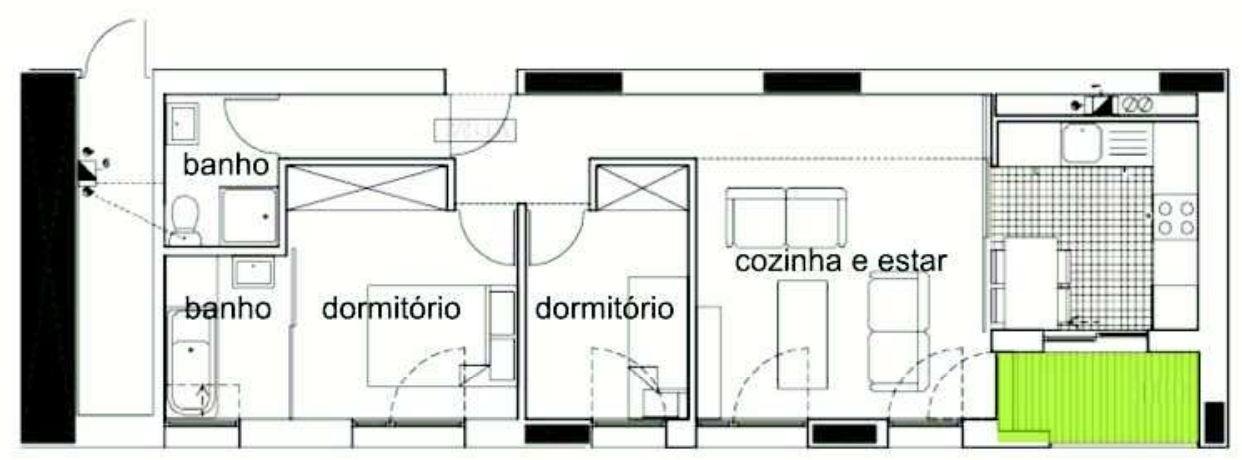



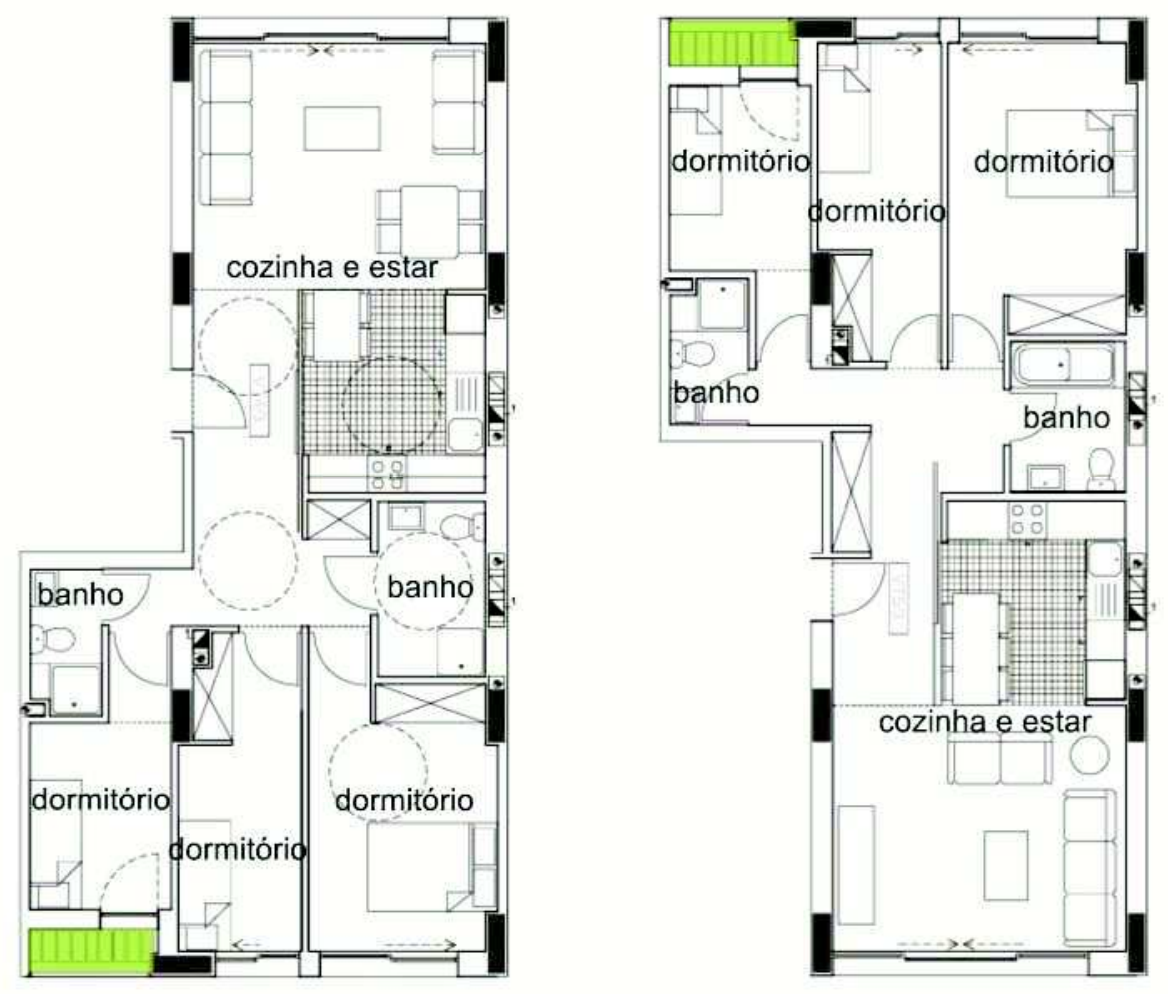

3_RUAA RUA EM L $87 \mathrm{~m}^{2}$
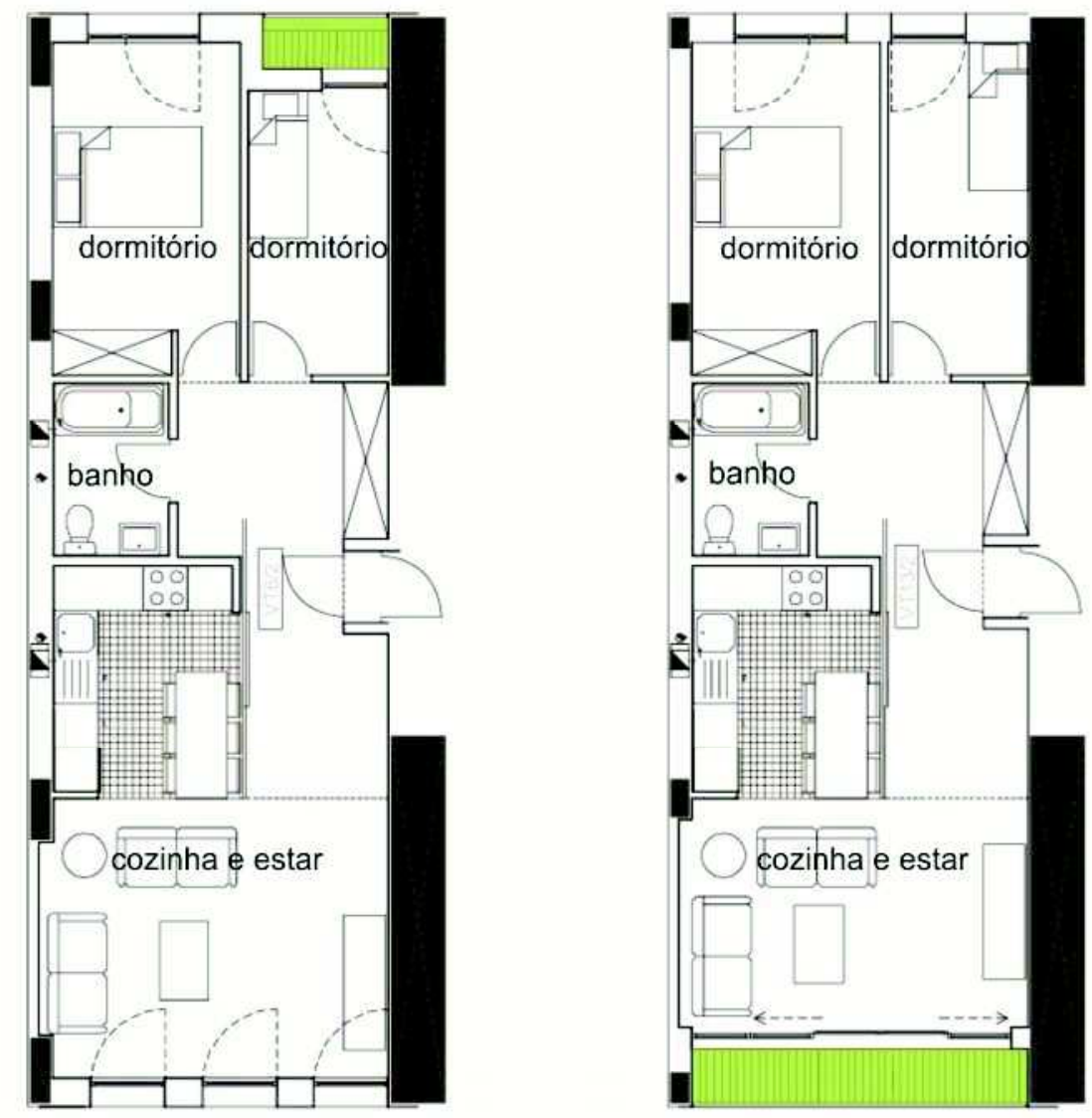

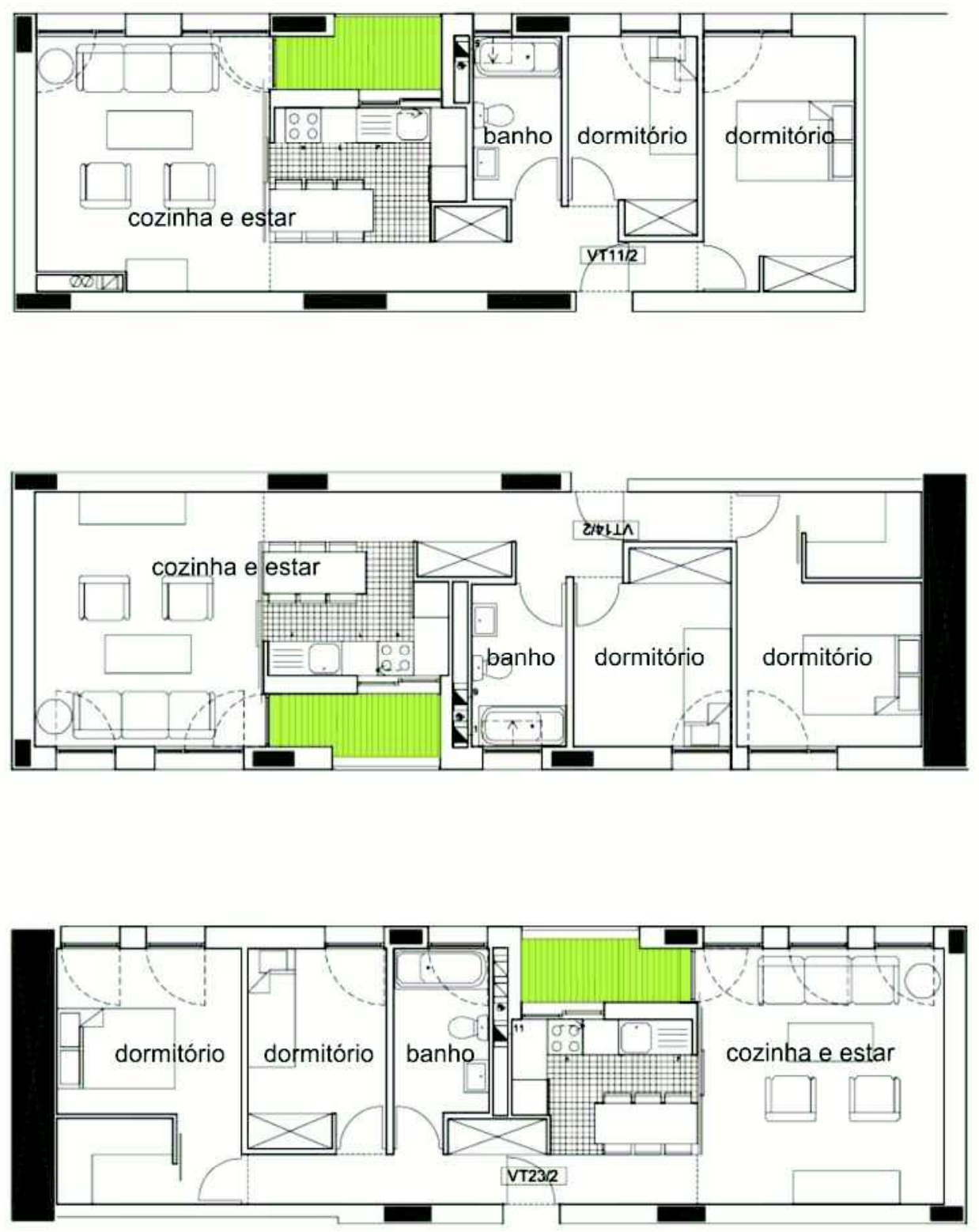

5_2_LONGAS B_67 $\mathrm{m}^{2}$
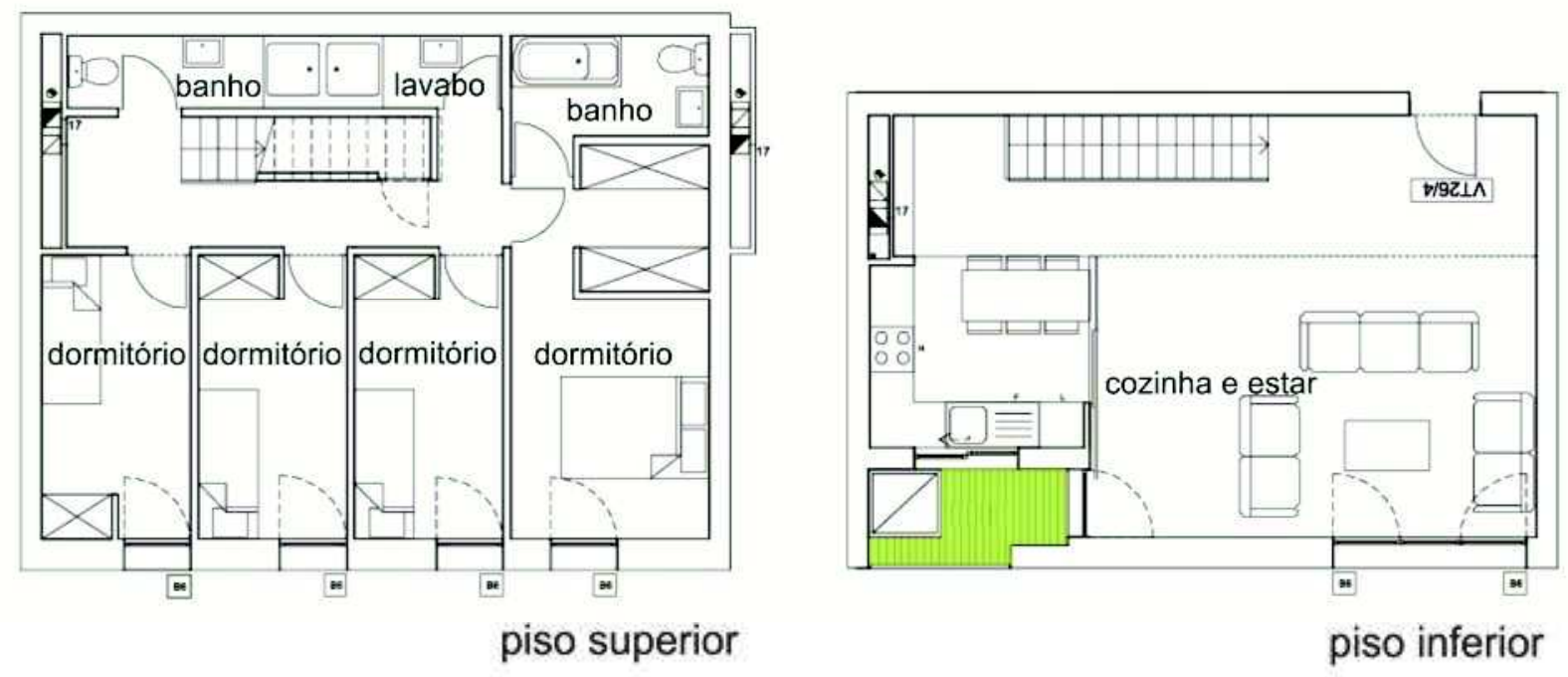

14_DUPLEX GRANDE_PONTA $107 \mathrm{~m}^{2}$ 


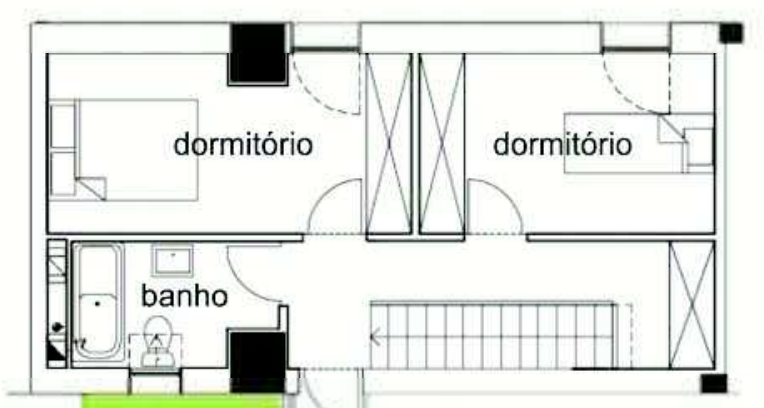

piso superior

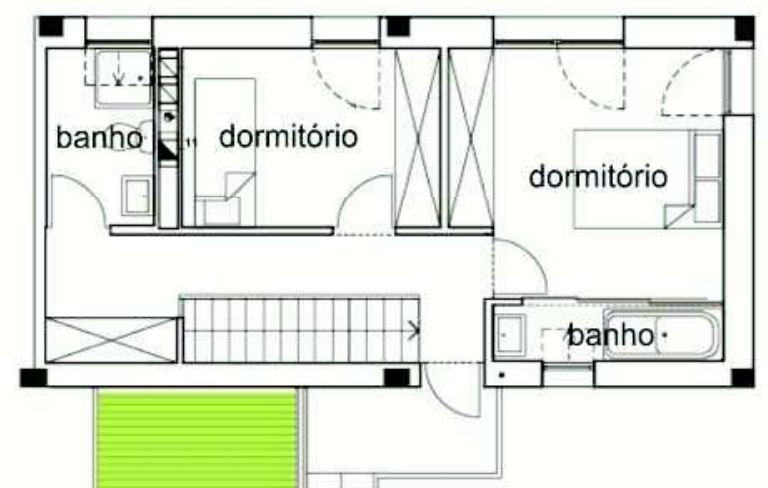

piso superior

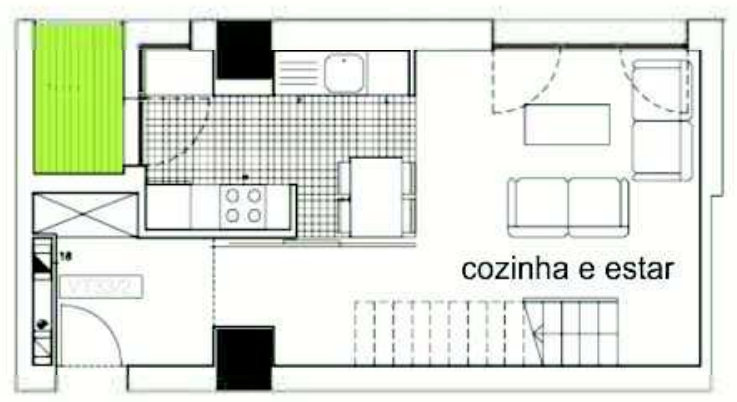

piso inferior
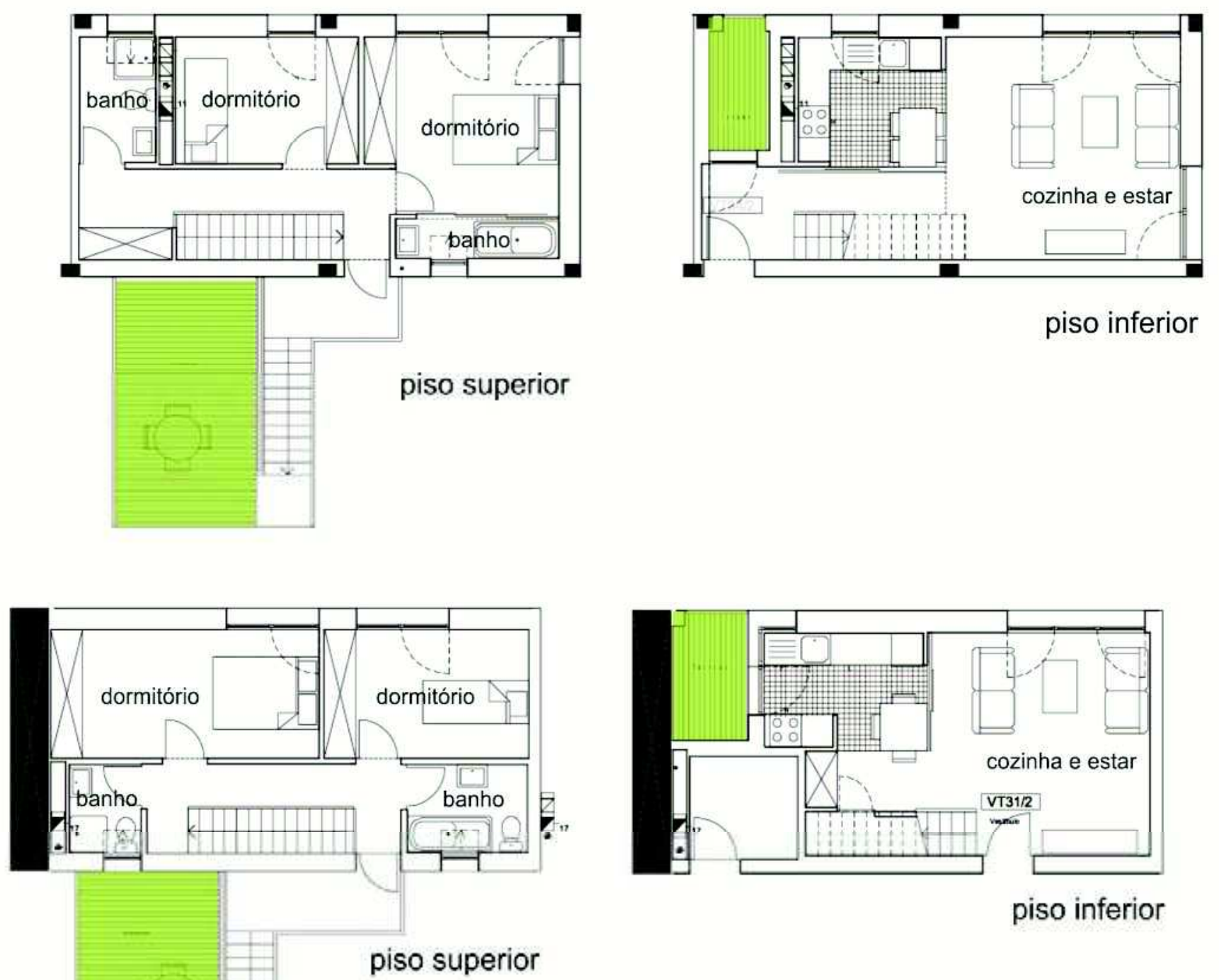

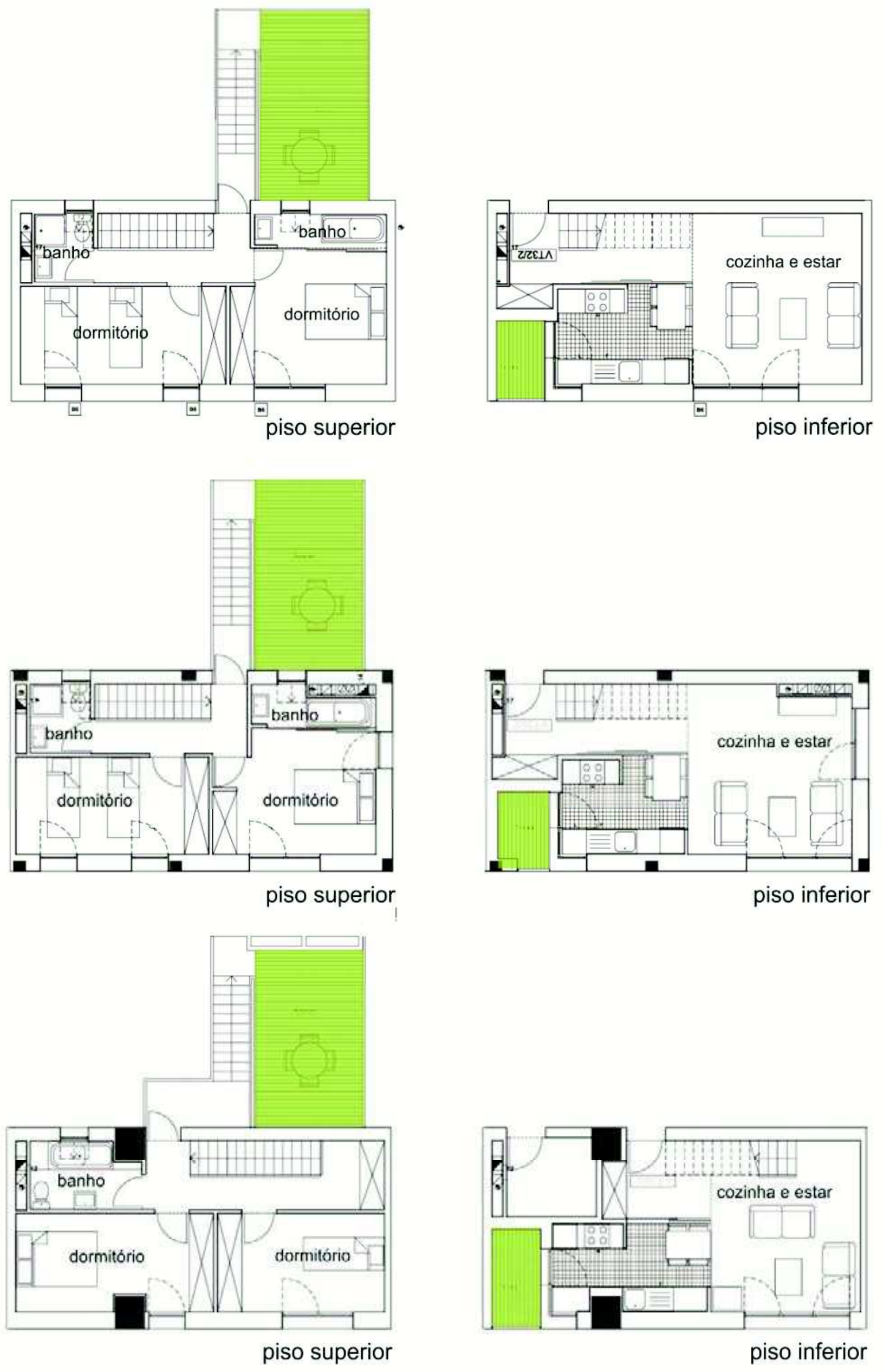

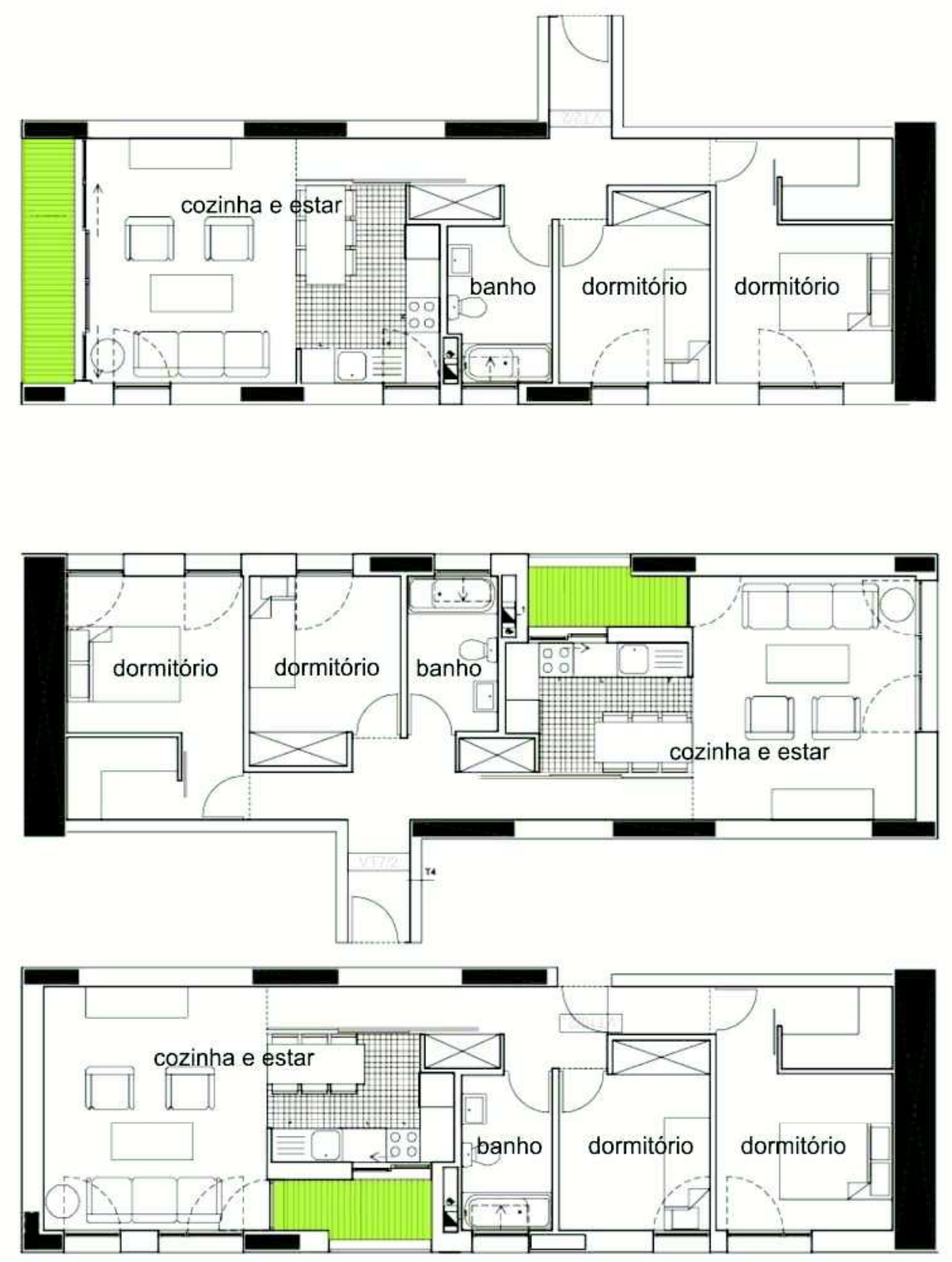

5_LONGAS $73 \mathrm{~m}^{2}$

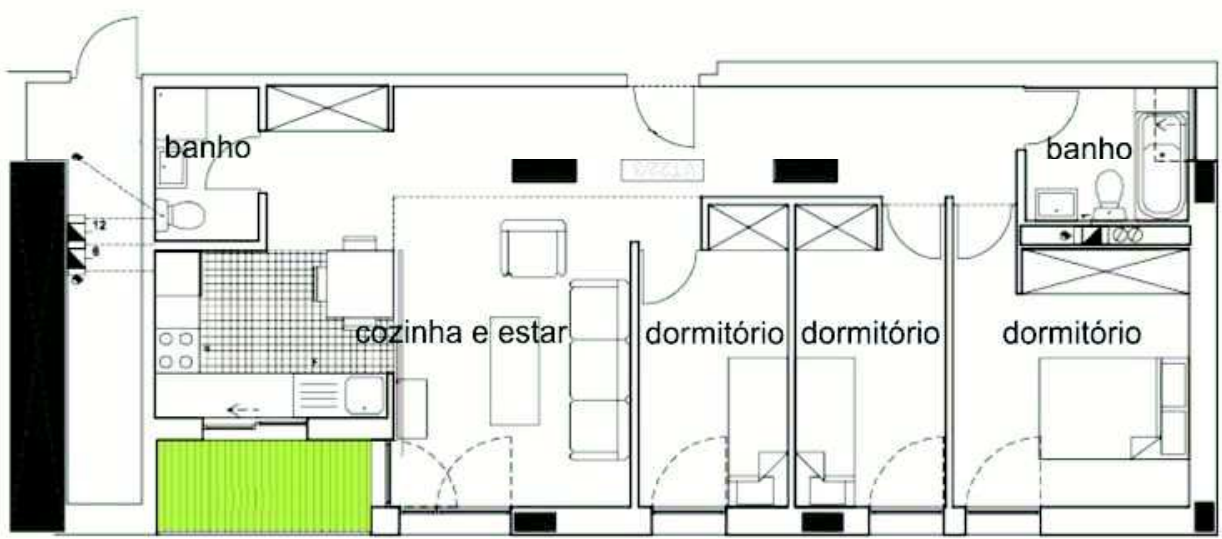




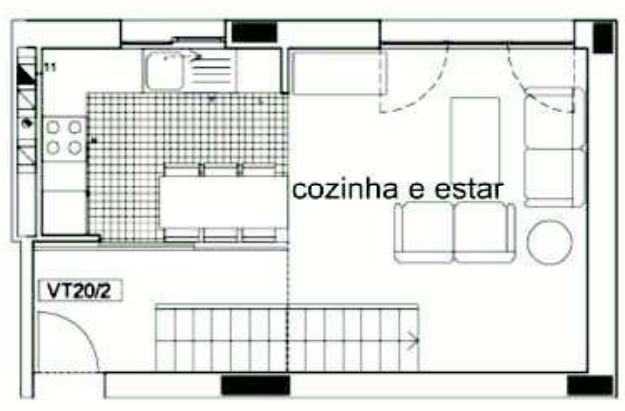

piso superior

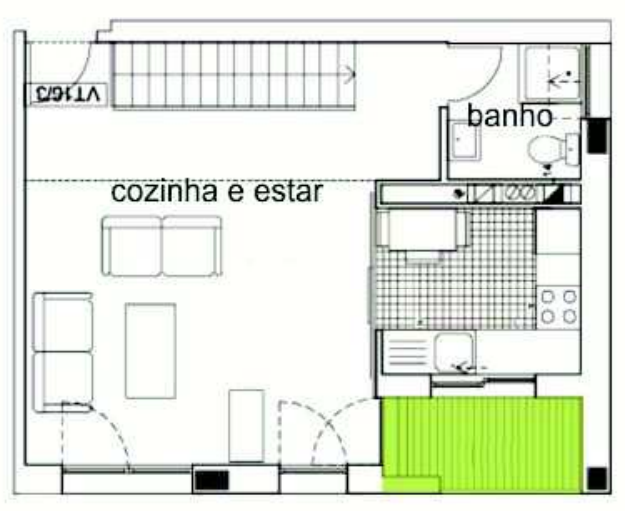

piso superior

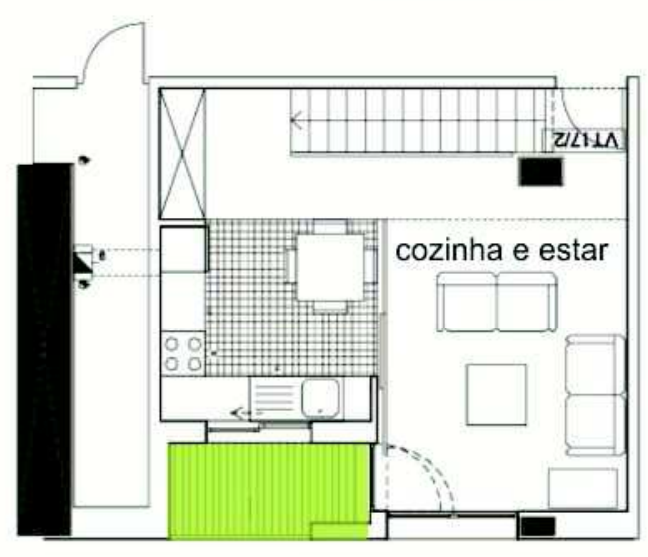

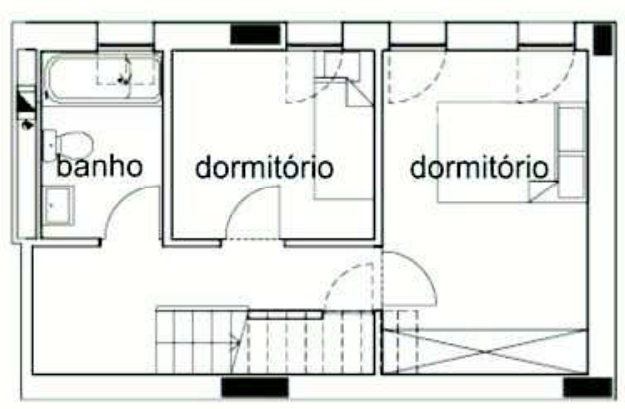

piso inferior

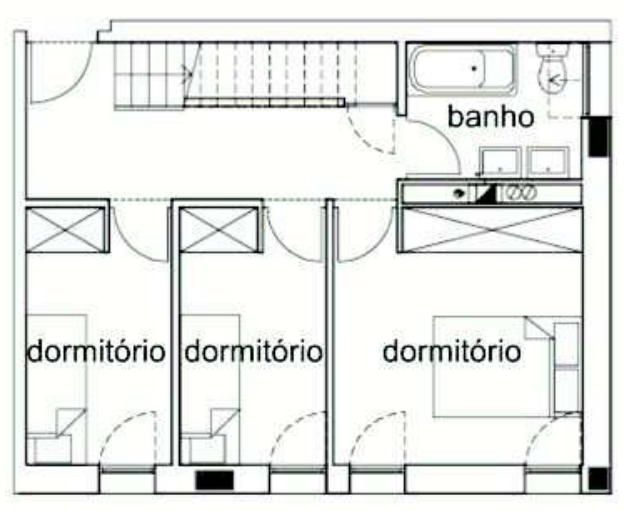

piso inferior

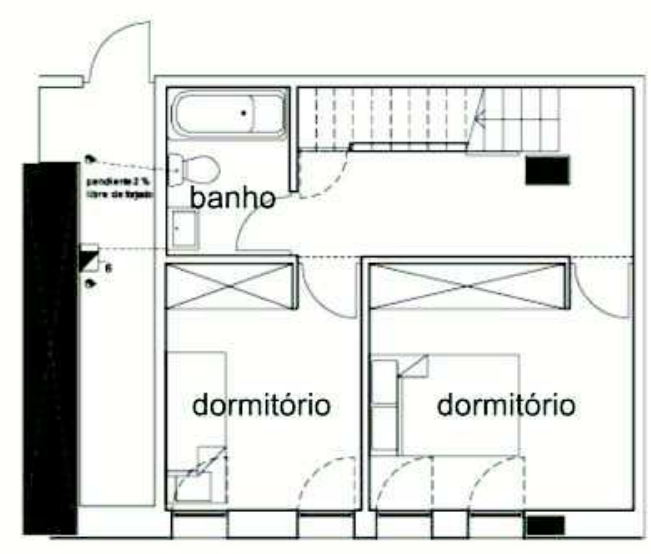

8_9_12_DUPLEX $80 \mathrm{~m}^{2}$ 


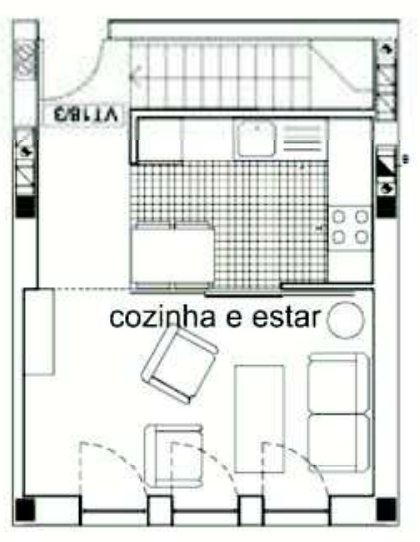

piso superior

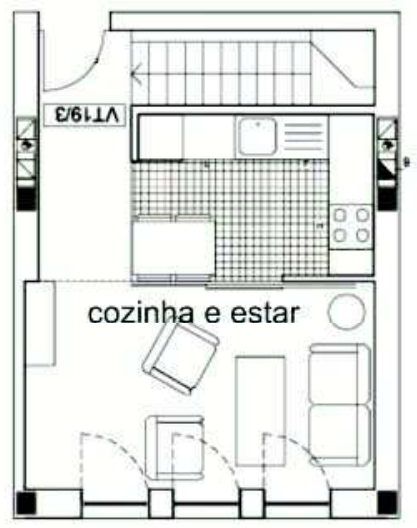

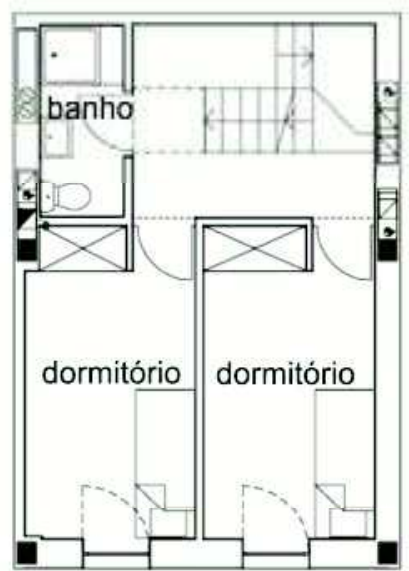

piso intermediário

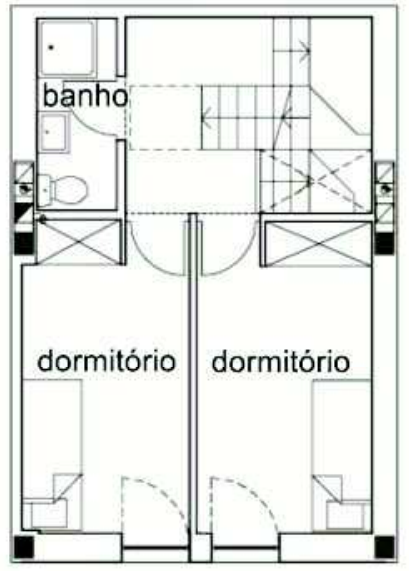

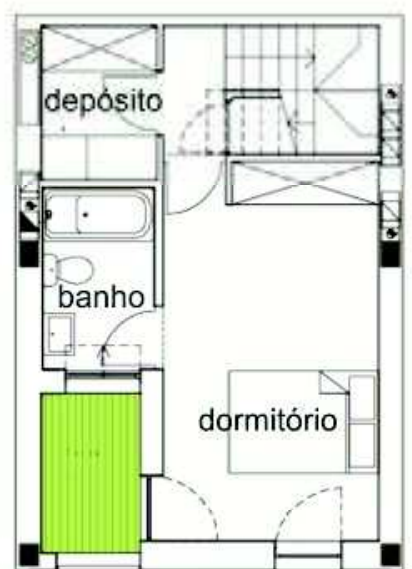

piso inferior

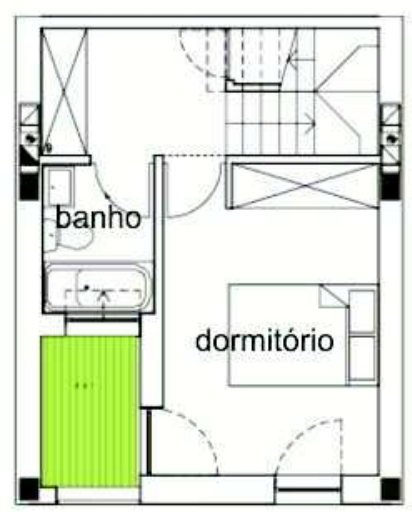

6_TRIPLEX $85 \mathrm{~m}^{2}$

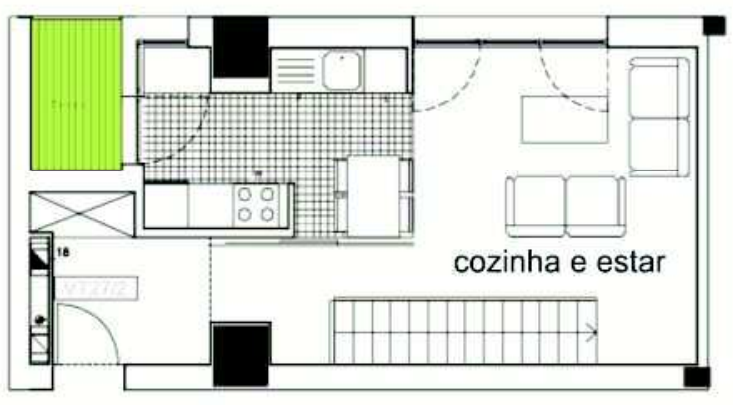

piso superior

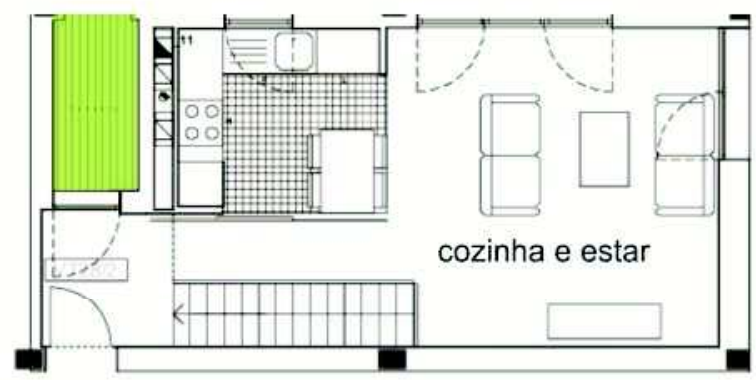

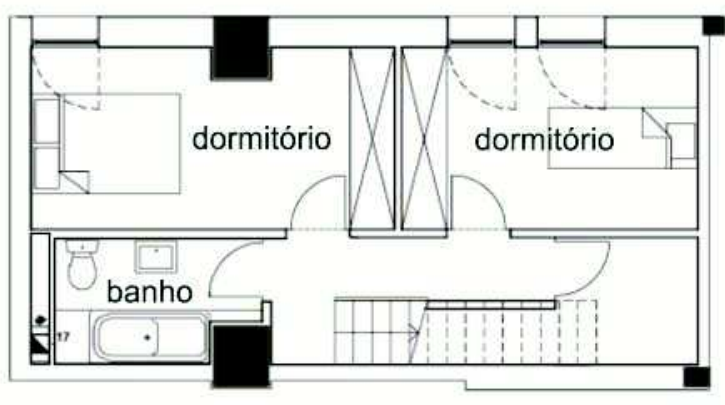

piso inferior

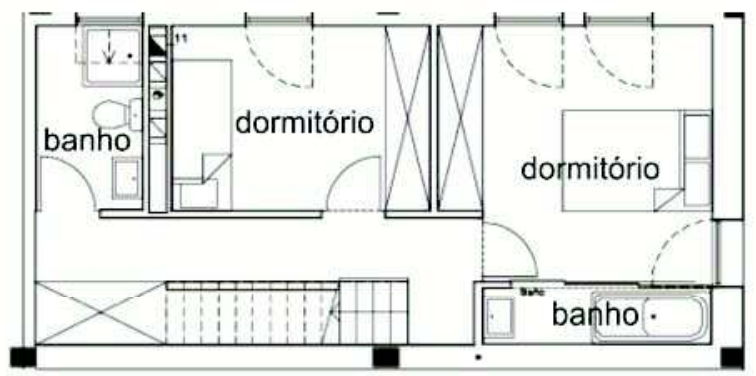

15_DUPLEX PONTE $72 \mathrm{~m}^{2}$ 

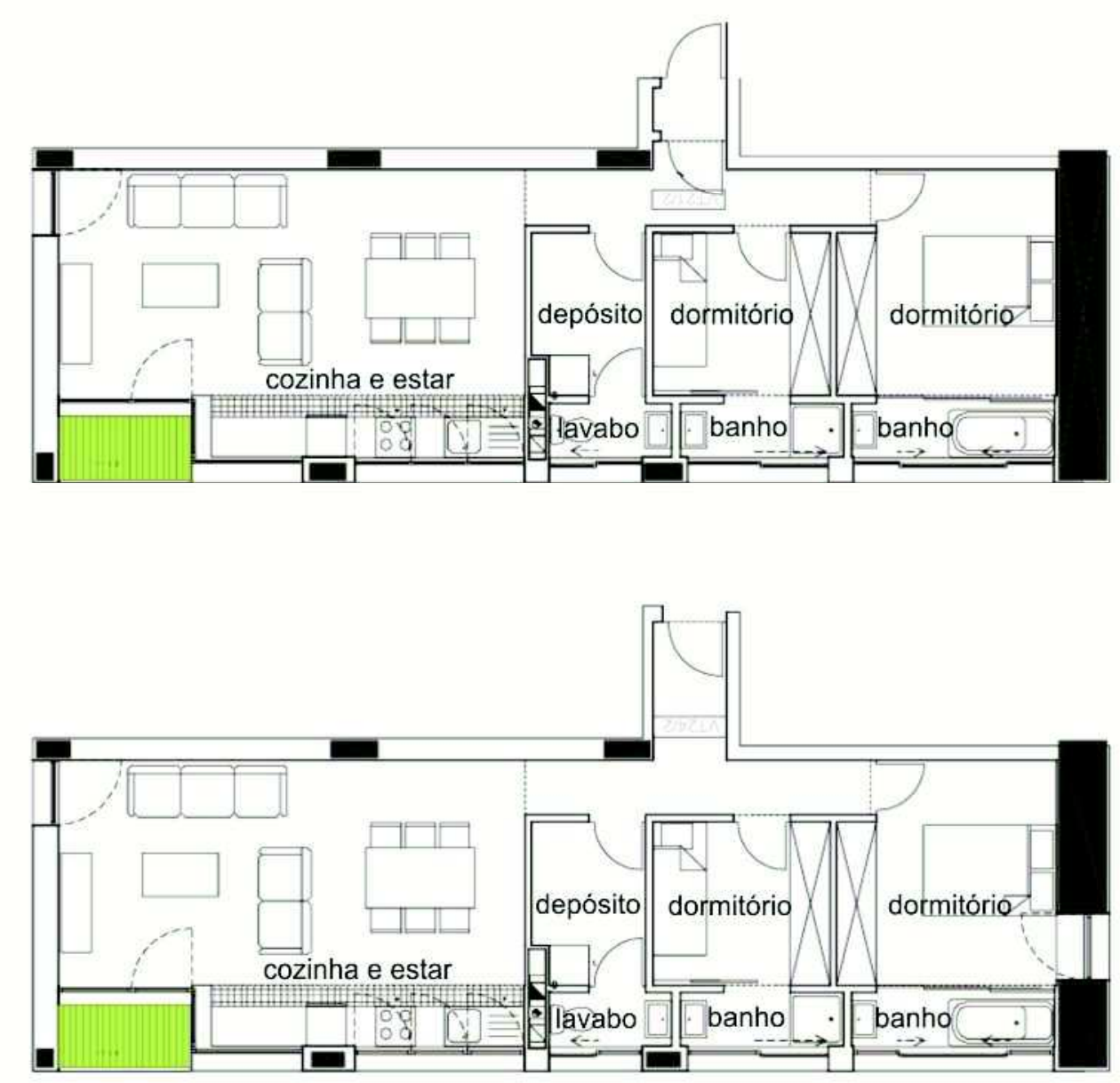

10_ESPAÇOS ABERTOS NA FACHADA $70 \mathrm{~m}^{2}$

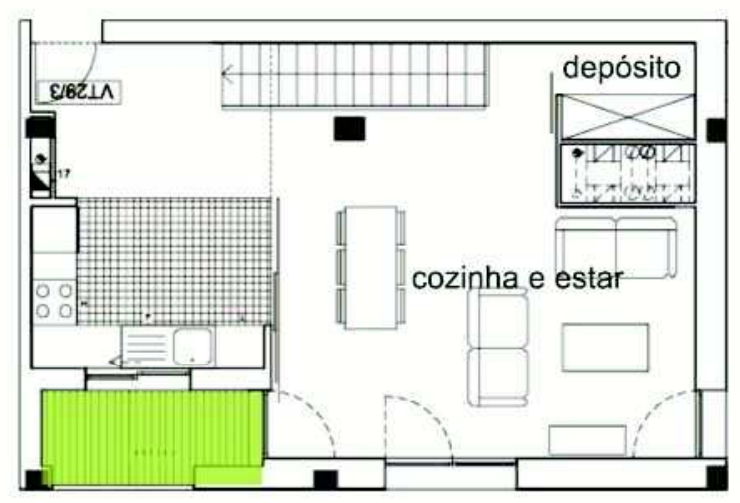

piso superior

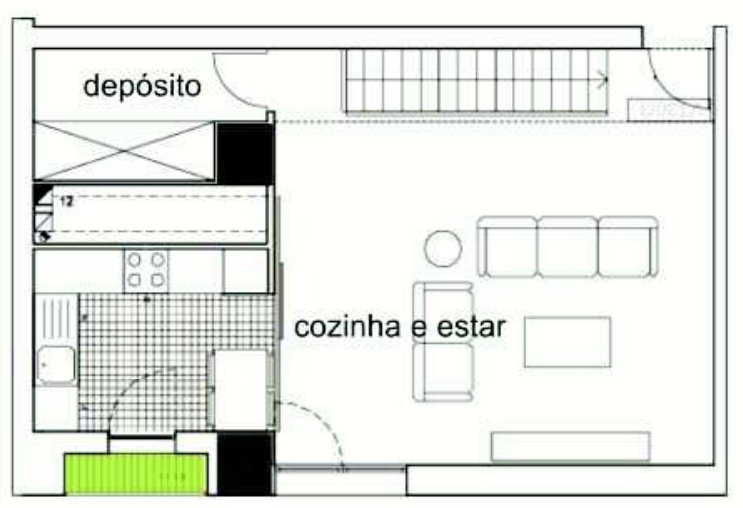

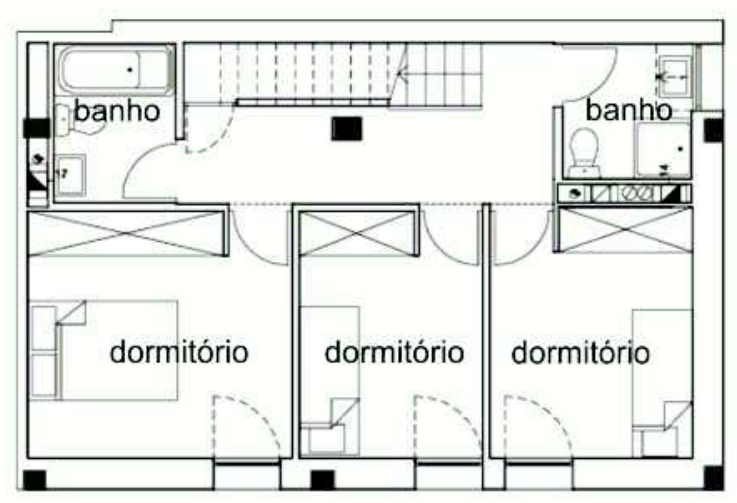

piso inferior

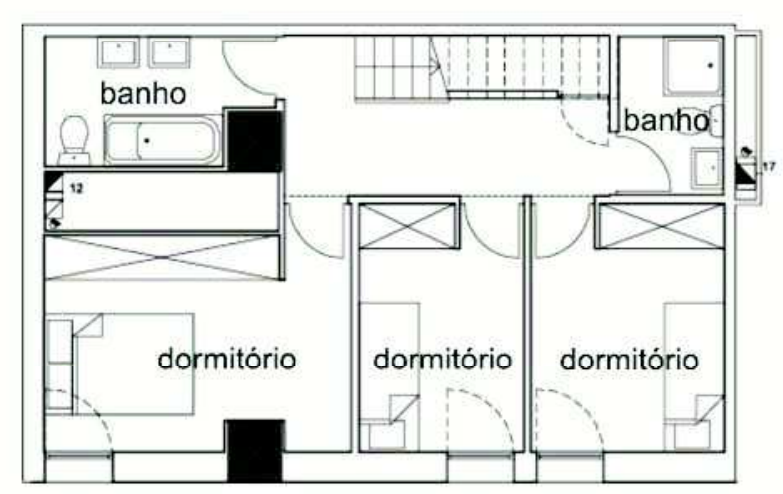

11_DUPLEX LONGO PONTA 95m² 


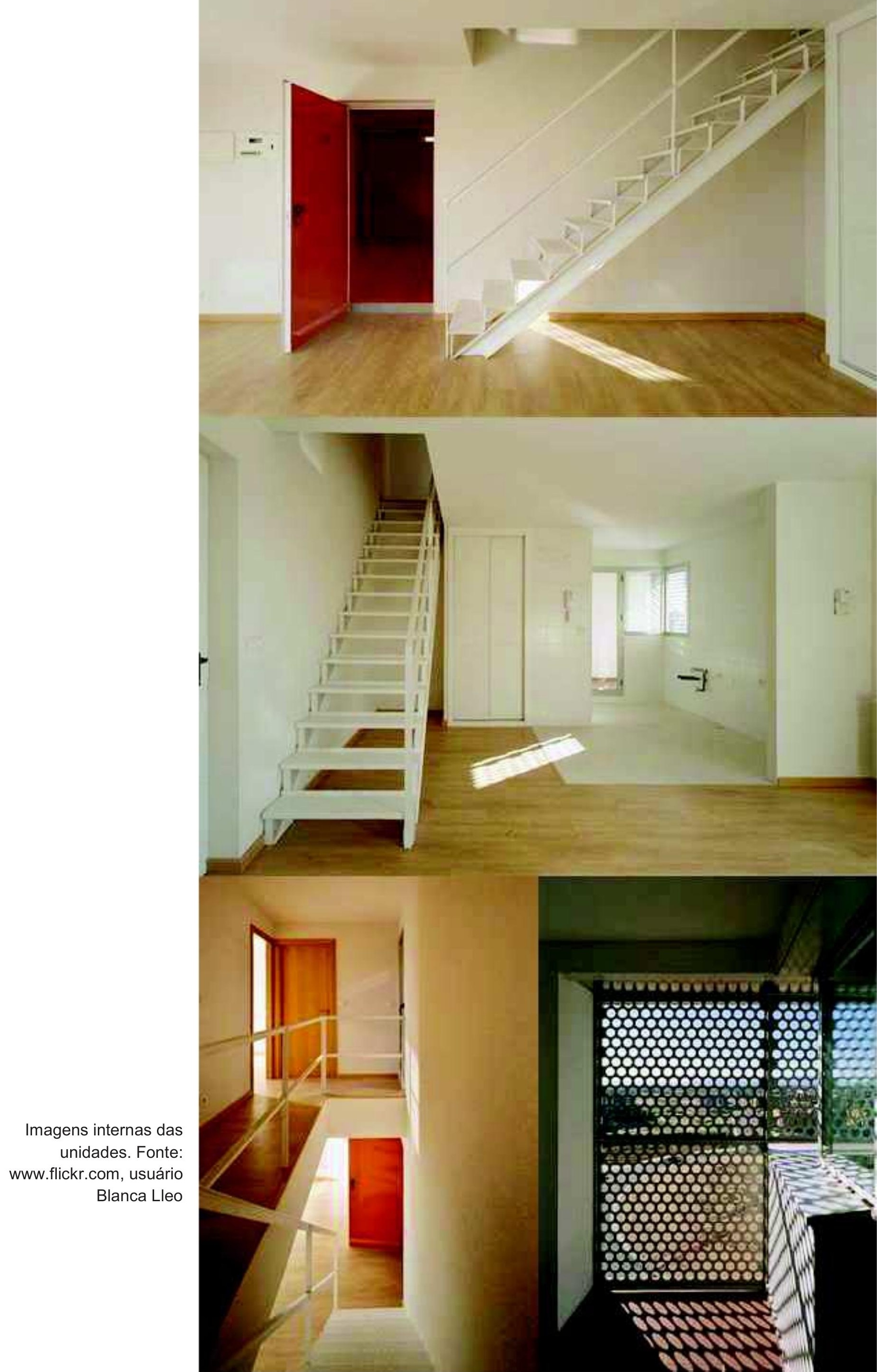




\section{Global sem Local}

O Mirador está em um bairro que dificulta a integração da habitação com a cidade. Sanchinarro não tem pequenos comércios, tem um superdimensionamento de ruas e espaços desocupados sem qualificação que empobrecem a vida urbana e fazem seus edifícios se voltarem para pátios internos.

Nesse cenário, o projeto teve a intenção de abrir um espaço privado para a cidade e seus territórios próximos. Por utilizar dados do local, o trabalho do MVRDV é muitas vezes contextual, porém, no Mirador, os arquitetos tentaram redescrever o entorno importando um modelo bem sucedido como o Silodam para uma cultura totalmente diferente. As preocupações no Mirador ficaram tão centradas em diferenciar o projeto dos aspectos existentes do bairro que a condição de tornar-se global através do local caiu no esquecimento.

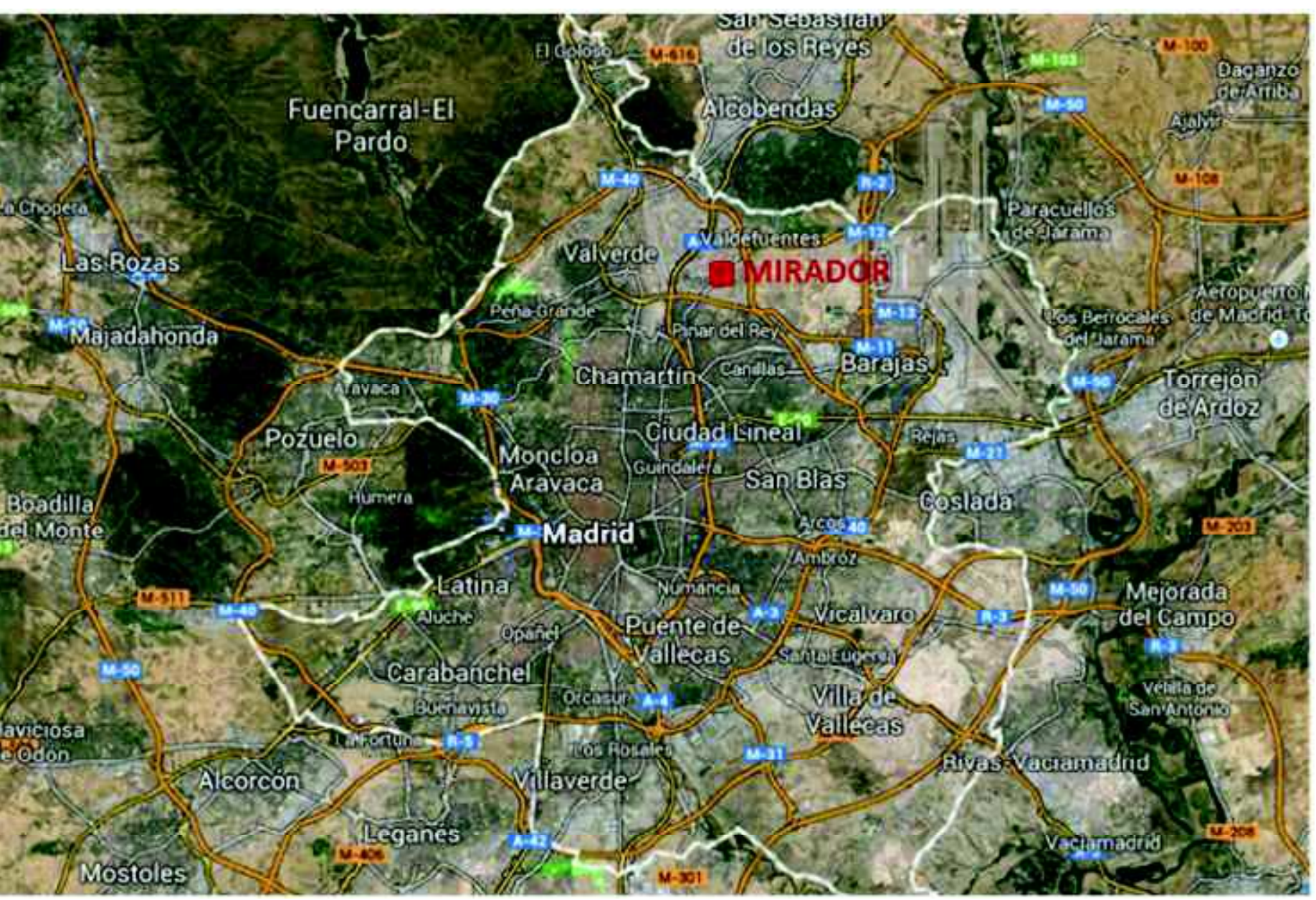

Localização do Mirador em Madrid. Fonte: Google Maps. 


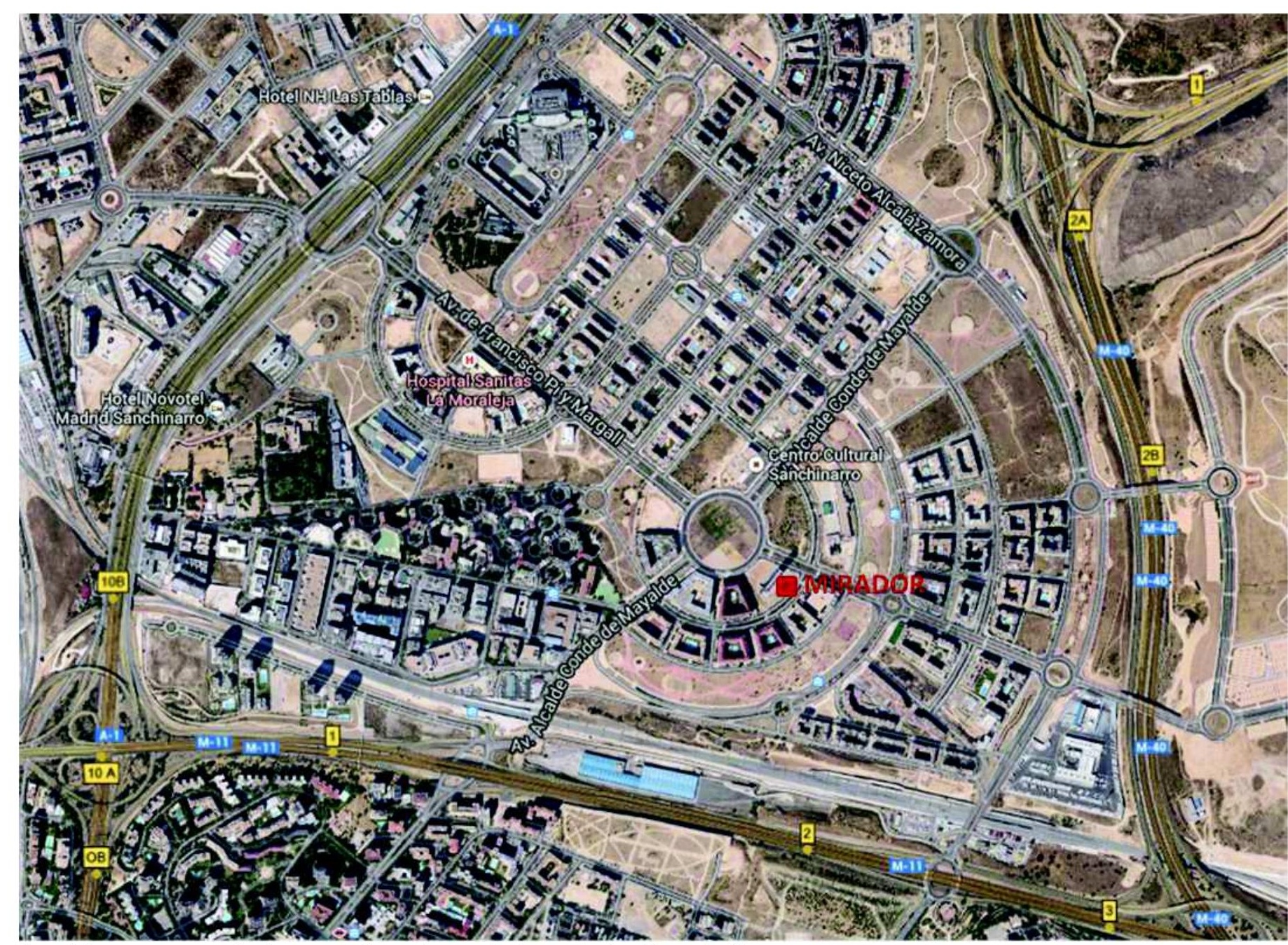

Sanchinarro e as rodovias que circundam o bairro. Fonte: Google Maps.

\section{Considerações sobre o projeto}

O Mirador apresenta novas ideias aos moradores de Sanchinarro. A Interiorização espacial e a Diversidade/ldentidade são os conceitos mais evidentes no projeto e instigaram debates sobre essas questões entre moradores e vizinhos do projeto. Novamente, ressaltamos que os habitantes do Mirador não escolheram viver ali, os apartamentos subsidiados foram ofertados a essa população após anos de espera na fila de um programa municipal de habitação, então, talvez o mais esperado por eles fosse um edifício parecido com os existentes na vizinhança. Diante desse cenário, lidar com a diversidade de elementos do projeto passa a ser uma estranha novidade para seus usuários. Somam-se a isso vários problemas oriundos da qualidade da construção (revestimentos das fachadas como placas metálicas e pedras que se desprendem, falta de isolamento térmico, infiltrações, problemas com 
os elevadores, etc) e a insatisfação dos moradores com o edifício de maneira geral aumenta consideravelmente ${ }^{38}$.

Quanto ao processo de projeto, notamos que os arquitetos trabalharam sozinhos em comparação ao Silodam, sem reuniões e debates com clientes e usuários para evolução das propostas. Muitas das decisões têm grandes influências políticas e econômicas e chegam definidas pelo cliente, dispensando o papel do arquiteto como coordenador de negociações. O afastamento da pesquisa é claro e o processo de projeto divulgado se resume a esquemas que mostram apenas o desenvolvimento formal e a distribuição do programa.

Após tantas polêmicas sobre o uso da praça elevada, observamos que o vazio passa a ser visto mais como um gesto urbano que tenta quebrar a monotonia dos novos bairros na periferia de Madrid do que como um espaço coletivo real. Desse modo, ao invés de se integrar à cidade, o edifício se converte em monumento que critica a arquitetura e urbanismo do seu entorno.

Ainda sobre os espaços coletivos, retomamos o conceito de um dos primeiros diagramas do Mirador, aquele que levanta a tipologia com pátio e a transforma em edifício com 20 pavimentos para liberar terreno, para lembrar que, apesar de todo esforço estrutural, esta área livre permanece pouco utilizada mesmo anos após a conclusão da obra. Da intenção inicial da arquitetura como mediadora das relações no espaço público apenas permaneceu o vazio como lembrança dessa ideia.

${ }^{38}$ Depoimentos presentes no livro MVRDV Buildings (2013), 


\subsection{Parkrand}

O parque Eendrachts não era considerado seguro antes porque poucas pessoas moravam ali e olhavam para ele. Agora com o Parkrand a população se sente mais segura no parque (MVRDV em MVRDV Buildings, p.176, tradução nossa).

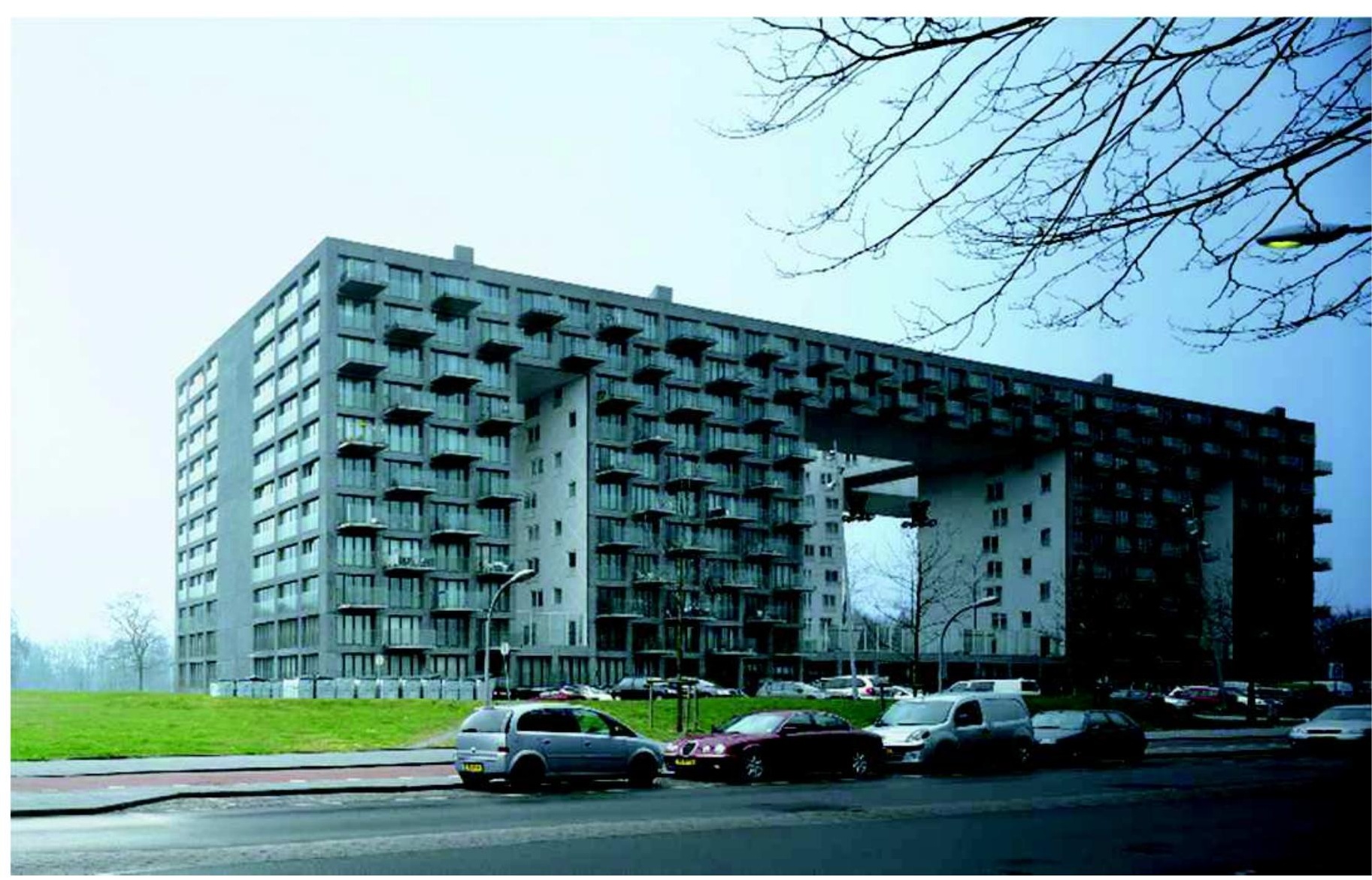

Parkrand, vista da rua Dr. Colijnstraat. Fonte: El Croquis.

Localização: Amsterdã

Data: 1999-2006

Cliente: Stadgenoot Ontwikkeling B.V.

Programa: $35.000 \mathrm{~m}^{2}, 240$ apartamentos, área comercial e estacionamento subterrâneo

Orçamento: EUR 28.5 milhões

Parkrand fica em Geuzenveld, um bairro em Nieuw-West, região planejada como cidade jardim. Nos últimos quinze anos, a área a oeste do anel viário de Amsterdã 
tem sido palco de várias renovações urbanas. As cidades jardins construídas a partir de 1950 com base em conceitos modernistas entraram em declínio e se transformaram em bairros marcados por problemas sociais.

A região abriga cerca de 130 mil habitantes em 54 mil habitações e o plano de renovação dessas moradias prevê a demolição de 10 mil unidades e a construção de 17 mil novas residências até $2015^{39}$. Realizado pela Stadgenoot, uma empresa de habitação sem fins lucrativos, o Parkrand faz parte de um projeto de remodelação que busca inovar a imagem das cidades jardins para atrair moradores da classe média e tem feito surgir vários ícones arquitetônicos no bairro (o edifício Wozoco fica a pouco mais de dois quilômetros dalí). O projeto se situa ao lado do eixo do parque Eendrachts (daí a origem do nome, Parkrand significa eixo do parque) e sua solução parte da não interrupção da vista dos outros edifícios para a área verde.

O edifício busca compactar as habitações em um único bloco de modo a conservar mais espaço para o parque. Com 135 metros de comprimento por 34 metros de largura e altura, o Parkrand também trabalha o agrupamento de blocos menores, como no Silodam e no Mirador, para compor um volume que, neste caso, é formado por cinco torres (nomeadas $\mathrm{V}, \mathrm{W}, \mathrm{X}, \mathrm{Y}, \mathrm{Z}$ ) conectadas pelo embasamento e pelos dois últimos pavimentos e conta com uma série de vazios caracterizados como pátios de uso coletivo. Tal desenho forma um bloco vazado e oferece vistas diferentes de cada unidade para o parque. Os pátios são caracterizados como um estar aberto, ideia que é reforçada pelo projeto do designer holandês Richard Hutten que faz uso de um mobiliário específico para áreas externas, acabamentos nos pisos, paredes e tetos, plantas e lustres, entre outros elementos decorativos.

O MVRDV buscou posicionar as torres de modo a garantir vistas e insolação para todas as unidades. Para isso, o último pavimento conta com três grandes aberturas, desenho que também se repete no primeiro nível formando dois pátios com acesso para os apartamentos desse pavimento.

\section{Datascapes de uma área em reconstrução}

Observamos que em termos de uso de dados, o Parkrand se assemelha ao que acontece com o Mirador. $O$ projeto também tem pouca divulgação sobre 0 uso

${ }^{39}$ Fonte: www. archex.info. Acessado em: 29/maio/2014. 
constante de informações durante processo de design divulgado e não tem a participação da comunidade no desenvolvimento das soluções (o que estimularia o uso de diagramas e as discussões sobre o programa), mas conta com um cliente aberto a novas propostas habitacionais.

As principais premissas que guiaram esse processo foram: aumentar a relação do bairro com o parque, dobrar o número de habitações e aumentar a diversidade de tipologias.

Os estudos iniciais consideravam soluções como torres em um embasamento, um grande volume suspenso por pilotis e blocos com diversos tipos de vazios.
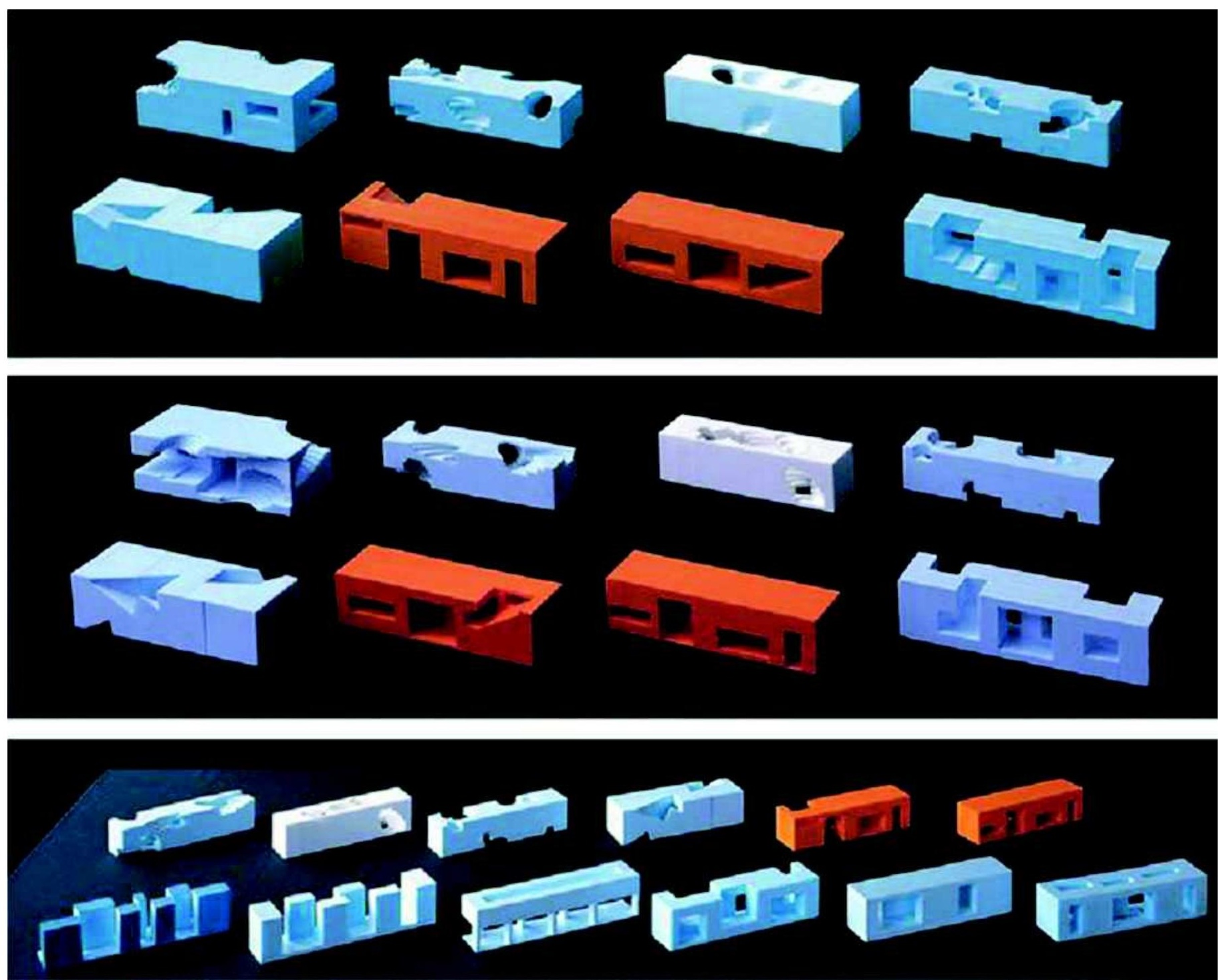

Maquetes de estudo. Fonte: El Croquis.

Como no Mirador, a divulgação do processo de projeto se resume a esquemas que narram a história da construção da solução final, os quais são claramente 
desenvolvidos após a conclusão do projeto e funcionam mais como material de divulgação do escritório. As maquetes de estudo são o único registro encontrado produzido durante o processo de projeto. Observando esses esquemas temos a impressão que, como no plano para o bairro dos anos 1950, o projeto tem mais preocupação com a forma do que com as relações que se estabelecem no espaço. Das possíveis soluções das maquetes de estudo, a grande maioria cria um volume ou um embasamento que bloqueia as relações da rua e dos pedestres com o parque, somente a solução que eleva um volume sobre pilotis parece, a priori, permitir uma comunicação mais efetiva entre o bairro e o parque. Desse modo, os dados do novo contexto em reconstrução parecem repetir as informações do antigo modelo.

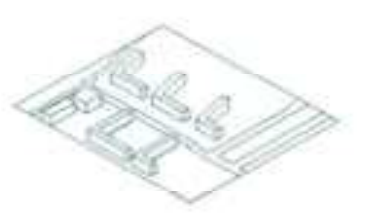

ต. cuosmunos

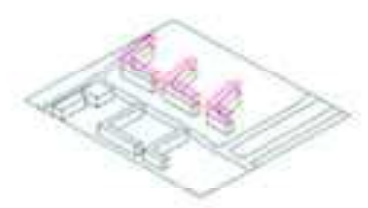

Q2. NEW (DOUBLED) PROGRAM

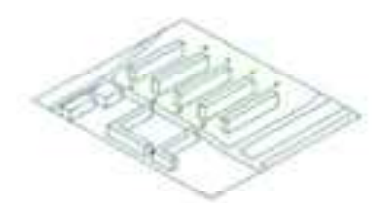

Q. LaWANTED NORTH-SOUTH ORERTATICY

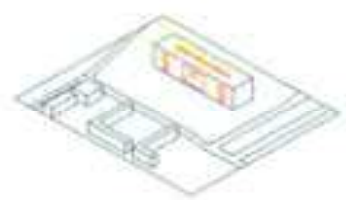

03. AR/LIGIT POCKETS, BLOCK 34M DEEP

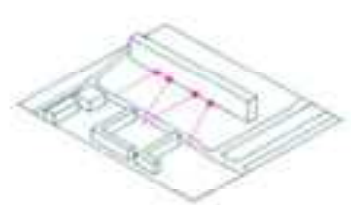

04. LONG SU8 BLOCXS PARK VIEW

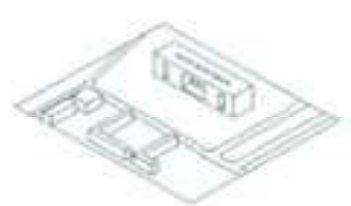

4. FINAL CoMposmos

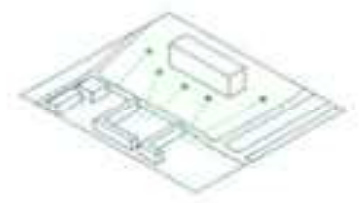

Esquema mostrando a evolução da solução, na primeira linha: 01. Antiga situação, 02. Novo programa (dobro do antigo), 03. Orientação norte-sul não desejada, 04. Grande lâmina bloqueando a vista do parque. Na segunda linha: 01. Bloco compacto no parque, 02. Bloco sólido com 24 metros de profundidade, 03. Bolsões de ar/luz e o bloco com 34 metros de profundidade, 04. Composição final. Fonte: www.mvrdv.nl.

\section{Iniciações de Uso misto/espaços múltiplos}

Além das habitações, o Parkrand também conta com os vazios utilizados como espaços coletivos e áreas comerciais no primeiro pavimento que hoje são ocupadas por uma escola infantil, o que enfatiza a importância da diversidade como condição de sucesso para a remodelação do bairro.

Os pátios do Parkrand se assemelham à praça elevada do Mirador e poderiam ser os principais espaços para usos múltiplos, cumprindo um papel que os antigos 
prédios do terreno não realizavam. No entanto, essas áreas parecem ter um uso um tanto restrito perto do seu potencial, podendo ser comparadas aos lobbies de hotéis estetizados e organizados devido ao seu projeto de interiores que vamos abordar com mais clareza no tópico interiorização espacial. Talvez com outra caracterização, ou até mesmo com a ideia inicial do MVRDV de um parque interior, esses vazios poderiam ser espaços menos privados, mais versáteis e que estabelecessem relações significativas dos moradores do bairro com o meio ambiente.

Por hora eles funcionam mais como grandes janelas para os prédios vizinhos visualizarem o parque, o que acontece somente a partir de determinada altura. $O$ desenho resultante desses espaços limita a vista e bloqueia o acesso ao parque.

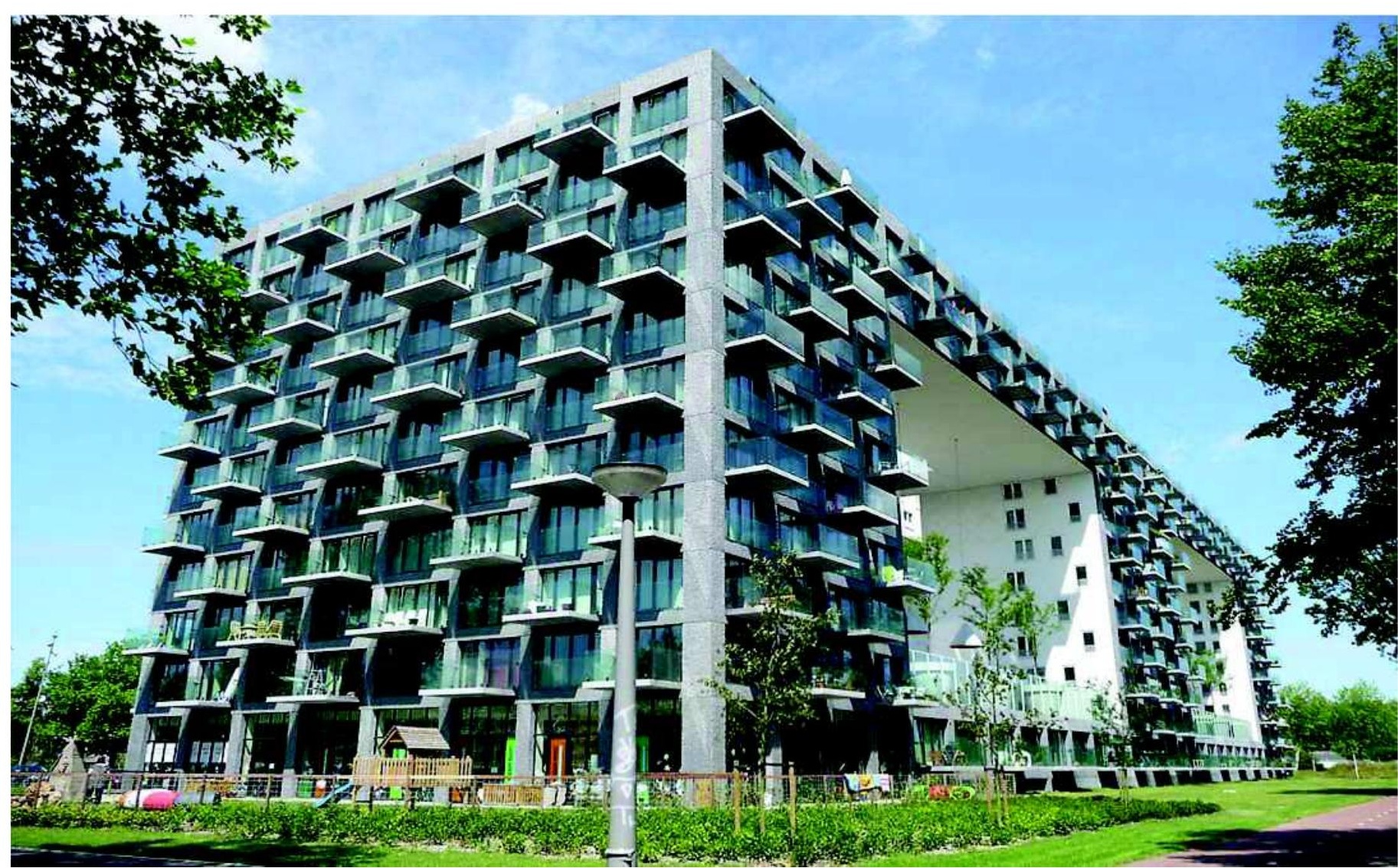

A escola infantil no térreo. Fonte: www.buildingbluter.com 


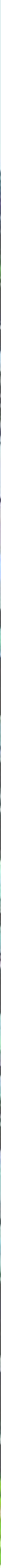

As "janelas" para o parque a partir da rua Dr. Colijnstraat. Fonte: www.google.com/maps O pátio visto do parque. Fonte: www.mvrdv.nl 
Pátio com acesso aos apartamentos do nível zero. Fonte: www.funda.nl






\section{Naturezas artificiais: transferindo área verde}

No Parkrand o conceito de natureza artificial está relacionado aos estudos do MVRDV que discutem a ocupação desregulada dos subúrbios e a consequente falta de preservação das suas áreas verdes. Além da intenção de reforçar o contato com o parque Eendrachts, o escritório soma a isso a ideia de adicionar área ao parque. Os arquitetos aumentam o número de unidades, mas mantêm a taxa de ocupação do lote da antiga construção. Desse modo, o terreno restante do Parkrand é somado ao parque (gesto enfatizado pela ausência de barreiras físicas entre as duas áreas) e o Parkrand parece estar implantado em pleno Eendrachts.

Além disso, com o projeto de renovação das cidades jardins de Amsterdã, o Parkrand, como elemento arquitetônico, participa da construção de uma nova paisagem artificial para os subúrbios planejados.

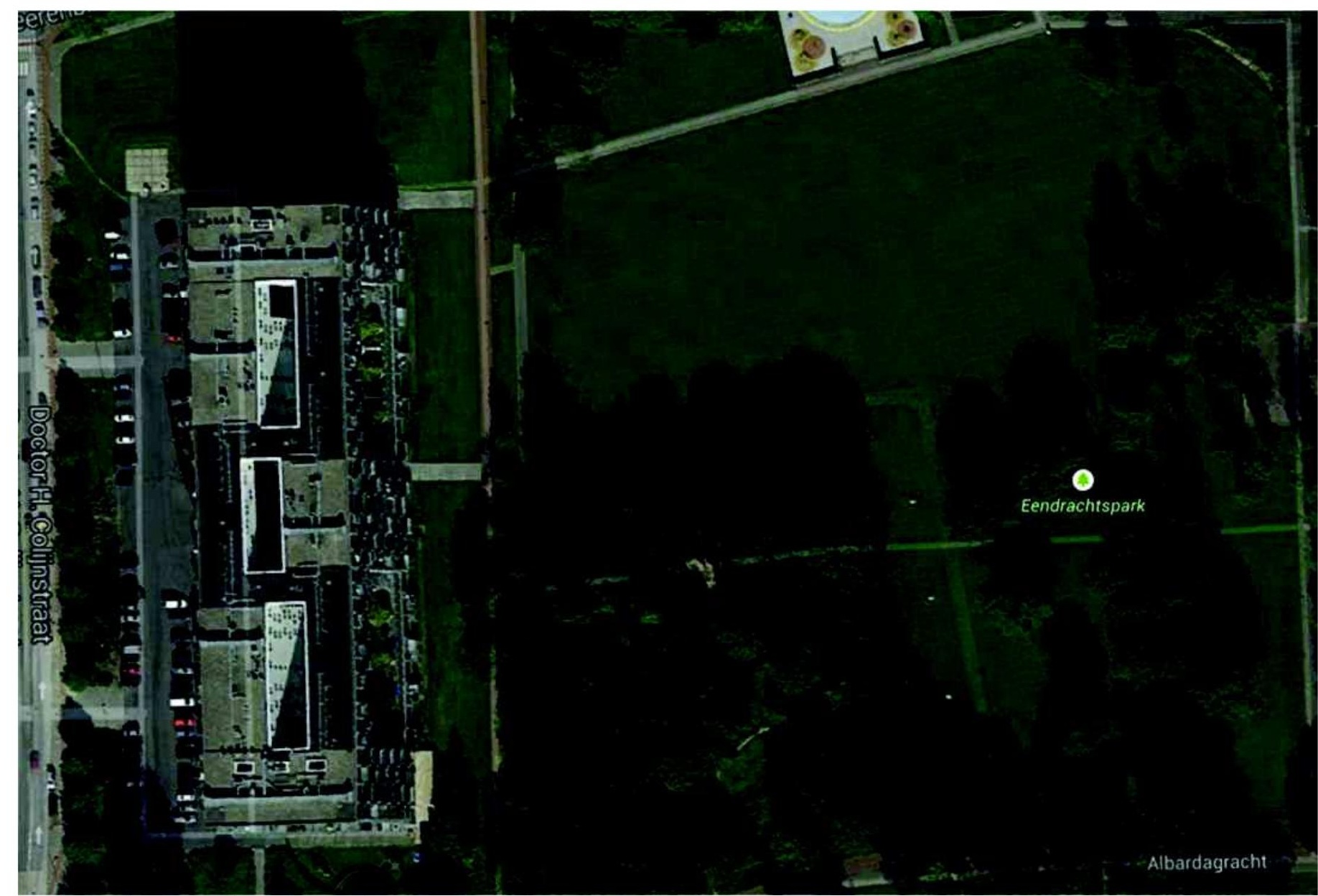

Implantação do Parkrand em relação ao parque Eendrachts. Fonte: www.google.com/maps 

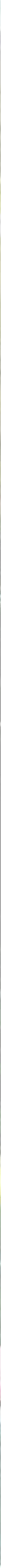

O parque visto do ultimo andar do Parkrand. Fonte: www.funda.nl Parkrand visto a partir da piscina do parque mostra a continuidade entre os terrenos. Fonte: www.mvrdv.nl 


\section{Interiorização espacial como solução da forma}

Mais uma vez o MVRDV insere vazios no projeto com a intenção de torná-los espaços intermediários entre o público e o privado. Inicialmente os arquitetos pensaram em caracterizar os vazios como jardins, relacionando essas áreas com o parque. No entanto, o projeto para os interiores do Parkrand ficou a cargo do designer holandês Richard Hutten (que também desenvolveu um projeto para a praça elevada do Mirador, cancelado por questões financeiras e que tem os bancos submersos como um resquício do seu desenho) que sugeriu enfatizar esses espaços como interiores definindo-os como três salas com vista para o parque. Duas delas, as "salas de jantar" e "estar" são equipadas com vasos de concreto gigantes com árvores, lustres e mesas. A terceira, chamada de "sala das crianças", é coberta com grama artificial, tem escorregadores e luminárias em forma de animais, entre outros objetos. As paredes são revestidas com cerâmica branca texturizada que reflete a luz dentro do bloco escavado destacando o desenho do vazio. Notamos que essa caracterização remete à ideia de uma grande varanda, como nas casas de subúrbio, que olha para o parque, especialmente porque esses espaços estão um andar e meio acima do nível da rua e são de uso exclusivo dos moradores do edifício.

Os revestimentos das fachadas em concreto acentuam a solidez do edifício e diferenciam as paredes do interior do bloco cobertas com cerâmica, esse revestimento forma uma comunicação visual em grande escala, desenvolvida pelo escritório holandês de design gráfico Thonik, identificando a entrada de cada torre.

Como no vazio do Mirador, o espaço coletivo tem, algumas vezes, problemas com controle de barulho. Segundo uma funcionária do edifício é muito conveniente as crianças brincarem nos pátios pela segurança, mas se elas começam a jogar bola fazendo barulho, então, elas precisam descer para o parque (MVRDV Buildings, p. 176).

Mesmo com menos problemas e polêmicas que a praça elevada do Mirador, os vazios do Parkrand parecem aquém do projeto de Madrid. Essas áreas em Amsterdã não atingiram todo seu potencial como espaço coletivo e acabam por cumprir mais uma função técnica de garantir ventilação e iluminação dos apartamentos do que realmente oferecer uma área de convivência utilizada com frequência por seus habitantes. Além disso, esses elementos perdem a força 
enquanto material arquitetônico interessante para seu entorno já que mal cumprem a função de 'janela' do bairro para o parque.

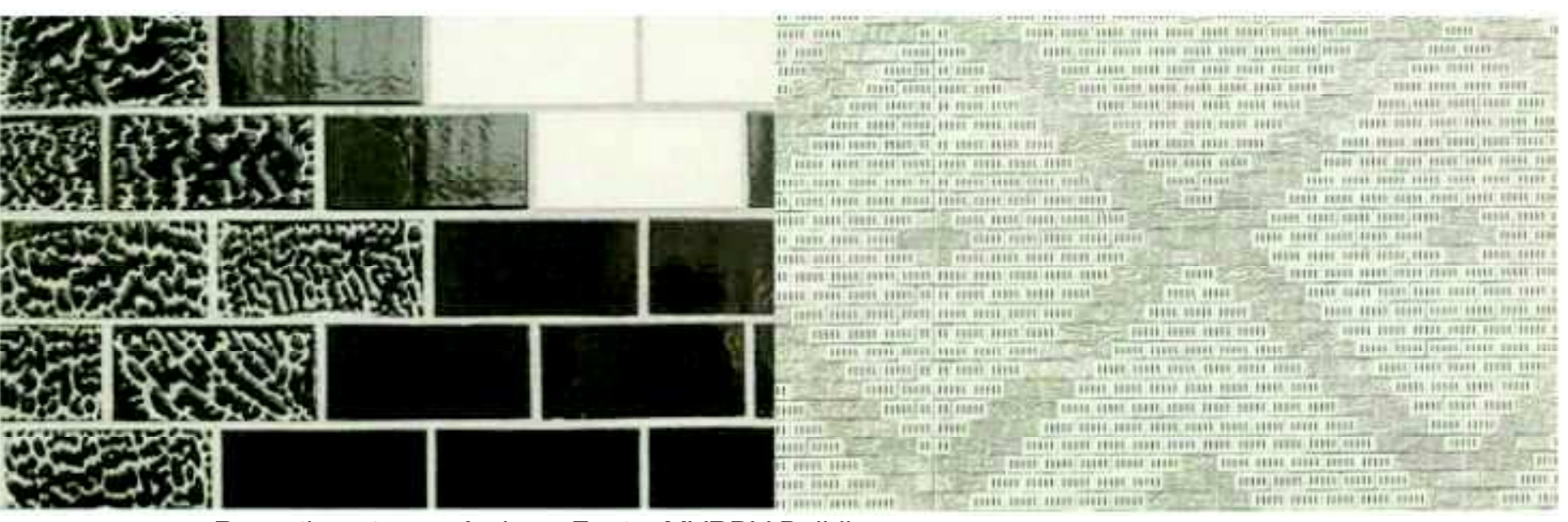

Revestimentos cerâmicos. Fonte: MVRDV Buildings.

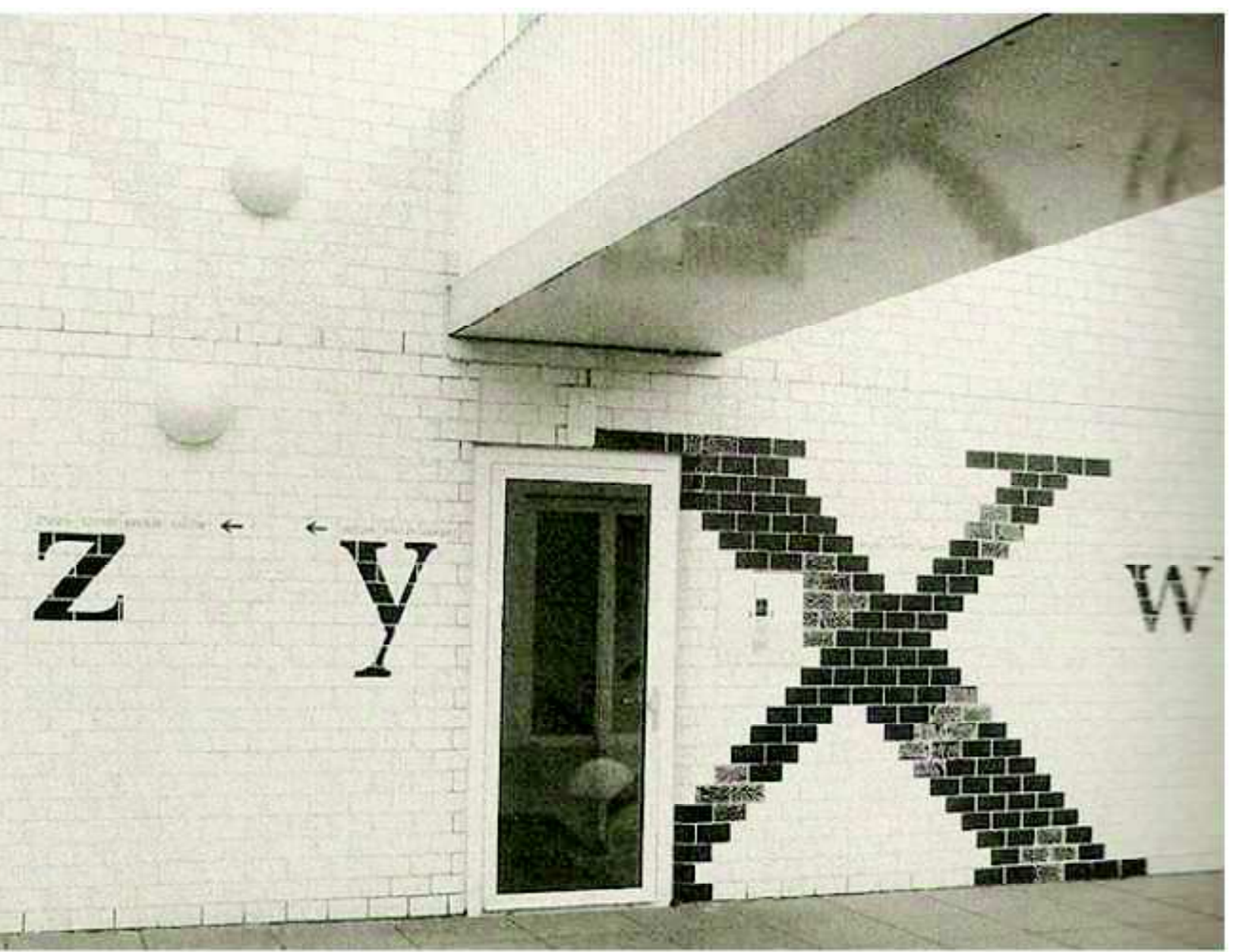

Comunicação do estúdio Thonik. Fonte: MVRDV Buildings. 
O vazio visto dos últimos andares. Fonte: MVRDV Buildings Lustres nas "salas de jantar e estar". Fonte: www.mvrdv.nl Luminárias. Fonte: www.designartnews.com

O vazio voltado para o parque. Fonte: www.muar.

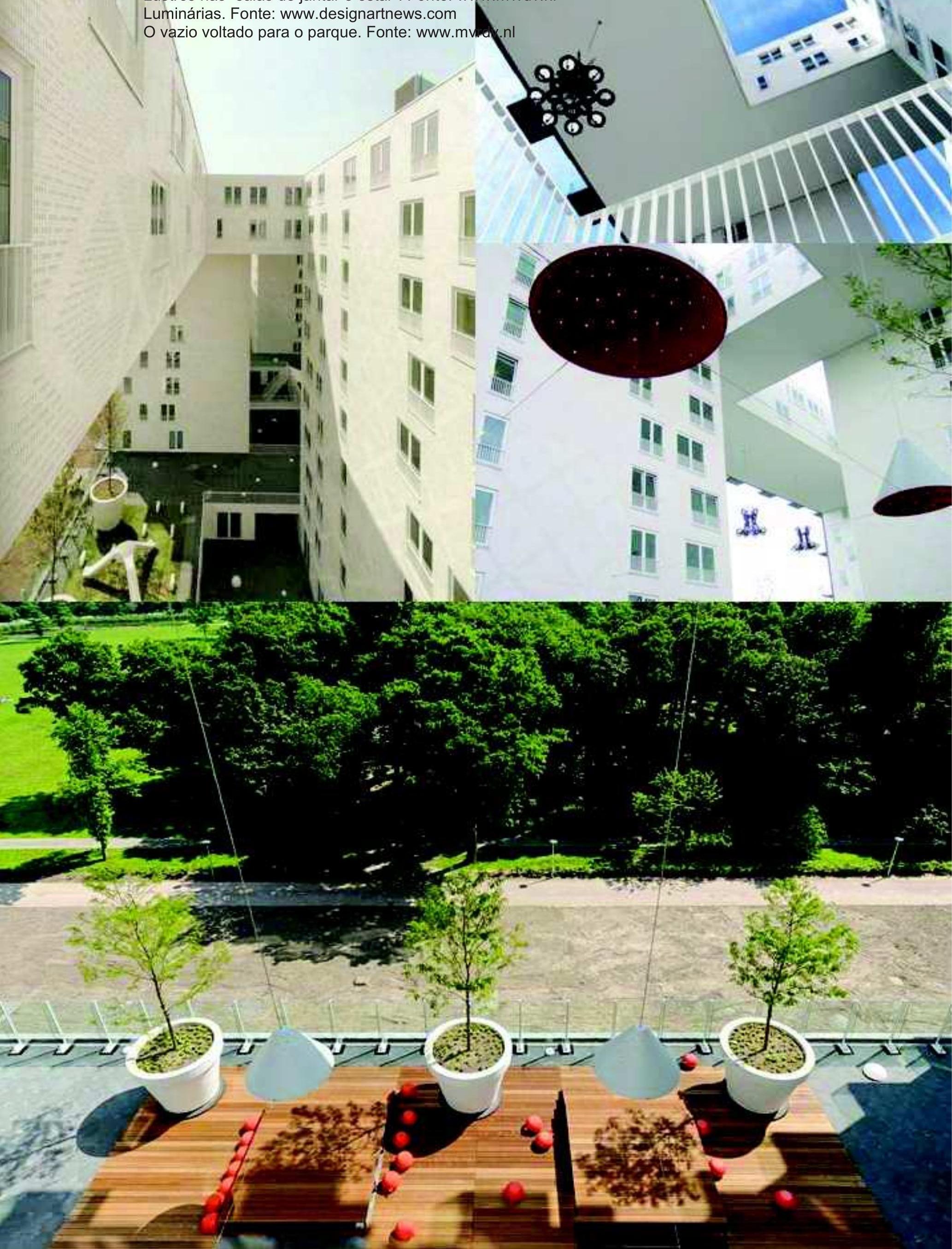




\section{Subúrbio urbano como solução urbana}

Geuzenveld é um bairro afastado do centro, mas relativamente denso, formado por prédios de apartamentos de quatro andares com blocos implantados em áreas verdes abertas.

O bairro é servido por linhas de ônibus e pelo tram e levam-se aproximadamente 30 minutos em transporte público para locomover-se do Parkrand até a estação central de Amsterdã (9 quilômetros por ciclovias).

A renovação do bairro, com o Parkrand participando desse modelo, pretende levar mais características do centro da cidade para Geuzenveld através de novos edifícios habitacionais com parcela de uso misto como solução para reativar a região em decadência. Nesse sentido, o projeto se assemelha ao Mirador que também tinha a intenção de alocar comércio e serviços junto à habitação levando cidade para periferia. Somam-se ainda outros aspectos não comuns ao subúrbio de Amsterdã como estacionamento subterrâneo e a diversidade de tipologias associado aos pátios coletivos e a área verde para manter as características de comunidade de bairro.

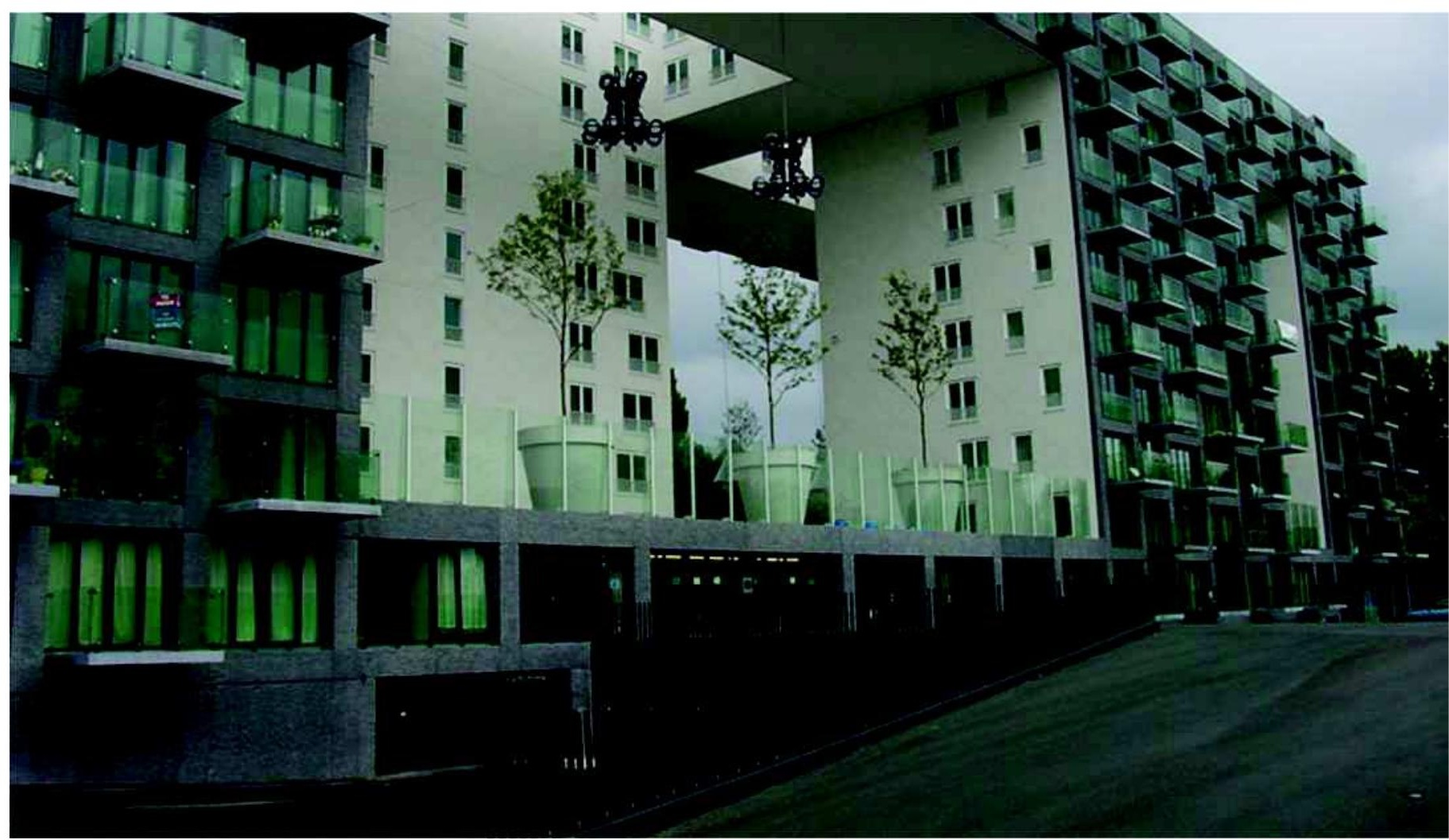

Entrada do estacionamento subterrâneo atrás da rampa. Fonte: www.designartnews.com 


\section{Densidade porosa}

O Parkrand aumentou a densidade do terreno em $38 \%$ comparado às antigas habitações existentes no local. O projeto contribui para alterar o adensamento no bairro com aumento da verticalidade quebrando a escala homogênea dos blocos de apartamento de quatro pavimentos.

Conforme acontece no Silodam e no Mirador, a lógica do empilhamento de diferentes casas em torno de espaços coletivos aparece novamente. Parkrand reúne aumento de densidade e de escala, mas seus vazios contribuem para aliviar a sensação de grandeza do bloco único.

Para calcular a densidade do edifício multiplicamos o número de unidades habitacionais do projeto pelo número de pessoas que podem morar nelas, os resultados obtidos seguem abaixo:

a- Número de moradores possíveis no Parkrand: 760 habitantes

b- Densidade Amsterdã (2013) 3.200 habitantes $/ \mathrm{km}^{2}$

c- Densidade Parkrand: 42.000 habitantes $/ \mathrm{km}^{2}$

A área do terreno é de $18.000 \mathrm{~m}^{2}$. A população de Amsterdã é 810.000 habitantes $^{41}$ (excluindo a região metropolitana). Desse modo, seguindo a classificação de níveis de adensamento abaixo, de Aurora Fernández $\operatorname{Per}^{42}$ (habitações $/ \mathrm{km}^{2}$ ), verificamos que o Parkrand se encaixa na terceira categoria: média densidade (13.300 habitações $/ \mathrm{km}^{2}$ ).

\begin{tabular}{l|l}
\hline Mais que 30.000 habitações $/ \mathrm{km}^{2}$ & $\begin{array}{l}\text { Elevada densidade. Habitação aparece associada à verticalidade como as torres nas grandes } \\
\text { metrópoles asiáticas e americanas. }\end{array}$ \\
\hline 20.000 a 30.000 habitações $/ \mathrm{km}^{2}$ & Alta densidade. Centros urbanos consolidados. \\
\hline 10.000 a 20.000 habitações $/ \mathrm{km}^{2}$ & Média densidade. Centros urbanos com blocos independentes e ampla área livre disponivel. \\
\hline 5.000 a 10.000 habitações $/ \mathrm{km}^{2}$ & Baixa densidade. O conceito de uso misto surge nas a tividades urba nas. \\
\hline Menos de 5.000 habitações $/ \mathrm{km}^{2}$ & $\begin{array}{l}\text { Baixa densidade associada as formas de ocupação de subúrbios. Os projetos originados do plano } \\
\text { Vinex tem tais caracteristicas esão, aproximadamente, } 95 \% \text { voltado para o uso residencial. }\end{array}$
\end{tabular}

\footnotetext{
40 Fonte: Demographia World Urban Areas, 10ạ edição anual, maio/2014.

${ }^{41}$ Central Bureau voor de Statistiek, maio/2014. http://statline.cbs.nl/

${ }^{42}$ PER, A. F. Densidad nueva vivienda colectiva. Vitoria: A+T, 2006.
} 
Como no Mirador a densidade média do Parkrand é combinada com sua localização, mais afastada do centro, a infraestrutura existente e os possíveis deslocamentos gerados por esses moradores para o centro da cidade.

Em contraste com as habitações sociais mínimas do entorno, o projeto apresenta uma nova atitude sobre a paisagem, a escala urbana e o tamanho/qualidade das habitações, no entanto, tais características se tornarão comuns ao bairro à medida que o programa de remodelação de Geuzenveld for concluído.

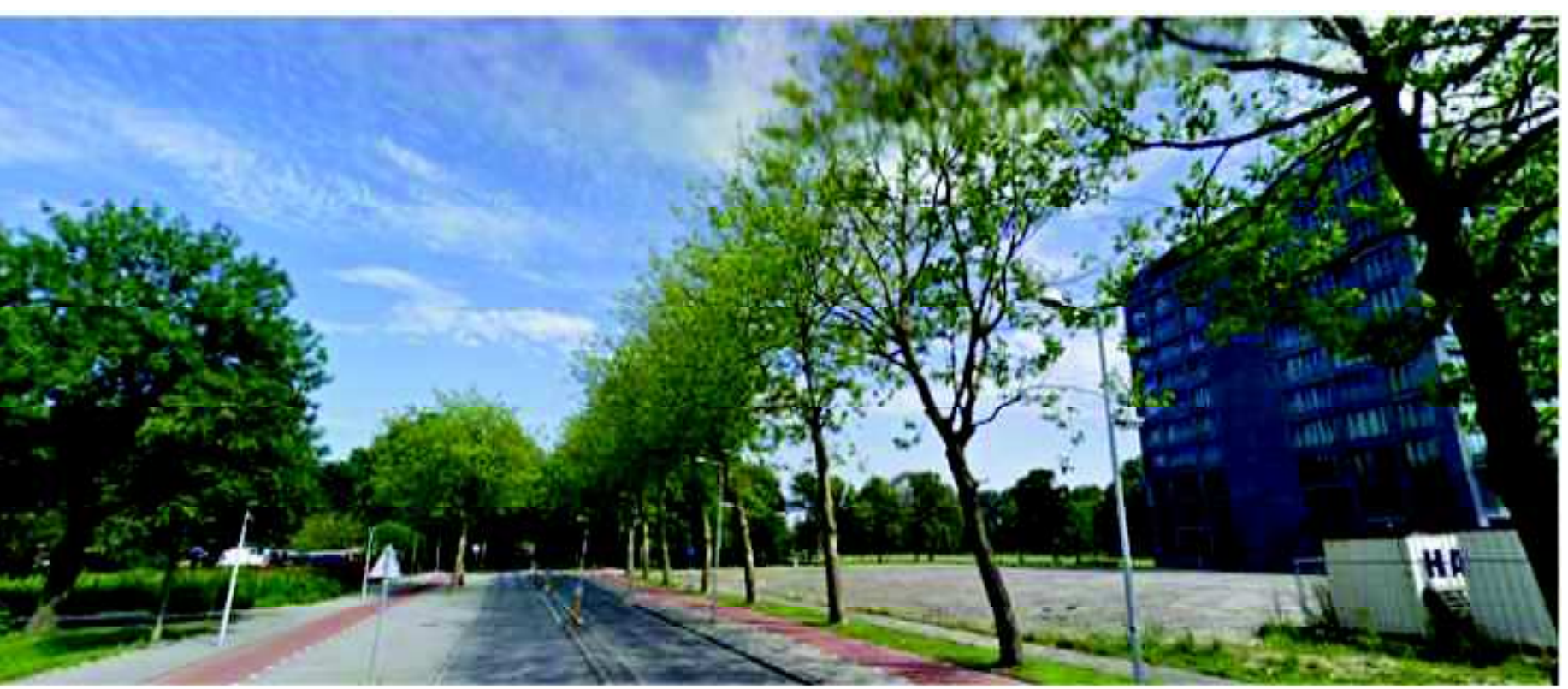

Lateral do Parkrand a direita e parque ao fundo. Fonte: www.google.com/maps 


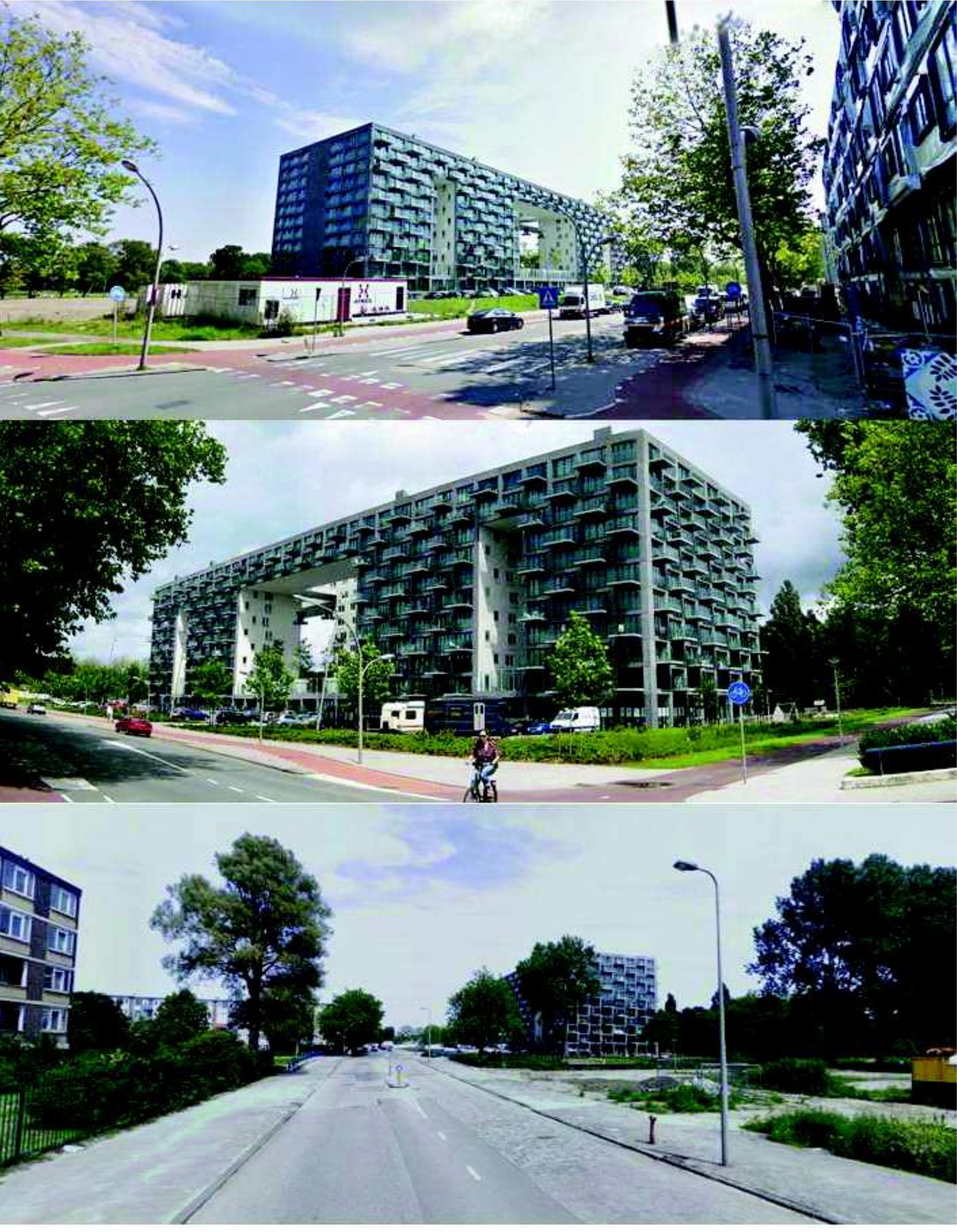

Entorno do Parkrand na rua Dr. Colijnstraat. Fonte: www.google.com/maps 


\section{Diversidade/identidade como mercado}

O projeto pode ser lido de duas maneiras: 1- como torres conectadas pelo embasamento e o topo; 2- como um bloco com partes subtraídas. Essa característica se repete nas plantas dos pavimentos, ou seja, os primeiros dois níveis e os últimos dois são organizados em torno de três vazios (pátios com acesso aos apartamentos no nível zero e aberturas para insolação e ventilação, respectivamente) enquanto os pavimentos intermediários aparecem como torres, cada uma com seu acesso e circulação vertical independente. Os dois últimos pavimentos, que fazem a conexão entre as torres no topo, contam com apartamentos duplex que têm seus acessos pelo penúltimo andar.

O Parkrand se diferencia dos outros edifícios do bairro não só pela materialidade das suas fachadas em concreto e vidro, mas também pelos seus interiores e seus espaços coletivos abertos. Para os moradores das habitações sociais - se não houver um processo de gentrificação com a renovação do bairro - a ligação com o parque por esse lote continua reduzida e acontece apenas visualmente através do enquadramento do verde pelo espaço ainda privado do Parkrand, desse modo, o edifício se apresenta mais como um marco para o bairro do que um elemento arquitetônico que favorece as relações no espaço.

Considerando que a habitação social da década de 1950 foi substituída por uma habitação de mercado, a qualidade e o tamanho das unidades foram nitidamente alterados. Para atender as novas demandas, o MVRDV mais uma vez lança mão da diversidade através de uma mescla de diferentes tipologias habitacionais.

Nas torres, unidades de um a quatro dormitórios são agrupadas em torno da circulação vertical. Os últimos dois pavimentos são organizados em volta de uma galeria contínua no nível nove que se conecta à circulação vertical das torres, mas também funciona como acesso aos apartamentos duplex desses andares. Algumas unidades do primeiro pavimento podem ser acessadas diretamente dos pátios e todas as unidades contam com espaço externo próprio, varandas em balanço ou cobertas.

São 36 tipologias diferentes, todas destinadas para locação, sendo 190 apartamentos com valor de aluguel entre 800 e 1400 euros $^{43}$ e 30 habitações

${ }^{43}$ www.stadswandelkantoor.nl/navigation/news/Parkrand.html. Acessado em 31/07/2014. 
sociais reservadas para idosos e pessoas com necessidades médicas. O tamanho das unidades varia entre 87 e $132 \mathrm{~m}^{2}$.

Notamos que, como no Mirador, todo o gesto de criar um edifício com grandes vãos e áreas comuns não se reflete nas plantas das unidades que são bastante segmentadas e sem nenhum aspecto inovador. Os apartamentos, de um a quatro dormitórios, são, na maioria, tradicionalmente divididos em salas, quartos e banheiros. As cozinhas são integradas ao estar e algumas tipologias contam com divisórias de correr nesses ambientes. Devido à segmentação da planta, alguns tipos acabam tendo longos corredores; no entanto, os ambientes não são hierarquizados e não existem espaços exclusivos, como suítes. Mais uma vez a variedade de tipologias não significa diversidade de programa dentro das unidades, a maioria dos apartamentos tem programas semelhantes e não são preparados para alterações radicais de espaços.

Assim como nos outros projetos, identificamos uma lógica tradicional de distribuição dos ambientes das unidades que é muito semelhante à configuração encontrada no Silodam. Através dos fluxogramas produzidos para essa análise (na sequência), concluímos que nos três projetos o modo de conexão entre os espaços internos dos apartamentos é sempre o mesmo, em unidades de um ou mais pavimentos a habitual separação entre as áreas social e íntima é bastante presente. $\mathrm{O}$ aspecto mais atual da configuração das tipologias passa a ser a integração do estar com a cozinha, esta última vista como ambiente de socialização e não mais de serviço. 


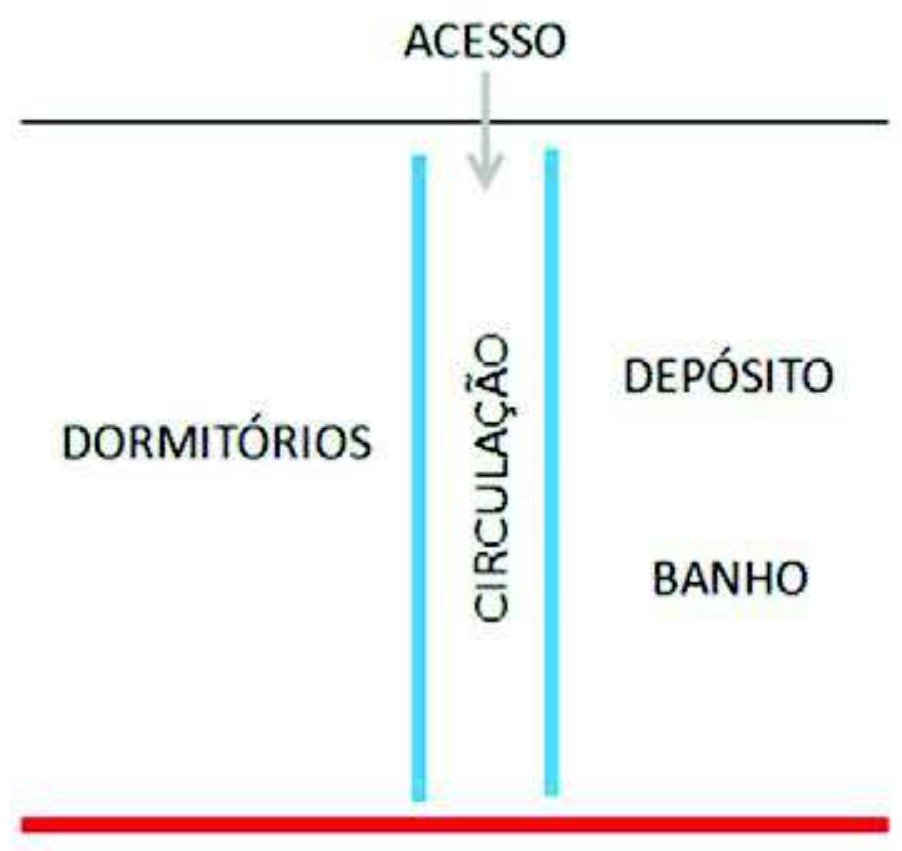

COZINHA

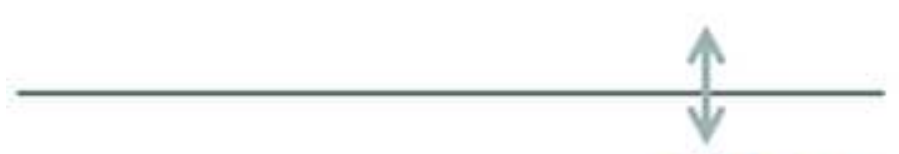

VARANDA
BANHO

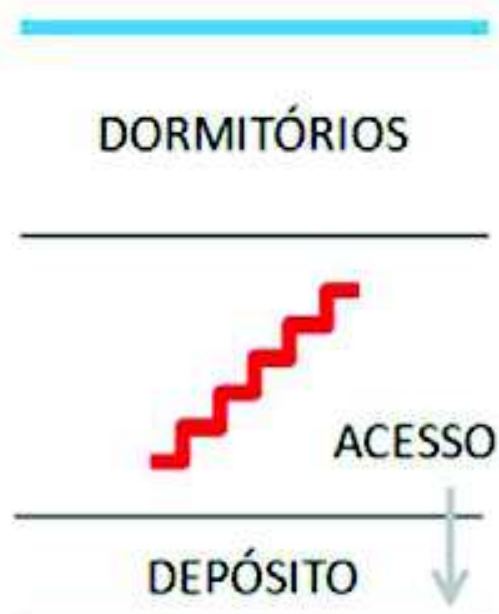

COZINHA

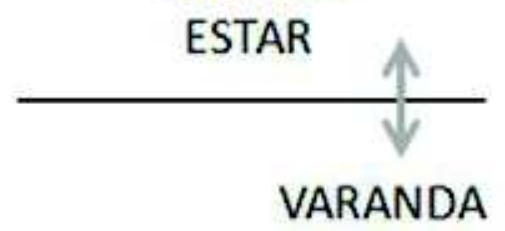

Fluxograma: lógica tradicional de configuração das unidades de um e dois pavimentos. As linhas vermelhas representam as divisões entre área social e íntima e as linhas em azul mostram as divisões nas áreas íntimas Fonte: autora.

Ao contrário do Silodam e do Mirador, no Parkrand o MVRDV não diferencia os subblocos com materiais diferentes nas fachadas, ao contrário, os arquitetos uniformizam o volume ao máximo unificando as torres e o embasamento para enfatizar a ideia de um bloco único escavado, o que ressalta as características dos vazios interiores. A circulação como elemento articulador e gerador de espaços coletivos, tão presente no Silodam, Mirador e outros projetos do MVRDV perde essa força no Parkrand e aparece apenas como espaço funcional.

O bloco com vazios do Parkrand tem similaridades com a Immeubles-Villas (1922) ${ }^{44}$ de Le Corbusier. Na reinterpretação do Parkrand os terraços das unidades habitacionais são convertidos em grandes espaços coletivos. Edifício-villa formado por unidades habitacionais com configurações que remetem à casa isolada de
subúrbios. 

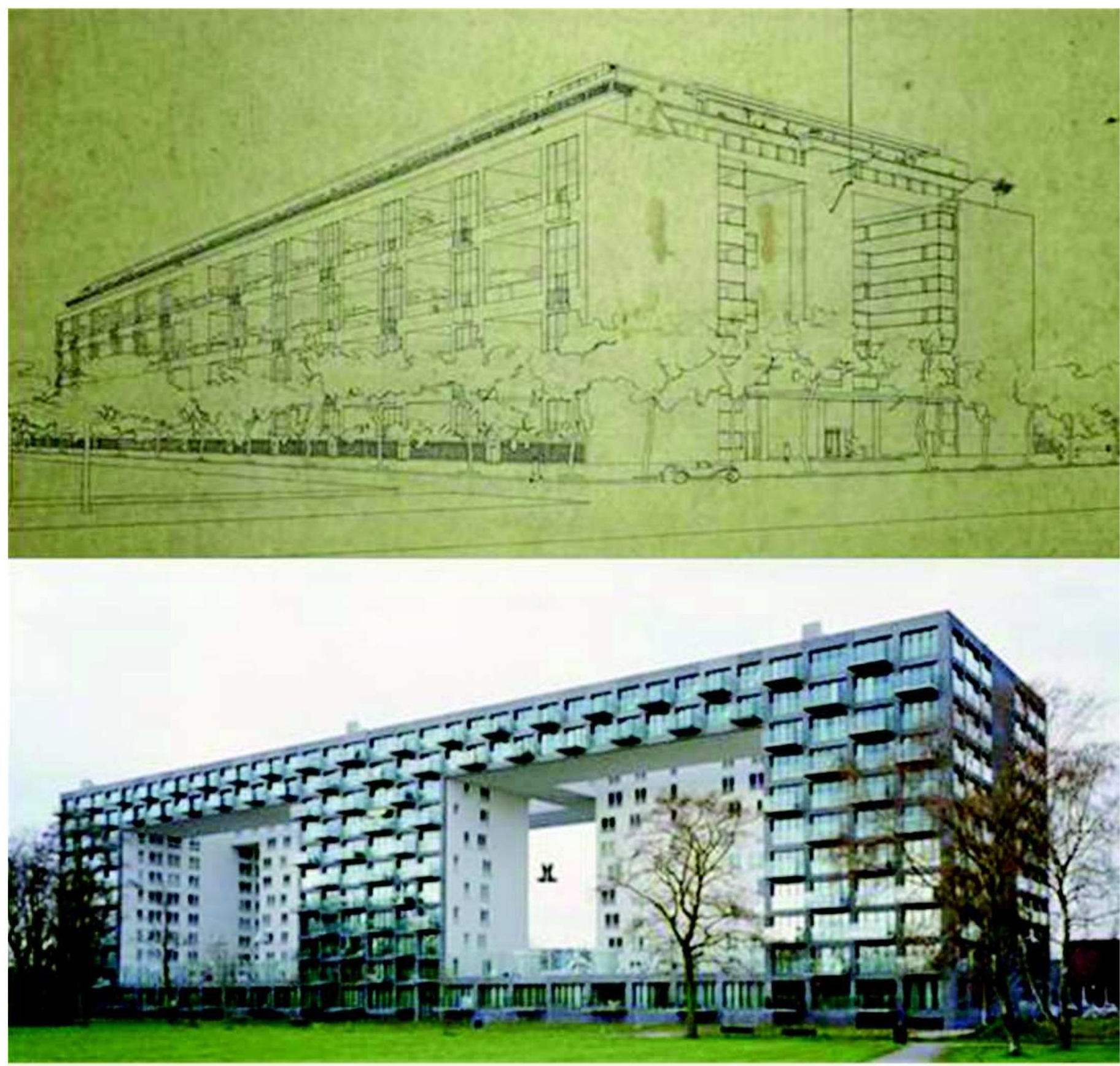

Immeubles-Villas com terraces e Parkrand com vazios. Fonte: www.fondationlecorbusier.fr e www.nytimes.com

A seguir, analisamos as plantas de cada pavimento, destacando as áreas coletivas, os apartamentos e as áreas comerciais representadas pelas cores vermelho, azul e amarelo, respectivamente. Na sequência apresentamos as tipologias dos apartamentos. 

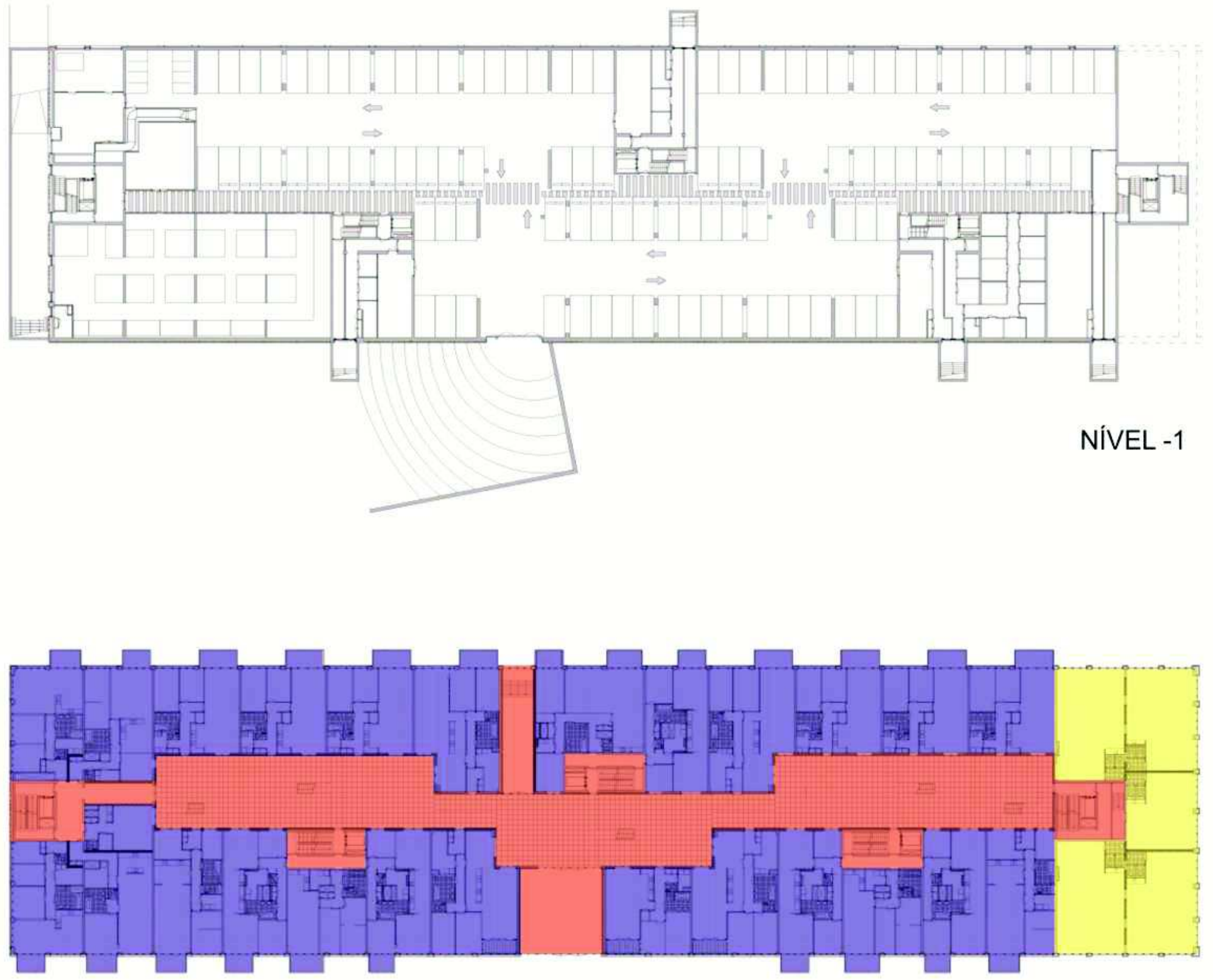

NÍVEL 0
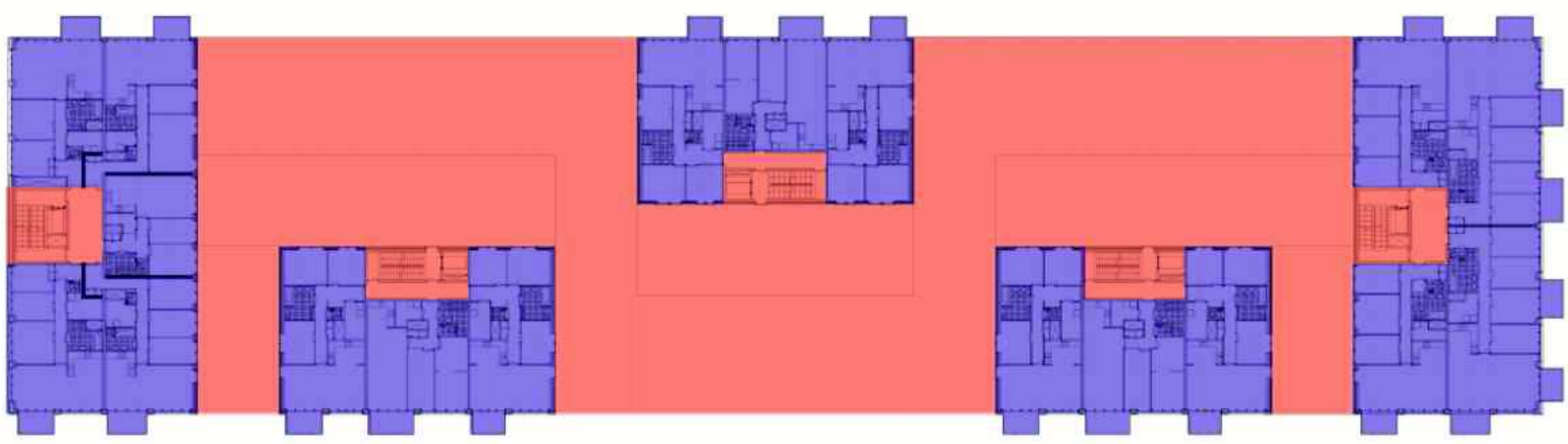

NÍVEL 1 AO 8 


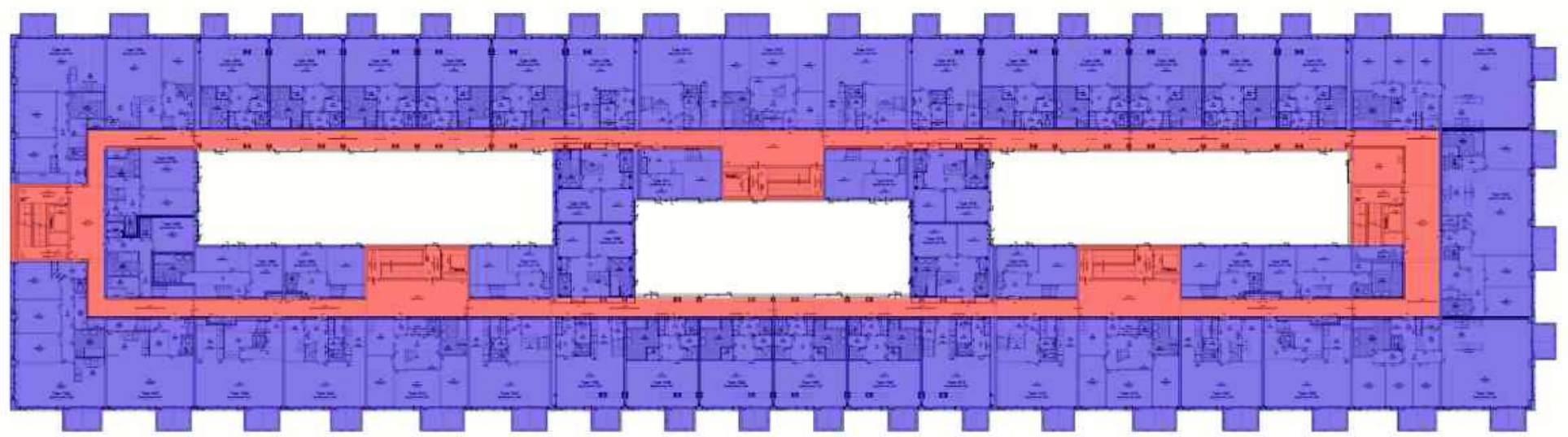

NÍVEL 9

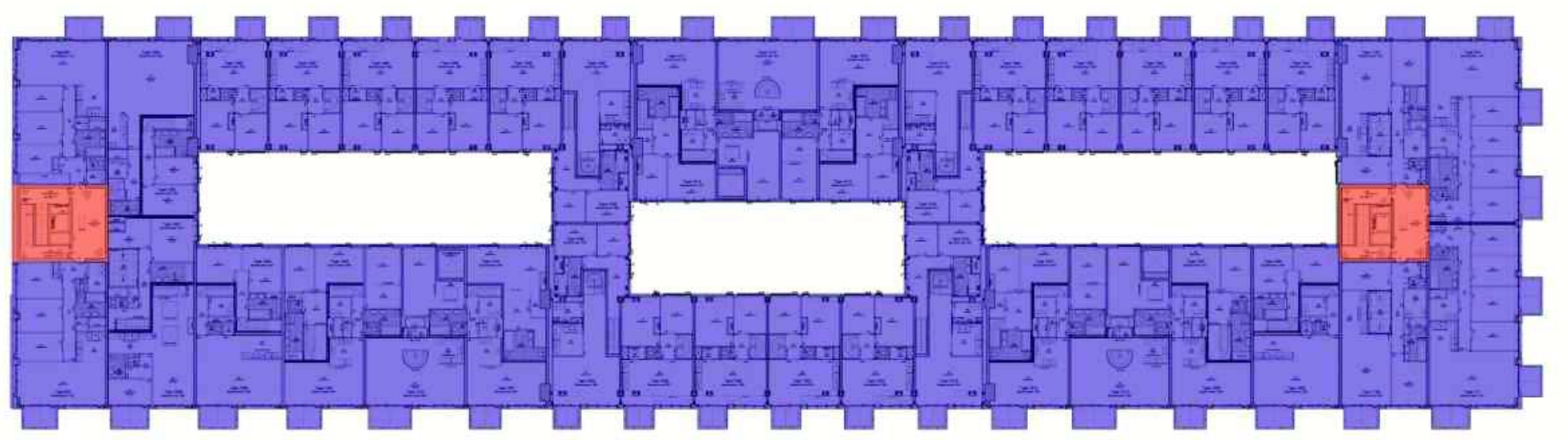

NÍVEL 10 

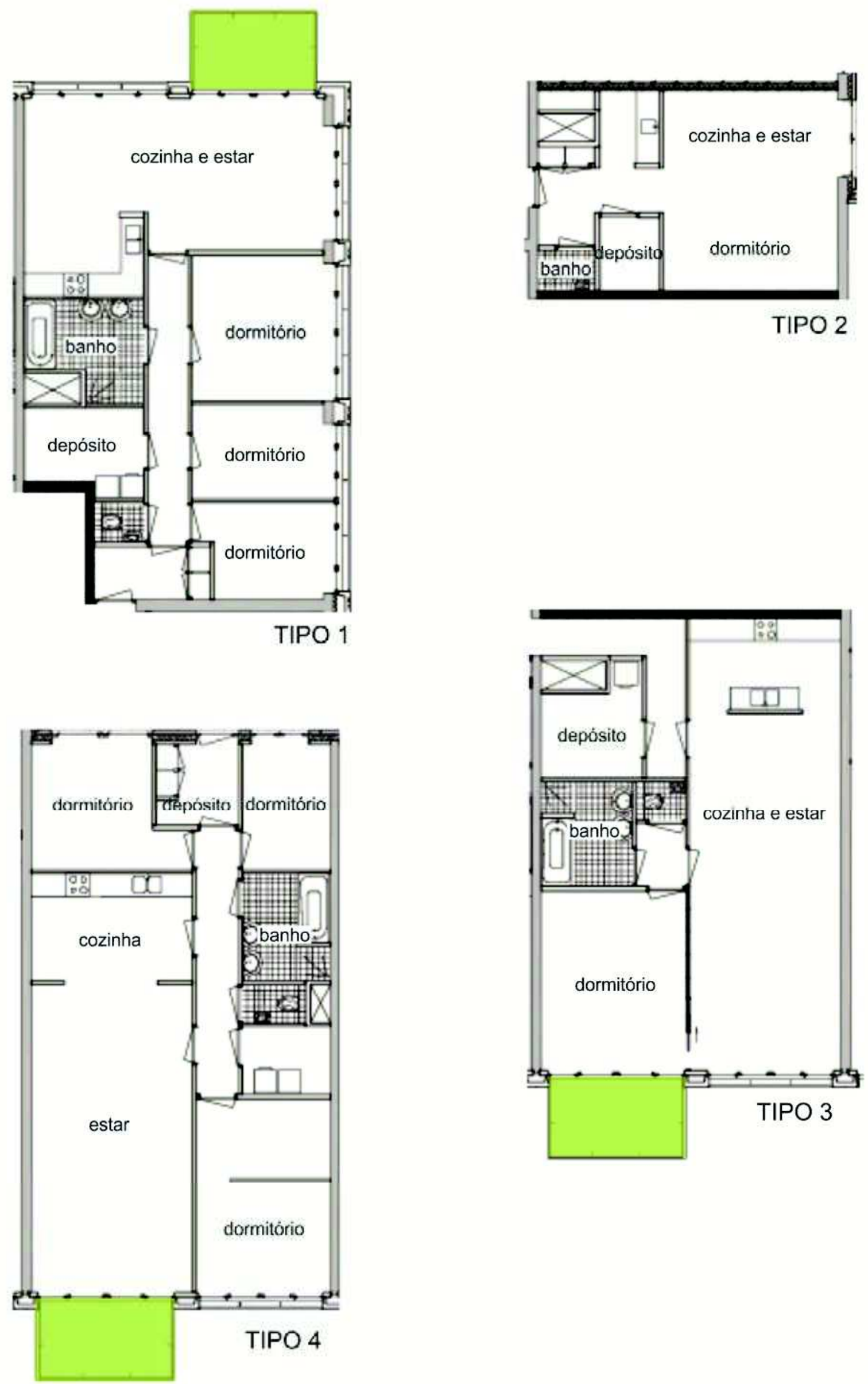

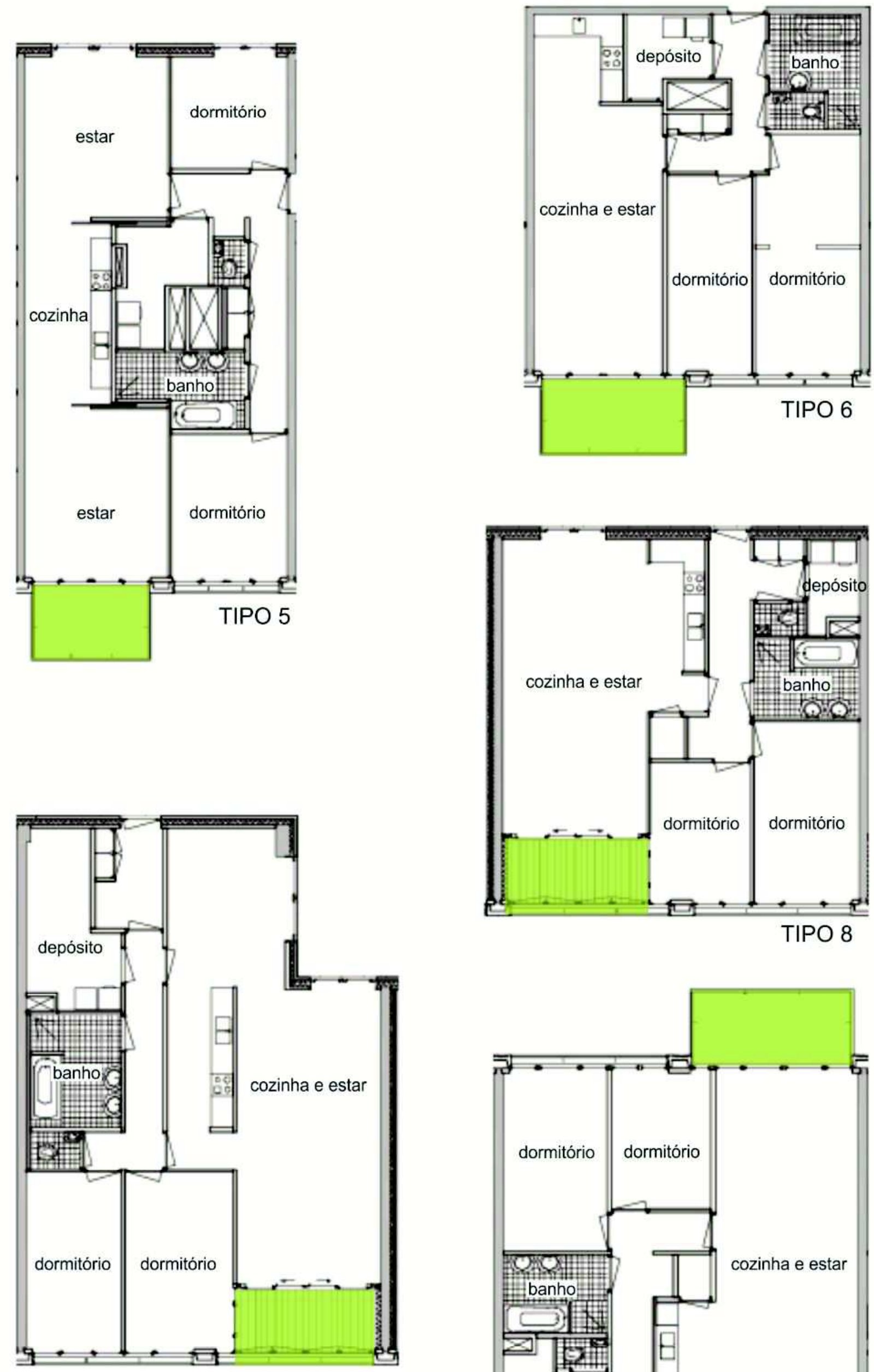

TIPO 7
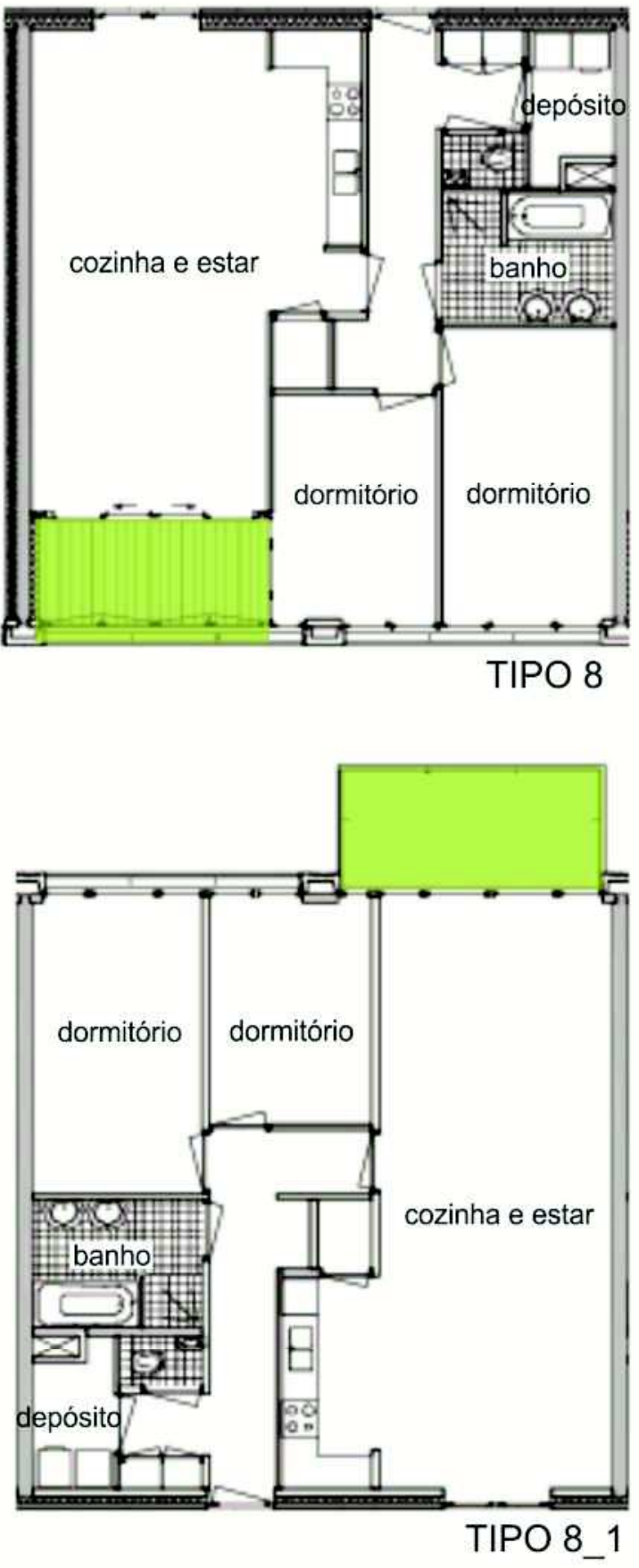



TIPO 12 

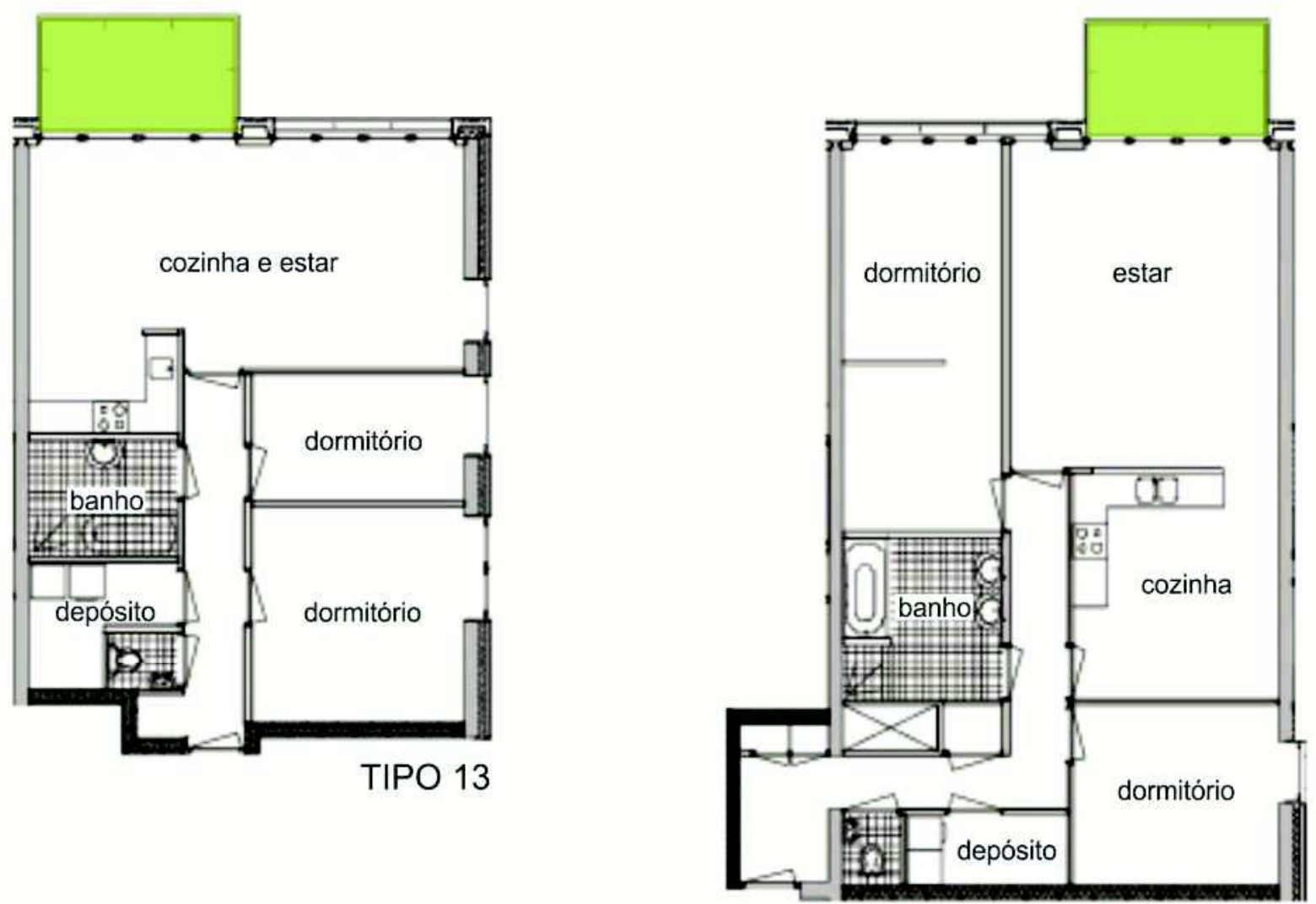

TIPO 14
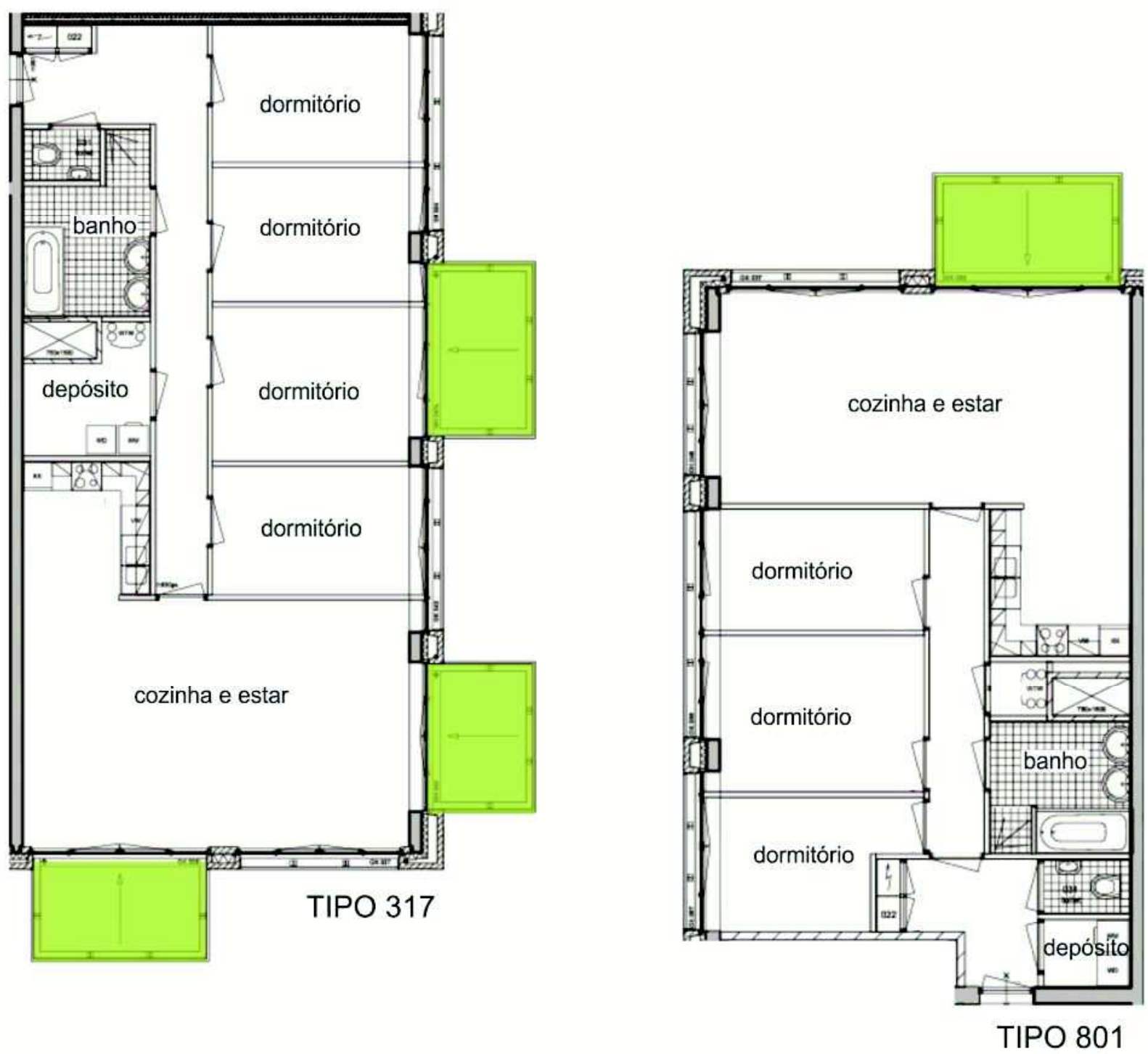

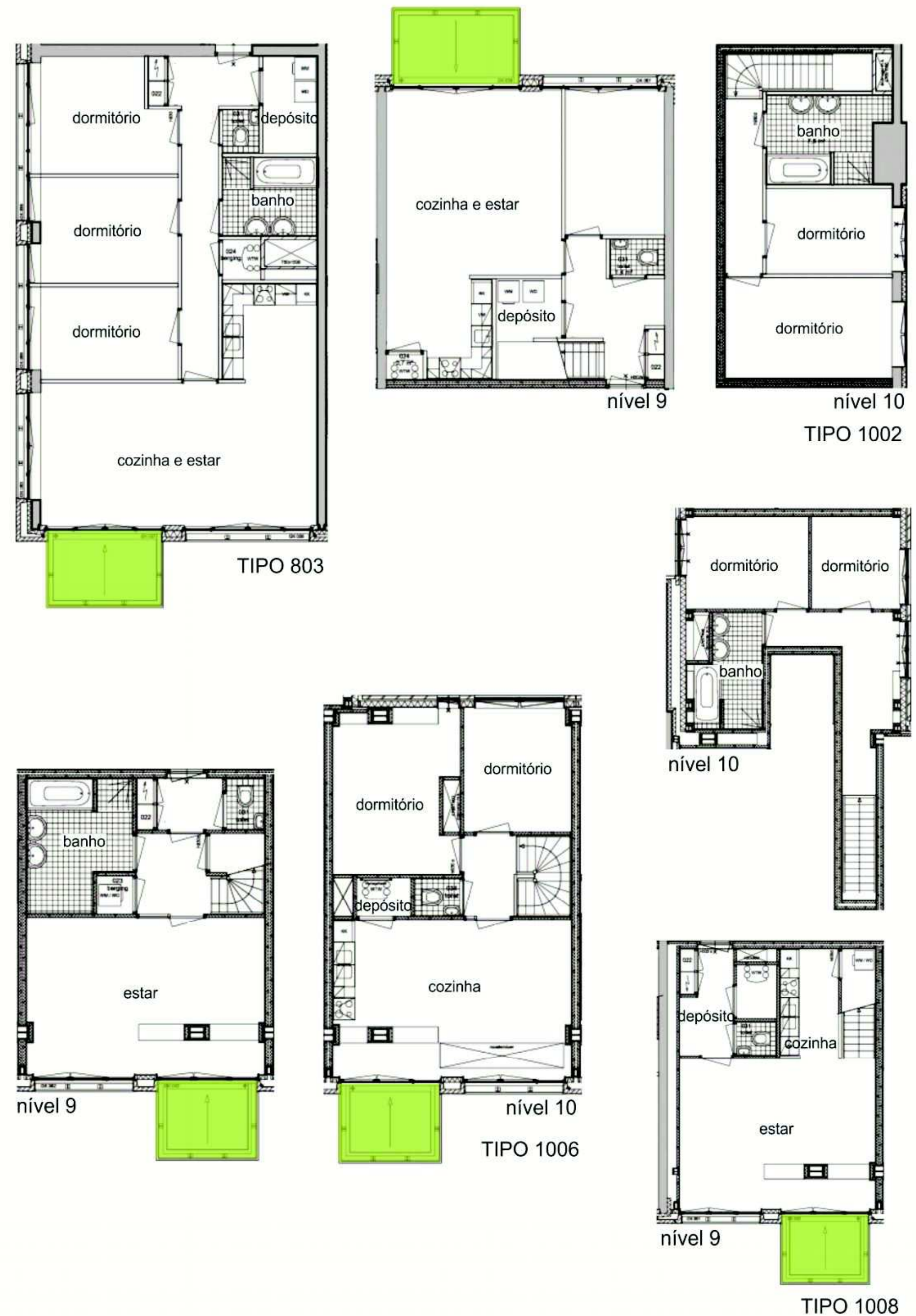

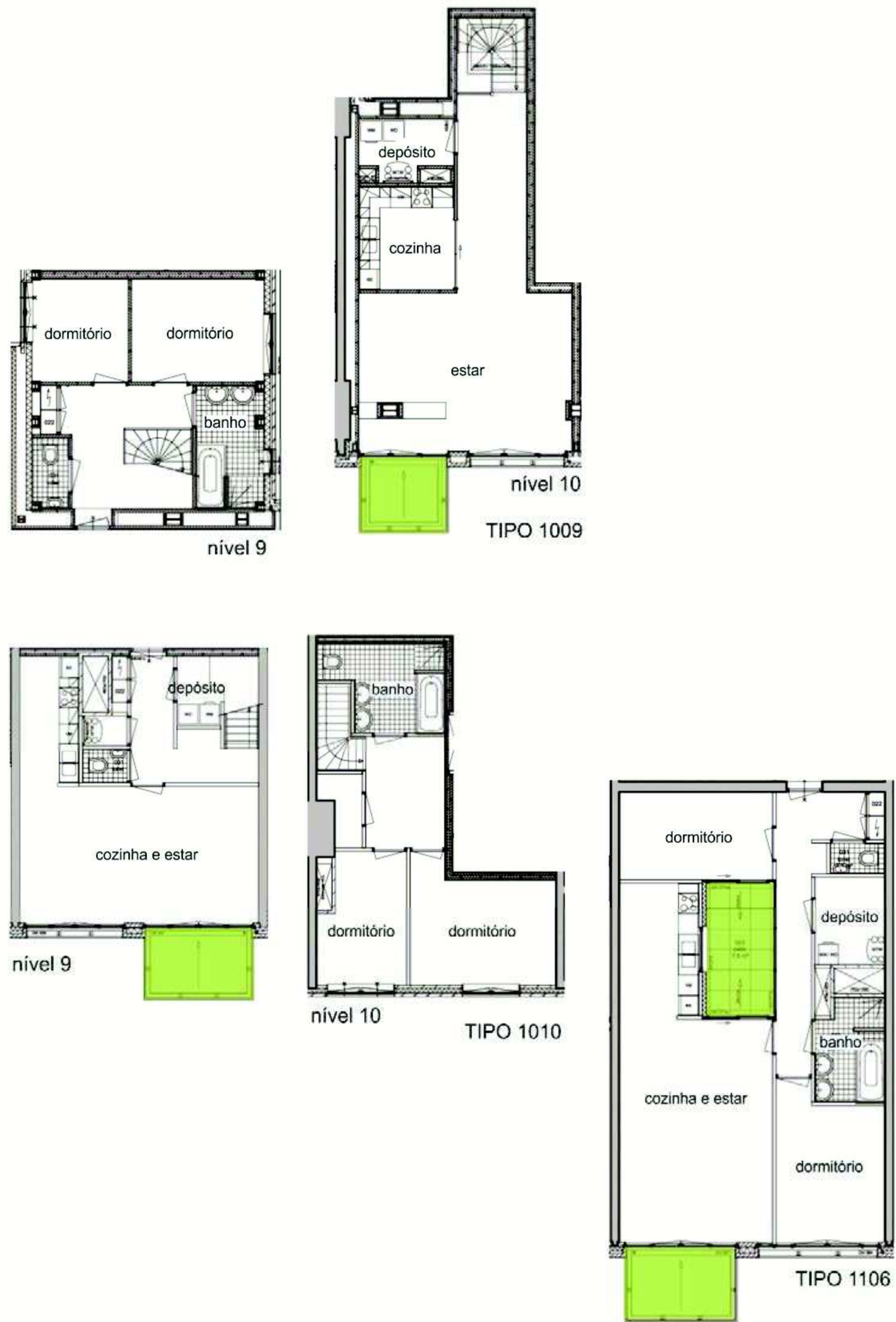

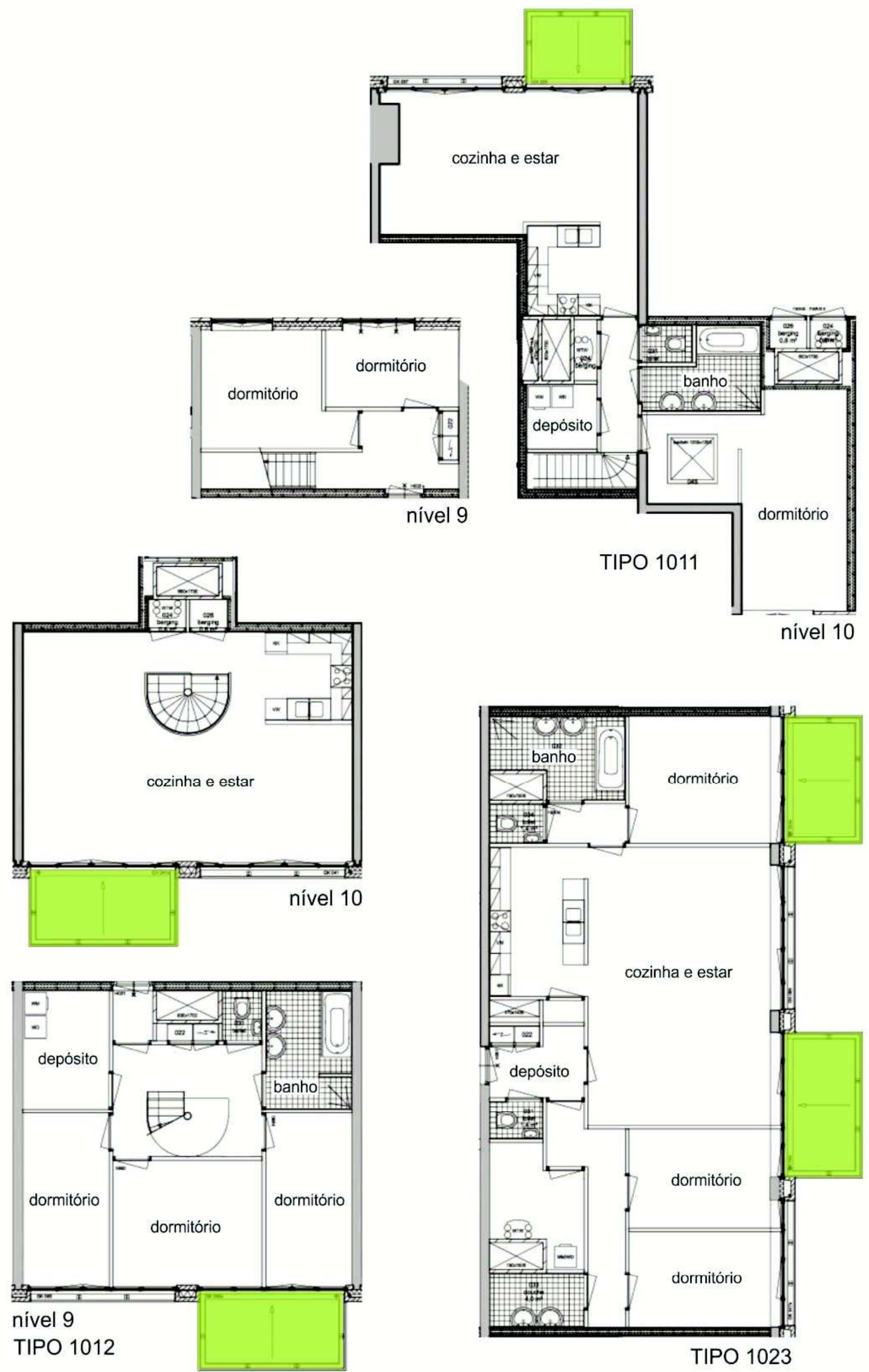

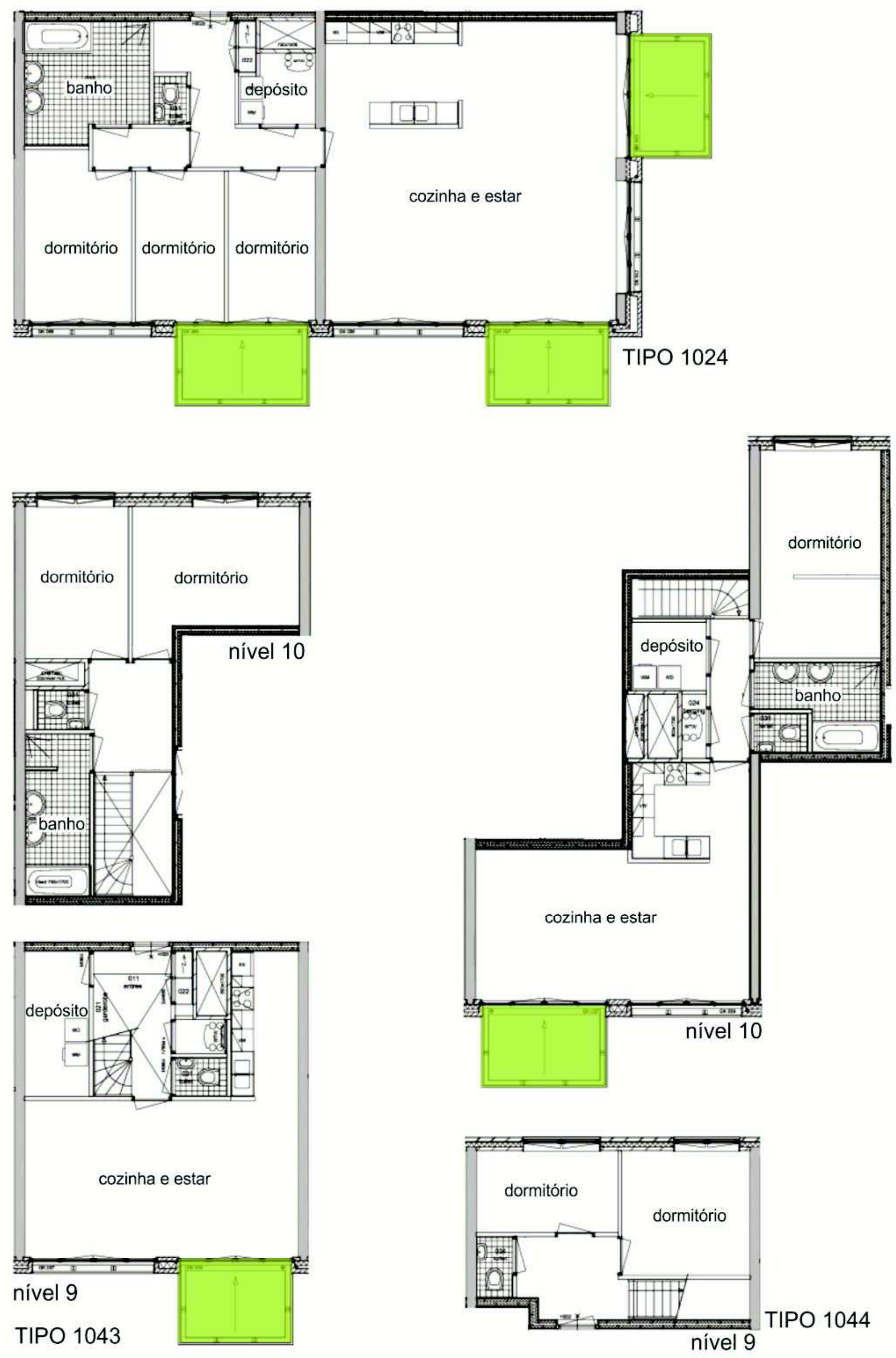

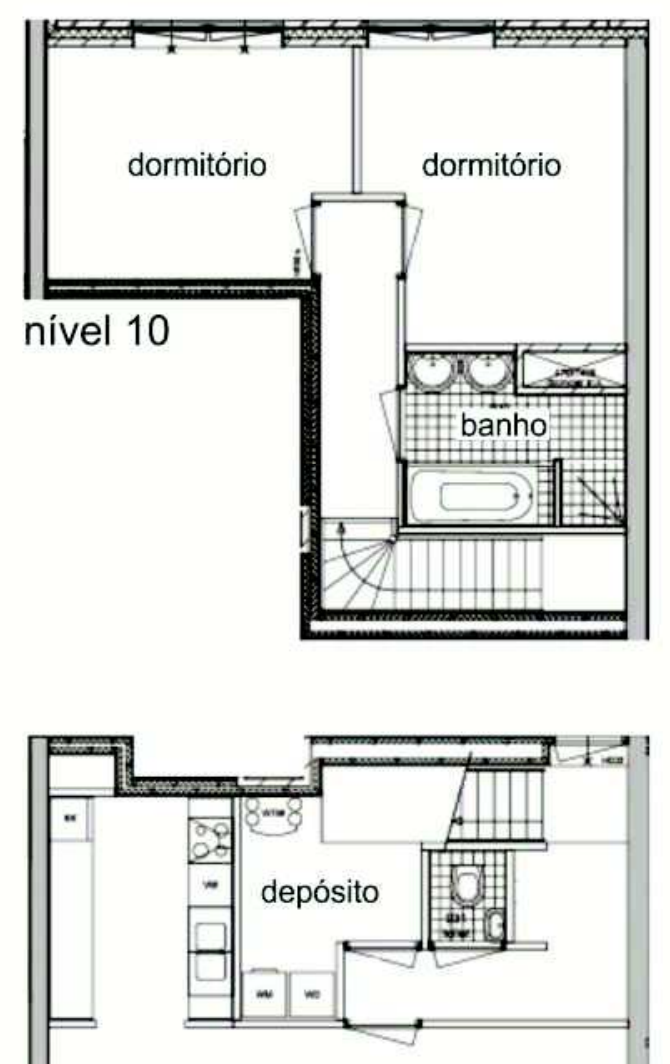

cozinha e estar

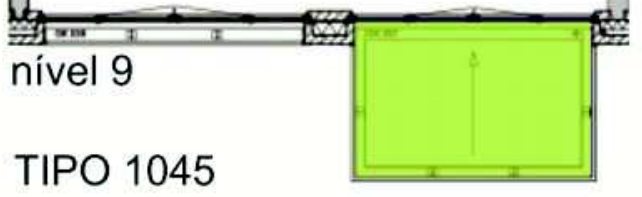

TIPO 1045

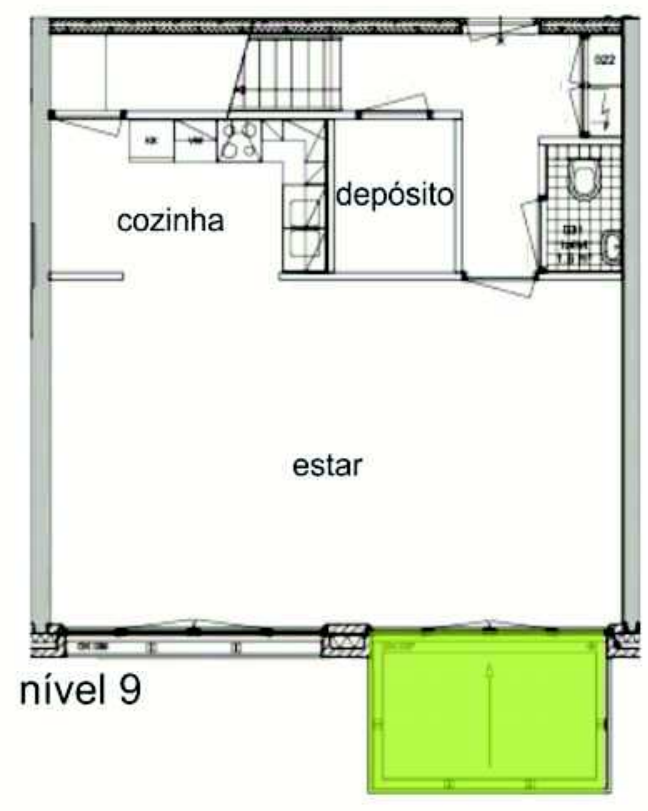

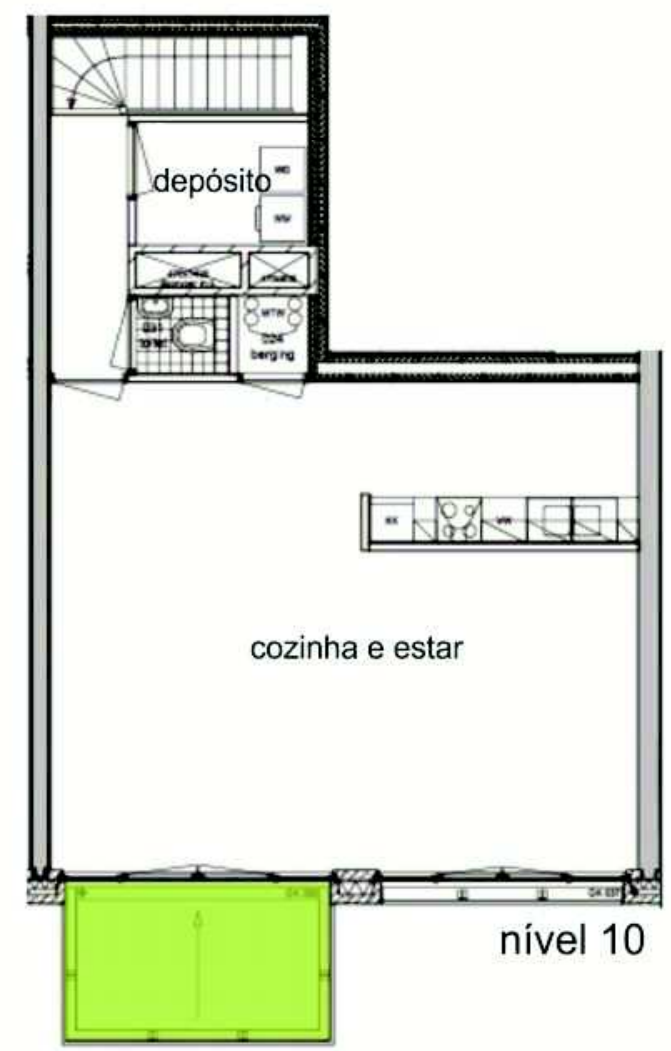
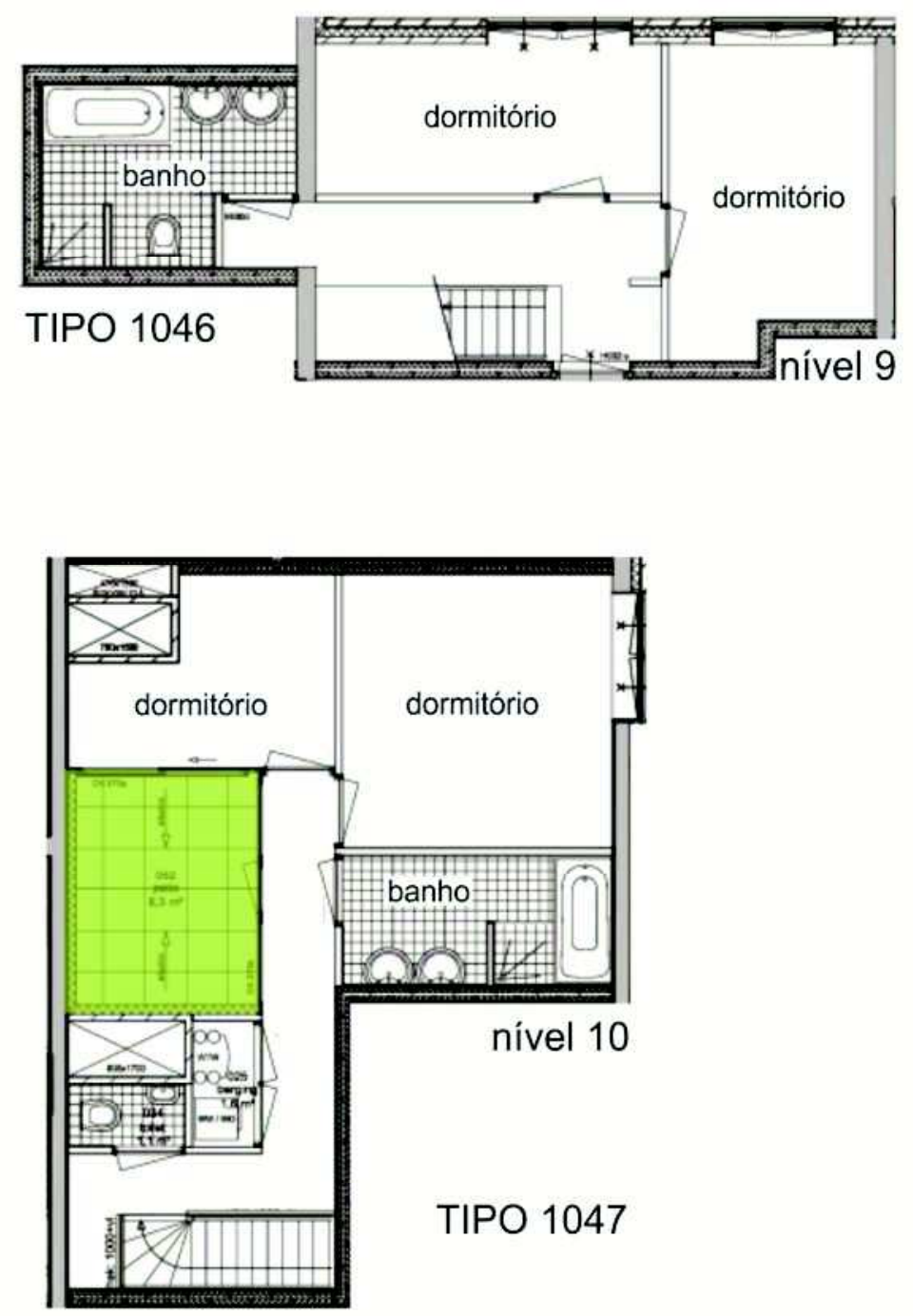

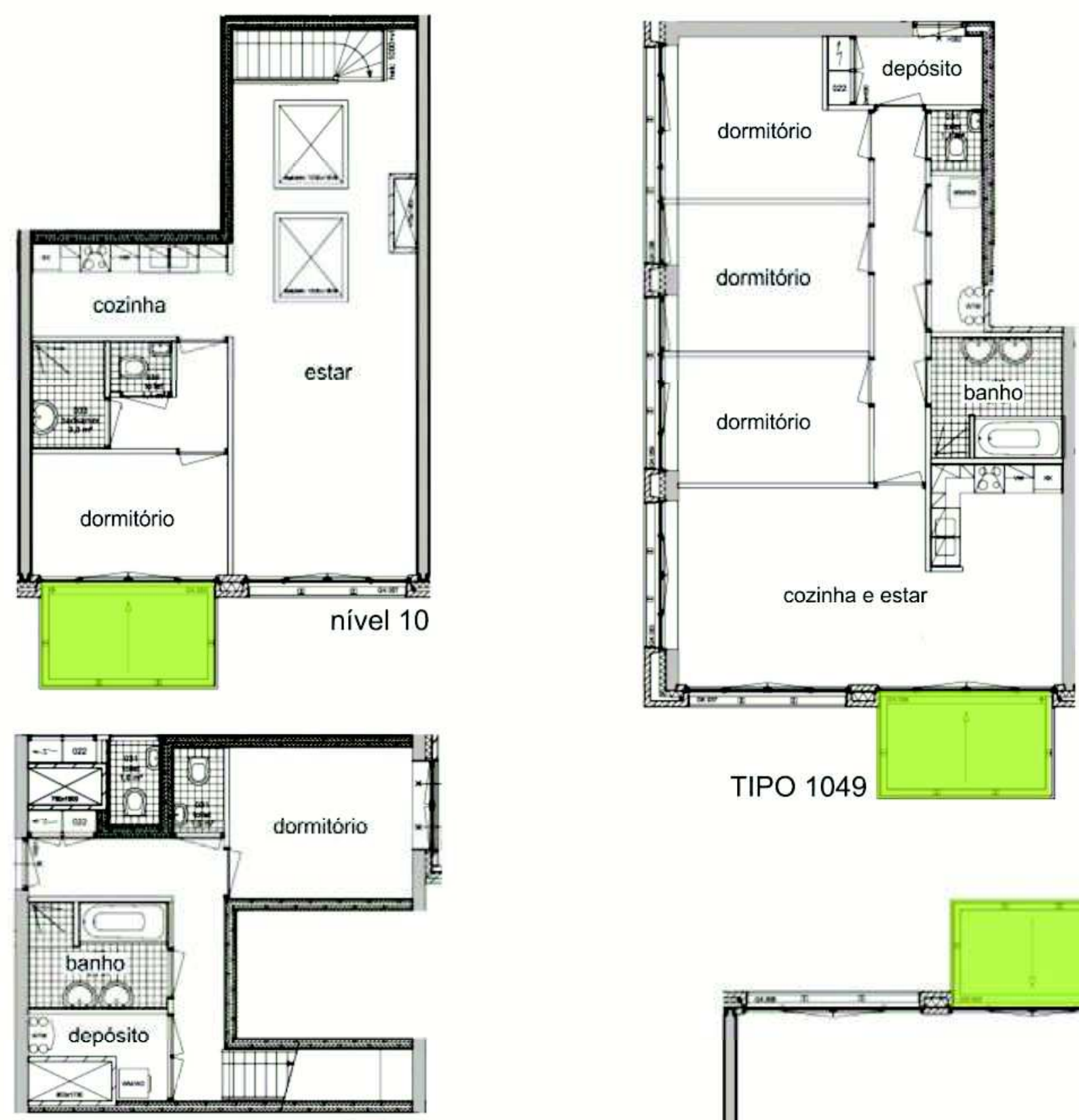

TIPO 1049

nível 9

TIPO 1048
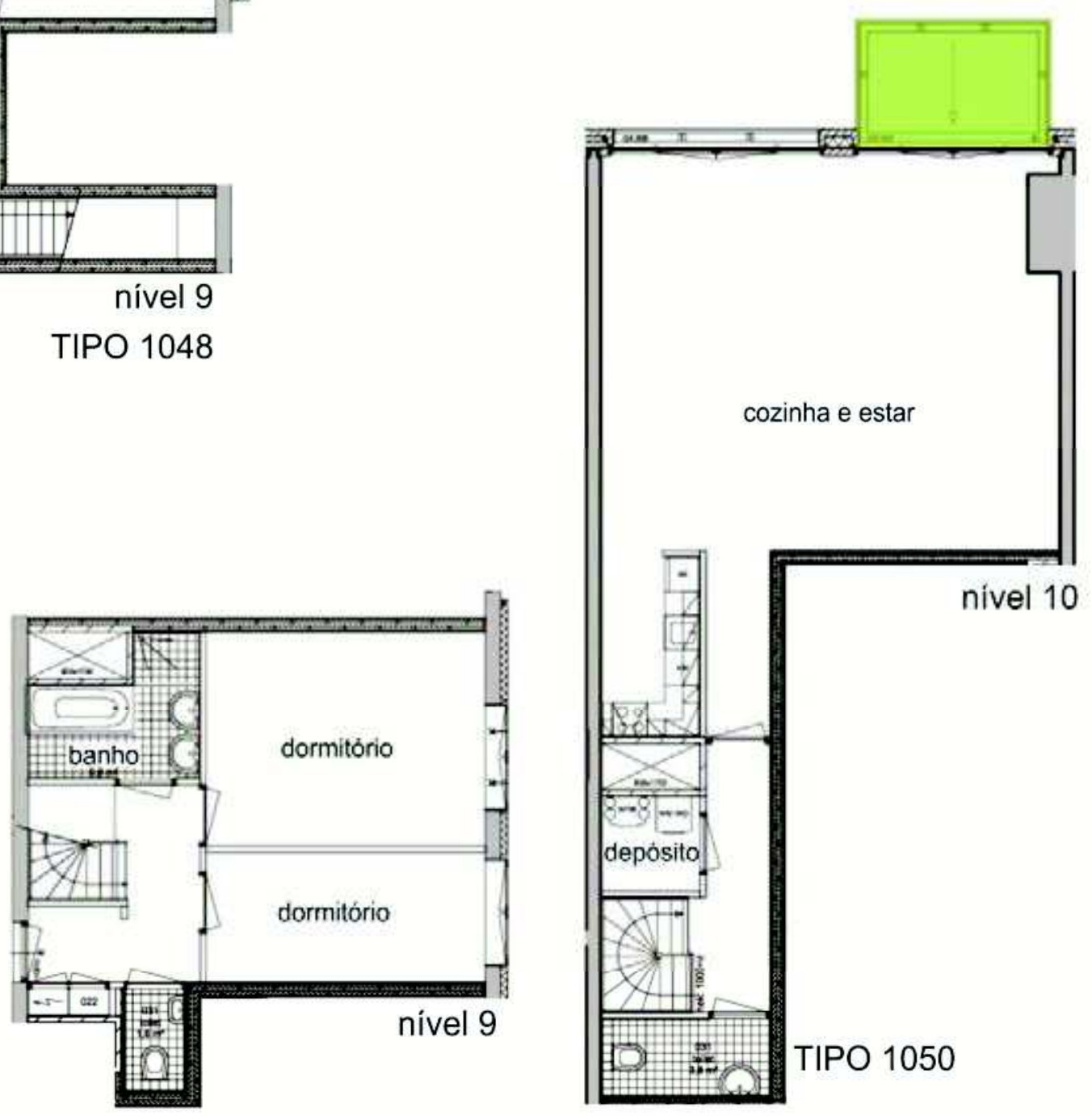


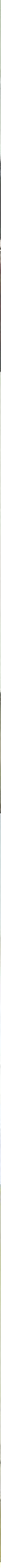




\section{Nem Global/ Nem Local}

O Parkrand traz um novo tipo de morador, de classe média, para Geuzeveld que era praticamente ausente nas habitações sociais existentes, o que se torna interessante desde que a população local permaneça no bairro.

No entanto, notamos que alguns erros dos planos de 1950 para a região parecem se repetir, especialmente as questões relacionadas à ausência do uso social do espaço, aspectos presentes no Parkrand a medida que o projeto se isenta do seu papel de mediador entre as relações rua e parque.

Silodam e Parkrand fazem parte de operações de renovação de duas áreas distintas de Amsterdã, mas o impacto que os dois projetos produzem no seu contexto são bastante diferentes: enquanto o Silodam mostra a habitação como possível ferramenta para formatação de novas ordens urbanas, suportando diferentes atividades da cidade, o Parkrand não avança além do antigo modelo de produzir habitação como célula isolada da cidade, ou seja, em Geuzeveld, os edifícios habitacionais ainda são os principais fatores determinantes da morfologia do bairro.

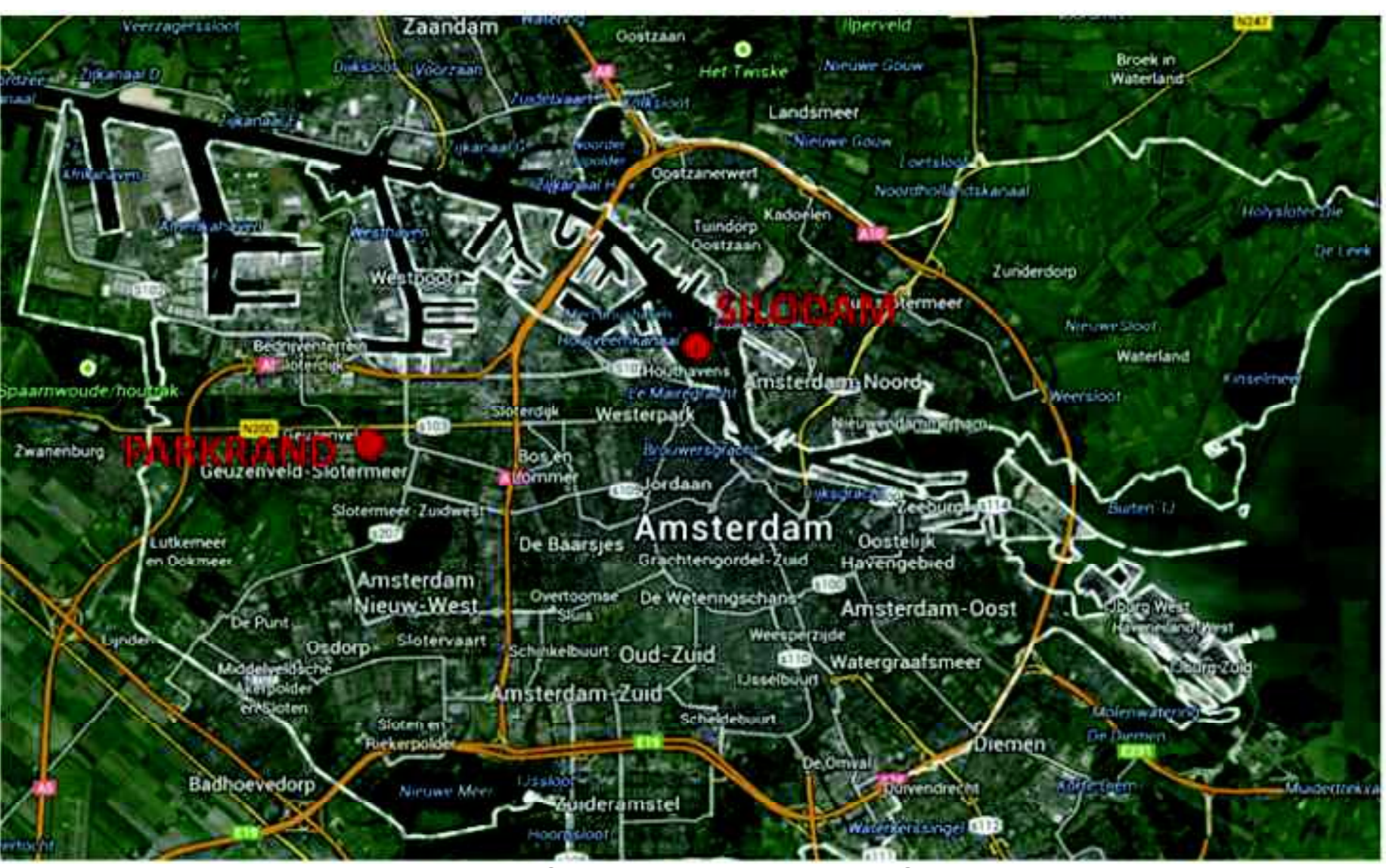

Localização do Parkrand e do Silodam em Amsterdã. Fonte: Google Maps. 


\section{Considerações sobre o projeto}

A premissa principal do Parkrand era estreitar a relação do bairro e do próprio edifício com o parque, mas a grande questão sobre o projeto é que esse objetivo não foi alcançado já que o grande embasamento, de 135 metros de comprimento e um nível e meio de altura, separa bairro e parque, e faz com que essa relação seja somente visual entre os espaços vazios do bloco. Curiosamente, ao analisar os diagramas que mostram a evolução da solução de projeto notamos que já era possível prever que tal proposta não solucionaria o problema da ligação bairroparque, ao contrário, o parque agora pode ser confundido com o 'quintal' do Parkrand.

Ainda, as maquetes de estudo são outra ferramenta que já indicava o afastamento da premissa inicial pela presença (e talvez preferência) dos vários modelos "bloco vazado". No entanto, não é a interiorização espacial o conceito que melhor define o projeto. Uso misto/espaços múltiplos, naturezas artificiais e densidade acabam aparecendo de maneira mais eficaz e a interiorização espacial se converte em solução simbólica ao invés de espaços coletivos convenientes ao bairro.

Apesar do contexto interessante para debates entre arquitetos, clientes e comunidade, o processo de projeto divulgado é muito enxuto e mostra apenas o desenvolvimento da forma do Parkrand. Os diversos estudos do MVRDV sobre ocupação de bairros afastados nas cidades holandesas (citados no capítulo 2) permaneceram separados da prática nesse projeto. 


\section{CAPÍTULO 4 CONSIDERAÇÕES SOBRE A PESQUISA}


O início deste trabalho partiu do interesse em investigar o processo de projeto do MVRDV e as articulações entre teoria e prática desenvolvidas pelo escritório - a teoria englobando o processo de projeto pautado por pesquisa e desenvolvimento de software e a prática focada em projetos habitacionais multifamiliares.

No que diz respeito ao desenvolvimento de estudos e teorias como forma de fazer arquitetura, este trabalho constatou que o MVRDV busca abordagens críticas para além do universo arquitetônico, fato que contribui para o reconhecimento do escritório como agente de um pensamento visionário. Desse modo, grande parte das experimentações examinadas neste trabalho traz reflexões sobre problemas da atualidade de diferentes disciplinas.

A noção de utopia do MVRDV tem influências do passado, especialmente das neovanguardas, e torna-se mais factível hoje do que as propostas dos seus antecessores. Alguns dos estudos e projetos do escritório não são impraticáveis, ao contrário, são baseados em conceitos de planejamento urbano.

Nesse ponto, as experimentações podem não ser totalmente originais, mas são uma tentativa de lidar com os problemas atuais enfrentados pela sociedade. Além disso, as análises dessas propostas nos fazem perceber que o caráter crítico da utopia pode ser uma estratégia útil para se refletir sobre o planejamento urbano. Os estudos radicais do MVRDV encorajam uma reflexão sobre os hábitos de vida da sociedade e outras formas possíveis de desenvolvimento, o método utilizado pelo escritório de simulação de cenários apresentados com imagens bastante enfáticas pode ser adotado para se discutir o crescimento das cidades na atualidade. As representações radicais de MetaCity/DataTown aplicadas na realidade urbana propiciam reflexões críticas e mostram aos habitantes os aspectos problemáticos do atual desenvolvimento das cidades.

Desse modo, é importante retomar os conceitos-chave do MVRDV no final desta pesquisa. Mesmo que os termos já tenham aparecido em momentos anteriores da história, eles são recombinados pelo escritório e podem ter sua possibilidade de aplicação no contexto atual demonstrada. Alguns dos conceitos já são identificados nas cidades hoje ou podem ser novamente reconstruídos e aplicados, como nos exemplos abaixo:

Densidade + interiorização espacial + subúrbio urbano: os estudos do MVRDV sugerem que os projetos urbanos devem priorizar cidades compactas com 
diversidade de programa, mas com inserção de espaços livres e áreas verdes, a densidade porosa. O tema mais presente nos projetos utópicos do MVRDV é o adensamento urbano que propicia facilidade de acesso a serviços e liberação do solo para áreas verdes ou outras atividades. Esses aspectos podem ser absorvidos pelas cidades na atualidade, com ressalva para as soluções que o escritório propõe para mobilidade. São propostas que não solucionam os problemas das grandes cidades, especialmente quando se pensa sobre as consequências ambientais. A maioria das alternativas dos arquitetos está relacionada à utilização de autoestradas, em diversos projetos a solução é dada através de vias elevadas (como 3D City) e do desenvolvimento tecnológico dos carros, promovendo poucas alternativas para os pedestres ou transporte público. Esses estudos sobre mobilidade nas cidades adensadas podem ser úteis para o desenvolvimento de tecnologias futuras na indústria automobilística, mas na atualidade pouco contribuem para solucionar as questões ambientais e de mobilidade dos grandes centros urbanos.

Uso misto + espaços múltiplos: a mescla de funções contribui para a diminuição das distâncias entre habitação e trabalho e pode reduzir a utilização de meios de transporte, além disso, esse conceito pode ser incorporado com mais ênfase nas habitações sociais, aumentando a oferta de opções de moradia com mescla de tipologias e o acesso à diferentes serviços.

Naturezas artificiais: as cidades podem tentar melhorar a qualidade de seus espaços verdes com as estratégias do MVRDV de otimização do uso do solo. Libera-se espaço para a inserção de áreas verdes que, quando associadas à densidade porosa, podem ser replicadas em altura, melhorando a relação entre natureza e espaço construído.

Local/Global: quando o MVRDV discute a importância do desenvolvimento regional, eles dão ênfase ao papel das áreas centrais das cidades, o que pode ser útil para os planos de reabilitação dos centros históricos no presente momento, mas deixa de olhar para os problemas dos subúrbios urbanos. 
Diversidade/identidade + datascapes: o MVRDV trabalha com um processo de tomada de decisão onde há participação de especialistas de outras áreas, clientes e a comunidade. A aplicação desse método pode ser útil para uma abordagem mais colaborativa no desenvolvimento dos projetos nas cidades, atendendo às diferentes necessidades da sociedade atual, principalmente através de um mapeamento de dados que amplie a leitura de tais informações.

Essa aproximação com a dinâmica atual das cidades é uma amostra da possível aplicação do discurso do MVRDV. Através dela notamos que a abordagem experimental pode sugerir soluções para o projeto urbano. Além de ressaltar a importância da projeção de cenários no planejamento das cidades, o encadeamento com os estudos do capítulo 2, a partir da análise dos projetos Silodam, Mirador e Parkrand, nos possibilitou avaliar a intensidade do uso dos conceitos-chave do MVRDV, ou seja, o quanto do discurso do escritório está presente nas três obras. Para isso foi desenvolvida uma representação visual que destaca a presença dos conceitos em maior ou menor grau, uma espécie de nuvem de tags, na qual os títulos maiores representam o discurso do MVRDV mais coerentemente inserido. 


\section{SILODAM \\ DATASCAPES NA PRÁTICA PROJETUAL}

INSERÇÕES DE USO MISTO/ESPAÇOS MÚLTIPLOS

\section{NATUREZAS \\ ARTIFICIAIS: \\ CRIANDO ESPAÇO}

\section{MIRADOR}

DATASCAPES EM OUTRA CULTURA

VESTIGIOS DE USO MISTO/ESPAÇOS MÚLTIPLOS

NATUREZAS ARTIFICIAIS: LIBERANDO TERRENO

\section{PARKRAND}

DATASCAPES DE UMA ÁREA EM RECONSTRUÇÃO

INICIAÇÕES DE USO MISTO/ESPAÇOS MÚLTIPLOS

NATUREZAS ARTIFICIAIS: TRANSFERINDO ÁREA VERDE
SUBÚRBIO URBANO E COMUNIDADE

DENSIDADE COMO QUEBRA-CABEÇAS TRIDIMENSIONAL
INVERSÃO DO SUBÚRBIO URBANO

DENSIDADE PERIFÉRICA
SUBÚRBIO URBANO COMO SOLUÇÃO URBANA

INTERIORIZACCÃO ESPACIAL COMO SOLUÇÃOO DA FORMA
DIVERSIDADE/IDENTIDADE COMO CENÁRIO
DIVERSIDADE IDENTIDADE COMO MARCO

GLOBAL ATRAVÉS DO GLOBAL SEM LOCAL NEM GLOBAL/NEM LOCAL

\section{LOCAL}

Relevância dos conceitos-chave em cada projeto. Fonte: autora. 
A partir de tal avaliação, concluímos que os aspectos teóricos do MVRDV estão presentes em maior grau no Silodam, seguido do Mirador e, por último, Parkrand. No entanto, vale ressaltar que enquanto a exploração projetual dos espaços coletivos varia em cada obra, o nível de desenvolvimento das unidades habitacionais é muito semelhante nos três trabalhos, encontrando-se em um patamar abaixo das outras investigações, conforme demonstra o gráfico abaixo. Assim, mesmo nos projetos mais elaborados, permanece a impressão de um trabalho incompleto.

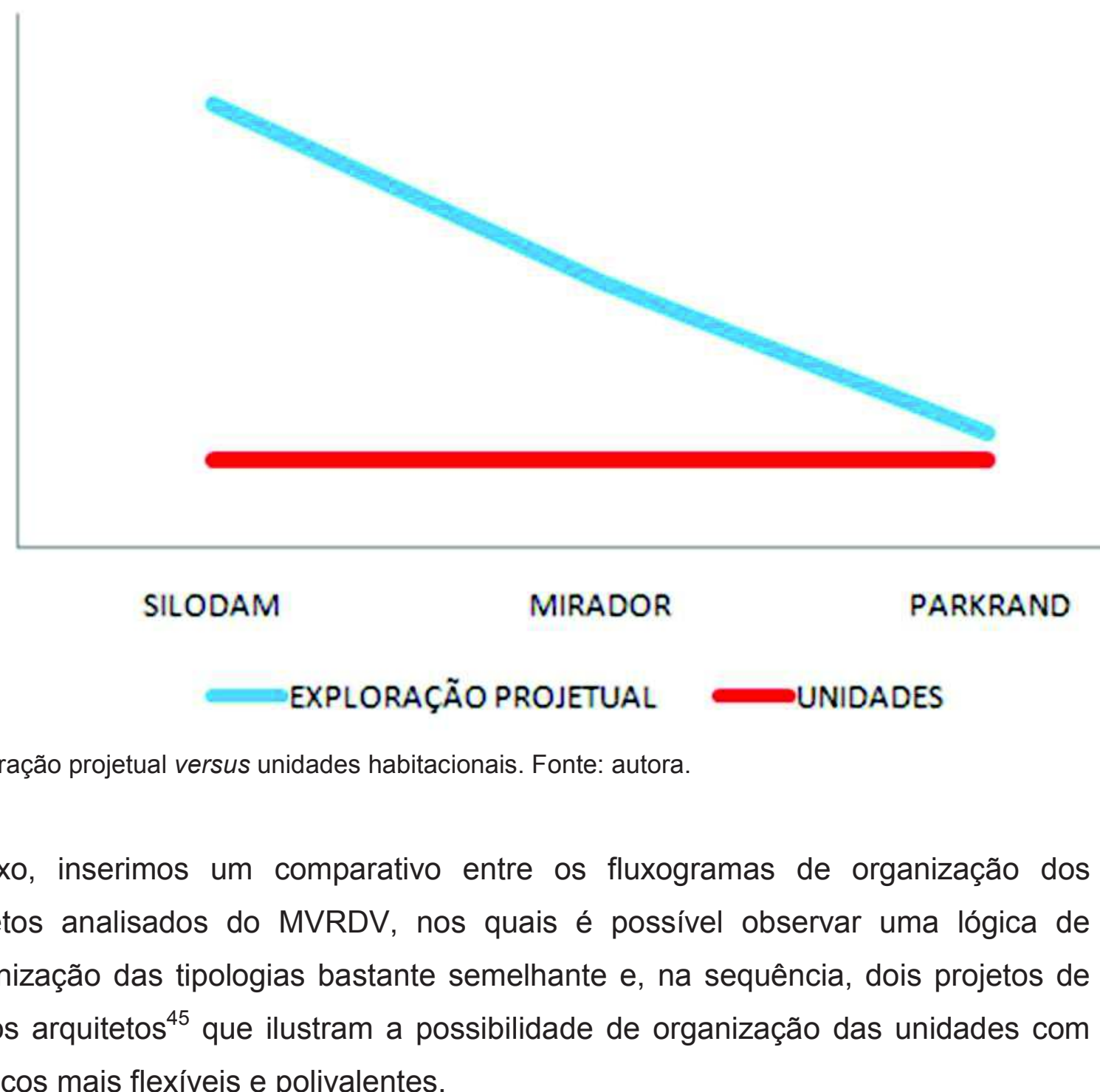

Abaixo, inserimos um comparativo entre os fluxogramas de organização dos projetos analisados do MVRDV, nos quais é possível observar uma lógica de organização das tipologias bastante semelhante e, na sequência, dois projetos de outros arquitetos ${ }^{45}$ que ilustram a possibilidade de organização das unidades com espaços mais flexíveis e polivalentes.

\footnotetext{
${ }^{45}$ Projetos construídos e contemporâneos ao surgimento do MVRDV.
} 

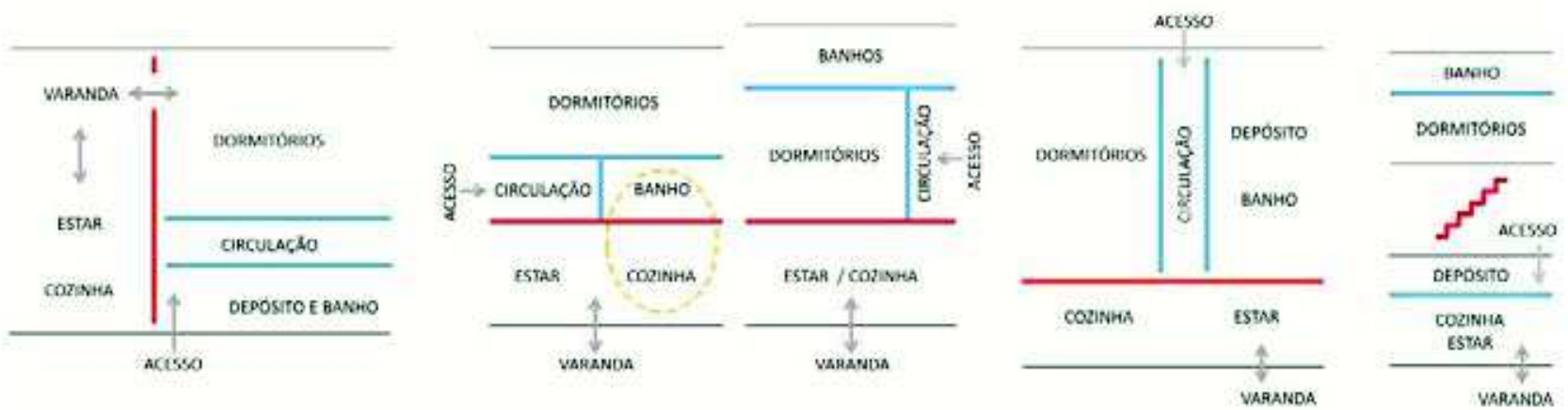

Fluxogramas de organização das unidades: Silodam, Mirador e Parkrand. Fonte: autora.
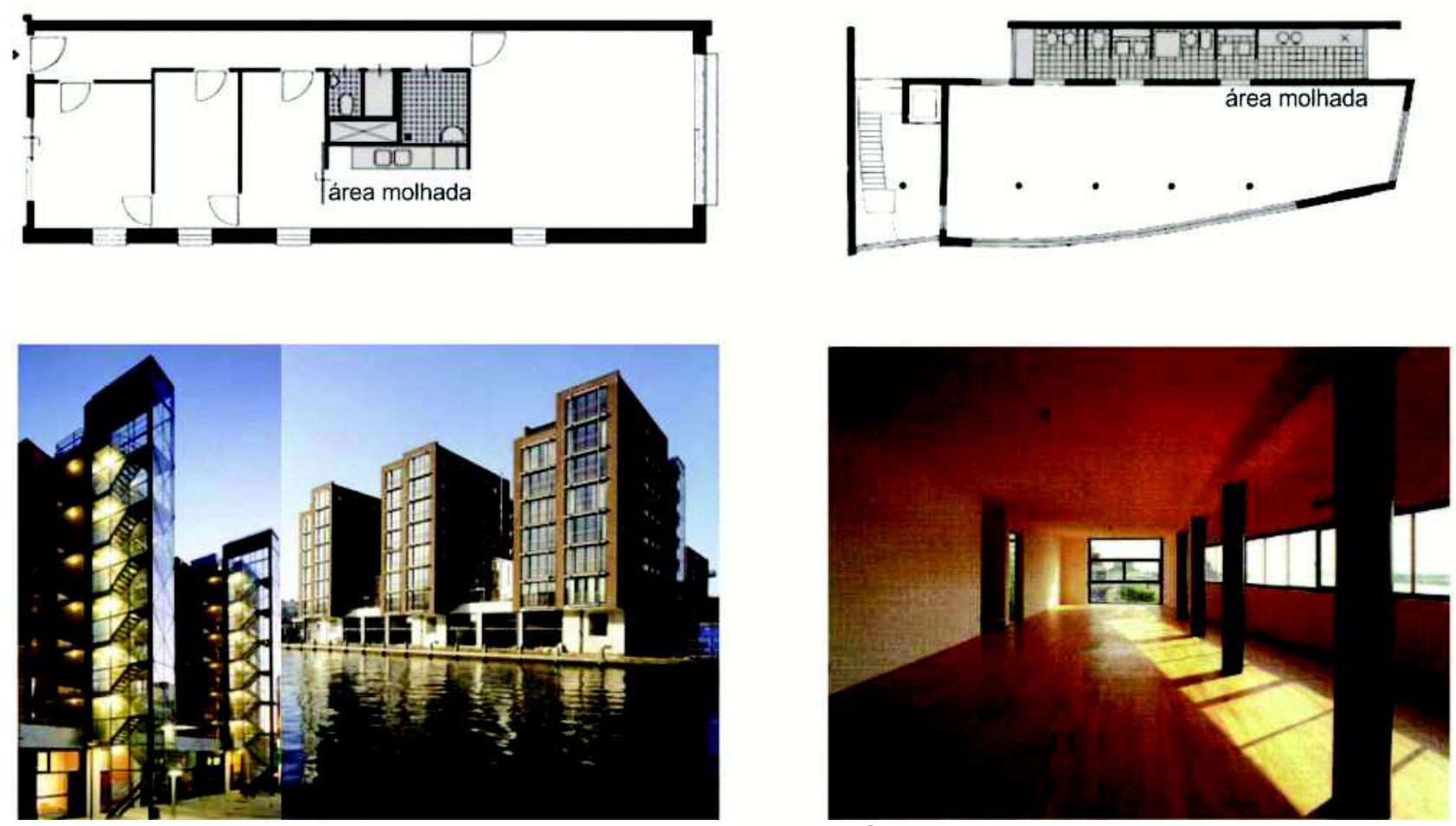

Van Der Waals, Zeinstra. Buys I, Amsterdã, Holanda, 1994. Área molhada agrupada em bloco e divisórias acústicas móveis organizando os espaços livres. Fonte: www.vanderwaalszeinstra.nl Neutelings-De Kooning. Loft em Amberes, Bélgica, 1993. Área molhada linear e espaço livre. Fonte: Gausa, M. Housing, nuevas alternativas, nuevos sistemas.

Após a aproximação dos conceitos-chave com a realidade das cidades e com os projetos analisados, desenvolvemos simulações de cenários ao 'modo MVRDV', utilizando as obras estudadas no capítulo 3. Esse exercício surgiu durante os cálculos de densidade no capítulo 3 e nos permitiu reconectar a prática do MVRDV com o lado investigativo dos estudos do capítulo 2.

Os critérios para o desenvolvimento dos cenários, retirados do processo de desenvolvimento dos próprios projetos, foram potencializados de modo a alcançar cenários utópicos: no Silodam extraímos a demanda por habitação e ausência de 
espaço associadas à recuperação da área portuária; no Mirador, a verticalização na periferia para liberar solo; no Parkrand buscamos a solução para um real contato do bairro com o parque em uma das maquetes de estudo do projeto. Assim, produzimos as simulações que apresentamos na sequência.

\section{Silodam:}

a- Número de moradores possíveis: 397 habitantes

b- Densidade Amsterdã $(2013)^{46}: 3.200$ habitantes $/ \mathrm{km}^{2}$

c- Densidade Silodam: 132.000 habitantes $/ \mathrm{km}^{2}$

O projeto apresenta alta densidade e nos permitem fazer o seguinte exercício: se a população de Amsterdã é 810.000 habitantes $^{47}$ (excluindo a região metropolitana), 2.040 edifícios tipo Silodam acomodariam toda a população da cidade. Tal ideia nos remete aos estudos Costa Ibérica e Metacity/Datatown. Enquanto o primeiro considera a inserção de grandes torres para liberar mais área de lazer, o segundo simula diferentes formas de ocupação do solo em um ambiente controlado.

Em nossa experimentação, a repetição de 2.040 edifícios Silodam atinge uma escala regional e a inserção dessas habitações no rio IJ traz duas possibilidades: 1libera o solo da cidade para outras atividades reforçando a tradição holandesa de construir território; 2-permite a duplicação do número de habitantes de Amsterdã aumentando em $100 \%$ a densidade da cidade.

\footnotetext{
${ }^{46}$ Fonte: Demographia World UrbanAreas, $10^{\mathrm{a}}$ edição anual, maio/2014.

${ }^{47}$ Central Bureau voor de Statistiek, maio/2014. http://statline.cbs.nl/
} 
2.040 edifícios Silodam. Fonte: autora.
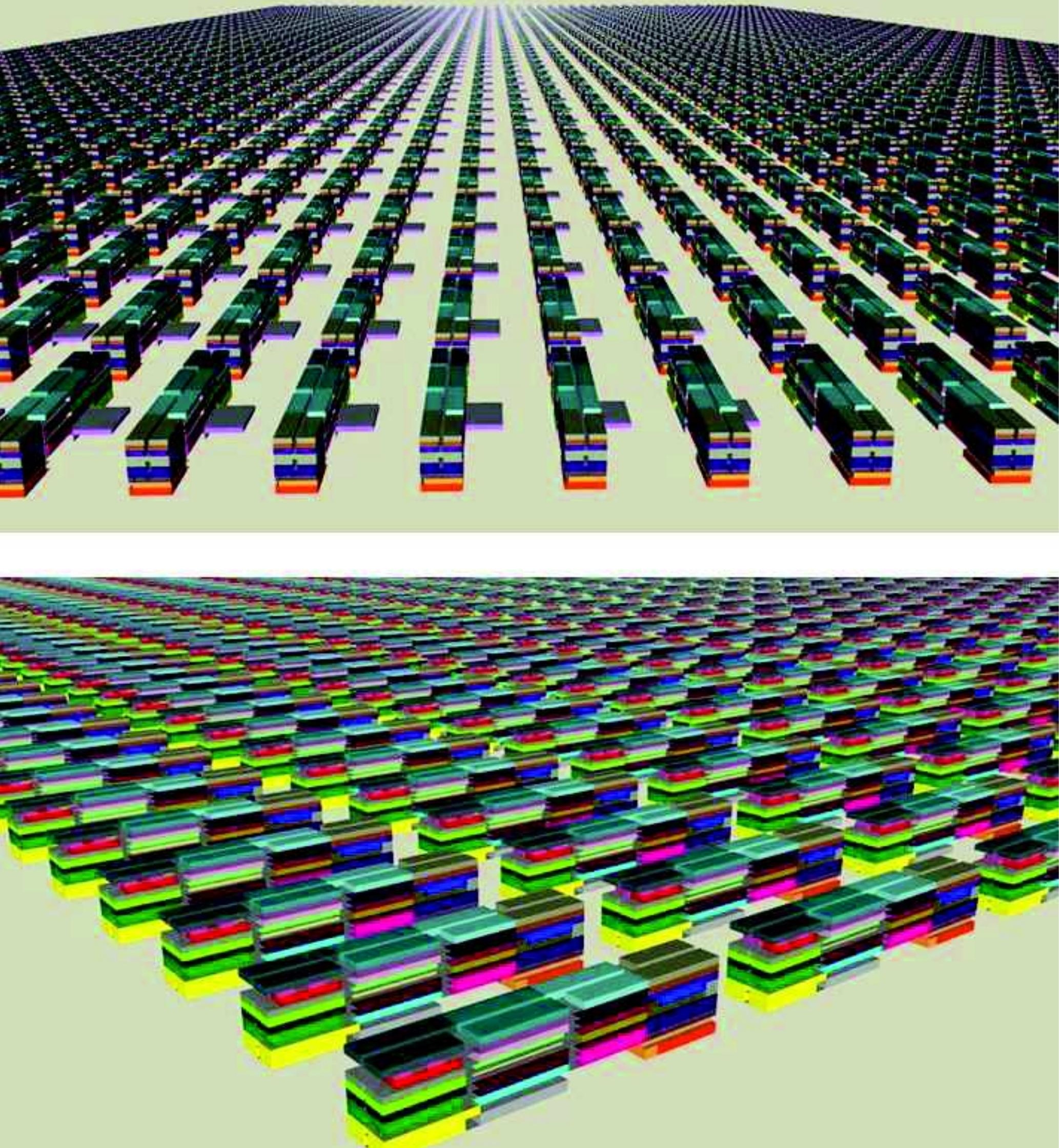


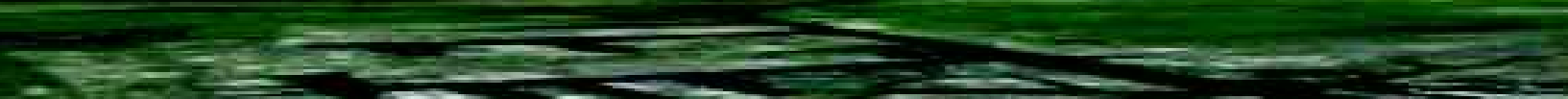

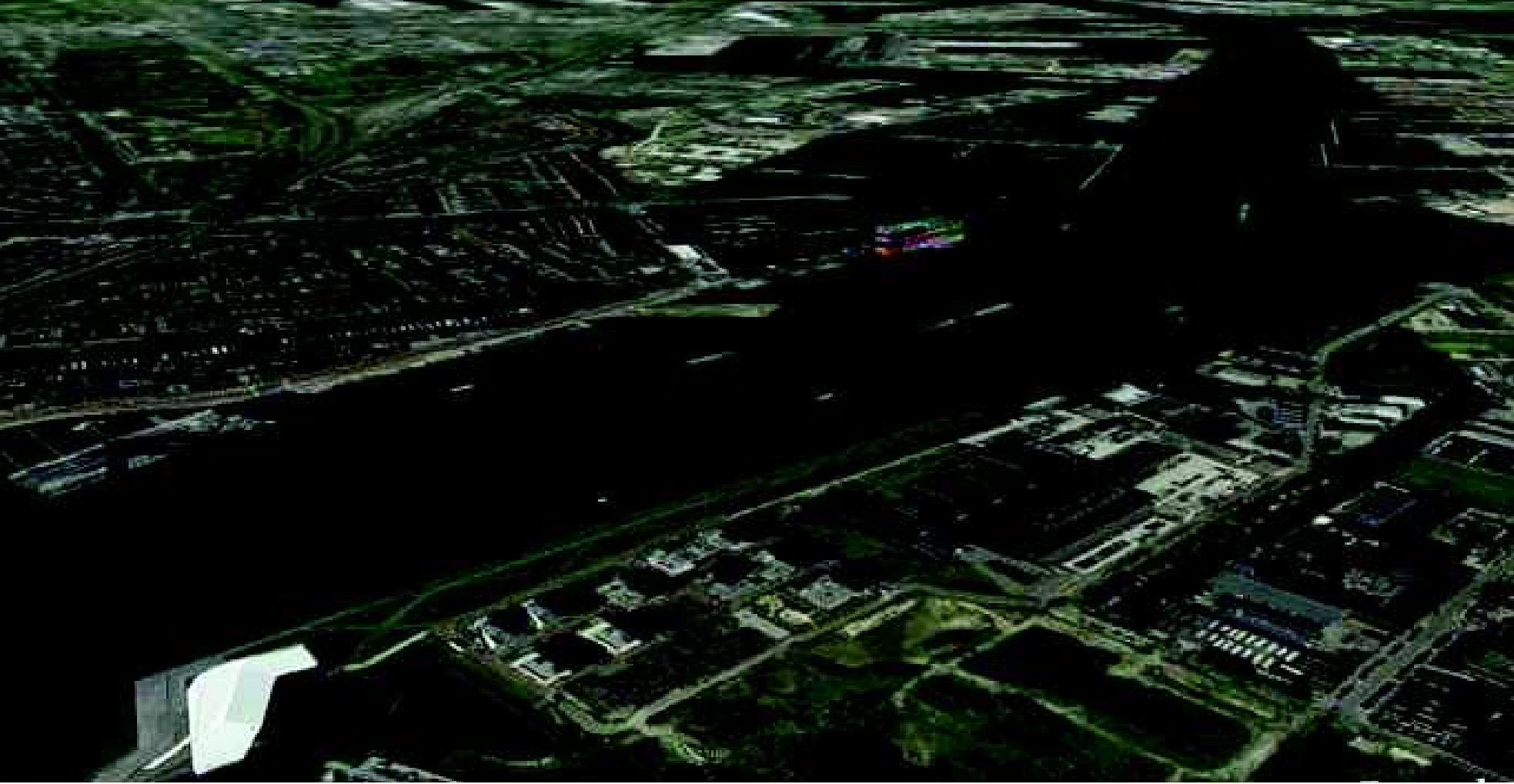

-

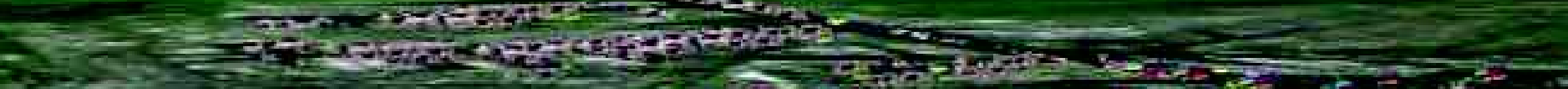

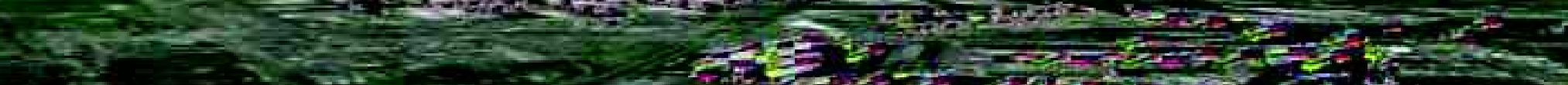

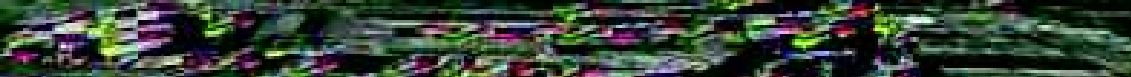

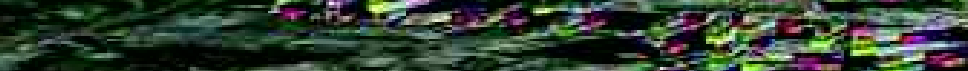

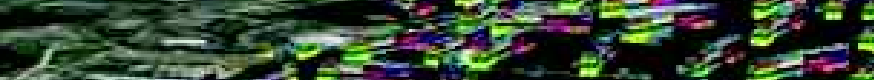

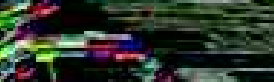

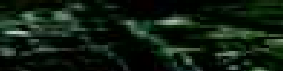

$$
\begin{aligned}
& 12 \\
& \text { 1iv }-3 e^{2}=
\end{aligned}
$$

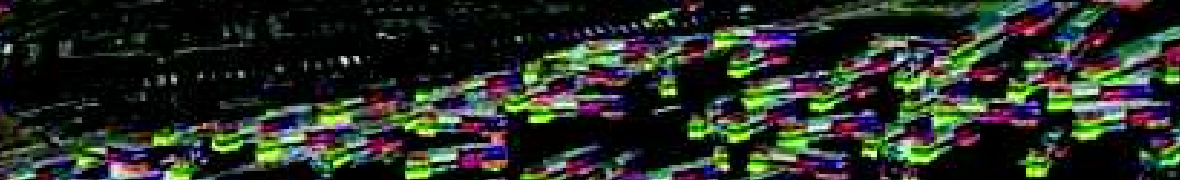
10. Sen $=2$

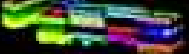
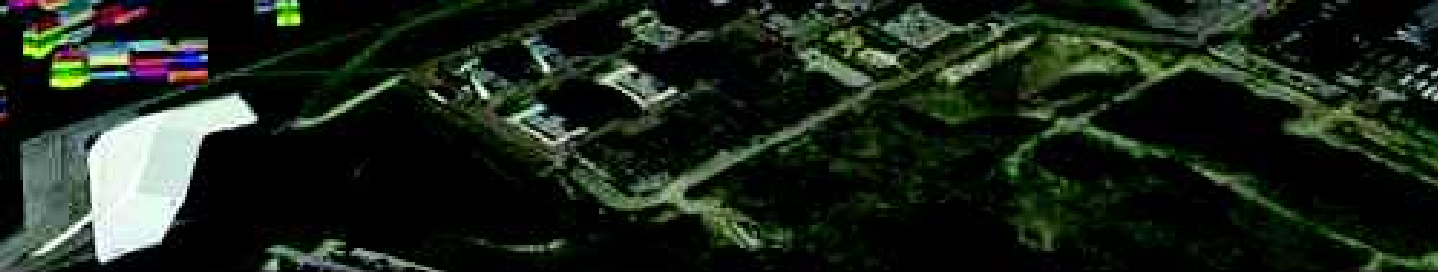

acion

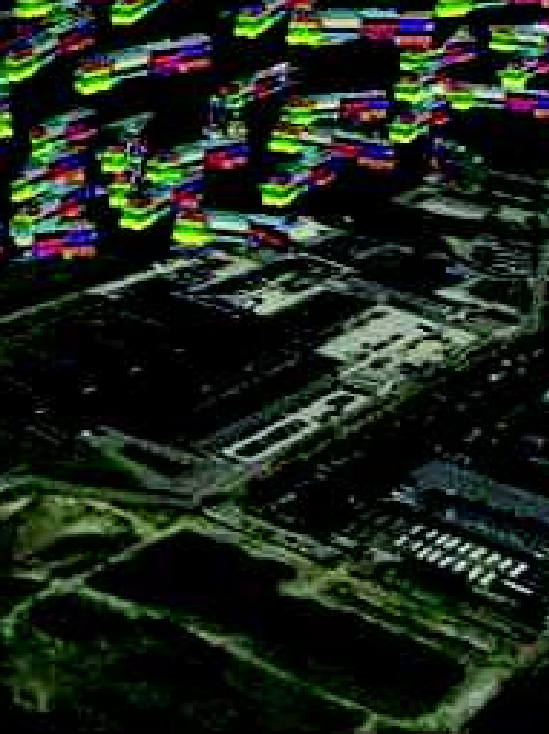


Mirador:

a- Número de moradores possíveis: 502 habitantes

b- Densidade Madrid (2014) 4.700 habitantes $/ \mathrm{km}^{2}$

c- Densidade Mirador: 50.200 habitantes $/ \mathrm{km}^{2}$

No Mirador a área do terreno é de $10.000 \mathrm{~m}^{2}$. A população de Madrid é 3.300 .000 habitantes $^{49}$ (excluindo a região metropolitana), então, 6.575 edifícios tipo Mirador acomodariam toda a população da cidade. Nesta simulação, escalonamos o projeto em cinco vezes, tendo como resultado grandes blocos perfurados de 100 andares que comportam a população de 125 Miradores por bloco. Desse modo, a população de Madrid seria acomodada em terrenos que somam 1,4 km² (na atualidade, a cidade ocupa uma área de $1.321 \mathrm{~km}^{2}$ ), uma hipótese de hiperdensidade que libera espaço para recuperação de áreas verdes, produção de alimentos e outras atividades para o mundo superpovoado que o MVRDV analisa em seus estudos.

\footnotetext{
${ }^{48}$ Fonte: Demographia World Urban Areas, $10^{\mathrm{a}}$ edição anual, maio/2014.

${ }^{49}$ Instituto Nacional de Estadística, janeiro/2012. www.ine.es
} 


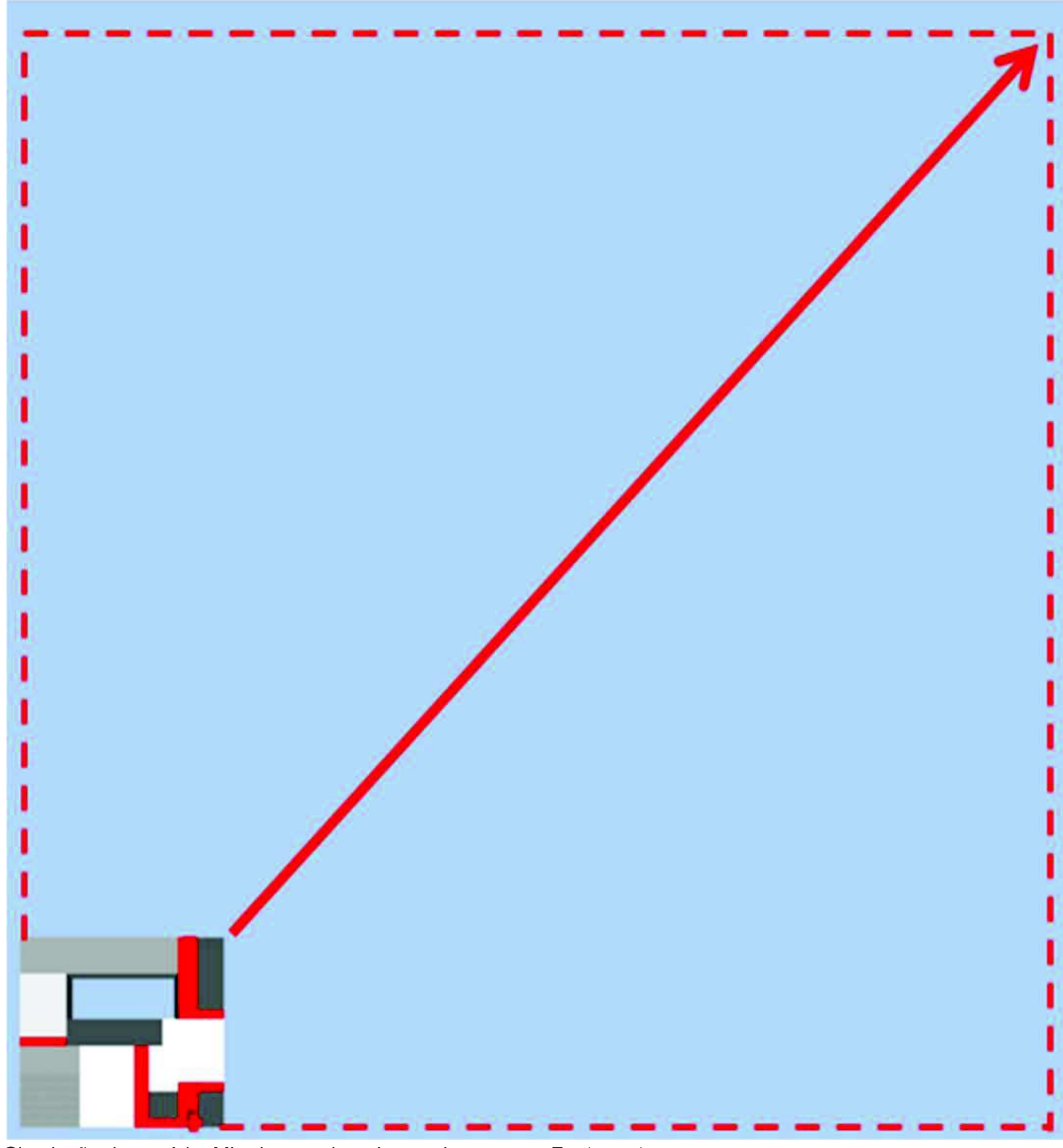

Simulação de cenário: Mirador escalonado em cinco vezes. Fonte: autora. 
6.575 edifícios Mirador. Fonte: autora.
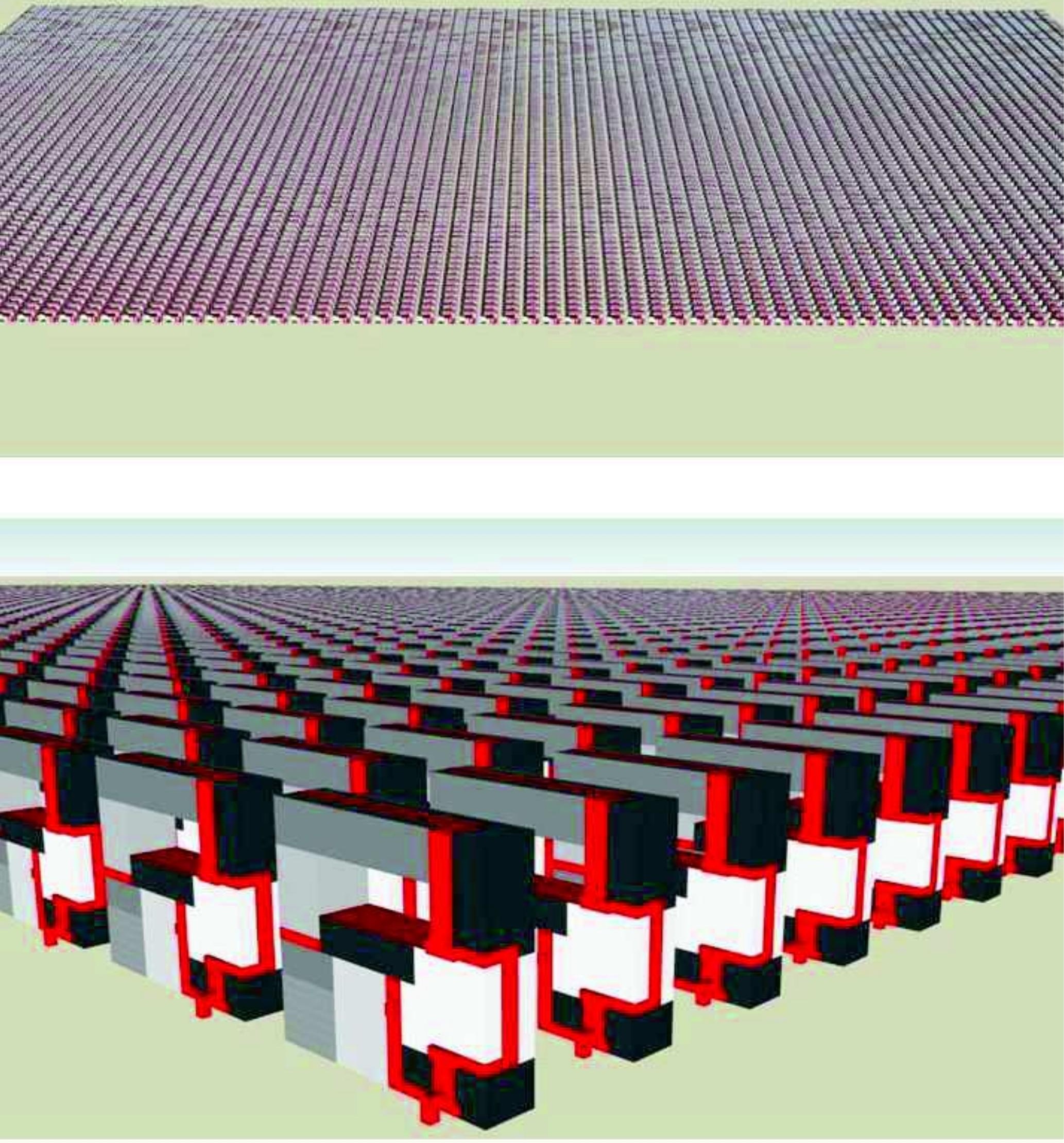


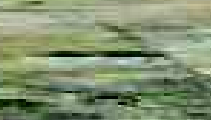

His:

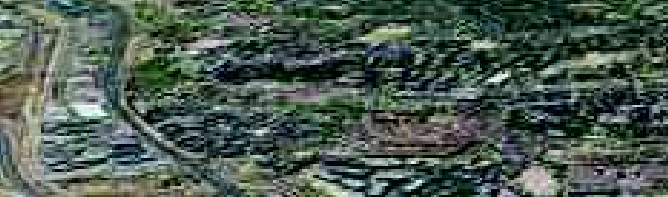

$3.1 \%$

-

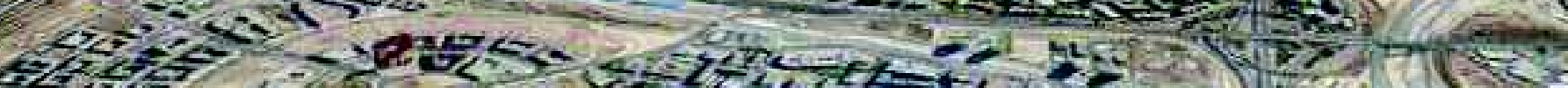

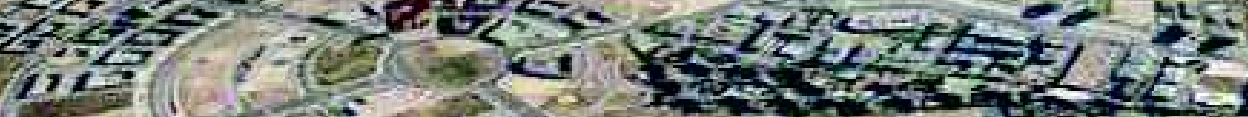

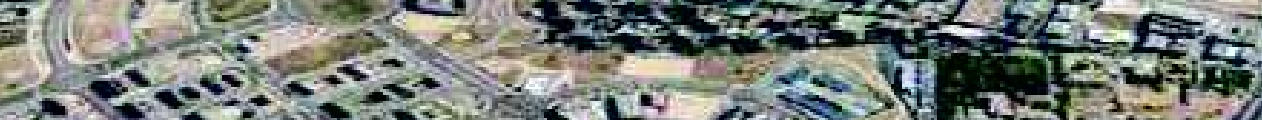

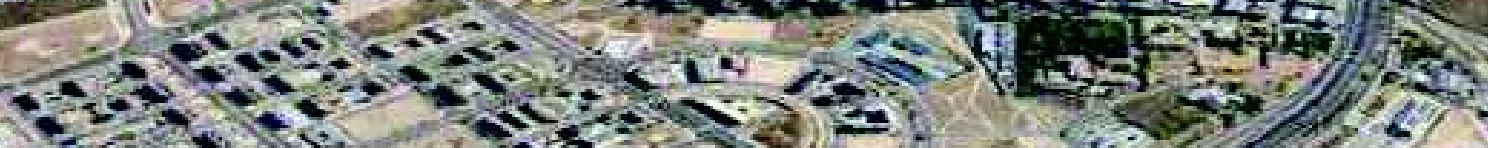

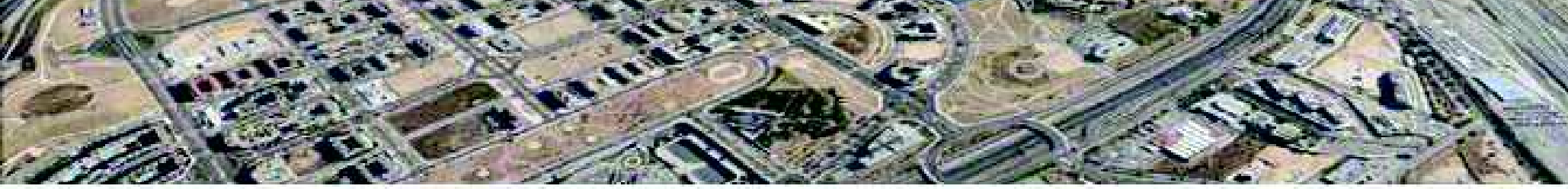
(1) In 

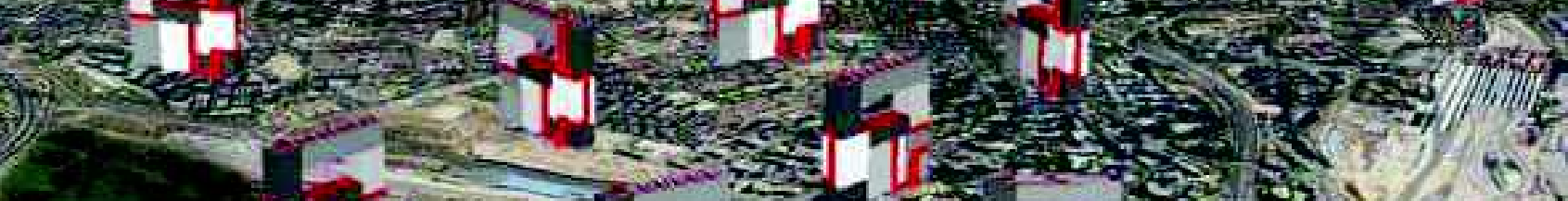

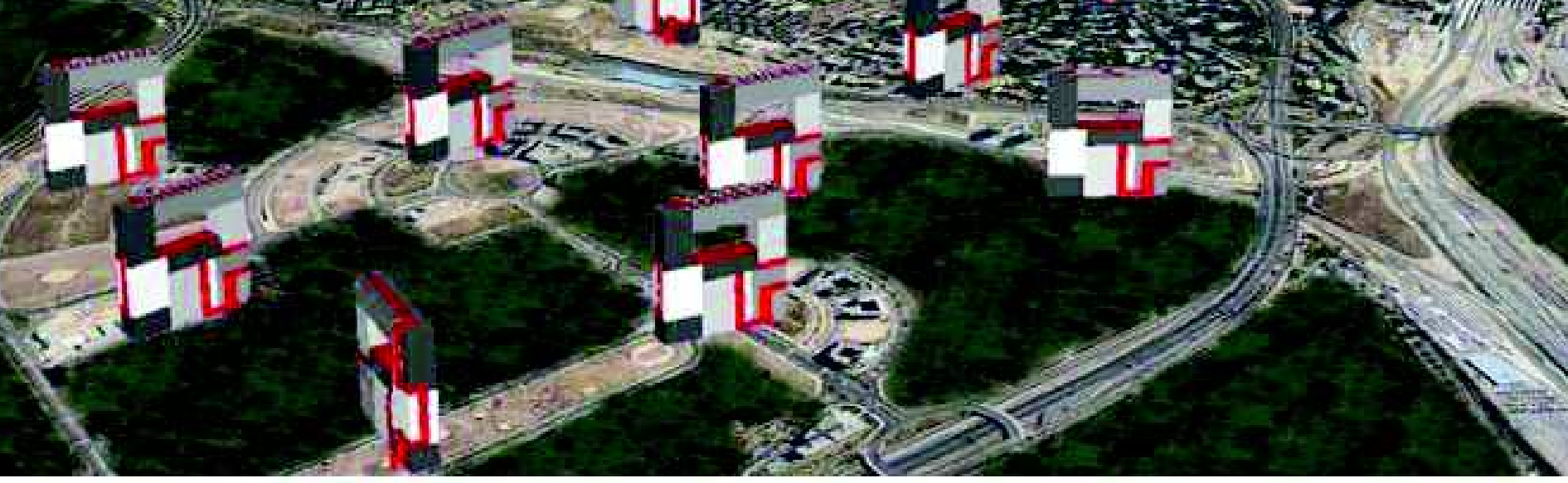

Cenários: real versus 52 'estruturas Mirador' com a periferia reconvertida em área verde. Fonte: autora 
Parkrand:

a- Número de moradores possíveis: 760 habitantes

b- Densidade Amsterdã (2013) 30.200 habitantes $/ \mathrm{km}^{2}$

c- Densidade Parkrand: 42.000 habitantes $/ \mathrm{km}^{2}$

A área do terreno onde o Parkrand está inserido é de $18.000 \mathrm{~m}^{2}$. A população de Amsterdã é 810.000 habitantes $^{51}$ (excluindo a região metropolitana), assim, 1.065 edifícios tipo Parkrand acomodariam toda a população da cidade (contra 2.040 edifícios do Silodam). Esse conjunto de edifícios, dispostos horizontalmente, ocuparia uma área de 7,8 km², em oposição a área de $505 \mathrm{~km}^{2}$ de Amsterdã, mas, em um cenário mais experimental, também poderiam estar agrupados em grandes estruturas habitacionais, maximizando o adensamento e liberando área para parques, bosques e outras atividades.

\footnotetext{
${ }^{50}$ Fonte: Demographia World Urban Areas, $10^{\mathrm{a}}$ edição anual, maio/2014.

${ }^{51}$ Central Bureau voor de Statistiek, maio/2014. http://statline.cbs.nl/
} 

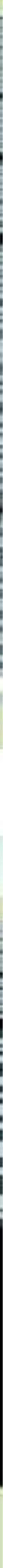

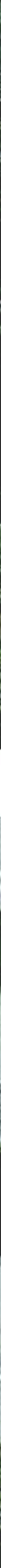
Além de reconectar as três obras com os estudos e teorias, as simulações de cenários propiciam o pensamento dos projetos além da escala local através de novos modelos que podem ser pensados como: 'cidade-Silodam', 'cidade-Mirador' e 'cidade-Parkrand'.

$\mathrm{Na}$ 'cidade-Silodam' acontece a duplicação da capacidade populacional de Amsterdã através da ocupação do rio IJ; a 'cidade-Mirador' recupera as áreas verdes da periferia e libera o solo para outras atividades e a 'cidade-Parkrand' propõe um resgate maciço dos parques nos subúrbios. Todas têm em comum o aumento da densidade e a otimização do solo, liberando área para novas ocupações no mundo superpovoado estudado pelo MVRDV, sejam elas habitacionais ou de produção de recursos.

Ao longo do desenvolvimento desta dissertação, observamos a consolidação da ideia inicial do projeto de pesquisa pautado na existência de um ciclo no trabalho do MVRDV de 'processo > teoria > habitação' onde o processo de projeto baseado em investigação projetual leva a formulação de novas teorias e estudos que conduzem à produção de projetos habitacionais que por sua vez suportam, com informações e conclusões, novas investigações.

Dentre as principais questões decorrentes desse ciclo estão: a teoria, assumindo a pesquisa como prática através de uma expansão do campo da arquitetura; o desenvolvimento de novas tecnologias dirigidas por arquitetos; as espacialidades coletivas dos projetos habitacionais (e sua inserção na cidade) resultantes destes processos.

\section{Processo de projeto e novas tecnologias}

A espacialização da informação assume a estatística como uma preexistência para depois torná-la concreta. No entanto, observamos que é difícil garantir a neutralidade dos dados, já que estes sofrem influências (políticas, econômicas e culturais) antes de serem coletados.

Essas influências acabam emergindo no trabalho do MVRDV já que o escritório utiliza-se do processamento de informações majoritariamente em planejamento e não na determinação de formas arquitetônicas geradas digitalmente. 
Além disso, uma especificidade dos programas computacionais do MVRDV é o fato dos software trabalharem com parâmetros específicos (densidade, diversidade funcional, sustentabilidade ambiental, econômica e social). Eles permitem a discussão de questões de outras áreas, como globalização e mudanças climáticas, e são construídos com base em argumentações objetivas diminuindo a distância com outras disciplinas e o público em geral.

Outro fator notório é que a ênfase do escritório em processamento de informações promove, em muitos dos seus estudos analisados no capítulo 2, a apresentação dos problemas relacionados à densidade urbana. Com essa leitura, as soluções determinadas através dessa abordagem resultam em formas conhecidas do vocabulário arquitetônico, como prismas, lâminas e barras e que permanecem nos projetos construídos.

O tema da 'forma' traz a tona questionamentos sobre as capacidades dos software do MVRDV: as soluções em formas de caixas podem ser vistas como um limite dos programas computacionais do escritório. Ressaltamos que isso não impede a criação de espaços interessantes no interior das caixas, mas, a evolução desse aspecto nos software para além do pixel poderia resultar em espacialidades ainda não exploradas.

No entanto, acreditamos que para o MVRDV o uso de novas tecnologias e software baseados em parâmetros é um meio que vai além da geração de infinitas soluções, é uma nova maneira de pensar a disciplina e que passa também por sua ampliação. Como exemplo, podemos citar a globalização e as novas formas de comunicação que abrem o foco da habitação para uma agenda da arquitetura mais diversificada e questiona seu modo de produção. É aí que a aplicação de tecnologias digitais como ferramenta, e não como mais um 'ismo', permite a proposição de teorias sobre possibilidades de transformação do espaço. Vale ressaltar que, no caso do escritório, os arquitetos não atuam como programadores, mas como pesquisadores e coordenadores no desenvolvimento dos software e, principalmente, usuários.

\section{Teoria}

Em seus estudos o MVRDV busca a volta do arquiteto como protagonista da realidade através de problemas não-arquitetônicos tais como migração, alterações climáticas e produção de alimentos. É notório que a conexão entre pesquisa e prática deixa de existir em sua totalidade nos projetos, mas o campo da 
investigação também pode ser analisado como uma obra com lógica própria que não precisa ser necessariamente aplicada para se validar. Essa 'arquitetura de papel' permite que o MVRDV (assim como Superstudio, Archigram, Tschumi e Koolhaas) discuta o que não pode ser comunicado em suas obras construídas e expande o campo da arquitetura para além da construção.

No entanto, no caso do MVRDV, a pesquisa sem a construção perde parte de sua força. Imaginemos um cenário onde o MVRDV se dedicasse exclusivamente à investigação. Em tal situação, os arquitetos não teriam desenvolvido o Silodam e, portanto, não chegariam à conclusão de que era necessário desenvolver um software (não como a versão existente) que simulasse soluções projetuais - o Functionmixer. Com isso, o escritório também não teria criado o Regionmaker e outros estudos de escala regional decorrentes dessa ferramenta. Certamente o MVRDV seria reconhecido pelo seu trabalho com pesquisa, mas eles não teriam a prática retroalimentando novas investigações, conforme o ciclo que desenhamos no início desta dissertação (processo>teoria>projeto>processo). Assim, sem a etapa do processo de projeto, é provável que houvesse um enfraquecimento de ideias para novos estudos e pesquisas.

\section{Projetos}

O MVRDV reformula aspectos de edifícios emblemáticos da história da habitação, de modo que é possível perceber a existência de um híbrido entre esses modelos preexistentes e características próprias do escritório. Soma-se a essa combinação, a aplicação de materiais e revestimentos atuais que reforçam esteticamente o aspecto contemporâneo do exterior dos edifícios.

Através das análises das unidades habitacionais, notamos que os arquitetos diminuem as experimentações nos espaços individuais e se concentraram no posicionamento do edifício em relação à cidade e no desenvolvimento dos espaços coletivos, aspecto que parece ser compensado pela pesquisa sobre a materialidade da edificação, especialmente seus revestimentos. São utilizados diversos materiais nas fachadas e nos interiores comuns que facilitam a identificação e apropriação do espaço pelos moradores, mas que também enfatizam uma diversidade que não acontece na mesma proporção nas células habitacionais.

De certa forma, esse fenômeno afeta a coerência do projeto e as fachadas acabam caracterizadas como um tipo de envelopamento. Tais questões estão presentes nos 
projetos aqui analisados, especialmente no Silodam e fica bastante evidente em outra obra do MVRDV, as casas Hagen Island (2002) do Ypenburg Masterplan. Esse caso é notório porque a homogeneidade da forma é compensada pela variedade de materiais e cores aplicados nas fachadas. No caso do Silodam, a comparação do edifício com contêineres empilhados passaria despercebida se um único material tivesse sido aplicado no seu exterior e, possivelmente, o projeto teria menos repercussão na mídia.

A impressão é que o interior das unidades é controlado pelo desenvolvedor e o exterior e os espaços comuns são definidos pelo arquiteto, principalmente no caso do Silodam, no qual houve uma pausa de anos no desenvolvimento do projeto para que ocorresse a valorização dos apartamentos. Vale ressaltar que a pouca experimentação em relação às unidades também pode estar associada a outros fatores, como, por exemplo, um respeito à cultura do morar que funciona como ponto de equilíbrio frente às outras mudanças espaciais nas áreas coletivas. $O$ Mirador, habitação social inserida em um contexto bastante tradicional da periferia de Madrid, ilustra bem essa delicada situação.

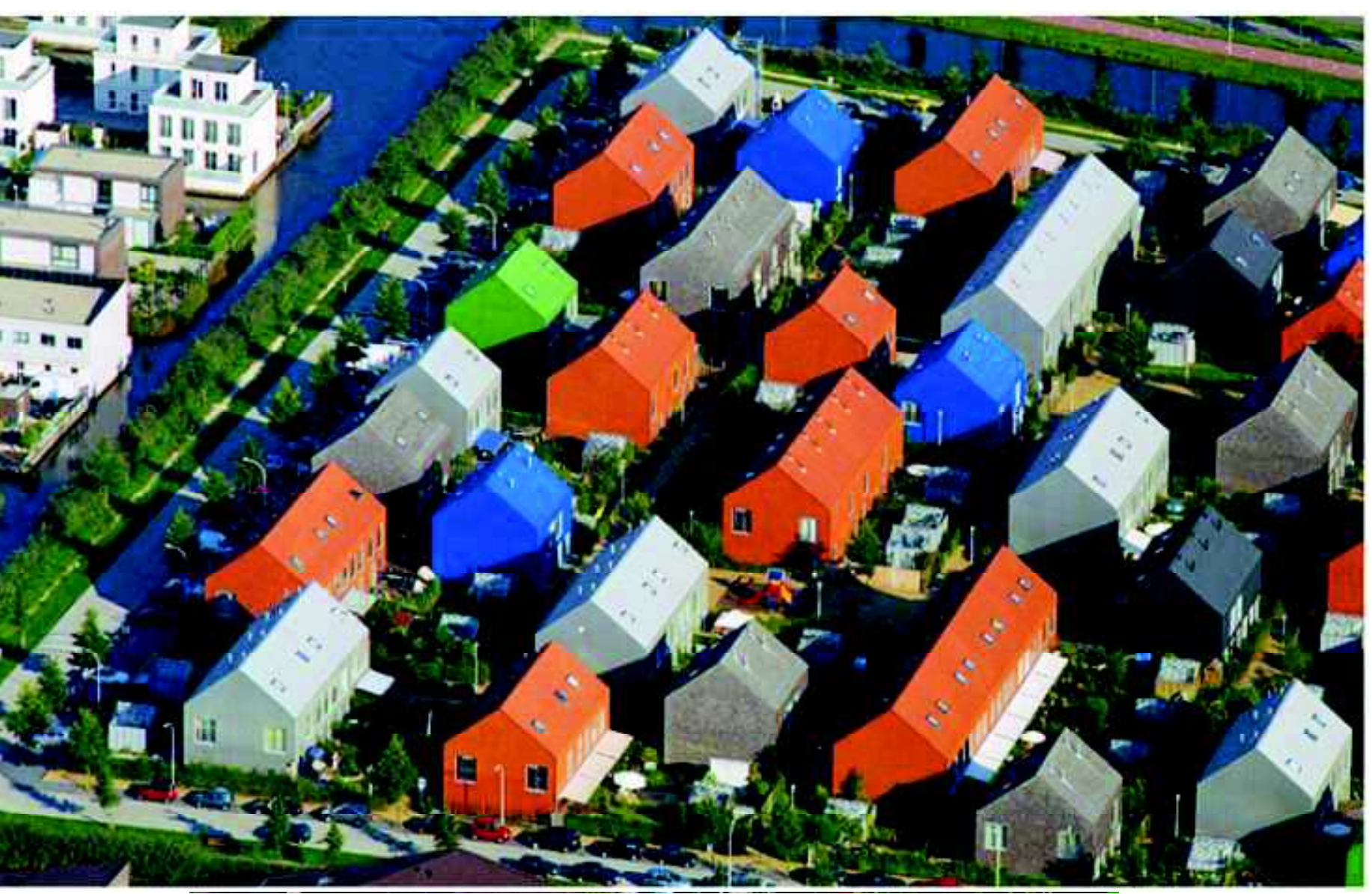

Hagen Island (2002). Fonte: www.mvrdv.nl 


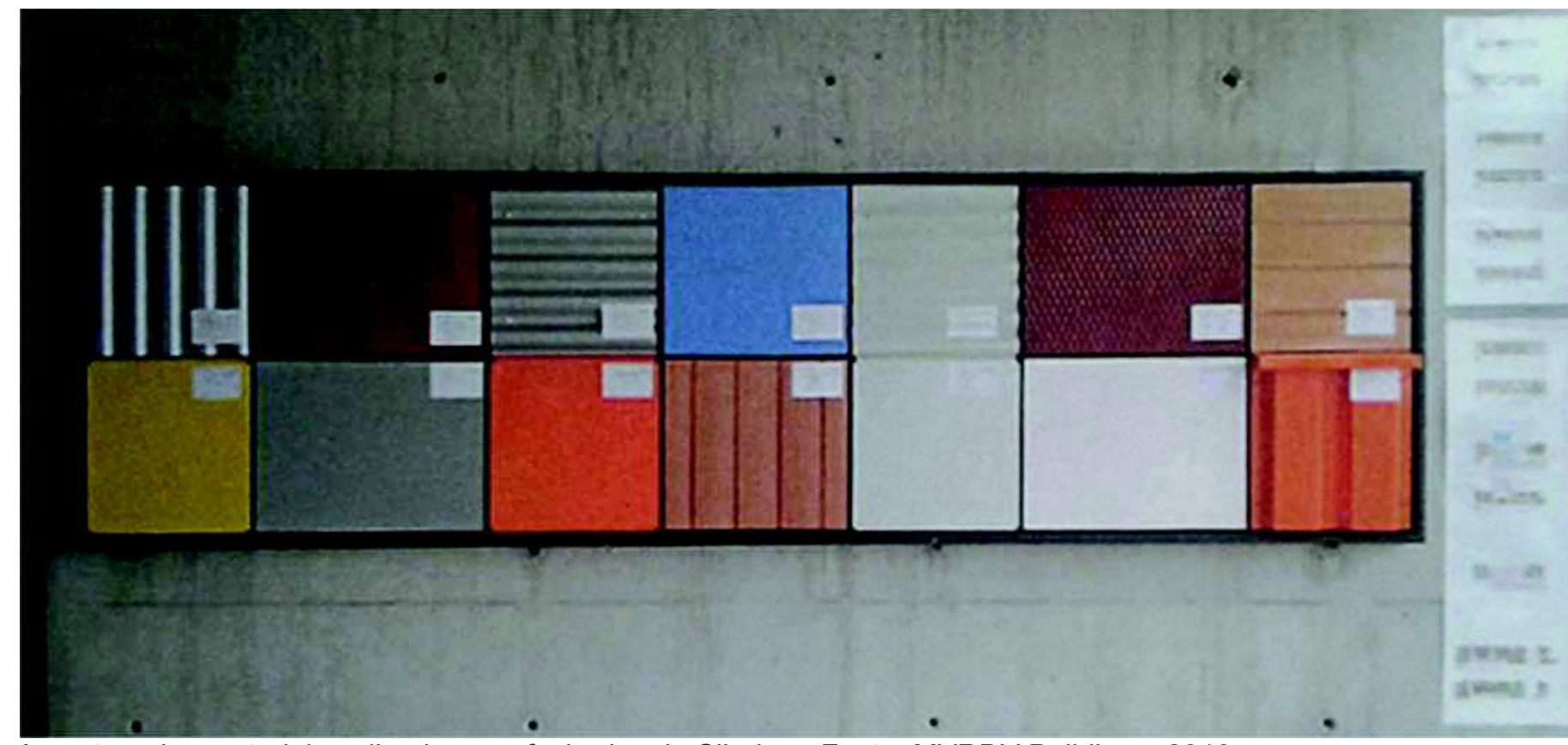

Amostras dos materiais aplicados nas fachadas do Silodam. Fonte: MVRDV Buildings, 2013.

A questão do envelopamento pode estar presente, mas não determina que os projetos sejam apenas releituras maquiadas do moderno. O passo além é que o MVRDV demonstra uma preocupação em projetar espaços que promovam relações sociais, áreas coletivas (que podem ter acesso público), indo além da solução tradicional de posicioná-los na base do edifício. Essa ideia está relacionada ao aumento da densidade, e nesses locais onde mais pessoas passam a viver, a ampliação dos espaços públicos torna-se necessidade. Nesse sentido, os moradores de um edifício disponibilizam suas áreas coletivas para outros moradores da cidade, é o caso do deck do Silodam e da praça elevada do Mirador.

A preocupação do MVRDV também passa pela eliminação da segregação nos espaços de convívio. No Silodam, todas as formas de circulação estão conectadas, impedindo a compartimentação social do edifício. Essa conexão forma um passeio que atravessa diferentes espaços e visuais que podem ser apropriados com usos diversos não previstos pelos arquitetos.

A abertura dos edifícios para a cidade mostra que as habitações não são elementos autônomos no território urbano. O tecido residencial deve atender tanto às necessidades de seus ocupantes como ao entorno que ocupa, favorecendo a formação de redes comunitárias e relações sociais. Por esse motivo é conveniente que o conjunto habitacional integre atividades diversas, tais como espaços de trabalho, espaços comerciais ou equipamentos públicos. No Silodam existem 
escritórios; no Mirador, um mercado (projetado, mas não implantado) e no Parkrand, a escola infantil.

Mesmo com a inserção desses usos múltiplos, notamos a seguinte contradição nos projetos analisados: os edifícios, especialmente Mirador e Parkrand, têm um caráter monumental e icônico que os fazem perder a especificidade e a relação com o local. Como última consideração sobre os projetos é importante citar uma limitação com que esta pesquisa se deparou. Apesar da ampla coleta de material gráfico sobre as tipologias dos apartamentos, não foram encontradas as razões (nem no discurso dos arquitetos e nem nas informações de processo de projeto) que levaram o MVRDV a manter as plantas das unidades em uma configuração tradicional, o que nos faz levantar as possibilidades citadas anteriormente (premissas do cliente desenvolvedor ou respeito às questões culturais da moradia). Essa lacuna poderia fornecer assunto para outras pesquisas que explorassem especificamente o desenvolvimento da unidade na produção habitacional contemporânea.

A retomada da pesquisa como prática pelo MVRDV tem desdobramentos importantes no campo da arquitetura e urbanismo, como: o reposicionamento do papel do arquiteto como coordenador; a interação com outras disciplinas; o desenvolvimento e aplicação de tecnologias digitais; a participação dos usuários no processo de projeto; a projeção de cenários futuros como ponto de articulação entre teoria e projeto e ferramenta de visualização para abertura de debates. Essas questões, mesmo que inseridas ainda pontualmente nas obras, são os aspectos mais positivos do trabalho do escritório e podem ser vistas como o início de uma revisão da disciplina. Tal afirmação não significa a defesa do método de trabalho do MVRDV, mas reconhece suas potencialidades e seu enfrentamento dos problemas atuais no ambiente acadêmico (especialmente com a The Why Factory?), na teoria/estudos e na prática.

Ressaltamos que o conteúdo apresentado e discutido nessa dissertação ainda não é suficiente para englobar toda produção teórica e de projetos habitacionais do MVRDV ao longo de seus vinte anos de existência. A intenção deste trabalho foi construir um panorama que articulasse teoria de arquitetura, processo de projeto e 
habitação contemporânea, a fim de analisar novas formas de produzir espacialidades, algo que não havia sido feito com profundidade para o trabalho do escritório. O incentivo ao debate sobre as relações entre pesquisa e projeto na arquitetura e urbanismo faz o trabalho do MVRDV ter significativa importância e pode servir de embasamento para pensamentos e práticas arquitetônicas futuras. 


\section{BIBLIOGRAFIA DE REFERÊNCIA}


ADAM, H. Stacking and layering. In El Croquis 111, 2002.

ALLEN, S. Diagrams matter. ANY: Architecture New York. 1998; n.23; p.16-19. Artificial Ecology. In Reading MVRDV. Rotterdam: NAi Publishers, 2003. ANDERSON, P. As origens da Pós-modernidade. Rio de Janeiro: Zahar, 1999. ARANTES, Otília. O lugar da arquitetura depois dos modernos. São Paulo: Edusp, 1993.

Urbanismo em fim-de-linha (e outros estudos sobre o colapso da modernização arquitetônica). São Paulo: Edusp, 1998.

BAHÁMON, A., SANJÍNÉS, M. C. Alta densidad. Barcelona: Parramon, 2008.

BETSKY, A. MVRDV: The matrix project. In Reading MVRDV. Rotterdam: NAi Publishers, 2003.

BERMUDEZ, J., AGUTTER, J., FORESTI, S. Architectural Research in Information Visualization: 10 Years After. International Journal of Architectural Computing. 2006; vol. 4; n. 3; p. 1-18.

BHATIA, N. The Urban Project of Plurality. Domusweb (internet). 6 de abril de 2011. Disponível em: http://www.domusweb.it/en/op-ed/2011/04/06/the-urbanproject-of-plurality.html

BRAHAM, W. After Typology: The Suffering of Diagrams. Architectural Design. 2000; n.70.3; p. 9-11.

BROUWER, J., MULDER, A., CHARLTON, S. Information Is Alive: Art And Theory On Archiving And Retrieving Data. Rotterdam: NAI Publishers, 2003.

CABRAL, C. P. C. Grupo Archigram, 1961-1974. Uma Fábula da técnica. Barcelona, 2002 (Tese, Doutorado) Barcelona: Universitat Politècnica de Catalunya, 2002.

CEVASCO, M. E. O sentido da crítica cultural. Revista Cult. 2008; n.122. Disponível em: http://revistacult.uol.com.br/home/2010/03/o-sentido-da-criticacultural/

DE LANDA, M. Deleuze, diagrams and the genesis of form. Amerikastudien/ American Studies. 2000; vol. 45, n. 1; p. 33-41.

DO, E. Y., GROSS, M. Thinking with Diagrams in Architectural Design. Artificial Intelligence Review. 2001; v. 15, p. 135-149.

EAGLETON, T. O caminho para o pós-modernismo. Depois da Teoria. Rio de Janeiro: Civilização Brasileira, 2005. 
FÓRUM DE CULTURA E ECONOMIA DE DÜSSELDORF, MVRDV. The Regionmaker RheinRuhrCity. Ostfildern: Hatje Cantz, 2002.

FRAMPTON, K. História crítica da arquitetura moderna. São Paulo: Martins Fontes, 2000.

FREY, D. Crowded House. New York Times Magazine, Architecture issue, 08 de Junho de 2008. Disponível em:

http://www.nytimes.com/2008/06/08/magazine/08mvrdv-.html?pagewanted=all\&_r=0 GARCIA, M. The diagrams of architecture. Nova York: Wiley, 2010.

GAUSA, M. Housing, nuevas alternativas, nuevos sistemas. Barcelona: Actar, 1998.

GRAAFLAND, A. On criticality. Em Crossover: Architecture I Urbanism I Technology. Rotterdam, 010 Publishers, 2006.

GUZZINI, G. Jacob van Rijs on MVRDV's new projects. Domusweb. 2 de janeiro de 2010. Disponível em: http://www.domusweb.it/en/architecture/2010/01/02/jacobvan-rijs-interview.html

HARVEY, D. A condição pós-moderna: uma pesquisa sobre as origens da mudança cultural. São Paulo: Loyola, 1996.

HAYS, K. M. Architectural theory since 1968. Londres: The MIT Press Cambridge, Architecture by numbers. Praxis 7: Untlited number Seven, 2005, p. 8899.

HAYS, K. M., KENNEDY, A. After All, or the End of "The End of". Assemblage, The MIT Press. 2000; n. 41; p. 6-7.

HUYSSEN, A. Mapeando o pós-moderno. In HOLLANDA, Heloisa B.(org). Pósmodernismo e política. Rio de Janeiro: Rocco, 1991.

IBELINGS, H. The Artificial Landscape: Contemporary Architecture, Urbanism, and Landscape Architecture in the Netherlands. Rotterdam: NAI Publishers, 2000.

JANSON, N. Mirador. In MVRDV Buildings. Rotterdam: NAI Publishers, 2013.

KIPNIS, J. Towars a new architecture. Architectural Design, 1993, n. 102, p. 43.

KIPNIS, J., EISENMAN, P., KOOLHAAS, R., SOMOL, R. Supercrítico. São Paulo: Cosac Naify, 2013.

KOOLHAAS, R. Nova York Delirante: Um Manifesto Retroativo Para Manhattan. São Paulo: Cosac \& Naify, 2008.

KOOLHAAS, R., MAU, B. S, M, L, XL. Nova York: The Monacelli Press, 1997. 
KOTNIK, T. Digital Architectural Design as Exploration of Computable Functions. International journal of architectural computing, 2010; v. 08; n.1

KWINTER, S. La trahison des clercs (und anderer moderner Mummenschanz). ARCH+; 1999; n.146, p. 84-86.

Who is afraid of formalism. In Phylogenesis: FOA's Ark. Barcelona: Actar, 2004.

LOOTSMA, B. SuperDutch: new architecture in the Netherlands. Londres: Thames \& Hudson, 2000.

What is (really) to be done? In Reading MVRDV. Rotterdam: NAi Publishers, 2003.

The diagram debate. In: SIGLER. J (ed), One Hundred and Nine Provisional Attempts to Address Six Simple and Hard Questions about what Architects Do Today and where Their Profession Might Go Tomorrow. Hunch, the Berlage Institute report on architecture, urbanism, and landscape, Episode publishers. 2003; v. 6-7.

MAAS, W. Massive Pluralism. In FARMAX: Excursions on Density. Rotterdam: 010 Publishers, 1998.

MAAS. W. (ed). Metacity/Datatown. Rotterdam: NAI Publishers, 1999.

Do regions exist? In The Regionmaker RheinRuhrCity. Ostfildern: Hatje Cantz, 2002.

Five minutes city. Rotterdam: Episode Publishers, 2003.

Architecture is a device. In Reading MVRDV. Rotterdam: NAi Publishers, 2003.

Winy Maas interview. Perspecta, The MIT Press. 2004; v. 35; pp. 54-61.

The evolutionary city, In KM3 Excursions on Capacities. Barcelona: Actar, 2005.

The Vertical Village: Individual, Informal, Intense. Rotterdam: NAI Publishers, 2013.

MAAS. W., VAN RIJS, J., MVRDV, ESARQ (eds). Costa Iberica. Barcelona: Actar, 1998.

MAAS, W; VAN RIJS; J. Icebergs. In FARMAX: Excursions on Density. Rotterdam: 010 Publishers, 1998.

MAAS, W., DELFT SCHOOL OF DESIGN (eds). Spacefighter. The Evolutionary City (Game:). Actar: Barcelona, 2007. 
MAAS, W., HAIKOLA, P., HACKAUF, U., THE WHY FACTORY (eds.). The Green Dream. How Future Cities Can Outsmart Nature. Rotterdam: NAI Publishers, 2013.

MAAS, W., LA, G. Skycar city. Barcelona: Actar, 2007.

MAAS, W., FEIREISS, K., OVINK, H., BOUMAN, O., VANSTIPHOUT, W., RIEDIJK, M.,

MAAS, W., VAN RIJS, J., DE VRIE, N. The Why Factor(y) \& The Future City. Rotterdam: NAI Publishers, 2013.

MAAS, W., MADRAZO, F. City Shock: Planning the Unexpected. Rotterdam: NAI Publishers, 2013.

MAAS, W., SALIJ, T., KALMEYER, B. Hong Kong Fantasies: Challenging WorldClass City Standards. Rotterdam: NAI Publishers, 2013.

MAAS, W., THE WHY FACTORY (eds). Visionary Cities. Rotterdam: NAI Publishers, 2013.

KM3 Excursions on Capacities. Barcelona: Actar, 2005.

MARTIN, R. Critical of what? Toward a utopian realism. Harvard Design Magazine. 2003; n. 22.

MEDRANO, L. Habitar no limiar crítico do espaço: idéias urbanas e conceitos sobre a habitação coletiva. São Paulo, 2000 (Tese, Doutorado) São Paulo: Faculdade de Arquitetura e Urbanismo da Universidade de São Paulo (USP), 2000.

Habitação coletiva, verticalidade e cidade. Modernidade sem estilo. Arquiteturarevista. 2005; v. 1 n. 2. Disponível em:

http://www.arquiteturarevista.unisinos.br/index.php?e=2\&s=9\&a=8

MENDES, L. T. Habitação coletiva contemporânea: inovações metodológicas e tecnologia da informação no processo de projeto. Campinas, 2010. (Dissertação, Mestrado) Campinas: Faculdade de Engenharia Civil, Arquitetura e Urbanismo da Universidade de Campinas (Unicamp), 2010.

MONEO, R. Inquietação teórica e estratégia projetual. São Paulo: Editora CosacNaify, 2008.

MORAIS, L. P. Z; SPERLING, D. M. MVRDV e Regionmaker: arquitetura e espacialização da informação. In: XVI Congresso da Sociedade Iberoamericana de Gráfica Digital, 2012, Fortaleza.

Datascapes: diálogos entre informação e espaço In: XVII Congresso da Sociedade Iberoamericana de Gráfica Digital, 2013, Valparaíso. 
MORENO, C. D; GRINDA, E. G. Redefing the tools of radicalism. In: El Croquis $111,2002$.

MONTANER, J. M. Depois do movimento moderno. São Paulo: Gustavo Gili, 2002.

Sistemas arquitetônicos contemporâneos. São Paulo: Gustavo Gili, 2008.

Arqueologia de los diagramas. Cuadernos de Proyectos Arquitectónicos. Innovación y tradición em la arquitectura contemporânea. 2010; ano $1, \mathrm{v} .1$.

MÜLLER, L. Book Builder at Harvard GSD. Disponível em: http://www.artelibro.it/en/2009/06/lars-muller-\%E2\%80\%93-book-builder-at-harvardgsd/

MVRDV. FARMAX: Excursions on Density. Rotterdam: 010 Publishers, 1998. The Functionmixer. In El Croquis 111, 2002.

Agendas On Urbanism. Seoul: Equal Books, 2012.

NESBITT, K. Uma nova agenda para arquitetura: antologia teórica 1965 -1995. São Paulo: Cosac Naify, 2013.

NORBERG-SCHULZ, C. Intenciones en arquitectura. Barcelona: Gustavo Gili, 1998.

OXMAN, R. Digital architecture as a challenge for design pedagogy: theory, knowledge, models and medium. Design Studies. 2008; v. 29; n. 2.

PATTEEUW, V. (ed). Reading MVRDV. Rotterdam: NAi Publishers, 2003.

PER, A. F. Densidad nueva vivienda colectiva. Vitoria: A+T, 2006

PER, A. F, MOZAS, J., ARPA, J. Dbook density, data, diagrams, dwellings: análisis visual de 64 proyectos de vivienda colectiva. Barcelona: Actar, 2009.

HoCo density housing construction \& costs. Vitoria: A+T, 2009.

PICON, A. Architectural and the virtual: towards a new materiality. PRAXIS 6: New Technologies :// New Architectures, 2004, p. 114-121.

PONS, J. P., LÓPEZ, V. M. El diagrama como interface del proyecto arquitectônico. Congreso Internacional Ega, Valencia 2010.

RUBANO, L. M. Tecidos Habitacionais em Amsterdã. $3^{\circ}$ Seminário Docomomo Brasil. São Paulo, 1999. Disponível em:

http://www.docomomo.org.br/seminario\%203\%20pdfs/subtema_A4F/Lizete_rubano. pdf 
RUBY, I., RUBY, A. MVRDV Buildings. Rotterdam: NAI Publishers, 2013.

SASSEN, S. Locating Cities on Global Circuits. Environment \& Urbanization. 2002, v.14.

Why Cities Matter. In: Cities. Architecture and Society, exhibition catalogue of the 10. Architecture Biennale Venice. 2006; p. 26-51.

Cities Today: A New Frontier for Major Developments. ANNALS, AAPSS, 626, Novembro, 2009.

SCALBERT, I. Utopia PIc. A view from London. Archis. 1998; n. 9. Disponível em: http://volumeproject.org/1998/09/utopia-bv-een-blik-vanuit-londen-utopia-plc-a-viewfrom-london/

SCHUMACHER, P. Rational in Retrospect - Reflections on the Logic of Rationality in Recent Design. In: AA files 38, Anais da Architectural Association School of Architecture, 1999

SILVA, R. C., AMORIM, L. M. E. Urbanismo paramétrico: emergência, limites e perspectivas de nova corrente de desenho urbano fundamentada em sistemas de desenho paramétrico. In V!RUS. 2010; n. 3. São Carlos: Nomads.usp. Disponível em:

http://www.nomads.usp.br/virus/virus03/submitted/layout.php?item=2\&lang=pt.

SHEPHERD, P., HUDSON, R., HINES, D. A parametric success. International journal of architectural computing. 2009; v. 9; n. 2.

SIMMEL, G. A metrópole e a vida mental. In: VELHO, Otávio G. (Org.). O fenômeno urbano. Rio de Janeiro: Guanabara, 1987.

SOLA MORALES, I. Diferencias: topografía de la arquitectura contemporánea. Barcelona: Gustavo Gili, 1995.

SPEAKS, M. Design Intelligence. A+U: Architecture and Urbanism. 2002; n. 12 (387).

Design, intelligence and the new economy. Architectural Record, 2002, v.190, n.1, p.72-76.

. Theory was interesting... but now we have work. Architectural Research Quarterly, 2002, v. 6, n. 3, p. $209-212$.

SPERLING, D. M. Arquiteturas contínuas e topologias: similaridades em processo. São Carlos, 2003. (Dissertação, Mestrado) São Carlos: Escola de Engenharia de São Carlos da Universidade de São Paulo (EESC-USP), 2003.

2012. Arquitetura e Mídia: espaço, tempo e informação (no prelo). 
SYKES, K. Constructing a new agenda. Architectural Theory, 1993-2009. Nova York: Princeton, 2010.

THACKARA, J. A tool to make cities. Domus (internet). 2003. Disponível em: http://www.domusweb.it/en/architecture/a-tool-to-make-cities/

THE WHY FACTORY, MADRAZO, F., SVERDLOV, A. The Death of Leisure: Towards the Next Resort. Rotterdam: NAI Publishers, 2012.

TILMAN, H. When dense, when lite? Em FARMAX: Excursions on Density. Rotterdam: 010 Publishers, 1998.

VAN TOORN, R. No more dreams? The passion for reality in recent dutch architecture... and its limitations. Harvard Design magazine, 2005, n. 21, p. 22-31. VIDLER, A. Diagrams of Diagrams: Architectural Abstraction and Modern Representation. Representations. 2000; n. 72; p. 1-20.

What is a Diagram anyway?, in Peter Eisenman: Feints. 2006; p.19-27. Architecture's expanded Field. Artforum, 2004, v. 42, n. 8.

WALL, R. Global-Local. In The Regionmaker RheinRuhrCity. Ostfildern: Hatje Cantz, 2002.

Periódicos

A+U \#323, 97:08, 1997.

$A+U$ \#429, 06:06, 2006.

A+U MVRDV files I, Projects 002-209, 02:11, 2002.

A+U MVRDV files II, Projects 069-349, \#436, 07:01, 2007.

Archis 9, 1998.

CLOG, maio de 2014.

Dash 4, 2011.

El Croquis MVRDV 1991-1997. El Croquis, 1997.

El Croquis MVRDV 1991-2002. El Croquis, 2003.

El Croquis MVRDV 2003-2014. El Croquis, 2014.

El Croquis 131-132, OMA 1996-2006.

El Croquis 134-135, OMA 1996-2007.

L'Architecture d'Aujourd'hui, n. 396, julho/ agosto 2013.

Metropolis, janeiro de 2011.

Praxis, março de 2003. 
Quaderns d'arquitectura i urbanisme 198, 1993.

Quaderns d'arquitectura i urbanisme 211, 1995.

Quaderns d'arquitectura i urbanisme 213, 1995.

Páginas da internet

www.mvrdv.com

www.thewhyfactory.com

www.oma.eu 